\title{
Magnitude and Frequency of Floods in the United States
}

\author{
Part 10. The Great Basin
}

By E. BUTLER, J. K. REID, and V. K. BERWICK

GEOLOGICAL SURVEY WATER-SUPPLY PAPEF 1684

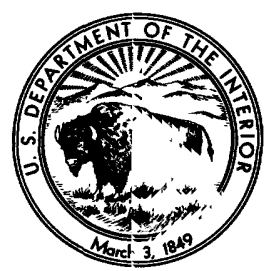


UNITED STATES DEPARTMENT OF THE INTERIOR

STEWART L. UDALL, Secretary

\author{
GEOLOGIGAL SURVEY \\ William T. Pecora, Director
}

Library of Congress catalog-card No. GS 64-192 


\section{CONTENTS}

Abstract
Introduction.
Purpose and scope
Description of the basin
Physiography
Climate

Flood-frequency analysis . . . .

Flood frequency at a gaging station

Types of flood series

Homogeneity . . . .

Regional flood frequency

Composite frequency curves . .

Derivation of the mean annual flood

Basin characteristics .

Mean annual flood relations............ 9

Major rivers.

Cloudburst floods and mud-rock flows._.

Application of flood curves

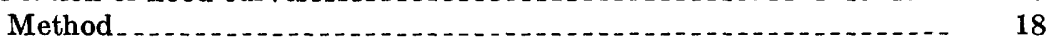

Use of flood-frequency analysis for major rivers . . . .

Limitations .... . . . . . . . . . . . . 19

Gaging-station records . . .

Maximum known floods.

Bear River basin ....................................... 41

Bear River near Utah-Wyoming State line_.............. 41

Mill Creek at Utah-Wyoming State line.................. 41

Bear River above Sulphur Creek, near Evanston, Wyo ........ 42

Sulphur Creek above reservoir, near Evanston, Wyo_......... 43

Sulphur Creek near Evanston, Wyo._................. 43

Yellow Creek near Evanston, Wyo

Bear River near Evanston, Wyo......................... 44

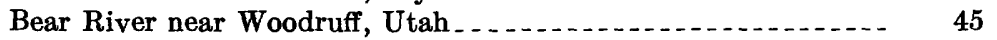

Woodruff Creek near Woodruff, Utah . . . . . . . . .

Birch Creek near Woodruff, Utah................. 46

Big Creek near Randolph, Utah....................... 47

Randolph Creek near Randolph, Utah . . . . . . .

Otter Creek near Randolph, Utah _. . . . . . .

Bear River near Randolph, Utah ..................... 48

Twin Creek at Sage, Wyo . .

Bear River below Pixley Dam, near Cokeville, Wyo_._...... 49

Bear River above Sublette Creek, near Cokeville, Wyo ........ 50

Smiths Fork near Border, Wyo ._. .

Smiths Fork at Cokeville, Wyo_...... 51

Bear River below Smiths Fork, near Cokeville, Wyo ......... 51 
Gaging-station records-Continued

Bear River basin-Continued

Bear River at Border, Wyo

Thomas Fork near Geneva, Idaho . . .

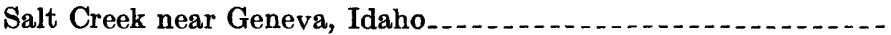

Thomas Fork near Wyoming-Idaho State line

Thomas Fork near Raymond, Idaho

Bear River at Harer, Idaho.

Bear River at Dingle, Idaho . . .

Bear River below Stewart Dam, near Montpelier, Idah?........

Montpelier Creek near Montpelier, Idaho...............

Montpelier Creek at irrigators weir, near Montpelier, Idaho....

Bloomington Creek near Bloomington, Idaho . .

Mill Creek near Liberty, Idaho

Bear River at Pescadero, Idaho ...

Georgetown Creek near Georgetown, Idaho

Skinner Creek at Nounan, Idaho . . .

Stauffer Creek near Nounan, Idaho . .

Bear River at Soda Springs, Idaho

Soda Creek near Soda Springs, Idaho .

Bear River at Alexander, Idaho .

Cottonwood Creek near Swan Lake, Idaho

Cottonwood Creek near Cleveland, Idaho

Bear River below Utah Power and Light Co.'s tailrace, s.t Oneida, Idaho

Mink Creek below Dry Fork, near Mink Creek, Idaho

Mink Creek near Mink Creek, Idaho

Bear River near Preston, Idaho

Bear River near Weston, Idaho

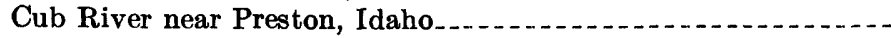

Cub River above Maple Creek, near Franklin, Idaho_..........

Maple Creek near Franklin, Idaho

High Creek near Richmond, Utah .

East Fork Little Bear River near Avon, Utah......

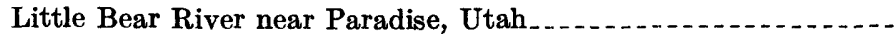

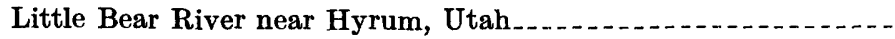

Logan River above State dam, near Logan, Utah............ .

Blacksmith Fork at Hardware Ranch, near Hyrum, Uteh...... .

Blacksmith Fork at municipal powerplant, near Hyrum, Utah.-

Blacksmith Fork above Utah Power \& Light Co.'s dam near Hyrum, Utah

Blacksmith Fork below Utah Power \& Light Co.'s plint, near Hyrum, Utah

Clarkston Creek near Newton, Utah . . .

Bear River near Collinston, Utah... . . . . . . . .

Little Malad River above Elkhorn Reservoir, near Malad City, Idaho

Little Malad River below Elkhorn Reservoir, near Malad City, Idaho

Little Malad River below Sand Ridge damsite, near Malad City, Idaho.

Malad River below springs, near Malad City, Idaho . . . . . . . .

Malad River near Samaria, Idaho. 
Gaging-station records-Continued

Page

Bear River basin-Continued

Devil Creek above Campbell Creek, near Malad City, Idaho....

Devil Creek above Evans dividers, near Malad City, Idaho.....

Devil Creek near Malad City, Idaho ........................

Deep Creek below First Creek, near Malad City, Idaho ........

Malad River at Woodruff, Idaho. . .

Bear River near Corinne, Utah.......

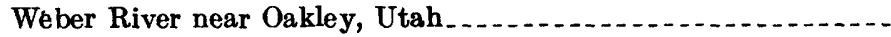

Weber River near Peoa, Utah..........

Weber River near Wanship, Utah. . . . . .

Silver Creek near Wanship, Utah......

Weber River near Coalville, Utah. . . . . . .

Chalk Creek at Coalville, Utah.......... 81

Weber River at Echo, Utah......... 82

Lost Creek near Croydon, Utah.

Lost Creek at Devils Slide, Utah . . .

Weber River at Devils Slide, Utah.....

East Canyon Creek near Morgan, Utah.

Hardscrabble Creek near Porterville, Utah................... 85

East Canyon Creek below diversions, near Morgan, Utah....... 86

Weber River near Morgan, Utah... . . .

Weber River at Gateway, Utah.

Weber River at Ogden, Utah.............. 87

South Fork Ogden River near Huntsville, Utah $\ldots \ldots \ldots \ldots$

Middle Fork Ogden River at Huntsville, Utah . . . . . . . . . 89

Spring Creek at Huntsville, Utah._...

Wheeler Creek near Huntsville, Utah $\ldots \ldots$

Ogden River near Ogden, Utah........................... 90

Ogden River below Pine View Dam, near Ogden, Utah. ..... 90

Weber River near Plain City, Utah......... 91

Tributaries between Weber and Jordan Rivers . . . . . . . . . . . . . 92

Holmes Creek near Kaysville, Utah................... 92

Farmington Creek above diversions, near Farmington, Utah..... 92

Ricks Creek above diversions, near Centerville, Utah. ........ 93

Parrish Creek above diversions, near Centerville, Utah........ 93

Centerville Creek above diversions, near Centerville, Utah..... 94

Stone Creek above diversion, near Bountiful, Utah. . . . . . . . 95

Mill Creek at Mueller Park, near Bountiful, Utah _...

Jordan River basin . . . . . . . . . . . . . 96

Salt Creek at Nephi, Utah........ 96

Summit Creek near Santaquin, Utah..................... 96

Payson Creek above diversions, near Payson, Utah............ 97

Payson Creek near Payson, Utah.

Dairy Fork near Thistle, Utah...

Spanish Fork at Thistle, Utah..... 98

Diamond Fork below Red Hollow, near Thistle, Utah....... 99

Diamond Fork near Thistle, Utah. . .

Spanish Fork at Castilla, Utah.

Spanish Fork near Spanish Fork, Utah.

Spanish Fork near Lake Shore, Utah....

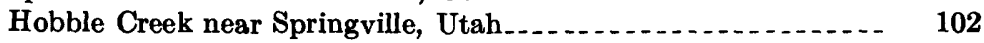


Gaging-station records-Continued

Page

Jordan River basin-Continued

Provo River near Kamas, Utah

Provo River near Hailstone, Utah.

Provo River near Charleston, Utah

Snake Creek near Charleston, Utah

Round Valley Creek near Wallsburg, Utah.

Provo River below Deer Creek Dam, Utah. . .

Deer Creek near Wildwood, Utah.

Provo River near Wildwood, Utah

Provo River at Vivian Park, Utah........

South Fork Provo River at Vivian Park, Utah . . . . . . .

Provo River above Telluride Power Co.'s dam, near Provo, Utah. .

Provo River at Provo, Utah. . . . . . . . . . . . . . . .

American Fork above upper powerplant, near American Fork, Utah.

Dry Creek near Alpine, Utah.

Fort Creek at Alpine, Utah.

Jordan River at narrows near Lehi, Utah.....................

Little Cottonwood Creek near Salt Lake City, Utah............

Big Cottonwood Creek near Salt Lake City, Utah ............

Mill Creek near Salt Lake City, Utah.

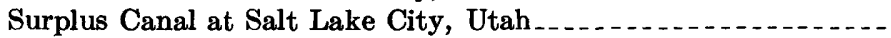

Jordan River at Salt Lake City, Utah.

Parleys Creek near Salt Lake City, Utah

Emigration Creek near Salt Lake City, Utah

Emigration Creek near Salt Lake City, Utah.......

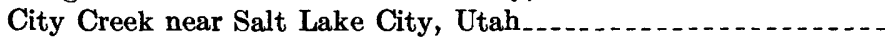

Rush Valley . . . . .

Vernon Creek near Vernon, Utah.

Great Salt Lake Desert. ...

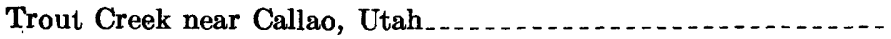

Deep Creek near Ibapah, Utah.....

Bar Creek near Ibapah, Utah .......

Tributaries between Great Salt Lake Desert and Bear River........

Dove Creek near Park Valley, Utah . . . . . . . . . . . . . .

West Fork Tenmile Creek near Park Valley, Utah...........

Blue Spring Creek near Snowville, Utah. ...

Sevier Lake basin

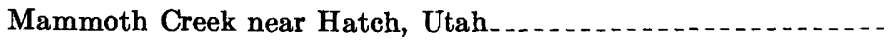

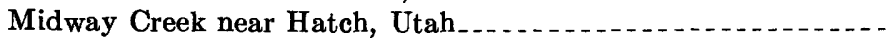

Duck Creek near Hatch, Utah. . . . . . . . .

Asay Creek above West Fork, near Hatch, Utah . . . . . . .

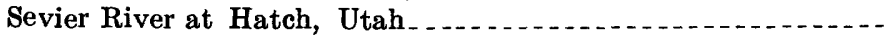

Red Canyon tributary near Bryce Canyon, Utah .............

Panguitch Creek above canals, near Panguitch, Utah........

Sevier River near Cireleville, Utah. . .

Sevier River near Kingston, Utah . . .

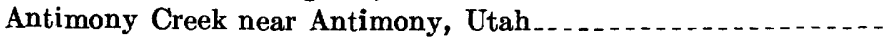

Otter Creek above reservoir, near Antimony, Utah............

East Fork Sevier River near Kingston, Utah. . . . . . . . .

Sevier River below Piute Dam, near Marysvale, Utah. .........

Sevier River above Clear Creek, near Sevier, Utah...........

Clear Creek above diversions, near Sevier, Utah. ............. 
Gaging-station records-Continued

Page

Sevier Lake basin-Continued

Clear Creek at Sevier, Utah

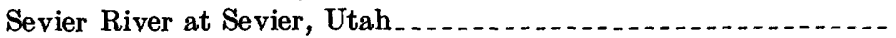

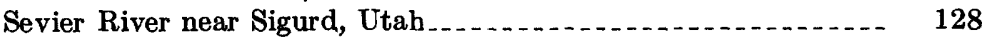

Salina Creek at Salina, Utah._._.

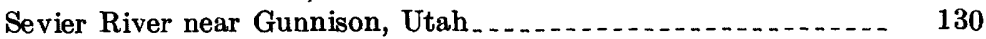

Pleasant Creek near Mount Pleasant, Utah................. 130

Twin Creek near Mount Pleasant, Utah. _... . . . . . . . . . 131

Sixmile Creek near Sterling, Utah. . . .

San Pitch River near Gunnison, Utah...................... 131

Sevier River below San Pitch River, near Gunnison, Utah....... 132

Sevier River near Juab, Utah. ......................... 133

Sevier River at Leamington, Utah....................... 133

Sevier River near Lynndyl, Utah.

Sevier River near Delta, Utah $\ldots \ldots \ldots \ldots$

Sevier River at Oasis, Utah_...

Pavant Valley

Chalk Creek near Fillmore, Utah _................... 135

Beaver River basin . .

Three Creeks near Beaver, Utah_.....

Beaver River near Beaver, Utah....................... 136

Beaver River at Adamsville, Utah....................... 137

Beaver River at Rockyford Dam, near Minersville, Utah._.... 138

Beaver River at Minersville, Utah.................... 139

Big Wash near Milford, Utah _.

Parowan Valley . . . . 139

Fremont Wash near Paragonah, Utah.

Center Creek near Parowan, Utah................ 140

Cedar City Valley . .

Ashdown Creek near Cedar City, Utah.................. 140

Coal Creek above Right Hand Creek, near Cedar City, Utah. . - 141

Coal Creek near Cedar City, Utah_................... 141

Shurtz Creek near Cedar City, Utah................... 142

Duncan Creek near Cedar City, Utah................. 142

Snake Valley

Baker Creek at narrows near Baker, Nev ...

Lehman Creek near Baker, Nev....... 143

Death Valley . . . . . . .

Big Dip Creek near Stovepipe Wells, Calif................. 144

Spring Creek at Furnace Creek Inn, Calif . . . . . . . . . 144

Ibex Creek near Tecopa, Calif .............. 144

Yucca Creek near Yucca Grove, Calif................ 145

Salsberry Creek near Shoshone, Calif _...

Bristol Lake basin _........... 145

Creosote Creek near Cadiz, Calif ............. 145

Gourd Creek near Ludlow, Calif ............ 146

Salton Sea basin

San Felipe Creek near Julian, Calif .

Coyote Creek near Borrego Springs, Calif

Borrego Palm Creek near Borrego Springs, Calif _... . . . . . . 147

Whitewater River at White Water, Calif . . . . 148

Tahquitz Creek near Palm Springs, Calif _................... 148 
Gaging-station records-Continued

Salton Sea basin-Continued

Palm Canyon Creek near Palm Springs, Calif ........ . . . . 149

Andreas Creek near Palm Springs, Calif ............... 150

Mojave River basin _...

Deep Creek near Hesperia, Calif

West Fork Mojave River near Hesperia, Calif ........... 152

Mojave River at lower narrows near Victorville, Calif......... 153

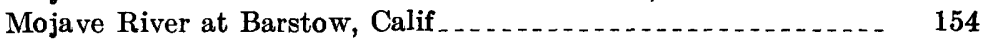

Zzyzx Creek near Baker, Calif...

Antelope Valley

Big Rock Creek near Valyermo, Calif _...

Little Rock Creek near Little Rock, Calif ................... 157

Amargosa Creek tributary near Palmdale, Calif . .

Pine Creek near Palmdale, Calif.................... 158

Spencer Canyon Creek near Fairmont, Calif . . . . . . 158

Oak Creek near Mojave, Calif

Joshua Creek near Mojave, Calif . . . .

Koehn Lake basin . . .

Pewee Creek near Randsburg, Calif.................. 159

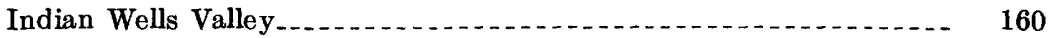

Salt Wells Creek near Westend, Calif _........ 160

Crust Creek near Westend, Calif . . . . . 160

Owens Lake basin . .

Convict Creek near Mammoth Lakes, Calif.............. 160

Owens River near Round Valley, Calif ..................... 161

Rock Creek at Little Round Valley, near Bishop, Calif ....... 162

Rock Creek at Sherwin Hill, near Bishop, Calif ............... 162

Rock Creek near Round Valley, Calif ...

Pine Creek at division box, near Bishop, Calif . . . . . . . . . 163

Pine Creek near Round Valley, Calif ...................... 164

Owens River at Pleasant Valley, near Bishop, Calif........... 165

Silver Canyon Creek near Laws, Calif ................... 165

Bishop Creek near Bishop, Calif...... . . . . . . . . .

Big Pine Creek near Big Pine, Calif......

Owens River near Big Pine, Calif........................ 167

Taboose Creek near Aberdeen, Calif . . . . . . . . . . . . . . . 168

Goodale Creek near Aberdeen, Calif . . . . . . . .

Oak Creek near Independence, Calif _... $\ldots \ldots$

Independence Creek below Pinyon Creek, near Independence, Calif

Independence Creek near Independence, Calif ..............

Owens River near Lone Pine, Calif . . . . . . .

Lone Pine Creek near Lone Pine, Calif . . . . .

Tuttle Creek near Lone Pine, Calif . . . . . . . . . . . . . . .

Owens River at Keeler Bridge, near Lone Pine, Calif..........

Cottonwood Creek near Olancha, Calif... . . .

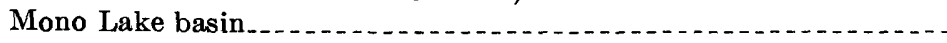

Rush Creek above Grant Lake, near June Lake, Calif

Lee Vining Creek near Lee Vining, Calif..................... 173

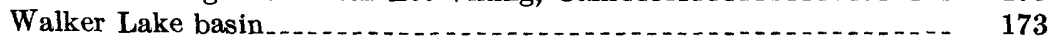

Virginia Creek near Bridgeport, Calif . . .

Green Creek near Bridgeport, Calif . . . . 
Gaging-station records-Continued

Walker Lake basin-Continued

Summers Creek near Bridgeport, Calif

Page

Robinson Creek at Twin Lakes Outlet, near Bridgeport, Calif - -

Buckeye Creek near Bridgeport, Calif.......

Swager Creek near Bridgeport, Calif

East Walker River near Bridgeport, Calif

East Walker River above Strosnider ditch, near Mason, Nev....

East Walker River near Yerington, Nev..........

East Walker River near Mason, Nev

West Walker River at Leavitt Meadows, near Coleville, Calif.--

Little Walker River near Bridgeport, Calif ..................

West Walker River below Little Walker River, near Coleville, Calif

West Walker River near Coleville, Calif . . . . . . . . . . . . . .

West Walker River at Hoye Bridge, near Wellington, Nev ......

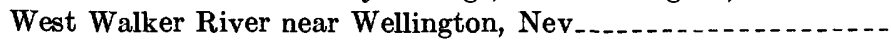

West Walker River near Hudson, Nev . . . . .

Walkei River at Mason, Nev . . . . .

Walker River near Wabuska, Nev . .

Walker River at Schurz, Nev

East Fork Carson River above Soda Springs ranger station, nee.r Markleeville, Calif

Silver King Creek near Coleville, Calif . . Wolf Creek near Markleeville, Calif

Silver Creek below Pennsylvania Creek, near Markleeville, Calif - -

Hot Springs Creek near Markleeville, Calif . . . . . . . . . . .

East Fork Carson River near Gardnerville, Nev ..............

West Fork Carson River above Woodfords, Calif . . . . . . . . .

West Fork Carson River at Woodfords, Calif . . . .

Clear Creek near Carson City, Nev....

Carson River near Carson City, Nev

Carson River near Empire, Nev

186

187

188

188

189

190

191

192

Carson River near Fort Churchill, Nev

Humboldt River basin

193

193

194

Starr Creek near Deeth, Nev.

194

Marys River near Deeth, Nev

Marys River above Hot Springs Creek, near Deeth, Nev ....... 195

Secret Creek near Halleck, Nev . .

Lamoille Creek near Lamoille, Nev .

Lamoille Creek near Halleck, Nev

North Fork Humboldt River at Devils Gate, near Halleck, Nev _ _ 197

North Fork Humboldt River near Halleck, Nev ... . . . . . . . 198

Humboldt River near Elko, Nev . . . . . .

South Fork Humboldt River near Lee, Nev

Huntington Creek near Lee, Nev ...................... 200

South Fork Humboldt River above Dixie Creek, near Elko, Nev - 200

South Fork Humboldt River near Elko, Nev...

Humboldt River near Carlin, Nev .

Maggie Creek at Carlin, Nev

Humboldt River at Palisade, Nev

Pine Creek near Palisade, Nev 
Gaging-station records-Continued

Humboldt River basin-Continued

Humboldt River near Argenta, Nev....................... 204

Rock Creek near Battle Mountain, Nev _...

Humboldt River at Battle Mountain, Nev ... . .

Reese River near Ione, Nev ................. 206

Humboldt River near Valmy, Nev _.._._.

Humboldt River at Comus, Nev .....

Little Humboldt River at Chimney damsite, near Paradise

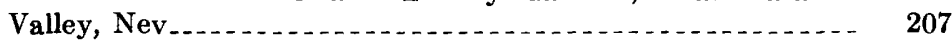

Little Humboldt River near Paradise Valley, Nev . . . . . . . . . 208

Martin Creek near Paıadise Valley, Nev _..._.

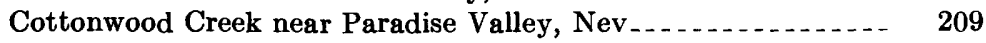

Cottonwood Creek at Paradise Valley, Nev _._. . . . . . . . 209

Humboldt River near Rose Creek, Nev_._._.

Humboldt River near Imlay, Nev . . . . _ .

Humboldt River near Rye Patch, Nev

Humboldt River near Lovelock, Nev. 212

Pyramid and Winnemucea Lakes basin.................... 212

Truckee River at Tahoe City, Calif _...

Truckee River near Truckee, Calif $\ldots \ldots$

Donner Creek at Donner Lake, near Truckee, Calif........... 214

Donner Creek near Truckee, Calif . . .

Martis Creek near Truckee, Calif _... _.

Prosser Creek at Hobart Mills, Calif . _ _ _ 215

Alder Creek near Truckee, Calif._.

Prosser Creek near Truckee, Calif . . .

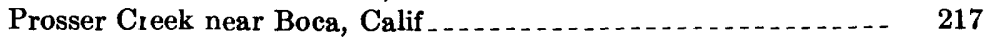

Little Truckee River near Hobart Mills, Calif _._. _ _._._. 217

Independence Creek near Truckee, Calif _... . . .

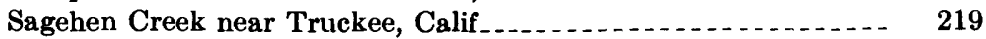

Little Truckee River above Boca Reservoir, near Boca, C ‘lif .... $\quad 219$

Little Truckee River at Boca, Calif....... . . . . . . . . . 220

Truckee River at Farad, Calif .......................... 221

Dog Creek near Verdi, Nev........ 222

Truckee River at Reno, Nev.......... 222

Franktown Creek at Franktown, Nev ..................... 223

Truckee River at Vista, Nev ...

Truckee River at Clarks, Nev ...

Truckee River below Derby Dam, near Wadsworth, Nev ...... 225

Truckee River near Nixon, Nev ......... . . . . . . . . . . . 226

Black Rock Desert. . . .

McDermitt Creek near McDermitt, Nev ............... 226

East Fork Quinn River near McDermitt, Nev............. 227

Quinn River near McDermitt, Nev . .

Honey Lake basin . . . . . . 228

Susan River at Susanville, Calif $\ldots \ldots \ldots$

Willow Creek near Susanville, Calif _...

Eagle Lake basin. . . . . . . . . .

Pine Creek near Westwood, Calif ......... 230

Warner Lakes basin................. 230

Twentymile Creek near Adel, Oreg .

Camas Creek near Lakeview, Oreg 
Gaging-station records-Continued

Warner Lakes basin-Continued

Drake Creek near Adel, Oreg .

Deep Creek above Adel, Oreg .

Deep Creek at Adel, Oreg . .

Honey Creek near Plush, Oreg ........... 234

Abert Lake basin . . . .

Chewaucan River near Paisley, Oreg

Chewaucan River at Paisley, Oreg

Chewaucan River at narrows, near Paisley, Oreg _._._.

Chewaucan River at Hotchkiss Ford, near Paisley, Oreg . . . 238

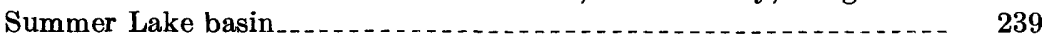

Ana River near Summer Lake, Oreg . .

Silver Lake basin._._. 239

West Fork Silver Creek near Silver Lake, Oreg _._._.

Silver Creek near Silver Lake, Oreg _._.

Buck Creek near Silver Lake, Oreg . . . . . . . . .

Malheur and Harney Lakes basin_.._.

Silvies River near Silvies, Oreg _...

Silvies River near Burns, Oreg . . . .

Donner und Blitzen River near Frenchglen, Oreg............. 243

Mud Creek near Diamond, Oreg....................... 244

Bridge Creek near Frenchglen, Oreg . .

Donner und Blitzen River near Narrows, Oreg ............. 245

Kiger Creek near Diamond, Oreg..................... 246

McCoy Creek near Diamond, Oreg . .

Riddle Creek near Diamond, Oreg...................... 247

Donner und Blitzen River near Voltage, Oreg ............... 247

Silver Creek near Riley, Oreg.

Silver Creek above Suntex, Oreg

Silver Creek near Narrows, Oreg.

Catlow Valley basin . . .

Home Creek near Beckley, Oreg . . . . . . . . . . . . . 249

Alvord Lake basin. ... . . . .

Trout Creek near Denio, Nev

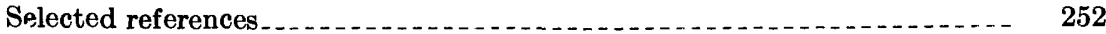

Index . . .

\section{ILLUSTRATIONS}

[Plates are in pocket]

Plates 1, 2. Maps of the Great Basin showing:

1. Hydrologic areas and location of gaging stations for which records are used in this report.

2. Flood regions.

Figure 1. Map of conterminous United States showing area covered

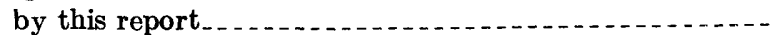

2, 3. Graph showing composite frequency curves:

2. Regions $\mathrm{A}, \mathrm{B}$, and $\mathrm{D}$

Page

3. Region $\mathrm{C}$ 
Figures 4, 5. Graphs showing variation of mean annual flood with drainPage age area and mean altitude:

4. Hydrologic area 1..... 10

5. Hydrologic area 2.

6. Graph showing variation of mean annual flood with drainage area in hydrologic areas 3-6, and 8............

7. Graph showing variation of mean annual flood with drainage area and mean altitude in hydrologic area 7

8-15. Graph showing variation of 50-year flood with channel distance upstream from-

8. Mouth, Bear River

9. Mouth, Weber River. 14

10. Mouth, Provo River

11. Mouth, Sevier River.

12. Walker Lake, Walker River. . .

13. Mouth, Carson River......... 16

14. Rye Patch Dam, Humboldt River. . . . . . . . . 16

15. Mouth, Truckee River....... 17

\section{TABLES}

TABLE 1. Data for gaging stations used to define regional flood-frequency relations

2. Maximum discharges at major river stations ................

3. Peak discharges at gaging stations not used to define regional flood-frequency relations

4. Peak discharges at miscellaneous sites and unusual foods at short-term gaging stations 


\title{
MAGNITUDE AND FREQUENCY OF FLOODS IN THE UNITED STATES
}

\section{PART 10. THE GREAT BASIN}

\author{
By E. Butler, J. K. Reid, and V. K. Berwick
}

\begin{abstract}
The probable magnitude of floods of any recurrence interval between 1.1 and 50 years for any stream in the Great Basin can be determined by methods presented in this report.

The Great Basin comprises nearly all of Nevada, western Utah, eastern California, and parts of Idaho, Oregon, and Wyoming. The physiography of the basin is a series of mountain ranges and desert valleys, which trend in a nor thsouth direction. Extreme variations in climate from arid to humid aris attributed to the mountains, which, in general, are at right angles to the prevailing westerly winds. The area is subject to cloudburst floods and mud-rock flows, and this situation of ten results in high rates of runoff and heavy erosion from small drainage basins. The greater part of the basin is desert, and kecause of the paucity of flood data, the flood characteristics are poorly defined.

Two sets of curves are provided for estimating the magnitude and frequency of floods: (1) curves that represent the ratio of a flood of any frequency to the mean annual flood, and (2) curves that relate the mean annual flood to the size of the drainage basin and, where significant, to the mean altitude of the basin. Using these curves, a flood of a selected frequency can be determined fo" any site within the range of the base data. Separate 50-year flood graphs are shown for most of the larger rivers that are affected by regulation or diversion.

The report also contains station descriptions and lists of peak discl arges for 364 gaging stations at which flood records have been collected for 5 or mrre years.
\end{abstract}

\section{INTRODUCTION \\ PURPOSE AND SCOPE}

The purpose of this report is to provide a method for estime ting the magnitude and the frequency of floods in the Great Basin and to present a compilation of flood data for gaging stations having 5 or more years of annual-flood record.

The area covered by this report (fig. 1) includes all the Gres.t Basin within the United States and is designated Part 10 in the series of reports published by the U.S. Geological Survey entitled "Surface Water Supply of the United States." 
The design of structures subject to floods should include a study of the magnitude and frequency of expected floods because a structure that has inadequate capacity may fail and one that has excessive hydraulic capacity may involve exorbitant costs.

The flood history of a stream serves as a guide for the determination of future floods. Flood records can be obtained for an individual site and used to predict future flood events, but predictions besed only on the record of the individual site may be considerably in error if the record is not representative of the long-term average. U.S. Geological Survey engineers and others have formulated methods for deriving flood-frequency relations by correlation of past flood records with basin characteristics. A composite flood-frequency curve based on many gaging-station records adjusted to a common time base is presently considered the most logical means for predicting f'ture floods anywhere within a homogeneous flood region.

\section{ACKNOWLEDGMENTS}

This report was prepared in the Surface Water district office of the U.S. Geological Survey, Salt Lake City, Utah, under the general direction of M. T. Wilson, district engineer. The authors were assisted in the preparation of this report by Leah L. Stewart, engineering aid, and other district personnel. Technical guidance on analytical procedure and review was furnished by Harry Hulsing, hydraulic engineer, U.S. Geological Survey, Menlo Park, Calif. Technical assistance was also furnished by Tate Dalrymple and A. Rice Green, hydraulic engineers, U.S. Geological Survey, Washington, D.C. The flood data were collected by the U.S. Geological Survey with the assistance of other Federal and State agencies, municiralities, and irrigation districts; credit is given in the series of water-supply papers of the U.S. Geological Survey entitled "Surface Water Supply of the United States."

\section{DESCRIPTION OF THE BASIN}

\section{PHYSIOGRAPHY}

The Great Basin comprises a large interior basin in the southwestern part of the United States and has an area of about $21 \mathrm{C}, 000$ square miles. It is a somewhat heart-shaped area about 800 miles long by about 500 miles wide. The basin includes nearly all of Nevada, western Utah, the eastern edge of California, and parts of Idaho, Oregon, and Wyoming. The drainage divide is easil: identified where formed by mountain ranges but is less discernil ${ }^{1} \mathrm{e}$ in many places where it crosses large desert areas. The prominent boundaries of the basin are tne Wasatch Range and High Plateaus on the east; 


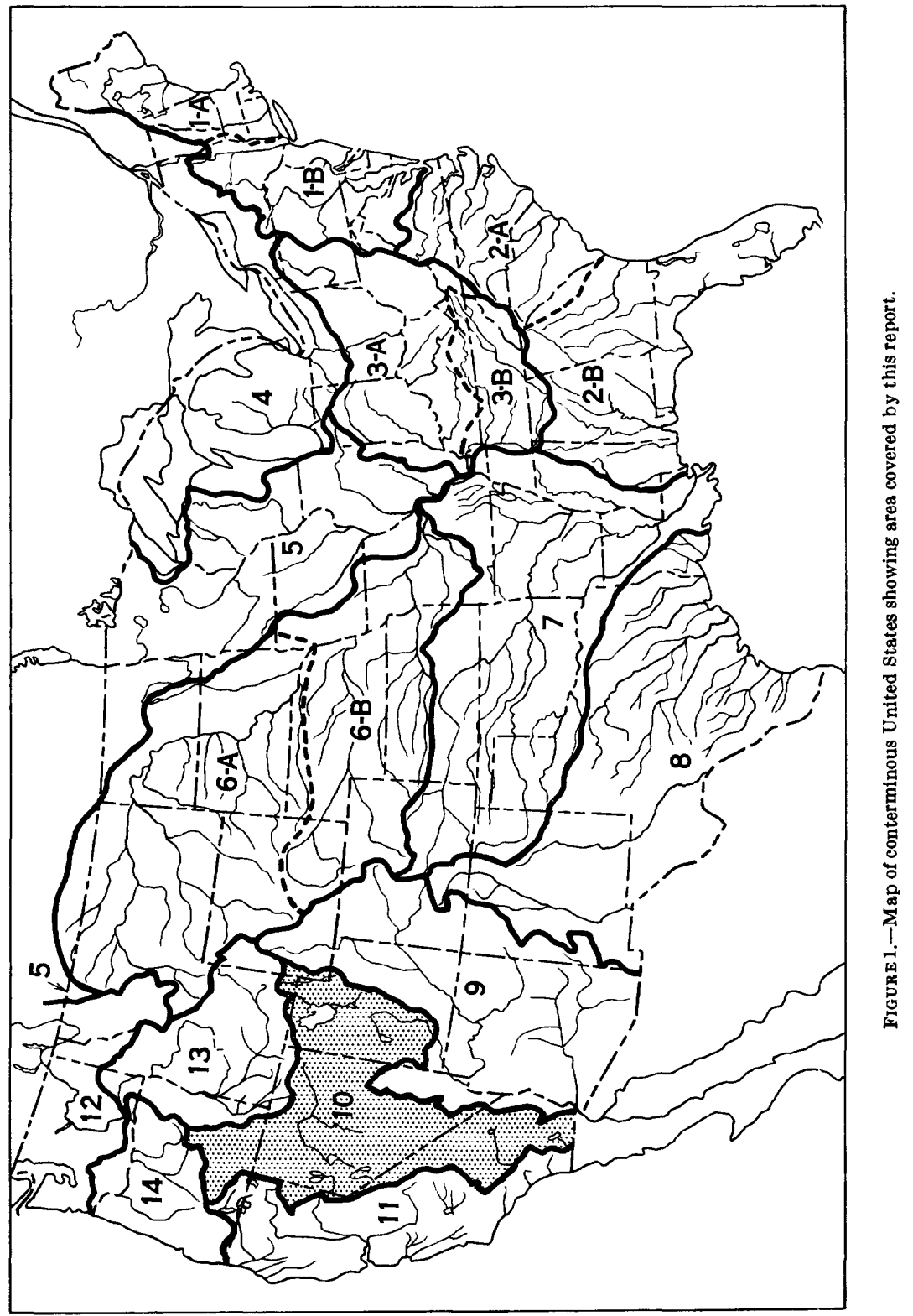


Columbia Plateau on the north; Sierra Nevada on the west; and Salton Sea and minor ranges on the south. The eastern boundary consists of mountains of the alpine type, which extend to the High Plateaus section of the south. Some of these mountains are exceptionally steep, ranging in altitude from 5,000 feet above mean sea level at their bases to more than 11,000 feet at their summits in a distance of less than 4 miles. The High Plateaus section, in general, is somewhat lower, but in places rises to about 11,000 feet. The Sierra Nevada form the central part of the western boundary. Thes mountains are of the alpine type and altitudes range from 5,000 feet above mean sea level to more than 14,000 feet. The southern boundary of the Great Basin, which extends to the Mexican border, is not clearly defined because it crosses desert areas.

A complex of mountains, valleys, and deserts forms the interior of the basin. In general, the mountains form a series of perallel ranges trending in a north-south direction, and several peaks reach an altitude of about 11,000 feet. The mountain ranges are about 50-75 miles long and 6-15 miles wide, and rise 3,000-5,000 feet above the adjacent valley floors. The altitude of the valleys ranges from 276 feet below sea level in Death Valley to about 7,000 feet above sea lovel in some valleys in the northern part of the basin. Total area of the basin is approximately equally divided between mountain ranges and valleys. The mountains rise abruptly from the valley floors; therefore, a great deal of detritus accumulates in the valleys. Much of this detrital material is permeable and accounts for some decrease in flood peaks as the water travels downstream across the valley fill. Some valley floors are covered by alkaline salts left by evaporation; the most noteworthy deposits are the Great Salt Lake Desert, Mojave Desert, and Carson Sinks. Moreover, several large flat desert areas are interspersed among the mountains; some are old lake bottoms which have not been covered with water for hundreds of years, whereas others temporarily accumulate water during a flood or a series of wet years.

The Great Basin once contained the ancient ice-age Lakes Bonneville and Lahontan. Great Salt Lake and Sevier Lake, of Utah, occupy areas which were once covered by Lake Bonneville; Honey, Pyramid, Winnemucca, Humboldt, North Carson, South Carson, and Walker Lakes occupy areas which were once coveret by Lake Lahontan. The major rivers in the Great Basin are Bear, Ogden, Weber, Provo, Jordan and Sevier in Utah; Humboldt, Reese, and Quinn in Nevada; and Truckee, Carson, and Walker in California and Nevada.

\section{CLIMATE}

The Great Basin has a wide variation in climate over short distances. Although the basin as a whole is one of the most arid regions 
in the United States, some of the high mountain areas are humid. Most of the moisture for the basin comes from the Pacifc Ocean and is carried by the prevailing westerly winds; however, the intervening mountains form barriers to the normal flow of this moistureladen air. Rain shadows (areas of lesser precipitation) on the leeward side of the mountains account for the low averaga annual rainfall in many of the interior valleys. Floods in the Great Basin occur from (1) snowmelt, (2) rain on snow, and (3) cloudburst-type storms.

Accumulation of snowfall during the winter months serves as a natural temporary reservoir from which water is released during the spring-runoff period. The snowpack is related to altitude and the higher altitudes receive the greater accumulation. Snowmelt floods occur during the April-June period.

Rain-on-snow floods generally occur during the November-March period. Snow can absorb a considerable volume of rainfall before runoff occurs. When melted, the snow contributes to the volume of water released, and this increase in volume often causes severe floods. A large number of these rain-on-snow floods have been recorded in the western part of the Great Basin along the Sierra Nevada. Occasionally rain on frozen ground causes floods because most of the rainfall appears directly as runoff.

Thunderstorms and resultant floods caused by the high-intensity precipitation of a small area occur principally during the summer and fall months. Thunderstorms often develop in flat desert ar as. All parts of the Great Basin are subject to thunderstorms; however, they are more frequent in the southeastern part.

\section{FLOOD-FREQUENCY ANALYSIS}

Methods used in the analytical part of this report are based on techniques formulated by engineers of the Water Resources $D$ : vision of the U.S. Geological Survey and others; these methods are described by Dalrymple (1960). In general, the methods consist of first defining flood-frequency relations at a point on a stream by using gagingstation records and then combining many point relations to obtain a regional frequency relation that can be applied to all streams in a large homogeneous region.

\section{FLOOD FREQUENCY AT A GAGING STATION}

The qualifications for streamflow records were that they should not be materially affected by regulation or diversion and that they should have more than 5 years of annual peak record; sucl records were collected at 113 gaging stations. (See pl. 1.) To be comparable, 
all flood records should represent natural streamflow for the same base period. For this study, the base period selected is 1938-59.

The flood peaks were arrayed in order of magnitude. The recurrence interval for each annual flood was computed by the formula $T=(n+1) / m . \quad T$ is the recurrence interval in years, $n$ is the number of years of record, and $m$ is the order number, beginning with the largest flood as 1 .

Coordinates of the frequency curves are the recurrenc? interval $T$ as the abscissa and the discharge as the ordinate. The frequency curve for many sites approaches a straight line when special probability paper is used (Powell, 1943).

\section{TYPES OF FLOOD SERHES}

Flood data for a gaging station can be analyzed two ways: (1) as an annual flood series in which the highest momentary peak discharge in a water year is used, and (2) as a partial-duration series in which all peak discharges above a selected base are u ed without regard to the number of floods in a water year. The partial-duration series is commonly used if the primary interest concerns floods with recurrence intervals of less than 10 years; however, if the primary interest concerns floods of greater than 10-year recurrence intervals, the annual flood series is usually used. For recurrence intervals of more than 10 years, the two series give virtually the same result, as shown (in years) by the following table (Langbein, 1949):

\begin{tabular}{|c|c|c|c|}
\hline $\begin{array}{l}\text { Annual } \\
\text { flood } \\
\text { series }\end{array}$ & $\begin{array}{c}\text { Partial- } \\
\text { duration } \\
\text { series }\end{array}$ & $\begin{array}{l}\text { Annual } \\
\text { flood } \\
\text { seties }\end{array}$ & $\begin{array}{c}\text { Partial } \\
\text { duration } \\
\text { series }\end{array}$ \\
\hline 1.16 & 0.5 & - n & 10 \\
\hline 1.58 & 1. 0 & 20.5 & 20 \\
\hline $2.00 \ldots$ & 1. 45 & 50.5 & 50 \\
\hline 2.54 & 2.0 & 100.5 & 100 \\
\hline $5.52 \ldots$ & 5. 0 & & \\
\hline
\end{tabular}

The difference between the two flood series is in the meaning of the recurrence interval. In the annual series, the recurrence interval is the average interval of time within which a flood of a given size will be equaled or exceeded once as an annual maximum. In the partial-duration series, the recurrence interval is the aver ge interval of time within which a flood of a given size will be equaled or exceeded once without regard to its relation to any time priod. If a frequency curve based on the partial-duration series is desired, the annual flood series curve can be converted to the partial-duration series curve from the relations shown in the preceding tal' $\mathbf{l}$.

The steps taken in this study were (1) preparation of a flcod-frequency curve for each gaging station, (2) definition of homogeneous flood 
regions based on the individual frequency curves, and (3) correlation of the mean annual flood (from step 1) with drainage area and, where significant, with mean basin altitude. All correlations in this analysis were made graphically.

\section{HOMOGENEITY}

Before numerous station records were combined on a regional basis, a test of homogeneity (see Dalrymple, 1960) was ruade to insure that all records were from a region of similar flood-frequency characteristics. Individual stations having flood-frequency curves of similar slope define a homogeneous flood region.

Outlines of the four flood regions shown on plate 2 are based on the results of the homogeneity test with due consideration given to geographic environments.

\section{REGIONAL FLOOD FREQUENCY}

A frequency graph based on the combined flood experience at several stations within a homogeneous region has much firmer support than one based on flood experience at a single station. If all gaged streams within a region show frequency graphs of tha same general shape and slope, the region is considered homogeneous with respect to flood-frequency characteristics, and the shape of the frequency graph as defined by gaged streams is considered applicable to ungaged streams in that region.

\section{COMPOSITE FREQUENCY CURVES}

A composite frequency curve based on individual curves for all gaging stations in a homogeneous flood region minimizes the variations due to chance sampling. For each gaging station, the mean annual flood was obtained from the station frequency curve. Dividing each annual flood by the mean annual flood provides a dimensionless ratio for each recurrence interval. Flood ratios from eacl station record for selected recurrence intervals were listed, and the median flood ratios derived. The median flood ratios were plotted versus their corresponding recurrence intervals. A curve averaging these points represents the flood-frequency relation for the region (firs. 2, 3). Flood ratios for any recurrence interval ( 50 years or less) are obtained from the composite frequency curves. The peak discharge is estimated by multiplying the flood ratio by the mean annual flood.

The maximum floods of record and other pertinent data for stations used in the analysis are listed in table 1.

\section{DERIVATION OF THE MEAN ANNUAL FLOOD}

To apply the regional flood-frequency curve to any selected basin, the mean annual flood for the site must be determined. A graphical 


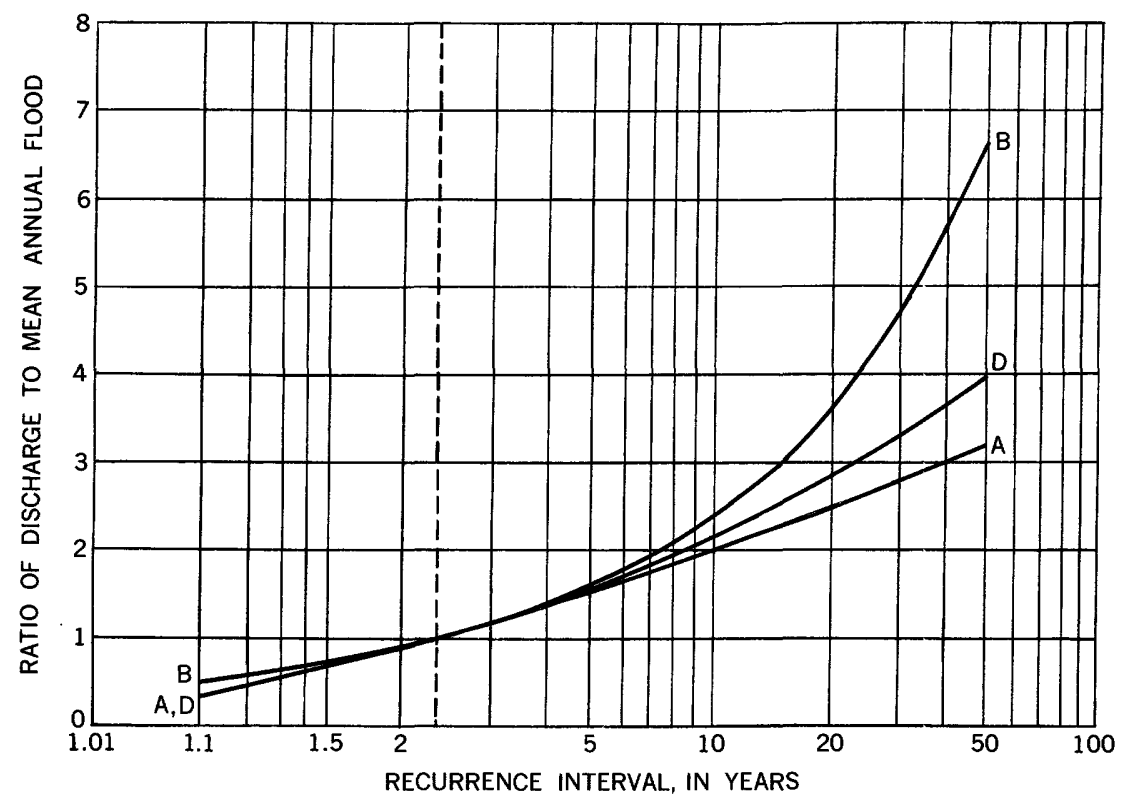

Figure 2.-Composite frequency curves, regions A, B, and D.

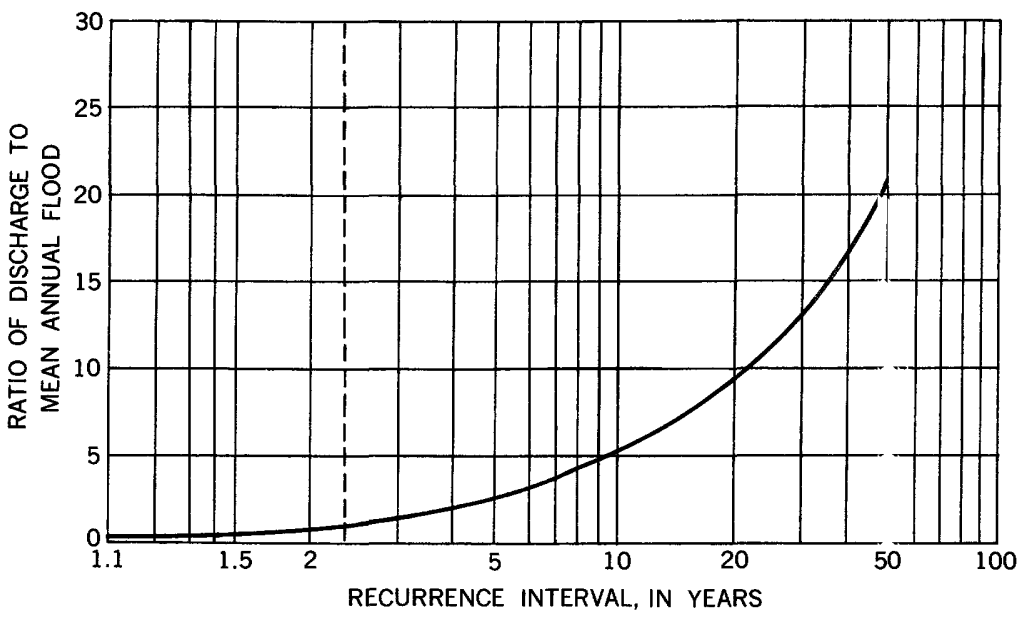

Figure 3,-Composite frequency curve, region $\mathbf{C}$.

multiple correlation of mean annual floods and drainage basin characteristics was used to determine the mean annual flood.

\section{BASIN CHARACTERISTICS}

Flood data at a given point on a stream integrate all the flood characteristics of the drainage basin to that point. Trose charac- 
teristics are complex and difficult to define or separate. Several have been used in this study to determine their significance in defining the mean annual flood.

The basin characteristics investigated were drainage are $\uparrow$, mean altitude, stream length, slope, shape, aspect, mean annual precipitation, and mean annual runoff. Those characteristics fo'ind statistically significant in multiple correlations are:

1. Drainage area.-The drainage area of a stream at a sperified location, in square miles, measured on horizontal plane.

2. Mean altitude.-The mean altitude of a drainage basin.

\section{MEAN ANNUAL FLOOD RELATIONS}

The mean annual floods for the 113 gaging stations were correlated with basin characteristics to define the 8 hydrologic areas as shown on plate 1.

The drainage area parameter was significant in each of the hydrologic areas, whereas mean altitude was significant only in areas 1, 2, and 7. For each hydrologic area a curve or a family of curves was drawn (figs. 4-7). The range of the data available in ench area determines the limits for wnich the curves should be used.

\section{MAJOR RIVERS}

Manmade development of the main stems of the Bear, Weber, Provo, Sevier, Walker, Carson, Humboldt, and Truckee Rivers has changed the regimen of these rivers to such a degree that each must be treated separately; consequently, the flood data for each part was analyzed independently, The parts referred to are identified on plates 1 and 2 by heavy dashed lines along either side of the river. Continuous records for these large rivers were available for longer periods than the 1938-59 base used in the general analysis.

The discharge for the 50-year flood at each gaging site w\& 9 related to the corresponding river miles upstream from the mouth or from a specified point (figs. 8-15). Because the regimen of the rivers is affected by regulation and diversion, it is impractical to estimate the magnitude of floods for recurrence intervals of less than 50 years.

The maximum flood of record and corresponding 50-year flood for 48 gaging stations on major rivers are listed in table 2 . The location of each station is shown on plate 1. 


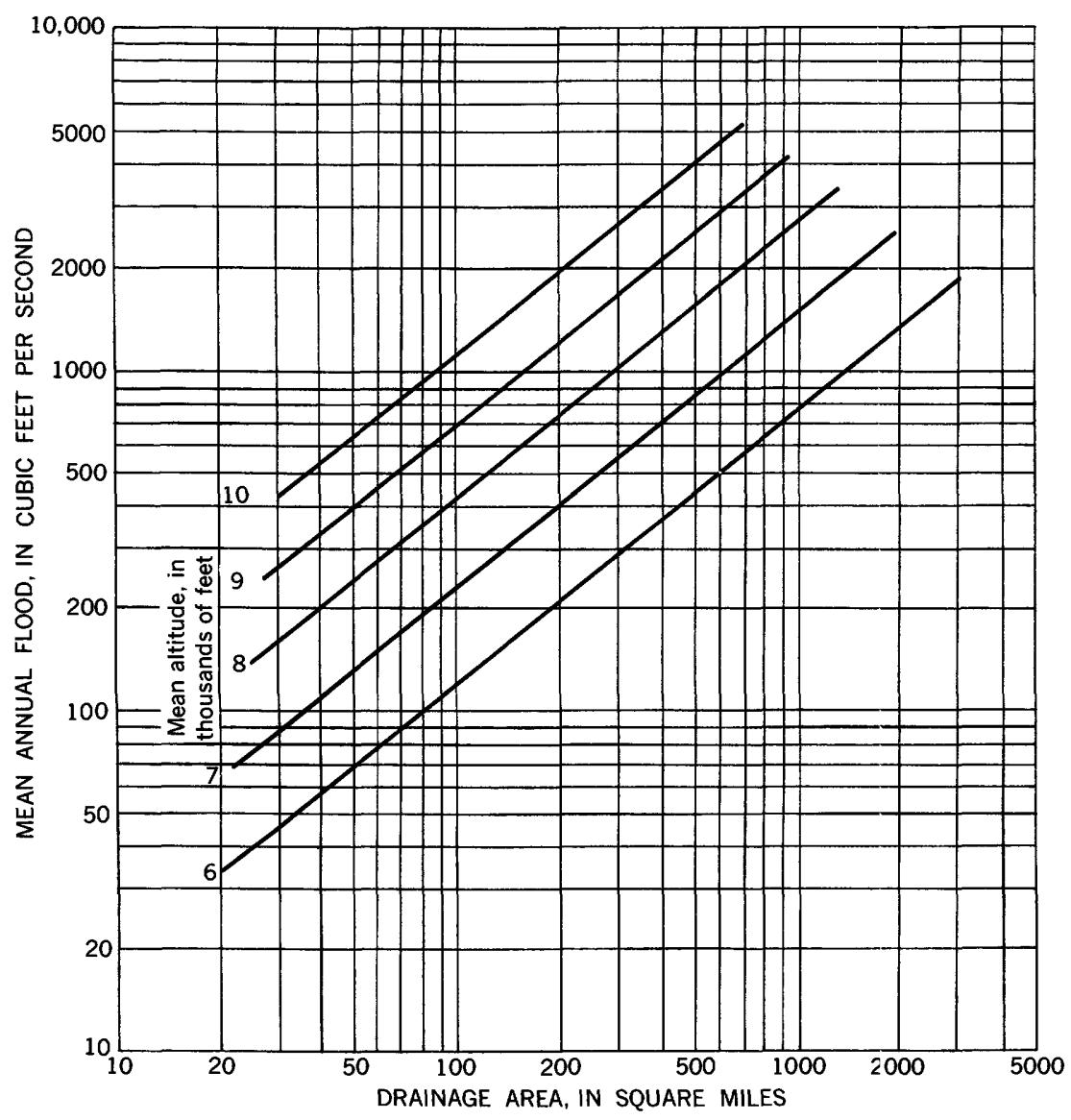

FIGURE 4.-Variation of mean annual flood with drainage area and mean altitude in hydrologic area 1. 


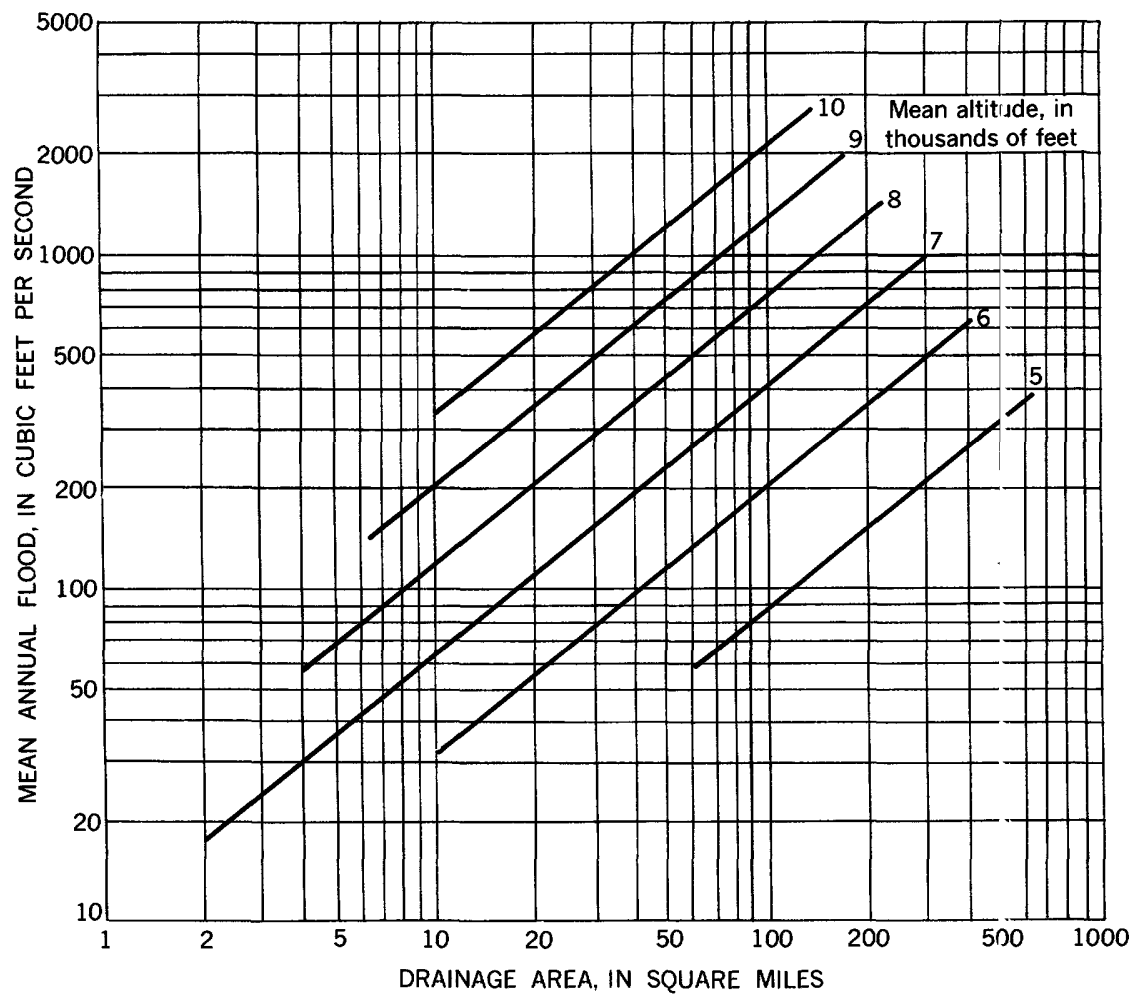

FIGURE 5.-Variation of mean annual flood with drainage area and mean altitude in hydrologic area 2. 


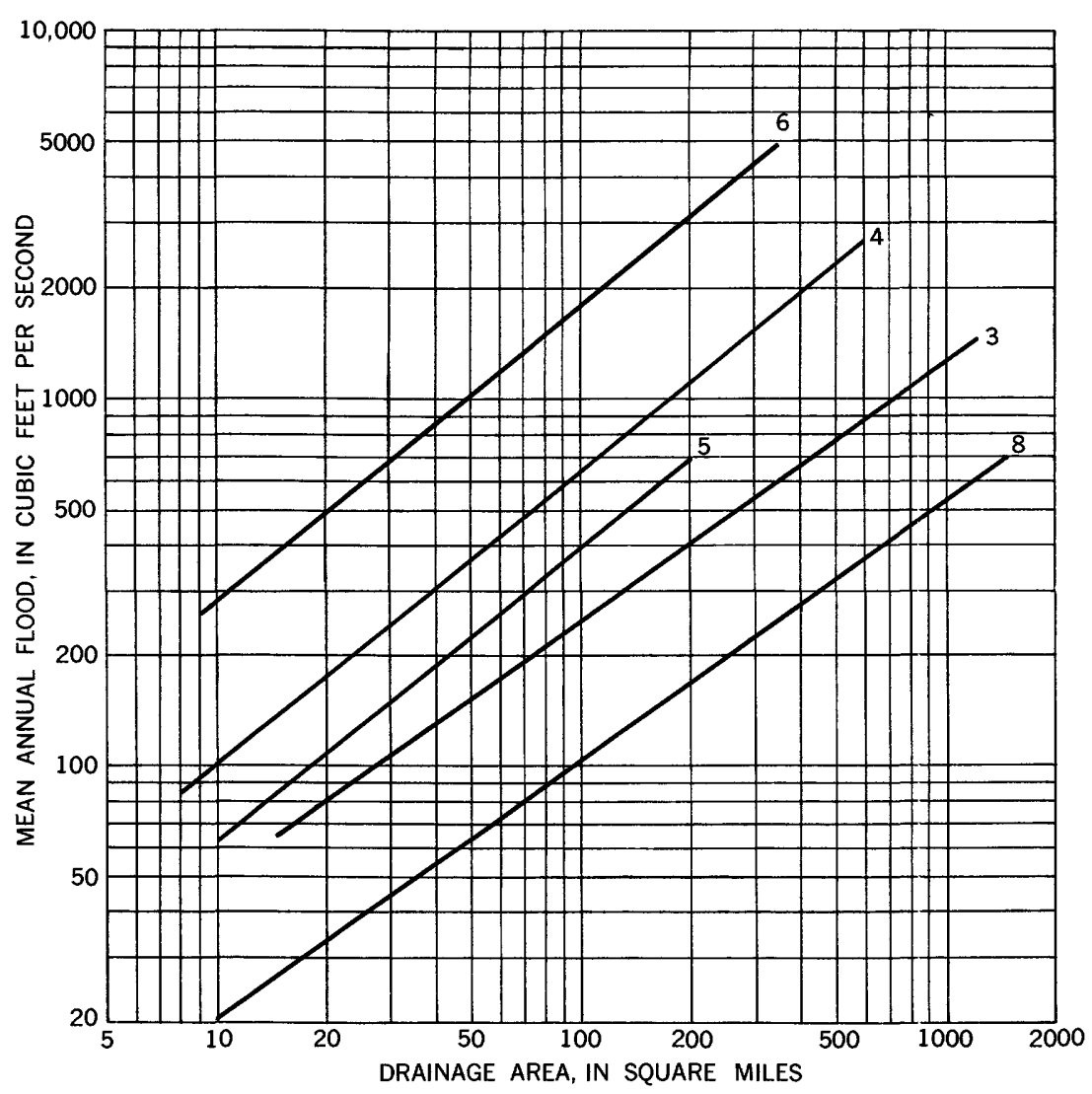

Figure 6. - Variation of mean annual flood with drainage area in hydrologic areas $3-6$, and 8 . 


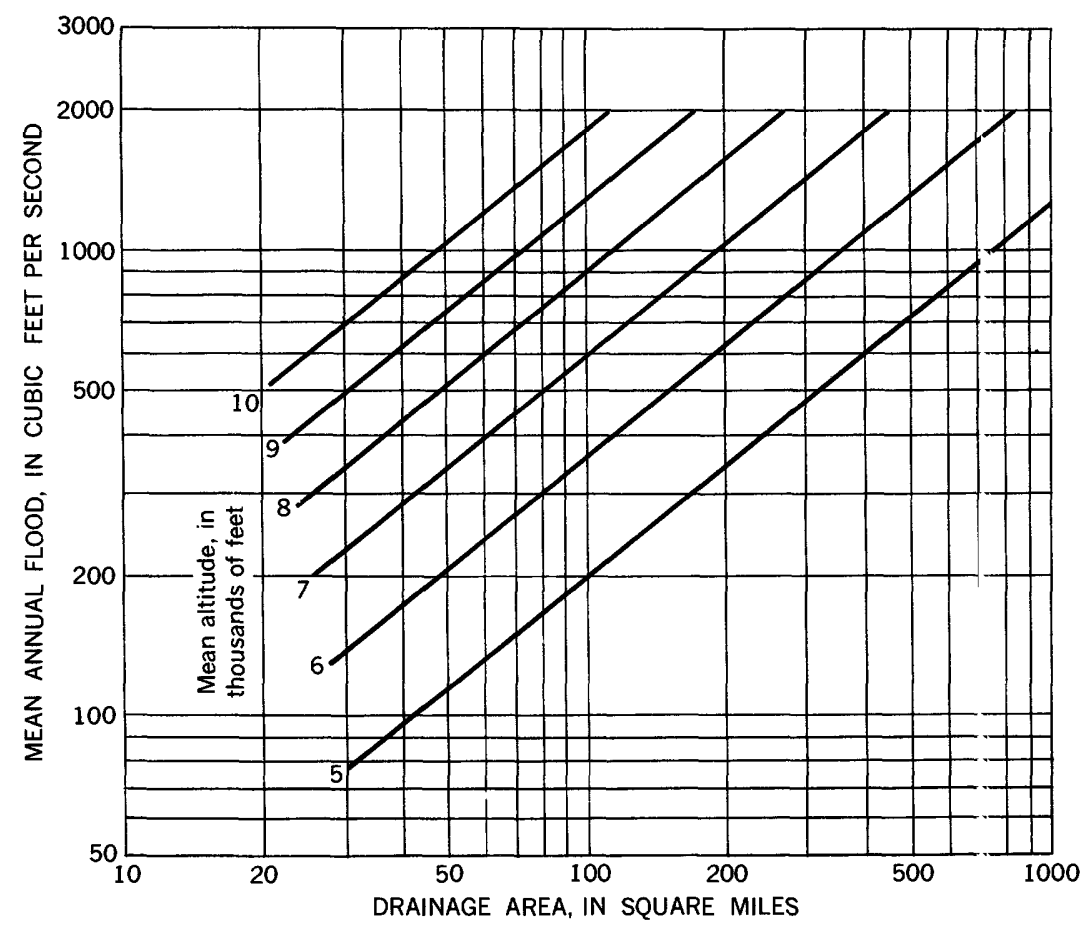

Figure 7.-Variation of mean annual flood with drainage area and mean altitude in hydrologic area 7.

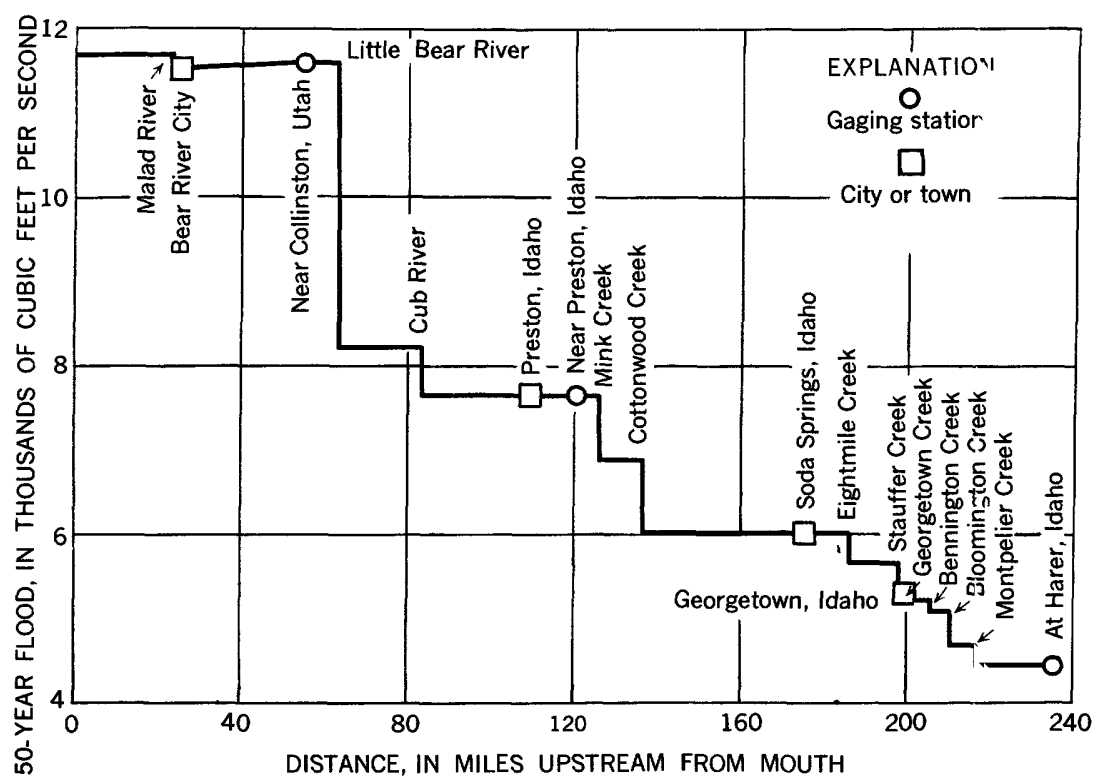

FIGURE 8.-Variation of 50-year flood with channel distance upstream from mouth, Bea- River. 


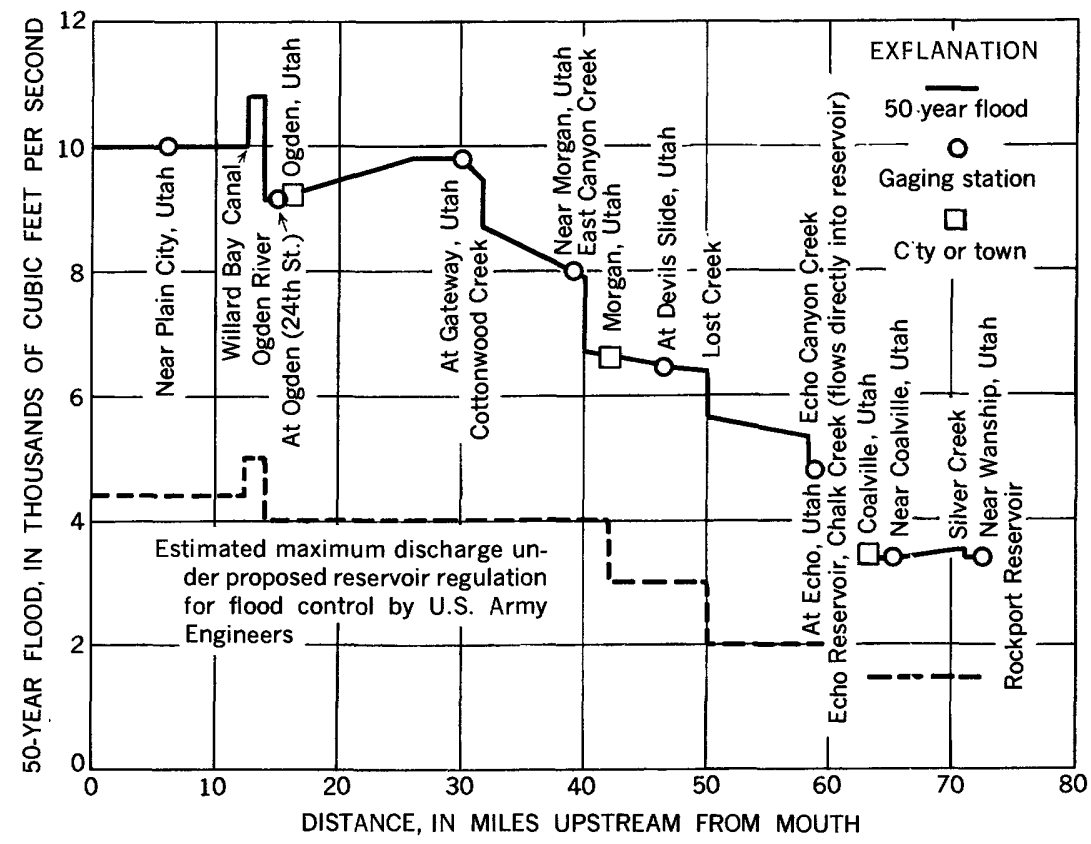

FuG ORE 9.- Variation of 50-year flood with channel distance upstream from mouth, Weber River.

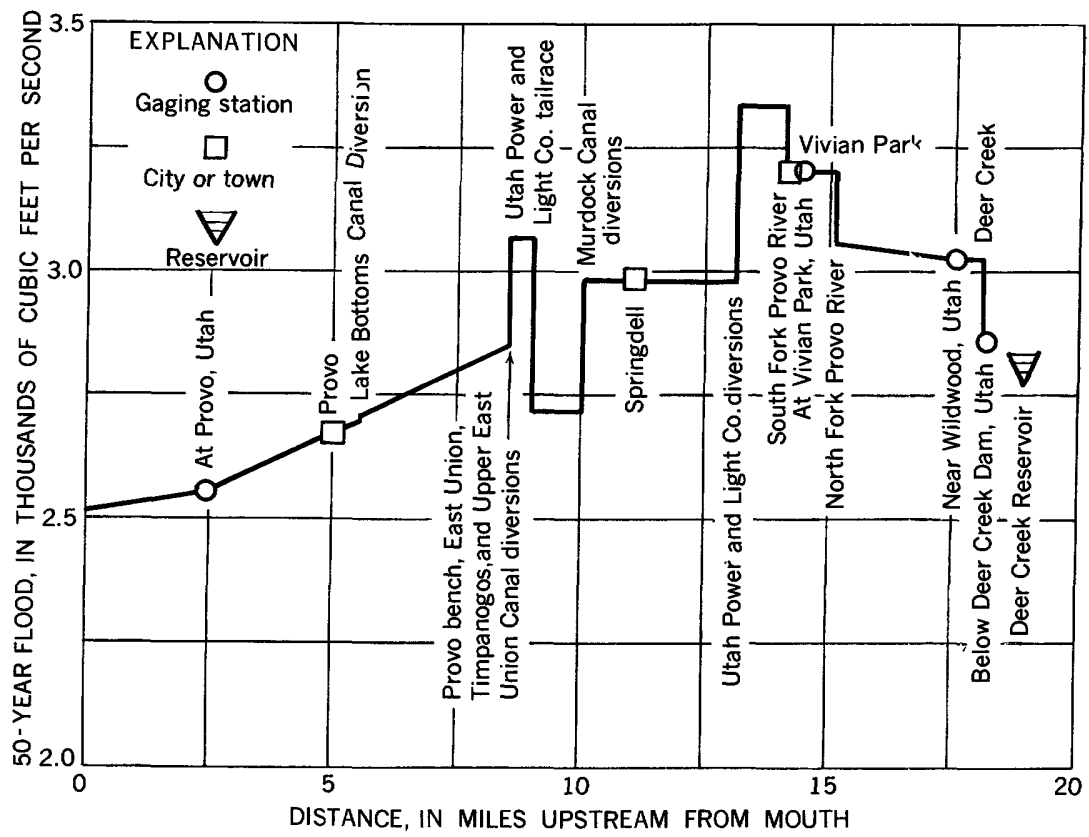

Fioure 10.- Variation of 50-year flood with channel distance upstream from mouth, Provo River. 


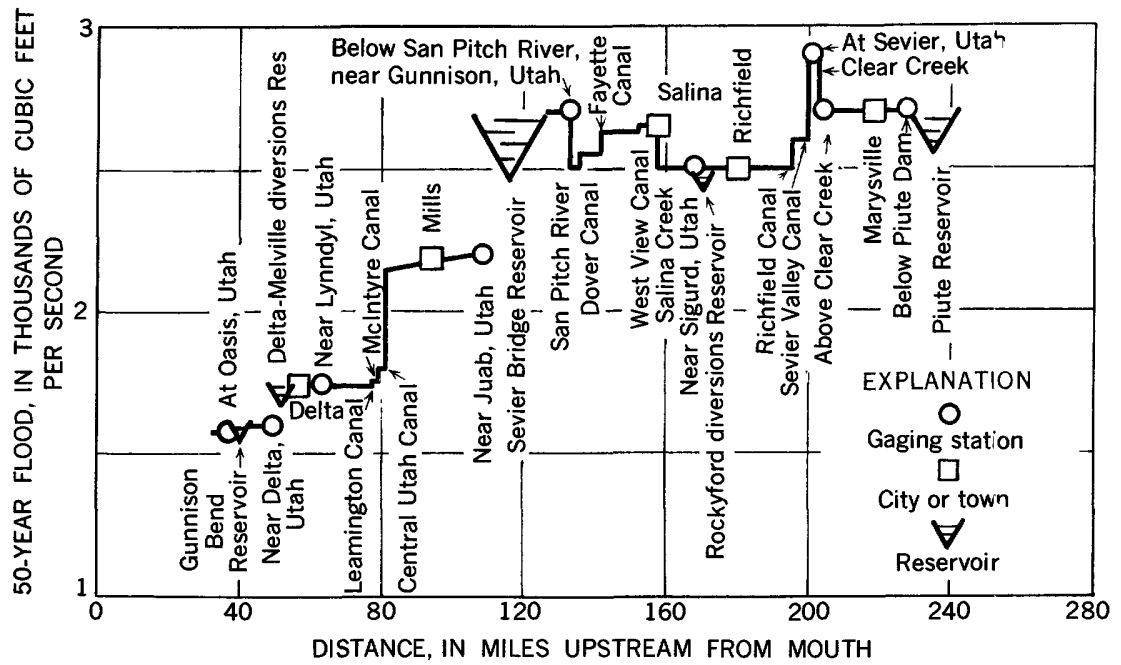

FIGURE 11.-Variation of 50-year flood with channel distance upstream from mouth, Sevier River.

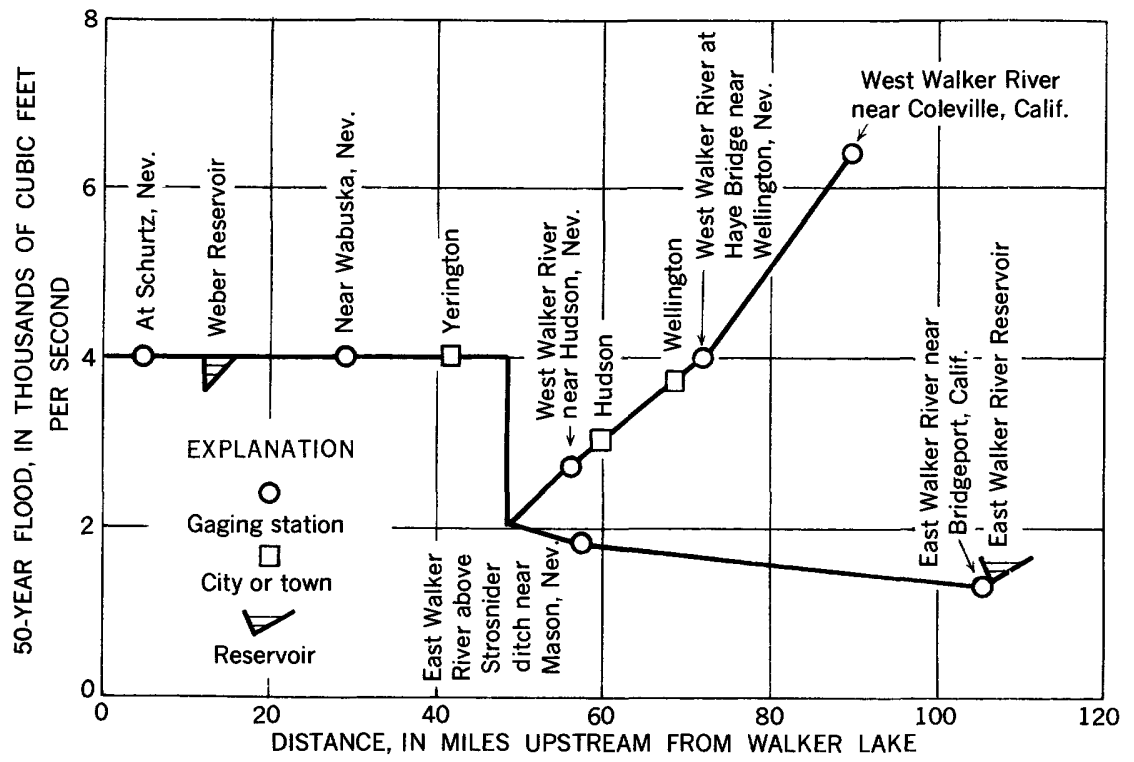

Figure 12.-Variation of 50-year flood with channel distance upstream from Walker Lake, Wal'rer River. 


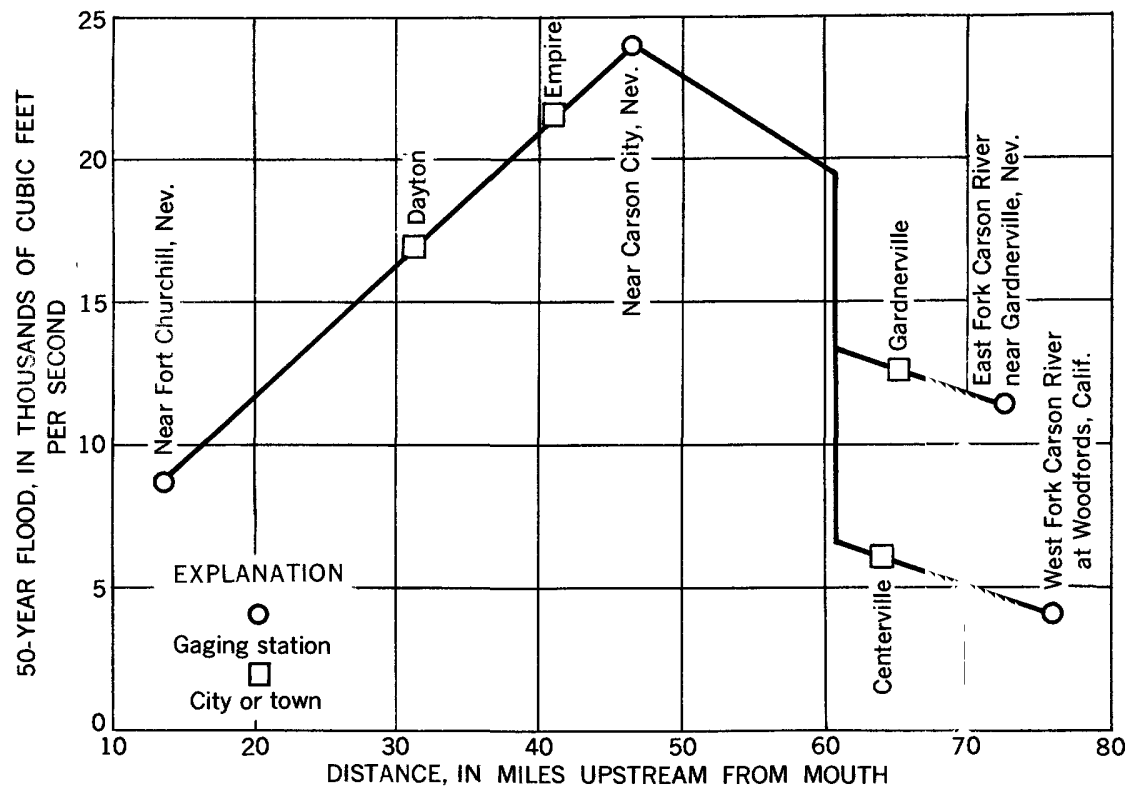

Fig URE 13.-Variation of 50-year flood with channel distance upstream from mouth, Carson River.

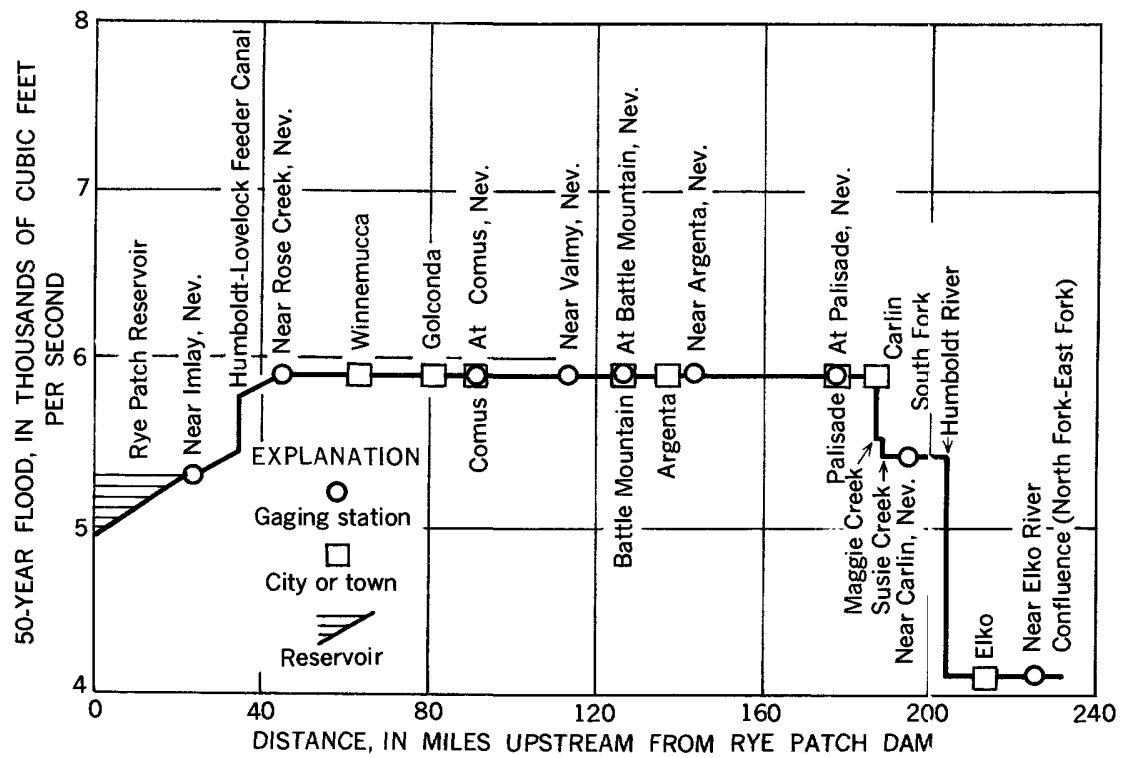

Figure 14.-Variation of 50-year flood with channel distance upstream from Rye Patch Dam, Humboldt River. 


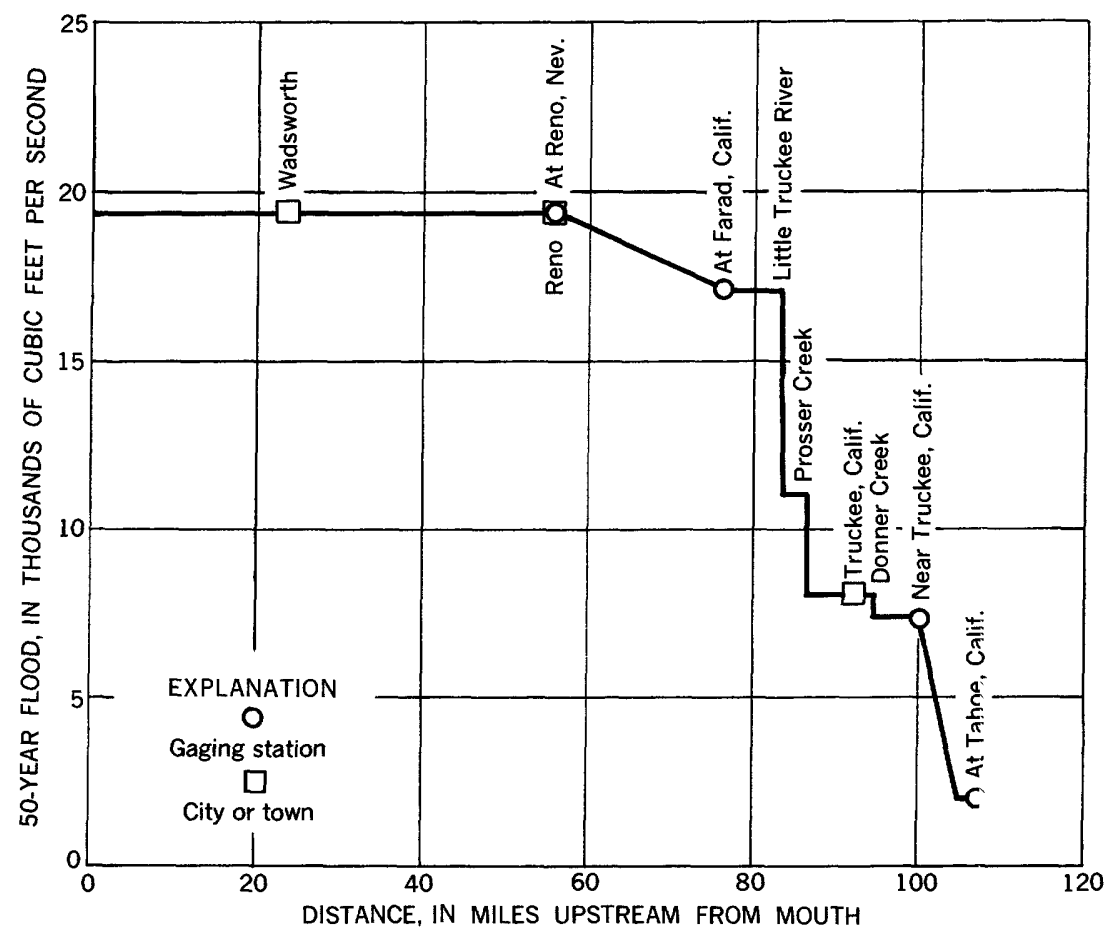

FIGURE 15.-Variation of 50-year flood with channel distance upstream from mouth, Truckee River.

\section{CLOUDBURST FLOODS AND MUD-ROCK FLOWS}

Cloudburst floods and mud-rock flows are common to most parts of the Great Basin. In general, these floods occur during the summer. Although cloudburst storms may occur on many days in on? season and cloudburst activity perhaps spread over a large area, the highintensity rainfall is limited to small areas, usually less than 1 square mile. Observations of rainfall intensities by unofficial observers have indicated that as much as 7 inches have fallen in less than 1 hour. Also, recent measurements have shown that flood peaks may exceed 3,000 cfs (cubic feet per second) per square mile from some small drainage basins. Examination of the channels and debris cones and flood history records collected from local residents indicate that the recurrence interval for these floods probably exceeds 50 years.

Some drainage basins are subject to more cloudburst floods than others even in the same general locality. For example, Pleasant Creek near Mount Pleasant, Utah, has experienced a greater number of floods than some nearby streams and has a large allurial cone covering more than 12 square miles; this cone is evidence of extreme flooding. 
Mud-rock flows are described as flows of mud, rock. debris, and water mixed to a consistency of wet concrete. Although mud-rock flows may be associated with cloudburst floods, the presence of certain conditions are required to produce them. A wide varisty of these flows has been observed, and the flows occur on mony types of streams ranging from those carrying a small load of sediment to those moving large amounts of mud, rock, and other debris. Some flows have just enough water to lubricate the mass of moving material and usually travel at a low velocity. The infrequent observation of mud-rock flows makes it difficult to estimate the probable recurrence interval at any one site.

\section{APPLICATION OF FLOOD CURVES}

The application of methods described in this report to a given drainage basin requires determining the drainage area and, for certain basins, the mean altitude.

\section{METHOD}

The magnitude of floods for selected recurrence intervals can be determined as follows:

1. Measure the drainage area in square miles above the site by planimeter or other acceptable procedure.

2. Locate site on plates 1 and 2 to determine the flood region and hydrologic area. It should be noted that the hatcring on these plates represents poorly defined areas. The hatched parts are extensions from the flood region or hydrologic ares which was considered to most nearly have similar runoff characteristics. The letter or number appearing in each hatched area is the suggested flood region or hydrologic area to use in estimating future floods in the poorly defined areas. The hatched $\varepsilon$ reas overlap adjacent areas to indicate that there is no definite line of demarcation between them; therefore, to estimate floods for streams in or near the crosshatched areas, a weighted mern should be applied to the results obtained from each of the two areas.

3. For hydrologic areas 1, 2, and 7, determine the mean basin altitude. This altitude can be determined by placing a transporent rectangular grid system overlay on a contour map and recording the altitude of the intersections within the drainage basin. The grid spacing should be such that sufficient points are picked off to determine the altitude adequately. The arithmetic average of these values represents the mean altitude of the drainage basin.

4. Use drainage area (and mean altitude, if applicable) and select the mean annual flood from appropriate hydrologic area curves (figs. 4-7). 
5. Obtain the flood ratio for the selected recurrence interval from the flood-frequency curves (figs. 2,3). When the basin is adjacent to, or in, more than one flood region or hydrologic area, weighted average values should be used.

6. Estimate the magnitude of the flood for the selected recurrence interval by multiplying the mean annual flood from ster 4 by the selected flood ratios from step 5.

\section{USE OF FLOOD-FREQUENCY ANALYSIS FOR MAJOR RIVITRS}

For the value of the 50-year flood at a point on a major river (main stem of Bear, Weber, Provo, Sevier, Walker, Carson, Humbold't, and Truckee Rivers):

1. Scale the mileage of the main stem from a known reference point as indicated on graph (figs. 8-15).

2. Select magnitude of 50-flood from graph.

Use of the main-stem analysis on some major rivers may rqquire knowledge of local conditions such as operation of reservoirs. The Weber River is the only stream that has a specific flood-contro! plan. The proposed magnitude of the controlled flow is shown for this river (fig. 9) along with the flood experience prior to the initiation of the plan.

\section{LIMITATIONS}

The magnitude and frequency of floods for recurrence intervals ranging between 1.1 and 50 years can be estimated for any site in the Great Basin, gaged or ungaged, within the limits of the base data.

Flood-frequency relations are defined from the records of streams with natural flow. Curves should not be extrapolated beyond the limits shown. Magnitude and frequency of floods on reg lated streams will require corrections for manmade development.

Frequency estimates presented are in terms of averages fo" very long periods of time, and no prediction is made for regularity of recurrence. For example, several 50-year floods may occur in a given 50 -year period, or no 50-year flood may occur in a period much longer than 50 years.

\section{GAGING-STATION RECORDS}

A tabulation of flood peaks and a brief description of the gaging stations are included in this report. All annual peaks are shown and the floods above a selected base are listed for most stations.

The downstream order of listing gaging stations and reference numbers corresponds to that used in Geological Survey water-supply papers. The peaks are listed by water year, October 1 through September 30, designated by the calendar year in which it ends. 
Peak discharges, unless otherwise noted, are the instantaneous peaks in cubic feet per second. In situations where instantaneous peak data are not available, the maximum daily discharge is shown with an appropriate footnote.

Underlines in the tabular data have the following significance:

1. Line in "Water year" column means discontinuous record.

2. Line beginning at "Date" column and extending through "Discharge" column means change in site and datum with no break in record.

3. Line in "Gage height" column means change in datum.

4. Line in "Date" and "Discharge" columns means cl ange in site, but no change in datum.

5. No underlines are used if changes in site and datum have been adjusted to present conditions.

The flood records for other gaging stations, including the 203 stations that are listed in table 3, were not used in this report for one of the following reasons: (1) Flow affected by diversions or regulations, (2) flow typical of other record used, (3) short record, less than 5 years through 1959, (4) spring fed, (5) irrigation season records only, (6) unable to extend record through base period, and (7) record consists of maximum daily only.

Peak discharges at miscellaneous sites and unusual flcods at shortterm gaging stations are listed in table 4 for 65 sites in the Great Basin. 



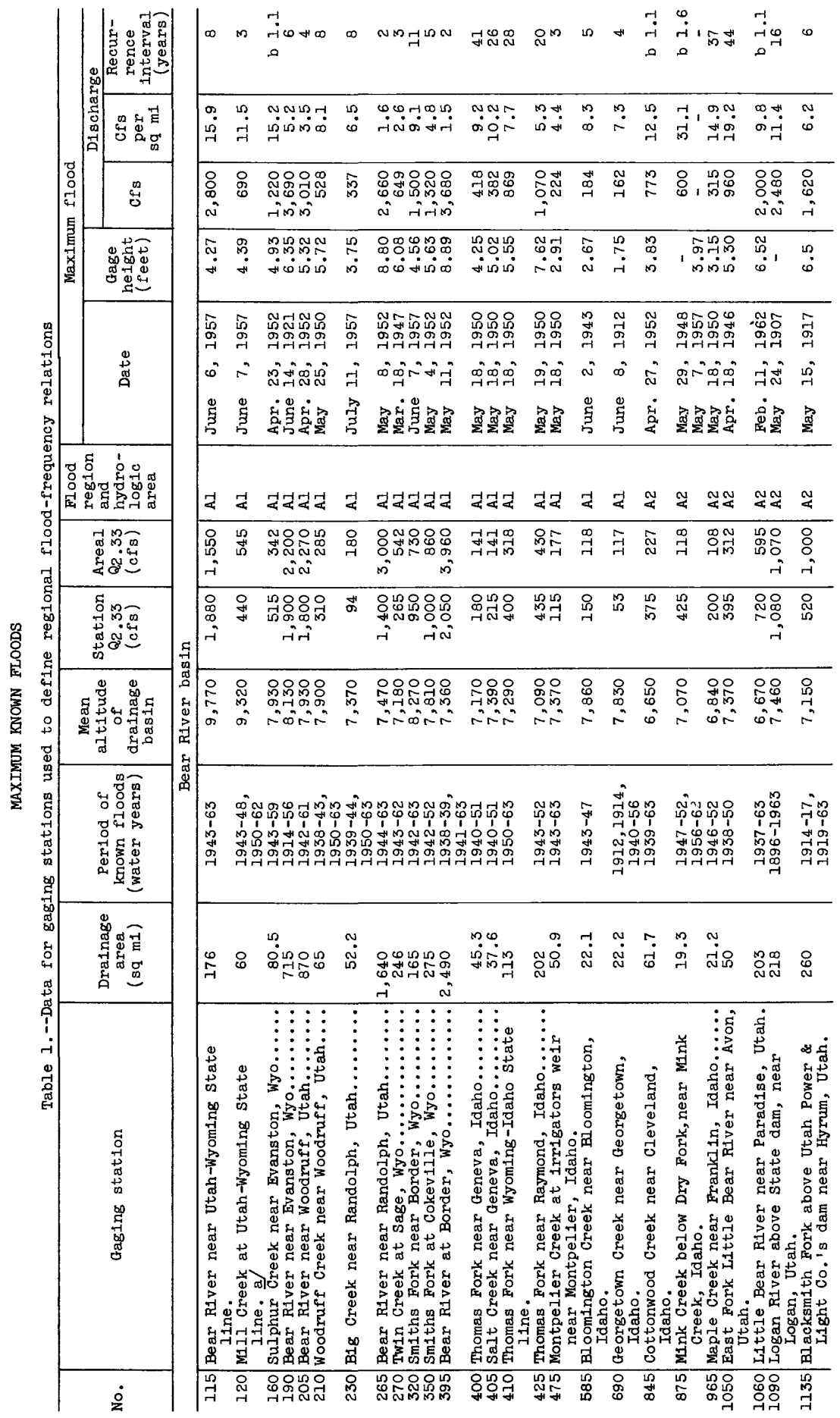




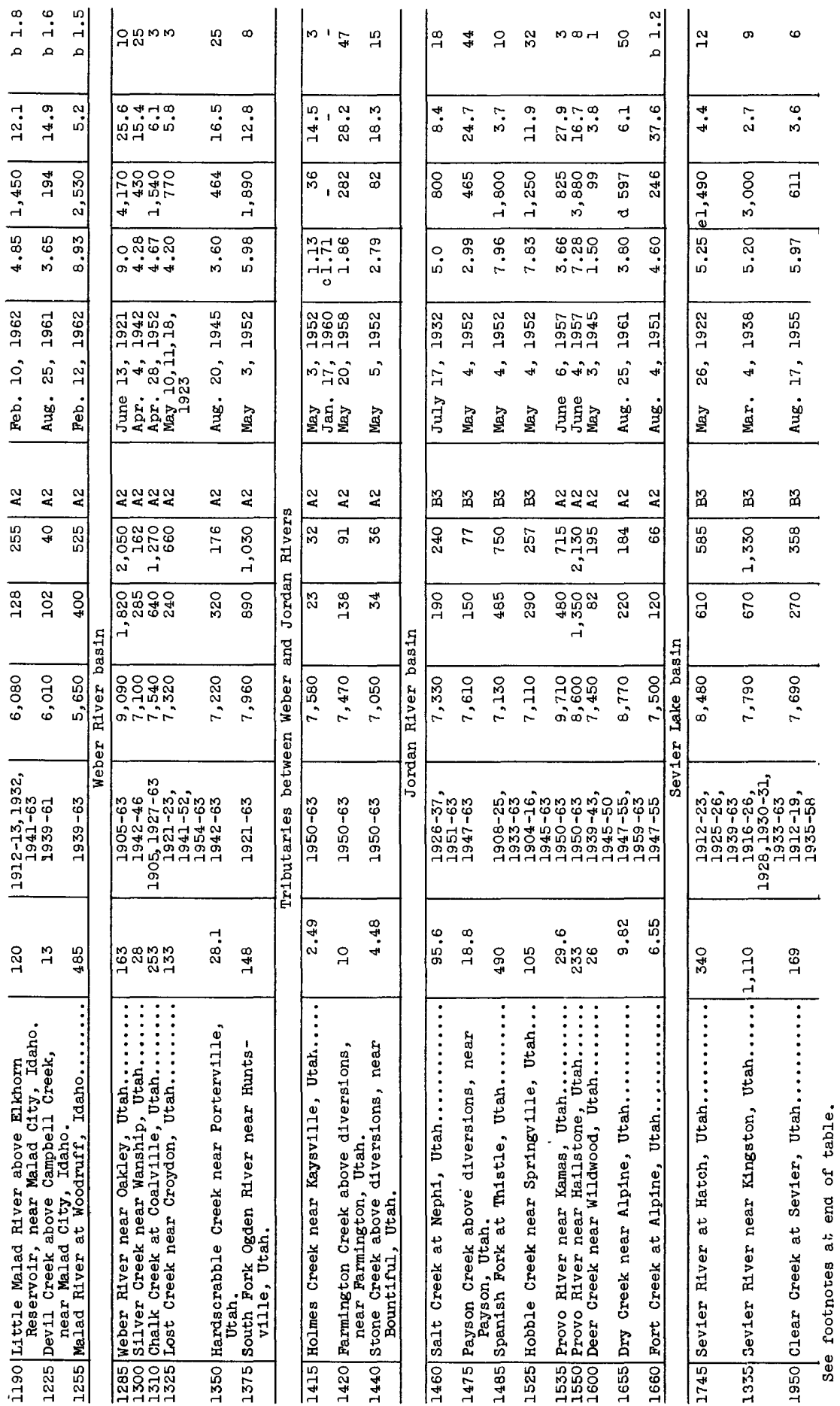




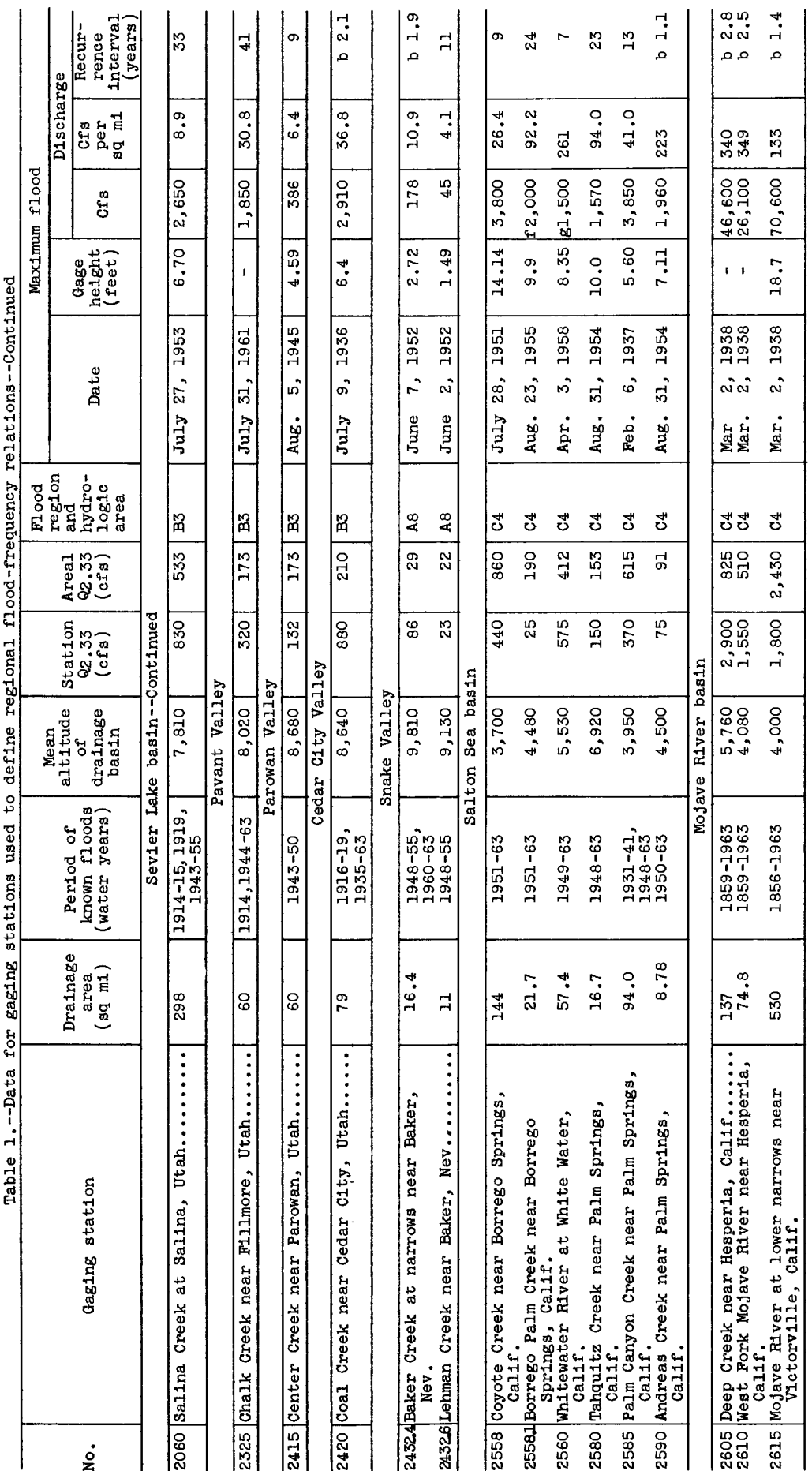




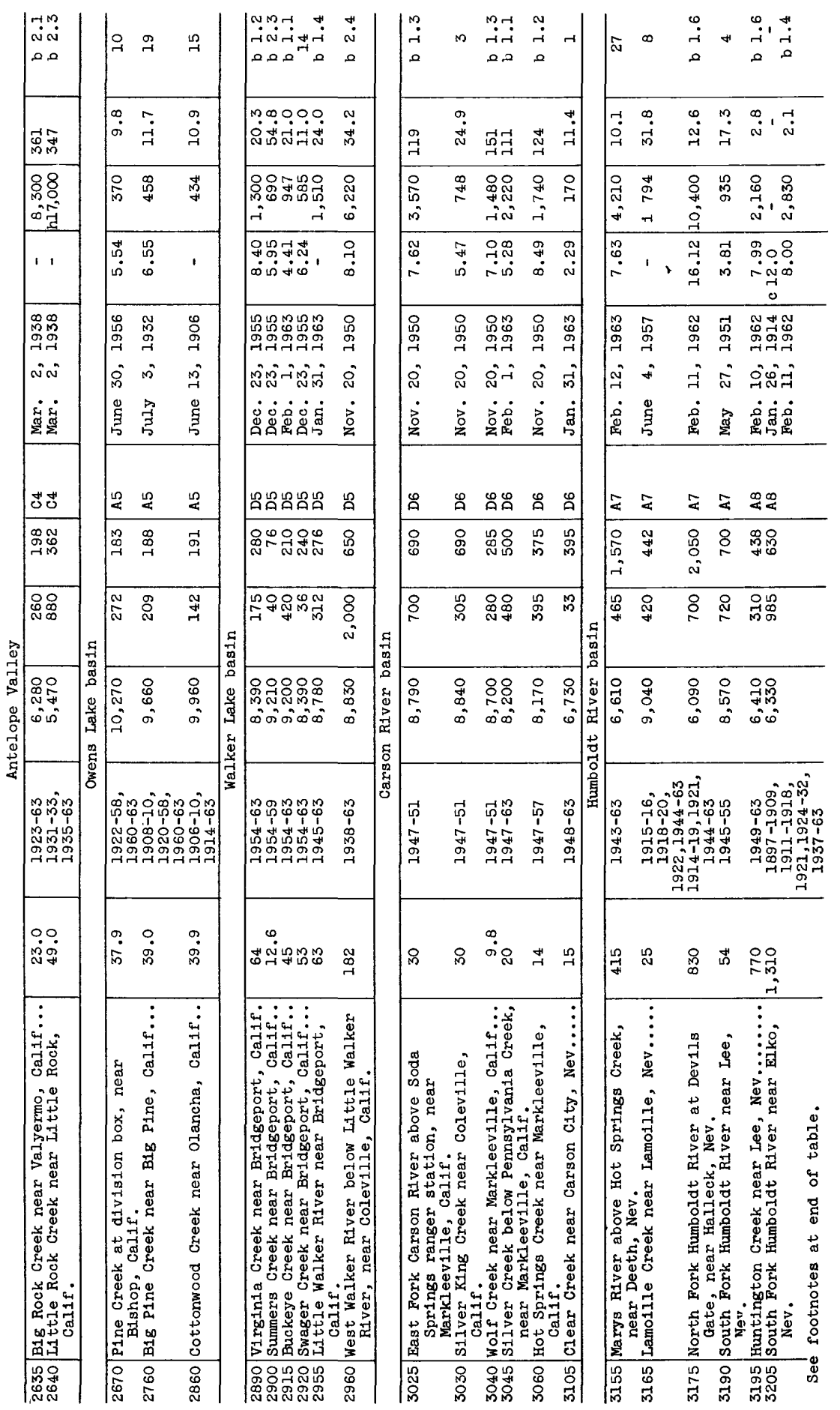




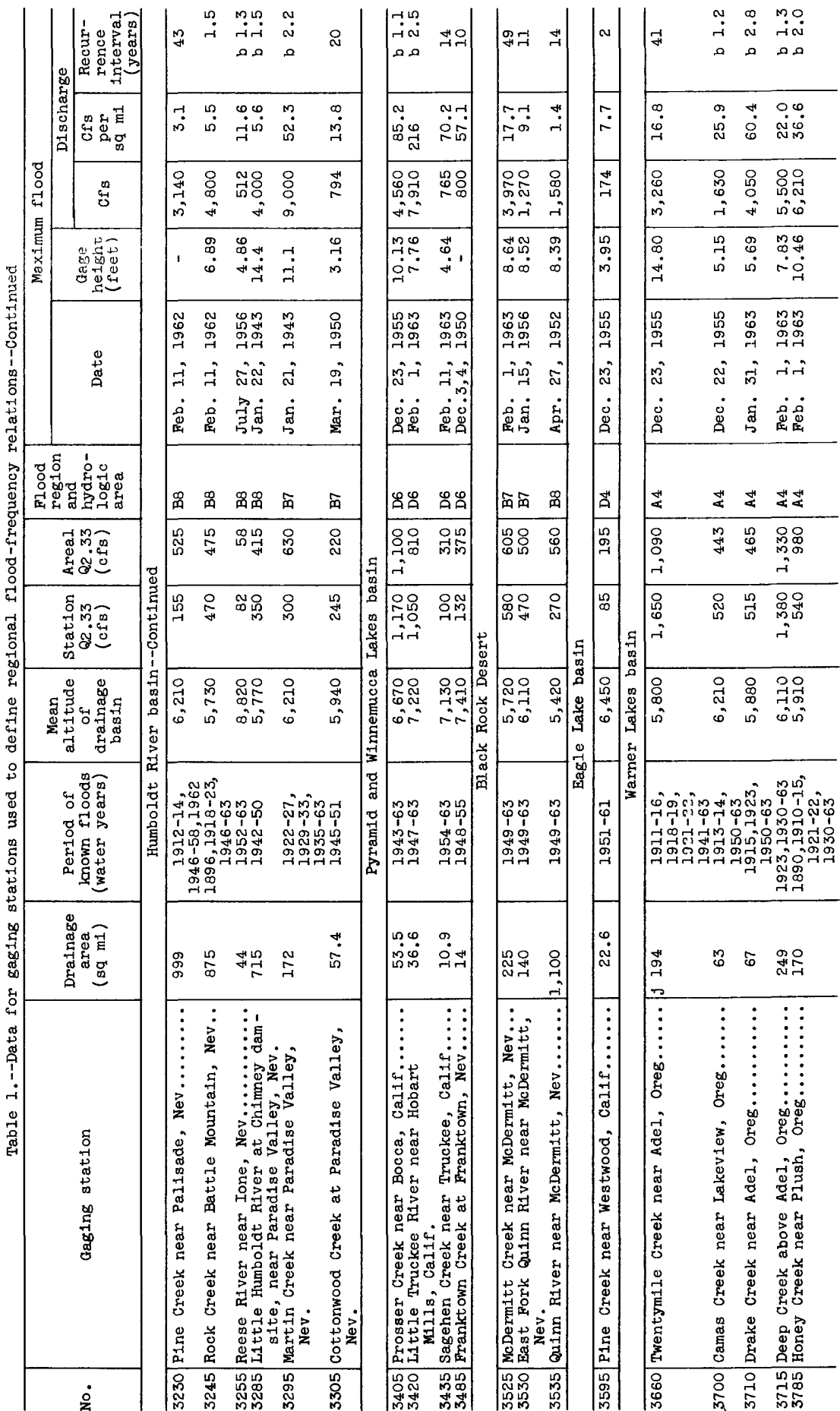




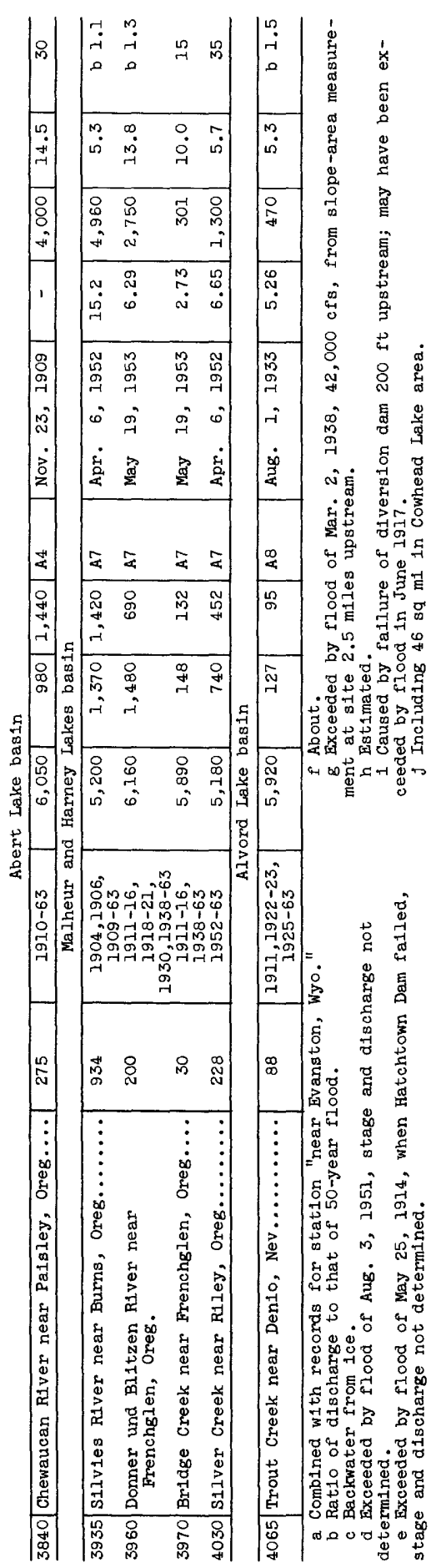




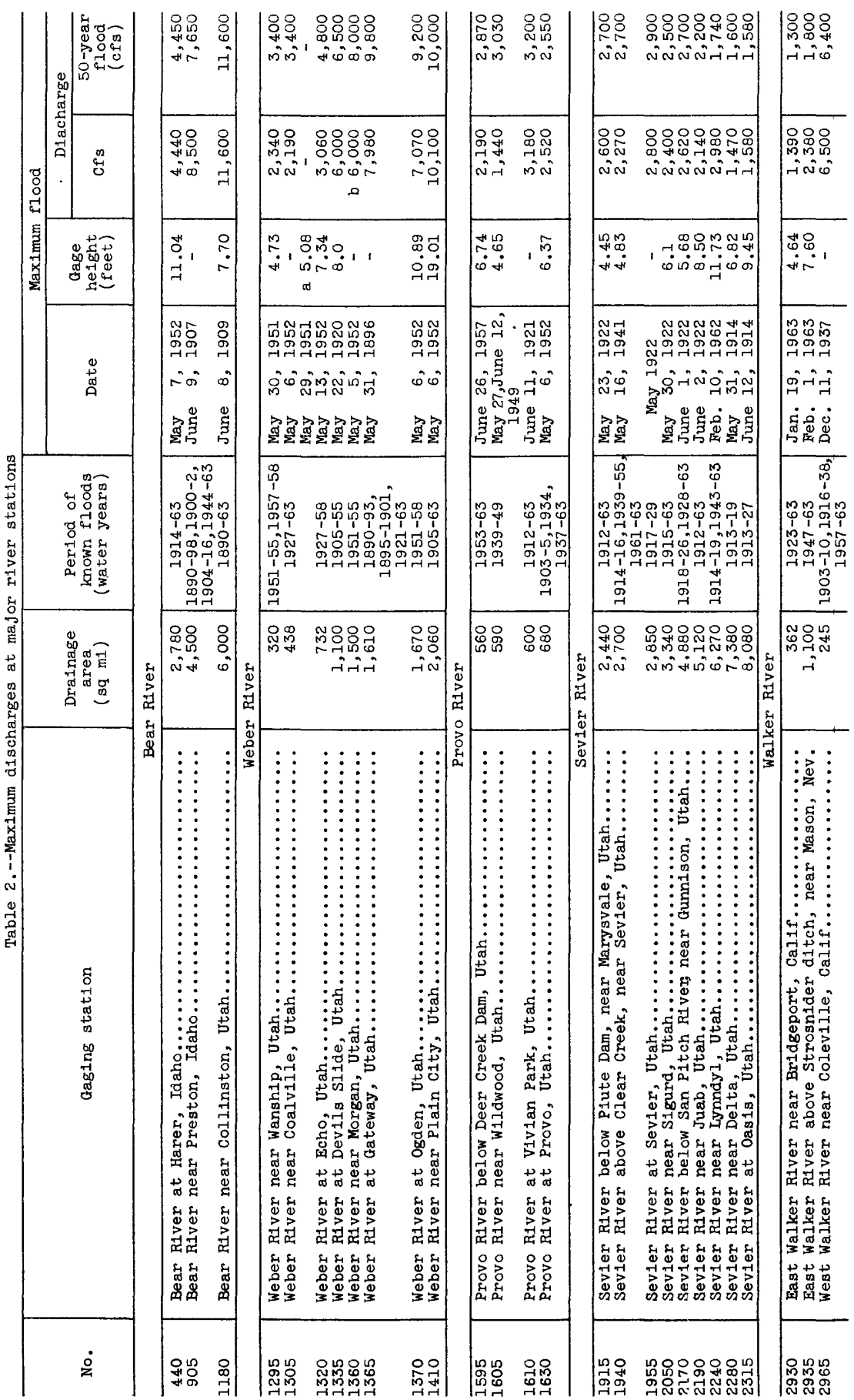




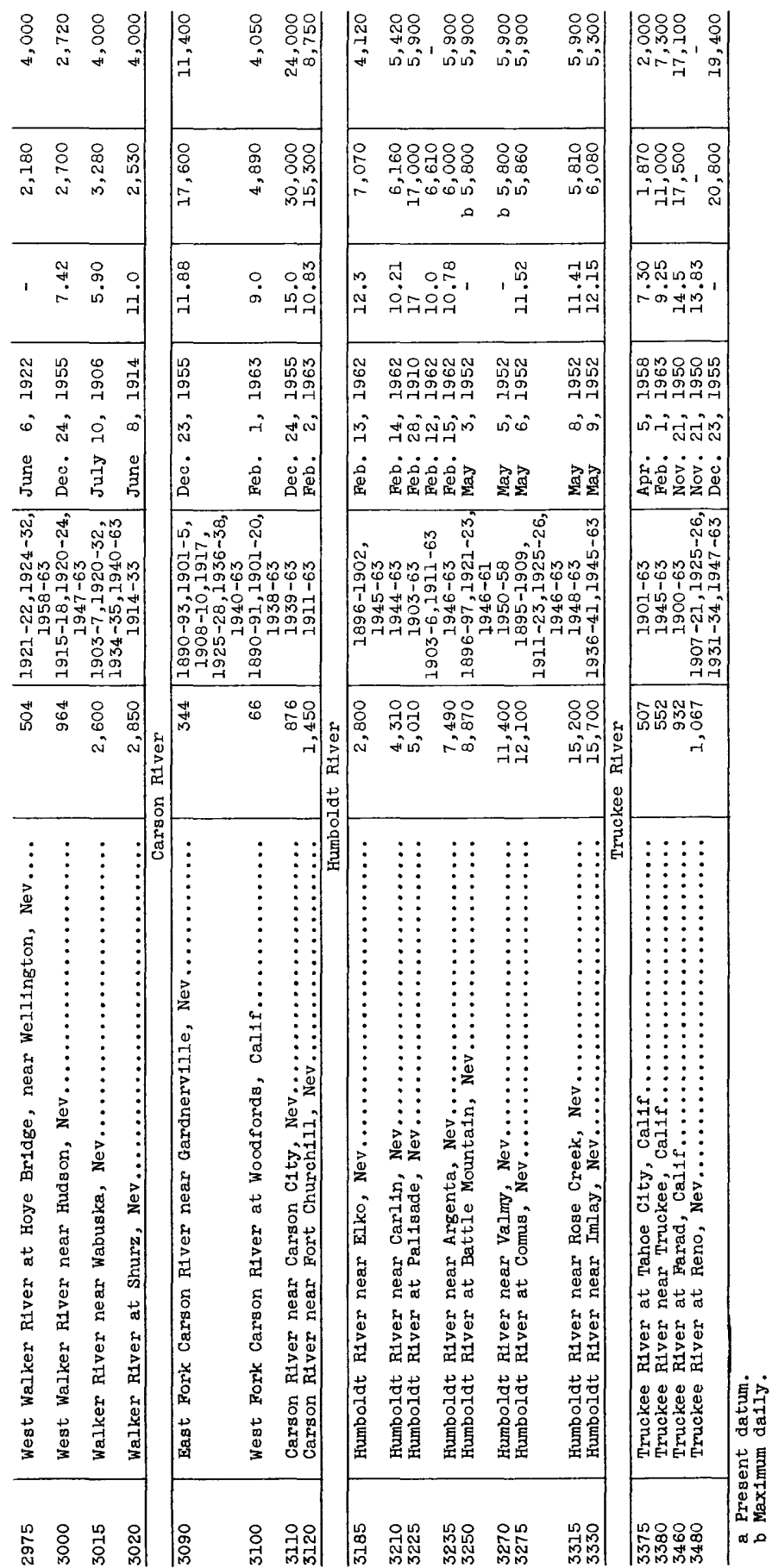




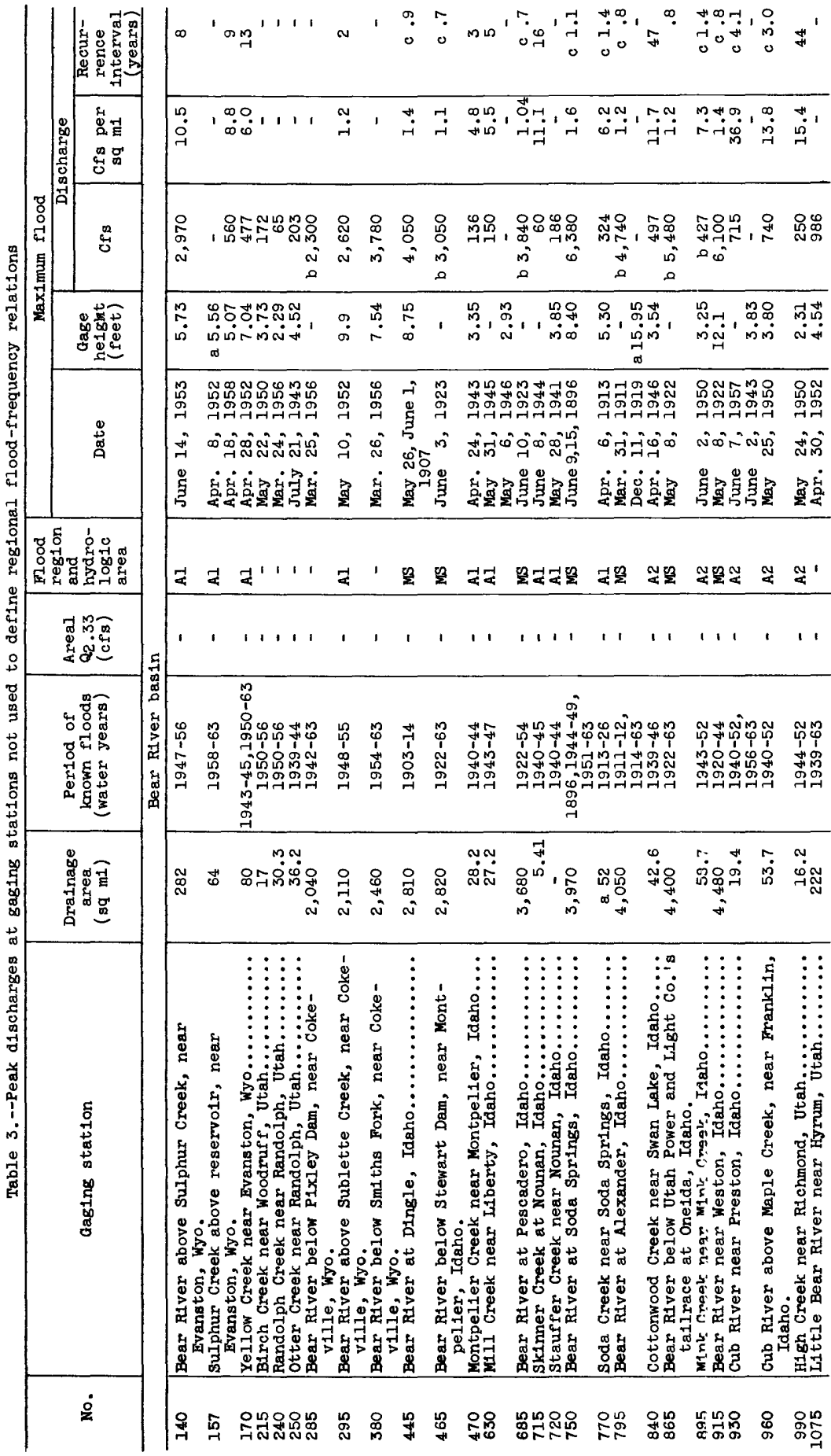




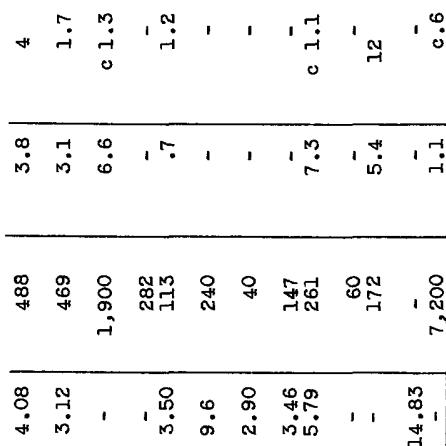

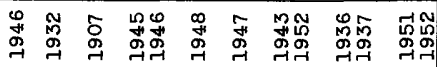

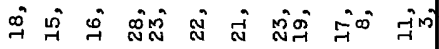

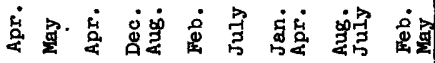

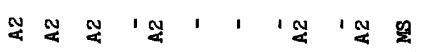

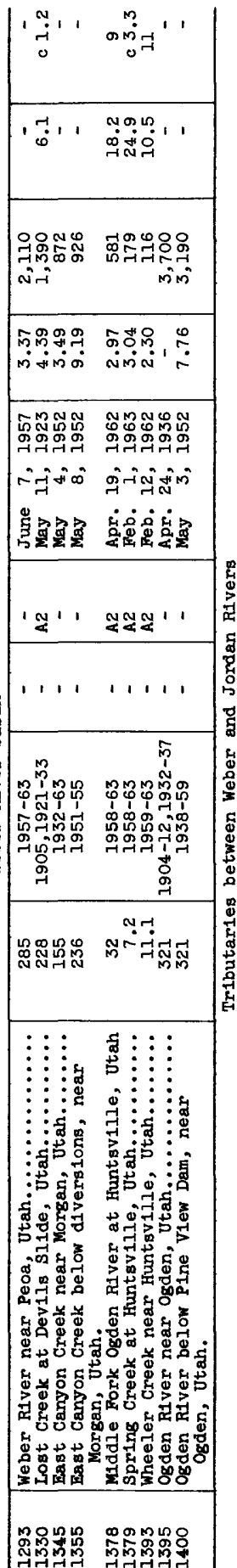

\begin{tabular}{|c|c|}
\hline$\infty \quad \infty \quad$ in $\underset{N}{\infty}$ & $\operatorname{lom}_{\pi} N \stackrel{m}{1}^{\prime}$ \\
\hline 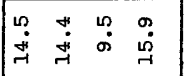 & 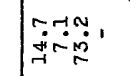 \\
\hline 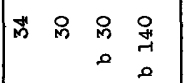 & 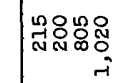 \\
\hline 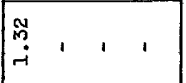 & 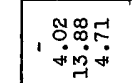 \\
\hline 怘 & 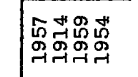 \\
\hline $\overrightarrow{\mathrm{N}}$ के & mö \\
\hline 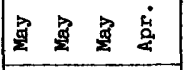 & 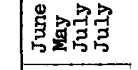 \\
\hline$\approx \approx \approx \approx$ & 岧㽞留 \\
\hline & 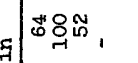 \\
\hline 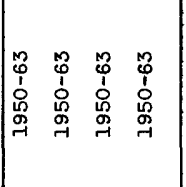 & 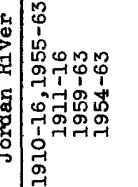 \\
\hline 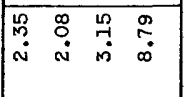 & 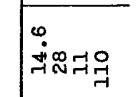 \\
\hline 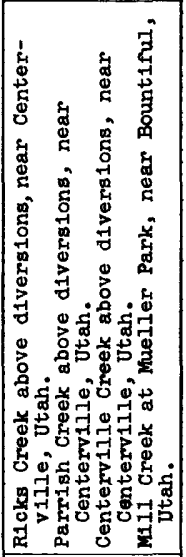 & 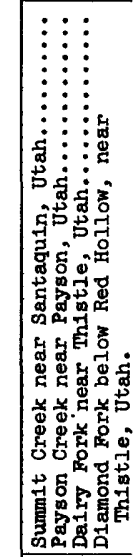 \\
\hline 怘品号虽品 & \\
\hline
\end{tabular}

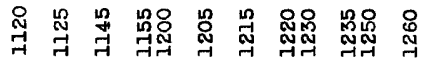




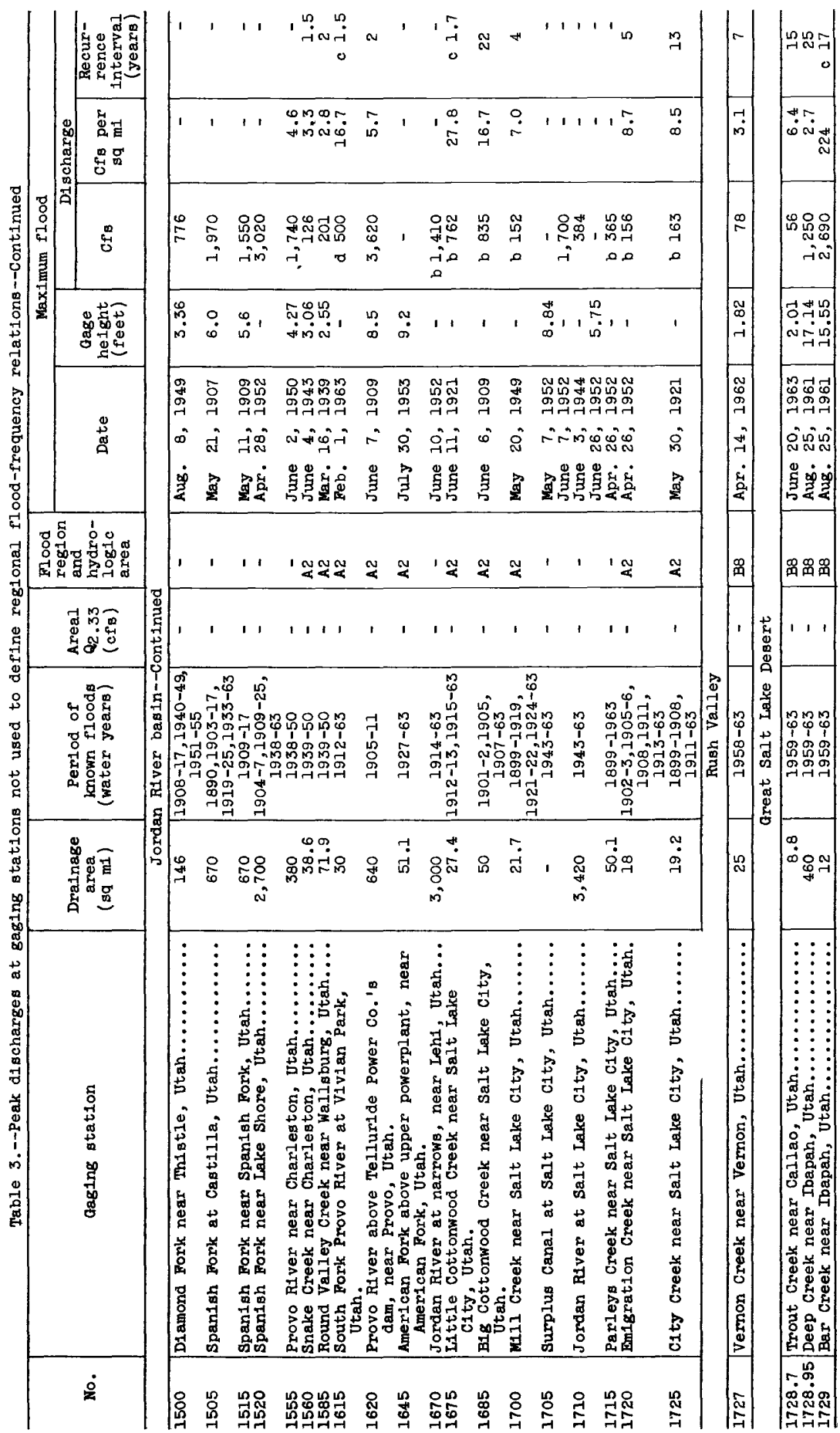




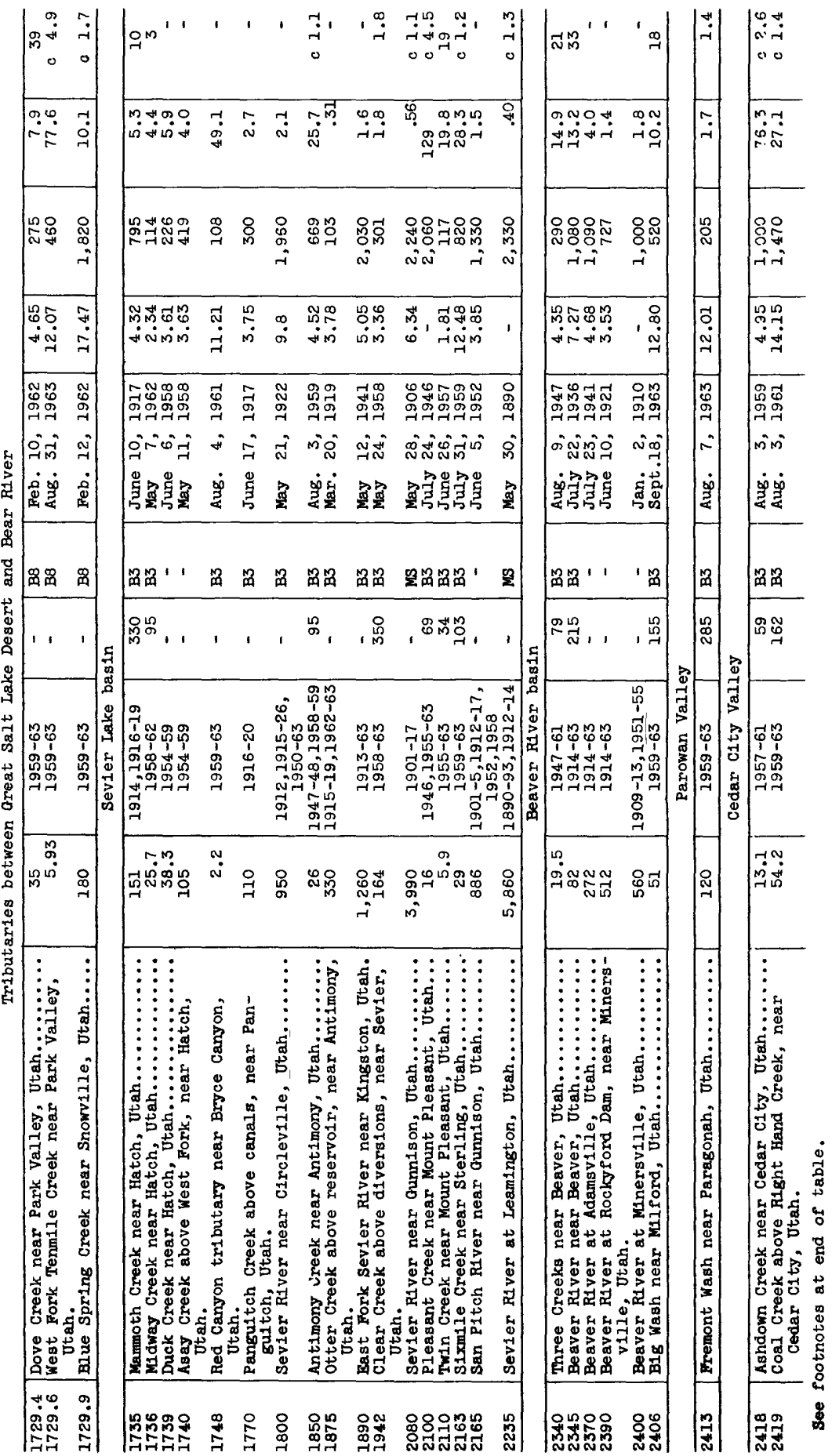




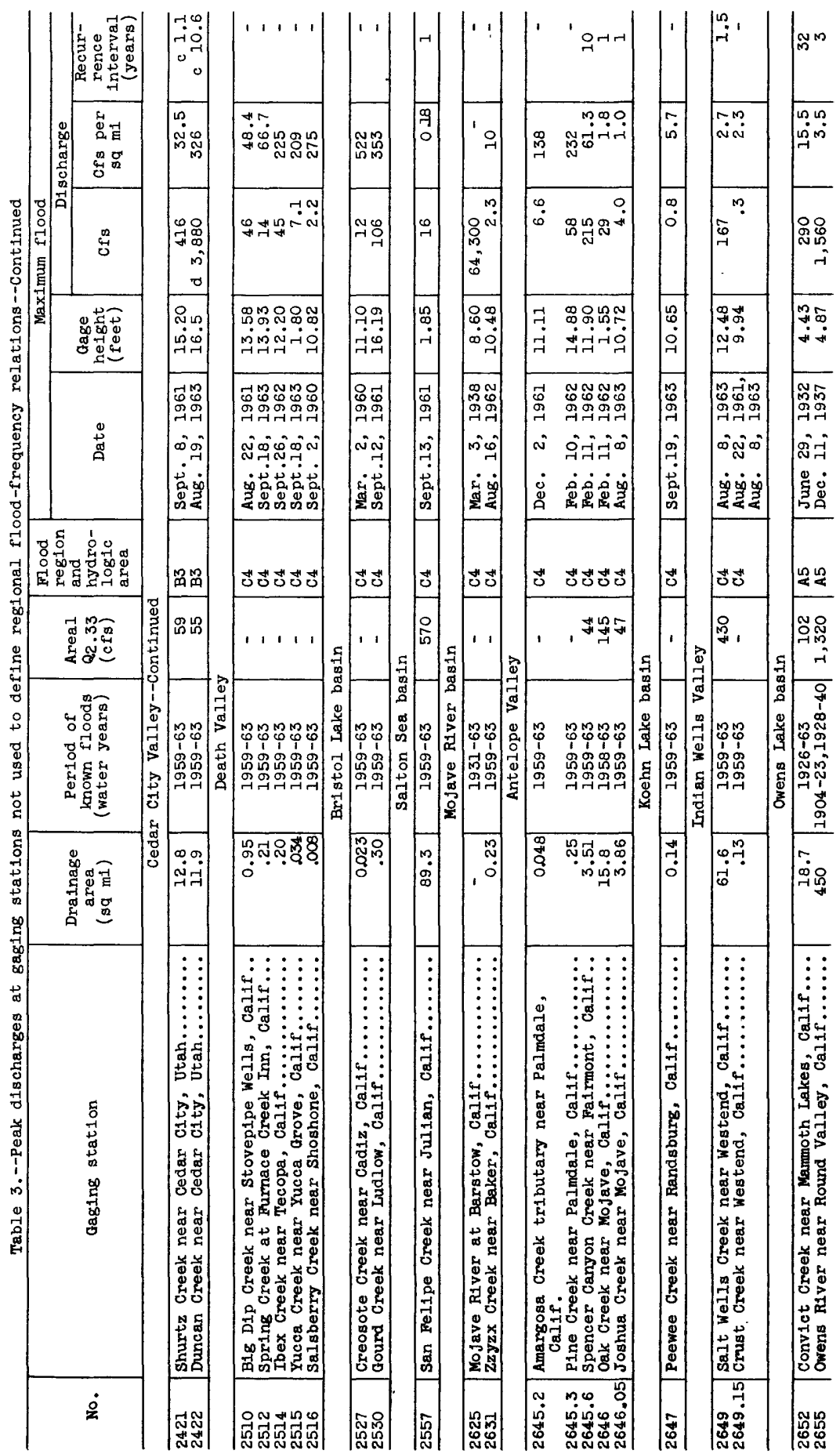




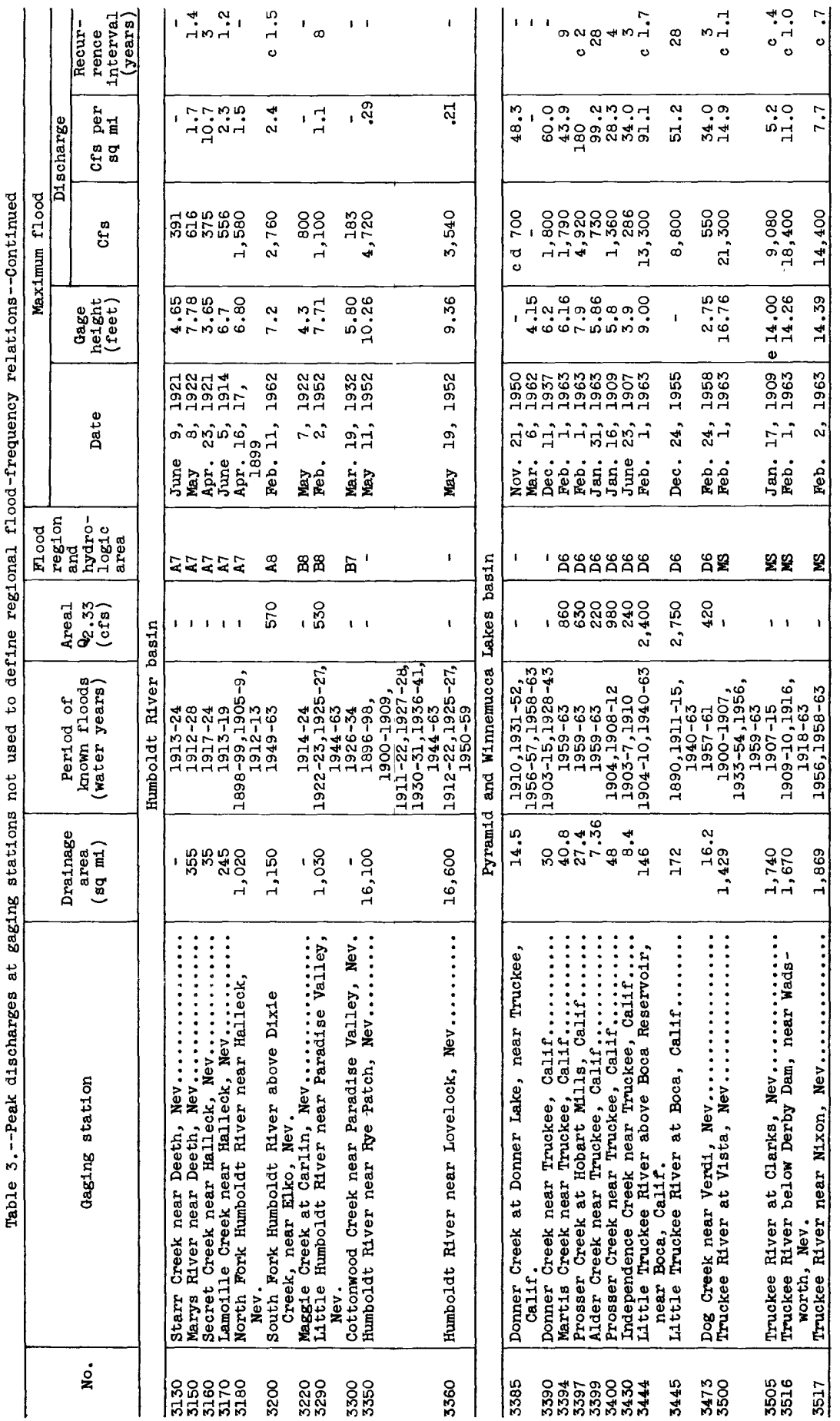




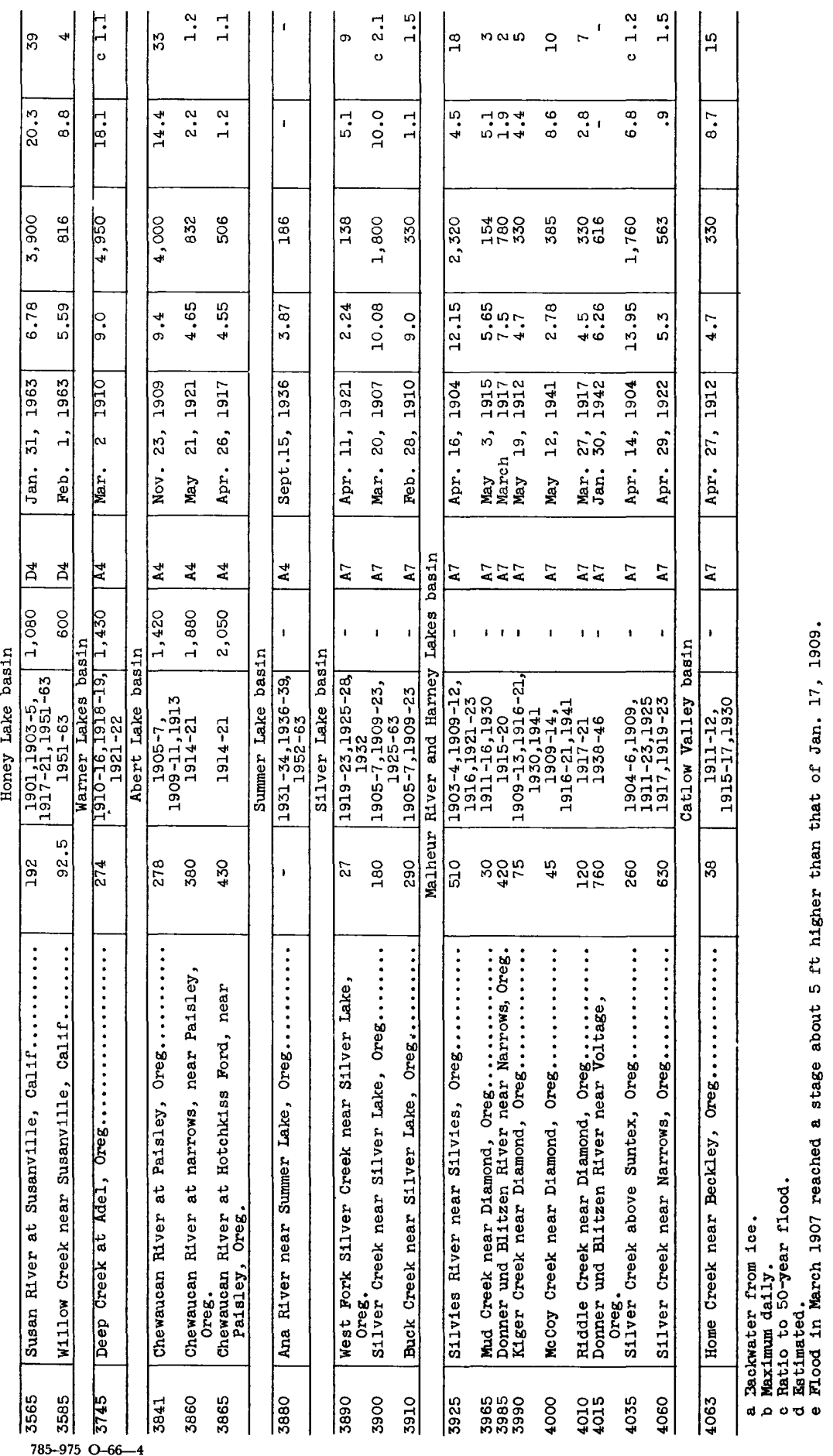




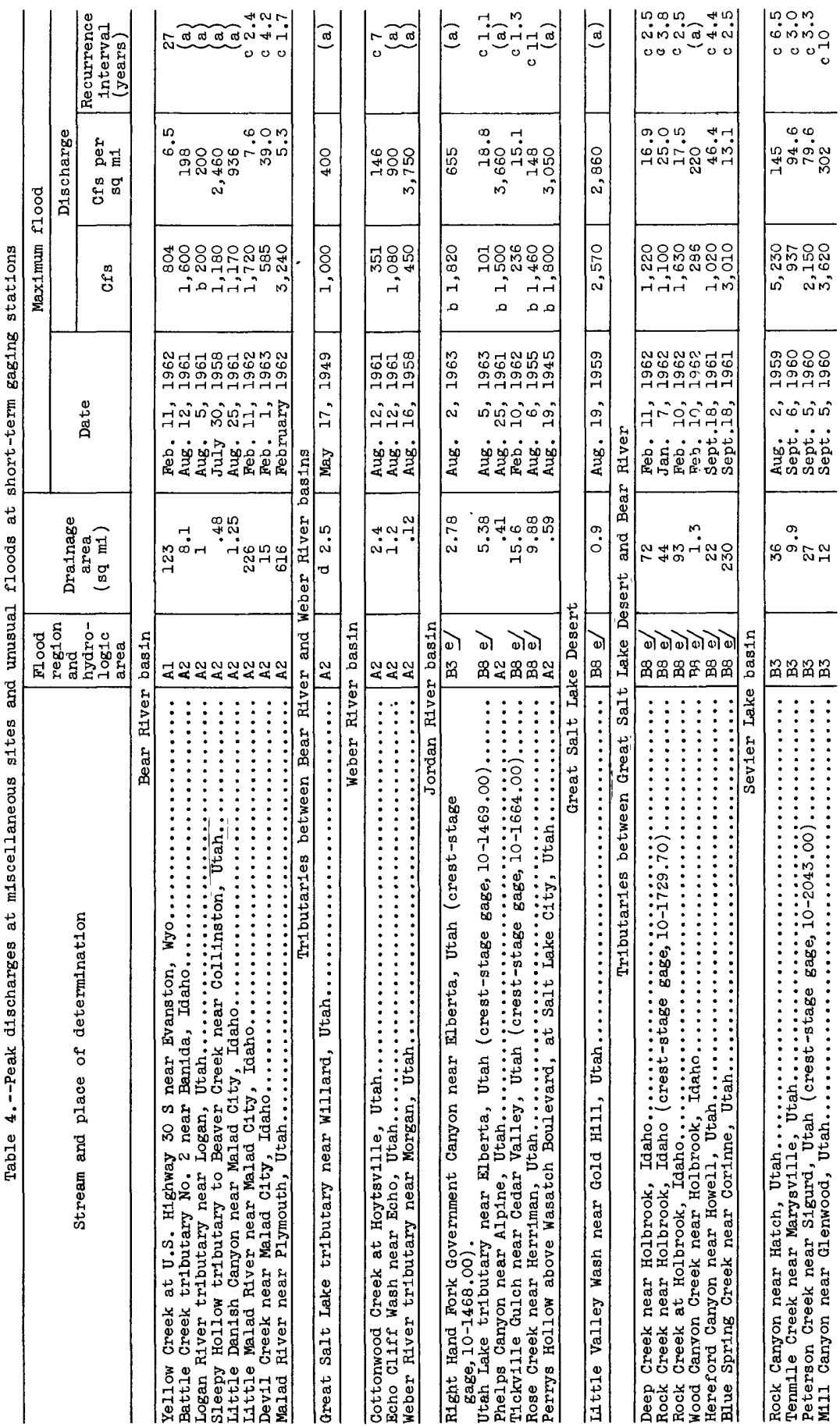




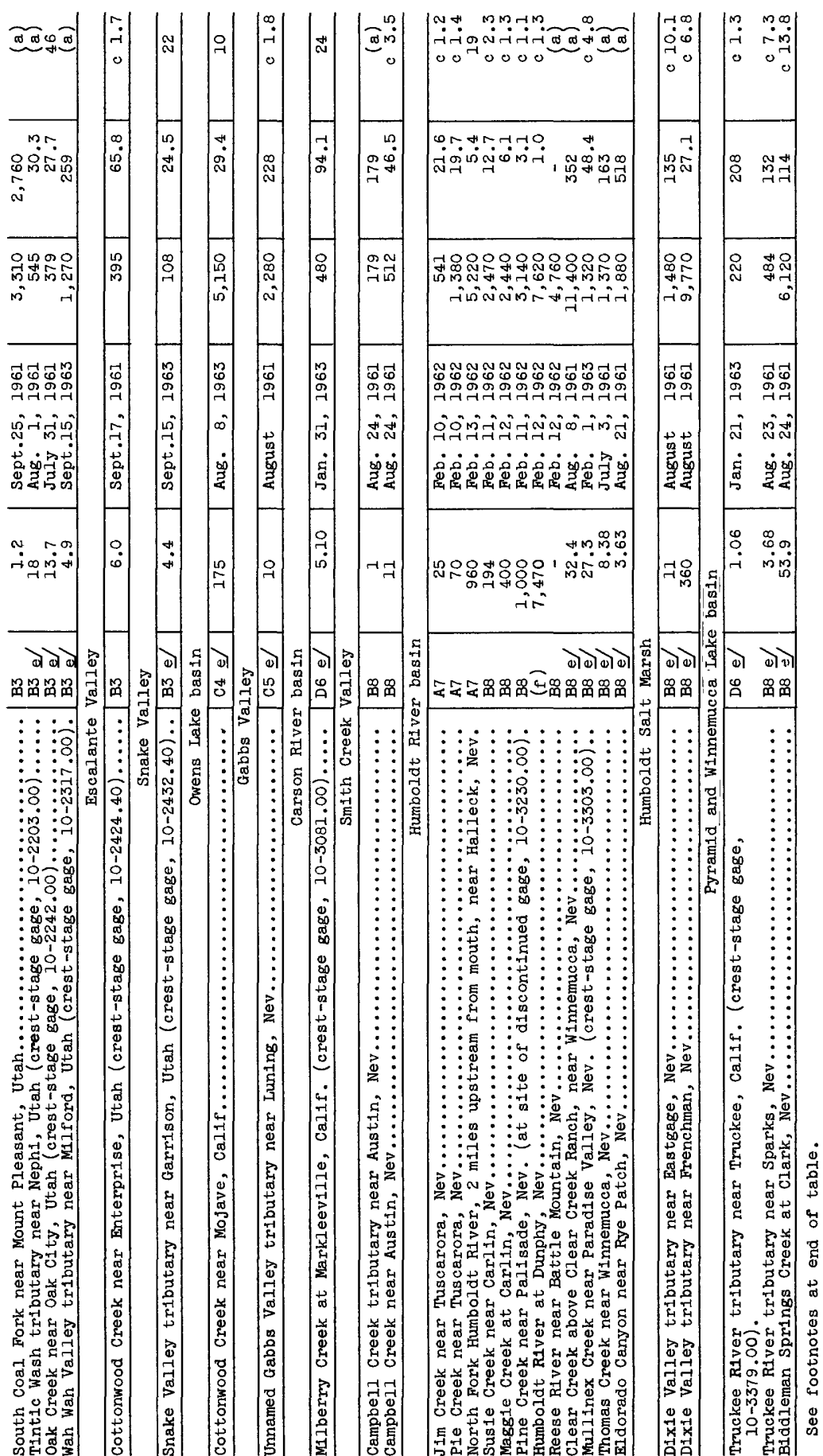




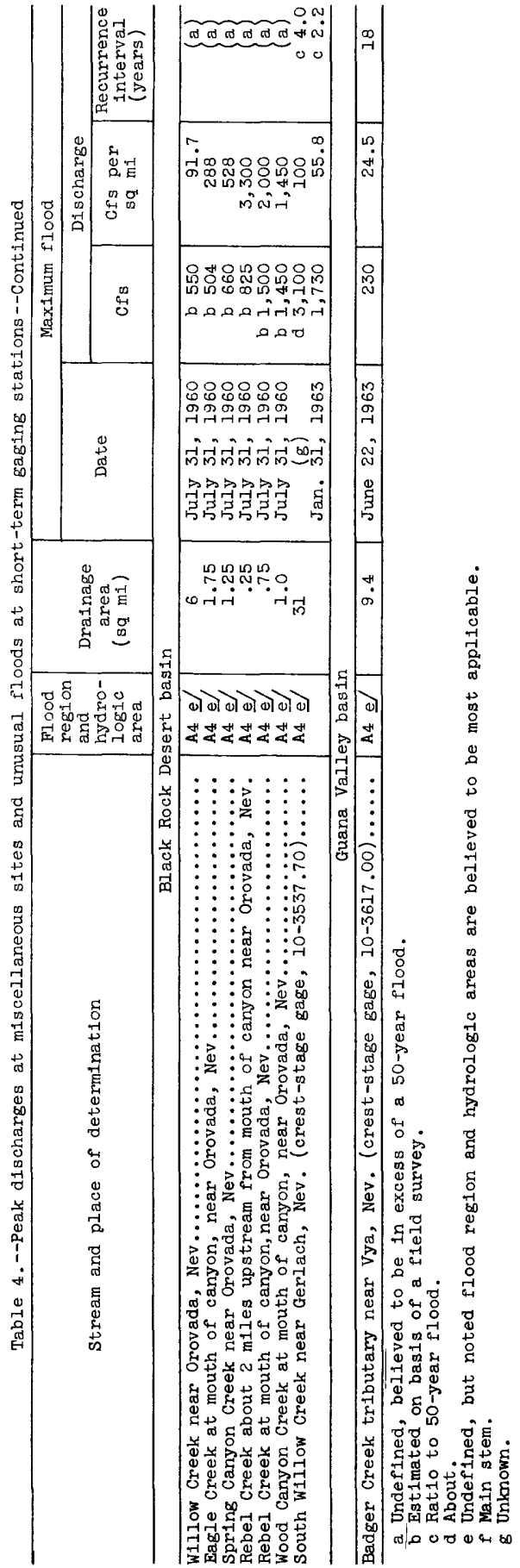


115. Bear River near Utah-Wyoming State line

Location:--Lat $40^{\circ} 58^{\prime}$, long $110^{\circ} 51^{\prime}$, in SE⿺ sec.30, T.3 N., R.10 E., or left bank just downstream from West Fork, 2.8 miles upstream from Utah-Wyoming State Iine.

Drainage area. $--176 \mathrm{sq}$ mi. Mean altitude, 9,770 ft.

Gage.--Recording. Altitude of gage is 7,965 ft (from river-profile mar).

Stage-discharge relation.--Defined by current-meter measurements below 2,100 cf's. High water causes some shifting.

Remarks.--Base for partial-duration series, 1,100 cfs.

Peak stages and discharges

\begin{tabular}{|c|c|c|c|c|c|c|c|c|c|}
\hline $\begin{array}{l}\text { Water } \\
\text { year }\end{array}$ & & Date & $\begin{array}{l}\text { Gage } \\
\text { helght } \\
\text { (feet) }\end{array}$ & $\begin{array}{c}\text { Discharge } \\
(\mathrm{cfs})\end{array}$ & $\begin{array}{l}\text { Water } \\
\text { year }\end{array}$ & & Date & $\begin{array}{c}\text { Gage } \\
\text { helght } \\
\text { (feet) }\end{array}$ & $\begin{array}{c}\text { Discharge } \\
\text { (cfs) }\end{array}$ \\
\hline 1943 & $\begin{array}{l}\text { May } \\
\text { June }\end{array}$ & $\begin{array}{r}28,1943 \\
1,1943\end{array}$ & $\begin{array}{l}3.12 \\
3.13\end{array}$ & $\begin{array}{l}1,120 \\
1,140\end{array}$ & 1952 & $\begin{array}{l}\text { May } \\
\text { June }\end{array}$ & $\begin{array}{l}4,1952 \\
7,1952\end{array}$ & $\begin{array}{l}3.60 \\
4.35\end{array}$ & $\begin{array}{l}1,590 \\
2,340\end{array}$ \\
\hline 1944 & $\begin{array}{l}\text { May } \\
\text { May } \\
\text { June }\end{array}$ & $\begin{array}{ll}14, & 1944 \\
30, & 1944 \\
26, & 1944\end{array}$ & $\begin{array}{l}3.40 \\
3.15 \\
3.60\end{array}$ & $\begin{array}{l}1,540 \\
1,270 \\
1,760\end{array}$ & $\begin{array}{l}1953 \\
1954\end{array}$ & $\begin{array}{l}\text { June } \\
\text { May }\end{array}$ & $\begin{array}{ll}14, & 1953 \\
22, & 1954\end{array}$ & $\begin{array}{l}4.89 \\
3.26\end{array}$ & $\begin{array}{l}2,750 \\
1,220\end{array}$ \\
\hline 1945 & June & 22,1945 & 3.73 & 1,170 & 1955 & $\begin{array}{l}\text { May } \\
\text { June }\end{array}$ & $\begin{array}{r}22,1955 \\
9,1955\end{array}$ & $\begin{array}{l}3.28 \\
3.46\end{array}$ & $\begin{array}{l}1,280 \\
1,430\end{array}$ \\
\hline 1946 & $\begin{array}{l}\text { June } \\
\text { June }\end{array}$ & $\begin{array}{r}5,1946 \\
10,1946\end{array}$ & $\begin{array}{l}3.56 \\
3.25\end{array}$ & $\begin{array}{l}1,540 \\
1,160\end{array}$ & 1956 & June & 1, 1956 & 3.91 & 1,940 \\
\hline 1947 & $\begin{array}{l}\text { May } \\
\text { May } \\
\text { May } \\
\text { June } \\
\text { June }\end{array}$ & $\begin{array}{rr}4, & 1947 \\
7, & 1947 \\
27, & 1947 \\
9, & 1947 \\
20, & 1947\end{array}$ & $\begin{array}{l}3.40 \\
3.60 \\
3.04 \\
3.24 \\
3.26\end{array}$ & $\begin{array}{l}1,450 \\
1,780 \\
1,240 \\
1,470 \\
1,490\end{array}$ & $\begin{array}{l}1957 \\
1958\end{array}$ & $\begin{array}{l}\text { June } \\
\text { June } \\
\text { May } \\
\text { June }\end{array}$ & 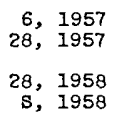 & $\begin{array}{l}4.27 \\
3.75 \\
3.54 \\
3.50\end{array}$ & $\begin{array}{l}2,800 \\
2,100 \\
1,920 \\
1,750\end{array}$ \\
\hline 1948 & $\begin{array}{l}\text { May } \\
\text { May } \\
\text { June }\end{array}$ & $\begin{array}{rr}19, & 1948 \\
25, & 1948 \\
2, & 1948\end{array}$ & $\begin{array}{l}4.23 \\
3.72 \\
3.73\end{array}$ & $\begin{array}{l}2,200 \\
1,820 \\
1,840\end{array}$ & $\begin{array}{l}1959 \\
1960\end{array}$ & $\begin{array}{l}\text { June } \\
\text { June }\end{array}$ & $\begin{array}{r}16,1959 \\
3,1960\end{array}$ & $\begin{array}{l}3.53 \\
3.28\end{array}$ & $\begin{array}{l}1,830 \\
1,490\end{array}$ \\
\hline 1949 & $\begin{array}{l}\text { June } \\
\text { June }\end{array}$ & $\begin{array}{ll}13, & 1949 \\
20, & 1949\end{array}$ & $\begin{array}{l}3.59 \\
3.56\end{array}$ & $\begin{array}{l}1,720 \\
1,690\end{array}$ & 1961 & $\begin{array}{l}\text { Dec. } \\
\text { May }\end{array}$ & $\begin{array}{rr}9, & 1960 \\
26, & 1961\end{array}$ & $\begin{array}{r}\mathrm{a} 2.90 \\
2.78\end{array}$ & $1, \overline{130}$ \\
\hline 1950 & $\begin{array}{l}\text { May } \\
\text { May } \\
\text { June }\end{array}$ & $\begin{array}{rr}24, & 1950 \\
30, & 1950 \\
7, & 1950\end{array}$ & $\begin{array}{l}3.76 \\
4.18 \\
4.09\end{array}$ & $\begin{array}{l}1,560 \\
1,960 \\
1,570\end{array}$ & 1962 & $\begin{array}{l}\text { May } \\
\text { June } \\
\text { June }\end{array}$ & 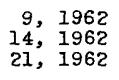 & $\begin{array}{r}3.01 \\
3.75 \\
\mathrm{~b} 4.20\end{array}$ & $\begin{array}{l}1,430 \\
1,590 \\
1,920\end{array}$ \\
\hline 1951 & $\begin{array}{l}\text { May } \\
\text { June }\end{array}$ & $\begin{array}{l}27,1951 \\
17,1951 \\
\end{array}$ & $\begin{array}{l}4.05 \\
3.65 \\
\end{array}$ & $\begin{array}{l}1,970 \\
1,540 \\
\end{array}$ & 1963 & June & 14,1963 & 2.94 & 1,180 \\
\hline
\end{tabular}

a Backwater from 1ce.

b Occurred on preceding day.

120. M111 Creek at Utah-Wyoming State line

(Published as "near Evanston" prior to 1949)

Location.--Lat $40^{\circ} 59^{\prime} 30^{\prime \prime}$, long $110^{\circ} 50^{\prime} 30^{\prime \prime}$, in W $\frac{1}{2}$ sec.17, T.3 N., R.10 E., in Utah on right bank 2,000 ft upstream from State line and $19 \frac{1}{2}$ miles south of Evanston, Wyo.

Drainage area.--60 sq $\mathrm{mi}$, approximately. Mean altitude, 9,320 ft.

Gage.--Recording. Prior to 1949 , at site 2.2 miles downstream at different datum. Altitude of gage is $7,860 \mathrm{ft}$ (from river-profile map).

Stage-discharge relation.--Defined by current-meter measurements below $700 \mathrm{cfs}$.

Remarks.--Flood records equivalent to those for station near Evanston. Base for partial-duration series, $250 \mathrm{cfs}$. 
Peak stages and discharges of Mill Creek at Utah-Wyoming State line

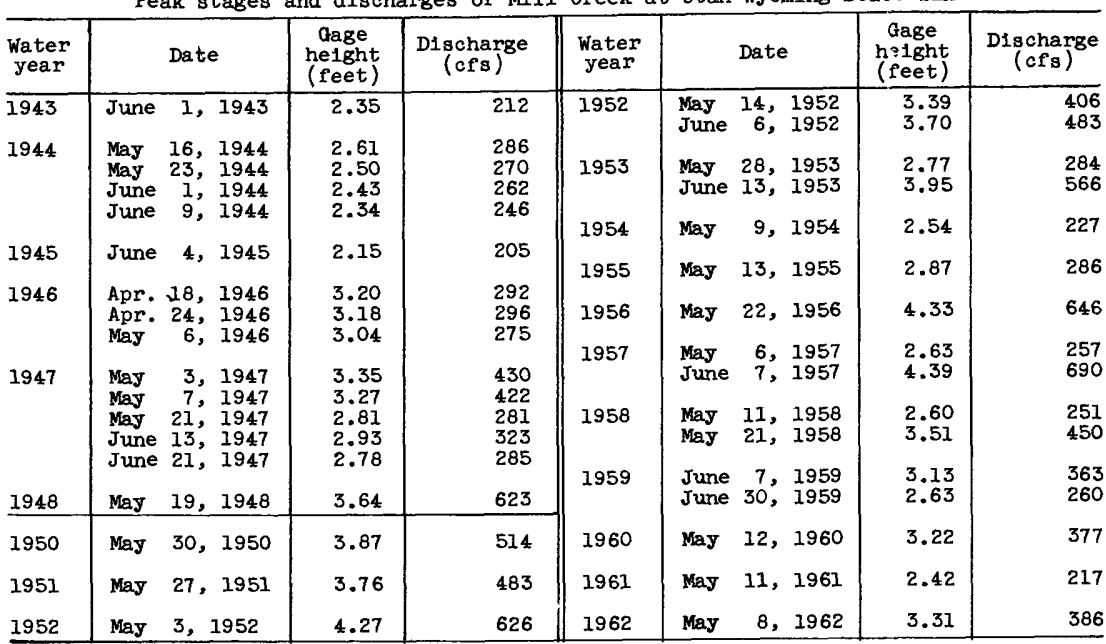

140. Bear River above Sulphur Creek, near Evanston, Wro.

Location.--Lat $41^{\circ} 08^{\prime}$, 1ong $110^{\circ} 53^{\prime}$, in NW $\frac{1}{4} \mathrm{NE} \frac{1}{4} \mathrm{sec} .6, \mathrm{~T} .13 \mathrm{~N} ., \mathrm{F} .119 \mathrm{~W}$., on right bank 2 miles upstream from Myers Bridge, $5 \frac{3}{4}$ miles upstream from Sulphur Creek, and $9 \frac{1}{2}$ miles southeast of Evanston.

Drainage area. $--282 \mathrm{sq} \mathrm{mi}$.

Gage.--Recording. Prior to 0ct. 1, 1953, at site 1,200 ft downstream at different datum. Altitude of gage is $7,130 \mathrm{ft}$ (from river-profile map).

Stage-discharge relation.--Defined by current-meter measurements.

Remarks.--Diversions for irrigation of about 19,000 acres upstresm from station. Base for partial-duration series, $1,100 \mathrm{cfs}$.

Peak stages and discharges

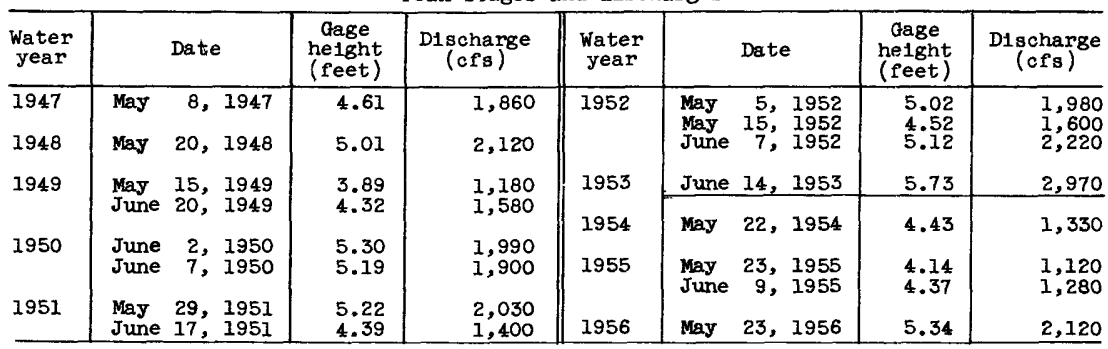


157. Sulphur Creek above reservoir, near Evanston, Wyo.

Location.--Lat $41^{\circ} 09^{\prime}$, long $110^{\circ} 48^{\prime}$, in SW $\frac{1}{4}$ sec.35, T.14 N., R.119 W., cn right bank $i \frac{1}{4}$ miles downstream from Wiliow Creek, 2 miles upstream from Sulphur Creek Dam, and $11 \frac{1}{2}$ miles southeast of Evanston.

Drainage area. $--64 \mathrm{sq} \mathrm{mi}$, approximately.

Gage.--Recording. Altitude of gage is 7,170 ft (from river-profile map).

Stage-discharge relation.--Defined by current-meter measurements below $\varepsilon_{100} \mathrm{cf}$ s and extended above by logarithmic plotting.

Remarks.--Only annual peaks are shown.

Peak stages and discharges

\begin{tabular}{|c|c|c|c|c|c|c|c|}
\hline $\begin{array}{l}\text { Water } \\
\text { year }\end{array}$ & Date & $\begin{array}{c}\text { Gage } \\
\text { height } \\
\text { (feet) }\end{array}$ & $\begin{array}{c}\text { Discharge } \\
(\mathrm{cfs})\end{array}$ & $\begin{array}{l}\text { Water } \\
\text { year }\end{array}$ & Date & $\begin{array}{c}\text { Gage } \\
\text { height } \\
\text { (feet) }\end{array}$ & $\begin{array}{c}\text { I:scharge } \\
\text { (cfs) }\end{array}$ \\
\hline $\begin{array}{l}1958 \\
1959 \\
1960\end{array}$ & $\begin{array}{lr}\text { Apr. } 18,1958 \\
\text { Apr. } 5,1959 \\
\text { Mar. } 26,1960\end{array}$ & $\begin{array}{l}5.07 \\
4.67 \\
4.88\end{array}$ & $\begin{array}{l}560 \\
436 \\
499\end{array}$ & $\begin{array}{l}1961 \\
1962 \\
1963\end{array}$ & $\begin{array}{l}\text { Apr. } 3,1961 \\
\text { Apr. 13, } 1962 \\
\text { Apr. } 29,1963\end{array}$ & $\begin{array}{l}4.07 \\
4.51 \\
3.81\end{array}$ & $\begin{array}{l}274 \\
397 \\
211\end{array}$ \\
\hline
\end{tabular}

160. Sulphur Creek near Evanston, Wyo.

Location.--Lat $41^{\circ} 10^{\prime}$, long $110^{\circ} 52^{\prime}$, in $\mathrm{SE}_{\frac{1}{4}}$ sec. 29 , T.14 N., R.119 W., on left bank 4.8 miles upstream from mouth and 9 miles southeast of Evanstion.

Drainage area. $--80.5 \mathrm{sq} \mathrm{mi}$. Mean altitude, 7,930 ft.

Gage.--Recording. Prior to June 16, 1948, at datum $2.00 \mathrm{ft}$ higher. Jure 16 , 1948 , to Aug. 21,1952 , at datum $1.00 \mathrm{ft}$ higher. Altitude of gage is 7,070 ft (from river-profile map).

Stage-discharge relation.--Defined by current-meter measurements below 1,200 cfs. Extremely high water causes some shifting.

Remarks.--Natural flow affected by Sulphur Creek Reservo1r (capac1ty, 4,600 acre-ft) completed December 1957. Base for partial-duration series, $300 \mathrm{cfs}$. Only annual peaks are show prior to 1947.

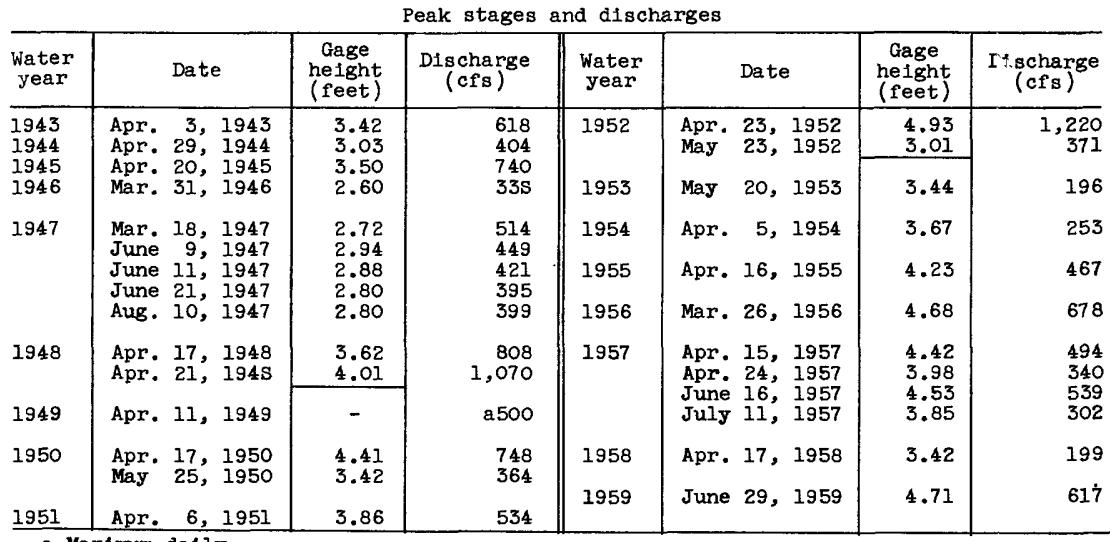

a Maximum da1ly. 
170. Yellow Creek near Evanston, Wyo.

Location.--Lat $41^{\circ} 09^{\prime}$, long $111^{\circ} 03^{\prime}$, in SW $\frac{1}{4}$ sec. 21 , T.5 N., R. 8 E., in Utah, on left bank $600 \mathrm{ft}$ downstream from Sage Creek, $1 \frac{1}{2}$ miles upstream from Coyote Creek, and $9 \frac{3}{4}$ miles southwest of Evanston.

Drainage area. $--80 \mathrm{sq} \mathrm{mi}$, approximately.

Gage.--Recording. At site $500 \mathrm{ft}$ upstream, at different datums $0 . t, 1,1944$, to Sept. 30,1945 . Alt1tude of gage is $6,920 \mathrm{ft}$ (from river-profile map).

Stage-discharge relation.--Defined by current-meter measurements.

Bankfull stage. $--5.5 \mathrm{ft}$.

Remarks.--Flow regulated by Barker Reservo1r (capac1ty, 162 acre-ft) completed in fall of 1959. Base for partial-duration series, $100 \mathrm{cfs}$.

Peak stages and discharges

\begin{tabular}{|c|c|c|c|c|c|c|c|}
\hline $\begin{array}{l}\text { Water } \\
\text { year }\end{array}$ & Date & $\begin{array}{c}\text { Gage } \\
\text { height } \\
\text { (feet) }\end{array}$ & $\begin{array}{c}\text { Discharge } \\
\text { (cfs) }\end{array}$ & $\begin{array}{l}\text { Water } \\
\text { year }\end{array}$ & Date & $\begin{array}{c}\text { Gege } \\
\text { hejght } \\
\text { (feet) }\end{array}$ & $\begin{array}{c}\text { Discharge } \\
(\mathrm{cfs})\end{array}$ \\
\hline 1943 & Apr. 16,1943 & 3.92 & 77 & 1954 & Apr. 14,1954 & 1.35 & 26 \\
\hline 1944 & $\begin{array}{ll}\text { Apr. } & 5,1944 \\
\text { Apr. } & 9,1944 \\
\text { May } & 2,1944 \\
\end{array}$ & $\begin{array}{l}6.00 \\
5.60 \\
4.60 \\
\end{array}$ & $\begin{array}{l}192 \\
172 \\
122 \\
\end{array}$ & $\begin{array}{l}1955 \\
1956\end{array}$ & $\begin{array}{cc}\text { May } & 11,1955 \\
\text { May } & 7,1956\end{array}$ & $\begin{array}{r}2.46 \\
3.22\end{array}$ & $\begin{array}{l}58 \\
68\end{array}$ \\
\hline 1945 & $\begin{array}{l}\text { Mar. 22, } 1945 \\
\text { Mar. 31, } 1945 \\
\text { Apr. 20, } 1945\end{array}$ & $\begin{array}{l}4.72 \\
6.00 \\
7.52 \\
\end{array}$ & $\begin{array}{l}109 \\
145 \\
303 \\
\end{array}$ & 1957 & $\begin{array}{lll}\text { May } & 20, & 1957 \\
\text { May } & 29, & 1957\end{array}$ & $\begin{array}{l}5.28 \\
4.50\end{array}$ & $\begin{array}{l}147 \\
114\end{array}$ \\
\hline 1950 & $\begin{array}{ll}\text { Apr. } 23,1950 \\
\text { May } 18,1950\end{array}$ & $\begin{array}{l}6.49 \\
6.16\end{array}$ & $\begin{array}{l}240 \\
234\end{array}$ & 1958 & Apr. 5,1959 & 4.60 & 110 \\
\hline 1951 & Apr. $\quad 8,1951$ & 5.16 & 126 & 1960 & Mar. 23, 1960 & 6.47 & 305 \\
\hline 1952 & $\begin{array}{ll}\text { Apr. } 28, & 1952 \\
\text { May } 17,1952 \\
\text { May } 23,1952\end{array}$ & $\begin{array}{l}7.04 \\
5.58 \\
5.48\end{array}$ & $\begin{array}{l}477 \\
178 \\
169\end{array}$ & $\begin{array}{l}1961 \\
1962\end{array}$ & $\begin{array}{l}\text { Mar. 24, } 1961 \\
\text { Mar. 29, } 1962\end{array}$ & $\begin{array}{l}2.94 \\
6.36\end{array}$ & $\begin{array}{r}68 \\
294\end{array}$ \\
\hline 1953 & May 20,1953 & 2.84 & 58 & 1963 & Feb. 2,1963 & 3.70 & 80 \\
\hline
\end{tabular}

190. Bear River near Evanston, Wyo.

Location.--Lat $41^{\circ} 19^{\prime}$, long $111^{\circ} 01^{\prime}$, in sec.1, T.15 N., R.121 W., on left bank $300 \mathrm{ft}^{t}$ upstream from road bridge and $3 \frac{1}{2}$ miles northwest of Evanston.

Drainage area. $--715 \mathrm{sq} \mathrm{mi}$. Mean altitude, 8,130 $\mathrm{ft}$.

Gage.--Nonrecording prior to Sept. 28, 1926; recording thereafter. Altitude of gage is $6,610 \mathrm{ft}$ (from river-profile map).

Stage-discharge relation.--Defined by current-meter measurements below 2,700 cf's.

Remarks.--Natural flow of stream affected by diversions for irrigation and

return flow from irrigated areas. Peaks are maximum observed prior to 1927. Base for partial-duration series, 1,200 cfs. Only annual peaks are shown prior to 1948 .

Peak stages and discharges

\begin{tabular}{|c|c|c|c|c|c|c|c|c|}
\hline $\begin{array}{l}\text { Water } \\
\text { year }\end{array}$ & & Date & $\begin{array}{c}\text { Gage } \\
\text { height } \\
\text { (feet) }\end{array}$ & $\begin{array}{c}\text { Discharge } \\
\text { (cfs) }\end{array}$ & $\begin{array}{c}\text { Water } \\
\text { year }\end{array}$ & Date & $\begin{array}{c}\text { Gage } \\
\text { helght } \\
\text { (feet) }\end{array}$ & $\begin{array}{c}\text { Djscharge } \\
\text { (cfs) }\end{array}$ \\
\hline $\begin{array}{l}1914 \\
1915\end{array}$ & $\begin{array}{l}\text { May } \\
\text { June }\end{array}$ & 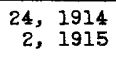 & $\begin{array}{l}5.90 \\
4.20\end{array}$ & $\begin{array}{l}2,480 \\
1,240\end{array}$ & $\begin{array}{l}1924 \\
1925\end{array}$ & $\begin{array}{l}\text { Apr. 14, } 1924 \\
\text { May } 21,31,1925\end{array}$ & $\begin{array}{l}5.75 \\
4.15\end{array}$ & $\begin{array}{l}2,800 \\
1,170\end{array}$ \\
\hline $\begin{array}{l}1916 \\
1917 \\
1918 \\
1919 \\
1920\end{array}$ & $\begin{array}{l}\text { May } \\
\text { June } 1 \\
\text { June } \\
\text { May } \\
\text { May }\end{array}$ & $\begin{array}{r}9,1916 \\
17,18,1917 \\
16,1918 \\
29,1919 \\
25,1920\end{array}$ & $\begin{array}{l}4.90 \\
- \\
5.5 \\
4.6 \\
6.1\end{array}$ & $\begin{array}{l}1,670 \\
2,500 \\
2,090 \\
1,430 \\
2,620\end{array}$ & $\begin{array}{l}1926 \\
1927 \\
1925 \\
1929 \\
1930\end{array}$ & $\begin{array}{lr}\text { May } & 21,1926 \\
\text { May } 18,1927 \\
\text { May } 9,1928 \\
\text { May } 25,1929 \\
\text { June } 12,1930\end{array}$ & $\begin{array}{l}4.9 \\
5.35 \\
5.80 \\
5.64 \\
4.66\end{array}$ & $\begin{array}{l}1,680 \\
1,910 \\
2,900 \\
2,590 \\
1,420\end{array}$ \\
\hline $\begin{array}{l}1921 \\
1922 \\
1923\end{array}$ & $\begin{array}{l}\text { June } \\
\text { May } \\
\text { May }\end{array}$ & $\begin{array}{l}14,1921 \\
26,1922 \\
27,1923\end{array}$ & $\begin{array}{l}6.35 \\
5.65 \\
6.1\end{array}$ & $\begin{array}{l}3,690 \\
2,580 \\
3,460\end{array}$ & $\begin{array}{l}1931 \\
1932 \\
1933\end{array}$ & $\begin{array}{lll}\text { May } 17, & 1931 \\
\text { May } 22, & 1932 \\
\text { June } 11, & 1933\end{array}$ & $\begin{array}{l}\Xi .58 \\
\Sigma .74 \\
5.19\end{array}$ & $\begin{array}{r}\$ 15 \\
2,500 \\
1,810\end{array}$ \\
\hline
\end{tabular}


Peak stages and discharges of Bear River near Evanston, Wyo. --Continued

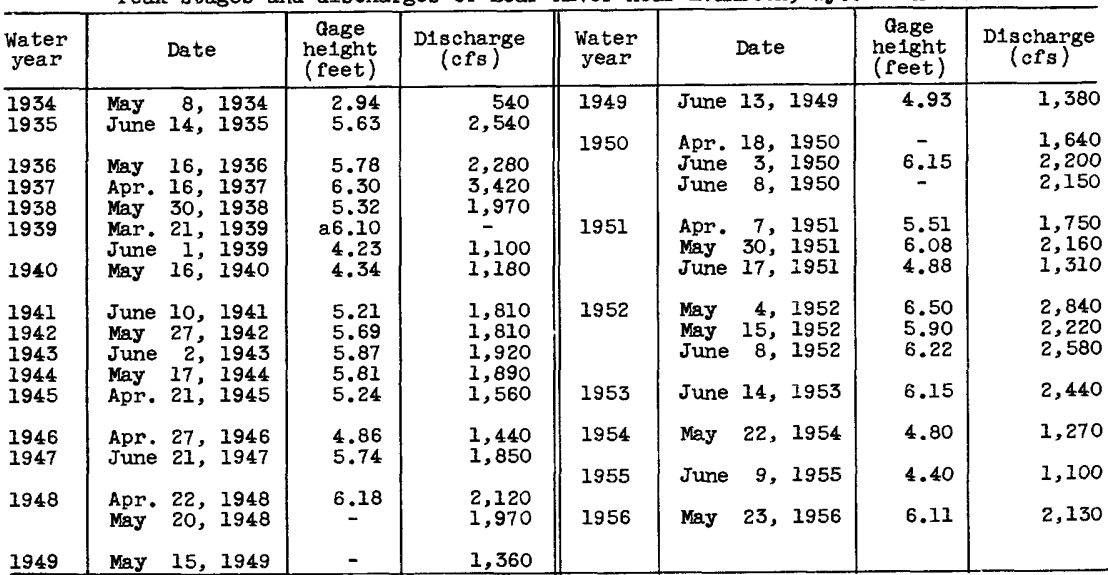

a Backwater from 1ce.

\section{Bear River near Woodruff, Utah}

Location.--Lat $41^{\circ} 31^{\prime} 25^{\prime \prime}$, long $111^{\circ} 01^{\prime} 00^{\prime \prime}$, in SW $\frac{1}{4}$ sec.20, T.18 N., R.120 W., in Wyoming, on left bank 2.8 miles upstream from Wyoming-Utah state Iine and 7.6 mlles east of Woodruff.

Drainage area. --870 sq $\mathrm{ml}$, approximately. Mean altitude, 7,930 ft.

Gage.--Recording. Alt1tude of gage is 6,360 ft (from river-profile mao).

Stage-discharge relation.--Defined by current-meter measurements below $2,700 \mathrm{cfs}$.

Remarks.--Diversions for imigation of about 45,000 acres above stat1on. Base for partial-duration series, $1,300 \mathrm{cfs}$.

Peak stages and discharges

\begin{tabular}{|c|c|c|c|c|c|c|c|c|}
\hline $\begin{array}{l}\text { Water } \\
\text { year }\end{array}$ & & Date & $\begin{array}{c}\text { Qage } \\
\text { height } \\
\text { (feet) }\end{array}$ & $\begin{array}{c}\text { Discharge } \\
(\mathrm{cfs})\end{array}$ & $\begin{array}{l}\text { Water } \\
\text { year }\end{array}$ & Date & $\begin{array}{l}\text { Gage } \\
\text { helght } \\
\text { (feet) }\end{array}$ & $\begin{array}{c}\text { D1scharge } \\
\text { (cfs) }\end{array}$ \\
\hline 1942 & $\begin{array}{l}\text { May } \\
\text { June }\end{array}$ & $\begin{array}{r}28,1942 \\
9,1942\end{array}$ & $\begin{array}{l}4.15 \\
3.52\end{array}$ & $\begin{array}{l}1,620 \\
1,320\end{array}$ & 1950 & June 9,1950 & 4.70 & 2,150 \\
\hline 1943 & $\begin{array}{l}\text { May } \\
\text { June }\end{array}$ & $\begin{array}{l}5,1943 \\
3,1943\end{array}$ & $\begin{array}{l}3.86 \\
4.27\end{array}$ & $\begin{array}{l}1,350 \\
1,720\end{array}$ & 1951 & $\begin{array}{ll}\text { Mar. } 21, & 1951 \\
\text { Apr. } 7, & 1951 \\
\text { May } 31, & 1951\end{array}$ & $\begin{array}{r}a 5.98 \\
3.51 \\
4.64\end{array}$ & $\begin{array}{l}- \\
1,310 \\
2,090\end{array}$ \\
\hline 1944 & $\begin{array}{l}\text { May } \\
\text { June } \\
\text { June } \\
\text { June }\end{array}$ & $\begin{array}{r}18,1944 \\
4,1944 \\
25,1944 \\
28,1944\end{array}$ & $\begin{array}{l}4.26 \\
3.99 \\
3.76 \\
3.89\end{array}$ & $\begin{array}{l}1,860 \\
1,560 \\
1,390 \\
1,510\end{array}$ & $\begin{array}{l}1952 \\
1953\end{array}$ & $\begin{array}{l}\text { Apr. 28, } 1952 \\
\text { June 16, } 1953\end{array}$ & $\begin{array}{l}5.32 \\
4.79\end{array}$ & $\begin{array}{l}3,010 \\
2,350\end{array}$ \\
\hline 1945 & Apr. & 22,1945 & 3.69 & 1,350 & 1954 & May 23,1954 & 3.49 & 1,060 \\
\hline 1946 & Apr. & 28,1946 & 3.83 & 1,330 & 1955 & May 26, 1955 & 3.26 & 898 \\
\hline 1947 & $\begin{array}{l}\text { Mar. } \\
\text { May } \\
\text { June } \\
\text { June }\end{array}$ & $\begin{array}{l}18,1947 \\
10,1947 \\
11,1947 \\
23,1947\end{array}$ & $\begin{array}{l}4.37 \\
4.23 \\
4.28 \\
4.38\end{array}$ & $\begin{array}{l}1,940 \\
1,720 \\
1,700 \\
1,850\end{array}$ & $\begin{array}{l}1956 \\
1957\end{array}$ & $\begin{array}{l}\text { Nay } 25,1956 \\
\text { June } 15,1957 \\
\text { June } 30,1957\end{array}$ & $\begin{array}{l}4.24 \\
4.84 \\
4.02\end{array}$ & $\begin{array}{l}1,750 \\
2,380 \\
1,540\end{array}$ \\
\hline 1948 & $\begin{array}{l}\text { Apr. } \\
\text { Apr. } \\
\text { May }\end{array}$ & $\begin{array}{l}19,1948 \\
24,1948 \\
22,1948\end{array}$ & $\begin{array}{l}4.01 \\
4.54 \\
4.50\end{array}$ & $\begin{array}{l}1,430 \\
1,940 \\
1,900\end{array}$ & $\begin{array}{l}1958 \\
1959\end{array}$ & $\begin{array}{l}\text { Nay } 29,1958 \\
\text { June } 7,1959 \\
\text { June } 30,1959\end{array}$ & $\begin{array}{l}3.94 \\
3.77 \\
4.03\end{array}$ & $\begin{array}{l}1,460 \\
1,300 \\
1,550\end{array}$ \\
\hline 1949 & June & 21,1949 & 3.74 & 1,240 & 1960 & May 14,1960 & 3.45 & 1,040 \\
\hline 1950 & $\begin{array}{l}\text { Apr. } \\
\text { June }\end{array}$ & $\begin{array}{r}23,1950 \\
4,1950 \\
\end{array}$ & $\begin{array}{l}3.91 \\
4.86\end{array}$ & $\begin{array}{l}1,410 \\
2,320\end{array}$ & 1961 & $\begin{array}{l}\text { Mar. } 17,1961 \\
\text { May } 29,1961\end{array}$ & $\begin{array}{r}23.63 \\
2.97\end{array}$ & -712 \\
\hline
\end{tabular}

a Backwater from ice. 
210. Woodruff Creek near Woodruff, Utah

Location.--Lat $41^{\circ} 29^{\prime}$, long $111^{\circ} 16^{\prime}$, in $\mathrm{SE} \frac{1}{4} \mathrm{SE} \frac{1}{4}$ sec. 28, T.9 N., R. 6 E., on left bañk $i \frac{1}{4}$ miles upstream from Birch Creek and 6 miles southwest of Woodruff.

Drainage area. $--65 \mathrm{sq} \mathrm{ml}$, approximately. Mean altitude, 7,900 f':

Gage.--Nonrecording prior to June 21, 1939, at site half a mile downstream at different datum; recording thereafter. June 21, 1939, to Sept. 30, 1943, at site $1 \frac{1}{2}$ miles upstream at different datum. Altitude of gage is $6,600 \mathrm{ft}$ (from topographic map).

Stage-discharge relation.--Defined by current-meter measurements below $500 \mathrm{cfs}$. Shif's caused by unstable gravel control and beaver dams.

Remarks.--No diversion above station. Only annual peaks are shown.

Peak stages and discharges

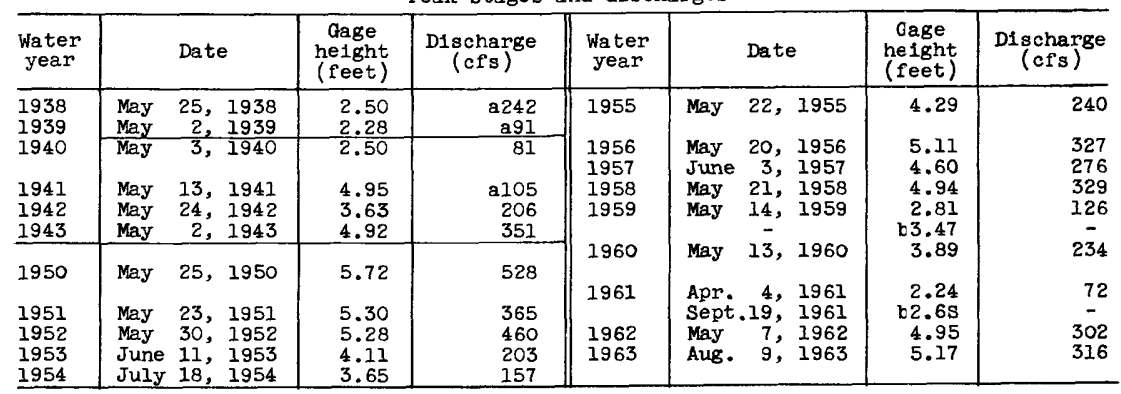

a Maximum da1ly.

b Backwater from beaver dam.

215. B1rch Creek near Woodruff, Utah

Location.--Lat $41^{\circ} 30^{\prime} 00^{\prime \prime}$, long $111^{\circ} 17^{\prime} 30^{\prime \prime}$, in NE⿺ sec.20, T.9 N., R.6 E., on lef't bank a quarter of a mile downstream from small tributary, 2 miles upstream from mouth, and 7 miles southwest of Woodruff.

Drainage area. $--17 \mathrm{sq} \mathrm{mi}$, approximately.

Gage.--Recording. Altitude of gage is 6,670 ft (from topographis map).

Stage-discharge relation.--Defined by current-meter measurements.

Remarks.--Flow regulated by Birch Creek Reservolr (capacity, 2,260 acre-ft)

completed in November 1951. Only annual peaks are shown.

Peak stages and discharges

\begin{tabular}{|c|c|c|c|c|c|c|c|c|}
\hline $\begin{array}{l}\text { Water } \\
\text { year }\end{array}$ & & Date & $\begin{array}{c}\text { Cage } \\
\text { height } \\
\text { (feet) }\end{array}$ & $\begin{array}{c}\text { Discharge } \\
\text { (cfs) }\end{array}$ & $\begin{array}{l}\text { Water } \\
\text { year }\end{array}$ & Date & $\begin{array}{c}\text { Grae } \\
\text { height } \\
\text { (fiet) }\end{array}$ & $\begin{array}{c}\text { Discharge } \\
\text { (cfs) }\end{array}$ \\
\hline 1950 & & 22,1950 & 3.73 & 172 & $\begin{array}{l}1954 \\
1955\end{array}$ & $\begin{array}{ll}\text { July } 1-6, & 1954 \\
\text { July } 10, & 1955\end{array}$ & $\begin{array}{l}1.58 \\
1.57\end{array}$ & $\begin{array}{l}\text { a22 } \\
\text { a31 }\end{array}$ \\
\hline $\begin{array}{l}1951 \\
1952 \\
1953\end{array}$ & $\begin{array}{l}\text { May } \\
\text { May } \\
\text { May }\end{array}$ & $\begin{array}{ll}12, & 1951 \\
16, & 1952 \\
29, & 1953\end{array}$ & $\begin{array}{l}2.62 \\
3.19 \\
2.28\end{array}$ & $\begin{array}{r}79 \\
102 \\
36\end{array}$ & 1956 & May 10,1956 & 2.49 & a.58 \\
\hline
\end{tabular}

a Maximum da11y. 
230. Big Creek near Randolph, Utah

Location.--Lat $41^{\circ} 37^{\prime}$, long $111^{\circ} 15^{\prime}$, in SE $\frac{1}{4}$ sec. 10 , T.10 N., R.6 E., on left bank $3 \frac{1}{2}$ miles downstream from main forks and $4 \frac{3}{4}$ miles southwest of Randolph.

Drainage area. $--52.2 \mathrm{sq} \mathrm{mi}$. Mean altitude, 7,370 ft.

Gage.--Recording. Prior to October 1944, at site a quarter of a mile downstream at different datum. Oct. 1, 1949, to Sept. 9, 1959, at site $100 \mathrm{ft}$ downstream at different datum. Altitude of gage is 6,390 ft (from topographic map).

Stage-discharge relation.--Defined by current-meter measurements below $130 \mathrm{cfs}$. Remarks.--0nly annual peaks are shown.

Peak stages and discharges

\begin{tabular}{|c|c|c|c|c|c|c|c|}
\hline $\begin{array}{c}\text { Water } \\
\text { year }\end{array}$ & Date & $\begin{array}{l}\text { Gage } \\
\text { height } \\
\text { (feet) }\end{array}$ & $\begin{array}{c}\text { Discharge } \\
\text { (cfs) }\end{array}$ & $\begin{array}{l}\text { Water } \\
\text { year }\end{array}$ & Date & $\begin{array}{l}\text { Gage } \\
\text { height } \\
\text { (feet) }\end{array}$ & $\begin{array}{c}\text { Discharge } \\
\text { (cfs) }\end{array}$ \\
\hline $\begin{array}{l}1939 \\
1940\end{array}$ & $\begin{array}{l}\text { Mar. } 19,1939 \\
\text { Nov. } 28,1939\end{array}$ & - & $\begin{array}{r}\text { a25 } \\
\text { b7.2 }\end{array}$ & \multirow{2}{*}{$\begin{array}{l}1955 \\
1956 \\
1957 \\
1958 \\
1959 \\
1960\end{array}$} & \multirow{3}{*}{$\begin{array}{l}\text { May } 14,1955 \\
\text { Apr. } 28,1956 \\
\text { July } 11,1957 \\
\text { May } 22,1958 \\
\text { Apr. } 2,1959 \\
\text { Jan. } 16,1960 \\
\text { Mar. } 18,1960\end{array}$} & \multirow{2}{*}{$\begin{array}{r}0.87 \\
1.38 \\
3.75 \\
1.02 \\
.90\end{array}$} & \multirow{3}{*}{$\begin{array}{r}36 \\
74 \\
337 \\
56 \\
54 \\
- \\
135\end{array}$} \\
\hline $\begin{array}{l}1941 \\
1942 \\
1943 \\
1944\end{array}$ & $\begin{array}{l}\text { Aug. } 12,1941 \\
\text { Apr. } 6,1942 \\
\text { Mar. 27, } 1943 \\
\text { Mar. } 31,1944\end{array}$ & $\begin{array}{l}3.57 \\
- \\
4.30 \\
2.94\end{array}$ & $\begin{array}{r}46 \\
\text { b15 } \\
117 \\
75\end{array}$ & & & & \\
\hline 1950 & May 18,1950 & 2.46 & 146 & & & & \\
\hline $\begin{array}{l}1951 \\
1952 \\
1953 \\
1954\end{array}$ & $\begin{array}{l}\text { Mar. } 21,1951 \\
\text { May } 7,1952 \\
\text { May 30, } 1953 \\
\text { July 1s, } 1954\end{array}$ & $\begin{array}{l}2.13 \\
2.05 \\
1.12 \\
1.21\end{array}$ & $\begin{array}{r}131 \\
128 \\
45 \\
49\end{array}$ & $\begin{array}{l}1962 \\
1963\end{array}$ & $\begin{array}{l}\text { Jan. 19, } 1961 \\
\text { Aug. } 5,1961 \\
\text { Mar. 27, } 1962 \\
\text { Feb. } 1,1963 \\
\text { Aug. } 7,1963\end{array}$ & $\begin{array}{r}c 4.00 \\
2.66 \\
3.41 \\
c 4.60 \\
3.60\end{array}$ & $\begin{array}{r}- \\
45 \\
117 \\
\overline{123}\end{array}$ \\
\hline
\end{tabular}

a Maximum dally for period Mar. 19 to Sept. 30 .

b Maximum daily.

c Backwater from ice.

240. Randolph Creek near Randolph, Utah

Location.--Lat $41^{\circ} 40^{\prime} 30^{\prime \prime}$, long $111^{\circ} 14^{\prime} 00^{\prime \prime}$, in SW $\frac{1}{4} \sec .23$, T.11 N., R. 6 E., on left bank a quarter of a mile downstream from confluence of old Canycn and New Canyon, half a mile upstream from Randolph Dam, and $2 \frac{3}{4}$ miles west of Randolph.

Drainage area. $--30.3 \mathrm{sq} \mathrm{ml}$.

Gage.--Recording. Altitude of gage is 6,370 ft (from topographic map).

Stage-discharge relation.--Defined by current-meter measurements below $10 \mathrm{cfs}$ and extended above by logarithmic plotting.

Remarks.--Only annual peaks are shown.

Peak stages and discharges

\begin{tabular}{|c|c|c|c|c|c|c|c|}
\hline $\begin{array}{l}\text { Water } \\
\text { year }\end{array}$ & Date & $\begin{array}{l}\text { Gage } \\
\text { helght } \\
\text { (feet) }\end{array}$ & $\begin{array}{c}\text { Discharge } \\
\text { (cfs) }\end{array}$ & $\begin{array}{l}\text { Water } \\
\text { year }\end{array}$ & Date & $\begin{array}{c}\text { Gage } \\
\text { helght } \\
\text { (feet) }\end{array}$ & $\begin{array}{c}I^{*} \text { scharge } \\
(\mathrm{cfs})\end{array}$ \\
\hline 1950 & Apr. 1,1950 & 1.35 & 22 & $\begin{array}{l}1954 \\
1955\end{array}$ & $\begin{array}{lll}\text { Mar. } & 9,1954 \\
\text { Apr. } & 8, & 1955\end{array}$ & $\begin{array}{r}1.17 \\
.97\end{array}$ & $\begin{array}{r}10 \\
8.9\end{array}$ \\
\hline $\begin{array}{l}1951 \\
1952 \\
1953\end{array}$ & $\begin{array}{l}\text { Mar. } 21,1951 \\
\text { Apr. 17, } 1952 \\
\text { May } 16,1953\end{array}$ & $\begin{array}{l}1.44 \\
1.18 \\
1.21\end{array}$ & $\begin{array}{l}32 \\
10 \\
10\end{array}$ & 1956 & Mar. 24, 1956 & & 65 \\
\hline
\end{tabular}


250. Otter Creek near Randolph, Utah

Location.--Lat $41^{\circ} 43^{\prime}$, long $111^{\circ} 12^{\prime}$, in NW/ sec.7, T.11 N., R.7 E., a quarter of a mile downstream from South Branch and 3 miles north of Rendolph.

Drainage area. $--36.2 \mathrm{sq} \mathrm{ml}$.

Gage.--Nonrecording prior to May 3, 1939; recording thereafter. Altitude of gage is $6,350 \mathrm{ft}$ (from topographic map).

Stage-discharge relation.--Defined by current-meter measurements below $40 \mathrm{cfs}$. Remarks.--Only annual peaks are show.

\begin{tabular}{|c|c|c|c|c|c|c|c|}
\hline $\begin{array}{l}\text { Water } \\
\text { year }\end{array}$ & Date & $\begin{array}{l}\text { Gage } \\
\text { he1ght } \\
\text { (feet) }\end{array}$ & $\begin{array}{c}\text { Discharge } \\
\text { (cfs) }\end{array}$ & $\begin{array}{l}\text { Water } \\
\text { year }\end{array}$ & Date & $\begin{array}{l}\text { Gige } \\
\text { nelght } \\
\text { (feet) }\end{array}$ & $\begin{array}{c}\text { Discharge } \\
\text { (cfs) }\end{array}$ \\
\hline $\begin{array}{l}1939 \\
1940 \\
1941\end{array}$ & $\begin{array}{l}\text { Mar. 17, } 1939 \\
\text { Feb. 29, } 1940 \\
\text { July 27, } 1941\end{array}$ & $\begin{array}{l}2.70 \\
1.89 \\
3.52\end{array}$ & $\begin{array}{r}a 57 \\
25 \\
125\end{array}$ & $\begin{array}{l}1942 \\
1943 \\
1944\end{array}$ & $\begin{array}{lr}\text { Apr. } 6, & 1942 \\
\text { July } 21, & 1943 \\
\text { Mar. } 30, & 1944\end{array}$ & $\begin{array}{l}1.54 \\
4.52 \\
3.40\end{array}$ & $\begin{array}{r}29 \\
203 \\
120\end{array}$ \\
\hline
\end{tabular}

a Maximum dally.

265. Bear River near Randolph, Utah

Location.--Lat $41^{\circ} 48^{1}$, long $111^{\circ} 06^{\prime}$, in $\mathrm{SE} \frac{1}{4} \mathrm{NE} \frac{1}{4} \sec .7$, T.12 N., R.8 E., on left bank 3.5 miles upstream from Twin Creek, 4.8 miles upstream from UtahWyoming state line, and 11 miles northeast of Randolph.

Drainage area. $--1,640 \mathrm{sq} \mathrm{mi}$, approximately. Mean altitude, $7,47 \mathrm{C} \mathrm{ft}$.

Gage.--Recording. Altitude of gage is 6,205 ft (from river-profile map).

Stage-discharge relation.--Defined by current-meter measurements below 2,500 cf's. Sandy streambed shifts almost continually at any stage.

Remarks.--Diversions for irrigation of about 96,000 acres above station. Only annual peaks are shown.

\begin{tabular}{|c|c|c|c|c|c|c|c|c|}
\hline $\begin{array}{l}\text { Water } \\
\text { year }\end{array}$ & \multicolumn{2}{|r|}{ Date } & $\begin{array}{l}\text { Qage } \\
\text { height } \\
\text { (feet) }\end{array}$ & $\begin{array}{c}\text { D1scharge } \\
\text { (cfs) }\end{array}$ & $\begin{array}{l}\text { Water } \\
\text { year }\end{array}$ & Date & $\begin{array}{l}\text { Gige } \\
\text { nelght } \\
\text { (feet) }\end{array}$ & $\begin{array}{c}\text { Discharge } \\
\text { (cfs) }\end{array}$ \\
\hline $\begin{array}{l}1944 \\
1945\end{array}$ & $\begin{array}{l}\text { Apr. } \\
\text { June }\end{array}$ & $\begin{array}{ll}8, & 1944 \\
8, & 1945\end{array}$ & $\begin{array}{l}7.00 \\
5.50\end{array}$ & $\begin{array}{r}1,360 \\
771\end{array}$ & 1955 & & & 348 \\
\hline $\begin{array}{l}1946 \\
1947 \\
1948 \\
1949 \\
1950\end{array}$ & $\begin{array}{l}\text { May } \\
\text { June } \\
\text { Apr. } \\
\text { May } \\
\text { June }\end{array}$ & $\begin{aligned} 1, & 1946 \\
14, & 1947 \\
27, & 1948 \\
21, & 1949 \\
6, & 1950\end{aligned}$ & $\begin{array}{l}6.68 \\
7.85 \\
7.27 \\
5.85 \\
8.30\end{array}$ & $\begin{array}{r}1,170 \\
1,600 \\
1,410 \\
923 \\
2,100\end{array}$ & $\begin{array}{l}1956 \\
1957 \\
1958 \\
1959 \\
1960\end{array}$ & $\begin{array}{ll}\text { Mar. } 23, & 1956 \\
\text { June } 15, & 1957 \\
\text { May 31, } & 1958 \\
\text { July 2, } & 1959 \\
\text { Mar. 22, } & 1960 \\
\text { Mar. 27, } & 1960\end{array}$ & $\begin{array}{r}8.44 \\
8.27 \\
4.88 \\
4.32 \\
25.51 \\
5.47\end{array}$ & $\begin{array}{r}2,350 \\
2,040 \\
717 \\
525 \\
- \\
753\end{array}$ \\
\hline $\begin{array}{l}1951 \\
1952 \\
1953 \\
1954 \\
\end{array}$ & $\begin{array}{l}\text { June } \\
\text { May } \\
\text { June } \\
\text { Apr. }\end{array}$ & $\begin{array}{rr}3, & 1951 \\
8, & 1952 \\
19, & 1953 \\
9, & 1954\end{array}$ & $\begin{array}{l}7.92 \\
8.80 \\
7.39 \\
3.09\end{array}$ & $\begin{array}{r}1,880 \\
2,660 \\
1,690 \\
258\end{array}$ & $\begin{array}{l}1961 \\
1962 \\
1963\end{array}$ & $\begin{array}{l}\text { Mar. 16, } 1961 \\
\text { Mar. 30, } 1962 \\
\text { June 18, } 1963\end{array}$ & $\begin{array}{r}23.85 \\
8.07 \\
4.17\end{array}$ & $\begin{array}{r}1, \overline{900} \\
383\end{array}$ \\
\hline
\end{tabular}

a Backwater from 1ce. 
270. Twin Creek at Sage, Wyo.

Location.--Lat $41^{\circ} 49^{\prime}$, long $110^{\circ} 58^{\prime}$, in SE⿺辶 $\frac{1}{4}$ sec.7, T.21 N, , R.119 W., on left bank half a mile southwest of Sage and 5 miles upstream from mouth.

Drainage area. $--246 \mathrm{sq} \mathrm{ml}$. Mean altitude, $7,180 \mathrm{ft}$.

Gage.--Nonrecording prior to oct. 1 , 1945 , at site 0.6 mile upstream at different datum; recording thereafter. Altitude of gage is $6,330 \mathrm{ft}$ ( $\mathrm{f}$ rom highway map).

Stage-discharge relation.--Defined by current-meter measurements below $610 \mathrm{cfs}$. Some shifting caused by extremely high water and moss.

Remarks.--Diversions for irrigation of about 1,100 acres above station. Base for partial-duration series, $200 \mathrm{cfs}$. Only annual peaks are shown prior to 1948 .

\begin{tabular}{|c|c|c|c|c|c|c|c|}
\hline $\begin{array}{l}\text { Water } \\
\text { year }\end{array}$ & Date & $\begin{array}{l}\text { Gage } \\
\text { helght } \\
\text { (feet) }\end{array}$ & $\begin{array}{c}\text { Discharge } \\
\text { (cfs) }\end{array}$ & $\begin{array}{l}\text { Water } \\
\text { year }\end{array}$ & Date & $\begin{array}{l}\text { Gage } \\
\text { height } \\
\text { (feet) }\end{array}$ & $\begin{array}{c}\text { Discharge } \\
\text { (cfs) }\end{array}$ \\
\hline $\begin{array}{l}1943 \\
1944 \\
1945\end{array}$ & $\begin{array}{l}\text { Aug. } 8,1943 \\
\text { Apr. } 5,1944 \\
\text { Aug. } 14,1945 \\
\end{array}$ & $\begin{array}{l}- \\
8.38 \\
6.88 \\
\end{array}$ & $\begin{array}{l}\text { a137 } \\
\text { b610 } \\
\text { b204 } \\
\end{array}$ & $\begin{array}{l}1953 \\
1954\end{array}$ & $\begin{array}{l}\text { Mar. } 27,1953 \\
\text { Apr. } 6,1954\end{array}$ & $\begin{array}{l}2.30 \\
2.99\end{array}$ & $\begin{array}{l}65 \\
69\end{array}$ \\
\hline $\begin{array}{l}1946 \\
1947\end{array}$ & $\begin{array}{l}\text { Mar. } 28,1946 \\
\text { Mar. } 18,1947\end{array}$ & $\begin{array}{l}3.73 \\
6.08\end{array}$ & $\begin{array}{l}246 \\
649\end{array}$ & 1955 & Apr. 15, 1955 & 3.28 & 11.7 \\
\hline 1948 & $\begin{array}{l}\text { Apr. } 3,1948 \\
\text { Apr. } 17,1948\end{array}$ & 3.77 & $\begin{array}{l}222 \\
246\end{array}$ & $\begin{array}{l}1956 \\
1957\end{array}$ & $\begin{array}{ll}\text { Mar. } 24, & 1956 \\
\text { May } 25, & 1957\end{array}$ & $\begin{array}{l}5.85 \\
2.55\end{array}$ & $\begin{array}{r}584 \\
56\end{array}$ \\
\hline 1949 & June 12,1949 & 2.81 & 139 & 1958 & Apr. 19,1958 & 3.88 & 230 \\
\hline 1950 & $\begin{array}{l}\text { Apr. } 2,1950 \\
\text { Apr. } 8,1950 \\
\text { Apr. } 18,1950\end{array}$ & $\begin{array}{l}5.04 \\
-\end{array}$ & $\begin{array}{l}460 \\
327 \\
265\end{array}$ & $\begin{array}{l}1959 \\
1960\end{array}$ & $\begin{array}{l}\text { Apr. 3, } 1959 \\
\text { Mar. 26, } 1960\end{array}$ & $\begin{array}{l}4.12 \\
4.59\end{array}$ & $\begin{array}{l}275 \\
422\end{array}$ \\
\hline 1951 & $\begin{array}{l}\text { Mar. 21, } 1951 \\
\text { Mar. 31, } 1951\end{array}$ & $\begin{array}{l}5.14 \\
4.79\end{array}$ & $\begin{array}{l}477 \\
418\end{array}$ & 1961 & Mar. 16,1961 & 4.45 & (c) \\
\hline 1952 & Apr. 2l, 1952 & 4.43 & 359 & 1962 & Apr. 3, 1962 & 5.90 & 613 \\
\hline
\end{tabular}

a Maximum observed during period April to September.

b Maximum observed.

c Not. determined; occurred during period of ice effect.

285. Bear River below P1xley Dam, near Cokeville, Wyo.

(Published as "Bear River near Cokeville" 1942-43)

Location. --Lat $41^{\circ} 56^{\prime} 2^{\prime \prime}$, long $110^{\circ} 59^{\prime} 05^{\prime \prime}$, In $\mathrm{SE}_{\frac{1}{4}} \mathrm{SE} \frac{1}{4} \mathrm{sec} .25$, T.23 N., F.120 W.,

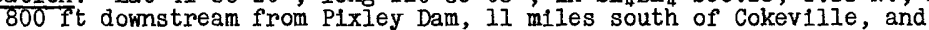

17.5 miles downstream from Twin Creek.

Drainage area. $--2,040 \mathrm{sq} \mathrm{ml}$, approximately.

Gage.--Recording. Prior to Dec. 1, 1943, at site $200 \mathrm{ft}$ downstream at different datum. Aititude of gage is $6,185^{\prime} \mathrm{ft}$ (from river-profile map).

Stage-discharge relation.--Defined by current-meter measurements.

Remark8.--Only annual peaks are shown.

Peak stages and discharges

\begin{tabular}{|c|c|c|c|c|c|c|c|}
\hline $\begin{array}{l}\text { Water } \\
\text { year }\end{array}$ & Date & $\begin{array}{l}\text { Cage } \\
\text { helght } \\
\text { (feet) }\end{array}$ & $\begin{array}{c}\text { Discharge } \\
(\mathrm{cfs})\end{array}$ & $\begin{array}{l}\text { Water } \\
\text { year }\end{array}$ & Date & $\begin{array}{c}\text { Gage } \\
\text { helght } \\
\text { (feet) }\end{array}$ & $\begin{array}{c}\text { Discharge } \\
\text { (cfs) }\end{array}$ \\
\hline $\begin{array}{l}1942 \\
1943 \\
\end{array}$ & $\begin{array}{l}\text { Apr. } 6,1942 \\
\text { Mar. } 29,1943\end{array}$ & $\begin{array}{l}8.35 \\
5.37 \\
\end{array}$ & $\begin{array}{r}1,640 \\
934 \\
\end{array}$ & \multirow{2}{*}{$\begin{array}{l}1958 \\
1959 \\
1960 \\
1961 \\
1962 \\
1963\end{array}$} & \multirow{2}{*}{$\begin{array}{lrl}\text { June } & 2, & 1958 \\
\text { July } & 7, & 1959 \\
\text { July } & 2, & 1960 \\
& & \\
\text { Sept } & 22, & 1961 \\
\text { May } 18, & 1962 \\
\text { July } & 5, & 1963\end{array}$} & \multirow{2}{*}{$\begin{array}{c}\overline{-} \\
3.49 \\
3.25 \\
5.93 \\
4.88\end{array}$} & \multirow{2}{*}{$\begin{array}{r}\text { a591 } \\
\text { a377 } \\
189 \\
\\
130 \\
659 \\
388\end{array}$} \\
\hline $\begin{array}{l}1953 \\
1954 \\
1955 \\
1956\end{array}$ & $\begin{array}{lrl}\text { June } 21, & 1953 \\
\text { Apr. } & 9, & 1954 \\
\text { June } & 5, & 1955 \\
& \\
\text { Mar. } 25, & 1956\end{array}$ & $\begin{array}{l}8.25 \\
4.18 \\
5.05\end{array}$ & $\begin{array}{r}1,220 \\
282 \\
382 \\
a 2,300\end{array}$ & & & & \\
\hline
\end{tabular}

a Maximum daily. 
295. Bear River above Sublette Creek, near Cokeville, Wyo.

Location. --Lat $42^{\circ} 02^{\prime} 20^{\prime \prime}$, long $110^{\circ} 57^{\prime} 05^{\prime \prime}$, in SW $\mathrm{I}_{4} \mathrm{SE} \frac{1}{4}$ sec.20, T.24 N., R.II9 W., on left bank $1,500 \mathrm{ft}$ upstream from Sublette Creek and $3 \frac{1}{4}$ miles south of Cokeville.

Drainage area. $--2,110 \mathrm{sq} \mathrm{ml}$, approximately.

Gage.--Recording. Altitude of gage is 6,165 ft (from river-prof:le map).

Stage-discharge relation.--Defined by current-meter measurements.

Bankfull stage. $--8.8 \mathrm{ft}$.

Remarks.--Diversions for irrigation of about 109,000 acres upstriam from station. Only annual peaks are shown.

Peak stages and discharges

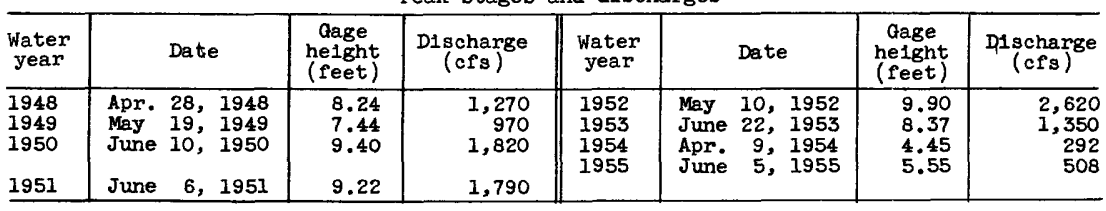

320. Smiths Fork near Border, Wyo.

Location.--Lat $42^{\circ} 17^{\prime}$, long $110^{\circ} 52^{\prime}$, in NW $\frac{1}{4}$ sec.33, T.27 N., R.118 W., on left bank $4 \frac{1}{2}$ miles upstream from Howland Creek, 6 miles downstream from Hobble Creek, and 12 miles northeast of Border.

Drainage area. $--165 \mathrm{sq}$ mi. Mean altitude, 8,270 ft.

Gage.--Recording. Prior to 0ct. 16, 1945, at site $0.8 \mathrm{mile}$ downstream at different datum. Altitude of gage is $6,650 \mathrm{ft}$ (from topographic map).

Stage-discharge relation.--Defined by current-meter measurements below $1,400 \mathrm{cfs}$.

Remarks.--Base for partial-duration series, $580 \mathrm{cfs}$. Only annual peaks are shown prior to 1948 .

Peak stages and discharges

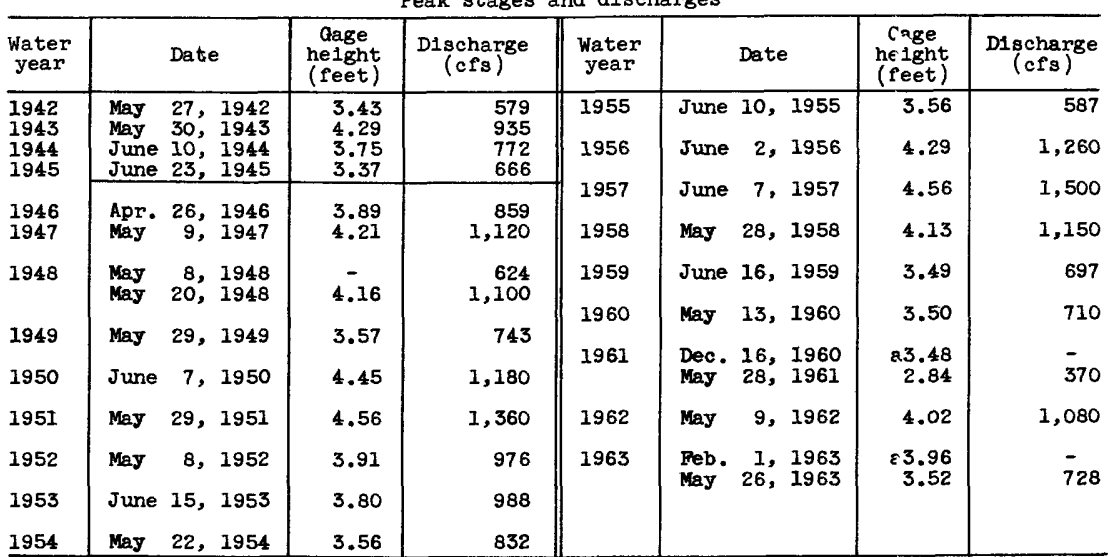

a Backwater from 1ce. 
350. Smiths Fork at Cokeville, Wyo.

Location. --Lat $42^{\circ} 06^{\prime}$, long $110^{\circ} 57^{\prime}$, in NW/ sec.4, T.24 N., R.119 W., on right bank 1 mile northeast of Cokevilie and 2 miles upstream from mouth.

Drainage area. $--275 \mathrm{sq} \mathrm{mi}$. Mean altitude, 7,810 ft.

Gage.--Recording. Prior to Aug. 11, 1949, at site $85 \mathrm{ft}$ downstream at different datum. Altitude of gage is $6,250 \mathrm{ft}$ (from topographic map).

Stage-discharge relation.--Defined by current-meter measurements .

Remarks.--Many diversions above station for irrigation above and below station. OnIy annual peaks are shown.

Peak stages and discharges

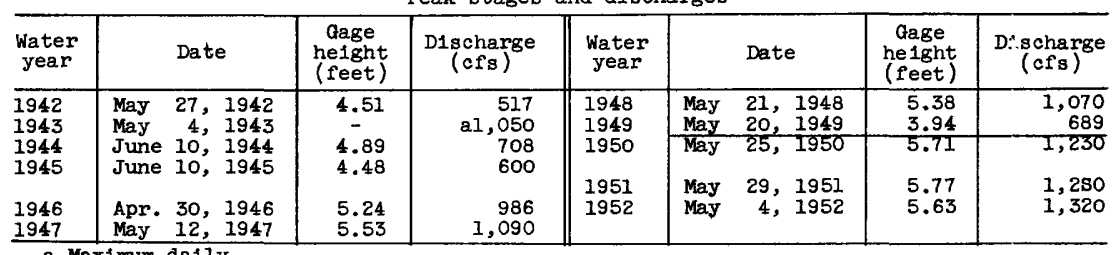

a Maximum daily.

380. Bear River below Smiths Fork, near Cokeville, Wyo.

Location. --Lat $42^{\circ} 07^{\prime} 30^{\prime \prime}$, long $110^{\circ} 58^{\prime} 20^{\prime \prime}$, in SE $\frac{1}{4} \mathrm{NE}_{\frac{1}{4}}$ sec.28, T.25 N., R.119 W., $1.1 \mathrm{miles}$ upstream from Wyman Dam, 2.8 miles northwest of Cokevilie, and 3.8 miles downstream from Smiths Fork.

Drainage area. $--2,460 \mathrm{sq} \mathrm{mi}$, approximately.

Gage.--Recording. Altitude of gage is 6,140 ft (from river-profile map).

Stage-discharge relation.--Defined by current-meter measurements.

Remarks.--Only annual peaks are shown.

Peak stages and discharges

\begin{tabular}{|c|c|c|c|c|c|c|c|c|}
\hline $\begin{array}{l}\text { Water } \\
\text { year }\end{array}$ & & Date & $\begin{array}{c}\text { Cage } \\
\text { he1ght } \\
\text { (feet) }\end{array}$ & $\begin{array}{c}\text { D1scharge } \\
\text { (cfs) }\end{array}$ & $\begin{array}{l}\text { Water } \\
\text { year }\end{array}$ & Date & $\begin{array}{l}\text { Gage } \\
\text { he1ght } \\
\text { (feet) }\end{array}$ & $\begin{array}{c}\text { D. scharge } \\
(\text { cfs })\end{array}$ \\
\hline $\begin{array}{l}1954 \\
1955\end{array}$ & $\begin{array}{l}\text { May } 1 \\
\text { June }\end{array}$ & $\begin{array}{r}11,1954 \\
5,1955\end{array}$ & $\begin{array}{l}3.83 \\
4.20\end{array}$ & $\begin{array}{l}673 \\
880\end{array}$ & $\begin{array}{l}1959 \\
1960\end{array}$ & $\begin{array}{l}\text { Apr. } 6,1959 \\
\text { Mar. } 25,1960\end{array}$ & $\begin{array}{l}4.21 \\
5.09\end{array}$ & $\begin{array}{r}931 \\
1,600\end{array}$ \\
\hline $\begin{array}{l}1956 \\
1957 \\
1958\end{array}$ & $\begin{array}{l}\text { Mar. } 2 \\
\text { June } 2 \\
\text { June }\end{array}$ & $\begin{aligned} 26, & 1956 \\
22, & 1957 \\
2, & 1958\end{aligned}$ & $\begin{array}{l}7.54 \\
6.26 \\
5.20\end{array}$ & $\begin{array}{l}3,780 \\
2,570 \\
1,660\end{array}$ & $\begin{array}{l}1961 \\
1962 \\
1963\end{array}$ & $\begin{array}{l}\text { Mar. 16, } 1961 \\
\text { Apr. 2, } 1962 \\
\text { June } 15,1963\end{array}$ & $\begin{array}{l}3.11 \\
6.85 \\
4.18\end{array}$ & $\begin{array}{r}329 \\
3,100 \\
904 \\
\end{array}$ \\
\hline
\end{tabular}

395. Bear River at Border, Wyo.

Location.--Lat $42^{\circ} 11^{\prime}$, long $111^{\circ} 03^{\prime}$, in $\mathrm{NE}_{4}^{\frac{1}{4} \mathrm{NE}} \frac{1}{4}$ sec.15, T.14 S., R.46 E., in Idaho, on left bank a quarter of a mile west of Wyoming-Idaho state ilne, half a mile west of Border, and 2.1 miles upstream from Thomas Fork.

Drainage area. $--2,490 \mathrm{sq} \mathrm{mi}$, approximately. Mean altitude, 7,360 ft.

Gage.--Recording. Datum of gage is $6,051.63 \mathrm{ft}$ above mean sea level, unadjusted.

Stage-discharge relation.--Defined by current-meter measurements below 3,650 cf's. Shifting at various stages caused mostly by backwater from Thomis Fork.

Remarks.--Diversions for irrigation of about 124,000 acres above station. Base for partial-duration series, $1,000 \mathrm{cfs}$. Only annual peaks are shown prior to 1948 and after 1951 . 
Peak stages and discharges of Bear River at Border, Wyo.

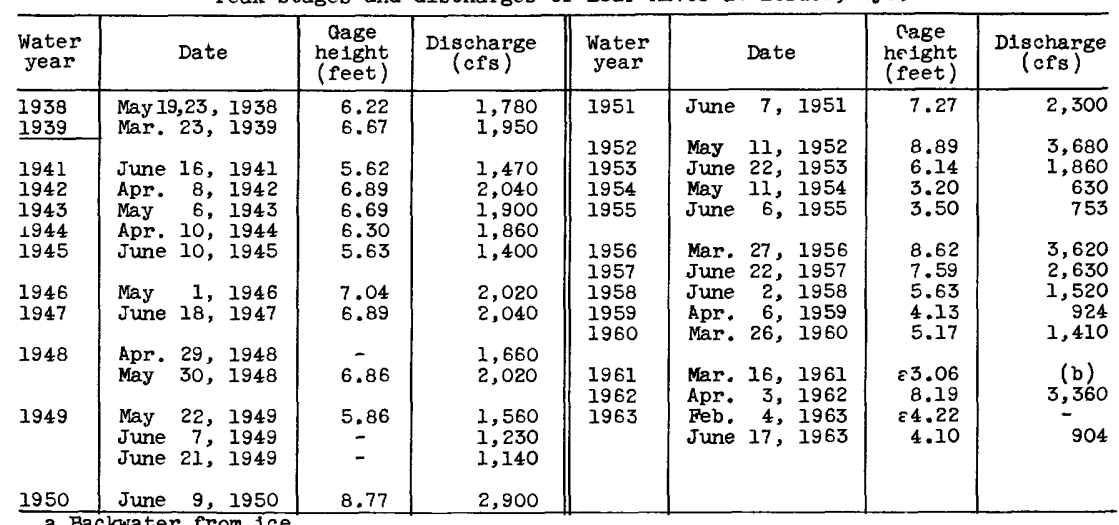

a Backwater from 1ce.

b Not determined.

400. Thomas Fork near Geneva, Idaho

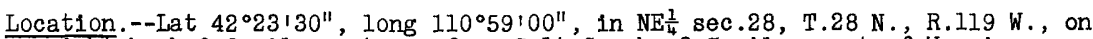
right bank 0.8 mile upstream from Salt Creek, 3.7 miles east of Wyoming-

Idaho State line, and 5.4 miles northeast of Geneva Post Office.

Drainage area. $--45.3 \mathrm{sq} \mathrm{mi}$. Mean altitude, 7,170 ft.

Gage.--Recording. Altitude of gage is 6,400 ft (from topographic map).

Stage-discharge relation.--Defined by current-meter measurements below $240 \mathrm{cfs}$.

Remarks.--Base for partial-duration series, $40 \mathrm{cfs}$. Only annual peaks are shown prior to 1948 .

\begin{tabular}{|c|c|c|c|c|c|c|c|}
\hline $\begin{array}{l}\text { Water } \\
\text { year }\end{array}$ & Date & $\begin{array}{c}\text { Gage } \\
\text { helght } \\
\text { (feet) }\end{array}$ & $\begin{array}{c}\text { Discharge } \\
\text { (cfs) }\end{array}$ & $\begin{array}{l}\text { Water } \\
\text { year }\end{array}$ & Date & $\begin{array}{c}\text { Gige } \\
\text { helght } \\
\text { (feet) }\end{array}$ & $\begin{array}{c}\text { Discharge } \\
(\mathrm{cfs})\end{array}$ \\
\hline 1940 & Sept.28, 1940 & & 23 & 1948 & $\begin{array}{l}\text { Apr. } 29,194 \mathrm{~S} \\
\text { May } 7,194 \mathrm{~S}\end{array}$ & 3.39 & $\begin{array}{l}267 \\
186\end{array}$ \\
\hline $\begin{array}{l}1941 \\
1942 \\
1943 \\
1944 \\
1945\end{array}$ & $\begin{array}{lr}\text { May } & 4,1941 \\
\text { Apr. } 5, & 1942 \\
\text { Apr. } 24,1943 \\
\text { Apr. } 4,1944 \\
\text { June } 10,1945\end{array}$ & $\begin{array}{l}2.77 \\
3.19 \\
3.95 \\
3.35 \\
2.92\end{array}$ & $\begin{array}{r}63 \\
122 \\
172 \\
119 \\
73\end{array}$ & 1949 & $\begin{array}{lrl}\text { Apr. } 24, & 1949 \\
\text { May } 17, & 1949 \\
\text { June } 8, & 1949\end{array}$ & $\begin{array}{c}2.57 \\
-\end{array}$ & $\begin{array}{l}78 \\
75 \\
49\end{array}$ \\
\hline $\begin{array}{l}1946 \\
1947\end{array}$ & $\begin{array}{lr}\text { Apr. } & 26,1946 \\
\text { May } & 3,1947\end{array}$ & $\begin{array}{l}4.07 \\
3.58\end{array}$ & $\begin{array}{l}241 \\
225\end{array}$ & 1950 & $\begin{array}{ll}\text { Apr. } 22, & 1950 \\
\text { May } 18, & 1950\end{array}$ & 4.25 & $\begin{array}{l}168 \\
418\end{array}$ \\
\hline 1948 & Apr. 17,1948 & - & 86 & 1951 & Apr. 29, 1951 & 3.36 & 224 \\
\hline
\end{tabular}

\section{Salt Creek near Geneva, Idaho}

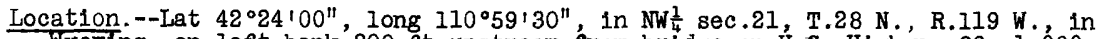
Wyoming, on left bank 800 ft upstream from bridge on U.S. Highray $89,1,000$ $f t$ upstream from mouth, 3.0 miles east of Wyoming-Idaho State Iine, and $4 \frac{3}{4}$ miles northeast of Geneva Post Office.

Drainage area. $--37.6 \mathrm{sq} \mathrm{mi}$. Mean altitude, 7,390 ft.

Gage.--Recording. Altitude of gage is 6,350 ft (from topographic map). Stage-discharge relation.--Defined by current-meter measurements.

Remarks.--Base for partial-duration series, $50 \mathrm{cfs}$. Only annual peaks are shown prior to 1948 . 
Peak stages and discharges of Salt Creek near Geneva, Idaho

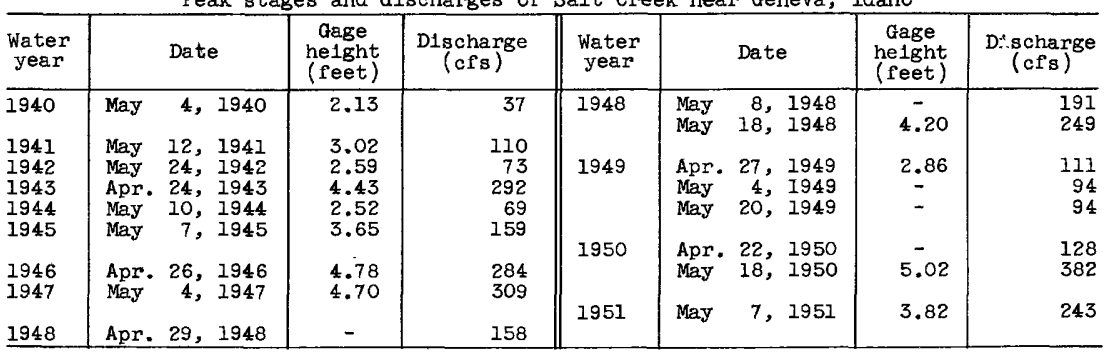

\section{Thomas Fork near Wyoming-Idaho State line}

Location.--Lat $42^{\circ} 24^{\prime} 10^{\prime \prime}$, long $111^{\circ} 01^{\prime} 30^{\prime \prime}$, in SE $\frac{1}{4} N W^{\frac{1}{4}}$ sec.19, T.28 N., R.119 W., in Wyoming, on right bank 1.3 miles upstream from State line, 1.5 miles

downstream from Giraffe Creek, and $3 \frac{1}{2}$ miles northeast of Geneva, Idaho.

Drainage area. $--113 \mathrm{sq} \mathrm{mi}$. Mean altitude, 7,290 ft.

Gage.--Recording. Prior to Aug. 23, 1957, at site 0.2 mile upstream at dif-

ferent datum. Altitude of gage is 6,280 $\mathrm{ft}$ (from topographic map).

Stage-discharge relation.--Defined by current-meter measurements below $670 \mathrm{cfs}$. Gravel bar control subject to some shifting.

Remarks.--Base for partial-duration series, $150 \mathrm{cfs}$.

Peak stages and discharges

\begin{tabular}{|c|c|c|c|c|c|c|c|c|}
\hline $\begin{array}{l}\text { Water } \\
\text { year }\end{array}$ & & Date & $\begin{array}{l}\text { Gage } \\
\text { height } \\
\text { (feet) }\end{array}$ & $\begin{array}{c}\text { Discharge } \\
\text { (cfs) }\end{array}$ & $\begin{array}{l}\text { Water } \\
\text { year }\end{array}$ & Date & $\begin{array}{l}\text { Gage } \\
\text { he1ght } \\
\text { (feet) }\end{array}$ & $\begin{array}{c}\text { D:scharge } \\
(\mathrm{cfs})\end{array}$ \\
\hline 1950 & $\begin{array}{l}\text { Apr. } \\
\text { May }\end{array}$ & $\begin{array}{l}21,1950 \\
18,1950\end{array}$ & 5.55 & $\begin{array}{l}423 \\
869\end{array}$ & 1957 & $\begin{array}{lll}\text { May } & 12, & 1957 \\
\text { May } & 19, & 1957 \\
\end{array}$ & $\begin{array}{l}4.02 \\
4.24 \\
\end{array}$ & $\begin{array}{l}626 \\
766 \\
\end{array}$ \\
\hline 1951 & Mey & 7,1951 & - & a 620 & 1958 & $\begin{array}{lll}\text { May } 12, & 1958 \\
\text { June } & 24, & 1958\end{array}$ & $\begin{array}{l}3.45 \\
2.59\end{array}$ & $\begin{array}{l}417 \\
190\end{array}$ \\
\hline 1952 & May & 4, 1952 & 6.53 & 848 & 1959 & Feb. 21, 1959 & a.3.96 & - \\
\hline 1953 & $\begin{array}{l}\text { Apr. } \\
\text { May } \\
\text { May }\end{array}$ & $\begin{array}{r}27,1953 \\
7,1953 \\
20,1953\end{array}$ & $\begin{array}{l}3.27 \\
3.24 \\
3.20\end{array}$ & $\begin{array}{l}171 \\
166 \\
159\end{array}$ & 1960 & $\begin{array}{lll}\text { May } & 2, & 1959 \\
\text { Apr. } & 9, & 1960\end{array}$ & $\begin{array}{l}2.38 \\
2.84\end{array}$ & $\begin{array}{l}157 \\
268\end{array}$ \\
\hline 1954 & $\begin{array}{l}\text { Apr. } \\
\text { May }\end{array}$ & $\begin{array}{rr}28, & 1954 \\
7, & 1954\end{array}$ & $\begin{array}{l}3.24 \\
3.39\end{array}$ & $\begin{array}{l}171 \\
200\end{array}$ & 1961 & $\begin{array}{lrl}\operatorname{Mar} & 9, & 1961 \\
\operatorname{Mar} .24, & 1961\end{array}$ & $\begin{array}{r}b 3.88 \\
1.85\end{array}$ & $\overline{69}$ \\
\hline 1955 & May & 8,1955 & 3.75 & 152 & 1962 & Apr. 28,1962 & 3.48 & 640 \\
\hline 1956 & $\begin{array}{l}\text { Dec. } \\
\text { Apr. }\end{array}$ & $\begin{array}{ll}24, & 1955 \\
24, & 1956\end{array}$ & $\begin{array}{l}3.83 \\
4.16\end{array}$ & $\begin{array}{l}246 \\
634\end{array}$ & 1963 & $\begin{array}{l}\text { Feb. } 1,1963 \\
\text { Mar. } 28,1963\end{array}$ & $\begin{array}{r}\mathrm{b} 3.38 \\
2.35\end{array}$ & 304 \\
\hline
\end{tabular}

a Maximum daily.

b Backwater from 1ce.

425. Thomas Fork near Raymond, Idaho

Location.--Lat $42^{\circ} 16^{\prime}$, long $111^{\circ} 05^{\prime}$, in $\mathrm{SE} \frac{1}{4} \mathrm{sec} .28$, T.13 S., R.46 E., on left bank at J. W. Mumford Ranch, $I \frac{1}{2}$ miles southwest of Raymond.

Drainage area. $--202 \mathrm{sq} \mathrm{mi}$. Mean altitude, 7,090 ft.

Gage.--Recording. Altitude of gage is 6,080 ft (from topographic map).

Stage-discharge relation.--Defined by current-meter measurements.

Remarks.--Diversions above station for irrigation of about 10,000 acres. Only annual peaks are shown. 
Peak stages and discharges of Thomas Fork near Raymond, Itaho

\begin{tabular}{|c|c|c|c|c|c|c|c|c|}
\hline $\begin{array}{l}\text { Water } \\
\text { year }\end{array}$ & Date & $\begin{array}{l}\text { Gage } \\
\text { helght } \\
\text { (feet) }\end{array}$ & $\begin{array}{c}\text { Discharge } \\
(c f s)\end{array}$ & $\begin{array}{l}\text { Water } \\
\text { year }\end{array}$ & & Date & $\begin{array}{c}\text { Gage } \\
\text { helght } \\
\text { (feet) }\end{array}$ & $\begin{array}{c}\text { Discharge } \\
\text { (cfs) }\end{array}$ \\
\hline $\begin{array}{l}1943 \\
1944 \\
1945\end{array}$ & $\begin{array}{l}\text { Apr. } 25,1943 \\
\text { Apr. } 6,1944 \\
\text { June } 11-13,1945\end{array}$ & $\begin{array}{l}7.66 \\
4.09 \\
5.48\end{array}$ & $\begin{array}{l}618 \\
104 \\
201\end{array}$ & $\begin{array}{l}1948 \\
1949 \\
1950\end{array}$ & $\begin{array}{l}\text { May } \\
\text { May } \\
\text { May }\end{array}$ & $\begin{array}{l}19,1948 \\
22,1949 \\
19,1950\end{array}$ & $\begin{array}{l}6.72 \\
4.54 \\
7.62\end{array}$ & $\begin{array}{r}325 \\
189 \\
1,070\end{array}$ \\
\hline $\begin{array}{l}1946 \\
1947\end{array}$ & $\begin{array}{l}\text { Apr. } 27,1946 \\
\text { May } 6,1947\end{array}$ & $\begin{array}{l}7.82 \\
6.92 \\
\end{array}$ & $\begin{array}{l}773 \\
427\end{array}$ & $\begin{array}{l}1951 \\
1952\end{array}$ & $\begin{array}{l}\text { May } \\
\text { May }\end{array}$ & $\begin{array}{l}9,1951 \\
5,1952\end{array}$ & $\begin{array}{l}7.05 \\
7.29\end{array}$ & $\begin{array}{l}522 \\
890 \\
\end{array}$ \\
\hline
\end{tabular}

440. Bear River at Harer, Idaho

Location.--Lat $42^{\circ} 11^{\prime} 50^{\prime \prime}$, long $111^{\circ} 10^{\prime} 0^{\prime \prime}$, in NW $\frac{1}{4}$ sec.23, T.14 S., R.45 E., on right bank $400 \mathrm{ft}$ downstream from Sheep Creek, three-quarters of a mile north of Harer siding on Union Pacific (Oregon Short Iine) Railroad, and 5 miles southeast of Dingle.

Drainage area. $--2,780 \mathrm{sq} \mathrm{mi}$, approximately.

Gage.--Nonrecording prior to Aug. 24, 1914, at site 1,500 ft downstream at different datum; recording thereafter. Altitude of gage is 6,0C0 ft (from topographic map).

Stage-discharge relation.--Defined by current-meter measurements .

Remarks.--Many diversions above station for irrigation. Only arnual peaks are shown.

\begin{tabular}{|c|c|c|c|c|c|c|c|c|}
\hline $\begin{array}{l}\text { Water } \\
\text { year }\end{array}$ & Date & $\begin{array}{c}\text { Gage } \\
\text { helght } \\
\text { (feet) }\end{array}$ & $\begin{array}{c}\text { D1scharge } \\
\text { (cfs) }\end{array}$ & $\begin{array}{l}\text { Water } \\
\text { year }\end{array}$ & \multicolumn{2}{|r|}{ Date } & $\begin{array}{l}\text { Gage } \\
\text { helght } \\
\text { (ieet) }\end{array}$ & $\begin{array}{c}\text { Discharge } \\
(\mathrm{cfs})\end{array}$ \\
\hline 1914 & May 26,1914 & - & 23,450 & \multirow{2}{*}{$\begin{array}{l}1939 \\
1940\end{array}$} & \multirow{2}{*}{\multicolumn{2}{|c|}{$\begin{array}{lr}\text { Mar. } 24, & 1939 \\
\text { Mar. } & 6,1940\end{array}$}} & - & 2,360 \\
\hline & June 7,1915 & - & 1,120 & & & & - & 227 \\
\hline $\begin{array}{l}1916 \\
1917 \\
1918 \\
1919 \\
1920\end{array}$ & $\begin{array}{l}\text { Mar. 22, } 1916 \\
\text { Apr.19,20, } 1917 \\
\text { June 21, } 1918 \\
\text { Mar. 29, } 1919 \\
\text { June 2, } 1920\end{array}$ & $\begin{array}{c}- \\
- \\
- \\
10.51\end{array}$ & $\begin{array}{l}3,630 \\
4,250 \\
2,460 \\
1,370 \\
3,860\end{array}$ & $\begin{array}{l}1941 \\
1942 \\
1943 \\
1944 \\
1945\end{array}$ & $\begin{array}{l}\text { June } \\
\text { Apr. } \\
\text { May } \\
\text { Apr. } \\
\text { June }\end{array}$ & 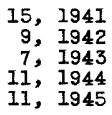 & $\begin{array}{c}\overline{-} \\
\overline{8.42} \\
\overline{6.81}\end{array}$ & $\begin{array}{l}1,580 \\
2,280 \\
2,400 \\
2,150 \\
1,680\end{array}$ \\
\hline $\begin{array}{l}1921 \\
1922 \\
1923 \\
1924 \\
1925\end{array}$ & $\begin{array}{l}\text { June } 19,1921 \\
\text { May } 28,1922 \\
\text { May 30, } 1923 \\
\text { Apr. 15, } 1924 \\
\text { May } 27,1925\end{array}$ & $\begin{array}{c}- \\
10.48 \\
- \\
6.07\end{array}$ & $\begin{array}{l}3,640 \\
3,840 \\
3,700 \\
3,790 \\
1,460\end{array}$ & $\begin{array}{l}1946 \\
1947 \\
1945 \\
1949 \\
1950\end{array}$ & $\begin{array}{l}\text { May } \\
\text { May } \\
\text { May } \\
\text { May } \\
\text { June }\end{array}$ & $\begin{aligned} 2, & 1946 \\
15, & 1947 \\
31, & 1948 \\
22, & 1949 \\
10, & 1950\end{aligned}$ & $\begin{array}{r}8.92 \\
8.40 \\
8.40 \\
7.32 \\
10.76\end{array}$ & $\begin{array}{l}2,680 \\
2,300 \\
2,290 \\
1,310 \\
3,780\end{array}$ \\
\hline $\begin{array}{l}1926 \\
1927 \\
1928 \\
1929 \\
1930\end{array}$ & $\begin{array}{l}\text { Mar. } 20,1925 \\
\text { Mar. 24, } 1927 \\
\text { May } 19,1928 \\
\text { May 27, } 1929 \\
\text { Apr. 12, } 1930\end{array}$ & $\begin{array}{l}5.90 \\
- \\
- \\
-\end{array}$ & $\begin{array}{l}1,350 \\
1,790 \\
2,720 \\
2,260 \\
1,200\end{array}$ & $\begin{array}{l}1951 \\
1952 \\
1953 \\
1954 \\
1955\end{array}$ & $\begin{array}{l}\text { June } \\
\text { May } \\
\text { June } \\
\text { May } \\
\text { Apr. }\end{array}$ & $\begin{array}{rr}\text { S, } & 1951 \\
7, & 1952 \\
23, & 1953 \\
14, & 1954 \\
15, & 1955\end{array}$ & $\begin{array}{r}9.05 \\
11.04 \\
7.65 \\
4.35 \\
4.98\end{array}$ & $\begin{array}{r}2,500 \\
4,440 \\
1,880 \\
680 \\
919\end{array}$ \\
\hline $\begin{array}{l}1931 \\
1932 \\
1933 \\
1934 \\
1935\end{array}$ & $\begin{array}{l}\text { Apr. } 12,1931 \\
\text { May } 24,1932 \\
\text { June } 1819,1933 \\
\text { Feb.19-23, } 1934 \\
\text { June } 19,1935\end{array}$ & $\begin{array}{l}3.35 \\
8.13 \\
6.01 \\
- \\
-\end{array}$ & $\begin{array}{r}440 \\
2,280 \\
1,330 \\
210 \\
1,510\end{array}$ & $\begin{array}{l}1956 \\
1957 \\
1958 \\
1959 \\
1960\end{array}$ & $\begin{array}{l}\text { Mar. } \\
\text { June } \\
\text { June } \\
\text { Apr. } \\
\text { Mar. }\end{array}$ & $\begin{array}{rr}28, & 1956 \\
23, & 1957 \\
2, & 1955 \\
6, & 1959 \\
27, & 1960\end{array}$ & $\begin{array}{c}10.82 \\
9.36 \\
7.06 \\
5.46 \\
-\end{array}$ & $\begin{array}{r}3,810 \\
2,640 \\
1,700 \\
1,100 \\
\text { b1, } 320\end{array}$ \\
\hline $\begin{array}{l}1936 \\
1937 \\
1938 \\
\end{array}$ & $\begin{array}{l}\text { May } 19,1936 \\
\text { Apr.23, 22, } 1937 \\
\text { May } 20,1938\end{array}$ & $\begin{array}{l}- \\
-\end{array}$ & $\begin{array}{l}3,040 \\
2,190 \\
2,080\end{array}$ & $\begin{array}{l}1961 \\
1962 \\
1963 \\
\end{array}$ & $\begin{array}{l}\text { Nar. } \\
\text { Apr: } \\
\text { June }\end{array}$ & $\begin{array}{rr}25, & 1961 \\
4, & 1962 \\
18, & 1963 \\
\end{array}$ & $\begin{array}{l}3.54 \\
9.68 \\
5.48\end{array}$ & $\begin{array}{r}350 \\
2,790 \\
1,110 \\
\end{array}$ \\
\hline
\end{tabular}

a Yaximum observed.

b Maximum datly. 
445. Bear River at Dingle, Idaho

Location.--Lat $42^{\circ} 13^{\prime} 30^{\prime \prime}$, long $111^{\circ} 14^{\prime} 10^{\prime \prime}$, in NW $\frac{1}{4}$ sec.7, T.14 S., R.45 E., half a mile southeast of Dingle.

Drainage area. $--2,810 \mathrm{sq} \mathrm{mi}$, approximately.

Gage.--Nonrecording. Altitude of gage is 5,950 ft (from topographic map).

Stage-discharge relation.--Defined by current-meter measurements .

Remarks.--Bear Lake Inlet Canal, records for which are not published separately In this report, began diverting upstream from station in May 1911. Pocords herein adjusted for this diversion May 1911 to September 1912. No record of diversion available after 1912. Record of canal diversion for 1924-50 in files of Geological Survey. Only annual maximum observed discharges are shown.

\begin{tabular}{|c|c|c|c|c|c|c|c|}
\hline $\begin{array}{l}\text { Water } \\
\text { year }\end{array}$ & Date & $\begin{array}{l}\text { Cage } \\
\text { helght } \\
\text { (feet) }\end{array}$ & $\begin{array}{c}\text { Discharge } \\
(\mathrm{cfs})\end{array}$ & $\begin{array}{l}\text { Water } \\
\text { year }\end{array}$ & Date & $\begin{array}{l}\text { Gage } \\
\text { neight } \\
\text { (feet) }\end{array}$ & $\begin{array}{c}\Gamma^{*} \text { scharge } \\
(\mathrm{cfs})\end{array}$ \\
\hline $\begin{array}{l}1903 \\
1904 \\
1905\end{array}$ & $\begin{array}{l}\text { June } 1903 \\
\text { May } 28,1904 \\
\text { June } 19,1905\end{array}$ & $\begin{array}{l}- \\
- \\
-\end{array}$ & $\begin{array}{r}1,410 \\
3,175 \\
765\end{array}$ & $\begin{array}{l}1909 \\
1910\end{array}$ & $\begin{array}{l}\text { June } 14,1909 \\
\text { Apr. } 30,1910\end{array}$ & - & $\begin{array}{l}3,990 \\
2,150\end{array}$ \\
\hline $\begin{array}{l}1906 \\
1907 \\
1908\end{array}$ & $\begin{array}{l}\text { June } 3,1906 \\
\text { May } 26,1907 \\
\text { June } 21,1908\end{array}$ & 8.75 & $\begin{array}{l}2,820 \\
4,050 \\
1,750\end{array}$ & $\begin{array}{l}1911 \\
1912 \\
1913 \\
1914\end{array}$ & $\begin{array}{l}\text { Mar. 27, } 1911 \\
\text { June 18, } 1912 \\
\text { May 14, } 1913 \\
\text { May 25, } 1914\end{array}$ & $\begin{array}{l}- \\
-\end{array}$ & $\begin{array}{l}3,650 \\
3,240 \\
1,610 \\
3,560\end{array}$ \\
\hline
\end{tabular}

465. Bear River below Stewart Dam, near Montpelier, Idaho

Location.--Lat $42^{\circ} 15^{\prime} 30^{\prime \prime}$, long $11^{\circ} 17^{\prime} 30^{\prime \prime}$, In NE $\frac{1}{4}$ sec.34, T.13 S., R.44 E., on right bank $300 \mathrm{ft}$ downstream from stewart Dam and $4 \frac{1}{2}$ miles south of Montpelier.

Drainage area. $--2,820 \mathrm{sq} \mathrm{mi}$, approximately.

Gage.--Recording. Alt1tude of gage is 5,950 ft (from topographic map).

Stage-d1scharge relation.--Defined by current-meter measurements.

Remarks.--Water diverted by Stewart Dam through Rainbow Inlet Canal for storage and regulation in Bear Lake. Records collected by Utah Power \& Iight Co., under general supervision of Geological Survey. Only annual peaks are shown (maximum da1ly 1922-46, 1948, 1954, 1956-58).

Peak stages and discharges

\begin{tabular}{|c|c|c|c|c|c|c|c|}
\hline $\begin{array}{l}\text { Water } \\
\text { year }\end{array}$ & Date & $\begin{array}{c}\text { Cage } \\
\text { helght } \\
\text { (feet) }\end{array}$ & $\begin{array}{c}\text { Discharge } \\
\text { (cfs) }\end{array}$ & $\begin{array}{l}\text { Water } \\
\text { year }\end{array}$ & Date & $\begin{array}{c}\text { Gage } \\
\text { helght } \\
\text { (feet) }\end{array}$ & $\begin{array}{c}\text { I1scharge } \\
\text { (cfs) }\end{array}$ \\
\hline $\begin{array}{l}1922 \\
1923 \\
1924 \\
1925\end{array}$ & $\begin{array}{l}\text { June 1-4, } 1922 \\
\text { June 3, } 1923 \\
\text { Oct. 18, } 1923 \\
\text { Apr. 14, } 1925\end{array}$ & $\begin{array}{l}- \\
\overline{-} \\
-\end{array}$ & $\begin{array}{r}3,000 \\
3,050 \\
576 \\
560\end{array}$ & $\begin{array}{l}1943 \\
1944 \\
1945\end{array}$ & $\begin{array}{l}\text { Aug. 12, } 1943 \\
\text { July 4,5, } 1944 \\
\text { Aug. 19, } 1945\end{array}$ & - & $\begin{array}{l}189 \\
660 \\
286\end{array}$ \\
\hline $\begin{array}{l}1926 \\
1927 \\
1928 \\
1929 \\
1930\end{array}$ & $\begin{array}{l}\text { Apr. } 27,1926 \\
\text { June } 24,1927 \\
\text { June 10, } 1928 \\
\text { June 12, } 1929 \\
\text { June } 5,1930\end{array}$ & $\begin{array}{l}- \\
\overline{-} \\
\overline{-}\end{array}$ & $\begin{array}{l}635 \\
895 \\
857 \\
925 \\
556\end{array}$ & $\begin{array}{l}1947 \\
1948 \\
1949 \\
1950\end{array}$ & $\begin{array}{lrl}\text { July } & 26, & 1947 \\
\text { Dec. } 9, & 1947 \\
\text { May } 31, & 1949 \\
\text { June } 7, & 1950\end{array}$ & $\overline{-}$ & $\begin{array}{l}281 \\
161 \\
470 \\
805\end{array}$ \\
\hline $\begin{array}{l}1931 \\
1932 \\
1933 \\
1934 \\
1935\end{array}$ & $\begin{array}{l}\text { Nov. } 2,1930 \\
\text { July } 14,1932 \\
\text { June } 19,1933 \\
\text { Oct. } 28,1933 \\
\text { Apr. } 22,1935\end{array}$ & $\begin{array}{l}- \\
- \\
- \\
-\end{array}$ & $\begin{array}{r}229 \\
515 \\
426 \\
123 \\
12\end{array}$ & $\begin{array}{l}1951 \\
1952 \\
1953 \\
1954 \\
1955\end{array}$ & $\begin{array}{l}\text { June } 26,1951 \\
\text { July } 1,1952 \\
\text { May } 9,1953 \\
\text { Mar. 27, } 1954 \\
\text { May } 12,1955 \\
\text { Sept. }\end{array}$ & $\begin{array}{l}- \\
- \\
1.32\end{array}$ & $\begin{array}{l}42 \\
37 \\
33 \\
28 \\
29 \\
54\end{array}$ \\
\hline $\begin{array}{l}1936 \\
1937 \\
1938 \\
1939 \\
1940\end{array}$ & $\begin{array}{l}\text { Sept.25, } 1936 \\
\text { Oct. } 28,1936 \\
\text { Sept.13, } 1938 \\
\text { Sept.27, } 1939 \\
\text { Oct. } 21,1939\end{array}$ & $\begin{array}{l}\overline{-} \\
\overline{-} \\
-\end{array}$ & $\begin{array}{l}113 \\
228 \\
200 \\
116 \\
150\end{array}$ & $\begin{array}{l}1957 \\
1958 \\
1959 \\
1960\end{array}$ & $\begin{array}{l}\text { Oct. 14, } 1956 \\
\text { July 4, } \\
\text { Mar. } 11,1958 \\
\text { Mar. } 28,1959 \\
\end{array}$ & $\begin{array}{l}\overline{-} \\
\overline{1.76}\end{array}$ & $\begin{array}{r}128 \\
31 \\
35 \\
50\end{array}$ \\
\hline $\begin{array}{l}1941 \\
1942 \\
\end{array}$ & $\begin{array}{l}\text { Nov. } 11,1940 \\
\text { Feb. } 18,19,1942\end{array}$ & - & $\begin{array}{l}109 \\
130\end{array}$ & $\begin{array}{l}1961 \\
1962 \\
1963\end{array}$ & $\begin{array}{l}\text { Apr. 2, } 1962 \\
\text { June 16, } 1963\end{array}$ & $\begin{array}{l}1.20 \\
1.73 \\
1.15\end{array}$ & $\begin{array}{l}48 \\
12 \\
\end{array}$ \\
\hline
\end{tabular}

Note.-D1scharges are maximum da11y means $1922-46,1948,1954,1956-58$. 


\section{Montpelier Creek near Montpelier, Idaho}

Location.--Lat $42^{\circ} 21^{\prime}$, long $111^{\circ} 11^{\prime}$, in NE $\frac{1}{4}$ sec.34, T.12 S., R.45 E., $150 \mathrm{ft}$ upstream from bridge on U.S. Highway $89,275 \mathrm{ft}$ upstream from South Fork, and 6.8 miles northeast of Montpelier.

Drainage area.$-28.2 \mathrm{sq} \mathrm{mi}$.

Gage.--Recording. Datum of gage is $6,427.46 \mathrm{ft}$ above mean sea level, adjustment of 1912 .

Stage-discharge relation.--Defined by current-meter measurements below $70 \mathrm{cfs}$. Remarks.--Only annual peaks are shown.

\begin{tabular}{|c|c|c|c|c|c|c|c|}
\hline $\begin{array}{l}\text { Water } \\
\text { year }\end{array}$ & Date & $\begin{array}{c}\text { Gage } \\
\text { height } \\
\text { (feet) }\end{array}$ & $\begin{array}{c}\text { Discharge } \\
\text { (cfs) }\end{array}$ & $\begin{array}{l}\text { Water } \\
\text { yeax }\end{array}$ & Date & $\begin{array}{c}\text { Gage } \\
h \geqslant 1 g h t \\
\text { (feet) }\end{array}$ & $\begin{array}{c}\text { Discharge } \\
\text { (cfs) }\end{array}$ \\
\hline $\begin{array}{l}1940 \\
1941 \\
\end{array}$ & $\begin{array}{ll}\text { July } & 1,1940 \\
\text { May } & 1,1941 \\
\end{array}$ & $\begin{array}{r}1.88 \\
2.06 \\
\end{array}$ & $\begin{array}{l}35 \\
42 \\
\end{array}$ & $\begin{array}{l}1942 \\
1943 \\
1944 \\
\end{array}$ & $\begin{array}{l}\text { Apr. } 12,1942 \\
\text { Apr. } 24,1943 \\
\text { Apr. } 12,1944 \\
\end{array}$ & $\begin{array}{r}2.23 \\
3.35 \\
2.15 \\
\end{array}$ & $\begin{array}{r}53 \\
136 \\
55 \\
\end{array}$ \\
\hline
\end{tabular}

475. Montpelier Creek at irrigators weir, near Montpelier, Idaho

Location.--Lat $42^{\circ} 20^{\prime}$, long $111^{\circ} 14^{\prime}$, in SE $\frac{1}{4}$ sec.31, T.12 S., R.45 E., on right bank 3 miles east of Montpelier and $3 \frac{1}{2}$ miles downstream from South Fork.

Drainage area $--50.9 \mathrm{sq} \mathrm{mi}$. Mean altitude, 7,370 ft.

Gage.--Recording gage and sharp-crested weir. Altitude of gage is $6,210 \mathrm{ft}$ (from topographic map).

Stage-discharge relation.--Defined by current-meter measurements below $180 \mathrm{cfs}$. Remarks.--Only annual peaks are shown.

\begin{tabular}{|c|c|c|c|c|c|c|c|c|}
\hline $\begin{array}{l}\text { Water } \\
\text { year }\end{array}$ & \multicolumn{2}{|r|}{ Date } & $\begin{array}{l}\text { Gage } \\
\text { helght } \\
\text { (feet) }\end{array}$ & $\begin{array}{c}\text { Discharge } \\
\text { (cfs) }\end{array}$ & $\begin{array}{l}\text { Water } \\
\text { year }\end{array}$ & Date & $\begin{array}{c}\text { Gage } \\
\text { height } \\
\text { (feet) }\end{array}$ & $\begin{array}{c}\text { Discharge } \\
\text { (cfs) }\end{array}$ \\
\hline $\begin{array}{l}1943 \\
1944 \\
1945\end{array}$ & $\begin{array}{l}\text { Apr. } \\
\text { Apr. } \\
\text { June }\end{array}$ & $\begin{array}{ll}24, & 1943 \\
12, & 1944 \\
10, & 1945\end{array}$ & $\begin{array}{l}5.43 \\
1.27 \\
1.57\end{array}$ & $\begin{array}{r}134 \\
62 \\
88\end{array}$ & $\begin{array}{l}1954 \\
1955\end{array}$ & $\begin{array}{lrl}\text { Apr. } & 24, & 1954 \\
\text { June } & 4, & 1955\end{array}$ & $\begin{array}{r}0.92 \\
.93\end{array}$ & $\begin{array}{l}49 \\
54\end{array}$ \\
\hline $\begin{array}{l}1946 \\
1947 \\
1948 \\
1949 \\
1950\end{array}$ & $\begin{array}{l}\text { Apr. } \\
\text { May } \\
\text { May } \\
\text { May } \\
\text { May }\end{array}$ & $\begin{array}{rr}19, & 1946 \\
11, & 1947 \\
8, & 1948 \\
19, & 1949 \\
18, & 1950\end{array}$ & $\begin{array}{l}2.45 \\
1.55 \\
1.97 \\
1.25 \\
2.91\end{array}$ & $\begin{array}{r}170 \\
89 \\
126 \\
73 \\
224\end{array}$ & $\begin{array}{l}1956 \\
1957 \\
1958 \\
1959 \\
1960\end{array}$ & $\begin{array}{l}\text { Apr. } 24,1956 \\
\text { May 19, } 1957 \\
\text { May 12, } 1958 \\
\text { Apr. 27, } 1959 \\
\text { Apr. } 7,1960\end{array}$ & $\begin{array}{l}1.81 \\
1.74 \\
1.67 \\
.87 \\
1.50\end{array}$ & $\begin{array}{r}124 \\
113 \\
107 \\
44 \\
91\end{array}$ \\
\hline $\begin{array}{l}1951 \\
1952 \\
1953\end{array}$ & $\begin{array}{l}\text { Apr. } \\
\text { May } \\
\text { Apr. }\end{array}$ & $\begin{array}{rr}29, & 1951 \\
4, & 1952 \\
28, & 1953\end{array}$ & $\begin{array}{l}1.98 \\
2.33 \\
1.11\end{array}$ & $\begin{array}{r}134 \\
164 \\
64\end{array}$ & $\begin{array}{l}1961 \\
1962 \\
1963\end{array}$ & $\begin{array}{l}\text { Apr. 3, } 1961 \\
\text { Apr. 28, } 1962 \\
\text { Mar. 28, } 1963\end{array}$ & $\begin{array}{l}1.89 \\
3.06 \\
2.02\end{array}$ & $\begin{array}{r}27 \\
192 \\
96\end{array}$ \\
\hline
\end{tabular}

585. Bloomington Creek near Bloomington, Idaho

Location.--Lat $42^{\circ} 11^{\prime}$, long $111^{\circ} 27^{\prime}$, in $S E \frac{1}{4} \sec .20$, T.14 S., R.43 E., 2.1 miles west of Bloomington.

Dralnage area. $--22.1 \mathrm{sq} \mathrm{mi}$. Mean altitude, 7,860 ft.

Gage.--Recording .

Stage-discharge relation.--Defined by current-meter measurements.

Remarks.--Only annual peaks are shown.

Peak stages and discharges

\begin{tabular}{|c|c|c|c|c|c|c|c|c|c|}
\hline $\begin{array}{l}\text { Water } \\
\text { year }\end{array}$ & & Date & $\begin{array}{l}\text { Gage } \\
\text { height } \\
\text { (feet) }\end{array}$ & $\begin{array}{c}\text { Discharge } \\
(\mathrm{cfs})\end{array}$ & $\begin{array}{l}\text { Water } \\
\text { year }\end{array}$ & & Date & $\begin{array}{c}\text { Gage } \\
\text { telght } \\
\text { (feet) }\end{array}$ & $\begin{array}{c}\text { Discharge } \\
\text { (cfs) }\end{array}$ \\
\hline $\begin{array}{l}1943 \\
1944 \\
1945\end{array}$ & $\begin{array}{l}\text { June } \\
\text { May } \\
\text { May }\end{array}$ & 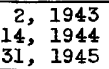 & $\begin{array}{l}2.67 \\
1.79 \\
2.07\end{array}$ & $\begin{array}{r}184 \\
85 \\
111\end{array}$ & $\begin{array}{l}1946 \\
1947\end{array}$ & $\begin{array}{l}\text { May } \\
\text { May }\end{array}$ & $\begin{array}{ll}5, & 1946 \\
7, & 1947\end{array}$ & $\begin{array}{l}2.24 \\
2.17\end{array}$ & $\begin{array}{l}143 \\
137\end{array}$ \\
\hline
\end{tabular}


630. Mill Creek near Liberty, Idaho

Location.--Lat $42^{\circ} 20^{\prime}$, long $111^{\circ} 29^{\prime}$, in SE $\frac{1}{4}$ sec.36, T.12 S., R.42 E., 2 miles northwest of Liberty and $3 \frac{1}{2}$ miles upstream from North Creek.

Drainage area. $--27.2 \mathrm{sq} \mathrm{ml}$.

Gage.--Recording. Altitude of gage is 6,290 ft (from topographic map).

Stage-discharge relation.--Defined by current-meter measurements.

Remarks.--Only annual peaks are shown.

Peak stages and discharges

\begin{tabular}{|c|c|c|c|c|c|c|c|c|c|}
\hline $\begin{array}{l}\text { Water } \\
\text { year }\end{array}$ & & Date & $\begin{array}{c}\text { Gage } \\
\text { helght } \\
\text { (feet) }\end{array}$ & $\begin{array}{c}\text { Discharge } \\
(\mathrm{cfs})\end{array}$ & $\begin{array}{l}\text { Water } \\
\text { year }\end{array}$ & & Date & $\begin{array}{c}\text { Gage } \\
\text { height } \\
\text { (feet) }\end{array}$ & $\begin{array}{c}\Gamma^{*} \text { scharge } \\
\text { (cfs) }\end{array}$ \\
\hline $\begin{array}{l}1943 \\
1944 \\
1945\end{array}$ & $\begin{array}{l}\text { June } \\
\text { June } \\
\text { May }\end{array}$ & $\begin{array}{rr}1, & 1943 \\
8, & 1944 \\
31, & 1945\end{array}$ & $\begin{array}{l}2.98 \\
2.62 \\
2.63\end{array}$ & $\begin{array}{l}144 \\
104 \\
150\end{array}$ & $\begin{array}{l}1946 \\
1947\end{array}$ & $\begin{array}{l}\text { May } \\
\text { May }\end{array}$ & $\begin{array}{l}6,1946 \\
8,1947\end{array}$ & $\begin{array}{l}2.93 \\
2.45\end{array}$ & $\begin{array}{l}150 \\
141\end{array}$ \\
\hline
\end{tabular}

685. Bear River at Pescadero, Idaho

Location.--Lat $42^{\circ} 24^{\prime} 30^{\prime \prime}$, long $111^{\circ} 21^{\prime} 30^{\prime \prime}$, in SE $\frac{1}{4}$ sec.6, T.12 S., R.44 F., on left bank at Pescadero, $400 \mathrm{ft}$ downstream from road bridge, 2 miles downstream from Bennington Creek, and $6 \frac{1}{2}$ miles northwest of Montpelier.

Drainage area. $--3,680 \mathrm{sq} \mathrm{mi}$, approximately.

Gage.--Recording. Alt1tude of gage is 5,950 ft (from topographic map).

Stage-discharge relation.--Defined by current-meter measurements.

Remarks.--Flow regulated by Bear Lake. Records collected by Utah Power \& L1ght Co., under general supervision of Geological Survey. Only annual peaks are shown (maximum daily 1922-46, 1948).

Peak stages and discharges

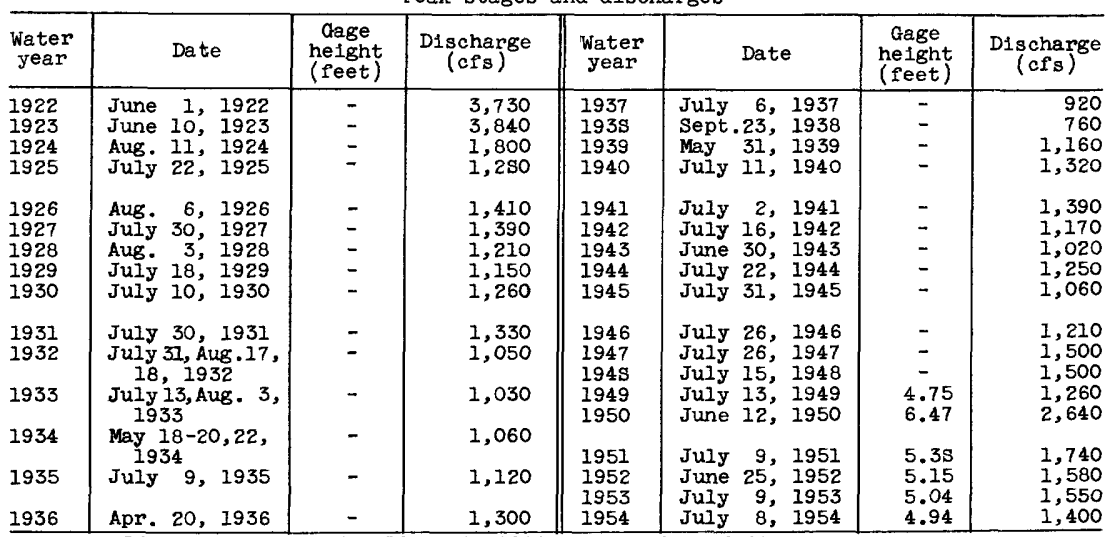

Note.--D1scharges shown for 1922-46, 1948, are maximum da11y means. 
690. Georgetown Creek near :- orgetown, Idaho

Location.--Lat $42^{\circ} 30^{\prime}$, long $111^{\circ} 19^{\prime}$, in NE $\frac{1}{4}$ sec.4, T.11 S., R.44 E., on left bank $150 \mathrm{ft}$ downstream from Littie Right Hand Fork and 3 miles northeast of Georgetown.

Drainage area. $--22.2 \mathrm{sq} \mathrm{ml}$. Mean alt1tude, $7,830 \mathrm{ft}$.

Gage.--Nonrecording prior to October 1914 at site 0.7 mile downstream at different datum; recording thereafter. Alt1tude of gage is $6,350 \mathrm{ft}$ (from topographic map).

Stage-discharge relation.--Defined by current-meter measurements.

Remarks.--Only annual peaks are shown.

Peak stages and discharges

\begin{tabular}{|c|c|c|c|c|c|c|c|c|}
\hline $\begin{array}{l}\text { Water } \\
\text { year }\end{array}$ & Date & $\begin{array}{l}\text { Gage } \\
\text { helght } \\
\text { (feet) }\end{array}$ & $\begin{array}{c}\text { Discharge } \\
\text { (cfs) }\end{array}$ & $\begin{array}{l}\text { Water } \\
\text { year }\end{array}$ & & Date & $\begin{array}{l}\text { Gage } \\
\text { height } \\
\text { (feet) }\end{array}$ & $\begin{array}{c}\text { Discharge } \\
\text { (cfs) }\end{array}$ \\
\hline 1912 & June 8,1912 & 1.75 & a162 & \multirow{6}{*}{$\begin{array}{l}1947 \\
1948 \\
1949 \\
1950 \\
1951 \\
1952 \\
1953 \\
1954 \\
1955 \\
1956\end{array}$} & \multirow{6}{*}{$\begin{array}{l}\text { May } \\
\text { May } \\
\text { June } \\
\text { June } \\
\text { May } \\
\text { May } \\
\text { June } \\
\text { Oct. } \\
\text { June } \\
\text { May }\end{array}$} & \multirow{3}{*}{$\begin{array}{r}11,1947 \\
20,1948 \\
6,1949 \\
2,1950\end{array}$} & \multirow{5}{*}{$\begin{array}{l}1.63 \\
2.10 \\
1.58 \\
2.12 \\
2.35 \\
2.22 \\
2.02 \\
2.01 \\
2.00\end{array}$} & \multirow{2}{*}{$\begin{array}{r}41 \\
88 \\
44 \\
110\end{array}$} \\
\hline 1914 & May 21,1914 & 1.57 & a.100 & & & & & \\
\hline 1940 & June 30,1940 & 1.64 & 38 & & & & & \\
\hline $\begin{array}{l}1941 \\
1942\end{array}$ & $\begin{array}{l}\text { Aug. } 12,1941 \\
\text { May } 28,1942 \\
\text { June } 1-15,1942\end{array}$ & $\begin{array}{l}1.67 \\
- \\
-\end{array}$ & $\begin{array}{l}43 \\
34 \\
34\end{array}$ & & & $\begin{array}{l}28,1951 \\
15,1952 \\
15,1953 \\
31,1953\end{array}$ & & $\begin{array}{l}75 \\
60 \\
42 \\
39\end{array}$ \\
\hline $\begin{array}{l}1943 \\
1944 \\
1945\end{array}$ & $\begin{array}{l}\text { June } 15,1943 \\
\text { June } 16,22,1944 \\
\text { June } 15,1945\end{array}$ & $\begin{array}{l}1.85 \\
1.66 \\
1.55\end{array}$ & $\begin{array}{l}51 \\
40 \\
51\end{array}$ & & & $\begin{array}{l}13,1955 \\
24,1956\end{array}$ & & 69 \\
\hline 1946 & Apr. 30,1946 & 1.82 & 55 & & & & & \\
\hline
\end{tabular}

715. Skinner Creek at Nounan, Idaho

Location.--Iat $42^{\circ} 29^{\prime}$, long $111^{\circ} 28^{\prime}$, in SW $\frac{1}{4} \mathrm{sec} .8$, T.11 S., R.43 E., $330 \mathrm{ft}$ downstream from point where flow through Minnig Mill is returned to creek and three-quarters of a mile west of Nounan Post Office.

Drainage area. $--5.41 \mathrm{sq} \mathrm{ml}$.

Gage.--Nonrecording. Altitude of gage is 6,100 ft (from topographic map). Stage-d1scharge relation.--Defined by current-meter measurements below $24 \mathrm{cfs}$. Remarks.--Only annual peaks are shown.

\begin{tabular}{|c|c|c|c|c|c|c|c|}
\hline $\begin{array}{l}\text { Water } \\
\text { year }\end{array}$ & Date & $\begin{array}{l}\text { Gage } \\
\text { height } \\
\text { (feet) }\end{array}$ & $\begin{array}{c}\text { Discharge } \\
\text { (cfs) }\end{array}$ & $\begin{array}{l}\text { Water } \\
\text { year }\end{array}$ & Date & $\begin{array}{l}\text { arce } \\
\text { helght } \\
\text { (feet) }\end{array}$ & $\begin{array}{c}\text { Discharge } \\
(\mathrm{cfs})\end{array}$ \\
\hline $\begin{array}{l}1940 \\
1941 \\
1942 \\
\end{array}$ & $\begin{array}{l}\text { May } 13,1940 \\
\text { May 12,13, } 1941 \\
\text { Apr. 21, } 1942\end{array}$ & $\begin{array}{c}- \\
1.60 \\
1.44\end{array}$ & $\begin{array}{l}20 \\
32 \\
20\end{array}$ & $\begin{array}{l}1943 \\
1944 \\
1945\end{array}$ & $\begin{array}{lll}\text { May } & 4, & 1943 \\
\text { June } & 8,1944 \\
\text { June } & 9, & 1945\end{array}$ & $\begin{array}{l}1.92 \\
-\end{array}$ & $\begin{array}{l}50 \\
60 \\
35\end{array}$ \\
\hline
\end{tabular}

720. Stauffer Creek near Nounan, Idaho

Location.--Lat $42^{\circ} 28^{\prime}$, long $111^{\circ} 25^{\prime}$, in N $\frac{1}{2}$ sec.15, T.11 S., R.43 E., $0.6 \mathrm{mile}$ upstream from mouth, 2 miles east of Nounan Post Office, and 2 miles west of Georgetown.

Drainage area.--Indeterminate. Skinner Creek divides just above Nounan, part of water flowing into Stauffer Creek and part flowing directly into Bear Lake.

Gage.--Recording. Prior to Dec. 11, 1942, at site $100 \mathrm{ft}$ downstram at different datum. Alt1tude of gage is 5,900 ft (from topographic map).

Stage-discharge relation.--Defined by current-meter measurements below 50 cfs. Remarks.--Only annual peaks are shown. 
Peak stages and discharges of Stauffer Creek near Nounan, Idaho

\begin{tabular}{|c|c|c|c|c|c|c|c|c|}
\hline $\begin{array}{l}\text { Water } \\
\text { year }\end{array}$ & & Date & $\begin{array}{c}\text { Gage } \\
\text { height } \\
\text { (feet) }\end{array}$ & $\begin{array}{c}\text { Discharge } \\
\text { (cfs) }\end{array}$ & $\begin{array}{l}\text { Water } \\
\text { year }\end{array}$ & Date & $\begin{array}{l}\text { Gage } \\
\text { height } \\
\text { (feet) }\end{array}$ & $\begin{array}{c}\text { Discharge } \\
(\mathrm{cfs})\end{array}$ \\
\hline $\begin{array}{l}1940 \\
1941\end{array}$ & $\begin{array}{l}\text { May } \\
\text { May }\end{array}$ & $\begin{array}{l}27,1940 \\
28,1941\end{array}$ & $\begin{array}{l}3.43 \\
3.85\end{array}$ & $\begin{array}{l}150 \\
186\end{array}$ & $\begin{array}{l}1942 \\
1943 \\
1944\end{array}$ & $\begin{array}{lll}\text { Apr. } & 6, & 1942 \\
\text { May } & 5, & 1943 \\
\text { Apr. } & 4, & 1944\end{array}$ & $\begin{array}{l}- \\
2.85 \\
2.23\end{array}$ & $\begin{array}{l}144 \\
133 \\
113\end{array}$ \\
\hline
\end{tabular}

750. Bear River at Soda Springs, Idaho

Location.--Iat $42^{\circ} 36^{\prime} 50^{\prime \prime}$, long $111^{\circ} 35^{1} 00^{\prime \prime}$, in NW $\frac{1}{4}$ sec.29, T.9 S., R.42 E., on lef't bank $800 \mathrm{ft}$ upstream from Balley Ćreek road bridge and $\dot{z}$ miles south of Soda Springs.

Dralnage area. $--3,970 \mathrm{sq} \mathrm{m1}$, approximately.

Gage.-Nonrecording prior to 1944 , at different datum; recording thereafter. Altitude of gage is $5,760 \mathrm{ft}$ (from topographic map).

Stage-discharge relation.--Defined by current-meter measurements below $1,750 \mathrm{cfs}$.

Remarks.--Records prior to 1954 in "Reports on Bear River hydrometric data" (U.S. Geological Survey open-file report). Flow regulated by storage in Bear Lake. Only annual peaks are shown.

\begin{tabular}{|c|c|c|c|c|c|c|c|}
\hline $\begin{array}{l}\text { Water } \\
\text { year }\end{array}$ & Date & $\begin{array}{l}\text { Gage } \\
\text { height } \\
\text { (feet) }\end{array}$ & $\begin{array}{c}\text { Discharge } \\
\text { (cfs) }\end{array}$ & $\begin{array}{l}\text { Watex } \\
\text { year }\end{array}$ & Date & $\begin{array}{l}\text { Gage } \\
\text { helght } \\
\text { (feet) }\end{array}$ & $\begin{array}{c}\text { Discharge } \\
\text { (cfs) }\end{array}$ \\
\hline 1896 & June 9,15, 1896 & 8.40 & 6,380 & 1953 & July $9,10,1953$ & - & a 1,480 \\
\hline $\begin{array}{l}1944 \\
1945\end{array}$ & $\begin{array}{l}\text { July } 22,1944 \\
\text { JuIy } 25, \text { Aug. } 1 \text {, } \\
\quad 1945\end{array}$ & - & $\begin{array}{l}\text { al, } 220 \\
\text { al, } 039\end{array}$ & 1955 & July 13, 1955 & 4.84 & 1,450 \\
\hline $\begin{array}{l}1946 \\
1947\end{array}$ & $\begin{array}{l}\text { July } 26,1946 \\
\text { July } 27, \text { Aug. } 4 \text {, } \\
1947\end{array}$ & - & $\begin{array}{l}a 1,166 \\
a 1,504\end{array}$ & $\begin{array}{l}1901 \\
1958 \\
1959 \\
1960\end{array}$ & $\begin{array}{ll}\text { July } 18,1958 \\
\text { July } 27,1959 \\
\text { July } 12,1960\end{array}$ & $\begin{array}{l}4.75 \\
4.69 \\
4.70 \\
4.77\end{array}$ & $\begin{array}{r}1,370 \\
21,400 \\
1,440\end{array}$ \\
\hline $\begin{array}{l}1948 \\
1949 \\
\end{array}$ & $\begin{array}{l}\text { July 15,16,194s } \\
\text { July } 14,1949\end{array}$ & - & $\begin{array}{l}\text { al }, 440 \\
\text { al, } 200\end{array}$ & 1961 & July 4, 1961 & 4.90 & 1,540 \\
\hline $\begin{array}{l}1951 \\
1952 \\
\end{array}$ & $\begin{array}{l}\text { June } 26,1951 \\
\text { June } 25,1952 \\
\end{array}$ & - & $\begin{array}{l}\text { al, } 675 \\
\text { al, } 710\end{array}$ & $\begin{array}{l}1962 \\
1963\end{array}$ & Feb. 1, 1963 & 7.61 & 4,020 \\
\hline
\end{tabular}

a Maximum daily.

770. Soda Creek near Soda Springs, Idaho

Location.--Lat $42^{\circ} 42^{\prime} 35^{\prime \prime}$, long $111^{\circ} 37^{\prime} 15^{\prime \prime}$, in SW $\frac{1}{4}$ SW $\frac{1}{4} \sec .24$, T.8 S., R.41 E., at George Schmidt Ranch, one-elghth mile below unnamed tributary and 4 miles north of Soda Springs.

Drainage area. --52 sq mi, approximately.

Gage.--Nonrecording. Prior to Aug. 1, 1913, at site $30 \mathrm{ft}$ upstream at datum about $3.10 \mathrm{ft}$ lower. Aug. 1, 1913, to June 28, 1921, at datum $3.30 \mathrm{ft}$ lower. Altitude of gage is $5,960 \mathrm{ft}$ (from topographic map).

Stage-discharge relation.--Defined by current-meter measurements below $30 \mathrm{cfs}$.

Remarks.--Flow regulated by outlet of Fivemile Meadows. Only annual maximum observed discharges are shown.

Maximum observed stages and discharges

\begin{tabular}{|c|c|c|c|c|c|c|c|}
\hline $\begin{array}{l}\text { Water } \\
\text { year }\end{array}$ & Date & $\begin{array}{c}\text { Gage } \\
\text { helght } \\
\text { (feet) }\end{array}$ & $\begin{array}{c}\text { Discharge } \\
(\text { cfs })\end{array}$ & $\begin{array}{l}\text { Water } \\
\text { year }\end{array}$ & Date & $\begin{array}{c}\text { Gage } \\
\text { height } \\
\text { (feet) }\end{array}$ & $\begin{array}{c}\text { Discharge } \\
(\text { cfs })\end{array}$ \\
\hline $\begin{array}{l}1913 \\
1914 \\
1915 \\
1916 \\
1917 \\
1918 \\
1919 \\
1920 \\
\end{array}$ & $\begin{array}{l}\text { Apr. } 6,1913 \\
\text { Apr.12-13, } 1914 \\
\text { Mar. } 28,1915 \\
\text { Mar. } 24,1916 \\
\text { Apr. 20, } 1917 \\
\text { Mar29,31, } 1918 \\
\text { Apr. } 1-2,1919 \\
\text { Apr. } 13,1920\end{array}$ & $\begin{array}{l}5.30 \\
5.0 \\
4.4 \\
4.42 \\
4.8 \\
4.65 \\
5.00 \\
4.90 \\
\end{array}$ & $\begin{array}{r}324 \\
241 \\
108 \\
95 \\
193 \\
150 \\
231 \\
200 \\
\end{array}$ & $\begin{array}{l}1921 \\
1922 \\
1923 \\
1924 \\
1925 \\
1926\end{array}$ & $\begin{array}{l}\text { Apr. } 4,1921 \\
\text { Apr } 28,29,1922 \\
\text { Apr. } 18,1923 \\
\text { Apr.13,14,1924 } \\
\text { Mar. 30, } 1925 \\
\text { Mar. 19, } 1926\end{array}$ & $\begin{array}{c}4.65 \\
1.70 \\
1.60 \\
-. \\
1.32 \\
1.24\end{array}$ & $\begin{array}{l}159 \\
229 \\
217 \\
241 \\
155 \\
140\end{array}$ \\
\hline
\end{tabular}


795. Bear River at Alexander, Idaho

Location.--Lat $42^{\circ} 38^{\prime} 45^{\prime \prime}$, long $111^{\circ} 41^{\prime} 55^{\prime \prime}$, in NW $\frac{1}{4}$ sec.17, T.9 S., R.41 E., on right bank $600 \mathrm{ft}$ downstream from Soda Hydroelectric plant of Utah Power \& Light Co., half a mile southeast of Alexander, and 5 miles dowstream from Soda Creek.

Drainage area. $--4,050 \mathrm{sq} \mathrm{ml}$, approximately.

Gage.--Recording. Altitude of gage is 5,650 ft (from topographic map).

Stage-discharge relation.--Defined by current-meter measurements .

Remarks.--Flow regulated by Bear Lake Reservoir and Soda hydroelectric plant. Records collected by Utah Power \& Light Co., under general suvervision of

Geological Survey. Only annual peaks are shown.

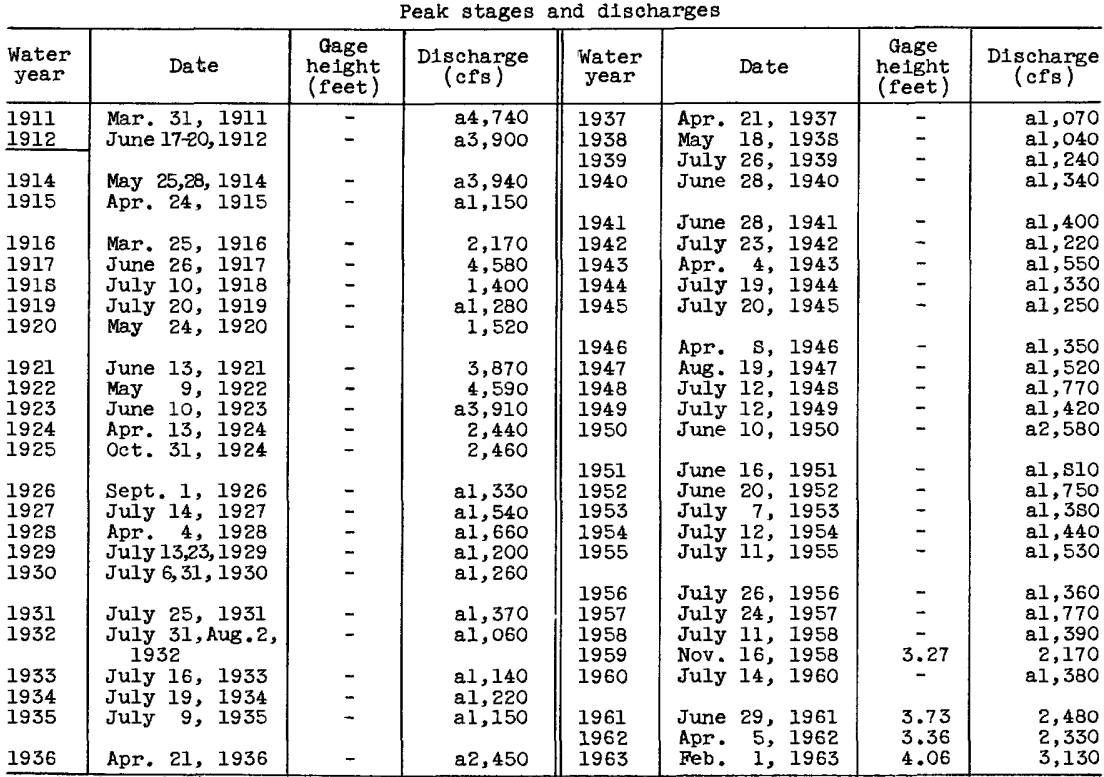

a Maximum da11y.

840. Cottonwood Creek near Swan Lake, Idaho

Location.--Lat $42^{\circ} 23^{\prime}$, long $111^{\circ} 55^{\prime}$, in SW $\frac{1}{4}$ sec.16, T.12 S., R. 39 E., I mile downstream from Treasureton Canai headgate, $6 \frac{1}{2}$ miles northeast of 'Swan Lake, and $11 \frac{1}{2}$ miles upstream from mouth.

Drainage area. $--42.6 \mathrm{sq} \mathrm{mi}$.

Gage.--Recording. Altitude of gage is 5,950 ft (from topographic map).

Stage-discharge relation.--Defined by current-meter measurements below $300 \mathrm{cfs}$.

Remarks.--Treasureton Canal diverts 1 mile above station. Records prior to June 1943 furnished by Bureau of Reclamation. Only annual peaks are shown.

\begin{tabular}{|c|c|c|c|c|c|c|c|}
\hline $\begin{array}{l}\text { Water } \\
\text { year }\end{array}$ & Date & $\begin{array}{l}\text { Gage } \\
\text { height } \\
\text { (feet) }\end{array}$ & $\begin{array}{c}\text { Discharge } \\
(\text { cfs })\end{array}$ & $\begin{array}{l}\text { Water } \\
\text { year }\end{array}$ & Date & $\begin{array}{l}\text { Gage } \\
\text { he Ight } \\
\text { (feet) }\end{array}$ & $\begin{array}{c}\text { Discharge } \\
\text { (cfs) }\end{array}$ \\
\hline $\begin{array}{l}1939 \\
1940\end{array}$ & $\begin{array}{l}\text { Apr. } 2,1939 \\
\text { Mar. } 27,1940\end{array}$ & $\begin{array}{l}2.36 \\
2.17\end{array}$ & $\begin{array}{l}192 \\
156\end{array}$ & $\begin{array}{l}1943 \\
1944 \\
1945\end{array}$ & $\begin{array}{lr}\text { Apr. } & 6,1943 \\
\text { June } 9, & 1944 \\
\text { Apr. } 20,1945\end{array}$ & $\begin{array}{l}3.15 \\
2.16 \\
3.10\end{array}$ & $\begin{array}{l}379 \\
161 \\
363\end{array}$ \\
\hline $\begin{array}{l}1941 \\
1942 \\
\end{array}$ & $\begin{array}{l}\text { Apr. } 29,1941 \\
\text { Apr. 11, } 1942\end{array}$ & $\begin{array}{l}2.25 \\
2.56\end{array}$ & $\begin{array}{l}170 \\
305\end{array}$ & 1946 & Apr. 16,1946 & 3.54 & 497 \\
\hline
\end{tabular}


845. Cottonwood Creek near Cleveland, Idaho

Location.--Lat $42^{\circ} 20^{\prime}$, long $111^{\circ} 46^{\prime}$, in SW $\frac{1}{4}$ sec.34, T.12 S., R.40 E., on right bank 500 ft upstream from Cleveland irrigation canal, $2 \frac{1}{2}$ 'mlies west of Cleveland, and 4 miles downstream from proposed Cottonwood Dam.

Drainage area. $--61.7 \mathrm{sq} \mathrm{mi}$. Mean altitude, 6,650 ft.

Gage.--Nonrecording prior to Dec. 29, 1944; recording thereafter. Altitude of gage is $5,150 \mathrm{ft}$ (from topographic map).

Stage-discharge relation.--Defined by current-meter measurements below $530 \mathrm{cfs}$. Extremely high water causes some shifting.

Remarks.--Base for partial-duration series, $150 \mathrm{cfs}$. Only annual peaks are shown prior to 1948 .

Peak stages and discharges

\begin{tabular}{|c|c|c|c|c|c|c|c|}
\hline $\begin{array}{l}\text { Water } \\
\text { year }\end{array}$ & Date & $\begin{array}{c}\text { Gage } \\
\text { height } \\
\text { (feet) }\end{array}$ & $\begin{array}{c}\text { Discharge } \\
\text { (cfs) }\end{array}$ & $\begin{array}{l}\text { Water } \\
\text { year }\end{array}$ & Date & $\begin{array}{l}\text { Gage } \\
\text { height } \\
\text { (feet) }\end{array}$ & $\begin{array}{c}\text { Discharge } \\
\text { (cfs) }\end{array}$ \\
\hline $\begin{array}{l}1939 \\
1940\end{array}$ & $\begin{array}{l}\text { Apr. } 1,1939 \\
\text { Mar. } 27,1940\end{array}$ & $\begin{array}{l}3.00 \\
2.40\end{array}$ & $\begin{array}{l}\text { a330 } \\
\text { a186 }\end{array}$ & 1954 & Apr. 28, 1954 & 1.98 & 133 \\
\hline $\begin{array}{l}1941 \\
1942 \\
1943 \\
1944 \\
1945\end{array}$ & $\begin{array}{lrl}\text { May } & 4, & 1941 \\
\text { Apr. } 14, & 1942 \\
\text { Apr. } & 4, & 1943 \\
\text { May } & 6, & 1944 \\
\text { Apr. } 20, & 1945\end{array}$ & $\begin{array}{l}2.44 \\
2.60 \\
3.00 \\
- \\
3.29\end{array}$ & $\begin{array}{r}\text { al } 197 \\
\text { a250 } \\
\text { a380 } \\
\text { bl20 } \\
486\end{array}$ & $\begin{array}{l}1955 \\
1956\end{array}$ & $\begin{array}{lll}\text { May } & 9, & 1955 \\
\text { June } & 3, & 1955 \\
& \\
\text { Mar. } & 25,1956 \\
\text { Apr. } & 22, & 1956\end{array}$ & $\begin{array}{l}2.31 \\
2.27 \\
2.28 \\
2.41\end{array}$ & $\begin{array}{l}202 \\
205 \\
214 \\
260\end{array}$ \\
\hline $\begin{array}{l}1946 \\
1947\end{array}$ & $\begin{array}{l}\text { Apr. } 16,1946 \\
\text { Mar. } 21,1947\end{array}$ & $\begin{array}{l}3.77 \\
2.28\end{array}$ & $\begin{array}{l}660 \\
205\end{array}$ & 1957 & $\begin{array}{lr}\text { Apr. } & 23,1957 \\
\text { May } & 6,1957 \\
\text { May } 14,1957 \\
\text { May } 19,1957\end{array}$ & $\begin{array}{l}2.74 \\
2.70 \\
2.82 \\
3.44\end{array}$ & $\begin{array}{l}233 \\
252 \\
374 \\
521\end{array}$ \\
\hline 1948 & $\begin{array}{l}\text { Apr. } 21,1948 \\
\text { Apr. } 29,1948 \\
\text { May } 7,1948 \\
\text { May } 17,1948\end{array}$ & $\begin{array}{l}3.60 \\
- \\
-\end{array}$ & $\begin{array}{l}650 \\
528 \\
316 \\
279\end{array}$ & 1958 & $\begin{array}{ll}\text { Apr. } 18,1958 \\
\text { May } 7,1958\end{array}$ & $\begin{array}{l}3.15 \\
2.70\end{array}$ & $\begin{array}{l}505 \\
378\end{array}$ \\
\hline 1949 & $\begin{array}{l}\text { Apr. 25, } 1949 \\
\text { May 21, } 1949\end{array}$ & 2.85 & $\begin{array}{l}308 \\
175\end{array}$ & 1959 & $\begin{array}{l}\text { Apr. } 5,1959 \\
\text { Apr. } 26,1959\end{array}$ & $\begin{array}{l}2.96 \\
2.27\end{array}$ & $\begin{array}{l}406 \\
179\end{array}$ \\
\hline 1950 & $\begin{array}{l}\text { Apr. } 20,1950 \\
\text { May } 18,1950\end{array}$ & $\overline{3.46}$ & $\begin{array}{l}508 \\
584\end{array}$ & $\begin{array}{l}1960 \\
1961\end{array}$ & $\begin{array}{ll}\text { Apr. } & 6,1960 \\
\text { Apr. } & 3,1961\end{array}$ & $\begin{array}{l}3.08 \\
2.41\end{array}$ & $\begin{array}{l}489 \\
224\end{array}$ \\
\hline 1951 & $\begin{array}{l}\text { Apr. } 8,1951 \\
\text { Apr. } 29,1951\end{array}$ & $\begin{array}{l}2.88 \\
2.62\end{array}$ & $\begin{array}{l}345 \\
260\end{array}$ & 1962 & $\begin{array}{l}\text { Feb. 12, } 1962 \\
\text { Apr. 14, } 1962\end{array}$ & $\begin{array}{l}2.19 \\
2.81\end{array}$ & $\begin{array}{l}164 \\
433\end{array}$ \\
\hline 1952 & $\begin{array}{l}\text { Apr. 27, } 1952 \\
\text { Apr. 28, } 1953\end{array}$ & $\begin{array}{l}3.83 \\
2.27\end{array}$ & $\begin{array}{l}773 \\
189\end{array}$ & 1963 & 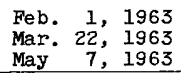 & $\begin{array}{l}3.2 \\
2.54 \\
2.65\end{array}$ & $\begin{array}{l}338 \\
162 \\
187 \\
\end{array}$ \\
\hline
\end{tabular}

a Maximum observed.

b Maximum daily.

865. Bear River below Utah Power \& Light Co.'s tallrace, at Oneida, Idaho

Location, --Lat $42^{\circ} 16^{\prime}$, long $111^{\circ} 45^{\prime}$, in sec.26, T.13 S., R.40 E., on right bank $200 \mathrm{f}^{\prime} \mathrm{downstream}$ from tailrace of oneida plant and 6 miles south of

Cleveland.

Drainage area. $--4,400 \mathrm{sq} \mathrm{mi}$, approximately.

Gage.- -Recording. Altitude of gage is 4,800 ft (from topographic map).

Stage-discharge relation.--Defined by current-meter measurements.

Remarks - - Flow regulated by Bear Lake and Soda, Grace, and One1da hydroslectric

plants. Records collected by Utah Power \& Iight Co., under general super-

vision of Geological Survey, in connection with a Federal Power Commission

project. Only annual maximum daily discharges are shown prior to $19: 1$. 
Peak stages and discharges of Bear RIver below Utah Power \& Light Co.'s tailrace, at Oneida, Idaho

\begin{tabular}{|c|c|c|c|c|c|c|c|}
\hline $\begin{array}{l}\text { Water } \\
\text { year }\end{array}$ & Date & $\begin{array}{l}\text { Gage } \\
\text { height } \\
\text { (feet) }\end{array}$ & $\begin{array}{c}\text { Discharge } \\
\text { (cfs) }\end{array}$ & $\begin{array}{l}\text { Water } \\
\text { year }\end{array}$ & Date & $\begin{array}{c}\text { Gige } \\
\text { helght } \\
(f \text { zet })\end{array}$ & $\begin{array}{c}\text { Discharge } \\
(\mathrm{cfs})\end{array}$ \\
\hline $\begin{array}{l}1922 \\
1923 \\
1924 \\
1925\end{array}$ & $\begin{array}{lrl}\text { May } & 8, & 1922 \\
\text { June } & 4, & 1923 \\
\text { Apr. } & 14, & 1924 \\
\text { May } & 1, & 1925\end{array}$ & $\begin{array}{l}- \\
- \\
-\end{array}$ & $\begin{array}{l}5,480 \\
4,120 \\
2,630 \\
2,320\end{array}$ & $\begin{array}{l}1943 \\
1944 \\
1945\end{array}$ & $\begin{array}{l}\text { Apr. } 5,1943 \\
\text { Apr. } 20,1944 \\
\text { June } 11,1945\end{array}$ & - & $\begin{array}{l}2,560 \\
1,650 \\
2,010\end{array}$ \\
\hline $\begin{array}{l}1926 \\
1927 \\
1928 \\
1929 \\
1930\end{array}$ & $\begin{array}{l}\text { Sept.24, } 1926 \\
\text { June 30, } 1927 \\
\text { Apr. } 2,1928 \\
\text { Apr. 14, } 1929 \\
\text { Aug. 8, } 1930\end{array}$ & $\begin{array}{l}- \\
- \\
-\end{array}$ & $\begin{array}{l}1,580 \\
1,670 \\
1,990 \\
1,690 \\
1,450\end{array}$ & $\begin{array}{l}1946 \\
1947 \\
1948 \\
1949 \\
1950\end{array}$ & $\begin{array}{l}\text { Apr. } 8,1946 \\
\text { Sept.13, } 1947 \\
\text { Apr. 19, } 1948 \\
\text { Apr. 16, } 1949 \\
\text { Apr. 17, } 1950\end{array}$ & $\begin{array}{l}- \\
- \\
-\end{array}$ & $\begin{array}{l}2,360 \\
1,790 \\
2,180 \\
1,750 \\
3,240\end{array}$ \\
\hline $\begin{array}{l}1931 \\
1932 \\
1933 \\
1934 \\
1935\end{array}$ & $\begin{array}{l}\text { Aug. 12, } 1931 \\
\text { Apr. 15, } 1932 \\
\text { July } 25,1933 \\
\text { Aug. 1, } 1934 \\
\text { Apr. 16, } 1935\end{array}$ & $\begin{array}{l}- \\
- \\
-\end{array}$ & $\begin{array}{l}1,230 \\
1,720 \\
1,370 \\
1,220 \\
1,260\end{array}$ & $\begin{array}{l}1951 \\
1952 \\
1953 \\
1954 \\
1955\end{array}$ & $\begin{array}{l}\text { June } 30,1951 \\
\text { May } 5,1952 \\
\text { Oct. } 6,1952 \\
\text { July 7, } 1954 \\
\text { July 10, } 1955\end{array}$ & $\begin{array}{l}- \\
\overline{-} \\
\overline{-}\end{array}$ & $\begin{array}{l}2,350 \\
2,650 \\
1,810 \\
1,750 \\
1,870\end{array}$ \\
\hline $\begin{array}{l}1936 \\
1937 \\
1938 \\
1939 \\
1940\end{array}$ & $\begin{array}{l}\text { Apr. } 21,1936 \\
\text { Apr. } 23,1937 \\
\text { Apr. } 14,1938 \\
\text { Mar. 23, } 1939 \\
\text { June } 29,1940\end{array}$ & $\begin{array}{l}- \\
\overline{-} \\
-\end{array}$ & $\begin{array}{l}3,680 \\
1,680 \\
1,750 \\
1,770 \\
1,490\end{array}$ & $\begin{array}{l}1956 \\
1957 \\
1958 \\
1959 \\
1960\end{array}$ & $\begin{array}{l}\text { Mar. } 26,1956 \\
\text { May } 20,1957 \\
\text { Apr. } 17,1958 \\
\text { Apr. 5, } 1959 \\
\text { July 11, } 1960\end{array}$ & $\begin{array}{l}- \\
- \\
- \\
-\end{array}$ & $\begin{array}{l}1,690 \\
2,300 \\
2,160 \\
1,350 \\
1,430\end{array}$ \\
\hline $\begin{array}{l}1941 \\
1942\end{array}$ & $\begin{array}{ll}\text { July } & 3,1941 \\
\text { Apr. } 27, & 1942\end{array}$ & - & $\begin{array}{l}1,430 \\
1,480\end{array}$ & $\begin{array}{l}1961 \\
1962 \\
1963\end{array}$ & $\begin{array}{l}\text { Aug. } 4,1961 \\
\text { Feb. 11, } 1962 \\
\text { Feb. } 1,1963\end{array}$ & $\begin{array}{l}6.73 \\
6.59 \\
6.58\end{array}$ & $\begin{array}{l}3,280 \\
3,220 \\
3,240\end{array}$ \\
\hline
\end{tabular}

Note.--Only maximum daily discharges are shown prior to 1961.

875. Mink Creek below Dry Fork, near Mink Creek, Idaho

Location.--Lat $42^{\circ} 15^{\prime} 30^{\prime \prime}$, long $111^{\circ} 40^{\prime} 30^{\prime \prime}$, in NE $\frac{1}{4} \mathrm{NW} \frac{1}{4}$ 8ec.33, T.13 S., R.41 E., on right bank $500 \mathrm{ft}$ downstream from Dry Fork and 3 miles northeast of town of Mink Creek.

Drainage area. $--19.3 \mathrm{sq} \mathrm{ml}$. Mean altitude, 7,070 ft.

Gage.--Recoraing. Altitude of gage is 5,300 ft (from topographic map).

Stage-discharge relation.--Defined by current-meter measurements below $550 \mathrm{cfs}$. shifting throughout the range in stage caused by high water nearly every year.

Remarks.--Mink Creek Canal began diverting above station in June 1950. Only annual peaks are shown.

\begin{tabular}{|c|c|c|c|c|c|c|c|c|c|}
\hline $\begin{array}{l}\text { Water } \\
\text { year }\end{array}$ & \multicolumn{2}{|r|}{ Date } & $\begin{array}{c}\text { Gage } \\
\text { helght } \\
\text { (feet) }\end{array}$ & $\begin{array}{c}\text { Discharge } \\
\left(\mathrm{cfs}^{\mathrm{s}}\right)\end{array}$ & $\begin{array}{l}\text { Water } \\
\text { year }\end{array}$ & \multicolumn{2}{|r|}{ Date } & $\begin{array}{l}\text { Gage } \\
\text { helght } \\
\text { (feet) }\end{array}$ & $\begin{array}{c}\text { Discharge } \\
\text { (cfs) }\end{array}$ \\
\hline $\begin{array}{l}1947 \\
1948 \\
1949 \\
1950\end{array}$ & $\begin{array}{l}\text { May } \\
\text { May } \\
\text { May } \\
\text { June }\end{array}$ & $\begin{array}{rr}8, & 1947 \\
29, & 1948 \\
18, & 1949 \\
2, & 1950\end{array}$ & $\begin{array}{l}3.25 \\
3.65 \\
3.40 \\
3.68\end{array}$ & $\begin{array}{l}415 \\
600 \\
373 \\
548\end{array}$ & $\begin{array}{l}1957 \\
1958 \\
1959 \\
1960\end{array}$ & $\begin{array}{l}\text { June } \\
\text { May } \\
\text { June } \\
\text { May }\end{array}$ & $\begin{array}{rr}7, & 1957 \\
28, & 1958 \\
7, & 1959 \\
13, & 1960\end{array}$ & $\begin{array}{l}3.97 \\
3.79 \\
3.06 \\
3.22\end{array}$ & $\begin{array}{l}472 \\
511 \\
245 \\
298\end{array}$ \\
\hline $\begin{array}{l}1951 \\
1952 \\
\end{array}$ & $\begin{array}{l}\text { May } \\
\text { June }\end{array}$ & $\begin{array}{rr}27, & 1951 \\
3, & 1952\end{array}$ & $\begin{array}{l}3.68 \\
3.64\end{array}$ & $\begin{array}{l}461 \\
438\end{array}$ & $\begin{array}{l}1961 \\
1962\end{array}$ & $\begin{array}{l}\text { May } \\
\text { May }\end{array}$ & $\begin{array}{ll}27, & 1961 \\
10, & 1962\end{array}$ & $\begin{array}{l}2.81 \\
3.54\end{array}$ & $\begin{array}{l}185 \\
421\end{array}$ \\
\hline 1956 & May & 25,1956 & 3.77 & 506 & & & & & \\
\hline
\end{tabular}


895. Mink Creek near Mink Creek, Idaho

Location.--Lat $42^{\circ} 12^{\prime}$, long $111^{\circ} 46^{\prime}$, in $\mathrm{SE} \frac{1}{4} \mathrm{sec} .15$, T.14 S., R.40 E., cn left bank $1,000 \mathrm{ft}$ upstream from Bear Hollow, $1 \frac{1}{4}$ miles upstream from mouth, and 3 miles southwest of town of Mink Creek.

Drainage area. $--58.7 \mathrm{sq} \mathrm{mi}$.

Gage.--Recording except nonrecording June 7 to Sept. 7, 1948. Prior tc Apr. 2, I948, at site $700 \mathrm{ft}$ downstream at different datum. Apr. 2 to June 6, 1948, at site half a mile downstream at different datum. Altitude of gage is $4,750 \mathrm{ft}$ (from topographic map).

Stage-discharge relation.--Defined by current-meter measurements.

Remarks.--Only annual peaks are shown.

Peak stages and discharges

\begin{tabular}{|c|c|c|c|c|c|c|c|c|}
\hline $\begin{array}{l}\text { Water } \\
\text { year }\end{array}$ & & Date & $\begin{array}{l}\text { Gage } \\
\text { height } \\
\text { (feet) }\end{array}$ & $\begin{array}{c}\text { Discharge } \\
(\text { cfs })\end{array}$ & $\begin{array}{c}\text { Water } \\
\text { year }\end{array}$ & Date & $\begin{array}{l}\text { Gage } \\
\text { he1ght } \\
\text { (feet) }\end{array}$ & $\begin{array}{c}\text { Discharge } \\
\text { (cfs) }\end{array}$ \\
\hline $\begin{array}{l}1943 \\
1944 \\
1945\end{array}$ & $\begin{array}{l}\text { June } \\
\text { May } \\
\text { June }\end{array}$ & 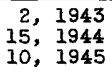 & $\begin{array}{l}2.74 \\
2.60 \\
3.06\end{array}$ & $\begin{array}{l}\text { a413 } \\
\text { a340 } \\
\text { a393 }\end{array}$ & $\begin{array}{l}1948 \\
1949 \\
1950\end{array}$ & $\begin{array}{lll}\text { May } & 28, & 1948 \\
\text { May } & 20, & 1949 \\
\text { June } & 2, & 1950\end{array}$ & $\begin{array}{c}- \\
2.46 \\
3.25\end{array}$ & $\begin{array}{r}2413 \\
302 \\
2427\end{array}$ \\
\hline $\begin{array}{l}1946 \\
1947\end{array}$ & $\begin{array}{l}\text { May } \\
\text { June I }\end{array}$ & $\begin{array}{r}7,1946 \\
11,1947\end{array}$ & $\begin{array}{l}3.12 \\
2.51\end{array}$ & $\begin{array}{l}\text { a.348 } \\
\text { a.283 }\end{array}$ & $\begin{array}{l}1951 \\
1952\end{array}$ & $\begin{array}{rr}12, & 1951 \\
5, & 1952\end{array}$ & $\begin{array}{l}2.68 \\
2.51\end{array}$ & $\begin{array}{r}331 \\
\text { a334 }\end{array}$ \\
\hline
\end{tabular}

a Maximum datly.

905. Bear River near Preston, Idaho

(Published as "at Battle Creek" prior to 1903)

Location.--Lat $42^{\circ} 10^{\prime}$, long $111^{\circ} 51^{\prime}$, in NW/ sec.36, T.14 S., R.39 E., on left bank 600 ft downstream from headgates of West Cache Canal, 5 miles downfrom Mink Creek, 5 miles north of Preston, and $5 \frac{1}{2}$ miles upstream from Battle Creek.

Drainage area. $--4,500 \mathrm{sq} \mathrm{ml}$, approximately.

Gage.--Nonrecording prior to october 1917 at several sites within 5 miles downstream at different datums; recording thereafter. Altitude of gage is 4,540 ft (from topographic map).

Stage-discharge relation.--Defined by current-meter measurements.

Remarks.--Natural flow of stream affected by storage reservoirs, power developments, diversions for irrigation, and return flow from irrigated aress. Only annual peaks are shown (maximum observed prior to 1944).

\begin{tabular}{|c|c|c|c|c|c|c|c|}
\hline $\begin{array}{l}\text { Water } \\
\text { year }\end{array}$ & Date & $\begin{array}{c}\text { Gage } \\
\text { height } \\
\text { (feet) }\end{array}$ & $\begin{array}{l}\text { Discharge } \\
\text { (cfs) }\end{array}$ & $\begin{array}{l}\text { Water } \\
\text { year }\end{array}$ & Date & $\begin{array}{c}\text { Gage } \\
\text { height } \\
\text { (feet) }\end{array}$ & $\begin{array}{l}\Gamma^{*} . \text { scharge } \\
(\mathrm{cfs})\end{array}$ \\
\hline 1890 & \multirow{10}{*}{ 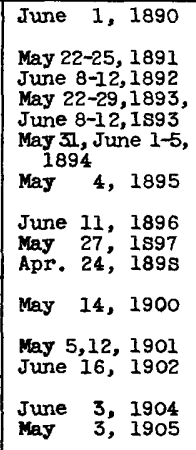 } & \multirow{8}{*}{$\begin{array}{l}- \\
= \\
= \\
- \\
= \\
=\end{array}$} & \multirow{2}{*}{$\begin{array}{l}5,980 \\
3,030 \\
5,260 \\
3,960\end{array}$} & \multirow{2}{*}{$\begin{array}{l}1907 \\
1908 \\
1909 \\
1910\end{array}$} & \multirow{2}{*}{$\begin{array}{l}\text { June } 9,1907 \\
\text { June } 23,1908 \\
\text { June } 4,1909 \\
\text { Mar. 15, } 1910\end{array}$} & \multirow{2}{*}{$\begin{array}{l}- \\
- \\
-\end{array}$} & \multirow{2}{*}{$\begin{array}{r}a 8,500 \\
2,210 \\
6,090 \\
6,380\end{array}$} \\
\hline $\begin{array}{l}1891 \\
1892 \\
1893\end{array}$ & & & & & & & \\
\hline & & & - & 1911 & Jan. 31, 1911 & - & 5,890 \\
\hline 1894 & & & 7,980 & $\begin{array}{l}1912 \\
1913\end{array}$ & $\begin{array}{l}\text { May 23, } 1912 \\
\text { Apr. 7, } 1913\end{array}$ & $\overline{-}$ & $\begin{array}{l}4,730 \\
5,600\end{array}$ \\
\hline 1895 & & & 3,640 & $\begin{array}{l}1914 \\
1915\end{array}$ & $\begin{array}{l}\text { May } 21,1914 \\
\text { Jan. } 28,1915\end{array}$ & $\overline{-}$ & $\begin{array}{l}4,920 \\
2,260\end{array}$ \\
\hline \multirow{2}{*}{$\begin{array}{l}1896 \\
1897 \\
1898 \\
\end{array}$} & & & $\begin{array}{l}6,000 \\
6,100\end{array}$ & 1916 & Mar. 26,1916 & - & 2,770 \\
\hline & & & & 1944 & Mar. 9,1944 & 4.8 & $2, \varepsilon+2<>$ \\
\hline 1900 & & & 2,540 & 1945 & June 11,1945 & 5.3 & 3,800 \\
\hline $\begin{array}{l}1901 \\
1902 \\
\end{array}$ & & $\overline{-}$ & $\begin{array}{l}2,920 \\
2,340\end{array}$ & $\begin{array}{l}1946 \\
1947 \\
1948\end{array}$ & 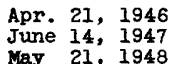 & $\begin{array}{l}5.47 \\
5.00 \\
5.02\end{array}$ & $\begin{array}{l}3,940 \\
3,200 \\
3,220\end{array}$ \\
\hline $\begin{array}{l}1904 \\
1905\end{array}$ & & $\overline{-}$ & $\begin{array}{l}5,050 \\
1,320\end{array}$ & $\begin{array}{l}1949 \\
1950\end{array}$ & $\begin{array}{l}\text { Jan. } 10,1949 \\
\text { Apr. } 17,1950\end{array}$ & $\begin{array}{l}5.07 \\
5.61\end{array}$ & $\begin{array}{l}3,300 \\
4,420\end{array}$ \\
\hline $\begin{array}{c}1906 \\
\text { B A }\end{array}$ & $\begin{array}{l}\text { June } 6,1906 \\
\text { ut. }\end{array}$ & - & 4,650 & 1951 & Dec. 2s, 1950 & 4.96 & 3,130 \\
\hline
\end{tabular}


Peak stages and discharges of Bear River near Preston, Idaho--Continued

\begin{tabular}{|c|c|c|c|c|c|c|c|c|}
\hline $\begin{array}{l}\text { Water } \\
\text { year }\end{array}$ & & Date & $\begin{array}{l}\text { Gage } \\
\text { helght } \\
\text { (feet) }\end{array}$ & $\begin{array}{c}\text { Discharge } \\
\text { (cfs) }\end{array}$ & $\begin{array}{l}\text { Water } \\
\text { year }\end{array}$ & Date & $\begin{array}{l}\text { Gage } \\
\text { height } \\
\text { (feet) }\end{array}$ & $\begin{array}{c}\text { Discharge } \\
\text { (cfs) }\end{array}$ \\
\hline $\begin{array}{l}1952 \\
1953 \\
1954 \\
1955\end{array}$ & $\begin{array}{l}\text { May } \\
\text { Dec. } \\
\text { Jan. } \\
\text { Apr. }\end{array}$ & 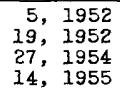 & $\begin{array}{l}5.32 \\
4.72 \\
4.65 \\
4.62\end{array}$ & $\begin{array}{l}3,990 \\
3,020 \\
2,920 \\
2,990\end{array}$ & $\begin{array}{l}1958 \\
1959 \\
1960\end{array}$ & $\begin{array}{l}\text { Apr. 12, } 1958 \\
\text { Apr. 4, } 1959 \\
\text { Aug. 10, } 1960\end{array}$ & $\begin{array}{l}4.67 \\
4.41 \\
4.60\end{array}$ & $\begin{array}{l}3,060 \\
2,710 \\
2,960\end{array}$ \\
\hline $\begin{array}{l}1956 \\
1957 \\
\end{array}$ & $\begin{array}{l}\text { May } \\
\text { May }\end{array}$ & $\begin{array}{l}21,1956 \\
20,1957\end{array}$ & $\begin{array}{l}4.75 \\
4.95\end{array}$ & $\begin{array}{l}3,160 \\
3,450\end{array}$ & $\begin{array}{l}1961 \\
1962 \\
1963\end{array}$ & $\begin{array}{l}\text { Nov. } 2,1960 \\
\text { Feb. 12, } 1962 \\
\text { Feb. } 1,1963\end{array}$ & $\begin{array}{l}4.57 \\
5.51 \\
5.11\end{array}$ & $\begin{array}{l}2,920 \\
4,240 \\
3,600\end{array}$ \\
\hline
\end{tabular}

915. Bear River near Weston, Idaho

Location. --Lat $42^{\circ} 01^{\prime} 50^{\prime \prime}$, long $111^{\circ} 55^{\prime} 15^{\prime \prime}$, in SW $\frac{1}{4}$ SE $\frac{1}{4}$ sec.17, T.16 S.,R.39 E., at Weston-Fairview highway bridge and 3 miles east of Weston.

Drainage area. $--4,480 \mathrm{sq} \mathrm{ml}$, approximately.

Gage---Recording. Altitude of gage is 4,430 ft (from topographic map).

Stage-discharge relation.--Defined by current-meter measurements below 4,000 cfs.

Remarks. --Natural flow of stream affected by storage reservolrs and power developments. Records since 1922 furnished by Utah Power \& Light Co. Only annual maximum dally discharges are shown.

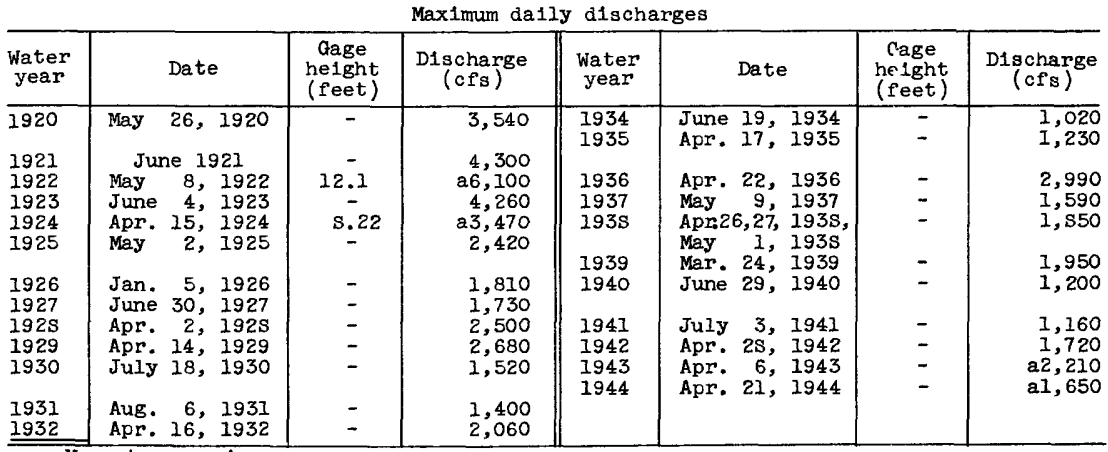

a Momentary maximum.

930. Cub River near Preston, Idaho

Location.--Lat $42^{\circ} 08^{\prime}$, long $111^{\circ} 41^{\prime}$, in SW $\frac{1}{4}$ sec.5, T.15 S., R.41 E., on right

bank 0.2 mile upstream from headgates of Cub River-Worm Creek Canal,

$0.7 \mathrm{mile}$ upstream from forest boundary, and $10 \mathrm{miles}$ east of Preston.

Drainage area. $--19.4 \mathrm{sq} \mathrm{m} 1$.

Gage.--Recording. Altitude of gage is 5,320 ft (from topographic map). Stage-discharge relation.--Defined by current-measurements.

Remarks.--Only annual peaks are shown. 
Peak stages and dfscharges of Cub RJver near Preston, Idaho

\begin{tabular}{|c|c|c|c|c|c|c|c|c|}
\hline $\begin{array}{l}\text { Water } \\
\text { year }\end{array}$ & & Date & $\begin{array}{l}\text { dage } \\
\text { hej.ght } \\
\text { (feet) }\end{array}$ & $\begin{array}{c}\text { Discharge } \\
(\text { cfs })\end{array}$ & $\begin{array}{l}\text { Water } \\
\text { year }\end{array}$ & Date & $\begin{array}{l}\text { Gage } \\
\text { hel.ght } \\
\text { (feet) }\end{array}$ & $\begin{array}{c}\text { Discharge } \\
(\mathrm{cfs})\end{array}$ \\
\hline 1940 & May & 14,1940 & 3.32 & 498 & $\begin{array}{l}1951 \\
1952 \\
\end{array}$ & $\begin{array}{lll}\text { May } & 26, & 1951 \\
\text { May } & 30, & 1952\end{array}$ & $\begin{array}{l}3.32 \\
3.21\end{array}$ & $\begin{array}{l}633 \\
571\end{array}$ \\
\hline $\begin{array}{l}1941 \\
1942 \\
1943 \\
1944 \\
1945\end{array}$ & $\begin{array}{l}\text { May } \\
\text { May } \\
\text { June } \\
\text { May } \\
\text { June }\end{array}$ & 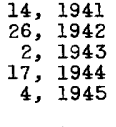 & $\begin{array}{l}3.34 \\
3.44 \\
3.83 \\
3.33 \\
3.19\end{array}$ & $\begin{array}{l}431 \\
499 \\
705 \\
498 \\
474\end{array}$ & $\begin{array}{l}1956 \\
1957 \\
1958 \\
1959 \\
1960\end{array}$ & $\begin{array}{lrl}\text { May } & 25,1956 \\
\text { June } 7, & 1957 \\
\text { May } 25, & 1958 \\
\text { June } 7,1959 \\
\text { May } 13,1960\end{array}$ & $\begin{array}{l}3.29 \\
3.39 \\
3.20 \\
2.57 \\
2.74\end{array}$ & $\begin{array}{l}695 \\
715 \\
692 \\
415 \\
505\end{array}$ \\
\hline $\begin{array}{l}1946 \\
1947 \\
1948 \\
1949 \\
1950 \\
\end{array}$ & $\begin{array}{l}\text { May } \\
\text { May } \\
\text { May } \\
\text { May } \\
\text { June }\end{array}$ & 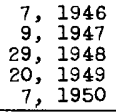 & $\begin{array}{l}3.25 \\
3.47 \\
3.66 \\
3.16 \\
3.47\end{array}$ & $\begin{array}{l}574 \\
566 \\
650 \\
533 \\
692\end{array}$ & $\begin{array}{l}1961 \\
1962 \\
1963\end{array}$ & $\begin{array}{lr}\text { May } 26, & 1961 \\
\text { May } 9,10, & 1962 \\
\text { May } 24, & 1963\end{array}$ & $\begin{array}{l}2.33 \\
2.85 \\
2.60\end{array}$ & $\begin{array}{l}331 \\
555 \\
442\end{array}$ \\
\hline
\end{tabular}

960. Cub River above Maple Creek, near Franklin, Idaho

Location.--Iat $42^{\circ} 03^{\prime}$, long $111^{\circ} 47^{\prime}$, in SW $\frac{1}{4}$ sec.9, T.16 S., R.40 E., or left bank $1 \frac{1}{2}$ miles upstream from Maple Creek and $2 \frac{1}{2}$ miles north of Franklin.

Drainage area. $--53.7 \mathrm{sq} \mathrm{mi}$.

Gage.--Nonrecording prior to Aug. 9, 1941; recording thereafter. Aug. 9, 1941, to June 29, 1951, at datum $1.0 \mathrm{ft}$ higher. Altitude of gage is $4,500 \mathrm{ft}$

(from topographic map).

Stage-discharge relation.--Defined by current-meter measurements.

Remarks.--Only annual peaks are shown.

Peak stages and discharges

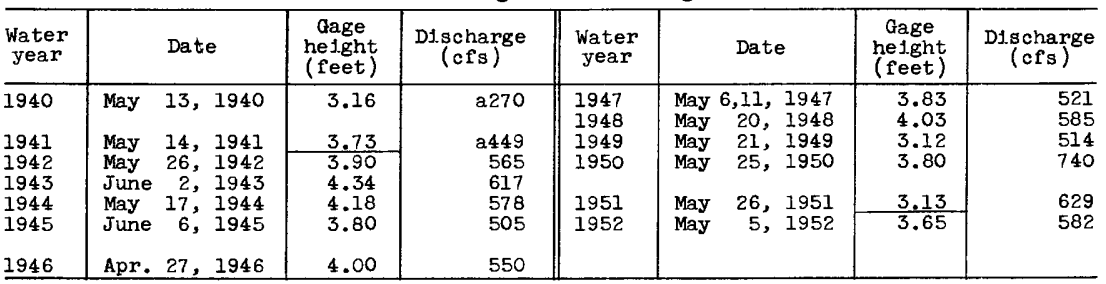

Maximum observed.

\section{Maple Creek near Franklin, Idaho}

Location.--Iat $42^{\circ} 02^{\prime} 30^{\prime \prime}$, long $11^{\circ} 45^{\prime} 00^{\prime \prime}$, in NW $\frac{1}{4}$ sec.14, T.16 S., R.4C E., on left bank $30 \mathrm{ft}$ downstream from Deep Creek and 3 miles east of Franklin.

Drainage area. $--21.2 \mathrm{sq} \mathrm{mi}$, Mean altitude, 6,840 ft.

Gage.--Nonrecording prior to Sept, 27, 1946; recording thereafter. Altitude of gage is $4,850 \mathrm{ft}$ (from topographic map).

Stage-discharge relation.--Defined by current-meter measurements .

Remarks.--Base for partial-duration series, $150 \mathrm{cfs}$. Only annual peaks are shown prior to 1948 . 
Peak stages and discharges of Maple Creek near Franklin, Icaho

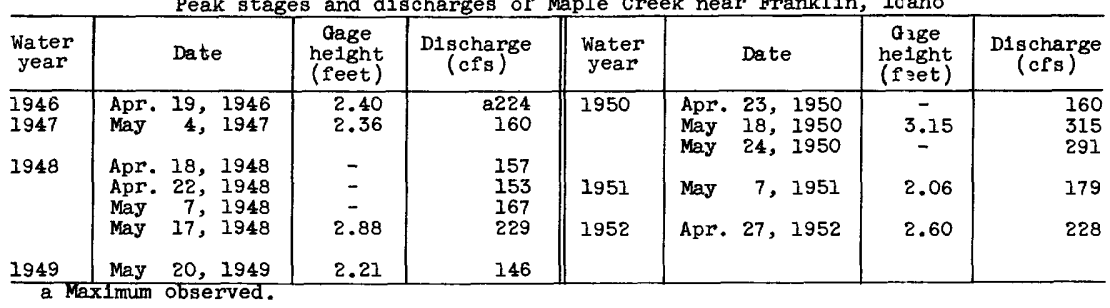

990. High Creek near Richmond, Utah

Location.--Lat $41^{\circ} 59^{\prime}$, long $111^{\circ} 45^{\prime}$, in SW $\frac{1}{4}$ SE $\frac{1}{4}$ sec.5, T. 14 N., R.2 E., on right bank at forest boundary, 2 miles downstream from North Fork an 5 miles northeast of Richmond.

Drainage area. $--16.2 \mathrm{sq} \mathrm{ml}$.

Gage.--Recording. Altitude of gage is 5,250 ft (from topographic map).

Stage-discharge relation.--Defined by current-meter measurements.

Remarks.--Only annual peaks are shown.

\begin{tabular}{|c|c|c|c|c|c|c|c|c|c|}
\hline $\begin{array}{l}\text { Water } \\
\text { year }\end{array}$ & & Date & $\begin{array}{c}\text { Cage } \\
\text { he1ght } \\
\text { (feet) }\end{array}$ & $\begin{array}{c}\text { Discharge } \\
(\mathrm{cfs})\end{array}$ & $\begin{array}{l}\text { Water } \\
\text { year }\end{array}$ & & Date & $\begin{array}{l}\text { Grge } \\
\text { helght } \\
\text { (feet) }\end{array}$ & $\begin{array}{c}\text { Digcharge } \\
(\text { cfs })\end{array}$ \\
\hline $\begin{array}{l}1944 \\
1945\end{array}$ & $\begin{array}{l}\text { June } \\
\text { June }\end{array}$ & $\begin{array}{ll}3, & 1944 \\
6, & 1945\end{array}$ & $\begin{array}{l}2.10 \\
2.31\end{array}$ & $\begin{array}{l}154 \\
184\end{array}$ & $\begin{array}{l}1949 \\
1950\end{array}$ & $\begin{array}{l}\text { May } \\
\text { May }\end{array}$ & $\begin{array}{ll}19, & 1949 \\
24, & 1950\end{array}$ & $\begin{array}{l}2.29 \\
2.31\end{array}$ & $\begin{array}{l}228 \\
250\end{array}$ \\
\hline $\begin{array}{l}1946 \\
1947 \\
1948\end{array}$ & $\begin{array}{l}\text { Apr. } \\
\text { May } \\
\text { May }\end{array}$ & $\begin{array}{rr}26, & 1946 \\
7, & 1947 \\
19, & 1948\end{array}$ & $\begin{array}{l}2.15 \\
2.26 \\
2.34\end{array}$ & $\begin{array}{l}169 \\
207 \\
242\end{array}$ & $\begin{array}{l}1951 \\
1952\end{array}$ & $\begin{array}{l}\text { May } \\
\text { May }\end{array}$ & $\begin{array}{rr}28, & 1951 \\
3, & 1952\end{array}$ & $\begin{array}{l}2.20 \\
2.20\end{array}$ & $\begin{array}{l}211 \\
186\end{array}$ \\
\hline
\end{tabular}

1050. East Fork Little Bear River near Avon, Utah

Location.--Lat $41^{\circ} 3 I^{\prime}$, long $111^{\circ} 45^{\prime}$, in NE $\frac{1}{4}$ sec.17, T.9 N., R.2 E., 0.2 mile downstream from Porcupine Creek, 0.4 mile upstream from Pole Creek, and

4 miles east of Avon.

Drainage area. $--50 \mathrm{sq} \mathrm{ml}$. Mean altitude, $7,370 \mathrm{ft}$.

Gage.--Recording. Altitude of gage is 5,380 ft (from topographic map).

Stage-discharge relation.--Defined by current-meter measurements.

Remarks.--Only annual peaks are shown.

\begin{tabular}{|c|c|c|c|c|c|c|c|}
\hline $\begin{array}{l}\text { Water } \\
\text { year }\end{array}$ & Date & $\begin{array}{c}\text { Cage } \\
\text { helght } \\
\text { (feet) }\end{array}$ & $\begin{array}{c}\text { D1scharge } \\
(\text { cis })\end{array}$ & $\begin{array}{l}\text { Water } \\
\text { year }\end{array}$ & Date & $\begin{array}{c}\text { Gage } \\
\text { he1ght } \\
\text { (feet) }\end{array}$ & $\begin{array}{c}\text { D1scharge } \\
\text { (cfs) }\end{array}$ \\
\hline $\begin{array}{l}1938 \\
1939 \\
1940 \\
1941 \\
1942 \\
1943 \\
1944\end{array}$ & 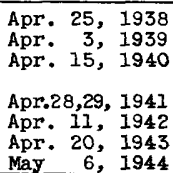 & $\begin{array}{l}3.25 \\
2.77 \\
2.23 \\
2.43 \\
2.94 \\
3.88 \\
2.98\end{array}$ & $\begin{array}{l}276 \\
198 \\
110 \\
146 \\
249 \\
449 \\
274\end{array}$ & $\begin{array}{l}1945 \\
1946 \\
1947 \\
1948 \\
1949 \\
1950\end{array}$ & $\begin{array}{lrl}\text { May } & 4, & 1945 \\
& \\
\text { Apr. } & 18, & 1946 \\
\text { Apr. } & 15, & 1947 \\
\text { May } & 7, & 1948 \\
\text { Apr. } 23, & 1949 \\
\text { Apr. } & 22, & 1950\end{array}$ & $\begin{array}{l}3.40 \\
5.30 \\
3.58 \\
4.80 \\
4.61 \\
4.69\end{array}$ & $\begin{array}{l}364 \\
960 \\
225 \\
569 \\
475 \\
539\end{array}$ \\
\hline
\end{tabular}


1060. Ittle Bear River near Paradise, Utah

Location.--Lat $41^{\circ} 35^{\prime} 25^{\prime \prime}$, long $111^{\circ} 51^{\prime} 10^{\prime \prime}$, in SE $\frac{1}{4}$ sec. 20 , T.10 N., R.1 E., on right bank 1 mile upstream from backwater of Hyrum Reservoir, 2 miles northwest of Paradise, and 5 miles downstream from East Fork.

Drainage area.--203 sq $\mathrm{mi}$. Mean altitude, 6,670 ft.

Gage.-Recording. Prior to Nov. 28, 1945, at site $150 \mathrm{ft}$ upstream at different datum. Nov. 28, 1945, to May 19, 1952, at datum $1.50 \mathrm{ft}$ higher. A.ltitude of gage is 4,680 ft (from topographic map).

Stage-discharge relation.--Defined by current-meter measurements below 1,200 cf's. Considerable shifting from unstable control.

Remarks.--Base for partial-duration series, $400 \mathrm{cfs}$. Only annual peaks are shown prior to 1948 .

Peak stages and discharges

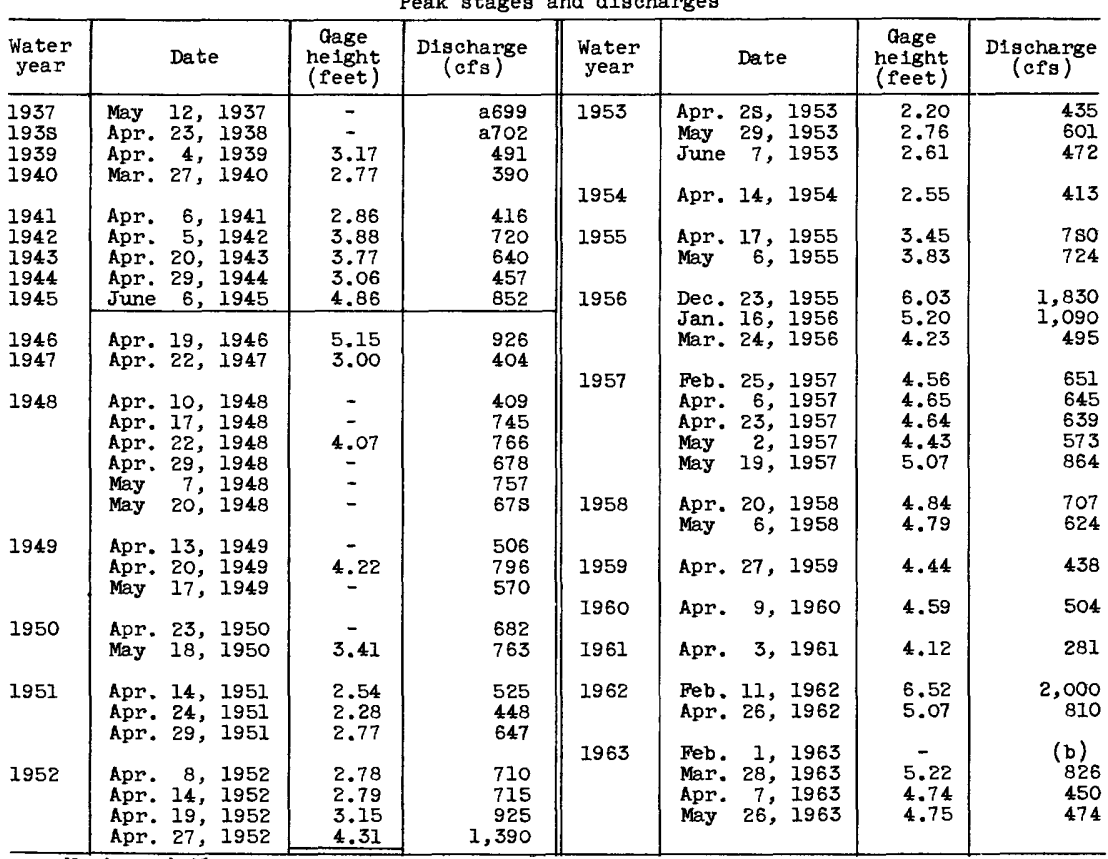

a Maximum da11y.

b Annual maximum not determined.

1075. Little Bear River near Hyrum, Utah

Location.--Lat $41^{\circ} 38^{\prime} 00^{\prime \prime}$, long $111^{\circ} 53^{\prime} 00^{\prime \prime}$, in NE $\frac{1}{4} \mathrm{SW} \frac{1}{4}$ Sec.6, T.10 N., R.1 E., on left bank 2,000 ft upstream from road bridge, 1 mile downstream fror Hyrum Dam, and $1 \frac{1}{2}$ miles west of Hyrum.

Drainage area. --222 $\mathrm{sq} \mathrm{mi}$.

Gage.--Recording. Prior to Nov. 9, 1949, at site 1,200 ft downstream at different datum. Altitude of gage is $4,520 \mathrm{ft}$ (from topographic map).

Stage-discharge relation.--Defined by current-meter measurements.

Remarks.--Flow regulated by Hyrum Reservoir. Only annual peaks are shown. 
Peak stages and discharges of Little Bear River near Hyrum, Utah

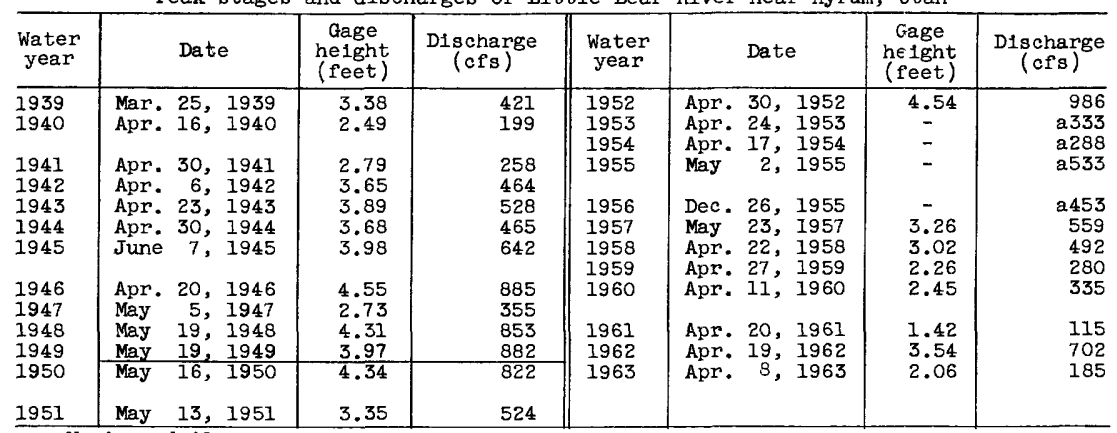

a Maximum daily.

1090. Iogan River above State dam, near Logan, Utah

(Published as Logan River near Logan prior to 1913)

Location.--Lat $41^{\circ} 44^{\prime} 40^{\prime \prime}$, long $111^{\circ} 47^{\prime} 00^{\prime \prime}$, in $\mathrm{NE} \frac{1}{4}$ sec. 36 , T.12 N., R.I E., on right bank at Logan plant of Utah Power \& Iight Co., i25 ft upstream from tailrace, half a mile upstream from State dam, and $2 \frac{1}{2}$ miles east of Logan.

Drainage area. $--218 \mathrm{sq} \mathrm{mi}$. Mean altitude, 7,460 ft.

Gage.--Nonrecording prior to May 7, 1913, at various sites within half a mile downstream below confluence of tailrace, at different datums; recording and concrete control thereafter. May 7 to Sept. 30, 1913, at various datums and Oct. 1, 1913, to Sept. 3, 1938, at datum about $2.3 \mathrm{ft}$ lower than present datum. Altitude of gage is $4,680 \mathrm{ft}$ (from topographic map).

Stage-discharge relation.--Defined by current-meter measurements below 1,000 cfs. Some shifting at all stages.

Remarks.--Only annual peaks are shown (maximum observed prior to 1915).

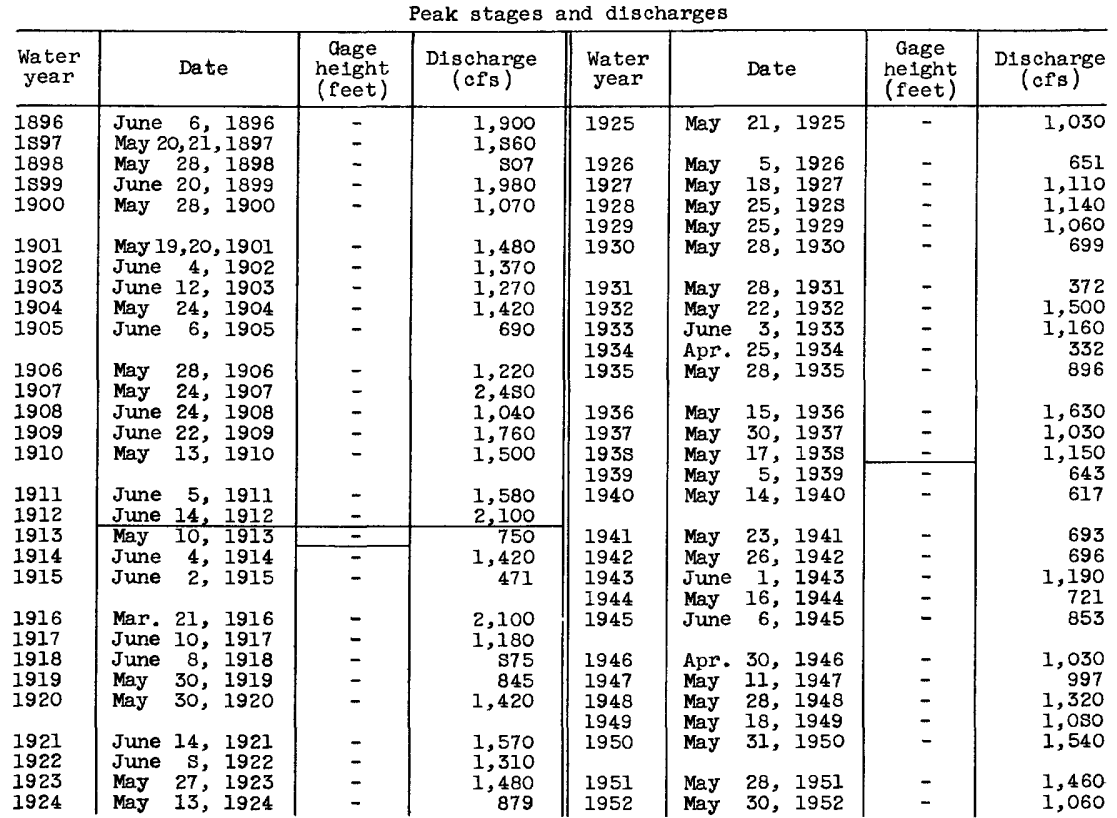


Peak stages and discharges of Logan River above State dam, near Logan, Utah--Continued

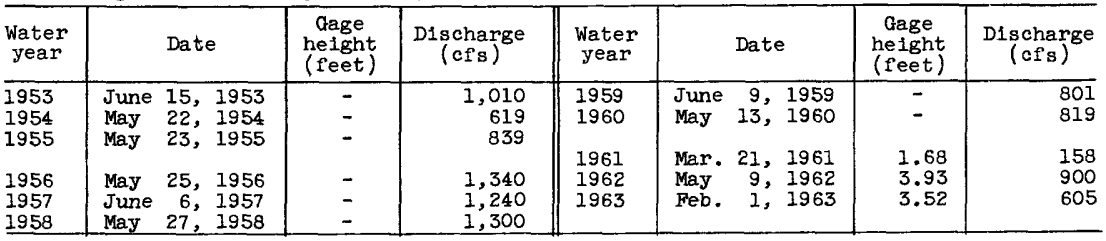

1120. Blacksmith Fork at Hardware Ranch, near Hyrum, Utah

Location.--Lat $41^{\circ} 37^{\prime}$, long $111^{\circ} 37^{\prime}$, in NE $\frac{1}{4}$ sec.17, T.10 N., R.3 E., $0.6 \mathrm{mile}$ upstream from South Cottonwood Canyon, 2.1 miles downstream from Rock Creek, and $12 \frac{1}{2}$ miles east of Hyrum.

Drainage area.--130 sq $\mathrm{ml}$, approximately.

Gage.--Recording. Prior to Apr. 24, 1945, at site 0.9 mile upstream at different datum. Altitude of gage is 5,340 ft (from topographic map).

Stage-discharge relation.--Defined by current-meter measurements.

Remarks.--Only annual peaks are shown.

Peak stages and discharges

\begin{tabular}{|c|c|c|c|c|c|c|c|}
\hline $\begin{array}{l}\text { Water } \\
\text { year }\end{array}$ & Date & $\begin{array}{c}\text { Gage } \\
\text { he1ght } \\
\text { (feet) }\end{array}$ & $\begin{array}{c}\text { D1scharge } \\
\text { (cfs) }\end{array}$ & $\begin{array}{l}\text { Water } \\
\text { year }\end{array}$ & Date & $\begin{array}{c}\text { Gage } \\
\text { helght } \\
\text { (feet) }\end{array}$ & $\begin{array}{c}\text { Discharge } \\
\text { (cfs) }\end{array}$ \\
\hline $\begin{array}{l}1944 \\
1945 \\
1946\end{array}$ & $\begin{array}{l}\text { Apr, } 22,1944 \\
\text { June } 6,1945 \\
\text { Apr. } 18,1946\end{array}$ & $\begin{array}{r}2.32 \\
2.96 \\
4.08\end{array}$ & $\begin{array}{l}\frac{141}{249} \\
488\end{array}$ & $\begin{array}{l}1947 \\
1948 \\
1949 \\
1950\end{array}$ & $\begin{array}{l}\text { Mar. } 16,1947 \\
\text { Apr. } 17,1948 \\
\text { Apr. } 20,1949 \\
\text { Apr. } 13,1950\end{array}$ & $\begin{array}{l}2.62 \\
3.50 \\
2.97 \\
3.11\end{array}$ & $\begin{array}{l}202 \\
370 \\
262 \\
297\end{array}$ \\
\hline
\end{tabular}

1125. Blacksmith Fork at munic1pal powerplant, near Hyrum, Uta'

Location.--Lat $41^{\circ} 37^{\prime} 40^{\prime \prime}$, long $11^{\circ} 41^{\prime} 20^{\prime \prime}$, in $\mathrm{SE}_{\frac{1}{4}}$ sec.2, T.10 N., R.2 E., $200 \mathrm{ft}$ downstream from Hyrum munlcipal powerplant, 1 mile above Lef't Fork, and $8 \frac{1}{2}$ miles east of Hyrum.

Drainage area. $--153 \mathrm{sq} \mathrm{ml}$.

Gage.--Recording. Prior to Apr. 7, 1931, at datum 2 ft lower. Altitude of gage is $5,150 \mathrm{ft}$ (from topographic map).

Stage-discharge relation,--Defined by current-meter measurements.

Remarks.--Only annual peaks are shown.

Peak stages and discharges

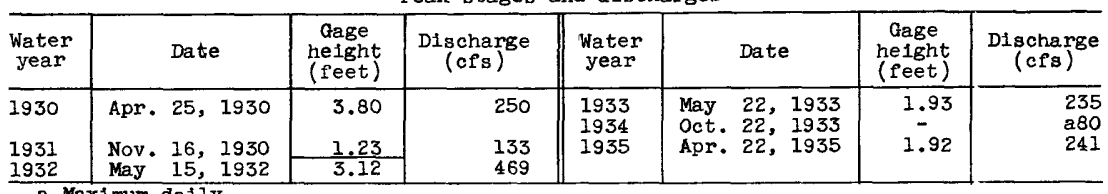

a Maximum daily. 
1135'. Blacksmith Fork above Utah Power \& Light Co.'s dam, near Hyrum, Utah

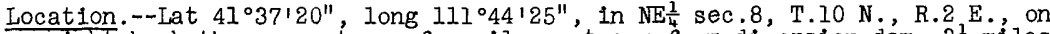
right bank three-quarters of a mile upstream from diversion dam, $3 \frac{1}{4}$ miles upstream from powerplant of Utah Power \& L1ght Co., and 6 miles east of Hyrum.

Drainage area. $--260 \mathrm{sq} \mathrm{mi}$. Mean altitude, 7,150 ft.

Gage.--Recording. Prior to Oct. 2, 1934, at site 1,000 ft upstream at different datum. Altitude of gage is $5,000 \mathrm{ft}$ (from topographic map).

Stage-discharge relation.--Defined by current-meter measurements below 1,200 cf's. Some shif'ting at extremely high stage.

Remarks.--Base for partial-duration series, $140 \mathrm{cfs}$. Only annual peaks are shown prior to 1948.

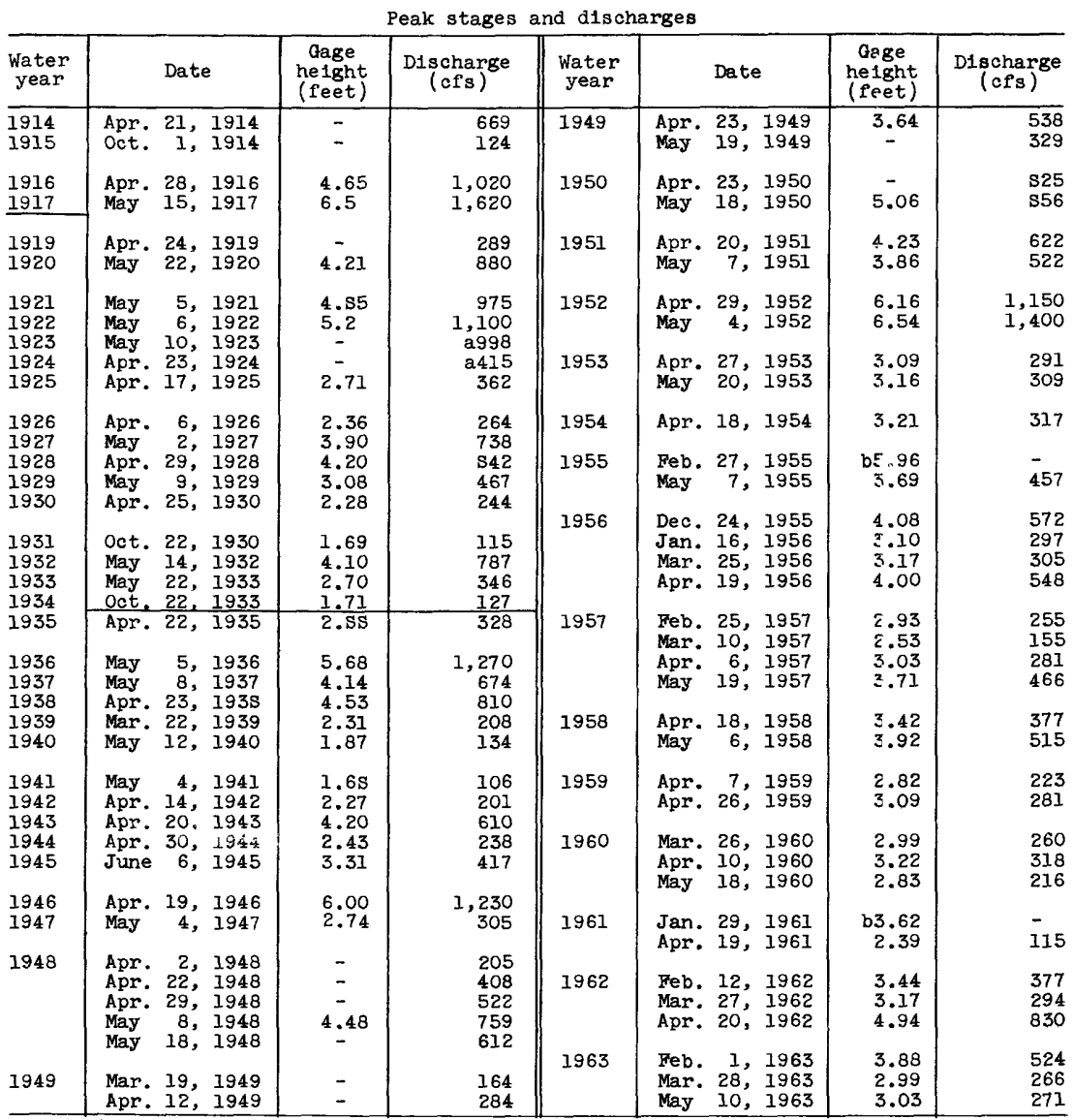

a Maximum daily.

b Backwater from snow or lce. 
1145. Blacksmith Fork below Utah Power \& Light Co.'s plant,

near Hyrum, Utah
(Published as "Blacksmith Fork at Hyrum" 1900-1902 and as "near Hyrum" 1904-10)

Location.--Lat $41^{\circ} 37^{\prime} 40^{\prime \prime}$, long $111^{\circ} 48^{\prime} 00^{\prime \prime}$, in S $\frac{1}{2}$ sec.2, T.10 N., R.I E., 600 ft downstream from intake of Hyrum City power canal, $700 \mathrm{ft}$ downstream from

Utah Power \& Light Co.'s talirace, and $2 \frac{1}{2}$ miles east of Hyrum.

Drainage area. $--286 \mathrm{sq} \mathrm{ml}$.

Gage.--Nonrecording prior to Jan. 1, 1903, at site 1,300 ft upstream above diversions, and May 16, 1904, to Dec. 31, 1910, at site $200 \mathrm{ft}$ upstream, both at different datums; recording thereafter. Altitude of gage is $4,740 \mathrm{ft}$ (from topographic map).

Stage-discharge relation.--Defined by current-meter measurements.

Remarks.--Only annual peaks are shown.

Peak stages and discharges

\begin{tabular}{|c|c|c|c|c|c|c|c|}
\hline $\begin{array}{l}\text { Water } \\
\text { year }\end{array}$ & Date & $\begin{array}{c}\text { Gage } \\
\text { height } \\
\text { (feet) }\end{array}$ & $\begin{array}{c}\text { Discharge } \\
\text { (cfs) }\end{array}$ & $\begin{array}{l}\text { Water } \\
\text { year }\end{array}$ & Date & $\begin{array}{l}\text { Gage } \\
\text { helght } \\
\text { (feet) }\end{array}$ & $\begin{array}{c}\text { Discharge } \\
\text { (cfs) }\end{array}$ \\
\hline 1902 & Oct. $28,29,1901$ & - & a293 & 1910 & Apr.9-12, 1910 & - & a 652 \\
\hline 1905 & $\begin{array}{l}\text { May } 24 \text { to June } 5 \text {, } \\
1905\end{array}$ & - & a282 & $\begin{array}{l}1914 \\
1915\end{array}$ & $\begin{array}{l}\text { Apr. } 22,1914 \\
\text { Oct. } 5,1914\end{array}$ & - & $\begin{array}{l}537 \\
172\end{array}$ \\
\hline $\begin{array}{l}1906 \\
1907 \\
1908 \\
\end{array}$ & $\begin{array}{l}\text { May } 29-31,1906 \\
\text { Apr. 16, } 1907 \\
\text { June } 19,20,1905\end{array}$ & $\begin{array}{l}- \\
-\end{array}$ & $\begin{array}{r}\text { a392 } \\
\text { al, } 900 \\
\text { a266 }\end{array}$ & 1916 & Apr. 2s, 1916 & - & 929 \\
\hline
\end{tabular}

a Maximum observed.

1155. Clarkston Creek near Newton, Utah

Location. - - Lat $41^{\circ} 54^{\prime}$, long $111^{\circ} 58^{\prime}$, in SE $\frac{1}{4} \mathrm{sec} .5$ T. 13 N., R.I W., 500 ft downstream from Newton Dam and $2 \frac{1}{2}$ miles north of Newton.

Drainage area. $--43 \mathrm{sq} \mathrm{mi}$, approximately.

Gage.--Recording and nonrecording prior to Apr. 11, 1946, at several sites within 1.5 miles at different datums; nonrecording in concrete outlet flume thereafter. Altitude of gage is $4,700 \mathrm{ft}$ (from topographic map).

Stage-discharge relation.--Defined by current-meter measurements .

Remarks.--Flow regulated by Newton Dam. Diversions above station for irrigation of several hundred acres above and below station. Only annuel peaks are shown.

\begin{tabular}{|c|c|c|c|c|c|c|c|}
\hline $\begin{array}{l}\text { Water } \\
\text { year }\end{array}$ & Date & $\begin{array}{l}\text { dage } \\
\text { helght } \\
\text { (feet) }\end{array}$ & $\begin{array}{c}\text { Discharge } \\
\text { (cfs) }\end{array}$ & $\begin{array}{l}\text { Water } \\
\text { year }\end{array}$ & Date & $\begin{array}{l}\text { Gage } \\
\text { helght } \\
\text { (feet) }\end{array}$ & $\begin{array}{c}\text { D1scharge } \\
(\mathrm{cfs})\end{array}$ \\
\hline $\begin{array}{l}1939 \\
1940\end{array}$ & $\begin{array}{l}\text { Mar. 23, } 1939 \\
\text { Apr. } 4,1940\end{array}$ & - & $\begin{array}{r}a 70 \\
28\end{array}$ & $\begin{array}{l}1944 \\
1945\end{array}$ & $\begin{array}{l}\text { July } 2-5,1944 \\
\text { Mar. } 18-22,1945\end{array}$ & $\begin{array}{l}1.42 \\
1.90 \\
\end{array}$ & $\begin{array}{l}\text { b23 } \\
\text { b76 } \\
\end{array}$ \\
\hline $\begin{array}{l}1941 \\
1942 \\
1943 \\
\end{array}$ & $\begin{array}{l}\text { Mar. 2, } 1941 \\
\text { Aug.5,6, } 1942 \\
\text { Feb. 23, } 1943\end{array}$ & $\begin{array}{c}- \\
3.10\end{array}$ & $\begin{array}{r}119 \\
\text { a } 69 \\
\text { b261 }\end{array}$ & $\begin{array}{l}1946 \\
1947\end{array}$ & $\begin{array}{ll}\text { Dec. } 30, & 1945 \\
\text { July } 12, & 1947\end{array}$ & - & $\begin{array}{r}\mathrm{b} 282 \\
\mathrm{a} 40\end{array}$ \\
\hline
\end{tabular}

a Maximum daily.

b Maximum observed. 
1180. Bear River near Collinston, Utah

(Published as "at Collinston" prior to 1900)

Location.--Lat $41^{\circ} 50^{\prime}$, long $112^{\circ} 03^{\prime}$, in NW $\frac{1}{4} \operatorname{SE} \frac{1}{4}$ sec.27, T.13 N., R.2 W., on right bank $800 \mathrm{ft}$ downstream from Cutler Plant of Utah Power \& Light Co.,

2,000 ft downstream from Cutler Dam, and $5 \frac{1}{2}$ miles north of Collinston.

Drainage area. $--6,000 \mathrm{sq} \mathrm{ml}$, approximately.

Gage.--Nonrecording prior to Nov. 8, 1913; recording thereafter. Prior to Sept. 10, 1938, at site three-quarters of a mile downstream at different datums. Datum of gage is $4,276.13 \mathrm{ft}$ above mean sea level (levels by Bureau of Reclamation).

Stage-discharge relation.--Defined by current-meter measurements .

Remarks.--Natural flow of stream affected by storage reservoirs, power developments, diversions for irrigation, and return flow from irrigated areas. Only annual peaks are shown (maximum observed 1890-1913; maximum de 11y 1927-35).

\begin{tabular}{|c|c|c|c|c|c|c|c|}
\hline $\begin{array}{l}\text { Water } \\
\text { year }\end{array}$ & Date & $\begin{array}{c}\text { Gage } \\
\text { height } \\
\text { (feet) }\end{array}$ & $\begin{array}{l}\text { Discharge } \\
\text { (cfs) }\end{array}$ & $\begin{array}{c}\text { Water } \\
\text { year }\end{array}$ & Date & $\begin{array}{c}\text { Gige } \\
\text { height } \\
\text { (feet) }\end{array}$ & $\begin{array}{c}\text { Discharge } \\
(\mathrm{cfs})\end{array}$ \\
\hline 1591 & $\begin{array}{l}\text { May } 10,1890 \\
\text { Apr.25,29, } 1591 \text {, } \\
\text { May 25-27, 1891 } \\
\text { May 31, 1892, } \\
\text { June 1, 1892 }\end{array}$ & - & $\begin{array}{l}s, 220 \\
5,000 \\
6,260\end{array}$ & $\begin{array}{l}1926 \\
1927 \\
1928 \\
1929 \\
1930\end{array}$ & $\begin{array}{l}\text { Apr. } 9,1926 \\
\text { Feb. 22, } 1927 \\
\text { Mar. 25, } 192 \mathrm{~s} \\
\text { Mar.12,13, } 1929 \\
\text { Feb. 20, } 1930\end{array}$ & $\begin{array}{l}- \\
- \\
-\end{array}$ & $\begin{array}{l}3,380 \\
4,310 \\
4,210 \\
4,000 \\
3,100\end{array}$ \\
\hline $\begin{array}{l}1893 \\
1594 \\
1595\end{array}$ & $\begin{array}{l}\text { May } 22,1893 \\
\text { June } 3-5,1894 \\
\text { May } 11,1895\end{array}$ & $\begin{array}{l}- \\
-\end{array}$ & $\begin{array}{l}6,470 \\
7,770 \\
4,990\end{array}$ & $\begin{array}{l}1931 \\
1932 \\
1933 \\
1934\end{array}$ & $\begin{array}{l}\text { Mar. } 11,1931 \\
\text { May } 16,1932 \\
\text { May } 28,1933 \\
\text { Dec. } 21,1933\end{array}$ & $\begin{array}{l}- \\
- \\
-\end{array}$ & $\begin{array}{l}1,720 \\
4,550 \\
3,410 \\
1,640\end{array}$ \\
\hline $\begin{array}{l}1596 \\
1597 \\
1895 \\
1899\end{array}$ & $\begin{array}{c}\text { June } 14,15,1596 \\
\text { May } 23-26,1897 \\
\text { June } 2-5,1598 \\
\text { June } 15,22-27, \\
29,30, \text { July } 1\end{array}$ & $\begin{array}{l}- \\
\overline{-} \\
-\end{array}$ & $\begin{array}{r}7,420 \\
10,600 \\
5,320 \\
6,640\end{array}$ & $\begin{array}{l}1935 \\
1936 \\
1937 \\
1938\end{array}$ & $\begin{array}{l}\text { May } 29,1935 \\
\text { Apr. 26, } 1936 \\
\text { May } 12,13,1937 \\
\text { Apr. 2s, } 1938\end{array}$ & $\begin{array}{l}- \\
- \\
-\end{array}$ & $\begin{array}{l}7,260 \\
5,330 \\
5,520 \\
\end{array}$ \\
\hline 1900 & May $14,15,1900$ & - & 4,650 & $\begin{array}{l}1939 \\
1940\end{array}$ & $\begin{array}{l}\text { Mar.22-23, } 1939 \\
\operatorname{Jan} .17,1940\end{array}$ & $\overline{-}$ & $\begin{array}{l}3,940 \\
3,610\end{array}$ \\
\hline $\begin{array}{l}1901 \\
1902 \\
1903 \\
1904 \\
1905\end{array}$ & $\begin{array}{l}\text { May } 6,19,21 \\
\text { June } 2,3,1902 \\
\text { Mar. } 16,17,1903 \\
\text { May } 2525,1904 \\
\text { May } 4,1905\end{array}$ & $\begin{array}{l}- \\
\overline{-} \\
-\end{array}$ & $\begin{array}{l}4,950 \\
3,340 \\
4,500 \\
6,700 \\
2,760\end{array}$ & $\begin{array}{l}1941 \\
1942 \\
1943 \\
1944 \\
1945\end{array}$ & $\begin{array}{l}\text { Feb. } 21,1941 \\
\text { May } 25,1942 \\
\text { Apr. } 23,1943 \\
\text { (a) } \\
\text { June 10, } 1945\end{array}$ & $\begin{array}{l}\overline{-} \\
\overline{-} \\
\overline{-}\end{array}$ & $\begin{array}{l}3,610 \\
3,590 \\
4,830 \\
3,650 \\
6,210\end{array}$ \\
\hline $\begin{array}{l}1906 \\
1907 \\
1905 \\
1909 \\
1910\end{array}$ & $\begin{array}{l}\text { June } 2,1906 \\
\text { June } 11,1907 \\
\text { June } 20,1908 \\
\text { June } 7-10,1909 \\
\text { Mar. } 18,1910\end{array}$ & $\begin{array}{l}- \\
- \\
7.70 \\
-\end{array}$ & $\begin{array}{r}7,080 \\
10,200 \\
5,470 \\
11,600 \\
7, \text { soo }\end{array}$ & $\begin{array}{l}1946 \\
1947 \\
1948 \\
1949 \\
1950\end{array}$ & $\begin{array}{l}\text { Apr. } 21,1946 \\
\text { (b) } \\
\text { May } 5,194 \mathrm{~s} \\
\text { May } 24,25,1949 \\
\text { June } 13,1950\end{array}$ & $\begin{array}{l}- \\
- \\
4.92 \\
4.56 \\
6.76\end{array}$ & $\begin{array}{l}7,160 \\
3,760 \\
3,900 \\
3,840 \\
6,790\end{array}$ \\
\hline $\begin{array}{l}1911 \\
1912 \\
1913 \\
1914 \\
1915\end{array}$ & $\begin{array}{l}\text { Feb. } 2,1911 \\
\text { June } 17,1912 \\
\text { Apr. 10, } 1913 \\
\text { May 27, June 6, } \\
\quad 1914 \\
\text { Feb. } 11,1915\end{array}$ & $\begin{array}{l}- \\
\overline{-} \\
-\end{array}$ & $\begin{array}{l}8,500 \\
6,380 \\
6,250 \\
6,580 \\
2,610\end{array}$ & $\begin{array}{l}1951 \\
1952 \\
1953 \\
1954 \\
1955\end{array}$ & $\begin{array}{l}\text { Feb. 11, } 1951 \\
\text { May 1, } 1952 \\
\text { June 10, } 1953 \\
\text { Apn 10,16, } 1954 \\
\text { May 10, } 1955\end{array}$ & $\begin{array}{l}5.94 \\
6.88 \\
- \\
- \\
-\end{array}$ & $\begin{array}{l}5,410 \\
7,020 \\
3,510 \\
2,210 \\
2,850\end{array}$ \\
\hline $\begin{array}{l}1916 \\
1917 \\
1918 \\
1919 \\
1920\end{array}$ & $\begin{array}{l}\text { Mar. } 23,1916 \\
\text { May } 19,1917 \\
\text { Mar. 13, } 1915 \\
\text { Apr. 1, } 1919 \\
\text { May } 25,1920\end{array}$ & $\begin{array}{l}- \\
- \\
- \\
-\end{array}$ & $\begin{array}{l}6,340 \\
5,170 \\
4,650 \\
3,540 \\
6,510\end{array}$ & $\begin{array}{l}1956 \\
1957 \\
1958 \\
1959 \\
1960\end{array}$ & $\begin{array}{l}\text { Dec. 28, } 1955 \\
\text { May 23, } 1957 \\
\text { Apr.23,24, } 1958 \\
\text { Apr. 16, } 1959 \\
\text { Jan. 22, } 1960\end{array}$ & $\begin{array}{l}- \\
5.50 \\
4.7 \mathrm{~s} \\
4.67 \\
4.75\end{array}$ & $\begin{array}{l}3,820 \\
4,920 \\
3,820 \\
3,640 \\
3,780\end{array}$ \\
\hline $\begin{array}{l}1921 \\
1922 \\
1923 \\
1924 \\
1925 \\
\end{array}$ & $\begin{array}{l}\text { June } 16,1921 \\
\text { May } 10,1922 \\
\text { June } 2,1923 \\
\text { Apr. } 16,1924 \\
\text { Feb. } 5,1925 \\
\end{array}$ & $\begin{array}{l}- \\
\overline{-} \\
\overline{-}\end{array}$ & $\begin{array}{r}6,760 \\
10,100 \\
6,060 \\
4,870 \\
4,280 \\
\end{array}$ & $\begin{array}{l}1961 \\
1962 \\
1963\end{array}$ & $\begin{array}{l}\text { Nov. } 2,1960 \\
\text { feb. 14, } 1962 \\
\text { May } 13,1963\end{array}$ & $\begin{array}{l}4.72 \\
8.23 \\
4.83\end{array}$ & $\begin{array}{l}3,730 \\
9,710 \\
3,900\end{array}$ \\
\hline
\end{tabular}

a Many times in May and June 1944.

b Several days in June 1947 .

Note.--Discharges are maximum observed 1890-1913, maximum da11y 1927-35. 
1190. Little Malad River above Elkhorn Reservoir, near Malad C1ty, Idaho (Published as Little Malad River near Malad 1911-13, and as Little Malad River above Elkhorm Reservolr near Malad 193i-32, 1940-48)

Location.--Lat $42^{\circ} 20^{\prime}$, long $112^{\circ} 26^{\prime}$, on line between secs. 35 and 36, T.12 S., R.34 E., on left bank three-quarters of a mile upstream from highway bridge, 2 miles downstream from Wright Creek, $2 \frac{1}{2}$ miles downstream from sprirgs,

$2 \frac{1}{2}$ miles upstream from Elkhorn Dam, and 14 miles northwest of Malad City.

Drainage area.--120 sq $\mathrm{mi}$, approximately. Mean altitude, 6,080 $\mathrm{ft}$.

Gage.--Nonrecording at different datums prior to Dec. 5, 1940; recordjng and Cippoletti weir thereafter. Altitude of gage is 5,050 ft (by barometer).

Stage-discharge relation.--Defined by current-meter measurements below $70 \mathrm{cfs}$ and extended above on basis of weir computation at gage height 3.63 ft and slope-area measurement at $1,450 \mathrm{cfs}$.

Remarks.--Only annual peaks are shown.

\begin{tabular}{|c|c|c|c|c|c|c|c|}
\hline $\begin{array}{l}\text { Water } \\
\text { year }\end{array}$ & Date & $\begin{array}{l}\text { Gage } \\
\text { neight } \\
\text { (feet) }\end{array}$ & $\begin{array}{l}\text { Discharge } \\
\text { (cfs) }\end{array}$ & $\begin{array}{l}\text { Water } \\
\text { year }\end{array}$ & Date & $\begin{array}{c}\text { Gage } \\
\text { neight } \\
\text { (feet) }\end{array}$ & $\begin{array}{c}\text { Discharge } \\
\text { (cfs) }\end{array}$ \\
\hline $\begin{array}{l}1912 \\
1913 \\
\end{array}$ & $\begin{array}{ll}\text { Aug. } & 2,1912 \\
\text { Apr. } & 1,1913\end{array}$ & $\overline{-}$ & $\begin{array}{r}a 61 \\
61\end{array}$ & $\begin{array}{l}1951 \\
1952 \\
1953\end{array}$ & Aug. 4,1951 & $\begin{array}{l}1.65 \\
1.52\end{array}$ & $\begin{array}{l}78 \\
70 \\
32\end{array}$ \\
\hline 1932 & Apr. 12,1932 & - & a21 & 1954 & June 27,1954 & 1.89 & $\begin{array}{r}95 \\
351\end{array}$ \\
\hline $\begin{array}{l}1941 \\
1942 \\
1943 \\
1944 \\
1945\end{array}$ & $\begin{array}{l}\text { Mar. 17, } 1941 \\
\text { Apr. 4, } 1942 \\
\text { Mar. 5, } 1943 \\
\text { Mar. 30, } 1944 \\
\text { Aus. 14, } 1945\end{array}$ & $\begin{array}{l}2.17 \\
2.28 \\
1.44 \\
2.15 \\
1.97\end{array}$ & $\begin{array}{r}118 \\
126 \\
63 \\
116 \\
100\end{array}$ & $\begin{array}{l}1956 \\
1957 \\
1958 \\
1959 \\
1960\end{array}$ & $\begin{array}{l}\text { Mar. 24, } 1956 \\
\text { Feb. 23, } 1957 \\
\text { Mar. 21, } 1958 \\
\text { Mar. 17, } 1959 \\
\text { July 31, } 1960\end{array}$ & $\begin{array}{l}1.83 \\
3.23 \\
2.19 \\
1.29 \\
3.19\end{array}$ & $\begin{array}{r}91 \\
259 \\
118 \\
56 \\
255\end{array}$ \\
\hline $\begin{array}{l}1946 \\
1947 \\
1948 \\
1949 \\
1950\end{array}$ & $\begin{array}{l}\text { Aug. } 23,1946 \\
\text { Feb. } 13,1947 \\
\text { Feb. } 22,1948 \\
\text { May 15, } 1949 \\
\text { Feb. 25, } 1950\end{array}$ & $\begin{array}{l}2.91 \\
2.94 \\
3.26 \\
2.31 \\
1.75\end{array}$ & $\begin{array}{r}197 \\
199 \\
270 \\
130 \\
84\end{array}$ & $\begin{array}{l}1961 \\
1962 \\
1963\end{array}$ & $\begin{array}{l}\text { Aug. 25, } 1961 \\
\text { Feb. 10, } 1962 \\
\text { Jan. 31, } 1963\end{array}$ & $\begin{array}{l}2.32 \\
4.85 \\
4.41\end{array}$ & $\begin{array}{r}130 \\
1,450 \\
1,100\end{array}$ \\
\hline
\end{tabular}

a Maximum daily.

1200. Little Malad River below Elkhorn Reservoir, near Malad City, Idaho

(Published as "near Malad" prior to 1949)

Location.--Lat $42^{\circ} 18^{\prime}$, long $112^{\circ} 25^{\prime}$, in sec.7, T.13 S., R.35 E., on left bank just downstream from Elkhom Dam, $4 \frac{1}{2}$ miles downstream from Wright Creek and $11 \frac{1}{2}$ miles northwest of Malad City.

Drainage area, $--153 \mathrm{sq} \mathrm{mi}$.

Gage.--Recording. Prior to Sept. 6, 1941, at weir 50 ft upstream at datum $4.36 \mathrm{ft}$ higher. Altitude of gage is $4,970 \mathrm{ft}$ (by barometer).

Stage-discharge relation:--Defined by current-meter measurements below $50 \mathrm{cfs}$ and extended above on basis of computation of flow over weir.

Remarks.-monly annual peaks are shown.

Peak stages and discharges

\begin{tabular}{|c|c|c|c|c|c|c|c|}
\hline $\begin{array}{l}\text { Water } \\
\text { year }\end{array}$ & Date & $\begin{array}{c}\text { Qage } \\
\text { height } \\
\text { (feet) }\end{array}$ & $\begin{array}{c}\text { Discharge } \\
(\mathrm{cfs})\end{array}$ & $\begin{array}{l}\text { Water } \\
\text { year }\end{array}$ & Date & $\begin{array}{c}\text { Gage } \\
\text { height } \\
\text { (feet) }\end{array}$ & $\begin{array}{c}\text { Discharge } \\
(\mathrm{cfs})\end{array}$ \\
\hline $\begin{array}{l}1941 \\
1942 \\
1943 \\
1944 \\
1945\end{array}$ & $\begin{array}{l}\text { Aug. } 10,1941 \\
\text { June } 8,1942 \\
\text { Aug. } 30,1943 \\
\text { June } 18,1944 \\
\text { June } 9,1945\end{array}$ & $\begin{array}{l}- \\
1.90 \\
2.06 \\
2.66 \\
2.34\end{array}$ & $\begin{array}{l}34 \\
44 \\
52 \\
66 \\
52\end{array}$ & \multirow{2}{*}{$\begin{array}{l}1947 \\
194 \mathrm{~S} \\
1949 \\
1950 \\
1951 \\
1952 \\
\end{array}$} & \multirow{2}{*}{ 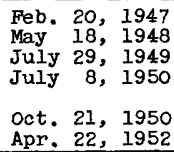 } & \multirow{2}{*}{$\begin{array}{c}2.30 \\
3.43 \\
- \\
2.26 \\
3.34 \\
4.72 \\
\end{array}$} & $\begin{array}{r}52 \\
108 \\
60 \\
52\end{array}$ \\
\hline 1946 & Aug. 23,1946 & 3.50 & 113 & & & & $\begin{array}{r}106 \\
54 \\
\end{array}$ \\
\hline
\end{tabular}


1205. Little Malad River below Sand Ridge damsite, near Malad City, Idaho (Published as "near Malad" prior to 1949)

Location.--Lat $42^{\circ} 12^{\prime}$, long $112^{\circ} 20^{\prime}$, in SE⿺ sec.14, T.14 S., R.35 E., on right bank $0.6 \mathrm{mlle}$ below proposed Sand Ridge damsite, $1 \frac{1}{2}$ miles belcw unnamed tributary, $3 \frac{1}{2}$ miles west of Malad City, and 9 miles downstream frcm Elkhom Reservoir.

Drainage area. $--223 \mathrm{sq} \mathrm{mi}$.

Gage.--Recording. Altitude of gage is 4,560 ft (by barometer).

Stage-discharge relation.--Defined by current-meter measurements below $30 \mathrm{cfs}$ and extended above on basis of submerged-orifice computation at $240 \mathrm{cfs}$.

Remarks.--Diversions upstream from station for irrigation of about 4,000 acres. Only annual peaks are shown.

\begin{tabular}{c|c|c|c||c|c|c|c}
\hline $\begin{array}{c}\text { Water } \\
\text { year }\end{array}$ & Date & $\begin{array}{c}\text { Gage } \\
\text { helght } \\
\text { (feet) }\end{array}$ & $\begin{array}{c}\text { Discharge } \\
\text { (cfs) }\end{array}$ & $\begin{array}{c}\text { Water } \\
\text { year }\end{array}$ & Date & $\begin{array}{c}\text { Gage } \\
\text { hefght } \\
\text { (feet) }\end{array}$ & $\begin{array}{c}\text { Discharge } \\
\text { (cfs) }\end{array}$ \\
\hline 1946 & Mar. 20, 1946 & 3.92 & 25 & 1950 & (a) & 2.91 & 14 \\
1947 & Feb. 13, 1947 & 5.1 & 54 & 1951 & Feb. 10, 1951 & - & b8.0 \\
\hline
\end{tabular}

a Nov. $27-29$, Dec. $1-3,5-7,1949$.

b Maximum daily.

1215. Malad River below springs, near Malad City, Idaho

(Published as "near Málad" 1932-47)

Location.--Lat $42^{\circ} 13^{\prime}$, long $112^{\circ} 22^{\prime}$, in sec.10, T.14 S., R.35 E., half a mile downstream from springs which form river, $13 / 8$ miles upstream from Samaria Dam, and $5 \frac{3}{4}$ miles northwest of Malad City.

Drainage area.--3.3 sq mi, approximately. Flow derived almost entirely from springs .

Gage.--Nonrecording prior to Jan. 27, 1941; recording thereafter. Prior to Nov. 24, 1940, at site $1 \frac{1}{4}$ miles downstream at different datum. Altitude of gage is $4,700 \mathrm{ft}$ (by barometer).

Stage-discharge relation.--Defined by current-meter rieasurements kalow $17 \mathrm{cfs}$ and extended above on basis of weir computation at $40 \mathrm{cfs}$.

Bankfull stage.--Not subject to overflow.

Remarks.--Only annual peaks are shown.

Peak stages and discharges

\begin{tabular}{|c|c|c|c|c|c|c|c|}
\hline $\begin{array}{l}\text { Water } \\
\text { year }\end{array}$ & Date & $\begin{array}{l}\text { Cage } \\
\text { helght } \\
\text { (feet) }\end{array}$ & $\begin{array}{c}\text { D1 scharge } \\
(\mathrm{cfs})\end{array}$ & $\begin{array}{l}\text { Water } \\
\text { year }\end{array}$ & Dete & $\begin{array}{c}\text { Gaze } \\
\text { height } \\
\text { (feet) }\end{array}$ & $\begin{array}{c}\text { Discharge } \\
\text { (cfs) }\end{array}$ \\
\hline 1932 & Apr. 13, 1932 & - & 13 & \multirow{2}{*}{$\begin{array}{l}1944 \\
1945 \\
1946 \\
1947\end{array}$} & \multirow{2}{*}{$\begin{array}{l}\text { Mar. } 17,1944 \\
\text { July } 19,1945 \\
\text { Feb. 28, } 1946 \\
\text { July 21, } 1947\end{array}$} & \multirow{2}{*}{$\begin{array}{r}1.81 \\
1.91 \\
2.90\end{array}$} & \multirow{2}{*}{$\begin{array}{l}16 \\
18 \\
20 \\
40\end{array}$} \\
\hline $\begin{array}{l}1941 \\
1942 \\
1943\end{array}$ & $\begin{array}{l}\text { Aug . } 18,1941 \\
\text { May 6-24, } 1942 \\
\text { (a) }\end{array}$ & $\begin{array}{l}1.84 \\
-\end{array}$ & $\begin{array}{l}19 \\
14 \\
16\end{array}$ & & & & \\
\hline
\end{tabular}

a Apr. 20-28, 30, May 3, 4, 1943. 
1220. Malad River near Samaria, Idaho

Location.--Lat $42^{\circ} 08^{\prime}$, long $112^{\circ} 20^{\prime}$, in sec.11, T.15 S., R.35 E., at Lervis Waldron Ranch, a quarter of a mile upstream from bridge on Malad-Samarla highway, three-eighths of a mile downstream from intake for Gwenford Mill ditch, and $1 \frac{1}{2}$ miles north of Samaria.

Drainage area. $--31 \mathrm{sq} \mathrm{ml}$, approximately.

Gage.--Nonrecording prior to Jan. 29, 1941; recording thereafter. Altitude of gage is 4,420 ft (by barometer).

Stage-discharge relation.--Defined by current-meter measurements below $20 \mathrm{cfs}$. Bankfull stage. $--4.5 \mathrm{ft}$.

Remarks.--Flow regulated by Samarla Reservolr. Only annual peaks are shown.

\begin{tabular}{|c|c|c|c|c|c|c|c|}
\hline \multicolumn{8}{|c|}{ Peak stages and discharges } \\
\hline $\begin{array}{l}\text { Water } \\
\text { year }\end{array}$ & Date & $\begin{array}{c}\text { Gage } \\
\text { helght } \\
\text { (feet) }\end{array}$ & $\begin{array}{c}\text { Discharge } \\
\text { (cfs) }\end{array}$ & $\begin{array}{l}\text { water } \\
\text { year }\end{array}$ & Date & $\begin{array}{c}\text { Gage } \\
\text { height } \\
\text { (feet) }\end{array}$ & $\begin{array}{c}\text { D1scharge } \\
\text { (cIs) }\end{array}$ \\
\hline $\begin{array}{l}1941 \\
1942 \\
1943 \\
\end{array}$ & $\begin{array}{l}\text { Aug. } 17,1941 \\
\text { Aug. } 25,1942 \\
\text { Jan. } 23,1943 \\
\end{array}$ & $\begin{array}{r}2.19 \\
1.85 \\
3.46 \\
\end{array}$ & $\begin{array}{r}64 \\
48 \\
147 \\
\end{array}$ & $\begin{array}{l}1944 \\
1945\end{array}$ & $\begin{array}{l}\text { Mar. } 10,1944 \\
\text { Feb. } 2,1945\end{array}$ & 2.06 & $\begin{array}{l}20 \\
49\end{array}$ \\
\hline
\end{tabular}

1225. Dev11 Creek above Campbe11 Creek, near Malad City, Idaho (Published as "near Malad" prior to 1949)

Location:--Lat $42^{\circ} 18^{\prime}$, long $112^{\circ} 12^{\prime}$, in sec.12, T.13 S., R.36 E., on right bank $0.6 \mathrm{mile}$ upstream from proposed dam, 1.3 miles upstream from highway crossing of Campbell Creek, 4.5 miles upstream from Evans dividers, and $7 \frac{1}{2}$ miles northeast of Malad City.

Drainage area.--13 sq $\mathrm{ml}$, approximately. Mean altitude, 6,0iv ft.

Gage.--Nonrecording prior to Dec. 16, 1943; recording thereafter. Prior to Aug. 23, 1954, at site $50 \mathrm{ft}$ upstream at datum $1.84 \mathrm{ft}$ higher. Altitude of gage is $5,150 \mathrm{ft}$ (by barometer).

Stage-discharge relation.--Defined by current-meter measurements below $216 \mathrm{cfs}$ and extended above on bas is of - lope-area measurement at $194 \mathrm{cfs}$.

Remarks.--Only annual peaks are shown.

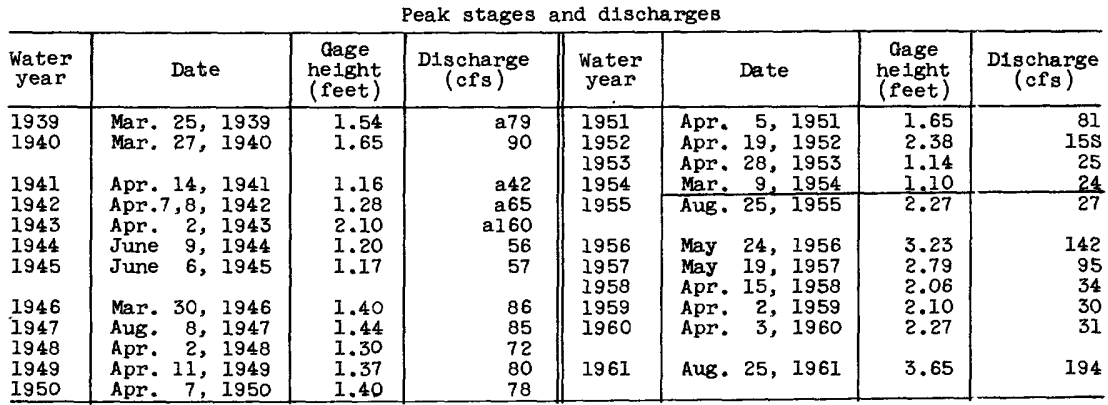

a Maximum observed. 
1230. Devil Creek above Evans dividers, near Malad City, Idaho (Published as "near Malad" prior to 1949)

Location.--Lat $42^{\circ} 15^{\prime}$, long $112^{\circ} 13^{\prime}$, in sec.35, T.13 S., R.36 E., at Evans Ranch, $900 \mathrm{ft}$ upstream from Evans dividers, 3.1 miles downstream from Campbell Creek, and 3.6 miles northeast of Malad C1ty.

Drainage area. --36 sq $\mathrm{mi}$, approximately.

Gage.--Recording. Prior to June 1I, 1942 , at site $400 \mathrm{ft}$ downstream at datum about $0.13 \mathrm{ft}$ higher. June 11, 1942, to Dec. 14, 1943, at present site at datum about $0.2 \mathrm{ft}$ higher. Altitude of gage is $4,900 \mathrm{ft}$ (by barometer).

Stage-discharge relation.--Defined by current-meter measurements.

Bankfull stage. --6 ft.

Remarks.--Diversions for irrigation of 600 to 800 acres upstream from station. Only annual peaks are shown.

Peak stages and discharges

\begin{tabular}{|c|c|c|c|c|c|c|c|}
\hline $\begin{array}{l}\text { Water } \\
\text { year }\end{array}$ & Date & $\begin{array}{c}\text { Gage } \\
\text { height } \\
\text { (feet) }\end{array}$ & $\begin{array}{c}\text { Discharge } \\
\text { (cfs) }\end{array}$ & $\begin{array}{l}\text { Water } \\
\text { year }\end{array}$ & Date & $\begin{array}{c}\text { Gage } \\
\text { helght } \\
\text { (feet) }\end{array}$ & $\begin{array}{c}\text { Discharge } \\
\text { (cfs) }\end{array}$ \\
\hline $\begin{array}{l}1941 \\
1942\end{array}$ & $\begin{array}{l}\text { Aug. } 17,1941 \\
\text { Apr. } 8,1942\end{array}$ & $\begin{array}{l}2.15 \\
1.65 \\
\end{array}$ & $\begin{array}{r}100 \\
78 \\
\end{array}$ & \multirow{3}{*}{$\begin{array}{l}1949 \\
1950 \\
1951 \\
1952\end{array}$} & \multirow{3}{*}{ 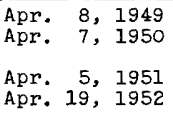 } & \multirow{3}{*}{$\begin{array}{c}- \\
- \\
4.18 \\
5.79\end{array}$} & \multirow[t]{2}{*}{$\begin{array}{l}81 \\
93\end{array}$} \\
\hline 1943 & Mar. 30,1943 & 5.29 & 220 & & & & \\
\hline $\begin{array}{l}1947 \\
1948\end{array}$ & $\begin{array}{r}\text { Mar. 16, } 1947 \\
\text { Apr. } 2,1948\end{array}$ & $\begin{array}{l}3.87 \\
4.26\end{array}$ & $\begin{array}{l}116 \\
151\end{array}$ & & & & $\begin{array}{l}112 \\
261\end{array}$ \\
\hline
\end{tabular}

\section{Devil Creek near Malad City, Idaho \\ (Published as "near Malad" 1932-40)}

Location.--Lat $42^{\circ} 13^{\prime}$, long $112^{\circ} 17^{\prime}$, in sec.8, T.14 S., R.36 E., 400 ft downstream from damsite for proposed reservoir, half a mile northesst of

St. John, $2 \frac{1}{2}$ miles northwest of Malad City, and 9 miles upstreom from mouth.

Drainage area. $--39 \mathrm{sq} \mathrm{mi}$, approximately.

Gage,-Nonrecording. Prior to Oct. 10, 1936, weir at site $180 \mathrm{ft}$ downstream at different datum. wooden weir with Cippoletti notch at last usad site thereafter. Altitudé of gage is 4,695 ft (from river-profile survey).

Stage-discharge relation.--Defined by current-meter measurements below $30 \mathrm{cfs}$.

Bankfull stage. $--3.5 \mathrm{ft}$, site and datum used after 0ct. 10, 1936.

Remarks.--Flow regulated by Evans dividers (an irrigation diversion works) 3 miles upstream from station. Only annual peaks are shown.

\begin{tabular}{|c|c|c|c|c|c|c|c|}
\hline $\begin{array}{l}\text { Water } \\
\text { year }\end{array}$ & Date & $\begin{array}{c}\text { Gage } \\
\text { helght } \\
\text { (feet) }\end{array}$ & $\begin{array}{c}\text { D1scharge } \\
(\text { cfs })\end{array}$ & $\begin{array}{l}\text { Water } \\
\text { year }\end{array}$ & Date & $\begin{array}{c}\text { Gage } \\
\text { helght } \\
\text { (feet) }\end{array}$ & $\begin{array}{c}\text { Discharge } \\
\text { (cfs) }\end{array}$ \\
\hline 1932 & $\frac{\text { (a) }}{\text { Apr } 18, \text { May } 6 .}$ & - & $\begin{array}{l}\text { b18 } \\
\text { b20 }\end{array}$ & $\begin{array}{l}1936 \\
1937\end{array}$ & Aug. 17,1936 & - & $\frac{60}{b 29}$ \\
\hline & 1933 & - & b5 5 & $\begin{array}{l}1938 \\
1939\end{array}$ & $\begin{array}{l}\text { Apr. } 20,1938 \\
\text { Mar. } 26,1939\end{array}$ & $\begin{array}{l}1.24 \\
1.23\end{array}$ & $\begin{array}{l}\text { b28 } \\
\text { b2s }\end{array}$ \\
\hline $\begin{array}{l}1934 \\
1935\end{array}$ & $\begin{array}{l}\text { Aug. } 30,1934 \\
\text { Apr. } 9,1935\end{array}$ & - & b16.5 & 1940 & Mar. 27,1940 & $\begin{array}{r}1.25 \\
.99 \\
\end{array}$ & b17 \\
\hline
\end{tabular}

a. Apr. 5, 12, May 5, 1932.

b Maximum observed. 
1250. Deep Creek below First Creek, near Malad City, Idaho

(Published as "near Malad" 1932-48)

Location.--Iat $42^{\circ} 14^{\prime}$, Iong $112^{\circ} 11^{\prime}$, in sec.7, T.14 S., R.37 E., just downstream from site of proposed reservolr, $i$ mile north and $3 \frac{1}{2}$ miles east of Malad City, and 12 miles upstream from mouth.

Drainage area. $--32 \mathrm{sq} \mathrm{mi}$, approximately.

Gage.--Nonrecording and wooden weir prior to Dec. 16, 1940, at sites within $40 \mathrm{ft}$ downstream at different datums; recording gage and wooden control thereafter. Altitude of gage is 5,074 ft (from river-profile survey).

Stage-discharge relation.--Defined by current-meter measurements below $40 \mathrm{cfs}$.

Remarks.--Flow regulated at times by reservoir (capacity, 261 acre-ft)

$2 \frac{1}{2} \mathrm{~m} i l e s$ upstream. Only annual peaks are shown (maximum observed prior to $1942)$.

Peak stages and discharges

\begin{tabular}{|c|c|c|c|c|c|c|c|}
\hline $\begin{array}{l}\text { Water } \\
\text { year }\end{array}$ & Date & $\begin{array}{c}\text { Qage } \\
\text { helght } \\
\text { (feet) }\end{array}$ & $\begin{array}{c}\text { Discharge } \\
\text { (cfs) }\end{array}$ & $\begin{array}{l}\text { Water } \\
\text { year }\end{array}$ & Date & $\begin{array}{l}\text { Gage } \\
\text { he1ght } \\
\text { (feet) }\end{array}$ & $\begin{array}{c}\text { Discharge } \\
\text { (cfs) }\end{array}$ \\
\hline $\begin{array}{l}1932 \\
1933 \\
1934 \\
1935\end{array}$ & $\begin{array}{l}\text { May } 14,1932 \\
\text { May } 22,1933 \\
\text { Apr. } 6,1934 \\
\text { Apr: } 30, \text { May 30, } \\
\quad 1935\end{array}$ & $\begin{array}{l}- \\
- \\
-\end{array}$ & $\begin{array}{l}64 \\
34 \\
5.5 \\
23\end{array}$ & $\begin{array}{l}1941 \\
1942 \\
1943 \\
1944 \\
1945\end{array}$ & $\begin{array}{l}\text { Aug. } 17,1941 \\
\text { May 16, } 1942 \\
\text { July } 21,1943 \\
\text { June } 9,1944 \\
\text { June } 9,1945\end{array}$ & $\begin{array}{l}2.38 \\
1.84 \\
3.05 \\
2.4 \\
2.33\end{array}$ & $\begin{array}{r}103 \\
62 \\
125 \\
76 \\
61\end{array}$ \\
\hline $\begin{array}{l}1936 \\
1937 \\
1938 \\
1939 \\
1940\end{array}$ & $\begin{array}{l}\text { Apr. } 18,1936 \\
\text { July } 8,1937 \\
\text { May } 1,1938 \\
\text { Mar:27, 31, } 1939 \\
\text { (a) }\end{array}$ & $\begin{array}{l}- \\
- \\
1.20 \\
1.10\end{array}$ & $\begin{array}{l}113 \\
172 \\
40.8 \\
25 \\
21\end{array}$ & $\begin{array}{l}1946 \\
1947 \\
1948\end{array}$ & $\begin{array}{l}\text { Apr. } 19,1946 \\
\text { Mar. } 10,1947 \\
\text { Apr. } 2,1948\end{array}$ & $\begin{array}{l}2.94 \\
2.68 \\
2.76\end{array}$ & $\begin{array}{l}85 \\
46 \\
60\end{array}$ \\
\hline
\end{tabular}

a May 11, 14, June 15, 1940.

1255. Malad River at Woodruff, Idaho

Location.--Lat $42^{\circ} 02^{\prime}$, long $112^{\circ} 14^{\prime}$, in sec.15, T.16 S., R.36 E., on dcwnstream lef't abutment of highway bridge at Woodruff, $2 \frac{1}{2}$ miles north of Idahc-Utah State line.

Drainage area. $--485 \mathrm{sq} \mathrm{mi}$, approximately. Mean altitude, 5,650 ft.

Gage.--Nonrecording prior to Sept. 30, 1960; recording thereafter. Prior to Mar. 6, 1951, at site $300 \mathrm{ft}$ downstream at datum $0.27 \mathrm{ft}$ lower. Alt itude of gage is $4,355 \mathrm{ft}$ (by barometer).

Stage-d1scharge relation.--Defined by current-meter measurements.

Remarks.--Some regulation by several small reservolrs above station. Tiversions above station for irrigation of 25,000 to 30,000 acres. Only annual peaks are shown.

Peak stages and discharges

\begin{tabular}{|c|c|c|c|c|c|c|c|}
\hline $\begin{array}{l}\text { Water } \\
\text { year }\end{array}$ & Date & $\begin{array}{c}\text { Gage } \\
\text { helght } \\
\text { (feet) }\end{array}$ & $\begin{array}{c}\text { Discharge } \\
(\cdot \mathrm{cfs})\end{array}$ & $\begin{array}{l}\text { Water } \\
\text { year }\end{array}$ & Date & $\begin{array}{c}\text { Gage } \\
\text { height } \\
\text { (feet) }\end{array}$ & $\begin{array}{c}\text { D1scharge } \\
(\mathrm{cfs})\end{array}$ \\
\hline $\begin{array}{l}1939 \\
1940\end{array}$ & $\begin{array}{l}\text { Mar20, 21, } 1939 \\
\text { Feb. 5, } 1940\end{array}$ & $\begin{array}{l}6.70 \\
4.80\end{array}$ & $\begin{array}{l}\text { a } 360 \\
\text { a } 199\end{array}$ & $\begin{array}{l}1952 \\
1953 \\
1954\end{array}$ & 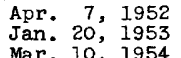 & $\begin{array}{l}6.7 \\
6.24 \\
4.95\end{array}$ & $\begin{array}{l}389 \\
312 \\
223\end{array}$ \\
\hline $\begin{array}{l}1941 \\
1942\end{array}$ & $\begin{array}{ll}\text { Mar. } & 2,1941 \\
\text { Apr. } & 1,1942\end{array}$ & $\begin{array}{l}6.70 \\
6.40\end{array}$ & $\begin{array}{l}\text { a360 } \\
\text { a } 341\end{array}$ & $\begin{array}{l}1954 \\
1955\end{array}$ & Mar. 12,1955 & $\begin{array}{l}4.75 \\
4.40\end{array}$ & $\begin{array}{l}220 \\
180\end{array}$ \\
\hline $\begin{array}{l}1943 \\
1944\end{array}$ & $\begin{array}{l}\text { Jan. } 22,1943 \\
\text { Mar. } 19,1944\end{array}$ & & $\begin{array}{r}650 \\
\mathrm{a} 223\end{array}$ & 1956 & $\begin{array}{l}\text { Mar. } 11,13 \\
21,1956\end{array}$ & 4.50 & 185 \\
\hline 1945 & $\mathrm{Feb} .15,1945$ & 6.58 & a348 & $\begin{array}{l}1957 \\
1958\end{array}$ & $\begin{array}{ll}\text { May } 21, & 1957 \\
\text { Feb, } 26, & 1958\end{array}$ & $\begin{array}{l}4.77 \\
5.18\end{array}$ & $\begin{array}{l}206 \\
238\end{array}$ \\
\hline $\begin{array}{l}1946 \\
1947 \\
1948\end{array}$ & $\begin{array}{l}\text { Dec. } 29,1945 \\
\text { Mar. 12, } 1947 \\
\text { Feb. } 23,1948\end{array}$ & $\begin{array}{l}6.99 \\
5.26 \\
7.80\end{array}$ & $\begin{array}{r}a 490 \\
a 250 \\
628\end{array}$ & $\begin{array}{l}1959 \\
1960\end{array}$ & $\begin{array}{l}\text { Feb. } 23,1959 \\
\text { Mar. } 10,1960\end{array}$ & 4.40 & $\begin{array}{r}172 \\
\mathrm{~b} 230\end{array}$ \\
\hline 1949 & $\begin{array}{l}\operatorname{Mar}, 18,20, \\
21,1949\end{array}$ & & a375 & $\begin{array}{l}1961 \\
1962\end{array}$ & $\begin{array}{l}\text { Feb. } 12,1961 \\
\text { Feb. } 12,1962\end{array}$ & $\begin{array}{l}2.95 \\
8.93\end{array}$ & $\begin{array}{r}84 \\
2,530\end{array}$ \\
\hline 1950 & Feb. 27,1950 & 5.94 & a340 & 1963 & Feb. $\quad 2,1963$ & 5.02 & 243 \\
\hline 1951 & Feb. 10,1951 & 7.0 & 490 & & & & \\
\hline
\end{tabular}

a Maximum observed.

b Maximum daily. 


\section{Bear River near Corinne, Utah}

Location.--Lat $41^{\circ} 34^{\prime} 35^{\prime \prime}$, Iong $112^{\circ} 06^{\prime} 00^{\prime \prime}$, in SW $\frac{1}{4} \mathrm{NE} \frac{1}{4} \sec .30$, T.10 N., R.2 W., on right bank 1.2 miles downstream from Salt Creek, 2.0 miles northeast of Corinne, and 2.8 miles downstream from Malad River.

Drainage area. $--6,800 \mathrm{sq} \mathrm{ml}$, approximately.

Gage.--Recording. Aux1llary nonrecording 7,800 ft downstream July 27, 1950, to Nov. 21, 1955. Datum of gage is $4,204.6 \mathrm{ft}$, unadjusted.

Stage-discharge relation.--Defined by current-meter measurements.

Remarks.--Natural flow of stream affected by storage reservolrs, power developments, and diversions for irrigation. Only annual peaks are shown.

Peak stages and discharges

\begin{tabular}{|c|c|c|c|c|c|c|c|}
\hline $\begin{array}{l}\text { Water } \\
\text { year }\end{array}$ & Date & $\begin{array}{l}\text { Gage } \\
\text { helght } \\
\text { (feet) }\end{array}$ & $\begin{array}{l}\text { Discharge } \\
\text { (cfs) }\end{array}$ & $\begin{array}{l}\text { Water } \\
\text { year }\end{array}$ & Date & $\begin{array}{l}\text { Cage } \\
\text { helght } \\
\text { (feet) }\end{array}$ & $\begin{array}{c}\text { Discharge } \\
(\mathrm{cfs})\end{array}$ \\
\hline & Apr. 23, 1950 & 13.36 & 5,920 & $\begin{array}{l}1954 \\
1955\end{array}$ & $\begin{array}{l}\text { Apr. } 16,1954 \\
\text { Apr. } 20,1955\end{array}$ & $\begin{array}{l}8.11 \\
8.91\end{array}$ & $\begin{array}{l}2,570 \\
2,850\end{array}$ \\
\hline $\begin{array}{l}1951 \\
1952 \\
1953\end{array}$ & $\begin{array}{l}\text { Feb. 11, } 1951 \\
\text { May 3, } 1952 \\
\text { June 11, } 1953\end{array}$ & $\begin{array}{r}14.83 \\
14.69 \\
9.97\end{array}$ & $\begin{array}{l}7,180 \\
7,200 \\
3,510\end{array}$ & $\begin{array}{l}1956 \\
1957\end{array}$ & $\begin{array}{lll}\text { Dec. } 29, & 1955 \\
\text { May } 26, & 1957\end{array}$ & $\begin{array}{l}10.67 \\
12.23\end{array}$ & $\begin{array}{l}4,130 \\
5,080\end{array}$ \\
\hline
\end{tabular}

\section{WEBER RIVER BASIN}

1285. Weber River near Oakley, Utah

Location.--Lat $40^{\circ} 44^{\prime} 10^{\prime \prime}$, long $11^{\circ} 14^{\prime} 45^{\prime \prime}$, in $\mathrm{SE} \frac{1}{4} \mathrm{NE} \frac{1}{4} \mathrm{sec} .15$, T.I S., R. 6 E., on right bank 1.4 miles downstream from South Fork, 2.6 miles upstream from Weber-Provo diversion canal, and $3 \frac{1}{4}$ miles northeast of oakley.

Drainage area.--163 sq $\mathrm{mi}$. Mean altitude, 9,090 ft.

Gage.--Nonrecording prior to oct. 25, 1933, at site a quarter of a mile downstream at different datum; recording thereafter. oct. 25, 1933, to Aug. 29, 1955, at datum $0.5 \mathrm{ft}$ higher. Altitude of gage is $6,600 \mathrm{ft}$ (from topographic map).

Stage-discharge relation.--Defined by current-meter measurements below 2,000 cfs. Considerable shifting at extremely high stages.

Remarks.--Base for partial-duration series, $1,200 \mathrm{cfs}$. Only annual peaks are shown prior to 1935 (maximum observed prior to 1934).

Peak stages and discharges

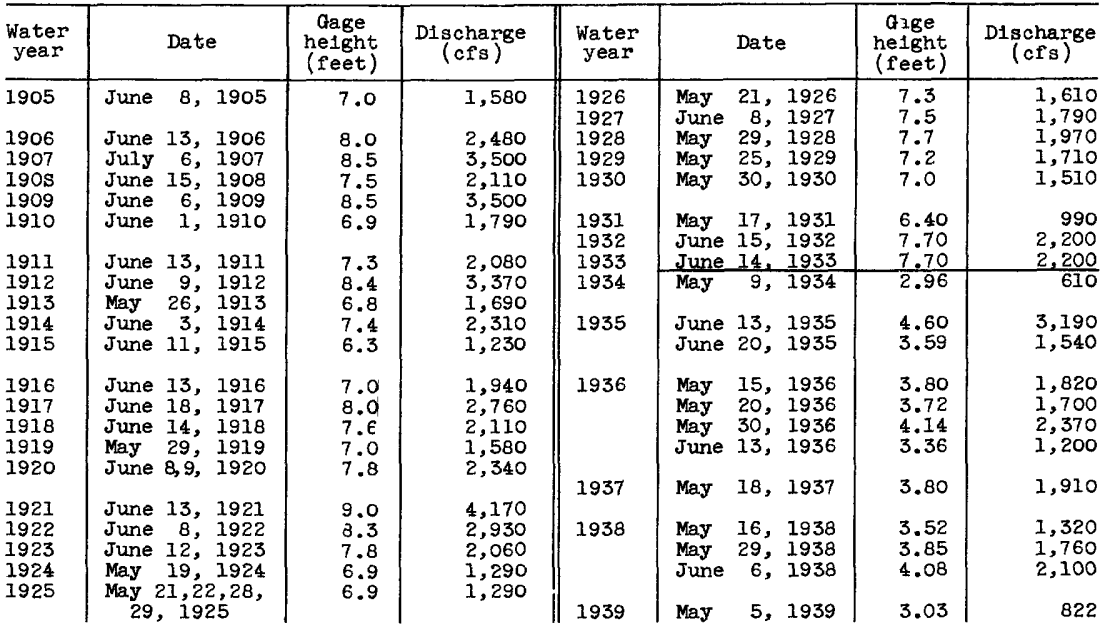


Peak stages and discharges of Weber River near OakIey, Utah--Cont1nued

\begin{tabular}{|c|c|c|c|c|c|c|c|c|c|}
\hline $\begin{array}{l}\text { Water } \\
\text { year }\end{array}$ & & Date & $\begin{array}{c}\text { Gage } \\
\text { height } \\
\text { (feet) }\end{array}$ & $\begin{array}{c}\text { D1scharge } \\
\text { (cfs) }\end{array}$ & $\begin{array}{l}\text { Water } \\
\text { year }\end{array}$ & & Date & $\begin{array}{c}\text { Gage } \\
\text { nelght } \\
\text { (feet) }\end{array}$ & $\begin{array}{c}\text { Discharge } \\
(\text { cfs })\end{array}$ \\
\hline $\begin{array}{l}1940 \\
1941\end{array}$ & $\begin{array}{l}\text { May } \\
\text { June }\end{array}$ & $\begin{array}{l}17,1940 \\
18,1941\end{array}$ & $\begin{array}{l}3.39 \\
3.34\end{array}$ & $\begin{array}{l}1,180 \\
1,160\end{array}$ & 1952 & $\begin{array}{l}\text { May } \\
\text { May } \\
\text { June }\end{array}$ & $\begin{array}{rr}4, & 1952 \\
15, & 1952 \\
7, & 1952\end{array}$ & $\begin{array}{l}3.53 \\
3.43 \\
3.96\end{array}$ & $\begin{array}{l}1,600 \\
1,580 \\
2,280\end{array}$ \\
\hline 1942 & $\begin{array}{l}\text { May } \\
\text { June }\end{array}$ & $\begin{array}{ll}- & \\
26, & 1942 \\
11, & 1942\end{array}$ & $\begin{array}{l}3.8 \\
3.39 \\
3.67\end{array}$ & $\begin{array}{l}1,900 \\
1,350 \\
1,720\end{array}$ & $\begin{array}{l}1953 \\
1954\end{array}$ & $\begin{array}{l}\text { June } \\
\text { May }\end{array}$ & $\begin{array}{l}14,1953 \\
21,1954\end{array}$ & $\begin{array}{l}4.12 \\
3.01\end{array}$ & $\begin{array}{l}2,540 \\
1,260\end{array}$ \\
\hline 1943 & June & 1,1943 & 3.55 & 1,560 & 1955 & $\begin{array}{l}\text { May } \\
\text { June }\end{array}$ & $\begin{array}{rr}22, & 1955 \\
9, & 1955\end{array}$ & $\begin{array}{l}2.77 \\
2.84 \\
\end{array}$ & $\begin{array}{l}1,450 \\
1,550\end{array}$ \\
\hline 1944 & $\begin{array}{l}\text { May } \\
\text { June } \\
\text { June } \\
\text { June }\end{array}$ & $\begin{array}{rr}16, & 1944 \\
2, & 1944 \\
10, & 1944 \\
26, & 1944\end{array}$ & $\begin{array}{l}3.53 \\
3.52 \\
3.38 \\
3.56\end{array}$ & $\begin{array}{l}1,530 \\
1,520 \\
1,340 \\
1,570\end{array}$ & 1956 & $\begin{array}{l}\text { May } \\
\text { June }\end{array}$ & $\begin{array}{rr}23, & 1956 \\
2, & 1956\end{array}$ & $\begin{array}{l}3.39 \\
3.55\end{array}$ & $\begin{array}{l}1,770 \\
1,940\end{array}$ \\
\hline 1945 & June & 22,1945 & 3.26 & 1,200 & 1957 & $\begin{array}{l}\text { June } \\
\text { June }\end{array}$ & $\begin{array}{rr}7, & 1957 \\
28, & 1957\end{array}$ & $\begin{array}{l}3.93 \\
3.63\end{array}$ & $\begin{array}{l}2,560 \\
1,600\end{array}$ \\
\hline 1946 & June & 6,1946 & 3.42 & 1,460 & 1958 & $\begin{array}{l}\text { May } \\
\text { June }\end{array}$ & $\begin{array}{r}27,1958 \\
7,1958\end{array}$ & $\begin{array}{l}3.57 \\
3.41\end{array}$ & $\begin{array}{l}1,740 \\
1,370\end{array}$ \\
\hline 1947 & $\begin{array}{l}\text { May } \\
\text { June }\end{array}$ & $\begin{array}{ll}8, & 1947 \\
8, & 1947\end{array}$ & $\begin{array}{l}3.38 \\
3.27\end{array}$ & $\begin{array}{l}1,340 \\
1,210\end{array}$ & 1959 & $\begin{array}{l}\text { June } \\
\text { June }\end{array}$ & $\begin{array}{rr}8, & 1959 \\
16, & 1959\end{array}$ & $\begin{array}{l}3.22 \\
3.17\end{array}$ & $\begin{array}{l}1,240 \\
1,290\end{array}$ \\
\hline 1948 & $\begin{array}{l}\text { May } \\
\text { June }\end{array}$ & 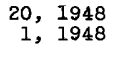 & $\begin{array}{l}3.76 \\
3.70\end{array}$ & $\begin{array}{l}1,890 \\
1,800\end{array}$ & 1960 & June & 3,1960 & 3.14 & 1,350 \\
\hline 1949 & $\begin{array}{l}\text { May } \\
\text { June }\end{array}$ & $\begin{array}{ll}29, & 1949 \\
13, & 1949\end{array}$ & $\begin{array}{l}3.46 \\
3.68\end{array}$ & $\begin{array}{l}1,470 \\
1,760\end{array}$ & 1961 & May & 28,1961 & & 862 \\
\hline 1950 & $\begin{array}{l}\text { June } \\
\text { June } \\
\text { June }\end{array}$ & $\begin{array}{rr}1, & 1950 \\
7, & 1950 \\
22, & 1950\end{array}$ & $\begin{array}{l}4.07 \\
3.87 \\
3.92\end{array}$ & $\begin{array}{l}2,140 \\
1,820 \\
2,000\end{array}$ & 1962 & $\begin{array}{l}\text { June } \\
\text { June }\end{array}$ & $\begin{array}{ll}10, & 1902 \\
14, & 1962 \\
21, & 1962\end{array}$ & $\begin{array}{l}3.05 \\
3.35 \\
3.42\end{array}$ & $\begin{array}{l}1,250 \\
I, 490 \\
I, 560\end{array}$ \\
\hline 1951 & May & 29,1951 & 4.24 & 2,510 & 1963 & May & 23,1963 & 2.84 & 1,140 \\
\hline
\end{tabular}

1293. Weber River near Peoa, Utah

Location.--Iat $40^{\circ} 45^{\prime} 10^{\prime \prime}$, long $111^{\circ} 22^{\prime} 20^{\prime \prime}$, in SE $\frac{1}{4} N W^{\frac{1}{4}}$ sec.10, T.I S., R.5 E., on left bank $60 \mathrm{ft}$ downstream from bridge on U.S. Highway 189, 2.4 miles north of Peoa, and 3.2 miles upstream from Wanship Dam.

Drainage area. $--285 \mathrm{sq} \mathrm{mi}$, approximately.

Gage.--Recording and concrete control. Altitude of gage is $6,050 \mathrm{ft}^{\prime}$ ( $\mathrm{f}^{\text {rom }}$ Bureau of Reclamation Rockport Reservoir map).

Stage-discharge relation.--Defined by current-meter measurements below 1,800 cfs.

Remarks.--Records do not include water diverted from Weber River basin through Weber-Provo diversion canal. Only annual peaks are shown.

Peak stages and discharges

\begin{tabular}{|c|c|c|c|c|c|c|c|}
\hline $\begin{array}{l}\text { Water } \\
\text { year }\end{array}$ & Date & $\begin{array}{l}\text { Gagge } \\
\text { height } \\
\text { (feet) }\end{array}$ & $\begin{array}{c}\text { Discharge } \\
\text { (cfs) }\end{array}$ & $\begin{array}{l}\text { Water } \\
\text { year }\end{array}$ & Date & $\begin{array}{c}\text { Gage } \\
\text { he1ght } \\
\text { (feet) }\end{array}$ & $\begin{array}{c}\text { Discharge } \\
\text { (cfs) }\end{array}$ \\
\hline $\begin{array}{l}1957 \\
1958 \\
1959 \\
1960 \\
\end{array}$ & $\begin{array}{lrl}\text { June } 7, & 1957 \\
\text { June } 8, & 1958 \\
\text { June } 16, & 1959 \\
\text { June } 2, & 1960\end{array}$ & $\begin{array}{l}3.37 \\
3.17 \\
3.18 \\
2.87 \\
\end{array}$ & $\begin{array}{r}2,110 \\
1,230 \\
1,250 \\
932\end{array}$ & $\begin{array}{l}1961 \\
1962 \\
1963\end{array}$ & $\begin{array}{l}\text { Mar. } 15,1961 \\
\text { Feb. 11, } 1962 \\
\text { May } 30,1963\end{array}$ & $\begin{array}{l}2.59 \\
3.25 \\
2.86\end{array}$ & $\begin{array}{r}579 \\
1,350 \\
813\end{array}$ \\
\hline
\end{tabular}


1295. Weber River near Wanship, Utah

Location.--Lat $40^{\circ} 47^{\prime} 30^{\prime \prime}$, long $111^{\circ} 24^{\prime} 1^{\prime \prime}$, in center sec.29, T.I N., R.5 E., on left bank 1.2 miles south of Wanship and $1 \frac{1}{4}$ miles upstream from Silver Creek.

Drainage area. $--320 \mathrm{sq} \mathrm{mi}$, approximately.

Gage---Recording. Alt1tude of gage is 5,900 ft (from topographic map).

Stage-discharge relation.--Defined by current-meter measurements.

Remarks.--Many diversions above station for irrigation. Records do not include water diverted from Weber River basin through Weber-Provo diversion canal.

Flow regulated by Rockport Reservoir, formed by Wanship dam, completed in

1957 (usable capacity, 60,000 acre-ft). Base for partial-duration series, $1,200 \mathrm{cfs}$.

\begin{tabular}{|c|c|c|c|c|c|c|c|c|}
\hline $\begin{array}{l}\text { Water } \\
\text { year }\end{array}$ & & Date & $\begin{array}{c}\text { Gage } \\
\text { helght } \\
\text { (feet) }\end{array}$ & $\begin{array}{c}\text { Discharge } \\
\text { (cfs) }\end{array}$ & $\begin{array}{l}\text { Water } \\
\text { year }\end{array}$ & Date & $\begin{array}{c}\text { Gage } \\
\text { height } \\
\text { (feet) }\end{array}$ & $\begin{array}{c}\text { Discharge } \\
(\mathrm{cfs})\end{array}$ \\
\hline 1951 & $\begin{array}{l}\text { May } \\
\text { June }\end{array}$ & $\begin{array}{ll}30, & 1951 \\
17, & 1951\end{array}$ & $\begin{array}{l}4.73 \\
4.07\end{array}$ & $\begin{array}{l}2,340 \\
1,550\end{array}$ & $\begin{array}{l}1954 \\
1955 \\
\end{array}$ & \multirow{3}{*}{$\begin{array}{lll}\text { May } 22, & 1954 \\
\text { May } 23, & 1955 \\
\text { July } 3, & 1957 \\
\text { Apr.15 } & -18,1958\end{array}$} & \multirow{3}{*}{$\begin{array}{l}3.64 \\
4.13 \\
2.69 \\
2.90\end{array}$} & \multirow{3}{*}{$\begin{array}{r}1,280 \\
1,320 \\
\text { a578 } \\
749\end{array}$} \\
\hline 1952 & $\begin{array}{l}\text { May } \\
\text { May } \\
\text { May } \\
\text { June }\end{array}$ & $\begin{array}{rr}5, & 1952 \\
15, & 1952 \\
21, & 1952 \\
7, & 1952\end{array}$ & $\begin{array}{l}4.71 \\
4.15 \\
3.95 \\
4.47\end{array}$ & $\begin{array}{l}2,240 \\
1,800 \\
1,600 \\
2,100\end{array}$ & $\begin{array}{l}1957 \\
1958\end{array}$ & & & \\
\hline 1953 & June & 14,1953 & 4.20 & 1,830 & & & & \\
\hline
\end{tabular}

a Maximum during period April to September.

1300. Silver Creek near Wanship, Utah

Location.--Lat $40^{\circ} 45^{\prime} 25^{\prime \prime}$, long $111^{\circ} 28^{\prime} 15^{\prime \prime}$, in SW $\frac{1}{4} S_{1} \frac{1}{4}$ sec. 2 , T.1 S., R.4 E., $1.3 \mathrm{miles}$ upstream from Tollgate Canyon, 5 miles southwest of Wanship, and $5 \frac{3}{4}$ miles upstream from mouth.

Drainage area. $--28 \mathrm{sq} \mathrm{ml}$, approximately. Mean altitude, 7,100 ft.

Gage.--Recording. Altitude of gage is 6,400 ft (from topographic map).

Stage-discharge relation.--Defined by current-meter measurements below $150 \mathrm{cfs}$. Considerable shif'ing at most stages.

Remarks.--Only annual peaks are shown.

Peak stages and discharges

\begin{tabular}{|c|c|c|c|c|c|c|c|}
\hline $\begin{array}{l}\text { Water } \\
\text { year }\end{array}$ & Date & $\begin{array}{c}\text { Gage } \\
\text { helght } \\
\text { (feet) }\end{array}$ & $\begin{array}{c}\text { Discharge } \\
\text { (cfs) }\end{array}$ & $\begin{array}{l}\text { Water } \\
\text { year }\end{array}$ & Date & $\begin{array}{c}\text { Gige } \\
\text { helght } \\
\text { (feet) }\end{array}$ & $\begin{array}{c}\text { Discharge } \\
\text { (cfs) }\end{array}$ \\
\hline $\begin{array}{l}1942 \\
1943 \\
1944\end{array}$ & $\begin{array}{l}\text { Apr. } 4,1942 \\
\text { Mar. } 28,1943 \\
\text { Apr. } 4,1944\end{array}$ & $\begin{array}{l}4.28 \\
3.56 \\
3.76\end{array}$ & $\begin{array}{l}430 \\
272 \\
334\end{array}$ & $\begin{array}{l}1945 \\
1946 \\
\end{array}$ & $\begin{array}{l}\text { Apr. 19, } 1945 \\
\text { Mar. } 30,1946\end{array}$ & $\begin{array}{l}2.75 \\
2.80 \\
\end{array}$ & $\begin{array}{l}134 \\
134 \\
\end{array}$ \\
\hline
\end{tabular}

1305. Weber River near Coalville, Utah

Location.--Lat $40^{\circ} 53^{\prime} 40^{\prime \prime}$, long $111^{\circ} 24^{\prime} 00^{\prime \prime}$, in SE $\frac{1}{4} \mathrm{NE} \frac{1}{4}$ sec.20, T.2 N., R.5 E., on left bank $1 \frac{1}{2}$ miles upstream from high-water line of Echo Re servolr,

$1 \frac{1}{2}$ miles south of Coalville, and 6 miles downstream from Silver Creek.

Drainage area. $--438 \mathrm{sq} \mathrm{mi}$.

Gage.--Nonrecording prior to Mar. 22, 1931, at different site and datum; recording thereafter. Mar. 22, 1931, to Sept. 30, 1952, at datum 1 ft higher. Altitude of gage is $5,600 \mathrm{ft}$ (from topographic map).

Stage-discharge relation.--Defined by current-meter measurements.

Remarks.--Many diversions above station for irrigation. No diversion between station and Echo Reservoir. Flow slightly regulated by several small reservoirs above station, and since Apr. 1, 1957, by Rockport Resorvoir (usual capacity 60,000 acre-ft). Only annual peaks are shown (maximun observed prior to 1931 ). 
Peak stages and discharges of Weber River near Coalville, Utah

\begin{tabular}{|c|c|c|c|c|c|c|c|c|c|}
\hline $\begin{array}{l}\text { Water } \\
\text { year }\end{array}$ & & Date & $\begin{array}{c}\text { Gage } \\
\text { helght } \\
\text { (feet) }\end{array}$ & $\begin{array}{c}\text { Discharge } \\
(\text { cIs })\end{array}$ & $\begin{array}{c}\text { Water } \\
\text { year }\end{array}$ & & Date & $\begin{array}{c}\text { Gage } \\
\text { helght } \\
\text { (feet) }\end{array}$ & $\begin{array}{c}\text { Discharge } \\
\text { (cIs) }\end{array}$ \\
\hline $\begin{array}{l}1927 \\
1928 \\
1929 \\
1930\end{array}$ & $\begin{array}{l}\text { June } \\
\text { May } \\
\text { June } \\
\text { May } \\
\end{array}$ & $\begin{array}{ll}10, & 1927 \\
29, & 1928 \\
17, & 1929 \\
30, & 1930 \\
\end{array}$ & $\begin{array}{l}4.00 \\
4.10 \\
4.30 \\
3.16 \\
\end{array}$ & $\begin{array}{l}1,580 \\
1,650 \\
1,960 \\
1,170 \\
\end{array}$ & $\begin{array}{l}1946 \\
1947 \\
1948 \\
1949 \\
1950\end{array}$ & \multicolumn{2}{|c|}{$\begin{array}{lrr}\text { Apr. } & 27, & 1946 \\
\text { May } 8, & 1947 \\
\text { May } & 20,1948 \\
\text { June } & 13, & 1949 \\
\text { June } & 2, & 1950\end{array}$} & $\begin{array}{l}2.83 \\
3.85 \\
4.14 \\
3.87 \\
3.98\end{array}$ & $\begin{array}{r}781 \\
1,320 \\
1,610 \\
1,450 \\
1,690\end{array}$ \\
\hline $\begin{array}{l}1931 \\
1932 \\
1933 \\
1934 \\
1935\end{array}$ & $\begin{array}{l}\text { May } \\
\text { May } \\
\text { June } \\
\text { May } \\
\text { June }\end{array}$ & $\begin{array}{r}17,1931 \\
22,1932 \\
14,1933 \\
9,1934 \\
13,1935\end{array}$ & $\begin{array}{l}2.32 \\
4.00 \\
3.86 \\
2.00 \\
4.23\end{array}$ & $\begin{array}{r}649 \\
1,780 \\
1,670 \\
490 \\
1,800\end{array}$ & $\begin{array}{l}1951 \\
1952 \\
1953 \\
1954 \\
1955\end{array}$ & $\begin{array}{l}\text { May } \\
\text { May } \\
\text { June } \\
\text { May } \\
\text { May }\end{array}$ & $\begin{array}{rr}29, & 1951 \\
6, & 1952 \\
14, & 1953 \\
22, & 1954 \\
24, & 1955\end{array}$ & $\begin{array}{l}4.08 \\
3.59 \\
4.36 \\
3.82 \\
3.36\end{array}$ & $\begin{array}{r}2,110 \\
2,190 \\
1,510 \\
1,200 \\
956\end{array}$ \\
\hline $\begin{array}{l}1936 \\
1937 \\
1938 \\
1939 \\
1940\end{array}$ & $\begin{array}{l}\text { May } \\
\text { May } \\
\text { June } \\
\text { Mar. } \\
\text { May }\end{array}$ & $\begin{aligned} 15, & 1936 \\
30, & 1937 \\
6, & 1938 \\
22, & 1939 \\
17, & 1940\end{aligned}$ & $\begin{array}{l}4.15 \\
4.15 \\
4.18 \\
3.43 \\
3.18\end{array}$ & $\begin{array}{r}1,740 \\
1,740 \\
1,660 \\
1,170 \\
988\end{array}$ & $\begin{array}{l}1956 \\
1957 \\
1958 \\
1959 \\
1960\end{array}$ & $\begin{array}{l}\text { May } \\
\text { Oct. } \\
\text { Apr. } \\
\text { June } \\
\text { June }\end{array}$ & 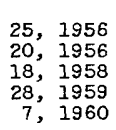 & $\begin{array}{l}3.78 \\
3.38 \\
3.29 \\
2.80 \\
2.34\end{array}$ & $\begin{array}{r}1,180 \\
960 \\
930 \\
708 \\
458\end{array}$ \\
\hline $\begin{array}{l}1941 \\
1942 \\
1943 \\
1944 \\
1945 \\
\end{array}$ & $\begin{array}{l}\text { June } \\
\text { May } \\
\text { June } \\
\text { June } \\
\text { May } \\
\end{array}$ & $\begin{array}{rr}10, & 1941 \\
27, & 1942 \\
2, & 1943 \\
3, & 1944 \\
12, & 1945 \\
\end{array}$ & $\begin{array}{l}4.07 \\
3.82 \\
4.08 \\
4.17 \\
2.88 \\
\end{array}$ & $\begin{array}{r}1,560 \\
1,380 \\
1,720 \\
1,630 \\
792 \\
\end{array}$ & $\begin{array}{l}1961 \\
1962 \\
1963\end{array}$ & $\begin{array}{l}\text { June } \\
\text { July } \\
\text { Feb. }\end{array}$ & $\begin{array}{rr}23, & 1961 \\
1, & 1962 \\
1, & 1963\end{array}$ & $\begin{array}{l}1.89 \\
2.98 \\
2.17\end{array}$ & $\begin{array}{l}284 \\
725 \\
390\end{array}$ \\
\hline
\end{tabular}

1310. Chalk Creek at Coalville, Utah

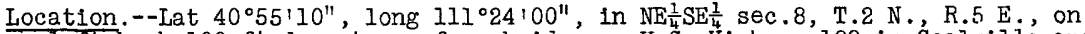
left bank $100 \mathrm{ft}$ downstream from bridge on U.S. Highway 189 in Coalville and a third of a mile upstream from mouth.

Drainage area. $--253 \mathrm{sq} \mathrm{mi}$, Mean altitude, 7,540 ft.

Gage.--Nonrecording prior to Feb. 13, 1931, at site $100 \mathrm{ft}$ upstream at different datum; recording thereafter. Feb. 13, 1931, to oct. 15, 1941, at site $300 \mathrm{ft}$ upstream at different datum. Datum of gage is $5,560.6 \mathrm{ft}$ above mean sea level, datum of 1929.

Stage-discharge relation.--Defined by current-meter measurements below 1,300 cf's.

Remarks.--Base for partial-duration series, $400 \mathrm{cfs}$. Only annual peaks are shown prior to 1932 .

Peak stages and discharges

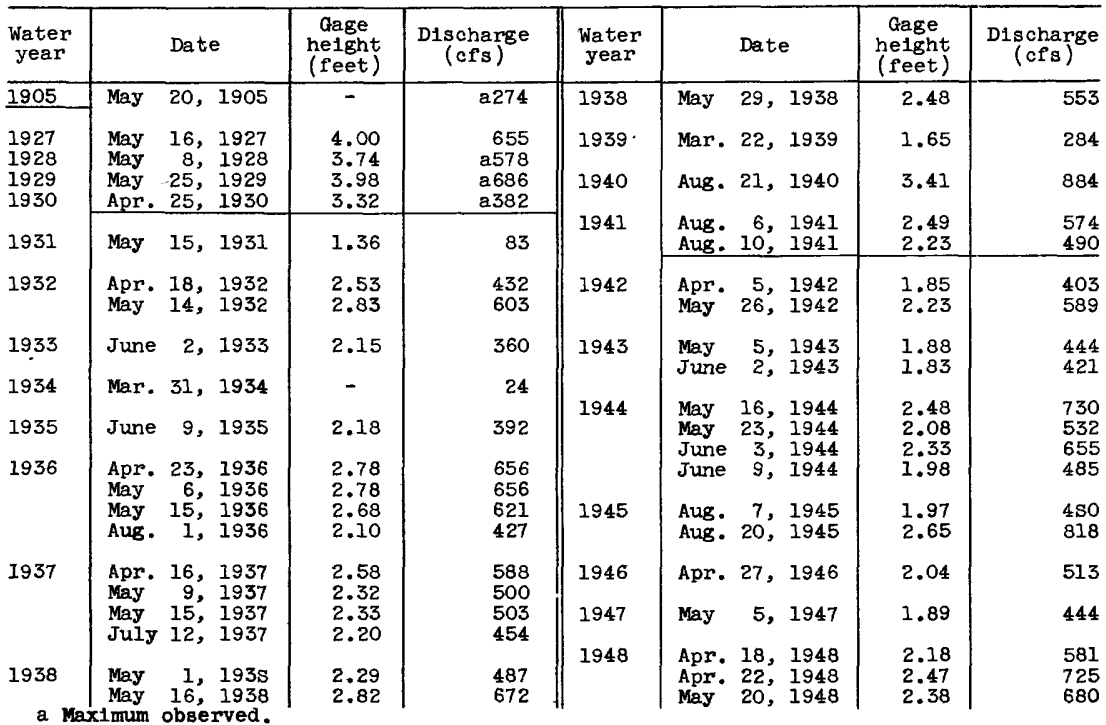


Peak stages and discharges of Chalk Creek at Coalville, Utah--'ontinued

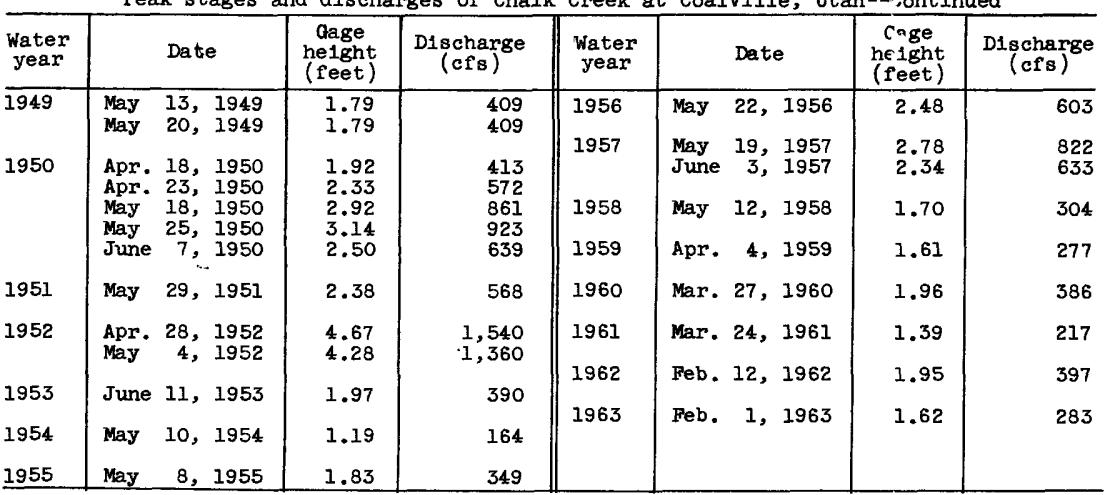

1320. Weber River at Echo, Utah

Location.--Lat $40^{\circ} 57^{\prime} 5^{\prime \prime}$, long $111^{\circ} 26^{\prime} 10^{\prime \prime}$, in SE $\frac{1}{4} \mathrm{NE} \frac{1}{4} \sec .25$, T. 3 N., R.4 E., on right bank a quarter of a mile downstream from Echo Dam, half a mile up-

stream from Echo Creek, and three-quarters of a mile southeast of Echo.

Drainage area. $--732 \mathrm{sq} \mathrm{mi}$.

Gage.-Nonrecording prior to Apr. 18, 1931, at site a quarter of a mile down-

stream at different datum; recording thereafter. Apr. 18, 1931, to Mar. 23,

1950 , at site 0.3 mile downstream at different datum. Altituile of gage is

5,440 ft (from Echo Reservoir elevations).

Stage-discharge relation.--Defined by current-meter measurements.

Remarks.--Many diversions above and below station for irrigation. Flow regulated by Echo Reservoir. Only annual peaks are shown.

Peak stages and discharges

\begin{tabular}{|c|c|c|c|c|c|c|c|}
\hline $\begin{array}{l}\text { Water } \\
\text { year }\end{array}$ & Date & $\begin{array}{l}\text { Gage } \\
\text { height } \\
\text { (feet) }\end{array}$ & $\begin{array}{c}\text { Discharge } \\
\text { (cfs) }\end{array}$ & $\begin{array}{l}\text { Water } \\
\text { year }\end{array}$ & Date & $\begin{array}{l}\text { Gage } \\
\text { height } \\
\text { (feet) }\end{array}$ & $\begin{array}{c}\text { Discharge } \\
\text { (cfs) }\end{array}$ \\
\hline $\begin{array}{l}1927 \\
1925 \\
1929 \\
1930\end{array}$ & $\begin{array}{lll}\text { May } & 17, & 1927 \\
\text { May } & 29,1928 \\
\text { May } & 21,1929 \\
\text { June } & 12,1930 \\
\end{array}$ & $\begin{array}{l}- \\
- \\
-\end{array}$ & $\begin{array}{r}2,410 \\
a 2,090 \\
a 2,300 \\
1,080\end{array}$ & $\begin{array}{l}1943 \\
1944 \\
1945\end{array}$ & $\begin{array}{l}\text { June } 2,1943 \\
\text { June } 2,3,1944 \\
\text { June } 10,1945\end{array}$ & $\begin{array}{l}6.12 \\
6.17 \\
3.60\end{array}$ & $\begin{array}{r}2,370 \\
2,290 \\
680\end{array}$ \\
\hline $\begin{array}{l}1931 \\
1932 \\
1933 \\
1934 \\
1935\end{array}$ & $\begin{array}{l}\text { May } 19,20,1931 \\
\text { May } 22,1932 \\
\text { June } 10,1933 \\
\text { Apr. } 22,1934 \\
\text { June } 5,1935\end{array}$ & $\begin{array}{l}- \\
5.20 \\
4.71 \\
2.66 \\
5.60\end{array}$ & $\begin{array}{r}437 \\
1,870 \\
1,530 \\
391 \\
2,100\end{array}$ & $\begin{array}{l}1946 \\
1947 \\
1948 \\
1949 \\
1950\end{array}$ & $\begin{array}{l}\text { Apr. } 27,1946 \\
\text { May } 9,10,1947 \\
\text { May } 21,1948 \\
\text { June } 14,1949 \\
\text { May } 26,1950\end{array}$ & $\begin{array}{l}4.30 \\
5.10 \\
5.91 \\
5.43 \\
6.96\end{array}$ & $\begin{array}{l}1,060 \\
1,600 \\
2,140 \\
1,740 \\
2,580\end{array}$ \\
\hline $\begin{array}{l}1936 \\
1937 \\
1935 \\
1939 \\
1940\end{array}$ & $\begin{array}{l}\text { June } 1,1936 \\
\text { May } 30,31,1937 \\
\text { May } 29,30,1938 \\
\text { May } 10,1939 \\
\text { May } 24-26,1940\end{array}$ & $\begin{array}{l}5.00 \\
5.83 \\
5.60 \\
3.49 \\
3.15\end{array}$ & $\begin{array}{r}1,730 \\
2,330 \\
2,090 \\
705 \\
548\end{array}$ & $\begin{array}{l}1951 \\
1952 \\
1953 \\
1954 \\
1955\end{array}$ & $\begin{array}{lll}\text { May } & 30, & 1951 \\
\text { May } 13, & 1952 \\
\text { June } & 15, & 1953 \\
\text { May } 20, & 1954 \\
\text { July } 9, & 1955\end{array}$ & $\begin{array}{l}6.54 \\
7.34 \\
6.01 \\
3.92 \\
4.07\end{array}$ & $\begin{array}{r}2,220 \\
3,060 \\
1,870 \\
613 \\
691\end{array}$ \\
\hline $\begin{array}{l}1941 \\
1942\end{array}$ & $\begin{array}{l}\text { June } 16,17,1941 \\
\text { May } 27 \text { to June } 3 \text {, } \\
1942\end{array}$ & $\begin{array}{r}3.92 \\
b 5.15\end{array}$ & $\begin{array}{r}922 \\
1,560\end{array}$ & $\begin{array}{l}1956 \\
1957 \\
1958\end{array}$ & $\begin{array}{l}\text { May 25, 26, } 1956 \\
\text { July 21, } 1957 \\
\text { Apr. 15, } 1958\end{array}$ & $\begin{array}{l}5.74 \\
4.52 \\
4.62\end{array}$ & $\begin{array}{r}1,620 \\
695 \\
822\end{array}$ \\
\hline
\end{tabular}

a Maximum observed.

b Peak stage occurred May 27. 
1325. Lost Creek near Croydon, Utah

Location.--Lat $41^{\circ} 10^{\prime} 35^{\prime \prime}$, long $111^{\circ} 24^{\prime} 20^{\prime \prime}$, In SW $\frac{1}{4} \mathrm{SE} \frac{1}{4}$ sec.8, T.5 N., R.5 E., on right bank $0.8 \mathrm{mile}$ downstream from Francis Fork, 1.6 miles upstream from Hell Canyon, and $9 \frac{1}{2}$ miles northeast of Croydon.

Drainage area. $--133 \mathrm{sq} \mathrm{ml}$. Mean altitude, 7,320 ft.

Gage.--Recording. Prior to Aug. 26, 1954, at several sites within $40 f^{\prime}$; of present site at various datums. Altitude of gage is $5,820 \mathrm{ft}$ (by barometer).

Stage-discharge relation.--Defined by current-meter measurements below $300 \mathrm{cfs}$. Considerable shlfiting at all stages.

Remarks.--Base for partial-duration series, $130 \mathrm{cfs}$. Only annual peaks are shown prior to 1948 .

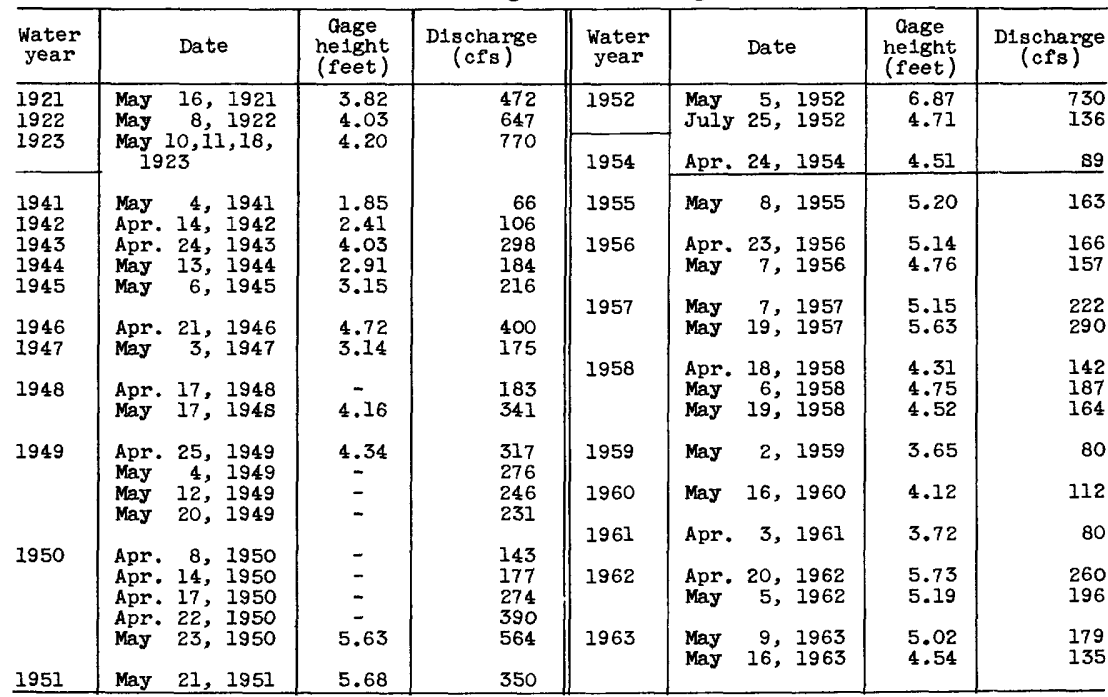

1330. Lost Creek at Devils Slide, Utah

(Published as "near Croydon" 1905; records not equivalent to those for station "near Croydon" 1921-23, 1941-50)

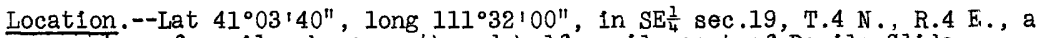
quarter of a mile above mouth and half a mile east of Devils Slide.

Drainage area. $--228 \mathrm{sq} \mathrm{mi}$.

Gage.--Nonrecording prior to December 1905, at site about 1,200 ft dowrstream at different datum; recording thereafter.

Stage-discharge relation.--Defined by current-meter measurements below $700 \mathrm{cfs}$.

Remarks.--Practically all flow diverted above gage during late irrigation season. Only annual peaks are shown.

Peak stages and discharges

\begin{tabular}{|c|c|c|c|c|c|c|c|c|}
\hline $\begin{array}{l}\text { Water } \\
\text { year }\end{array}$ & Date & $\begin{array}{l}\text { Cage } \\
\text { helght } \\
\text { (feet) }\end{array}$ & $\begin{array}{l}\text { Discharge } \\
(\mathrm{cfs})\end{array}$ & $\begin{array}{l}\text { Water } \\
\text { year }\end{array}$ & \multicolumn{2}{|r|}{ Date } & $\begin{array}{l}\text { Gage } \\
\text { neight } \\
\text { (feet) }\end{array}$ & $\begin{array}{c}\text { Discharge } \\
\text { (cfs) }\end{array}$ \\
\hline 1905 & 2,1905 & 3.50 & al81 & \multirow{4}{*}{$\begin{array}{l}1927 \\
1928 \\
1929 \\
1930 \\
1931 \\
1932 \\
1933 \\
\end{array}$} & \multirow{4}{*}{$\begin{array}{l}\text { May } \\
\text { May } \\
\text { May } \\
\text { Apr. } \\
\text { May } \\
\text { May } \\
\text { May } \\
\end{array}$} & \multirow{4}{*}{$\begin{array}{r}1,1927 \\
2,1928 \\
15,1929 \\
23,1930 \\
8,1931 \\
14,1932 \\
22,1933\end{array}$} & \multirow{4}{*}{$\begin{array}{l}3.38 \\
3.64 \\
3.09 \\
1.73 \\
1.10 \\
3.70 \\
3.37 \\
\end{array}$} & \multirow{4}{*}{$\begin{array}{r}810 \\
975 \\
719 \\
186 \\
54 \\
765 \\
650\end{array}$} \\
\hline $\begin{array}{l}1921 \\
1922 \\
1923\end{array}$ & $\begin{array}{l}\text { May } 17,1921 \\
\text { May } 8,1922 \\
\text { May } 11,1923\end{array}$ & $\begin{array}{l}4.05 \\
4.26 \\
4.39\end{array}$ & $\begin{array}{l}1,040 \\
1,190 \\
1,390\end{array}$ & & & & & \\
\hline $\begin{array}{l}1924 \\
1925\end{array}$ & $\begin{array}{ll}\text { May } & 5,1924 \\
\text { May } & 7,1925\end{array}$ & $\begin{array}{l}2.30 \\
2.28\end{array}$ & $\begin{array}{l}335 \\
325\end{array}$ & & & & & \\
\hline 1926 & Apr. $21,22,1926$ & 2.14 & 277 & & & & & \\
\hline
\end{tabular}

a Maximum observed. 
1335. Weber River at Devils Slide, Utah

(Published as "near Croydon" 1905-8)

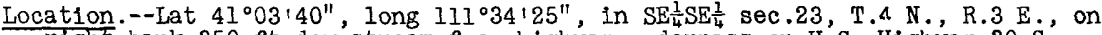
right bank $350 \mathrm{ft}$ downstream from highway underpass on U.S. Highway $30 \mathrm{~S}$

$I \frac{1}{2}$ miles west of Devils Slide, and $1 \frac{3}{4}$ miles downstream from Lost Creek.

Drainage area. $--1,100 \mathrm{sq} \mathrm{mi}$, approximately.

Gage.--Nonrecording prior to 0ct. 1,1934 , at site $1 \frac{1}{2}$ miles upstream at dif-

ferent datum; recording thereafter. Altitude of gage is $5,300 \mathrm{ft}$.

Stage-discharge relation.--Defined by current-meter measurements below 4,700

cfs. Fairly stable at all stages.

Remarks.--Many diversions, above station for irrigation. Flow regulated by Echo Reservoir. Only annual peaks are shown (maximum observed 19(5-19, 1921-33).

Peak stages and discharges

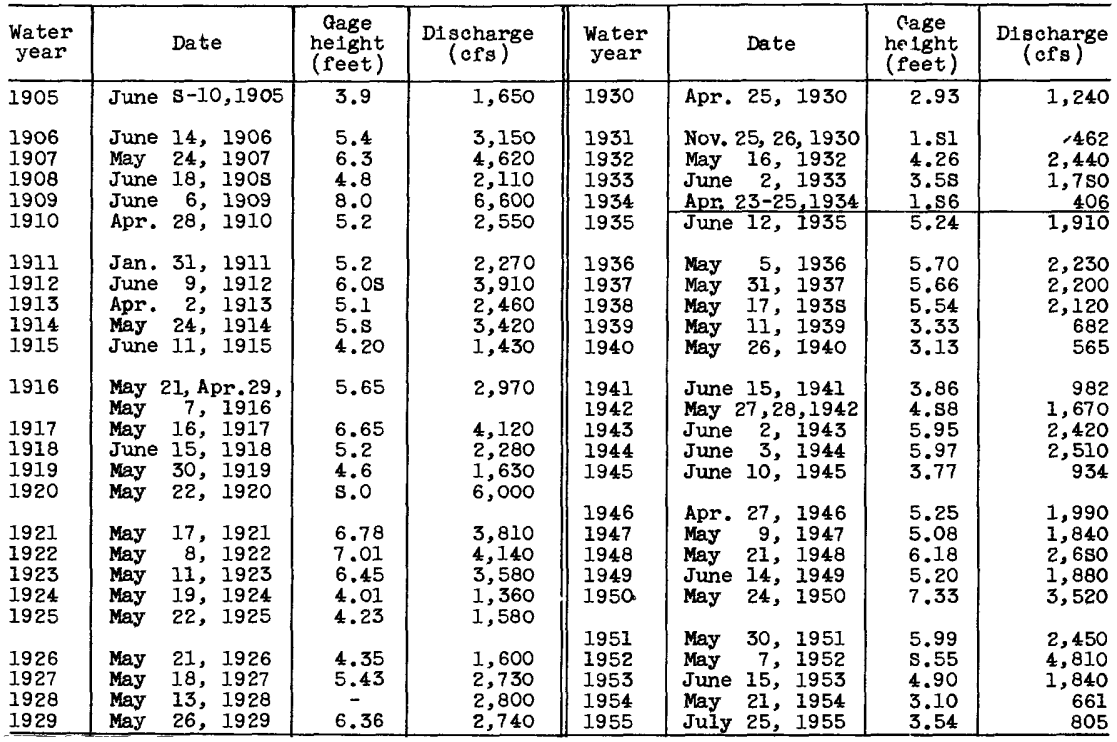

1345. East Canyon Creek near Morgan, Utah

Location.--Lat $40^{\circ} 55^{\prime} 20^{\prime \prime}$, long $111^{\circ} 36^{\prime} 20^{\prime \prime}$, in NW $\frac{1}{4} \mathrm{NW} \frac{1}{4} \sec .10$, T.2 N., R.3 E., on right bank 2,500 ft downstream from East Canyon Dam, $2 \frac{1}{2}$ miles upstream from Sheep Canyon, and $9 \mathrm{miles}$ southeast of Morgan.

Drainage area. $--155 \mathrm{sq} \mathrm{mi}$, approximately.

Gage.--Recording gage and Lyman rectangular weir. Altitude of gege is $5,460 \mathrm{ft}$ (from river-profile map).

Stage-discharge relation.--Defined by current-meter measurements below $600 \mathrm{cfs}$.

Remarks.--East Canyon Reservoir completely regulates flow. Only annual peaks are shown (maximum daily prior to 1952). 
Peak stages and discharges of East Canyon Creek near Morgan, Utah

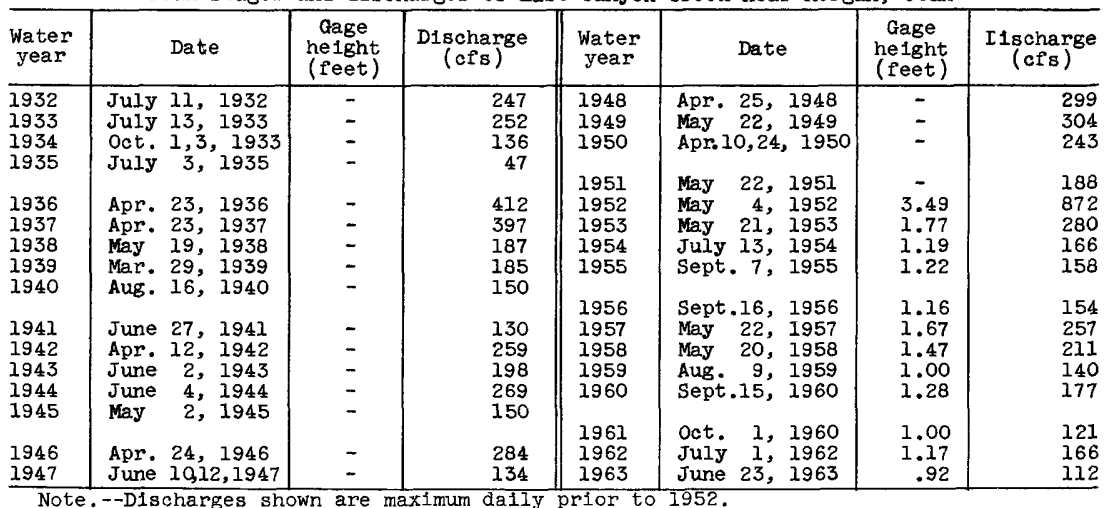

Note.-Discharges shown are maximum daily prior to 1952 .

\section{Hardscrabble Creek near Porterville, Utah}

Location.--Lat $40^{\circ} 57^{\prime} 10^{\prime \prime}$, Iong $111^{\circ} 43^{\prime} 00^{\prime \prime}$, in SW $\frac{1}{4} \mathrm{NW} \frac{1}{4} \sec .34$, T.3 N., R. 2 E., on right bank two-thirds of a mile upstream from Tucker Hollow and $2 \frac{3}{4}$ miles southwest of Porterville.

Dralnage area. $--28.1 \mathrm{sq} \mathrm{mi}$. Mean altitude, 7,220 ft.

Gage.--Recording. Altitude of gage is 5,500 ft (from topographic map).

Stage-discharge relation.--Defined by current-meter measurements below $350 \mathrm{cfs}$.

Remarks.--Base for partial-duration series, $220 \mathrm{cfs.} \mathrm{Only} \mathrm{annual} \mathrm{peaks} \mathrm{are}$ shown prior to 1948 .

Peak stages and discharges

\begin{tabular}{|c|c|c|c|c|c|c|c|c|c|}
\hline $\begin{array}{l}\text { Water } \\
\text { year }\end{array}$ & & Date & $\begin{array}{c}\text { Gage } \\
\text { helght } \\
\text { (feet) }\end{array}$ & $\begin{array}{c}\text { Discharge } \\
\text { (cfs) }\end{array}$ & $\begin{array}{c}\text { Water } \\
\text { year }\end{array}$ & & Date & $\begin{array}{c}\text { Gage } \\
\text { helght } \\
\text { (feet) }\end{array}$ & $\begin{array}{c}\text { Discharge } \\
\text { (cfs) }\end{array}$ \\
\hline $\begin{array}{l}1942 \\
1943 \\
1944 \\
1945\end{array}$ & $\begin{array}{l}\text { May } \\
\text { Apr. } \\
\text { June } \\
\text { Aug. }\end{array}$ & $\begin{array}{rr}25, & 1942 \\
17, & 1943 \\
2, & 1944 \\
20, & 1945\end{array}$ & $\begin{array}{l}3.10 \\
2.64 \\
2.76 \\
3.60\end{array}$ & $\begin{array}{l}311 \\
216 \\
234 \\
464\end{array}$ & 1954 & $\begin{array}{l}\text { Nay } \\
\text { June } \\
\text { Apr. }\end{array}$ & $\begin{array}{ll}20, & 1953 \\
10, & 1953 \\
28, & 1954\end{array}$ & $\begin{array}{l}3.45 \\
3.02 \\
1.91\end{array}$ & $\begin{array}{r}406 \\
290 \\
64\end{array}$ \\
\hline $\begin{array}{l}1946 \\
1947\end{array}$ & $\begin{array}{l}\text { Apr. } \\
\text { May }\end{array}$ & $\begin{array}{rr}26, & 1946 \\
7, & 1947\end{array}$ & $\begin{array}{l}2.83 \\
2.73\end{array}$ & $\begin{array}{l}257 \\
233\end{array}$ & $\begin{array}{l}1955 \\
1956\end{array}$ & $\begin{array}{l}\text { May } \\
\text { Dec. }\end{array}$ & $\begin{array}{l}21,1955 \\
23,1955\end{array}$ & $\begin{array}{l}2.49 \\
2.54\end{array}$ & $\begin{array}{l}149 \\
182\end{array}$ \\
\hline 1948 & $\begin{array}{l}\text { Apr. } \\
\text { May }\end{array}$ & $\begin{array}{l}21,1948 \\
17,1948\end{array}$ & 3.28 & $\begin{array}{l}294 \\
409\end{array}$ & & $\begin{array}{l}\text { May } \\
\text { June }\end{array}$ & $\begin{array}{rr}19, & 1957 \\
5, & 1957\end{array}$ & $\begin{array}{l}2.88 \\
2.85\end{array}$ & $\begin{array}{l}227 \\
234\end{array}$ \\
\hline 1949 & $\begin{array}{l}\text { Apr. } \\
\text { May } \\
\text { May } \\
\text { May }\end{array}$ & $\begin{array}{rr}24, & 1949 \\
3, & 1949 \\
13, & 1949 \\
20, & 1949\end{array}$ & $\begin{array}{l}3.19 \\
- \\
-\end{array}$ & $\begin{array}{l}337 \\
230 \\
254 \\
285\end{array}$ & 1958 & May & $\begin{array}{rr}6, & 1958 \\
22, & 1958\end{array}$ & $\begin{array}{l}3.02 \\
3.12\end{array}$ & $\begin{array}{l}261 \\
320\end{array}$ \\
\hline 1950 & $\begin{array}{l}\text { May } \\
\text { May } \\
\text { May }\end{array}$ & $\begin{array}{ll}18, & 1950 \\
24, & 1950 \\
28, & 1950\end{array}$ & 3.31 & $\begin{array}{l}356 \\
383 \\
288\end{array}$ & $\begin{array}{l}1959 \\
1960\end{array}$ & $\begin{array}{l}\text { May } \\
\text { May }\end{array}$ & $\begin{array}{c}1,1959 \\
12,1960\end{array}$ & $\begin{array}{l}2.31 \\
2.67\end{array}$ & $\begin{array}{r}79 \\
177\end{array}$ \\
\hline 1951 & $\begin{array}{l}\text { May } \\
\text { July }\end{array}$ & $\begin{array}{l}27,1951 \\
28,1951\end{array}$ & $\begin{array}{l}2.88 \\
3.53\end{array}$ & $\begin{array}{l}220 \\
439\end{array}$ & $\begin{array}{l}1961 \\
1962\end{array}$ & $\begin{array}{l}\text { May } \\
\text { May }\end{array}$ & $\begin{array}{l}1,1961 \\
6,1962\end{array}$ & $\begin{array}{l}1.91 \\
2.58\end{array}$ & $\begin{array}{r}40 \\
175\end{array}$ \\
\hline 1952 & May & 4, 1952 & 3.66 & 413 & 1963 & May & 9,1963 & 2.28 & 124 \\
\hline 1953 & Apr. & 28,1953 & 2.79 & 224 & & & & & \\
\hline
\end{tabular}


1355. East Canyon Creek below diversions, near Morgan, Utah

Location.--Lat $41^{\circ} 02^{\prime} 10^{\prime \prime}$, long $111^{\circ} 41^{\prime} 30^{\prime \prime}$, in SW $\frac{1}{4} \sec .35$, T.4 N., R.2 E., on

left bank 1 mile southwest of Morgan and 3 miles upstream from mouth.

Drainage area. $--236 \mathrm{sq} \mathrm{m} 1$, approximately.

Gage.--Recording. Altitude of gage is 5,050 ft (from river-prof:.le map).

Stage-discharge relation.--Defined by current-meter measurements.

Remarks.--Flow regulated by East Canyon Reservolr. Only annual peaks are shown.

\begin{tabular}{|c|c|c|c|c|c|c|c|c|}
\hline $\begin{array}{l}\text { Water } \\
\text { year }\end{array}$ & & Date & $\begin{array}{c}\text { Gage } \\
\text { helght } \\
\text { (feet) }\end{array}$ & $\begin{array}{c}\text { Discharge } \\
\text { (cfs) }\end{array}$ & $\begin{array}{l}\text { Water } \\
\text { year }\end{array}$ & Date & $\begin{array}{c}\text { Gage } \\
\text { hetght } \\
\text { (feet) }\end{array}$ & $\begin{array}{c}\text { Discharge } \\
\text { (cfs) }\end{array}$ \\
\hline $\begin{array}{l}1951 \\
1952 \\
1953 \\
\end{array}$ & $\begin{array}{l}\text { May } \\
\text { May } \\
\text { May } \\
\end{array}$ & $\begin{array}{rr}22, & 1951 \\
8, & 1952 \\
20, & 1953 \\
\end{array}$ & $\begin{array}{l}6.18 \\
9.19 \\
8.0 \mathrm{~S}\end{array}$ & $\begin{array}{l}382 \\
926 \\
724\end{array}$ & $\begin{array}{l}1954 \\
1955\end{array}$ & 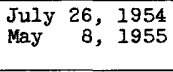 & $\begin{array}{l}3.22 \\
3.26\end{array}$ & $\begin{array}{l}190 \\
206\end{array}$ \\
\hline
\end{tabular}

1360. Weber River near Morgan, Utah

Location. --Lat $41^{\circ} 03^{\prime} 50^{\prime \prime}$, long $111^{\circ} 43^{\prime} 40^{\prime \prime}$, in $\mathrm{NE} \frac{\mathrm{I}}{4} \sec .21$, T.4 N., R.2 E., on right bank $300 \mathrm{ft}$ downstream from Line Creek and $2 \frac{i}{2}$ miles northeast of Morgan.

Drainage area. $--1,500 \mathrm{sq} \mathrm{m} 1$, approximately.

Gage.--Recording. Prior to Dec. 3, 1952 , at site a quarter of a mile upstream at different datum. Altitude of gage is $4,970 \mathrm{ft}$ (by barometer).

Stage-discharge relation.--Defined by current-meter measurements.

Remarks.--Many diversions above and below station for irrigation. Flow regulated by Echo and East Canyon Reservolrs. Only annual peaks are shown.

Peak stages and discharges

\begin{tabular}{|c|c|c|c|c|c|c|c|}
\hline $\begin{array}{l}\text { Water } \\
\text { year }\end{array}$ & Date & $\begin{array}{c}\text { Gage } \\
\text { helght } \\
\text { (feet) }\end{array}$ & $\begin{array}{c}\text { D1scharge } \\
(\mathrm{cfs})\end{array}$ & $\begin{array}{l}\text { Water } \\
\text { year }\end{array}$ & Date & $\begin{array}{c}\text { Cage } \\
\text { height } \\
\text { (feet) }\end{array}$ & $\begin{array}{c}\text { Discharge } \\
\text { (cfs) }\end{array}$ \\
\hline $\begin{array}{l}1951 \\
1952 \\
1953 \\
\end{array}$ & $\begin{array}{lrl}\text { May } & 30, & 1951 \\
\text { May } & 5,2 & 1952 \\
\text { June } & 16, & 1953\end{array}$ & $\begin{array}{r}4.94 \\
- \\
4.72\end{array}$ & $\begin{array}{r}2,640 \\
26,000 \\
2,360\end{array}$ & $\begin{array}{l}1954 \\
1955\end{array}$ & $\begin{array}{lll}\text { May } 21, & 1954 \\
\text { July } & 25, & 1955\end{array}$ & $\begin{array}{l}3.11 \\
3.30\end{array}$ & $\begin{array}{l}607 \\
735\end{array}$ \\
\hline
\end{tabular}

a Maximum daily.

1365. Weber River at Gateway, Utah

(Published as "near Uinta" 1889-1903)

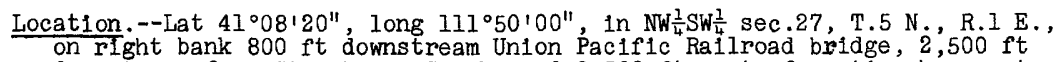
downstream from Strawberry Creek, and 2,500 ft east of section house at Gateway.

Drainage area. $--1,610 \mathrm{sq} \mathrm{m} 1$, approximately.

Gage.--Nonrecording prior to July 12, 1903, at site I mile downstream at different datum; recording thereafter. June 22, 1919, to 0ct. 22, 1929, at site 2,200 ft upstream at different datum. oct. 22, 1929, to oct. 30, 1947, at site $50 \mathrm{ft}$ downstream at datum $0.80 \mathrm{ft}$ higher. 0ct. 31, 1947, to Dec. 9, 1959 , at present site at datum $0.80 \mathrm{ft}^{\prime}$ higher. Altitude of gage is $4,790 \mathrm{ft}$ (by barometer).

Stage-discharge relation.--Defined by current-meter measurements.

Remarks.--Many diversions above and below station for irrigation. Flow regulated by Rockport, Echo, and East Canyon Reservolrs. Only annual peaks are shown (maximum observed prior to 1902). 
Peak stages and discharges of Weber River at Gateway, Utah

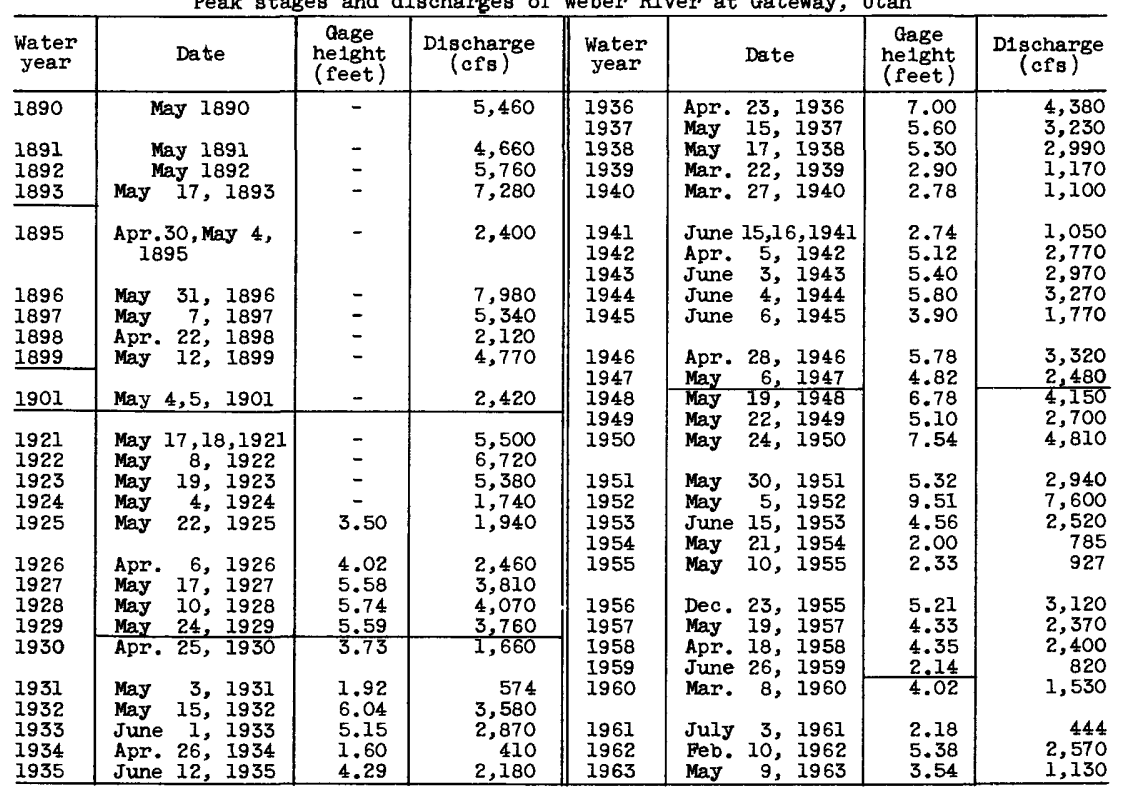

1370. Weber River at Ogden, Dtah

Location.--Lat $41^{\circ} 13^{\prime} 40^{\prime \prime}$, Iong $111^{\circ} 59^{\prime} 15^{\prime \prime}$, in sec. 30 , T.6 N., R.I W., cn right bank $200 \mathrm{ft}$ southeast of intersection of 21 st street and Middleton Foad in Ogden and 1 mile upstream from Ogden River.

Drainage area. $--1,670 \mathrm{sq} \mathrm{mi}$, approximately.

Gage.--Recording. Altitude of gage is 4,270 ft (by barometer).

Stage-discharge relation.--Defined by current-meter measurements.

Remarks.--Many diversions above and below station for irrigation. Flow regulated by Rockport, Echo, and East Canyon Reservolrs. Only annual peaks are shown.

Peak stages and discharges

\begin{tabular}{|c|c|c|c|c|c|c|c|c|}
\hline $\begin{array}{l}\text { Water } \\
\text { year }\end{array}$ & & Date & $\begin{array}{c}\text { Gage } \\
\text { he1ght } \\
\text { (feet) }\end{array}$ & $\begin{array}{c}\text { Discharge } \\
\text { (cfs) }\end{array}$ & $\begin{array}{l}\text { Water } \\
\text { year }\end{array}$ & Date & $\begin{array}{c}\text { Gage } \\
\text { he1ght } \\
\text { (feet) }\end{array}$ & $\begin{array}{c}\text { D1scharge } \\
\text { (cfs) }\end{array}$ \\
\hline $\begin{array}{l}1951 \\
1952 \\
1953 \\
1954 \\
1955\end{array}$ & $\begin{array}{l}\text { May } \\
\text { May } \\
\text { May } \\
\text { Apr. } \\
\text { May }\end{array}$ & $\begin{array}{rr}7, & 1951 \\
6, & 1952 \\
30, & 1953 \\
19, & 1954 \\
7, & 1955\end{array}$ & $\begin{array}{r}6.44 \\
10.89 \\
6.13 \\
3.38 \\
4.20\end{array}$ & $\begin{array}{r}2,340 \\
7,070 \\
2,040 \\
525 \\
\$ 64\end{array}$ & $\begin{array}{l}1956 \\
1957 \\
1958\end{array}$ & $\begin{array}{ll}\text { Dec. } 24, & 1955 \\
\text { May } 20,1957 \\
\text { Apr. } 18,1958\end{array}$ & $\begin{array}{l}6.98 \\
6.65 \\
6.45\end{array}$ & $\begin{array}{l}2,870 \\
2,360 \\
2,320\end{array}$ \\
\hline
\end{tabular}


1375. South Fork Ogden River near Huntsville, Utah

Location.--Lat $41^{\circ} 16^{\prime}$, long $111^{\circ} 40^{\prime}$, in SE $\frac{1}{4}$ sec.12, T.6 N., R.2 E., on right bank half a mile downstream from Magpie Creek, 1 mile upstream from Huntsville Mountain Canal, and $5 \frac{1}{2}$ miles east of Huntsville.

Drainage area. $--148 \mathrm{sq} \mathrm{mi}$. Mean altitude, 7,960 ft.

Gage.--Recording. Prior to Aug. 14, 1934, at site $300 \mathrm{ft}$ upstream at different datum. Altitude of gage is $5,190 \mathrm{ft}$ (by barometer).

Stage-discharge relation.--Defined by current-meter measurements below 1,500

cfs. Falrly stable except at extremely high stage.

Remarks.--Base for partial-duration series, $400 \mathrm{cfs}$. Only annual peaks are shown prior to 1923.

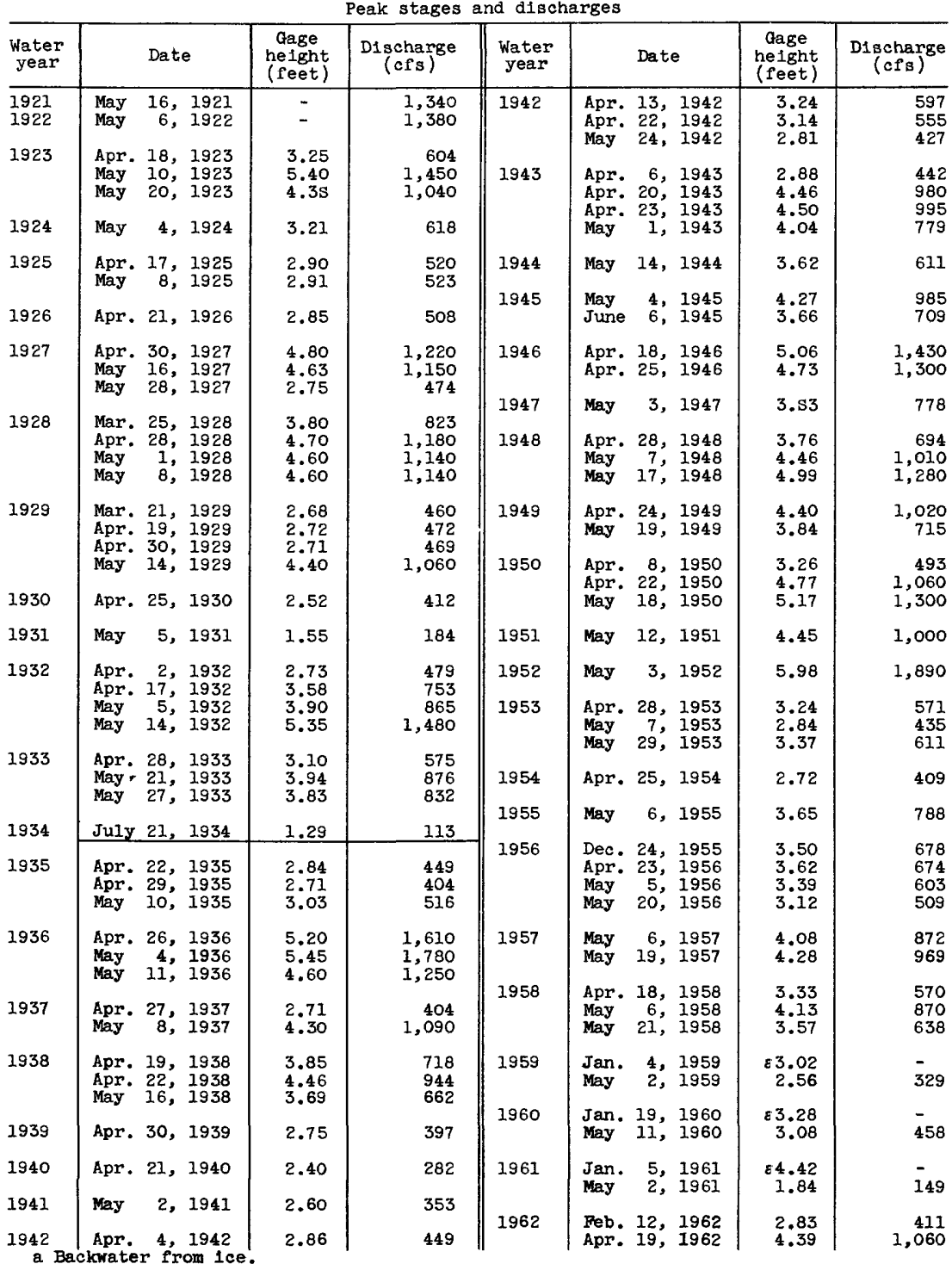




\begin{tabular}{|c|c|c|c|c|c|c|c|c|}
\hline $\begin{array}{l}\text { Water } \\
\text { year }\end{array}$ & Date & $\begin{array}{c}\text { Gage } \\
\text { helght } \\
\text { (feet) }\end{array}$ & $\begin{array}{c}\text { Discharge } \\
\text { (cfs) }\end{array}$ & $\begin{array}{l}\text { Water } \\
\text { year }\end{array}$ & & Date & $\begin{array}{c}\text { Gage } \\
\text { he1ght } \\
\text { (feet) }\end{array}$ & $\begin{array}{c}\text { I.scharge } \\
\text { (cfs) }\end{array}$ \\
\hline 1962 & $\begin{array}{lr}\text { Apr. } 26, & 1962 \\
\text { May } & 6,1962\end{array}$ & $\begin{array}{l}4.13 \\
4.09\end{array}$ & $\begin{array}{l}888 \\
830\end{array}$ & 1963 & $\begin{array}{l}\text { May } \\
\text { May }\end{array}$ & $\begin{array}{rr}9, & 1963 \\
18, & 1963\end{array}$ & $\begin{array}{l}3.76 \\
3.20\end{array}$ & $\begin{array}{l}713 \\
506\end{array}$ \\
\hline 1963 & Mar. 28,1963 & 2.83 & 401 & & & & & \\
\hline
\end{tabular}

1378. Middle Fork Ogden River at Huntsville, Utah

Location.--Lat $41^{\circ} 17^{\prime} 15^{\prime \prime}$, long $111^{\circ} 46^{\prime} 35^{\prime \prime}$, in SE $\frac{1}{4} \mathrm{NE} \frac{1}{4}$ sec.1, T.6 N., R.1 E., on left bank $20 \mathrm{ft}$ downstream from bridge on State Highway 162 and $1 \frac{1}{2}$ miles north of Huntsville.

Drainage area. --32 sq mi, approximately.

Gage.--Recording and concrete control. Datum of gage is 4,915.41 ft above mean sea level, datum of 1929 (levels by Bureau of Reclamation).

Stage-discharge relation.--Defined by current-meter measurements.

Remarks.--Diversions above station for irrigation. Only annual peaks are shown. Peak stages and discharges

\begin{tabular}{l|l|r|r||r|r|r|r}
\hline $\begin{array}{l}\text { Water } \\
\text { year }\end{array}$ & Date & $\begin{array}{c}\text { Gage } \\
\text { helght } \\
\text { (feet) }\end{array}$ & $\begin{array}{c}\text { Discharge } \\
\text { (cfs) }\end{array}$ & $\begin{array}{c}\text { Water } \\
\text { year }\end{array}$ & Date & $\begin{array}{c}\text { Gage } \\
\text { he1ght } \\
\text { (feet) }\end{array}$ & $\begin{array}{c}\Gamma^{*} \text {.scharge } \\
\text { (cfs) }\end{array}$ \\
\hline 1958 & May 5,1958 & 2.72 & 450 & 1961 & Apr. 30, 1961 & 1.64 & \\
1959 & Apr. 26, 1959 & 2.03 & 175 & 1962 & Apr. 19, 1962 & 2.97 & 289 \\
1960 & May 10, 1960 & 2.18 & 273 & 1963 & May 4, 1963 & 2.23 & 277 \\
\hline
\end{tabular}

1379. Spring Creek at Huntsville, Utah

Location.--Lat $41^{\circ} 15^{\prime} 55^{\prime \prime}$, long $111^{\circ} 45^{\prime} 55^{\prime \prime}$, in SW $\frac{1}{4} \mathrm{SE} \frac{1}{4}$ sec.7, T.6 N., R.2 E., on lef't bank at north edge of Huntsville.

Drainage area. $-7.2 \mathrm{sq} \mathrm{mi}$, approximately.

Gage.--Recording and Parshall flume. Datum of gage is 4,902.99 ft abov? mean Sea level, datum of 1929 (levels by Bureau of Reclamation).

Stage-d1scharge relation.--Defined by current-meter measurements below $70 \mathrm{cfs}$. Remarks.--Only annual peaks are shown.

Peak stages and discharges

\begin{tabular}{l|c|c|c||c|c|r|r}
\hline $\begin{array}{c}\text { Water } \\
\text { year }\end{array}$ & Date & $\begin{array}{c}\text { Gage } \\
\text { height } \\
\text { (feet) }\end{array}$ & $\begin{array}{c}\text { D1scharge } \\
\text { (cfs) }\end{array}$ & $\begin{array}{c}\text { Water } \\
\text { year }\end{array}$ & Date & $\begin{array}{c}\text { Gage } \\
\text { he1ght } \\
\text { (feet) }\end{array}$ & $\begin{array}{c}\text { Discharge } \\
\text { (cfs) }\end{array}$ \\
\hline 1958 & June 12, 1958 & 0.97 & 28 & 1961 & Mar. 16, 1961 & 1.02 & 2.82 \\
1959 & Mar. 13, 1959 & 1.48 & 55 & 1962 & Feb. 12, 1962 & 158 \\
1960 & Mar. 28, 1960 & 2.13 & 101 & 1963 & Feb. 1, 1963 & 3.04 & 179 \\
\hline
\end{tabular}

\section{Wheelen Creek near Huntsville, Utah}

Location.--Lat $41^{\circ} 15^{\prime} 15^{\prime \prime}$, long $111^{\circ} 50^{\prime} 35^{\prime \prime}$, In NW $\frac{1}{4} \mathrm{SE} \frac{1}{4} \sec .16$, T.6 N., R.1 E., on right bank $150 \mathrm{ft}$ upstream from mouth, '150 ft downstream from culvert, under State Highway 39 , $250 \mathrm{ft}$ downstream from Pine View Dam on Ogden Riven, $3 \frac{3}{4}$ miles west of Huntsville, and 6 miles northeast of Ogden.

Drainage area. $--11.1 \mathrm{sq} \mathrm{mi}$.

Gage.--Recording and concrete control. Altitude of gage is 4,800 ft (from topographic map).

Stage-discharge relation.--Defined by current-meter measurements below $70 \mathrm{cfs}$.

Remarks.--Records include flow diverted around station by city of Ogder pipe-

line. Only annual peaks are shown. 
Peak stages and discharges of Wheeler Creek near Huntsv11le, Utah

\begin{tabular}{|c|c|c|c|c|c|c|c|}
\hline $\begin{array}{l}\text { Water } \\
\text { year }\end{array}$ & Date & $\begin{array}{c}\text { Gage } \\
\text { helght } \\
\text { (feet) }\end{array}$ & $\begin{array}{c}\text { Discharge } \\
(\text { efs })\end{array}$ & $\begin{array}{l}\text { Water } \\
\text { year }\end{array}$ & Date & $\begin{array}{c}\text { Cage } \\
\text { height } \\
\text { (feet) }\end{array}$ & $\begin{array}{c}\text { Discharge } \\
(\mathrm{cfs})\end{array}$ \\
\hline $\begin{array}{l}1959 \\
1960\end{array}$ & $\begin{array}{l}\text { Apr. } 27,1959 \\
\text { Apr. } 6,1960\end{array}$ & $\begin{array}{l}2.04 \\
2.10\end{array}$ & $\begin{array}{l}45 \\
51\end{array}$ & $\begin{array}{l}1962 \\
1963\end{array}$ & $\begin{array}{lr}\text { Feb. } 12,1962 \\
\text { Apr. }\end{array}$ & $\begin{array}{l}2.30 \\
2.14\end{array}$ & $\begin{array}{r}116 \\
84\end{array}$ \\
\hline 1961 & Apr. 3, 1961 & 1.73 & 22 & & & & \\
\hline
\end{tabular}

1395. Ogden River near Ogden, Utah

Location. --Lat $41^{\circ} 15^{\prime} 17^{\prime \prime}$, 1ong $111^{\circ} 50147^{\prime \prime}$, in $\mathrm{NE} \frac{1}{4} \mathrm{SW} \frac{1}{4}$ sec.16, T.6 N., R.1 E., $\overline{1,500} \mathrm{ft}$ downstream from Wheeler Creek, 2,000 ft downstream from Pine View Dam, and $6 \frac{1}{2}$ miles northeast of Ogden.

Drainage area. $--321 \mathrm{sq} \mathrm{mi}$.

Gage.--Nonrecording prior to Aug. 24, 1932; recording thereafter. Prior to Mar. 22, 1937, at different datums. Datum of gage is 4,798.30 ft above mean sea level (levels by Bureau of Reclamation).

Stage-discharge relation. --Defined by current-meter measurements .

Remarks.--Flow of river affected by storage in Pine View Reservoir (capacity, 41,798 acre-ft) beginning November 1936. Only annual peaks are shown (maxImum daily, except 1935, 1936).

\begin{tabular}{|c|c|c|c|c|c|c|c|c|c|}
\hline $\begin{array}{l}\text { Water } \\
\text { year }\end{array}$ & & Date & $\begin{array}{l}\text { Gage } \\
\text { helght } \\
\text { (feet) }\end{array}$ & $\begin{array}{c}\text { Discharge } \\
(\text { cfs })\end{array}$ & $\begin{array}{l}\text { Water } \\
\text { year }\end{array}$ & & Dete & $\begin{array}{c}\text { Gige } \\
\text { height } \\
\text { (feet) }\end{array}$ & $\begin{array}{c}\text { Discharge } \\
\text { (cfs) }\end{array}$ \\
\hline $\begin{array}{l}1904 \\
1905\end{array}$ & $\begin{array}{l}\text { May } \\
\text { May }\end{array}$ & $\begin{array}{ll}15, & 1904 \\
18, & 1905\end{array}$ & - & $\begin{array}{r}1,830 \\
785\end{array}$ & 1912 & \multirow{2}{*}{\multicolumn{2}{|c|}{$\begin{array}{lrl}\text { May } & 22, & 1912 \\
& & \\
\text { May } & 14, & 1932 \\
\text { May } & 22, & 1933 \\
\text { Apr. } & 1, & 1934 \\
\text { May } & 11, & 1935\end{array}$}} & - & 2,470 \\
\hline $\begin{array}{l}1906 \\
1907 \\
1908 \\
1909 \\
1910\end{array}$ & $\begin{array}{l}\text { May } \\
\text { Feb. } \\
\text { June } \\
\text { Apr. } \\
\text { Mar. }\end{array}$ & $\begin{array}{r}30,1906 \\
5,1907 \\
5,1908 \\
28,1909 \\
23,1910\end{array}$ & $\begin{array}{l}- \\
- \\
- \\
-\end{array}$ & $\begin{array}{r}1,350 \\
3,260 \\
935 \\
2,250 \\
1,920\end{array}$ & $\begin{array}{l}1932 \\
1933 \\
1934 \\
1935 \\
1936\end{array}$ & & & $\begin{array}{l}- \\
- \\
- \\
-\end{array}$ & $\begin{array}{r}2,790 \\
1,760 \\
140 \\
\text { a } 1,130 \\
\text { a } 3,700\end{array}$ \\
\hline 1911 & Jan. & 31,1911 & - & 2,440 & 1937 & & 11,1937 & - & 1,930 \\
\hline
\end{tabular}

a Momentary maximum.

1400. Ogden River below Pine View Dam, near Ogden, Utah

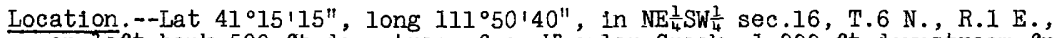
on left bank $500 \mathrm{f}^{\prime} \mathrm{t}$ downstream from Wheeler Creek, 1,000'ft downstream from Pine View Dam, and $6 \frac{1}{2}$ miles northeast of Ogden.

Drainage area. $--321 \mathrm{sq} \mathrm{ml}$.

Gage.--Recording. Prior to 0ct. 1, 1954, at site 1,000 ft downstream at datum $5.03 \mathrm{ft}$ lower. Datum of gage is $4,803.33 \mathrm{ft}$ above mean sea level (levels by Bureau of Reclamation).

Stage-discharge relation.--Defined by current-meter measurements.

Remarks.--Flow regulated by Pine View Reservoir (capacity, 41,798 acre-ft). Only annual peaks are shown. 
Peak stages and discharges of Ogden River below P1ne View Dam, near Ogden, Utah

\begin{tabular}{|c|c|c|c|c|c|c|c|}
\hline $\begin{array}{l}\text { Water } \\
\text { year }\end{array}$ & Date & $\begin{array}{c}\text { Cage } \\
\text { helght } \\
\text { (feet) }\end{array}$ & $\begin{array}{c}\text { Discharge } \\
\text { (cfs) }\end{array}$ & $\begin{array}{l}\text { Water } \\
\text { year }\end{array}$ & Date & $\begin{array}{c}\text { Gage } \\
\text { height } \\
\text { (feet) }\end{array}$ & $\begin{array}{c}\text { Discharge } \\
\text { (cfs) }\end{array}$ \\
\hline $\begin{array}{l}1938 \\
1939 \\
1940\end{array}$ & $\begin{array}{l}\text { Apr:25,26, } 1938 \\
\text { Apr. } 1,1939 \\
\text { May } 11,1940\end{array}$ & $\begin{array}{l}5.30 \\
4.20 \\
3.59\end{array}$ & $\begin{array}{r}1,260 \\
730 \\
482\end{array}$ & $\begin{array}{l}1949 \\
1950\end{array}$ & $\begin{array}{ll}\text { May } & 20,1949 \\
\text { May } 20,1950\end{array}$ & $\begin{array}{l}5.85 \\
5.78\end{array}$ & $\begin{array}{l}1,630 \\
1,460\end{array}$ \\
\hline $\begin{array}{l}1941 \\
1942 \\
1943 \\
1944 \\
1945\end{array}$ & $\begin{array}{l}\text { May } 14,1941 \\
\text { May } 26,1942 \\
\text { Apr:24, 25, } 1943 \\
\text { June } 3,1944 \\
\text { June } 7,1945\end{array}$ & $\begin{array}{l}3.60 \\
4.23 \\
5.43 \\
5.20 \\
6.73\end{array}$ & $\begin{array}{r}485 \\
718 \\
1,260 \\
1,100 \\
2,290\end{array}$ & $\begin{array}{l}1951 \\
1952 \\
1953 \\
1954 \\
1955\end{array}$ & $\begin{array}{lr}\text { May } 24, & 1951 \\
\text { May } 3, & 1952 \\
\text { June } 8, & 1953 \\
\text { Nov. } & 13,1953 \\
\text { May } 22,23,1955\end{array}$ & $\begin{array}{l}5.40 \\
7.76 \\
5.49 \\
2.53 \\
3.24\end{array}$ & $\begin{array}{r}1,190 \\
3,190 \\
1,140 \\
117 \\
383\end{array}$ \\
\hline $\begin{array}{l}1946 \\
1947 \\
1948\end{array}$ & $\begin{array}{lr}\text { Apr. } & 29,1946 \\
\text { May } & 8,1947 \\
\text { May } 20,1948\end{array}$ & $\begin{array}{l}5.70 \\
4.36 \\
5.84\end{array}$ & $\begin{array}{r}1,540 \\
722 \\
1,590\end{array}$ & $\begin{array}{l}1956 \\
1957 \\
1958 \\
1959\end{array}$ & $\begin{array}{lll}\text { May } & 14, & 1956 \\
\text { May } & 23, & 1957 \\
\text { Apr. } & 20, & 1958 \\
\text { July } & 28, & 1959\end{array}$ & $\begin{array}{l}5.17 \\
5.90 \\
5.21 \\
2.54\end{array}$ & $\begin{array}{r}971 \\
1,400 \\
1,060 \\
81 \\
\end{array}$ \\
\hline
\end{tabular}

\section{Weber River near Plain City, Utah}

Location.--Lat $41^{\circ} 16^{\prime} 42^{\prime \prime}$, long $112^{\circ} 05^{\prime} 30^{\prime \prime}$, in NW $\frac{1}{4} \mathrm{NE} \frac{1}{4} \sec .8$, T. 6 N., R.2 W., on right bank at highway bridge, 1 mile downstream from Fourmile Creek,

$1 \frac{1}{2}$ miles south of Plain City, and 6 miles upstream from mouth.

Drainàge area. $--2,060 \mathrm{sq} \mathrm{mi}$, approximately.

Gage.--Nonrecording prior to Aug. 30, 1949; recording thereafter. Altitude of gage is 4,210 fit (from topographic map).

Stage-discharge relation.--Defined by current-meter measurements.

Remarks.--During summer months practically entire flow is diverted abovo

station for irrigation. Flow regulated by Rockport, Echo, East Canyon, and Pine View Reservoirs. Only annual peaks are shown.

Peak stages and discharges

\begin{tabular}{|c|c|c|c|c|c|c|c|}
\hline $\begin{array}{c}\text { Water } \\
\text { year }\end{array}$ & Date & $\begin{array}{c}\text { Cage } \\
\text { nelght } \\
\text { (feet) }\end{array}$ & $\begin{array}{c}\text { Discharge } \\
\text { (cfs) }\end{array}$ & $\begin{array}{l}\text { Water } \\
\text { year }\end{array}$ & Date & $\begin{array}{c}\text { Gage } \\
\text { height } \\
\text { (feet) }\end{array}$ & $\begin{array}{c}\text { Discharge } \\
\text { (cfs) }\end{array}$ \\
\hline 1905 & May 21,1905 & - & 2,270 & 1935 & May 31,1935 & 10.48 & 1,620 \\
\hline $\begin{array}{l}1906 \\
1907 \\
1908 \\
1909 \\
1910\end{array}$ & $\begin{array}{l}\text { May } 31,1906 \\
\text { Apr. } 16,1907 \\
\text { June } 16,1908 \\
\text { June } 6,1909 \\
\text { Mar. } 23,1910\end{array}$ & $\begin{array}{r}- \\
- \\
19.1\end{array}$ & $\begin{array}{l}5,150 \\
5,880 \\
3,650 \\
7,580 \\
5,130\end{array}$ & $\begin{array}{l}1936 \\
1937 \\
1935 \\
1939 \\
1940\end{array}$ & $\begin{array}{l}\text { Apr. 25, } 1936 \\
\text { May 11, } 1937 \\
\text { Apr. 26, } 1938 \\
\text { Mar. 25, } 1939 \\
\text { Mar. 27, } 1940\end{array}$ & $\begin{array}{l}19.0 \\
17.36 \\
17.05 \\
10.30 \\
8.45\end{array}$ & $\begin{array}{l}6,050 \\
4,390 \\
3,960 \\
1,610 \\
1,060\end{array}$ \\
\hline $\begin{array}{l}1911 \\
1912 \\
1913 \\
1914 \\
1915\end{array}$ & $\begin{array}{l}\text { Feb. } 1,1911 \\
\text { May } 22,1912 \\
\text { Apr. } 3,1913 \\
\text { Apr. 17, } 1914 \\
\text { Apr. } 21,1915\end{array}$ & $\begin{array}{l}\overline{-} \\
\overline{-} \\
\overline{-}\end{array}$ & $\begin{array}{l}5,900 \\
6,450 \\
4,900 \\
5,700 \\
1,880\end{array}$ & $\begin{array}{l}1941 \\
1942 \\
1943 \\
1944 \\
1945\end{array}$ & $\begin{array}{lr}\text { May } & 7,1941 \\
\text { Apr. } 5, & 1942 \\
\text { Apr. } 26,1943 \\
\text { June } 4,1944 \\
\text { June } 8,1945\end{array}$ & $\begin{array}{r}9.00 \\
14.32 \\
15.89 \\
16.74 \\
16.33\end{array}$ & $\begin{array}{l}1,220 \\
2,770 \\
3,310 \\
3,740 \\
3,430\end{array}$ \\
\hline $\begin{array}{l}1916 \\
1917 \\
1918 \\
1919 \\
1920\end{array}$ & $\begin{array}{l}\text { Mar. } 22,1916 \\
\text { May } 17,1917 \\
\text { Mar. } 13,1918 \\
\text { Apr. 25, } 1919 \\
\text { May } 23,1920\end{array}$ & $\begin{array}{l}\overline{-} \\
\bar{z} \\
\bar{z}\end{array}$ & $\begin{array}{l}6,460 \\
6,910 \\
2,370 \\
2,650 \\
7,100\end{array}$ & $\begin{array}{l}1946 \\
1947 \\
1948 \\
1949 \\
1950\end{array}$ & $\begin{array}{ll}\text { Apr.28,29, } 1946 \\
\text { May } 14,1947 \\
\text { May } 20,1948 \\
\text { May } 23,1949 \\
\text { May } 20,1950\end{array}$ & $\begin{array}{l}18.20 \\
13.27 \\
18.47 \\
16.18 \\
17.25\end{array}$ & $\begin{array}{l}4,470 \\
2,480 \\
4,930 \\
4,170 \\
5,500\end{array}$ \\
\hline $\begin{array}{l}1921 \\
1922 \\
1923 \\
1924 \\
1925\end{array}$ & $\begin{array}{l}\text { May } 18,1921 \\
\text { May } 8,9,1922 \\
\text { May } 12,1923 \\
\text { Apr. 15, } 1924 \\
\text { Apr.19,20, } 1925\end{array}$ & $\begin{array}{c}- \\
- \\
- \\
12 . \\
-\end{array}$ & $\begin{array}{l}7,000 \\
7,270 \\
6,820 \\
2,520 \\
2,790\end{array}$ & $\begin{array}{l}1951 \\
1952 \\
1953 \\
1954 \\
1955\end{array}$ & $\begin{array}{lrr}\text { May } & 8,1951 \\
\text { May } & 6,1952 \\
\text { May } & 21,1953 \\
\text { Apr. } 19,1954 \\
\text { May } & 9,1955\end{array}$ & $\begin{array}{r}14.09 \\
19.01 \\
12.13 \\
4.71 \\
5.43\end{array}$ & $\begin{array}{r}3,860 \\
10,100 \\
3,340 \\
679 \\
976\end{array}$ \\
\hline $\begin{array}{l}1926 \\
1927 \\
1928 \\
1929 \\
1930\end{array}$ & $\begin{array}{lr}\text { Apr. } & 7,1926 \\
\text { May } & 2,1927 \\
\text { May } 13,1928 \\
\text { May } 17,1929 \\
\text { Apr. } 15,1930\end{array}$ & $\begin{array}{l}14.32 \\
17.40 \\
16.81 \\
17.05 \\
10.24\end{array}$ & $\begin{array}{l}3,410 \\
5,030 \\
4,620 \\
4,780 \\
1,790\end{array}$ & $\begin{array}{l}1956 \\
1957 \\
1958 \\
1959 \\
1960\end{array}$ & $\begin{array}{l}\text { Dec. } 24,1955 \\
\text { May } 22,1957 \\
\text { Apr. } 19,1958 \\
\text { Apr. } 27,1959 \\
\text { Mar. 9, } 1960\end{array}$ & $\begin{array}{r}10.92 \\
13.08 \\
13.24 \\
5.31 \\
8.37\end{array}$ & $\begin{array}{r}2,610 \\
3,390 \\
3,360 \\
707 \\
1,680\end{array}$ \\
\hline $\begin{array}{l}1931 \\
1932 \\
1933 \\
1934 \\
\end{array}$ & $\begin{array}{l}\text { Nov. } 29,1930 \\
\text { May 16, } 1932 \\
\text { June 1, } 1933 \\
\text { Feb 24,25, } 1934 \\
\end{array}$ & $\begin{array}{r}6.46 \\
18.38 \\
14.36 \\
5.02 \\
\end{array}$ & $\begin{array}{r}577 \\
5,500 \\
3,300 \\
285\end{array}$ & $\begin{array}{l}1961 \\
1962 \\
1963\end{array}$ & $\begin{array}{l}\text { Sept.19, } 1961 \\
\text { Feb. 11, } 1962 \\
\text { May 11, } 1963\end{array}$ & $\begin{array}{r}4.22 \\
10.74 \\
9.25\end{array}$ & $\begin{array}{r}415 \\
2,450 \\
1,740\end{array}$ \\
\hline
\end{tabular}


1415. Holmes Creek near Kaysville, Utah

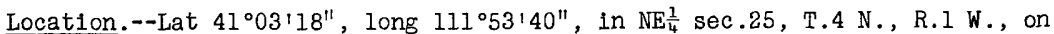
left bank 2 miles northeast of Kaysvilie.

Drainage area. $--2.49 \mathrm{sq} \mathrm{mi}$. Mean altitude, 7,580 ft.

Gage.--Recording and concrete control. Datum of gage is 5,095.1 ft above mean sea level, unadjusted.

Stage-discharge relation.--Defined by current-meter measurements below $25 \mathrm{cf}$. Moderate shifting at all stages.

Remarks.--Base for partial-duration series, $10 \mathrm{cfs.}$ only annual peaks are shown prior to 1953 .

\begin{tabular}{|c|c|c|c|c|c|c|c|}
\hline $\begin{array}{l}\text { Water } \\
\text { year }\end{array}$ & Date & $\begin{array}{c}\text { Gage } \\
\text { helght } \\
\text { (feet) }\end{array}$ & $\begin{array}{c}\text { Discharge } \\
\text { (cfs) }\end{array}$ & $\begin{array}{l}\text { Water } \\
\text { year }\end{array}$ & Date & $\begin{array}{l}\text { Gige } \\
\text { height } \\
\text { (feet) }\end{array}$ & $\begin{array}{c}\text { Discharge } \\
(\text { cfs })\end{array}$ \\
\hline 1950 & May 17,1950 & 1.06 & a20 & 1958 & $\begin{array}{l}\text { Apr. 1s, } 1958 \\
\text { May } 24,1958\end{array}$ & $\begin{array}{l}0.79 \\
1.05\end{array}$ & $\begin{array}{l}13 \\
33\end{array}$ \\
\hline $\begin{array}{l}1951 \\
1952\end{array}$ & $\begin{array}{lrl}\text { May } & 23, & 1951 \\
\text { May } & 3, & 1952\end{array}$ & $\begin{array}{l}1.02 \\
1.13\end{array}$ & $\begin{array}{l}22 \\
36\end{array}$ & 1959 & May 16,1959 & .71 & 7.5 \\
\hline 1953 & $\begin{array}{l}\text { Apr. } 28,1953 \\
\text { June } 10,1953\end{array}$ & $\begin{array}{l}. \text { ss } \\
.95\end{array}$ & $\begin{array}{l}19 \\
27\end{array}$ & 1960 & $\begin{array}{l}\text { Jan. } 17,1960 \\
\text { Apr. } 11,1960 \\
\text { May } 13,1960\end{array}$ & $\begin{array}{r}\text { bl. } \\
.71 \\
.80 \\
.83\end{array}$ & $\begin{array}{l}14 \\
15\end{array}$ \\
\hline 1954 & $\begin{array}{l}\text { Apr. } 14, \text { May } 21 \text {, } \\
1954\end{array}$ & - & 6.2 & 1961 & $\begin{array}{l}\text { Apr. } 3,1961 \text {, } \\
\text { May } 13-23,1961\end{array}$ & .66 & 5.1 \\
\hline 1955 & May $s, 1955$ & & 11 & 1962 & Apr. 26, 1962 & .92 & 22 \\
\hline 1957 & $\begin{array}{lll}\text { Dec. } & 23, & 1955 \\
\text { May } & 21, & 1956 \\
\text { May } 27, & 1956 \\
\text { July } & 25,1956 \\
& \\
\text { June } & 5,1957\end{array}$ & $\begin{array}{l}.50 \\
.78 \\
.82 \\
.92 \\
.93\end{array}$ & $\begin{array}{l}13 \\
11 \\
14 \\
21 \\
28\end{array}$ & 1963 & $\begin{array}{lll}\text { May } & 7, & 1962 \\
& \\
\text { May } & 3, & 1963 \\
\text { May } & 23, & 1963 \\
\text { June } & 3, & 1963\end{array}$ & $\begin{array}{r}1.00 \\
.82 \\
.81 \\
.77\end{array}$ & $\begin{array}{l}28 \\
15 \\
14 \\
11\end{array}$ \\
\hline
\end{tabular}

a Maximum for period May to September.

b Backwater from ice.

1420. Farmington Creek above diversions, near Farmington, Utah

Location.--Iat $41^{\circ} 00^{\prime} 05^{\prime \prime}$, long $111^{\circ} 52^{1} 25^{\prime \prime}$, in $\mathrm{NE}_{\frac{1}{4}}$ sec.18, T.3 N., R.1 E., on right bank 1.0 mile northeast of Farmington.

Drainage area $--10.0 \mathrm{sq} \mathrm{mi}$. Mean altitude, 7,470 ft.

Gage.--Recording and concrete control. Prior to 0ct. 1, 1951 , at site 600 ft downstream at different datum. Altitude of gage is $5,100 \mathrm{ft}$ (from U.S.

Forest Service topographic map).

Stage-discharge relation.--Defined by current-meter measurements below $200 \mathrm{cfs}$. Considerable shifting at all stages.

Remarks.--Base for partial duration series, $80 \mathrm{cfs}$.

Peak stages and discharges

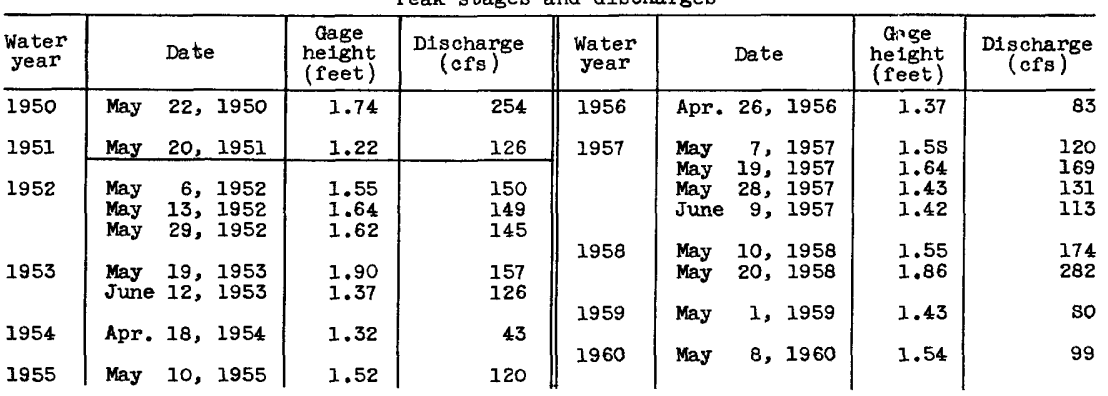


Peak stages and discharges of Farmington Creek above diversions, near Farmington, Utah--Continued

\begin{tabular}{|c|c|c|c|c|c|c|c|c|}
\hline $\begin{array}{l}\text { Water } \\
\text { year }\end{array}$ & Date & $\begin{array}{c}\text { Cage } \\
\text { helght } \\
\text { (feet) }\end{array}$ & $\begin{array}{l}\text { D1scharga } \\
\text { (cfs) }\end{array}$ & $\begin{array}{c}\text { Water } \\
\text { year }\end{array}$ & & Date & $\begin{array}{l}\text { Gage } \\
\text { helght } \\
\text { (feet) }\end{array}$ & $\begin{array}{c}\text { Is scharge } \\
(\mathrm{cfs})\end{array}$ \\
\hline $\begin{array}{l}1961 \\
1962\end{array}$ & $\begin{array}{l}\text { Mar. 1, } 1961 \\
\text { Apr. 19, } 1962 \\
\text { Apr. 26, } 1962 \\
\text { May } 6,1962\end{array}$ & $\begin{array}{l}1.34 \\
1.53 \\
1.61 \\
1.88\end{array}$ & $\begin{array}{r}63 \\
106 \\
146 \\
266\end{array}$ & 1963 & $\begin{array}{l}\text { May } \\
\text { May I } \\
\text { May I } \\
\text { June }\end{array}$ & $\begin{array}{rr}9, & 1963 \\
16, & 1963 \\
19, & 1963 \\
1, & 1963\end{array}$ & $\begin{array}{l}1.70 \\
1.56 \\
1.59 \\
1.46\end{array}$ & $\begin{array}{r}166 \\
110 \\
117 \\
86\end{array}$ \\
\hline
\end{tabular}

1425. Ricks Creek above diversions, near Centerville, Utah

Location.--Lat $40^{\circ} 56^{\prime} 25^{\prime \prime}$, long $111^{\circ} 52^{\prime} 00^{\prime \prime}$, in NW $\frac{1}{4}$ sec.5, T.2 N., R.I E., on left bank half a mile east of alternate U.S. Highway $91,1.2$ miles north of Centerville.

Drainage area. $-2.35 \mathrm{sq} \mathrm{ml}$.

Gage.--Recording and concrete control. Altitude of gage is 4,840 ft (from topographic map).

Stage-discharge relation.--Defined by current-meter measurements .

Remarks.--Base for partial-duration series, $10 \mathrm{cfs}$.

Peak stages and discharges

\begin{tabular}{|c|c|c|c|c|c|c|c|c|}
\hline $\begin{array}{l}\text { Water } \\
\text { year }\end{array}$ & & Date & $\begin{array}{c}\text { Gage } \\
\text { helght } \\
\text { (feet) }\end{array}$ & $\begin{array}{l}\text { D1scharge } \\
\text { (cfs) }\end{array}$ & $\begin{array}{l}\text { Water } \\
\text { year }\end{array}$ & Date & $\begin{array}{l}\text { Gage } \\
\text { height } \\
\text { (feet) }\end{array}$ & $\begin{array}{l}\text { D1scharge } \\
\text { (cfs) }\end{array}$ \\
\hline 1950 & May & 23,1950 & 1.27 & 227 & 1957 & June $I, 1957$ & 1.13 & 26 \\
\hline 1951 & May & 22,1951 & 1.11 & 20 & 1958 & $\begin{array}{ll}\text { May } & 11,1958 \\
\text { May } & 22,1958\end{array}$ & $\begin{array}{l}1.02 \\
1.32\end{array}$ & $\begin{array}{l}15 \\
34\end{array}$ \\
\hline 1952 & $\begin{array}{l}\text { May } \\
\text { May }\end{array}$ & $\begin{array}{r}7,1952 \\
15,1952\end{array}$ & $\begin{array}{l}1.30 \\
1.16\end{array}$ & $\begin{array}{l}30 \\
31\end{array}$ & 1959 & May 15,1959 & .84 & s.2 \\
\hline 1953 & $\begin{array}{l}\text { May } \\
\text { June }\end{array}$ & $\begin{array}{rr}20, & 1953 \\
6, & 1953\end{array}$ & $\begin{array}{l}1.02 \\
1.20\end{array}$ & $\begin{array}{l}16 \\
29\end{array}$ & 1960 & May 10,1960 & 1.02 & 17 \\
\hline 1954 & Apr. & 28,1954 & .79 & 4.0 & 1961 & $\begin{array}{l}\text { Apr. 3, May 10, } \\
1961\end{array}$ & - & 3.0 \\
\hline 1955 & May & 13,1955 & .95 & 10 & 1962 & $\begin{array}{l}\text { Apr. 16, } 1962 \\
\text { May } 8,1962\end{array}$ & $\begin{array}{l}1.03 \\
1.03\end{array}$ & $\begin{array}{l}19 \\
30\end{array}$ \\
\hline 1956 & May & 27,1956 & 1.12 & 23 & 1963 & May 21,1963 &.$\$ 7$ & 27 \\
\hline 1957 & May & 19,1957 & 1.10 & 19 & & & & \\
\hline
\end{tabular}

a. Maximum for period May to September.

1430. Parrish Creek above diversions, near Centerville, Utah

Location. --Lat $40^{\circ} 55^{\prime} 25^{\prime \prime}$, long $111^{\circ} 51^{\prime} 50^{\prime \prime}$, in NW/ sec.8, T.2 N., R.I E., on right bank 1 mile northeast of Centervilie.

Dra1nage area. $--2.08 \mathrm{sq} \mathrm{ml}$.

Gage.--Recording. Sharp-crested V-notch weir since October 1957. Prior to oct. 1, 1957, at site $500 \mathrm{ft}$ downstream at different datum. Altitude of gage is 4,600 ft (from topographic map).

Stage-discharge relation.--Defined by current-meter measurements .

Remarks.--Record includes flow through pipeline for Centerville city water supply. Base for partial-duration series, $10 \mathrm{cfs}$. 
Peak stages and discharges of Parrish Creek above diversions, near Certerville, Utah

\begin{tabular}{|c|c|c|c|c|c|c|c|c|c|}
\hline $\begin{array}{l}\text { Water } \\
\text { year }\end{array}$ & \multicolumn{2}{|r|}{ Date } & $\begin{array}{c}\text { Cage } \\
\text { helght } \\
\text { (feet) }\end{array}$ & $\begin{array}{c}\text { Discharge } \\
(\text { cfs })\end{array}$ & $\begin{array}{l}\text { Water } \\
\text { year }\end{array}$ & & Date & $\begin{array}{c}\text { Azge } \\
\text { height } \\
\text { (feet) }\end{array}$ & $\begin{array}{c}\text { Discharge } \\
(\text { ofs })\end{array}$ \\
\hline 1950 & May & 24,1950 & 2.02 & 19 & 1958 & May & 22,1958 & 1.92 & 21.9 \\
\hline 1951 & May & 7,1951 & 1.52 & 13 & 1959 & May & 15,1959 & 1.06 & 5.11 \\
\hline 1952 & May & 5,1952 & - & 30 & 1960 & May & 11,1960 & 1.39 & 9.92 \\
\hline 1953 & June & 6,1953 & - & 26 & 1961 & May & 2,1961 & .87 & 3.15 \\
\hline 1954 & Apr. & 18,1954 & - & 2.7 & 1962 & $\begin{array}{l}\text { May } \\
\text { May }\end{array}$ & $\begin{array}{rr}8, & 1962 \\
26, & 1962\end{array}$ & $\begin{array}{l}1.77 \\
1.51\end{array}$ & $\begin{array}{l}17.9 \\
12.2\end{array}$ \\
\hline 1955 & May & 13,1955 & - & 11 & 1963 & 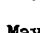 & 1963 & $14 ?$ & 10 \\
\hline 1956 & May & 8,1956 & 1.59 & 12 & & May & 19,1963 & 1.40 & 10.1 \\
\hline 1957 & June & 2,1957 & 2.05 & 21 & & & & & \\
\hline
\end{tabular}

1435. Centerville Creek above diversions, near Centerville, Utah

Location.--Lat $40^{\circ} 55^{100^{\prime \prime}}$, long $111^{\circ} 51^{\prime 4} 45^{\prime \prime}$, in SE $\frac{1}{4}$ sec.8, T.2 N., R.1 E., on right bank 1.2 miles east of Centervilie.

Drainage area. $--3.15 \mathrm{sq} \mathrm{mi}$.

Gage.--Recording. Concrete rating flume at site $250 \mathrm{ft}$ downstream at different datum prior to Nov. 21,1960 . V-notch sharp-crested weir thereafter. Altitude of gage is $4,650 \mathrm{ft}$ (from topographic map).

Stage-discharge relation.--Defined by current-meter measurements.

Remarks.--Records include flow on one ditch which diverts water about a quarter of a mile above station. Only annual maximum daily discharges are shown.

\begin{tabular}{|c|c|c|c|c|c|c|c|c|}
\hline \multicolumn{9}{|c|}{ Maximum daily mean discharges } \\
\hline $\begin{array}{l}\text { Water } \\
\text { year }\end{array}$ & & Date & $\begin{array}{c}\text { Cage } \\
\text { height } \\
\text { (feet) }\end{array}$ & $\begin{array}{c}\text { Discharge } \\
\text { (cfs) }\end{array}$ & $\begin{array}{l}\text { Water } \\
\text { year }\end{array}$ & Date & $\begin{array}{l}\text { arge } \\
\text { hejght } \\
\text { (feet) }\end{array}$ & $\begin{array}{c}\text { Discharge } \\
\text { (cfs) }\end{array}$ \\
\hline 1950 & \multirow{3}{*}{\multicolumn{2}{|c|}{$\begin{array}{l}\text { May } 17,1950 \\
\text { May } 6,1952 \\
\text { June } 7,12,1953 \\
\text { Apr. } 14,1954 \\
\text { May } 9,1955\end{array}$}} & \multirow{4}{*}{$\begin{array}{l}- \\
- \\
-\end{array}$} & \multirow{4}{*}{$\begin{array}{l}22 \\
30 \\
20 \\
3.6 \\
8.4 \\
8.2\end{array}$} & \multirow{4}{*}{$\begin{array}{l}1957 \\
1958 \\
1959 \\
1960 \\
1961 \\
1962 \\
1963\end{array}$} & \multirow{2}{*}{$\begin{array}{l}(\mathrm{a}) \\
\text { May } 21-24,1958 \\
\text { May } 1,1959 \\
\text { Apr. } 10,1960 \\
\end{array}$} & \multirow{2}{*}{$\begin{array}{l}- \\
- \\
-\end{array}$} & \multirow{2}{*}{$\begin{array}{r}18 \\
18 \\
3.7 \\
7.9 \\
\end{array}$} \\
\hline $\begin{array}{l}1952 \\
1953\end{array}$ & & & & & & & & \\
\hline $\begin{array}{l}1954 \\
1955\end{array}$ & & & & & & Apr. $\quad \frac{4}{b}, 1961$ & $\overline{-}$ & $\frac{2.6}{13}$ \\
\hline 1956 & May & 24,1956 & & & & $\left\{\begin{array}{l}0 \\
0\end{array}\right.$ & - & 8.0 \\
\hline
\end{tabular}

a May 28, 29, June 2, 3, 1957.

b Apr. 26-28, May 7-11, 1962 .

c May $5,6,8,9,1963$. 
1440. Stone Creek above diversions, near BountifuI, Utah

Location.--Lat $40^{\circ} 53140^{\prime \prime}$, long $111^{\circ} 50140^{\prime \prime}$, In NW $\frac{1}{4}$ sec.21, T.2 N., R.1 E., on right bank 2.2 miles east of Bountiful.

Drainage area. $--4.48 \mathrm{sq} \mathrm{mi}$. Mean altitude, 7,050 ft.

Gage.--Recording and concrete control. Alt1tude of gage is 5,080 ft (from topographic map).

Stage-discharge relation.--Defined by current-meter measurements below $30 \mathrm{cfs}$. hoderate shif'ing at all stages.

Remarks.--Base for partial-duration series, 15 cfs.

\begin{tabular}{|c|c|c|c|c|c|c|c|c|c|}
\hline $\begin{array}{l}\text { Water } \\
\text { year }\end{array}$ & & Date & $\begin{array}{c}\text { Cage } \\
\text { he1ght } \\
\text { (feet) }\end{array}$ & $\begin{array}{c}\text { Discharge } \\
(\text { cfs })\end{array}$ & $\begin{array}{l}\text { Water } \\
\text { year }\end{array}$ & & Date & $\begin{array}{c}\text { Gage } \\
\text { height } \\
\text { (feet) }\end{array}$ & $\begin{array}{c}\text { Discharge } \\
(\mathrm{cfs})\end{array}$ \\
\hline 1950 & May & 16,1950 & $1.3 \mathrm{~s}$ & 64 & 1957 & May & 31,1957 & 1.39 & 39 \\
\hline 1951 & May & 7,1951 & 1.23 & 21 & 1958 & Apr. & $\begin{array}{ll}22, & 195 s \\
22, & 1958\end{array}$ & $\begin{array}{l}1.17 \\
1.38\end{array}$ & $\begin{array}{l}17 \\
49\end{array}$ \\
\hline 1952 & May & 5, 1952 & 2.79 & 82 & 1959 & May & 1,1959 & 1.08 & 8.2 \\
\hline 1953 & $\begin{array}{l}\text { Apr. } \\
\text { June }\end{array}$ & $\begin{array}{rr}24, & 1953 \\
5, & 1953\end{array}$ & $\begin{array}{l}1.20 \\
1.37\end{array}$ & $\begin{array}{l}18 \\
49\end{array}$ & 1960 & May & 13,1960 & 1.16 & 14 \\
\hline 1954 & Apr. & 14,1954 & 1.03 & 6.4 & 1961 & Apr. & 3,1961 & 1.03 & 5.6 \\
\hline 1955 & May & 13,1955 & 1.23 & 16 & 1962. & $\begin{array}{l}\text { Apr. } \\
\text { Apr. }\end{array}$ & $\begin{array}{ll}16, & 1962 \\
26, & 1962\end{array}$ & $\begin{array}{l}1.26 \\
1.27\end{array}$ & $\begin{array}{l}20 \\
35\end{array}$ \\
\hline 1956 & $\begin{array}{l}\text { Dec. } \\
\text { May }\end{array}$ & $\begin{array}{ll}23, & 1955 \\
27, & 1956\end{array}$ & $\begin{array}{l}1.20 \\
1.18\end{array}$ & $\begin{array}{l}16 \\
15\end{array}$ & & May. & 11,1962 & 1.30 & 46 \\
\hline 1957 & May & $19, \quad 1957$ & 1.37 & 39 & 1963 & May & 3,1963 & 1.20 & 20 \\
\hline
\end{tabular}

1450. Mill Creek at Mueller Park, near Bountiful, Utah

Location.--Lat $40^{\circ} 51^{\prime} 50^{\prime \prime}$, long $111^{\circ} 50110^{\prime \prime}$, in SE $\frac{1}{4}$ sec.33, T.2 N., R.1 E., on right bank 2 miles southeast of Bountiful.

Drainage area. $--8.79 \mathrm{sq} \mathrm{ml}$.

Gage.--Recording gage and concrete control. Altitude of gage is 5,240 ft (from topographic map).

Stage-discharge relation.--Defined by current-meter measurements below $90 \mathrm{cfs}$.

Remarks.--Only annual maximum dally discharges are shown.

Maximum daily mean discharges

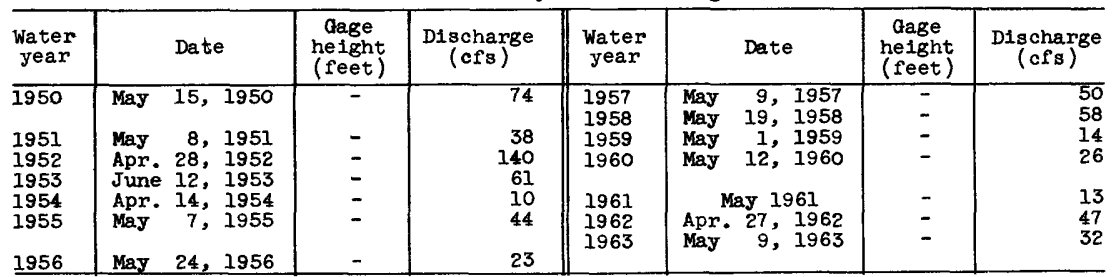


1460. Salt Creek at Neph1, Utah

(Published as "near Neph1" 1925-38)

Location.--Lat $39^{\circ} 42^{\prime} 45^{\prime \prime}$, long $111^{\circ} 48^{\prime} 2^{\prime \prime}$, in $\mathrm{NE} \frac{1}{4}$ sec.3, T.13 S., R.1 E., on right bank I mile east of Nephi.

Drainage area. $--95.6 \mathrm{sq} \mathrm{ml}$. Mean altitude, 7,330 ft.

Gage.--Nonrecording at site 2 miles upstream at different datums prior to Dec. 2, 1950; recording thereafter. Parshall flume Sept. 15, 1933, to Feb. 28, 1938. Dec. 2, 1950 , to Nov. 5, 1952 , at site 75 ft upstream at datum 1.43 ft higher. Alt1tude of gage $1 \mathrm{~s} 5,240 \mathrm{ft}$ (by barometer).

Stage-discharge relation.--Defined by current-meter measurements below $300 \mathrm{cf}$. Falrly stable except at extremely high stage.

Remarks.--Fiood records at two sites are equivalent. Only annual peaks are shown.

\begin{tabular}{|c|c|c|c|c|c|c|c|}
\hline $\begin{array}{l}\text { Water } \\
\text { year }\end{array}$ & Date & $\begin{array}{l}\text { Gage } \\
\text { helght } \\
\text { (feet) }\end{array}$ & $\begin{array}{c}\text { Discharge } \\
\text { (cfs) }\end{array}$ & $\begin{array}{l}\text { Water } \\
\text { year }\end{array}$ & Date & $\begin{array}{l}\text { aige } \\
\text { height } \\
(\mathrm{f} \geqslant e t)\end{array}$ & $\begin{array}{c}\text { Discharge } \\
\text { (cfs) }\end{array}$ \\
\hline $\begin{array}{l}1926 \\
1927 \\
1928 \\
1929 \\
1930\end{array}$ & $\begin{array}{l}\text { Apr. 7, May 6, } 1926 \\
\text { Apr.29, May 17,1927 } \\
\text { Mar. 25, } 1928 \\
\text { Aug. } 27,1929 \\
\text { Aug. 13, } 1930\end{array}$ & $\begin{array}{l}1.60 \\
1.50 \\
1.20 \\
3.65 \\
4.4\end{array}$ & $\begin{array}{l}199 \\
184 \\
144 \\
600 \\
550\end{array}$ & \multirow{4}{*}{$\begin{array}{l}1952 \\
1953 \\
1954 \\
1955 \\
1956 \\
1957 \\
1955 \\
1959 \\
1960 \\
1961 \\
1962 \\
1963\end{array}$} & \multirow{3}{*}{ 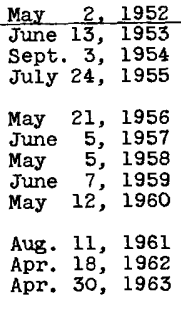 } & \multirow{4}{*}{$\begin{array}{l}- \\
- \\
- \\
- \\
- \\
- \\
- \\
- \\
- \\
3.45 \\
2.71\end{array}$} & \multirow[t]{3}{*}{$\begin{array}{l}724 \\
125 \\
299 \\
217\end{array}$} \\
\hline $\begin{array}{l}1931 \\
1932 \\
1933 \\
1934 \\
1935\end{array}$ & $\begin{array}{lll}\text { Aug. } & 13, & 1930 \\
& & \\
\text { July } & 30, & 1931 \\
\text { July } & 17, & 1932 \\
\text { May } & 31, & 1933 \\
\text { Aug. } 5, & 1934 \\
\text { Aug. } & 31, & 1935\end{array}$ & $\begin{array}{l}4.4 \\
3.28 \\
5.0 \\
2.00 \\
= \\
-\end{array}$ & $\begin{array}{l}336 \\
800 \\
131 \\
240 \\
260\end{array}$ & & & & \\
\hline $\begin{array}{l}1936 \\
1937 \\
\end{array}$ & $\begin{array}{lll}\text { July } 22, & 1936 \\
\text { July } 28, & 1937\end{array}$ & - & $\begin{array}{l}300 \\
270 \\
\end{array}$ & & & & \\
\hline 1951 & June 17,1951 & $=$ & 164 & & & & \\
\hline
\end{tabular}

1470. Summit Creek near Santaquin, Utah

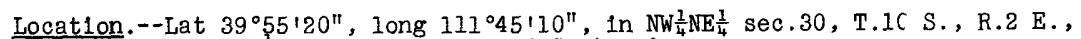
on right bank $3 \frac{1}{2}$ miles southeast of Santaquin.

Drainage area. $--14.6 \mathrm{sq} \mathrm{ml}$.

Gage.--Nonrecording gage and sharp-crested weir in powerplant tailrace and weir in main river channel at site $2 \frac{1}{2}$ miles downstream at different datums prior to October 1916; recording and concrete control thereafter. Altitude of gage is $5,900 \mathrm{ft}$ (from topographic map).

Stage-discharge relation.--Defined by current-meter measurements below 95 cfs.

Remarks.--Base for partial-duration series, $30 \mathrm{cfs}$. Only annual peaks are shown prior to 1955 .

\begin{tabular}{|c|c|c|c|c|c|c|c|c|}
\hline $\begin{array}{l}\text { Water } \\
\text { year }\end{array}$ & Date & $\begin{array}{c}\text { Gage } \\
\text { helght } \\
\text { (feet) }\end{array}$ & $\begin{array}{l}\text { D1scharge } \\
\text { (cfs) }\end{array}$ & $\begin{array}{l}\text { Water } \\
\text { year }\end{array}$ & & Date & $\begin{array}{c}\text { Gage } \\
\text { hej.ght } \\
\text { (feet) }\end{array}$ & $\begin{array}{c}\text { Discharge } \\
\text { (cfs) }\end{array}$ \\
\hline 1910 & May 10,1910 & 2.0 & 154 & $195 \mathrm{~s}$ & May & $25,195 \mathrm{~s}$ & 1.60 & $\overline{118}$ \\
\hline $\begin{array}{l}1911 \\
1912\end{array}$ & $\begin{array}{l}\text { May } s-10,1911 \\
\text { June } 10,1912\end{array}$ & $\overline{-}$ & $\frac{2 \pi}{135} \cdot 1$ & 1959 & May & 14,1959 & .78 & 23 \\
\hline $\begin{array}{l}1913 \\
1914\end{array}$ & $\begin{array}{l}\text { May } 12,1913 \\
\text { May } 20,1914\end{array}$ & - & $\begin{array}{r}76.1 \\
105\end{array}$ & 1960 & May & 13,1960 & .95 & 65 \\
\hline 1915 & May 14, 1915 & - & $4 \mathrm{~s} .9$ & 1961 & May & 2,1961 & .77 & 23 \\
\hline 1916 & Apr. 2S, 1916 & - & 97 & 1962 & Apr. & 17,1962 & 1.00 & 68 \\
\hline 1955 & $\begin{array}{lrl}\text { May } & 6, & 1955 \\
\text { July } 24, & 1955\end{array}$ & $\begin{array}{l}1.57 \\
1.37\end{array}$ & $\begin{array}{l}65 \\
48\end{array}$ & & $\begin{array}{l}\text { May } \\
\text { June } \\
\text { June }\end{array}$ & $\begin{array}{r}6,1962 \\
3,1962 \\
12,1962\end{array}$ & $\begin{array}{l}1.54 \\
1.11 \\
1.01\end{array}$ & $\begin{array}{r}112 \\
70 \\
54\end{array}$ \\
\hline 1956 & $\begin{array}{lr}\text { May } & 6,1956 \\
\text { May } & 22,1956\end{array}$ & $\begin{array}{l}1.32 \\
1.40\end{array}$ & $\begin{array}{l}40 \\
46\end{array}$ & 1963 & May & 6, 1963 & .94 & $\begin{array}{l}3 s \\
3 s\end{array}$ \\
\hline 1957 & 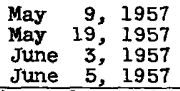 & $\begin{array}{l}1.70 \\
1.70 \\
1.92\end{array}$ & $\begin{array}{r}91 \\
55 \\
\text { a215 } \\
(\mathrm{b}) \\
\end{array}$ & & $\begin{array}{l}\text { May } \\
\text { May }\end{array}$ & $\begin{array}{ll}22, & 1963 \\
25, & 1963\end{array}$ & $\begin{array}{l}.98 \\
.98\end{array}$ & $\begin{array}{l}41 \\
44\end{array}$ \\
\hline
\end{tabular}

a Maximum observed. 
1475. Payson Creek above diversions, near Payson, Utah

Location.--Iat $39^{\circ} 58^{1} 10^{\prime \prime}$, long $111^{\circ} 41^{\prime} 35^{\prime \prime}$, in SE $\frac{1}{4} \mathrm{SE} \frac{1}{4} \mathrm{sec} .3$, T.10 S., R.2 E., on left bank a quarter of a mile above diversion dam for Strawberry Water Users Association powerplant, 5 miles southeast of Payson, and 12 miles upstream from Utah Lake.

Drainage area. $--18.8 \mathrm{sq} \mathrm{mi}$. Mean altitude, $7,610 \mathrm{ft}$.

Gage.--Recording. Altitude of gage is 5,670 ft (by barometer).

Stage-discharge relation.--Defined by current-meter measurements below $150 \mathrm{cfs}$. Moderate shifting at medium and high stage.

Remarks. --Base for partial-duration series, $80 \mathrm{cfs}$.

\begin{tabular}{|c|c|c|c|c|c|c|c|c|c|}
\hline $\begin{array}{l}\text { Water } \\
\text { year }\end{array}$ & & Date & $\begin{array}{c}\text { Gage } \\
\text { helght } \\
\text { (feet) }\end{array}$ & $\begin{array}{c}\text { D1scharge } \\
(\mathrm{cfs})\end{array}$ & $\begin{array}{l}\text { Water } \\
\text { year }\end{array}$ & & Date & $\begin{array}{l}\text { Gage } \\
\text { height } \\
\text { (feet) }\end{array}$ & $\begin{array}{c}\text { D1scharge } \\
(\text { cfs })\end{array}$ \\
\hline 1948 & $\begin{array}{l}\text { Apr. } \\
\text { Apr. } \\
\text { May } \\
\text { May }\end{array}$ & 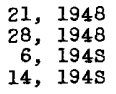 & $\begin{array}{l}- \\
\overline{-} \\
2.69\end{array}$ & $\begin{array}{r}84 \\
103 \\
177 \\
194\end{array}$ & $\begin{array}{l}1955 \\
1956\end{array}$ & $\begin{array}{l}\text { May } \\
\text { Apr. }\end{array}$ & $\begin{array}{r}6,1955 \\
21,1956\end{array}$ & $\begin{array}{l}2.68 \\
1.91\end{array}$ & $\begin{array}{r}294 \\
70\end{array}$ \\
\hline 1949 & $\begin{array}{l}\text { Aṕr. } \\
\text { May } \\
\text { May }\end{array}$ & $\begin{array}{rr}27, & 1949 \\
2, & 1949 \\
10, & 1949\end{array}$ & $\begin{array}{l}2.30 \\
-\end{array}$ & $\begin{array}{r}139 \\
111 \\
56\end{array}$ & 1957 & $\begin{array}{l}\text { May } \\
\text { May } \\
\text { May }\end{array}$ & $\begin{array}{rr}8, & 1957 \\
19, & 1957 \\
28, & 1957\end{array}$ & $\begin{array}{l}2.54 \\
2.76 \\
2.68\end{array}$ & $\begin{array}{l}180 \\
203 \\
197\end{array}$ \\
\hline & May & 17,1949 & - & 109 & 1958 & $\begin{array}{l}\text { May } \\
\text { May }\end{array}$ & $\begin{array}{ll}10, & 1958 \\
20, & 1958\end{array}$ & $\begin{array}{l}2.60 \\
2.70\end{array}$ & $\begin{array}{l}171 \\
191\end{array}$ \\
\hline 1950 & $\begin{array}{l}\text { Apr. } \\
\text { May }\end{array}$ & $\begin{array}{ll}23, & 1950 \\
16, & 1950\end{array}$ & 2.29 & $\begin{array}{l}107 \\
140\end{array}$ & 1959 & May & 1,1959 & 1.69 & 44 \\
\hline 1951 & May & 20,1951 & 1.70 & 61 & 1960 & May & 11,1960 & 2.36 & 109 \\
\hline 1952 & $\begin{array}{l}\text { May } \\
\text { May }\end{array}$ & $\begin{array}{rr}4, & 1952 \\
20, & 1952\end{array}$ & $\begin{array}{l}2.99 \\
2.70\end{array}$ & $\begin{array}{l}465 \\
367\end{array}$ & 1961 & & 1. 1961 & & 39 \\
\hline $\begin{array}{l}1953 \\
1954\end{array}$ & $\begin{array}{l}\text { May } \\
\text { May }\end{array}$ & 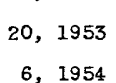 & $\begin{array}{l}2.22 \\
1.05\end{array}$ & $\begin{array}{r}281 \\
71\end{array}$ & 1962 & $\begin{array}{l}\text { Apr. } \\
\text { Apr. } \\
\text { May }\end{array}$ & $\begin{array}{cc}19, & 1962 \\
24, & 1962 \\
6, & 1962\end{array}$ & $\begin{array}{l}2.42 \\
2.73 \\
3.00\end{array}$ & $\begin{array}{l}117 \\
186 \\
300\end{array}$ \\
\hline
\end{tabular}

1480. Payson Creek near Payson, Utah

(Published as "Peteetneet Creek" 1911-16)

Location.--Lat $40^{\circ} 00^{\prime}$, long $111^{\circ} 42^{\prime}$, in SE $\frac{1}{4} S W \frac{1}{4}$ sec.27, T.9 S., R.2 E., about half a mile upstream from power canal intake and 3 miles southeast of Payson. Drainage area. $--28 \mathrm{sq} \mathrm{mi}$, approximately.

Gage.--Nonrecording. Altitude of gage is 5,060 ft (from topographic map). Stage-discharge relation.--Defined by current-meter measurements below 170-cfs.

Remarks.--Flow partly regulated by several small reservolrs upstream. Records furmished by Bureau of Reclamation. Only annual maximum observed discharges are shown.

Peak stages and discharges

\begin{tabular}{|c|c|c|c|c|c|c|c|c|}
\hline $\begin{array}{l}\text { Water } \\
\text { year }\end{array}$ & & Date & $\begin{array}{c}\text { Gage } \\
\text { helght } \\
\text { (feet) }\end{array}$ & $\begin{array}{c}\text { Discharge } \\
(\text { cfs })\end{array}$ & $\begin{array}{c}\text { Water } \\
\text { year }\end{array}$ & Date & $\begin{array}{c}\text { Gage } \\
\text { helght } \\
\text { (feet) }\end{array}$ & $\begin{array}{c}\text { D1scharge } \\
\text { (cfs) }\end{array}$ \\
\hline $\begin{array}{l}1911 \\
1912 \\
1913 \\
1914 \\
\end{array}$ & $\begin{array}{l}\text { May } \\
\text { May } \\
\text { Apr. } \\
\text { May }\end{array}$ & $\begin{array}{ll}10, & 1911 \\
24, & 1912 \\
29, & 1913 \\
10, & 1914 \\
\end{array}$ & $\begin{array}{l}2.18 \\
3.74 \\
3.60 \\
4.02\end{array}$ & $\begin{array}{l}38.7 \\
122 \\
154 \\
200\end{array}$ & $\begin{array}{l}1915 \\
1916\end{array}$ & $\begin{array}{l}\text { Apr. 24, } 1915 \\
\text { Apr. 27, } 1916\end{array}$ & $\begin{array}{l}3.20 \\
-\end{array}$ & $\begin{array}{r}93 \\
165\end{array}$ \\
\hline
\end{tabular}


1483. Da1ry Fork near Thistle, Utah

Location.-- Lat $39^{\circ} 58^{\prime}$, long $111^{\circ} 21^{\prime}$, in center of sec.11, T.10 S., R.5 E., on

left bank $0.6 \mathrm{mile}$ upstream from mouth, and 9 miles east of Tristle.

Drainage area. - - 11 sq $\mathrm{mi}$, approximately.

Gage.--Crest-stage gage. Altitude of gage is 5,750 ft (from topcgraphic map).

Stage-discharge relation.--Defined by current-meter measurement at $0.57 \mathrm{cfs}$ and slope-area measurements at $191 \mathrm{cfs}$ and $805 \mathrm{cfs}$.

Remarks.--Only annual peaks are shown.

Peak stages and discharges

\begin{tabular}{c|c|c|c||c|c|c|c}
\hline $\begin{array}{c}\text { Water } \\
\text { year }\end{array}$ & Date & $\begin{array}{c}\text { Gage } \\
\text { height } \\
\text { (feet) }\end{array}$ & $\begin{array}{c}\text { Discharge } \\
\text { (cfs) }\end{array}$ & $\begin{array}{c}\text { Water } \\
\text { year }\end{array}$ & $\begin{array}{c}\text { Grge Date } \\
\text { he1ght } \\
\text { (feet) }\end{array}$ & $\begin{array}{c}\text { Discharge } \\
\text { (cfs) }\end{array}$ \\
\hline 1959 & July 14, 1959 & 13.88 & 805 & 1962 & Mar. 27, 1962 & 11.25 & 180 \\
1960 & July 31, 1960 & 11.31 & 191 & 1963 & Aug. 9, 1963 & 10.65 \\
1961 & Aug. 3,1961 & 11.87 & 285 & & & \\
\hline
\end{tabular}

1485. Spanish Fork at Thistle, Utah

Location.--Lat $40^{\circ} 00^{\prime}$, long $111^{\circ} 30^{\prime}$, in NE $\frac{1}{4} \mathrm{SE} \frac{1}{4}$ sec.29, T.9 S., R.4 E., on right bank at Thistle, $600 \mathrm{ft}$ downstream from confluence of Soldier Fork and

Thistle Creek and $2 \frac{1}{2}$ miles upstream from Diamond Fork.

Drainage area. $--490 \mathrm{sq} \mathrm{ml}$, approximately. Mean altitude, $7,130 \mathrm{f}$.

Gage.-Nonrecording prior to 0ct. 8, 1938; recording thereafter. Prior to Nov. 21, 1912 , at site 1 mile downstream at different datum. Nov. 21, 1912, to Dec. 31, 1925, at site $600 \mathrm{ft}$ upstream at different datum. Jan. 1, 1933, to May 10,1937 , at site $800 \mathrm{ft}$ upstream at different datum. May 12, 1937, to June 27, 1960, at site $800 \mathrm{ft}$ upstream at datum $2.42 \mathrm{ft}$ higher. Datum of gage is $5,027.28 \mathrm{ft}$ above mean sea level, datum of 1929 .

Stage-discharge relation.--Defined by current-meter measurements below $800 \mathrm{cfs}$. Moderate shifting at medium and high stage.

Remarks.--Base for partial-duration series, $330 \mathrm{cfs}$. Only annual peaks are shown prior to 1948 (maximum observed 1908-25, 1933 36, 1938).

Peak stages and discharges

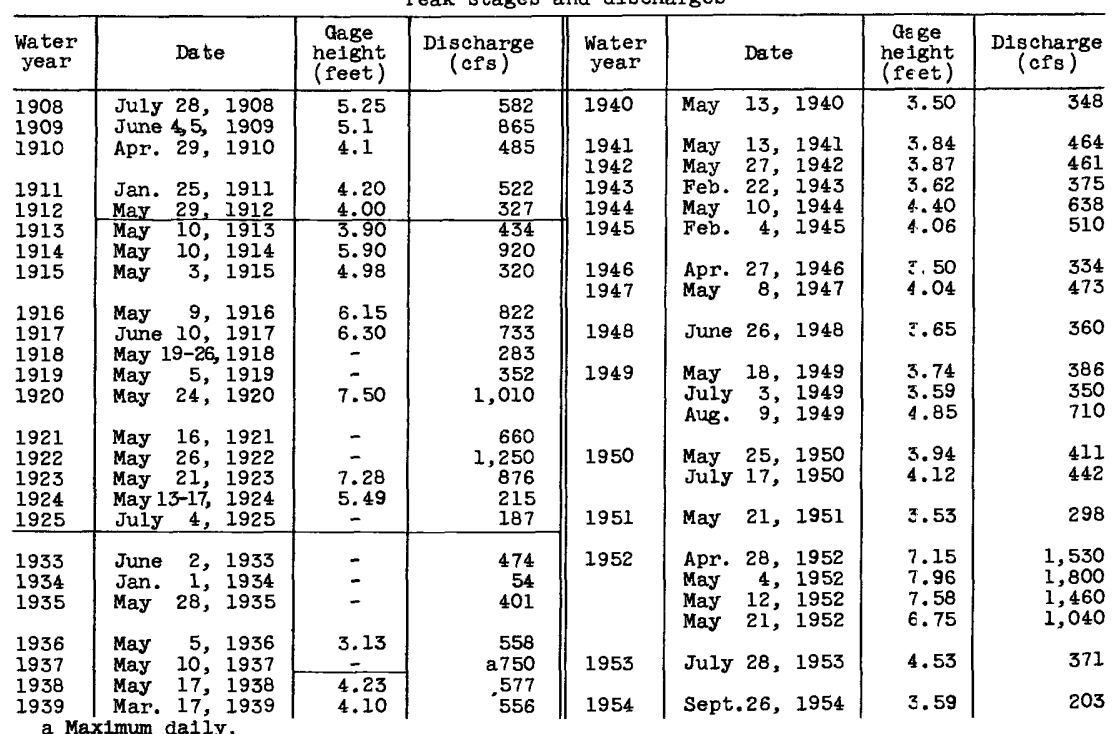


Peak stages and discharges of Spanish Fork at Thistle, Utah--Continuec'

\begin{tabular}{|c|c|c|c|c|c|c|c|}
\hline $\begin{array}{l}\text { Water } \\
\text { year }\end{array}$ & Date & $\begin{array}{c}\text { Cage } \\
\text { helght } \\
\text { (feet) }\end{array}$ & $\begin{array}{l}\text { Discharge } \\
\text { (cfs) }\end{array}$ & $\begin{array}{l}\text { Water } \\
\text { year }\end{array}$ & Date & $\begin{array}{c}\text { Gage } \\
\text { helght } \\
\text { (feet) }\end{array}$ & $\begin{array}{c}\text { Discharge } \\
(\mathrm{cfs})\end{array}$ \\
\hline \multirow[t]{2}{*}{1955} & \multirow{2}{*}{$\begin{array}{lrr}\text { Mar. } 14, & 1955 \\
\text { Aug. } & 6, & 1955\end{array}$} & \multirow{2}{*}{$\begin{array}{l}4.81 \\
4.85\end{array}$} & \multirow{2}{*}{$\begin{array}{l}530 \\
554\end{array}$} & 1959 & July 14, 1959 & 5.60 & 686 \\
\hline & & & & 1960 & Sept. 5, 1960 & 7.31 & 1,240 \\
\hline 1956 & Aug. 13, 1956 & 4.18 & 357 & 1961 & Aug. 3,1961 & 4.92 & 611 \\
\hline 1957 & 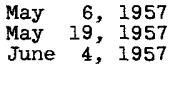 & $\begin{array}{l}4.17 \\
4.28 \\
5.03\end{array}$ & $\begin{array}{l}376 \\
423 \\
565\end{array}$ & 1962 & $\begin{array}{l}\text { Feb. } 12,1962 \\
\text { Mar. 28, } 1962 \\
\text { Apr. } 25,1962\end{array}$ & $\begin{array}{l}- \\
4.66 \\
4.21\end{array}$ & $\begin{array}{l}630 \\
541 \\
430\end{array}$ \\
\hline 1958 & $\begin{array}{l}\text { Apr. } 19,1958 \\
\text { May 11, } 1958 \\
\text { May 23, } 1958 \\
\text { Sept. 3, } 1958\end{array}$ & $\begin{array}{l}4.32 \\
5.03 \\
5.42 \\
4.52\end{array}$ & $\begin{array}{l}342 \\
565 \\
609 \\
339\end{array}$ & 1963 & $\begin{array}{ll}\text { May } & 7,1962 \\
\text { Aug. } & 7,1963\end{array}$ & $\begin{array}{l}4.56 \\
3.86\end{array}$ & $\begin{array}{l}503 \\
322\end{array}$ \\
\hline
\end{tabular}

1495. Diamond Fork below Red Hollow, near Thistle, Utah

Location.--Lat $40^{\circ} 04^{1} 40^{\prime \prime}$, long $111^{\circ} 24^{\prime} 00^{\prime \prime}$, in NW $\frac{1}{4} 8$ ec.32, T.8 S., R.5 E., on right bank $0.5 \mathrm{mile}$ downstream from Red Hollow, 7.2 miles upstream from mouth, and 8 miles northeast of Thistle.

Drainage area. $--110 \mathrm{sq} \mathrm{ml}$, approximately.

Gage.--Recording. Altitude of gage is 5,300 ft (from river-profile mas).

Stage-discharge relation.--Defined by current-meter measurements below $500 \mathrm{cfs}$.

Remarks.--Flow includes water diverted from Strawberry Reservoir (caparity, 270,000 acre- $f$ () in Colorado River basin via Strawberry tunnel for Irrigation in the vicinity of Spanish Fork. Only annual peaks are shown.

Peak stages and discharges

\begin{tabular}{|c|c|c|c|c|c|c|c|c|c|}
\hline $\begin{array}{l}\text { Water } \\
\text { year }\end{array}$ & & Date & $\begin{array}{c}\text { Cage } \\
\text { he1ght } \\
\text { (feet) }\end{array}$ & $\begin{array}{c}\text { Discharge } \\
\text { (cfs) }\end{array}$ & $\begin{array}{l}\text { Water } \\
\text { year }\end{array}$ & & Date & $\begin{array}{c}\text { Gage } \\
\text { he1ght } \\
\text { (feet) }\end{array}$ & $\begin{array}{c}\text { D1scharge } \\
(\mathrm{cfs})\end{array}$ \\
\hline $\begin{array}{l}1954 \\
1955\end{array}$ & $\begin{array}{l}\text { July } 1 \\
\text { Aug. } 2\end{array}$ & $\begin{array}{ll}13, & 1954 \\
25, & 1955\end{array}$ & $\begin{array}{l}4.71 \\
3.53\end{array}$ & $\begin{array}{r}1,020 \\
576\end{array}$ & $\begin{array}{l}1959 \\
1960\end{array}$ & $\begin{array}{l}\text { June } \\
\text { June }\end{array}$ & $\begin{array}{ll}24, & 1959 \\
24, & 1960\end{array}$ & $\begin{array}{l}3.35 \\
3.21\end{array}$ & $\begin{array}{l}566 \\
479\end{array}$ \\
\hline $\begin{array}{l}1956 \\
1957 \\
1958\end{array}$ & $\begin{array}{l}\text { June } 2 \\
\text { July } \\
\text { July }\end{array}$ & 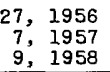 & $\begin{array}{l}3.56 \\
3.69 \\
3.37\end{array}$ & $\begin{array}{l}519 \\
539 \\
478\end{array}$ & $\begin{array}{l}1961 \\
1962 \\
1963\end{array}$ & $\begin{array}{l}\text { May } \\
\text { June } \\
\text { Aug. }\end{array}$ & $\begin{array}{ll}25, & 1961 \\
29, & 1962 \\
19, & 1963\end{array}$ & $\begin{array}{l}3.14 \\
3.43 \\
3.85\end{array}$ & $\begin{array}{l}458 \\
599 \\
725 \\
\end{array}$ \\
\hline
\end{tabular}

\section{Diamond Fork near Thistle, Utah}

Location.--Lat $40^{\circ} 03^{\prime} 50^{\prime \prime}$, long $11^{\circ} 26^{\prime} 30^{\prime \prime}$, in NW/ sec.1, T.9 S., R.4 E., on left bank about $0.4 \mathrm{mile}$ downstream from Little Diamond Creek, 5.0 miles upstream from mouth, and 5.2 miles northwest of Thistle.

Drainage area. $--146 \mathrm{sq} \mathrm{mi}$.

Gage.--Nonrecording prior to Apr. 9, 1940, at site 4 miles downstream at different datum; recording thereafter. Apr. 9, 1940, to 0ct. 6, 1949, at site $2.7 \mathrm{mlles}$ downstream at different datum. Altitude of gage is $5,14 \mathrm{C}$ ft (from river-profile map).

Stage-discharge relation.--Defined by current-meter measurements belon $720 \mathrm{cfs}$ prior to 1940 , below 540 cfs 1940 to 1949 , and below 330 cfs after 1949 .

Remarks.--Beginning in 1915, flow Includes water diverted from Strawberry Reservolr in Colorado River basin via Strawberry tunnel. Only annual peaks are shown (maximum observed prior to 1940).

Peak stages and discharges

\begin{tabular}{|c|c|c|c|c|c|c|c|c|}
\hline $\begin{array}{l}\text { Water } \\
\text { year }\end{array}$ & & Date & $\begin{array}{l}\text { Cage } \\
\text { helght } \\
\text { (feet) }\end{array}$ & $\begin{array}{c}\text { D1scharge } \\
(\text { cfs })\end{array}$ & $\begin{array}{l}\text { Water } \\
\text { year }\end{array}$ & Date & $\begin{array}{l}\text { Gage } \\
\text { he1ght } \\
\text { (feet) }\end{array}$ & $\begin{array}{c}\text { D1scharge } \\
(\mathrm{cfs})\end{array}$ \\
\hline $\begin{array}{l}1908 \\
1909 \\
1910\end{array}$ & $\begin{array}{l}\text { June } \\
\text { May } \\
\text { Apr. }\end{array}$ & $\begin{array}{r}17,1908 \\
9,1909 \\
12,1910\end{array}$ & $\begin{array}{l}- \\
- \\
-\end{array}$ & $\begin{array}{r}59 \\
735 \\
256\end{array}$ & $\begin{array}{l}191 \overline{3} \\
1914 \\
1915\end{array}$ & $\begin{array}{lrr}\text { May } & 16, & 1913 \\
\text { May } & 5, & 1914 \\
\text { July } & 17, & 1915\end{array}$ & $\begin{array}{l}- \\
-\end{array}$ & $\begin{array}{l}178 \\
364 \\
124\end{array}$ \\
\hline $\begin{array}{l}1911 \\
1912\end{array}$ & $\begin{array}{l}\text { May } \\
\text { May }\end{array}$ & $\begin{array}{ll}13, & 1911 \\
20, & 1912\end{array}$ & - & $\begin{array}{r}76 \\
170\end{array}$ & $\begin{array}{l}1916 \\
1917\end{array}$ & $\begin{array}{ll}\text { May } 7, & 1916 \\
\text { July } 28, & 1917\end{array}$ & - & $\begin{array}{l}457 \\
560 \\
\end{array}$ \\
\hline
\end{tabular}


Peak stages and discharges of Diamond Fork near Thistle, Utah--Continued

\begin{tabular}{|c|c|c|c|c|c|c|c|c|}
\hline $\begin{array}{l}\text { Water } \\
\text { year }\end{array}$ & & Date & $\begin{array}{c}\text { Cage } \\
\text { helght } \\
\text { (feet) }\end{array}$ & $\begin{array}{c}\text { Discharge } \\
\text { (cfs) }\end{array}$ & $\begin{array}{c}\text { Water } \\
\text { year }\end{array}$ & Date & $\begin{array}{c}\text { arge } \\
\text { neight } \\
\text { (feet) }\end{array}$ & $\begin{array}{c}\text { Discharge } \\
(\mathrm{cfs})\end{array}$ \\
\hline 1940 & $\begin{array}{l}\text { June } \\
\text { June }\end{array}$ & $\begin{array}{l}20,1940 \\
27,1941\end{array}$ & $\begin{array}{l}2.97 \\
3.07\end{array}$ & $\begin{array}{l}535 \\
579\end{array}$ & $\begin{array}{l}1947 \\
1948 \\
1949 \\
\end{array}$ & $\begin{array}{lr}\text { Aug. } 21, & 1947 \\
\text { July } 10,1948 \\
\text { Aug. } 8,1949\end{array}$ & $\begin{array}{r}3.96 \\
3.75 \\
3.36 \\
\end{array}$ & $\begin{array}{l}556 \\
586 \\
766 \\
\end{array}$ \\
\hline $\begin{array}{l}1942 \\
1943 \\
1944 \\
1945\end{array}$ & $\begin{array}{l}\text { July } \\
\text { June } \\
\text { July } \\
\text { July }\end{array}$ & $\begin{array}{rr}9, & 1942 \\
30, & 1943 \\
7, & 1944 \\
8, & 1945\end{array}$ & $\begin{array}{l}3.07 \\
3.07 \\
3.76 \\
3.52\end{array}$ & $\begin{array}{l}470 \\
486 \\
541 \\
532\end{array}$ & $\begin{array}{l}1951 \\
1952 \\
1953\end{array}$ & $\begin{array}{lll}\text { July } & 1, & 1951 \\
\text { May } & 4, & 1952 \\
\text { July } & 2, & 1953\end{array}$ & $\begin{array}{r}4.25 \\
5.18 \\
a 5.07\end{array}$ & $\begin{array}{r}550 \\
1,610 \\
532\end{array}$ \\
\hline 1946 & June & 29,1946 & 3.64 & 565 & 1955 & 1,1955 & 6.17 & 510 \\
\hline
\end{tabular}

a Occurred June 26, 1953.

1505. Spanish Fork at Cast1lia, Utah

(Published as "near Spanish Fork" 1889-90, 1903-8)

Location.--Lat $40^{\circ} 03^{\prime} 00^{\prime \prime}$, long $111^{\circ} 32150^{\prime \prime}$, in SW $\frac{1}{4} \mathrm{NE} \frac{1}{4}$ sec.12, T.9 S., R. 3 E., on left bank $600 \mathrm{ft}$ upstream from outlet of cold Springs, 1 mile upstream from diversion dam of Bureau of Reclamation, $1 \frac{1}{4}$ miles northwest of Castilla, and 3 miles downstream from Diamond Fork.

Drainage area. $--670 \mathrm{sq} \mathrm{ml}$, approximately.

Gage.--Nonrecording prior to Apr. 15, 1920; recording thereafter. Prior to May 3, 1919, at various sites $1 \frac{1}{2}$ to $2 \frac{1}{2}$ miles downstream below power canal at different datums. May 3, 1919, to Apr. 16, 1940, at present site upstream from power canal at datum $2.00 \mathrm{ft}$ lower. Altitude of gage if $4870 \mathrm{ft}$ (from topographic map).

Stage-d1scharge relation.--Defined by current-meter measurements below 2,800 cfs.

Remarks.--Flow since June 1915 includes water diverted from Strawberry Reservoir (capacity, 270,000 acre-ft) in Colorado River basin via Strawberry tunnel for irrigation in vicinity of Spanish Fork. Only annual peaks are shown (maximum observed prior to 1909; maximum dally 1909-1936).

Peak stages and discharges

\begin{tabular}{|c|c|c|c|c|c|c|c|}
\hline $\begin{array}{l}\text { Water } \\
\text { year }\end{array}$ & Date & $\begin{array}{l}\text { Gage } \\
\text { helght } \\
\text { (feet) }\end{array}$ & $\begin{array}{c}\text { Discharge } \\
\text { (cfs) }\end{array}$ & $\begin{array}{c}\text { Water } \\
\text { year }\end{array}$ & Date & $\begin{array}{c}\text { Gege } \\
\text { helght } \\
\text { (feet) }\end{array}$ & $\begin{array}{c}\text { Discharge } \\
\text { (cfs) }\end{array}$ \\
\hline 1890 & May 1890 & - & 1,040 & 1936 & May 5,1936 & - & 890 \\
\hline $\begin{array}{l}1903 \\
1904 \\
1905\end{array}$ & $\begin{array}{l}\text { June } 3,1903 \\
\text { May 16, } 1904 \\
\text { May } 23,1905\end{array}$ & $\begin{array}{l}- \\
-\end{array}$ & $\begin{array}{l}388 \\
415 \\
410\end{array}$ & $\begin{array}{l}1937 \\
1938 \\
1939 \\
1940\end{array}$ & $\begin{array}{lll}\text { May } & 10, & 1937 \\
\text { May } & 17, & 1938 \\
\text { May } & 31, & 1939 \\
\text { June } & 20, & 1940\end{array}$ & $\begin{array}{l}6.78 \\
5.87 \\
6.80 \\
3.87\end{array}$ & $\begin{array}{r}1,010 \\
694 \\
905 \\
541\end{array}$ \\
\hline $\begin{array}{l}1906 \\
1907 \\
1908 \\
1909 \\
1910\end{array}$ & $\begin{array}{ll}\text { May 12, } 1906 \\
\text { May 21, } 1907 \\
\text { July 29, } 1908 \\
\text { May 11, } 1909 \\
\text { Apr.27-29, } 1910\end{array}$ & $\begin{array}{l}- \\
- \\
-\end{array}$ & $\begin{array}{r}907 \\
1,970 \\
318 \\
1,530 \\
777\end{array}$ & $\begin{array}{l}1941 \\
1942 \\
1943 \\
1944 \\
1945\end{array}$ & $\begin{array}{lll}\text { Aug. } 10, & 1941 \\
\text { May } 26,1942 \\
\text { Aug. } 11,1943 \\
\text { May } 10,1944 \\
\text { May } 12,1945\end{array}$ & $\begin{array}{l}4.88 \\
4.72 \\
4.79 \\
5.42 \\
4.94\end{array}$ & $\begin{array}{l}776 \\
627 \\
568 \\
923 \\
696\end{array}$ \\
\hline $\begin{array}{l}1911 \\
1912 \\
1913 \\
1914 \\
1915\end{array}$ & $\begin{array}{l}\text { Jan. } 31,1911 \\
\text { May } 30,1912 \\
\text { May } 12,1913 \\
\text { May 10, } 1914 \\
\text { Apr. 30, } 1915\end{array}$ & $\begin{array}{l}- \\
\overline{-} \\
-\end{array}$ & $\begin{array}{r}755 \\
581 \\
545 \\
1,290 \\
330\end{array}$ & $\begin{array}{l}1946 \\
1947 \\
1948 \\
1949 \\
1950\end{array}$ & $\begin{array}{lr}\text { Apr. } 21, & 1946 \\
\text { July } 8, & 1947 \\
\text { July } 11, & 1948 \\
\text { July 3, } & 1949 \\
\text { June } 29,30,1950\end{array}$ & $\begin{array}{l}4.96 \\
5.20 \\
5.25 \\
5.79 \\
5.44\end{array}$ & $\begin{array}{l}645 \\
664 \\
664 \\
841 \\
679\end{array}$ \\
\hline $\begin{array}{l}1916 \\
1917 \\
\end{array}$ & $\begin{array}{l}\text { Apr } 29, \text { May } 9,1916 \\
\text { May } 16,1917\end{array}$ & $\overline{-}$ & $\begin{array}{l}1,000 \\
1,110\end{array}$ & $\begin{array}{l}1951 \\
1952\end{array}$ & $\begin{array}{lll}\text { July } & 5,1951 \\
\text { May } & 3,1952\end{array}$ & $\begin{array}{l}5.49 \\
9.83\end{array}$ & $\begin{array}{r}622 \\
3,610\end{array}$ \\
\hline $\begin{array}{l}1919 \\
1920\end{array}$ & $\begin{array}{lrl}\text { July } 2, & 1919 \\
\text { May } 22, & 1920\end{array}$ & - & $\begin{array}{r}528 \\
1,520\end{array}$ & $\begin{array}{l}1954 \\
1955\end{array}$ & $\begin{array}{lll}\text { July 13, } & 1954 \\
\text { Aug. } 7, & 1955\end{array}$ & $\begin{array}{l}5.77 \\
5.98\end{array}$ & $\begin{array}{l}622 \\
732\end{array}$ \\
\hline $\begin{array}{l}1921 \\
1922 \\
1923 \\
1924 \\
1925 \\
\end{array}$ & $\begin{array}{lr}\text { May } & 16,1921 \\
\text { May } & 7,1922 \\
\text { May } 20, & 1923 \\
\text { May } 9, & 1924 \\
\text { July } 1, & 1925\end{array}$ & $\begin{array}{l}- \\
\overline{-} \\
-\end{array}$ & $\begin{array}{r}998 \\
1,440 \\
1,140 \\
603 \\
586\end{array}$ & $\begin{array}{l}1956 \\
1957 \\
1958 \\
1959 \\
1960\end{array}$ & $\begin{array}{lr}\text { Aug. 13, } & 1956 \\
\text { June 4, } & 1957 \\
\text { May 21, } & 1958 \\
\text { July 14, } & 1959 \\
\text { Sept. 5, } & 1960\end{array}$ & $\begin{array}{l}6.04 \\
6.16 \\
7.03 \\
7.30 \\
7.04\end{array}$ & $\begin{array}{l}688 \\
758 \\
880 \\
958 \\
656\end{array}$ \\
\hline 1933 & June $1,2,1933$ & - & 617 & 1961 & Aug. & 7.00 & 622 \\
\hline 1935 & May 28,1935 & $=$ & 551 & 1963 & $\begin{array}{l}\text { Feb. } 12,1962 \\
\text { Aug. } 7,1963 \\
\end{array}$ & & $\begin{array}{r}1,030 \\
712 \\
\end{array}$ \\
\hline
\end{tabular}


1515. Spanish Fork near Spanish Fork, Utah

Location.--Lat $40^{\circ} 04^{\prime}$, long $111^{\circ} 34^{\prime}$, in middle half of $S \frac{1}{2}$ sec.2, T.9 S., R.3 E., half a mile downstream from Bureau of Reclamation power canal, about half a mile upstream from intake of East Bench Canal, and 5 miles southeast of Spanish Fork.

Drainage area.--670 sq $\mathrm{ml}$, approximately.

Gage.--Nonrecording. Prior to Ju1y 31,1912 , at site about half a mile downstream and about $600 \mathrm{ft}$ upstream from East Bench Canal diversion at different datum. Aug. 1 to Dec. 31, 1912, at site about a quarter of a mile downstream at different datum.

Stage-discharge relation.--Defined by current-meter measurements below 720 cfs.

Remarks.--Diversion by Bureau of Reclamation power canal half a mile urstream and after June 1915 by transmountain diversion from Strawberry Reservoir. Records Jan. 1, 1911, to Sept. 30, 1917, furnished by Bureau of Reclamation. Only annual peaks are shown.

\begin{tabular}{|c|c|c|c|c|c|c|c|c|c|}
\hline $\begin{array}{l}\text { Water } \\
\text { year }\end{array}$ & & Date & $\begin{array}{c}\text { Gage } \\
\text { height } \\
\text { (feet) }\end{array}$ & $\begin{array}{c}\text { Discharge } \\
(\text { cfs })\end{array}$ & $\begin{array}{l}\text { Water } \\
\text { year }\end{array}$ & & Date & $\begin{array}{c}\text { Gage } \\
\text { height } \\
\text { (feet) }\end{array}$ & $\begin{array}{c}\text { Discharge } \\
\text { (cfs) }\end{array}$ \\
\hline $\begin{array}{l}1909 \\
1910\end{array}$ & $\begin{array}{l}\text { May } \\
\text { Apr. }\end{array}$ & $\begin{array}{ll}11, & 1909 \\
28, & 1910\end{array}$ & 5.6 & $\begin{array}{r}\text { a. }, 550 \\
724\end{array}$ & $\begin{array}{l}1914 \\
1915\end{array}$ & $\begin{array}{l}\text { May } \\
\text { Apr. }\end{array}$ & $\begin{array}{ll}10, & 1914 \\
30, & 1915\end{array}$ & $\begin{array}{l}9.83 \\
5.88\end{array}$ & $\begin{array}{r}1,200 \\
283\end{array}$ \\
\hline $\begin{array}{l}1911 \\
1912 \\
1913\end{array}$ & $\begin{array}{l}\text { Jan. } \\
\text { May }\end{array}$ & $\begin{array}{ll}31, & 1911 \\
30, & 1912 \\
12, & 1913\end{array}$ & $\begin{array}{l}2.55 \\
2.16 \\
7.38\end{array}$ & $\begin{array}{l}694 \\
500 \\
459\end{array}$ & $\begin{array}{l}1916 \\
1917\end{array}$ & $\begin{array}{l}\text { Mar. } \\
\text { May }\end{array}$ & $\begin{array}{l}21,1916 \\
16,1917\end{array}$ & $\begin{array}{l}9.08 \\
9.47\end{array}$ & $\begin{array}{r}879 \\
1,020\end{array}$ \\
\hline
\end{tabular}

a Maximum observed.

1520. Spanish Fork near Lake Shore, Utah

(Published as "at Lake Shore" [1909,1913-25)

Location. --Lat $40^{\circ} 09^{\prime} 30^{\prime \prime}$, 1ong $111^{\circ} 43^{\prime} 50^{\prime \prime}$, in $\mathrm{SE} \frac{1}{4} \mathrm{SE} \frac{1}{4}$ sec.32, T.7 S., R.2 E., on left bank 1 mile upstream from mouth and $2 \frac{1}{2} \mathrm{miles}$ north of Lake Shore.

Drainage area. $--700 \mathrm{sq} \mathrm{mi}$, approximately.

Gage.--Nonrecording prior to Jan. 23, 1938, at several sites about 3 miles upstream at various datums; recording thereafter. Jan. 23, 1938, to Nar. 23, 1953, at different datums. Mar. 24, 1953, to Sept. 15, 1957, at datum

$4.0 \mathrm{ft}$ higher. A1titude of gage is 4,500 ft (from topographic map).

Stage-discharge relation.--Defined by current-meter measurements below $530 \mathrm{cfs}$.

Remarks. - Flow is regulated by many small diversions for irrigation. Fecords for 1911-25 furnished by Bureau of Reclamation. Only annual peaks are shown (maximum observed prior to 1938).

Peak stages and discharges

\begin{tabular}{|c|c|c|c|c|c|c|c|}
\hline $\begin{array}{l}\text { Water } \\
\text { year }\end{array}$ & Date & $\begin{array}{l}\text { Gage } \\
\text { helght } \\
\text { (feet) }\end{array}$ & $\begin{array}{c}\text { Discharge } \\
\text { (cfs) }\end{array}$ & $\begin{array}{l}\text { Water } \\
\text { year }\end{array}$ & Date & $\begin{array}{l}\text { Gage } \\
\text { height } \\
\text { (feet) }\end{array}$ & $\begin{array}{c}\text { Discharge } \\
\text { (cfs) }\end{array}$ \\
\hline $\begin{array}{l}1904 \\
1905 \\
1906 \\
1907 \\
\end{array}$ & $\begin{array}{l}\text { May } 11,12,13,1904 \\
\text { Apr. } 10,1905 \\
\text { May } 6,1906 \\
\text { May } 21,1907\end{array}$ & $\begin{array}{l}- \\
-\end{array}$ & $\begin{array}{l}333 \\
129 \\
552 \\
608\end{array}$ & $\begin{array}{l}1921 \\
1922 \\
1923 \\
1924 \\
1925 \\
\end{array}$ & $\begin{array}{lrl}\text { May } & 5, & 1921 \\
\text { May } & 7, & 1922 \\
\text { May } 13, & 1923 \\
\text { July } & 3, & 1924 \\
\text { July } & 5, & 1925 \\
\end{array}$ & $\begin{array}{l}- \\
- \\
- \\
-\end{array}$ & $\begin{array}{r}671 \\
1,100 \\
1,060 \\
179 \\
276 \\
\end{array}$ \\
\hline $\begin{array}{l}1909 \\
1910\end{array}$ & $\begin{array}{lll}\text { May } 11, & 1909 \\
\text { Mar. } 23, & 1910\end{array}$ & $\overline{-}$ & $\begin{array}{r}1,430 \\
675\end{array}$ & $\begin{array}{l}1938 \\
1939 \\
1940\end{array}$ & $\begin{array}{ll}\text { May } 19, & 1938 \\
\text { Mar. 1s, } 1939 \\
\text { Mar. 2s, } 1940\end{array}$ & $\begin{array}{l}5.18 \\
9.16 \\
6.45\end{array}$ & $\begin{array}{l}437 \\
449 \\
252\end{array}$ \\
\hline $\begin{array}{l}1911 \\
1912 \\
1913 \\
1914 \\
1915\end{array}$ & $\begin{array}{l}\text { Jan. } 31,1911 \\
\text { May } 31,1912 \\
\text { Apr. } 2,1913 \\
\text { May 11, } 1914 \\
\text { Apr. } 22,1915\end{array}$ & $\begin{array}{l}- \\
\overline{-} \\
\overline{-}\end{array}$ & $\begin{array}{l}570 \\
213 \\
945 \\
942 \\
336\end{array}$ & $\begin{array}{l}1941 \\
1942 \\
1943 \\
1944 \\
1945\end{array}$ & $\begin{array}{l}\text { Aug. } 11,1941 \\
\text { Apr. } 12,1942 \\
\text { Mar. } 10,1943 \\
\text { May } 15,1944 \\
\text { May } 9,1945\end{array}$ & $\begin{array}{l}6.42 \\
9.17 \\
\text { S.98 } \\
- \\
-\end{array}$ & $\begin{array}{r}220 \\
382 \\
334 \\
2720 \\
541\end{array}$ \\
\hline $\begin{array}{l}1916 \\
1917 \\
1918 \\
1919 \\
1920\end{array}$ & $\begin{array}{l}\text { Apr. } 29,1916 \\
\text { May } 16,1917 \\
\text { Mar. 25, } 1918 \\
\text { Apr. 21, } 1919 \\
\text { May } 23,24,1920\end{array}$ & $\begin{array}{l}- \\
- \\
-\end{array}$ & $\begin{array}{r}792 \\
925 \\
543 \\
327 \\
1,030\end{array}$ & $\begin{array}{l}1946 \\
1947 \\
1948 \\
1949\end{array}$ & $\begin{array}{l}\text { Apr. } 19,1946 \\
\text { Mar. } 23,1947 \\
\text { Apr. } 22,194 \mathrm{~S} \\
\text { May } 21,1949\end{array}$ & $\overline{-}$ & $\begin{array}{r}548 \\
\text { a360 } \\
338 \\
325\end{array}$ \\
\hline
\end{tabular}

a Maximum dat 
Peak stages and discharges of Span1sh Fork near Lake Shore, Utah--Contined

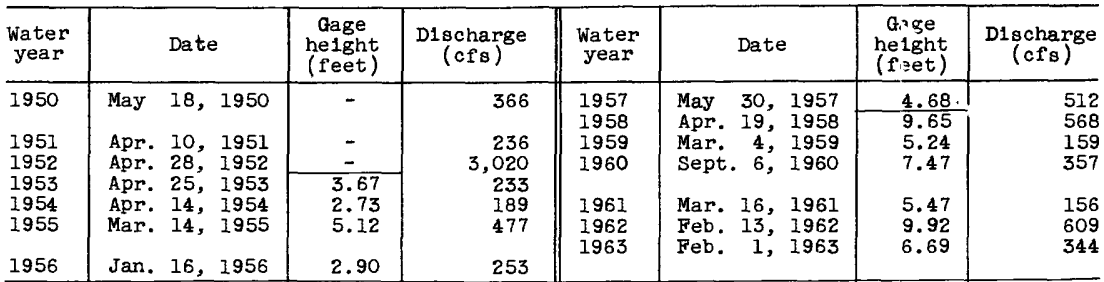

1525. Hobble Creek near Springville, Utah

Location.--Lat $40^{\circ} 09^{\prime} 30^{\prime \prime}$, long $111^{\circ} 31^{\prime} 30^{\prime \prime}$, in $\mathrm{NE} \frac{1}{4}$ sec.6, T.8 S., R.4 E., on right bank l,000 ft downstream from Springville hydroelectric plant,

$1 \frac{1}{4}$ miles downstream from Right Fork, and 4 miles southeast of Springville.

Drainage area.--105 sq mi. Mean altitude, 7,110 ft.

Gage.--Nonrecording prior to Apr. 17, 1945; recording thereafter. Prior to June 1, 1909, at site 200 ft downstream at different datum (destroyed by flood). June 1, 1909, to Dec. 31, 1916, at site $800 \mathrm{ft}$ upstream at different datum. Apr. 17, 1945, to July 23, 1952, at datum $1.70 \mathrm{ft}$ higher. Altitude of gage is 4,920 ft (from topographic map).

Stage-discharge relation.--Defined by current-meter measurements below 300 cfs. Considerable shifting at high stages.

Remarks. - -Base for partial-duration series, $120 \mathrm{cfs}$. Only annual peaks are shown prior to 1945 (maximum observed prior to 1917).

Peak stages and discharges

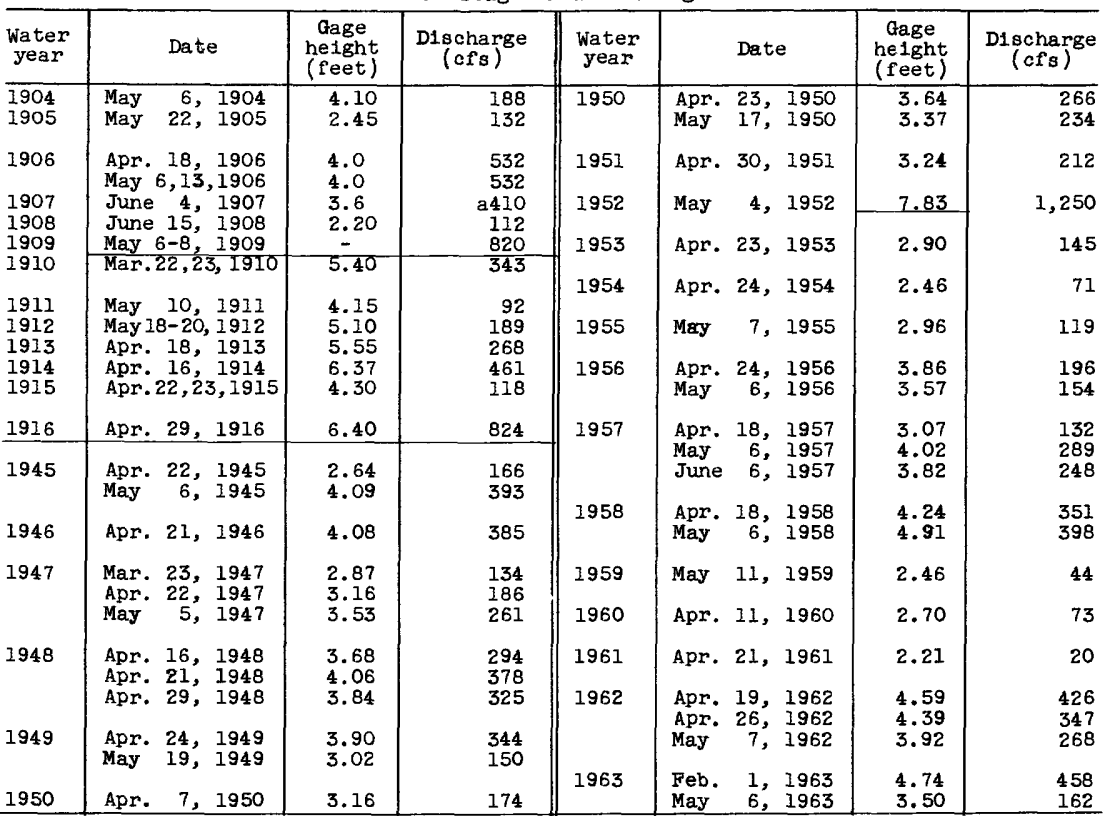

a During per1od June to September, 1907. 
1535. Provo River near Kamas, Utah

Location.--Lat $40^{\circ} 35^{\prime} 00^{\prime \prime}$, long $110^{\circ} 00^{\prime} 30^{\prime \prime}$, in $\mathrm{NE} \frac{1}{4}$ sec.2, T.3 S., R.8 E., on right bank 3 miles upstream from Soapstone Creek and 14 miles east cf Kamas.

Drainage area.--29.6 sq $\mathrm{ml}$. Mean altitude, 9,710 ft.

Gage.--Recording. Altitude of gage is $8,110 \mathrm{ft}$ (by barometer).

Stage-discharge relation.--Defined by current-meter measurement below $\varepsilon 00 \mathrm{cfs}$.

Remarks.--Flow regulated by several small lakes at headwaters, which have dams and outlet works. Comblned regulated capacity, 10,841 acre-ft. Station is Immediately above outlet of Duchesne tunnel. Base for partial-duration series, $400 \mathrm{cfs}$.

Peak stages and discharges

\begin{tabular}{|c|c|c|c|c|c|c|c|c|c|}
\hline $\begin{array}{c}\text { Water } \\
\text { year }\end{array}$ & \multicolumn{2}{|r|}{ Date } & $\begin{array}{l}\text { Gage } \\
\text { helght } \\
\text { (feet) }\end{array}$ & $\begin{array}{c}\text { D1scharge } \\
\text { (cfs) }\end{array}$ & $\begin{array}{l}\text { Water } \\
\text { year }\end{array}$ & & Date & $\begin{array}{l}\text { Gage } \\
\text { height } \\
\text { (feet) }\end{array}$ & $\begin{array}{c}\text { Discharge } \\
\text { (cfs) }\end{array}$ \\
\hline 1950 & $\begin{array}{l}\text { June } \\
\text { June } \\
\text { June }\end{array}$ & $\begin{array}{r}1,1950 \\
5,1950 \\
13,1950\end{array}$ & $\begin{array}{l}3.26 \\
3.16 \\
2.94\end{array}$ & $\begin{array}{l}591 \\
539 \\
465\end{array}$ & 1957 & $\begin{array}{l}\text { May } \\
\text { June } \\
\text { June }\end{array}$ & $\begin{array}{rr}19, & 1956 \\
1, & 1956 \\
6, & 1957\end{array}$ & $\begin{array}{l}3.10 \\
3.26 \\
3.66\end{array}$ & $\begin{array}{l}494 \\
536 \\
825\end{array}$ \\
\hline 1951 & $\begin{array}{l}\text { May } \\
\text { June }\end{array}$ & $\begin{array}{ll}27, & 1951 \\
15, & 1951\end{array}$ & $\begin{array}{l}3.49 \\
2.95\end{array}$ & $\begin{array}{l}765 \\
495\end{array}$ & $\begin{array}{l}1958 \\
1959\end{array}$ & $\begin{array}{l}\text { May } \\
\text { June }\end{array}$ & $\begin{array}{r}26,1958 \\
6, \quad 1959\end{array}$ & $\begin{array}{l}3.39 \\
2.52\end{array}$ & $\begin{array}{l}554 \\
314\end{array}$ \\
\hline 1952 & $\begin{array}{l}\text { May } \\
\text { June }\end{array}$ & $\begin{array}{rr}14, & 1952 \\
6, & 1952\end{array}$ & $\begin{array}{l}2.83 \\
3.09\end{array}$ & $\begin{array}{l}459 \\
554\end{array}$ & 1960 & May & 12,1960 & 3.08 & 456 \\
\hline 1953 & June & 13,1953 & 3.13 & 576 & 1961 & May & 11,1961 & 2.55 & 204 \\
\hline 1954 & May & 9,1954 & 2.58 & 345 & 1962 & June & 13,1962 & 3.14 & 430 \\
\hline 1955 & May & 22,1955 & 2.83 & 454 & 1963 & May & 20,1963 & 3.10 & 394 \\
\hline
\end{tabular}

1550. Provo River near Hallstone, Utah

Location.--Lat $40^{\circ} 36^{\prime}$, long $111^{\circ} 22^{\prime}$, in SE⿺ sec.34, T.2 S., R.5 E., on right bank 3 miles upstream from Ross Creek and Hallstone.

Drainage area.--233 sq mi. Mean altitude, 8,600 ft.

Gage.--Recording. Altitude of gage is 6,100 ft (from river-profile maf).

Stage-discharge relation.--Defined by current-meter measurements below 3,100 cfs. Unstable above $2,000 \mathrm{cfs}$.

Remarks.--Records include flow of Weber-Provo diversion canal and Duchesne tunnel. Flow affected by irrigation diversions above station and by storage in several small reservoirs at headwaters. Base for partial-duraticn series, $1,200 \mathrm{cfs}$.

Peak stages and discharges

\begin{tabular}{|c|c|c|c|c|c|c|c|c|c|}
\hline $\begin{array}{l}\text { Water } \\
\text { year }\end{array}$ & \multicolumn{2}{|r|}{ Date } & $\begin{array}{c}\text { Clage } \\
\text { helght } \\
\text { (feet) }\end{array}$ & $\begin{array}{c}\text { Discharge } \\
\text { (cfs) }\end{array}$ & $\begin{array}{l}\text { Water } \\
\text { year }\end{array}$ & & Date & $\begin{array}{l}\text { Gage } \\
\text { helght } \\
\text { (feet) }\end{array}$ & $\begin{array}{c}\text { Discharge } \\
\text { (cfs) }\end{array}$ \\
\hline 1950 & $\begin{array}{l}\text { June } \\
\text { June } \\
\text { June }\end{array}$ & $\begin{array}{r}2,1950 \\
7,1950 \\
14,1950\end{array}$ & $\begin{array}{l}6.24 \\
5.81 \\
5.22\end{array}$ & $\begin{array}{l}2,150 \\
1,850 \\
1,350\end{array}$ & 1957 & $\begin{array}{l}\text { May } \\
\text { May } \\
\text { June } \\
\text { June }\end{array}$ & 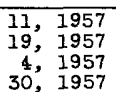 & $\begin{array}{l}4.68 \\
4.72 \\
7.28 \\
5.76\end{array}$ & $\begin{array}{l}1,30 \mathrm{C} \\
1,30 \mathrm{C} \\
3,88 \mathrm{C} \\
2,17 \mathrm{C}\end{array}$ \\
\hline 1951 & $\begin{array}{l}\text { May } \\
\text { June }\end{array}$ & $\begin{array}{ll}29, & 1951 \\
17, & 1951\end{array}$ & $\begin{array}{l}6.43 \\
4.84\end{array}$ & $\begin{array}{l}2,190 \\
1,250\end{array}$ & 1958 & $\begin{array}{l}\text { May } \\
\text { May }\end{array}$ & $\begin{array}{ll}12, & 1958 \\
22, & 1958\end{array}$ & $\begin{array}{l}4.77 \\
6.30\end{array}$ & $\begin{array}{l}1,56 \mathrm{C} \\
2,82 \mathrm{C}\end{array}$ \\
\hline 1952 & $\begin{array}{l}\text { May } \\
\text { May } \\
\text { May }\end{array}$ & 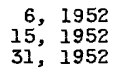 & $\begin{array}{l}5.69 \\
5.72 \\
5.65\end{array}$ & $\begin{array}{l}1,730 \\
1,820 \\
1,820\end{array}$ & 1959 & $\begin{array}{l}\text { June } \\
\text { June }\end{array}$ & $\begin{array}{r}7,1958 \\
8,1959\end{array}$ & $\begin{array}{l}5.64 \\
5.55\end{array}$ & $\begin{array}{l}1,97 \mathrm{C} \\
1,74 \mathrm{C}\end{array}$ \\
\hline 1953 & June & 14,1953 & 6.03 & 2,220 & 1960 & May & 13,1960 & 6.08 & a2, 226 \\
\hline 1954 & May & 14,1954 & 4.70 & 1,480 & 1961 & May & 29,1961 & 4.39 & 1,090 \\
\hline 1955 & $\begin{array}{l}\text { May } \\
\text { May } \\
\text { June }\end{array}$ & $\begin{array}{ll}12, & 1955 \\
23, & 1955 \\
10, & 1955\end{array}$ & $\begin{array}{l}5.10 \\
5.20 \\
5.74\end{array}$ & $\begin{array}{l}1,630 \\
1,670 \\
2,020\end{array}$ & 1962 & $\begin{array}{l}\text { May } \\
\text { June }\end{array}$ & $\begin{array}{r}7, \quad 1962 \\
12,1962\end{array}$ & 6.38 & a3, $\overline{05 c}$ \\
\hline 1956 & $\begin{array}{l}\text { May } \\
\text { May }\end{array}$ & $\begin{array}{ll}10, & 1956 \\
20, & 1956\end{array}$ & $\begin{array}{l}4.79 \\
6.32\end{array}$ & $\begin{array}{l}1,540 \\
3,030\end{array}$ & 1963 & & 1,1963 & 6.80 & a3, 281 \\
\hline
\end{tabular}

a Annual peak only. 
1555. Provo River near Charleston, Utah

Location. - Lat $40^{\circ} 29^{\prime}$, long $111^{\circ} 28^{\prime}$, in SW $\frac{1}{4}$ sec.11, T.4 S., R.4 E., 900 ft upstream from Snake Creek and $1 \frac{1}{2}$ miles northeast of Charleston.

Drainage area. $--380 \mathrm{sq} \mathrm{ml}$, approximately.

Gage.--Recording. Prior to vet. 16, 1943, at different site and datum.

oct. 16, 1943, to Sept. 30, 1945, at datum $0.85 \mathrm{ft}$ higher. Altitude of gage is about $5,460 \mathrm{ft}$ (from river-profile map).

Stage-discharge relation.--Defined by current-meter measurements below 1,700 cf's.

Remarks --Records prior to October 1945, furnished by Bureau of Reclamation. Ma iv liversions above station for irrigation. Records include flow of We, r-Provo diversion canal. Base for partial-duration series, $800 \mathrm{cfs}$.

Peak stages and discharges

\begin{tabular}{|c|c|c|c|c|c|c|c|c|c|}
\hline $\begin{array}{l}\text { Water } \\
\text { year }\end{array}$ & \multicolumn{2}{|r|}{ Date } & $\begin{array}{c}\text { Gage } \\
\text { he ight } \\
\text { (feet) }\end{array}$ & $\begin{array}{c}\text { Discharge } \\
(\mathrm{cfs})\end{array}$ & $\begin{array}{l}\text { Water } \\
\text { year }\end{array}$ & \multicolumn{2}{|r|}{ Date } & $\begin{array}{l}\text { Gage } \\
\text { helght } \\
\text { (feet) }\end{array}$ & $\begin{array}{c}\text { Discharge } \\
(\mathrm{cfs})\end{array}$ \\
\hline 1938 & $\begin{array}{l}\text { May } \\
\text { May }\end{array}$ & $\begin{array}{ll}16, & 1938 \\
29, & 1938\end{array}$ & $\begin{array}{l}3.35 \\
3.65\end{array}$ & $\begin{array}{l}1,630 \\
1,650\end{array}$ & 1945 & $\begin{array}{l}\text { June } \\
\text { June } 2\end{array}$ & $\begin{array}{rr}6, & 1945 \\
23, & 1945\end{array}$ & $\begin{array}{r}2.75 \\
2.59 \\
\end{array}$ & $\begin{array}{l}1,250 \\
1,100\end{array}$ \\
\hline 1939 & May & 5, 1939 & 2.33 & 633 & 1946 & $\begin{array}{l}\text { Apr. } 2 \\
\text { June }\end{array}$ & $\begin{array}{rr}21, & 1946 \\
6, & 1946\end{array}$ & $\begin{array}{l}3.61 \\
3.26\end{array}$ & $\begin{array}{l}1,280 \\
1,030\end{array}$ \\
\hline 1940 & May & 16,1940 & 2.81 & 720 & 1947 & May & 5, 1947 & 2.57 & 1,470 \\
\hline .941 & May & 14,1941 & 3.05 & 1,030 & & $\begin{array}{l}\text { May } 2 \\
\text { June }\end{array}$ & $\begin{array}{rr}28, & 1947 \\
9, & 1947\end{array}$ & $\begin{array}{l}2.85 \\
2.77\end{array}$ & $\begin{array}{l}1,620 \\
1,550\end{array}$ \\
\hline 1942 & $\begin{array}{l}\text { May } \\
\text { June }\end{array}$ & $\begin{array}{r}27,1942 \\
8,1942\end{array}$ & $\begin{array}{l}3.56 \\
2.72\end{array}$ & $\begin{array}{r}1,300 \\
843\end{array}$ & 1948 & May & 20,1948 & 3.45 & 1,160 \\
\hline 1943 & $\begin{array}{l}\text { Apr. } \\
\text { May } \\
\text { May }\end{array}$ & $\begin{array}{rr}24, & 1943 \\
4, & 1943 \\
29, & 1943 \\
\end{array}$ & $\begin{array}{l}3.22 \\
3.62 \\
3.00 \\
\end{array}$ & $\begin{array}{r}1,110 \\
1,330 \\
995 \\
\end{array}$ & 1949 & $\begin{array}{l}\text { May } \\
\text { May } \\
\text { May }\end{array}$ & $\begin{array}{rr}4, & 1949 \\
15, & 1949 \\
27, & 1949\end{array}$ & $\begin{array}{l}3.40 \\
3.91 \\
3.76\end{array}$ & $\begin{array}{r}966 \\
1,330 \\
1,230\end{array}$ \\
\hline 1944 & $\begin{array}{l}\text { May } \\
\text { June }\end{array}$ & $\begin{array}{rr}15, & 1944 \\
2, & 1944\end{array}$ & $\begin{array}{l}3.31 \\
3.22\end{array}$ & $\begin{array}{l}1,580 \\
1,640\end{array}$ & 1950 & June 1 & $\begin{array}{ll}12, & 1949 \\
2, & 1950\end{array}$ & 4.27 & 1,740 \\
\hline 1945 & May & 11,1945 & 2.74 & 1,230 & & June 1 & 14,1950 & $\begin{array}{l}3.00 \\
3.42 \\
\end{array}$ & 1,100 \\
\hline
\end{tabular}

1560. Snake Creek near Charleston, Utah

Location.--Lat $40^{\circ} 29^{\prime}$, long $111^{\circ} 28^{\prime}$, in SW $\frac{1}{4}$ sec.11, T.4 S., R.4 E., 600 ft upstream from mouth and $1 \frac{1}{2}$ miles northeast of Charleston.

Drainage area. $--38.6 \mathrm{sq} \mathrm{mi}$.

Gage.--Recording. Altitude of gage is 5,460 ft (from river-profile map). Stage-discharge relation.--Defined by current-meter measurements.

Remarks.--Records prior to October 1945, furnished by Bureau of Raclamation. Diversions above station for irrigation. Only annual peaks are shown.

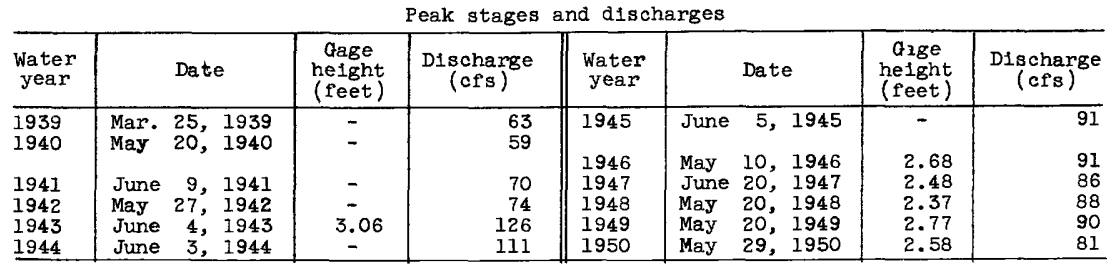


1585. Round Valley Creek near Wallsburg, Utah

Location. --Lat $40^{\circ} 24^{\prime} 30^{\prime \prime}$, long $111^{\circ} 28^{\prime} 30^{\prime \prime}$, in $\mathrm{SE} \frac{1}{4}$ sec.3, T.5 S., R.4 E., 1,900 ft upstream from high-water line of Deer Creek Reservoir and $3 \frac{1}{4}$ miles northwest of Wallsburg.

Drainage area. $--71.9 \mathrm{sq} \mathrm{mi}$.

Gage.--Recording. Prior to Mar. 20, 1940, at site $500 \mathrm{ft}$ downstream at different datum. Altitude of gage is $5,480 \mathrm{ft}$ (from river-profile map).

Stage-discharge relation.--Defined by current-meter measurements below $110 \mathrm{cf}$ prior to March 1940 and below 140 cfs thereafter.

Remarks.--Records prior to October 1945, furnished by Bureau of Reclamation. Many diversions above station for irrigation. Only annual peaks are shown.

\begin{tabular}{|c|c|c|c|c|c|c|c|}
\hline $\begin{array}{l}\text { Water } \\
\text { year }\end{array}$ & Date & $\begin{array}{l}\text { Gage } \\
\text { helght } \\
\text { (feet) }\end{array}$ & $\begin{array}{c}\text { D1scharge } \\
\text { (cfs) }\end{array}$ & $\begin{array}{l}\text { Water } \\
\text { year }\end{array}$ & Date & $\begin{array}{l}\text { Gage } \\
\text { he1ght } \\
\text { (feet) }\end{array}$ & $\begin{array}{c}\text { Discharge } \\
\text { (cfs) }\end{array}$ \\
\hline $\begin{array}{l}1939 \\
1940\end{array}$ & $\begin{array}{ll}\text { Mar. } 16, & 1939 \\
\text { Feb. } 28, & 1940\end{array}$ & $\begin{array}{l}2.55 \\
- \\
\end{array}$ & $\begin{array}{r}201 \\
40 \\
\end{array}$ & \multirow{2}{*}{$\begin{array}{l}1945 \\
1946 \\
1947 \\
1948 \\
1949 \\
1950\end{array}$} & \multirow{2}{*}{$\begin{array}{lrl}\text { May } & 8, & 1945 \\
& \\
\text { Apr. } & 21, & 1946 \\
\text { May } 4, & 1947 \\
\text { Apr. } & 30, & 1948 \\
\text { Apr. } & 25, & 1949 \\
\text { Apr. } & 27, & 1950\end{array}$} & \multirow{2}{*}{$\begin{array}{c}- \\
3.24 \\
2.85 \\
3.48 \\
3.72 \\
4.26\end{array}$} & \multirow{2}{*}{$\begin{array}{r}163 \\
179 \\
96 \\
120 \\
115 \\
161 \\
\end{array}$} \\
\hline $\begin{array}{l}1941 \\
1942 \\
1943 \\
1944\end{array}$ & $\begin{array}{lll}\text { May } & 13, & 1941 \\
\text { Dec. } & 3,1941 \\
\text { Mar. } & 9,1943\end{array}$ & $\begin{array}{l}- \\
- \\
-\end{array}$ & $\begin{array}{r}90 \\
78 \\
93 \\
105 \\
\end{array}$ & & & & \\
\hline
\end{tabular}

a occurred between May 6 and 20,1944 .

\section{Provo River below Deer Creek Dam, Utah}

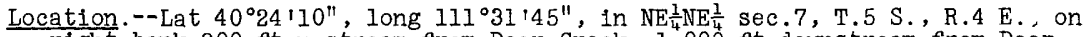
right bank $200 \mathrm{ft}$ upstream from Deer Creek, 1,000 ft downstream from Deer Creek Dam, and 4 miles northeast of Vivian Park.

Drainage area. $--560 \mathrm{sq} \mathrm{mi}$.

Gage.--Recording. Altitude of gage is 5,270 ft (from topographic map).

Stage-discharge relation.--Defined by current-meter measurements.

Remarks.--Flow affected by regulation of Deer Creek Reservoir and by Irrigati diversions above and water diverted to Provo River by iWeber-Provo diversi canal and Duchesne tunnel. Only annual peaks are shown.

Peak stages and discharges

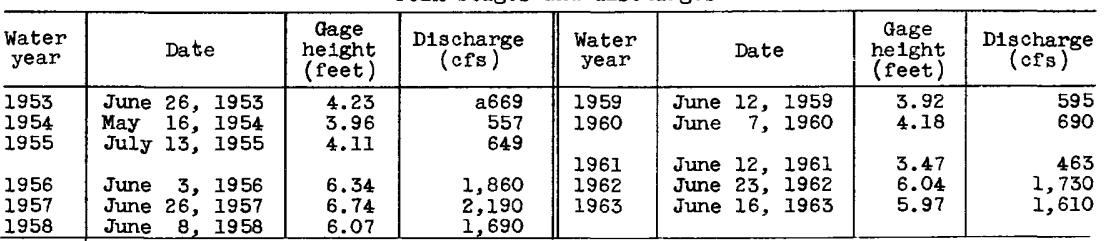

a Maximum for period May to September.

1600. Deer Creek near Wildwood, Utah

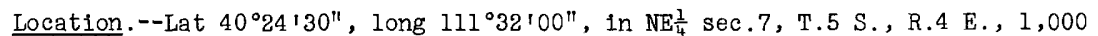
ft upstream from mouth and 2 miles northeast of Wildwood.

Drainage area.--26 sq $\mathrm{mi}$, approximately. Mean altitude, 7,450 ft.

Gage.--Recording. Altitude of gage is 5,300 ft (from topographic map).

Stage-discharge relation.--Defined by current-meter measurements below $85 \mathrm{cfs}$.

Remarks.--Base for partial-duration series, $50 \mathrm{cfs}$. Only annual peaks are shown prior to 1948 . 
Peak stages and discharges of Deer Creek near W1ldwood, Utah

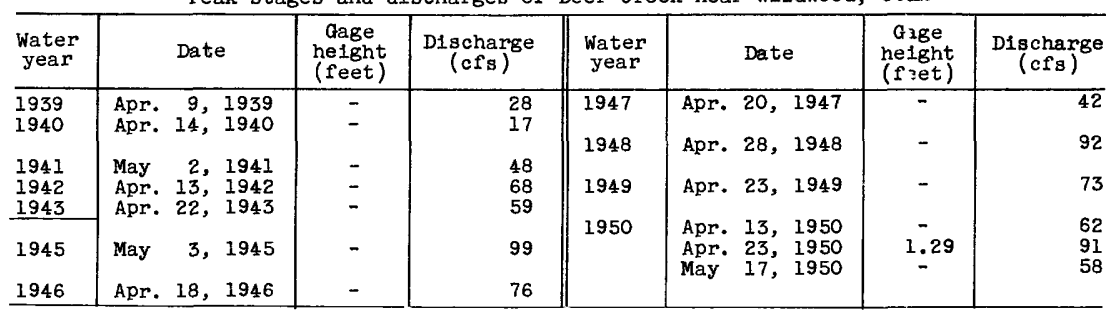

1605. Provo River near W1ldwood, Utah

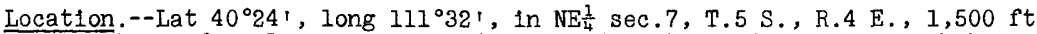
downstream from Deer Creek, half a mile downstream from Deer Creek Reservoir, and 2 miles northeast of Wildwood.

Drainage area. $-590 \mathrm{sq} \mathrm{ml}$, approximately.

Gage.--Recording. Prior to May 13, 1941, at site about two-thirds of a mile downstream at datum 11.70 ft lower.

Stage-discharge relation.--Defined by current-meter measurements.

Remarks.--Station is below diversions for irrigation in Heber Vajley and above those in vicinity of Provo. Flow regulated by Deer Creek Reservoir and small lakes at headwaters that serve as reservoirs. Small trensmountain diversions from Strawberry River drainage to Daniels Creek. Includes flow of Weber-Provo diversion canal. Only annual peaks are shown.

\begin{tabular}{|c|c|c|c|c|c|c|c|}
\hline $\begin{array}{l}\text { Water } \\
\text { year }\end{array}$ & Date & $\begin{array}{c}\text { Qage } \\
\text { helght } \\
\text { (feet) }\end{array}$ & $\begin{array}{c}\text { Discharge } \\
(\mathrm{cfs})\end{array}$ & $\begin{array}{l}\text { Water } \\
\text { year }\end{array}$ & Date & $\begin{array}{c}\text { Gage } \\
\text { height } \\
\text { (feet) }\end{array}$ & $\begin{array}{c}\text { Discharge } \\
(\mathrm{cfs})\end{array}$ \\
\hline $\begin{array}{l}1939 \\
1940\end{array}$ & $\begin{array}{lrr}\text { May } & 5, & 1939 \\
\text { May } & 16, & 1940 \\
\end{array}$ & - & $\begin{array}{l}766 \\
796 \\
\end{array}$ & 1945 & May 5,1945 & - & 844 \\
\hline $\begin{array}{l}1941 \\
1942 \\
1943 \\
1944 \\
\end{array}$ & 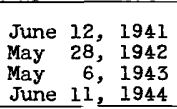 & $\begin{array}{l}- \\
- \\
-\end{array}$ & $\begin{array}{r}809 \\
900 \\
976 \\
1,100 \\
\end{array}$ & $\begin{array}{l}1946 \\
1947 \\
1948 \\
1949\end{array}$ & $\begin{array}{l}\text { May } 15,1946 \\
\text { May } 14,1947 \\
\text { May } 22,1948 \\
\text { May } 27, \text { June } 12, \\
\quad 1949\end{array}$ & $\begin{array}{l}3.92 \\
3.99 \\
4.59 \\
4.65\end{array}$ & $\begin{array}{r}891 \\
897 \\
1,350 \\
1,440\end{array}$ \\
\hline
\end{tabular}

1610. Provo River at Vivian Park, Utah

(Published as "at Forks" 1911-37)

Location. --Lat $40^{\circ} 21^{1} 40^{\prime \prime}$, long $111^{\circ} 33^{1} 45^{\prime \prime}$, in NW $\frac{1}{4} N W \frac{1}{4} \sec .25$, T.5 S., R.3 E., on right bank half a milé downstream from North Fork, 3,500 ft northwest of Vivian Park, and three-quarters of a mile upstream from South Fork.

Drainage area. $--600 \mathrm{sq} \mathrm{ml}$, approximately.

Gage.--Nonrecording prior to Nov. 13, 1933, at site three-quarters of a mile downstream at different datum; recording thereafter. Altitude of gage is $5,200 \mathrm{ft}$ (from topographic map).

Stage-discharge relation.--Defined by current-meter measurements below 3,000 cfs .

Remarks.--Flow regulated by Deer Creek Reservoir since December 1940. Flow also affected by irrigation diversions above reservoir. Recorls include flow of 'Weber-Provo diversion canal and Duchesne tunnei. Only annual peaks are shown (maximum observed prior to 1935). 
Peak stages and discharges of Provo River at Vivian Park, Utah

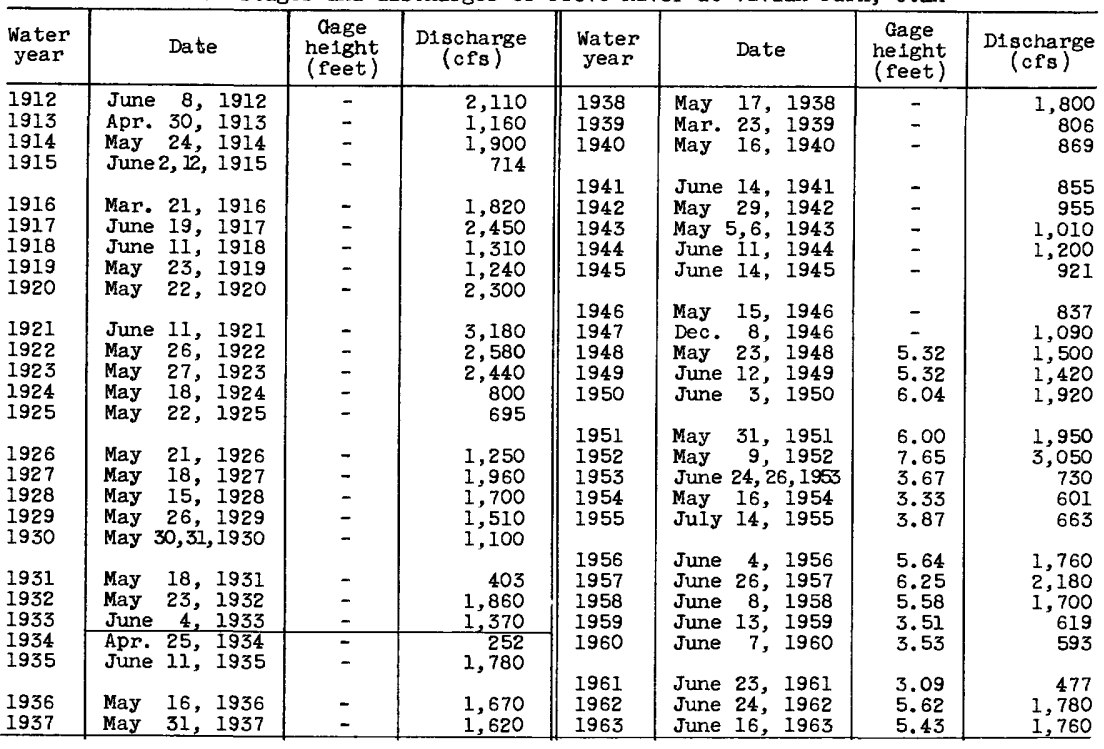

1615. South Fork Provo River at Vivian Park, Utah

(Published as "at Forks" 1911-37)

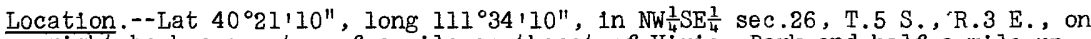
right bank a quarter of a mile southeast of Vivian Park and half a mile upstream from mouth.

Drainage area.--30 sq $\mathrm{m} 1$, approximately.

Gage.--Nonrecording prior to June 15, 1913, at site half a mile downstream at different datum and June 15, 1913, to Nov. 21, 1933, at site a quarter of a mile downstream at different datum; recording and Parshall flume thereafter. Altitude of gage is $5,240 \mathrm{ft}$ (from topographic map).

Stage-discharge relation.--Defined by current-meter measurements below $87 \mathrm{cfs}$. Minor shifting probabiy caused by changes in velocity of approach at flume.

Remarks.--Flow affected by irrigation diversions upstream. Only annual peaks are shown (maximum observed prior to 1934).

Peak stages and discharges

\begin{tabular}{|c|c|c|c|c|c|c|c|c|}
\hline $\begin{array}{l}\text { Water } \\
\text { year }\end{array}$ & Date & $\begin{array}{l}\text { Gage } \\
\text { helght } \\
\text { (feet) }\end{array}$ & $\begin{array}{c}\text { Discharge } \\
\text { (cfs) }\end{array}$ & $\begin{array}{l}\text { Water } \\
\text { year }\end{array}$ & & Date & $\begin{array}{l}\text { Gage } \\
\text { helght } \\
\text { (feet) }\end{array}$ & $\begin{array}{l}\text { Discharge } \\
\text { (cfs) }\end{array}$ \\
\hline $\begin{array}{l}1912 \\
1913 \\
1914 \\
1915\end{array}$ & $\begin{array}{l}\text { June 10, } 1912 \\
\text { June } 5,1913 \\
\text { May } 18,1914 \\
\text { Oct.4, Dec. } 4,6 \text {, } \\
1914\end{array}$ & $\begin{array}{r}4.05 \\
2.32 \\
2.91 \\
2.70\end{array}$ & $\begin{array}{l}74 \\
47 \\
58 \\
44\end{array}$ & $\begin{array}{l}1928 \\
1929 \\
1930\end{array}$ & $\begin{array}{l}\text { May } \\
\text { May } \\
\text { Oct. } \\
\text { Nov } \\
\text { Dec }\end{array}$ & $\begin{array}{l}28,1925 \\
26,1929 \\
9,10, \\
\text { v. } 11,12, \\
\text { c. } 1,2,1929\end{array}$ & $\begin{array}{l}1.68 \\
1.76 \\
1.44\end{array}$ & $\begin{array}{l}71 \\
79 \\
37\end{array}$ \\
\hline $\begin{array}{l}1916 \\
1917 \\
1918 \\
1919 \\
1920\end{array}$ & $\begin{array}{l}\text { May } 12,1916 \\
\text { May } 16-2,1917 \\
\text { Sept.23, } 1918 \\
\text { May 30, } 1919 \\
\text { May } 24,1920\end{array}$ & $\begin{array}{r}.76 \\
.92 \\
.66 \\
.62 \\
1.40\end{array}$ & $\begin{array}{l}50 \\
72 \\
45 \\
45 \\
96\end{array}$ & $\begin{array}{l}1931 \\
1932 \\
1933 \\
1934 \\
1935\end{array}$ & $\begin{array}{l}\text { Oct.1 } \\
\text { May } \\
\text { June } \\
\text { Dec. } \\
\text { June }\end{array}$ & 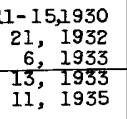 & $\begin{array}{r}1.30 \\
1.86 \\
1.52 \\
.94 \\
.96\end{array}$ & $\begin{array}{r}27 \\
104 \\
140 \\
32 \\
32\end{array}$ \\
\hline $\begin{array}{l}1921 \\
1922 \\
1923 \\
1924 \\
1925\end{array}$ & $\begin{array}{l}\text { May 31, } 1921 \\
\text { May } 27,1922 \\
\text { May 27, } 1923 \\
\text { Oct. 9, } 1923 \\
\text { Sept.19, } 1925\end{array}$ & $\begin{array}{l}1.40 \\
1.78 \\
1.88 \\
1.68 \\
1.48\end{array}$ & $\begin{array}{r}85 \\
123 \\
106 \\
46 \\
39\end{array}$ & $\begin{array}{l}1936 \\
1937 \\
1938 \\
1939 \\
1940\end{array}$ & $\begin{array}{l}\text { May } \\
\text { May } \\
\text { May } \\
\text { July } \\
\text { oct. }\end{array}$ & $\begin{array}{ll}16, & 1936 \\
18, & 1937 \\
18, & 1938 \\
29, & 1939 \\
18, & 1939\end{array}$ & $\begin{array}{r}1.39 \\
1.67 \\
1.46 \\
1.36 \\
.93\end{array}$ & $\begin{array}{l}56 \\
73 \\
60 \\
54 \\
31\end{array}$ \\
\hline $\begin{array}{l}1926 \\
1927\end{array}$ & $\begin{array}{l}\text { May } \\
\text { May } 18,1926 \\
1927\end{array}$ & $\begin{array}{l}1.60 \\
1.90\end{array}$ & $\begin{array}{l}55 \\
83\end{array}$ & $\begin{array}{l}1941 \\
1942\end{array}$ & $\begin{array}{l}\text { May } \\
\text { May }\end{array}$ & $\begin{array}{ll}14, & 1941 \\
27, & 1942\end{array}$ & $\begin{array}{l}1.20 \\
1.39\end{array}$ & $\begin{array}{l}46 \\
5 \overline{9}\end{array}$ \\
\hline
\end{tabular}


Peak stages and discharges of South Fork Provo River at Vivian Park, Utah--Continued

\begin{tabular}{|c|c|c|c|c|c|c|c|c|}
\hline $\begin{array}{c}\text { Water } \\
\text { year }\end{array}$ & \multicolumn{2}{|r|}{ Date } & $\begin{array}{l}\text { Gage } \\
\text { helght } \\
\text { (feet) }\end{array}$ & $\begin{array}{c}\text { Discharge } \\
(\text { cfs })\end{array}$ & $\begin{array}{c}\text { Water } \\
\text { year }\end{array}$ & Date & $\begin{array}{c}\text { Gage } \\
\text { nalght } \\
(\text { feet })\end{array}$ & $\begin{array}{c}\text { Discharge } \\
\text { (cfs) }\end{array}$ \\
\hline $\begin{array}{l}1943 \\
1944 \\
1945\end{array}$ & $\begin{array}{l}\text { Mar. } \\
\text { June } \\
\text { Feb. }\end{array}$ & $\begin{array}{ll}9, & 1943 \\
2, & 1944 \\
2, & 1945\end{array}$ & $\begin{array}{l}1.46 \\
1.17 \\
1.45\end{array}$ & $\begin{array}{l}65 \\
44 \\
62\end{array}$ & $\begin{array}{l}1954 \\
1955 \\
1956\end{array}$ & $\begin{array}{ll}\text { Jan. } 25, & 1954 \\
\text { Nov. } 16,1954 \\
\end{array}$ & $\begin{array}{r}1.09 \\
.79 \\
1.00\end{array}$ & $\begin{array}{l}39 \\
24 \\
33\end{array}$ \\
\hline $\begin{array}{l}1946 \\
1947 \\
1948 \\
1949 \\
1950\end{array}$ & $\begin{array}{l}\text { Oct. } \\
\text { Oct. } \\
\text { May } \\
\text { May } \\
\text { June }\end{array}$ & $\begin{array}{rr}12, & 1945 \\
1, & 1946 \\
21, & 1948 \\
19, & 1949 \\
1, & 1950\end{array}$ & $\begin{array}{l}1.10 \\
1.58 \\
1.25 \\
1.34 \\
1.37\end{array}$ & $\begin{array}{l}41 \\
71 \\
48 \\
54 \\
59\end{array}$ & $\begin{array}{l}1957 \\
1958 \\
1959 \\
1960\end{array}$ & $\begin{array}{lrl}\text { June } & 7, & 1957 \\
\text { May } 27, & 1958 \\
\text { Oct. } & 3, & 1958 \\
\text { Feb. } & 8, & 1960\end{array}$ & $\begin{array}{r}1.25 \\
1.29 \\
.81 \\
.72\end{array}$ & $\begin{array}{l}49 \\
55 \\
25 \\
20\end{array}$ \\
\hline $\begin{array}{l}1951 \\
1952 \\
1953\end{array}$ & $\begin{array}{l}\text { May } \\
\text { May } \\
\text { Oct. }\end{array}$ & $\begin{array}{rr}28, & 1951 \\
6, & 1952 \\
1, & 1952\end{array}$ & $\begin{array}{l}1.49 \\
1.90 \\
1.18\end{array}$ & $\begin{array}{r}61 \\
102 \\
49 \\
\end{array}$ & $\begin{array}{l}1961 \\
1962 \\
1963\end{array}$ & $\begin{array}{l}\text { Aug. 31, } 1961 \\
\text { Apr. 28, } 1962 \\
\text { Feb. } 1,1963\end{array}$ & $\begin{array}{l}.62 \\
.81 \\
-\end{array}$ & $\begin{array}{r}15 \\
24 \\
2500\end{array}$ \\
\hline
\end{tabular}

a Estimated on basis of fleld survey.

1620. Provo River above Telluride Power Co.'s dam, near Provo, Utah (Published as "Provo River near Provo" 1911)

Location.--Lat $40^{\circ} 21^{\prime} 10^{\prime \prime}$, long $111^{\circ} 34^{1} 50^{\prime \prime}$, in NW $\frac{1}{4}$ SW $\frac{1}{4}$ sec.26, T.5 S., R. 3 E., a quarter of a mile downstream from South Fork, three-quarters of a mile upstream from dam formerly owned by Telluride Power Co., $1 \frac{1}{4}$ miles downstream from North Fork, and about 11 miles northeast of Provo.

Drainage area.--640 sq $\mathrm{ml}$, approximately.

Gage.--Nonrecording. Prior to July 24, 1908, a quarter of a mile downstream at different datum. Altitude of gage is $5,180 \mathrm{ft}$ (from topographic map).

Stage-discharge relation.--Defined by current-meter measurements below 1,900 cf's prior to July 1908 and below 2,200 cf's after July 1908.

Remarks.--Diversions for irrigation.above station. Only annua maximum observed discharges are shown.

\begin{tabular}{|c|c|c|c|c|c|c|c|}
\hline $\begin{array}{l}\text { Water } \\
\text { year }\end{array}$ & Date & $\begin{array}{c}\text { Gage } \\
\text { height } \\
\text { (feet) }\end{array}$ & $\begin{array}{c}\text { Discharge } \\
(\text { cfs })\end{array}$ & $\begin{array}{c}\text { Water } \\
\text { year }\end{array}$ & Date & $\begin{array}{c}\text { rage } \\
\text { helght } \\
\text { (feet) }\end{array}$ & $\begin{array}{c}\text { Discharge } \\
\text { (cfs) }\end{array}$ \\
\hline $\begin{array}{l}1905 \\
1906 \\
1907\end{array}$ & $\begin{array}{l}\text { June } 9,1905 \\
\text { June 14, } 1906 \\
\text { May 24, June.8, } \\
\text { 1907 }\end{array}$ & $\begin{array}{l}6.10 \\
7.10 \\
7.90\end{array}$ & $\begin{array}{l}1,220 \\
1,860 \\
2,340\end{array}$ & $\begin{array}{l}1905 \\
1909 \\
1910 \\
1911\end{array}$ & $\begin{array}{l}\text { June } 16,1908 \\
\text { June } 7,1909 \\
\text { Apr. } 28,1910 \\
\text { Jan. 31, } 1911\end{array}$ & $\begin{array}{l}7.00 \\
8.50 \\
4.70 \\
5.75\end{array}$ & $\begin{array}{l}1,800 \\
3,620 \\
1,450 \\
1,920\end{array}$ \\
\hline
\end{tabular}

1630. Provo River at Provo, Utah

(Published as "at San Pedro, Los Angeles, and Salt Lake Railroad bridge near Provo", 1903-4 and as "at Rio Grande Western Ra11way bridge near Provo" 1905)

Location.--Lat $40^{\circ} 14^{\prime} 15^{\prime \prime}$, long $111^{\circ} 41^{\prime} 55^{\prime \prime}$, in NW $\frac{1}{4} \mathrm{SE} \frac{1}{4} \mathrm{sec} .3$, T.7 S., R.2 E., on left bank $1,300 \mathrm{ft}$ downstream from bridge on State Highway 114,2 miles west of Provo, and 2 miles upstream from mouth.

Drainage area. - -680 sq $\mathrm{ml}$, approximately.

Gage.--Nonrecording prior to October 1934; recording thereafter. May 1903 to June 1905 , at site three-quarters of a mile upstream at different datums. May 1933 to September 1934, at present site at different datum. January 1937 to November 1938, at site $1,000 \mathrm{ft}$ upstream at different datum. November 1938 to Aug. 23, 1957, at present site lat datum $2.00 \mathrm{ft}$ higher.

Stage-discharge relation.--Defined by current-meter measurements.

Remarks.--Station is below all diversions. At times entire flow is diverted above station for irrigation. Flow affected by regulation of Deer Creek Reservoir and by Weber-Provo diversion canal and Duchesne tunnel. Only
annual peaks are shown. 
Peak stages and discharges of Provo River at Provo, Utah

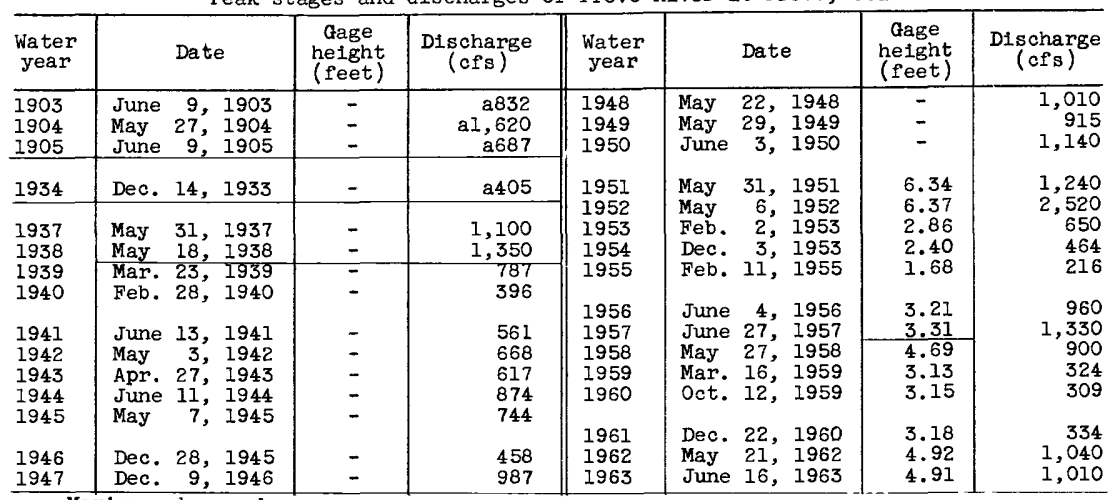

a Max1mum observed.

1645. American Fork above upper powerplant, near American Fork, Utah

Location.--Lat $40^{\circ} 26^{\prime} 50^{\prime \prime}$, long $111^{\circ} 40^{\prime} 55^{\prime \prime}$, In $N{ }^{\frac{1}{4}} \mathrm{NE} \frac{1}{4}$ sec.26, T.4 S., R.2 E., on right bank $600 \mathrm{ft}$ downstream from Rock Creek, $1,000 \mathrm{ft}$ upstream from intake for upper powerplant of Utah Power \& Light Co., 4 miles upstream from mouth of Canyon, and 8 miles northeast of American Fork.

Drainage area. $--51.1 \mathrm{sq} \mathrm{ml}$.

Gage.--Recording. Altitude of gage is 5,950 ft (from topographic map).

Stage-discharge relation.--Defined by current-meter measurements below 418 ofs.

Remarks. --Records collected by Utah Power \& Light Co., under general supervision of Geological Survey, Only annual peaks are shown lmaximum daily prior to 1944).

\begin{tabular}{|c|c|c|c|c|c|c|c|c|c|}
\hline $\begin{array}{l}\text { Water } \\
\text { year }\end{array}$ & & Date & $\begin{array}{c}\text { Gage } \\
\text { helght } \\
\text { (feet) }\end{array}$ & $\begin{array}{c}\text { Discharge } \\
\text { (cfs) }\end{array}$ & $\begin{array}{l}\text { Water } \\
\text { year }\end{array}$ & & Date & $\begin{array}{c}\text { Gage } \\
\text { height } \\
\text { (feet) }\end{array}$ & $\begin{array}{c}\text { Discharge } \\
\text { (cfs) }\end{array}$ \\
\hline $\begin{array}{l}1927 \\
1928 \\
1929 \\
1930\end{array}$ & $\begin{array}{l}\text { May } \\
\text { May } \\
\text { June } \\
\text { Apr. }\end{array}$ & $\begin{array}{ll}17, & 1927 \\
27, & 1928 \\
16, & 1929 \\
24, & 1930\end{array}$ & $\begin{array}{l}- \\
- \\
-\end{array}$ & $\begin{array}{l}429 \\
339 \\
326 \\
193\end{array}$ & $\begin{array}{l}1946 \\
1947 \\
1948 \\
1949 \\
1950\end{array}$ & $\begin{array}{l}\text { Apr. } \\
\text { May } \\
\text { May } \\
\text { May } \\
\text { May }\end{array}$ & $\begin{array}{rr}29, & 1946 \\
7, & 1947 \\
17, & 1948 \\
28, & 1949 \\
30, & 1950\end{array}$ & $\begin{array}{l}6.36 \\
6.64 \\
6.65 \\
6.73 \\
6.70\end{array}$ & $\begin{array}{l}315 \\
399 \\
455 \\
367 \\
383\end{array}$ \\
\hline $\begin{array}{l}1931 \\
1932 \\
1933 \\
1934 \\
1935\end{array}$ & $\begin{array}{l}\text { May } \\
\text { May } \\
\text { June } \\
\text { Apr. 24, } \\
\text { June }\end{array}$ & $\begin{array}{c}16,1931 \\
21,1932 \\
3,1933 \\
4, \text { May } 8,1934 \\
13,1935\end{array}$ & $\begin{array}{l}\overline{-} \\
\overline{-} \\
\bar{z}\end{array}$ & $\begin{array}{r}124 \\
314 \\
300 \\
65 \\
306\end{array}$ & $\begin{array}{l}1951 \\
1952 \\
1953 \\
1954 \\
1955\end{array}$ & $\begin{array}{l}\text { Aug. } \\
\text { June } \\
\text { July } \\
\text { May } \\
\text { May }\end{array}$ & $\begin{array}{rr}3, & 1951 \\
6, & 1952 \\
30, & 1953 \\
21, & 1954 \\
21, & 1955\end{array}$ & $\begin{array}{l}7.38 \\
6.92 \\
9.2 \\
6.04 \\
6.10\end{array}$ & $\begin{array}{l}645 \\
531 \\
(a) \\
273 \\
292\end{array}$ \\
\hline $\begin{array}{l}1936 \\
1937 \\
1938 \\
1939 \\
1940\end{array}$ & $\begin{array}{l}\text { May } \\
\text { May } \\
\text { May } \\
\text { May } \\
\text { May }\end{array}$ & $\begin{aligned} 15, & 1936 \\
18, & 1937 \\
29, & 1938 \\
4, & 1939 \\
17, & 1940\end{aligned}$ & $\begin{array}{l}- \\
- \\
-\end{array}$ & $\begin{array}{l}335 \\
346 \\
318 \\
190 \\
210\end{array}$ & $\begin{array}{l}1956 \\
1957 \\
1958 \\
1959 \\
1960\end{array}$ & $\begin{array}{l}\text { May } \\
\text { June } \\
\text { May } \\
\text { June } \\
\text { May }\end{array}$ & $\begin{array}{rr}25, & 1956 \\
6, & 1957 \\
26, & 1958 \\
15, & 1959 \\
13, & 1960\end{array}$ & $\begin{array}{l}6.19 \\
6.49 \\
7.36 \\
6.05 \\
6.42\end{array}$ & $\begin{array}{l}344 \\
509 \\
624 \\
203 \\
293\end{array}$ \\
\hline $\begin{array}{l}1941 \\
1942 \\
1943 \\
1944 \\
1945 \\
\end{array}$ & $\begin{array}{l}\text { May } \\
\text { May } \\
\text { June } \\
\text { June } \\
\text { June }\end{array}$ & $\begin{array}{rr}26, & 1941 \\
26, & 1942 \\
1, & 1943 \\
2, & 1944 \\
23, & 1945 \\
\end{array}$ & $\begin{array}{l}- \\
- \\
- \\
6.74 \\
6.40 \\
\end{array}$ & $\begin{array}{l}285 \\
265 \\
208 \\
430 \\
312 \\
\end{array}$ & $\begin{array}{l}1961 \\
1962 \\
1963\end{array}$ & $\begin{array}{l}\text { May } \\
\text { May } \\
\text { June }\end{array}$ & $\begin{array}{rr}27, & 1961 \\
8, & 1962 \\
1, & 1963\end{array}$ & $\begin{array}{l}5.68 \\
7.54 \\
7.29\end{array}$ & $\begin{array}{r}84 \\
379 \\
293\end{array}$ \\
\hline
\end{tabular}

a Discharge not determined; believed to be maximum of record. 


\section{Dry Creek near Alpine, Utah}

Location.--Lat $40^{\circ} 28^{\prime} 35^{\prime \prime}$, long $111^{\circ} 45^{\prime} 25^{\prime \prime}$, in NE⿺辶 sec.18, T.4 S., R.2 E., on right bank 2 miles northeast of Alpine and $3 \frac{1}{2}$ miles upstream from Fort Creek.

Drainage area. $--9.82 \mathrm{sq} \mathrm{mi}$. Mean altitude, 8,770 ft.

Gage.--Recording. Prior to Aug. 3, 1951, at site $500 \mathrm{ft}$ downstream at different datum (destroyed by flood). Auxiliary crest-stage gage since Dec.4, 1959

Stage-discharge relation.--Defined by current-meter measurements below 210 cfs and extended above on basis of slope-area measurement at 294 cf's and $597 \mathrm{cf}$.

Remarks.--Base for partial-duration series, $100 \mathrm{cfs}$. Only annual peaks are shown since 1955 .

\begin{tabular}{|c|c|c|c|c|c|c|c|}
\hline $\begin{array}{l}\text { Water } \\
\text { year }\end{array}$ & Date & $\begin{array}{l}\text { Gage } \\
\text { he1ght } \\
\text { (feet) }\end{array}$ & $\begin{array}{l}\text { Discharge } \\
(\text { cfs })\end{array}$ & $\begin{array}{l}\text { Water } \\
\text { year }\end{array}$ & Date & $\begin{array}{c}\text { Cage } \\
\text { height } \\
\text { (feet) }\end{array}$ & $\begin{array}{c}\text { Discharge } \\
(\text { cfs })\end{array}$ \\
\hline 1947 & July 2,1947 & 1.58 & a76 & 1952 & June 6,1952 & 3.15 & 244 \\
\hline \multirow[t]{2}{*}{$194 \mathrm{~S}$} & $\begin{array}{l}\text { Apr. } 21,1948 \\
\text { May } 6,1948\end{array}$ & $\overline{-}$ & $\begin{array}{l}71 \\
80\end{array}$ & 1953 & June 13,1953 & 2.27 & 304 \\
\hline & May 17,1948 & 2.69 & 187 & 1954 & $\begin{array}{lll}\text { May } & 13, & 1954 \\
\text { June } & 27, & 1954\end{array}$ & $\begin{array}{l}1.72 \\
1.78\end{array}$ & $\begin{array}{l}185 \\
120\end{array}$ \\
\hline 1949 & $\begin{array}{lll}\text { May } & 17, & 1949 \\
\text { May } & 28, & 1949 \\
\text { June } & 12, & 1949\end{array}$ & 2.60 & $\begin{array}{l}127 \\
158 \\
196\end{array}$ & 1955 & $\begin{array}{lrl}\text { May } & 11, & 1955 \\
\text { May } & 23, & 1955 \\
\text { June } & 8, & 1955\end{array}$ & $\begin{array}{l}1.90 \\
1.88 \\
1.93\end{array}$ & $\begin{array}{l}166 \\
187 \\
168\end{array}$ \\
\hline 1950 & May 30,1950 & 2.55 & 236 & & Aug. 5, 1955 & 1.83 & 118 \\
\hline \multirow[t]{2}{*}{1951} & $\begin{array}{lll}\text { May } 27, & 1951 \\
\text { June } 15, & 1951 \\
\text { JuIy } 21, & 1951 \\
\end{array}$ & $\begin{array}{l}2.78 \\
2.35 \\
1.85 \\
\end{array}$ & $\begin{array}{l}290 \\
182 \\
100 \\
\end{array}$ & $\begin{array}{l}1959 \\
1960\end{array}$ & 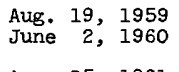 & $\begin{array}{l}4.96 \\
1.98\end{array}$ & $\begin{array}{l}294 \\
120\end{array}$ \\
\hline & $\begin{array}{lll}\text { Aug. } & 3,1951 \\
\text { May } & 3, & 1952\end{array}$ & $\begin{array}{r}\text { (b) } \\
2.75 \\
\end{array}$ & $\begin{array}{l}\text { (b) } \\
292 \\
\end{array}$ & $\begin{array}{l}1961 \\
1962 \\
1963\end{array}$ & $\begin{array}{lll}\text { Aug. } 25, & 1961 \\
\text { June } 29, & 1962 \\
\text { June } 17, & 1963\end{array}$ & $\begin{array}{l}3.80 \\
1.64 \\
1.39 \\
\end{array}$ & $\begin{array}{l}597 \\
190 \\
155 \\
\end{array}$ \\
\hline
\end{tabular}

a July to September.

b Maximum gage height and discharge not determined; occurred during flood which dedestroyed gaging station.

1660. Fort Creek at Alpine, Utah

Location.--Lat $40^{\circ} 27^{\prime} 55^{\prime \prime}$, long $111^{\circ} 46^{\prime} 45^{\prime \prime}$, in SE $\frac{1}{4} \sec .13$, T.4 S., R.1 E., on right bank three-quarters of a mile north of Alpine and $1 \frac{1}{2}$ miles upstream from mouth.

Drainage area. $--6.55 \mathrm{sq} \mathrm{mi}$. Mean altitude, 7,500 ft.

Gage.--Recording. Altitude of gage is 5,050 ft (from topographic map).

Stage-discharge relation.--Defined by current-meter measurements below $110 \mathrm{cfs}$. Remarks.--Base for partial-duration series, $75 \mathrm{cfs}$.

Peak stages and discharges

\begin{tabular}{|c|c|c|c|c|c|c|c|c|c|}
\hline $\begin{array}{l}\text { Water } \\
\text { year }\end{array}$ & \multicolumn{2}{|r|}{ Date } & $\begin{array}{c}\text { Gage } \\
\text { helght } \\
\text { (feet) }\end{array}$ & $\begin{array}{c}\text { Discharge } \\
(\mathrm{cfs})\end{array}$ & $\begin{array}{c}\text { Water } \\
\text { year }\end{array}$ & & Date & $\begin{array}{c}\text { Gage } \\
\text { height } \\
\text { (feet) }\end{array}$ & $\begin{array}{c}\text { Discharge } \\
\text { (cfs) }\end{array}$ \\
\hline 1948 & June & 2,1948 & 3.60 & 172 & 1953 & $\begin{array}{l}\text { June } \\
\text { Aug. }\end{array}$ & $\begin{array}{r}12,1953 \\
2,1953\end{array}$ & $\begin{array}{l}2.92 \\
2.91\end{array}$ & $\begin{array}{r}100 \\
96\end{array}$ \\
\hline 1949 & May & 17,1949 & 2.84 & 97 & 1954 & June & $27 \quad 1954$ & 238 & 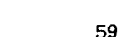 \\
\hline 1950 & May & 21,1950 & 2.46 & 70 & & Jurle & 61,1924 & & \\
\hline 1951 & $\begin{array}{l}\text { May } \\
\text { Aug. } \\
\text { Aug. }\end{array}$ & $\begin{array}{rr}27, & 1951 \\
3, & 1951 \\
4, & 1951\end{array}$ & $\begin{array}{l}2.70 \\
3.50 \\
4.60\end{array}$ & $\begin{array}{r}84 \\
148 \\
246\end{array}$ & 1955 & $\begin{array}{l}\text { May } \\
\text { May } \\
\text { June }\end{array}$ & $\begin{array}{ll}11, & 1955 \\
20, & 1955 \\
14, & 1955\end{array}$ & $\begin{array}{l}3.12 \\
2.77 \\
2.74\end{array}$ & $\begin{array}{r}105 \\
81 \\
83\end{array}$ \\
\hline 1952 & May & 3,1952 & 3.55 & 134 & & & & & \\
\hline
\end{tabular}


1670. Jordan River at /narrows, near Lehi, Utah

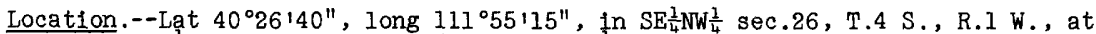
narrows $5 \frac{1}{2}$ miles northwest of Leh1 and $7 \frac{1}{2}$ miles downstream from Utah Lake.

Drainage area.--3,000 sq $\mathrm{mi}$, approximately, including $255 \mathrm{sq} \mathrm{mi}$ in closed basin In Cedar Valley.

Gage.--Nonrecording prior to May 16, 1920; recording thereafter. Prior to Oct. 1, 1934, at outlet of Utah Lake $7 \frac{1}{2}$ miles upstream at different datum. Altitude of gage is $4,470 \mathrm{ft}$ (by barometer).

Stage-discharge relation.--Defined by current-meter measurements prior to 1935 and below 892 of's the reafter.

Remarks.--Figures given herein represent combined flow of Jordan River, Utah and Salt Lake Canal, and East Jordan Canal. Flow regulated by gates and pumps at outlet of Utah Lake, pumps at Pellcan Point, and diversion cam at narrows. Only annual maximum daily discharges are shown.

Maximum daily mean discharges

\begin{tabular}{|c|c|c|c|c|c|c|c|c|c|}
\hline $\begin{array}{l}\text { Water } \\
\text { year }\end{array}$ & & Date & $\begin{array}{c}\text { Cage } \\
\text { helght } \\
\text { (feet) }\end{array}$ & $\begin{array}{c}\text { D1scharge } \\
\text { (cfs) }\end{array}$ & $\begin{array}{l}\text { Water } \\
\text { year }\end{array}$ & \multicolumn{2}{|r|}{ Date } & $\begin{array}{c}\text { Gage } \\
\text { he1ght } \\
\text { (feet) }\end{array}$ & $\begin{array}{c}\text { I1scharge } \\
\text { (cfs) }\end{array}$ \\
\hline $\begin{array}{l}1914 \\
1915\end{array}$ & $\begin{array}{l}\text { May } \\
\text { July }\end{array}$ & $\begin{array}{ll}31, & 1914 \\
17, & 1915\end{array}$ & $\begin{array}{l}5.7 \mathrm{~s} \\
5.50\end{array}$ & $\begin{array}{l}794 \\
755\end{array}$ & $\begin{array}{l}1939 \\
1940\end{array}$ & $\begin{array}{l}\text { May } \\
\text { July }\end{array}$ & $\begin{array}{rr}21, & 1939 \\
8, & 1940\end{array}$ & - & $\begin{array}{l}747 \\
793\end{array}$ \\
\hline $\begin{array}{l}1916 \\
1917 \\
1918 \\
1919 \\
1920\end{array}$ & $\begin{array}{l}\text { July } \\
\text { June } \\
\text { Apr. } \\
\text { June } \\
\text { June }\end{array}$ & $\begin{array}{ll}25, & 1916 \\
25, & 1917 \\
22, & 1918 \\
18, & 1919 \\
23, & 1920\end{array}$ & $\begin{array}{l}5.50 \\
6.30 \\
5.72 \\
5.57 \\
5.69\end{array}$ & $\begin{array}{l}755 \\
922 \\
753 \\
820 \\
812\end{array}$ & $\begin{array}{l}1941 \\
1942 \\
1943 \\
1944 \\
1945\end{array}$ & $\begin{array}{l}\text { July } \\
\text { July } \\
\text { July } \\
\text { July } \\
\text { July }\end{array}$ & $\begin{array}{rr}3, & 1941 \\
8, & 1942 \\
14, & 1943 \\
17, & 1944 \\
30, & 1945\end{array}$ & $\begin{array}{l}- \\
- \\
-\end{array}$ & $\begin{array}{l}754 \\
807 \\
844 \\
858 \\
847\end{array}$ \\
\hline $\begin{array}{l}1921 \\
1922 \\
1923 \\
1924 \\
1925\end{array}$ & $\begin{array}{l}\text { June } \\
\text { June } \\
\text { May } \\
\text { June } \\
\text { July }\end{array}$ & $\begin{array}{rr}15, & 1921 \\
8, & 1922 \\
31, & 1923 \\
27, & 1924 \\
21, & 1925\end{array}$ & $\begin{array}{l}6.63 \\
7.78 \\
7.00 \\
6.34 \\
5.90\end{array}$ & $\begin{array}{r}1,020 \\
a 1,370 \\
1,110 \\
970 \\
855\end{array}$ & $\begin{array}{l}1946 \\
1947 \\
1948 \\
1949 \\
1950\end{array}$ & $\begin{array}{l}\text { July } \\
\text { July } \\
\text { July } \\
\text { July } \\
\text { July }\end{array}$ & $\begin{array}{rr}2, & 1946 \\
21, & 1947 \\
18, & 1948 \\
15, & 1949 \\
9, & 1950\end{array}$ & $\begin{array}{l}- \\
- \\
- \\
-\end{array}$ & $\begin{array}{l}876 \\
887 \\
918 \\
870 \\
857\end{array}$ \\
\hline $\begin{array}{l}1926 \\
1927 \\
1928 \\
1929 \\
1930\end{array}$ & $\begin{array}{l}\text { June } \\
\text { Aug. } \\
\text { July } \\
\text { July } \\
\text { July }\end{array}$ & 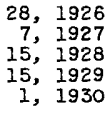 & $\begin{array}{l}5.86 \\
5.63 \\
5.90 \\
5.76 \\
5.87\end{array}$ & $\begin{array}{l}845 \\
750 \\
821 \\
784 \\
817\end{array}$ & $\begin{array}{l}1951 \\
1952 \\
1953 \\
1954 \\
1955\end{array}$ & $\begin{array}{l}\text { July } \\
\text { June } \\
\text { July } \\
\text { July } \\
\text { July }\end{array}$ & $\begin{array}{rr}12, & 1951 \\
10, & 1952 \\
9, & 1953 \\
8, & 1954 \\
3, & 1955\end{array}$ & $\begin{array}{l}- \\
- \\
-\end{array}$ & $\begin{array}{r}873 \\
1,410 \\
560 \\
877 \\
855\end{array}$ \\
\hline $\begin{array}{l}1931 \\
1932 \\
1933 \\
1934 \\
1935\end{array}$ & $\begin{array}{l}\text { May } \\
\text { May } \\
\text { July } \\
\text { Apr. } \\
\text { May }\end{array}$ & $\begin{array}{rr}31, & 1931 \\
17, & 1932 \\
7, & 1933 \\
12, & 1934 \\
17, & 1935\end{array}$ & $\begin{array}{l}5.50 \\
9.00 \\
9.50 \\
8.00 \\
\end{array}$ & $\begin{array}{l}727 \\
801 \\
770 \\
648 \\
486\end{array}$ & $\begin{array}{l}1956 \\
1957 \\
1958 \\
1959 \\
1960\end{array}$ & $\begin{array}{l}\text { July } \\
\text { July } \\
\text { July } \\
\text { July } \\
\text { June }\end{array}$ & $\begin{array}{rr}9, & 1956 \\
18, & 1957 \\
11, & 1958 \\
10, & 1959 \\
28, & 1960\end{array}$ & $\begin{array}{l}- \\
- \\
-\end{array}$ & $\begin{array}{l}817 \\
790 \\
859 \\
855 \\
804\end{array}$ \\
\hline $\begin{array}{l}1936 \\
1937 \\
1938\end{array}$ & $\begin{array}{l}\text { June } \\
\text { July } \\
\text { Aug. }\end{array}$ & $\begin{array}{rr}22, & 1936 \\
5, & 1937 \\
9, & 1938\end{array}$ & - & $\begin{array}{l}615 \\
727 \\
757\end{array}$ & $\begin{array}{l}1961 \\
1962 \\
1963\end{array}$ & $\begin{array}{l}\text { May } \\
\text { July } \\
\text { July }\end{array}$ & $\begin{array}{ll}15, & 1961 \\
12, & 1962 \\
12, & 1963\end{array}$ & - & $\begin{array}{l}736 \\
766 \\
758 \\
\end{array}$ \\
\hline
\end{tabular}

a Does not include ungaged bypass (probably about 10 percent).

1675. Little Cottonwood Creek near Salt Lake City, Jtah

Location. --Lat $40^{\circ} 34^{1} 40^{\prime \prime}$, long $111^{\circ} 47^{\prime} 50^{\prime \prime}$, in $\mathrm{NE}_{\frac{1}{4}} \mathrm{NE} \frac{1}{4}$ sec.11, T.3 S., R.1 E., at mouth of canyon $100 \mathrm{ft}$ west of Wasatch Drive, 2 miles downstream from Wasatch Resort, and 14 miles southeast of Salt Lake City.

Drainage area. $--27.4 \mathrm{sq} \mathrm{mi}$.

Gage.--Nonrecording and two weirs prior to 1920 , at site about 1 mile downstream at different datum. Method of measurement not known for 1920-23; recording thereafter. Concrete flume $1 \frac{1}{2}$ miles upstream at different datum 1924 to January 1940. Altitude of gage is $5,080 \mathrm{ft}$ (from topographic map).

Stage-discharge relation.--Defined by current-meter measurements.

Remarks.--Records since 1913 furnished by loffice of City Engineer of Salt Lake City. Discharge is computed as combined flow of creek and all diverisions. only annual peaks are shown (maximum dally prior to 1947). 
Peak stages and discharges of Little Cottonwood Creek near Salt La'ce C1ty, Utah

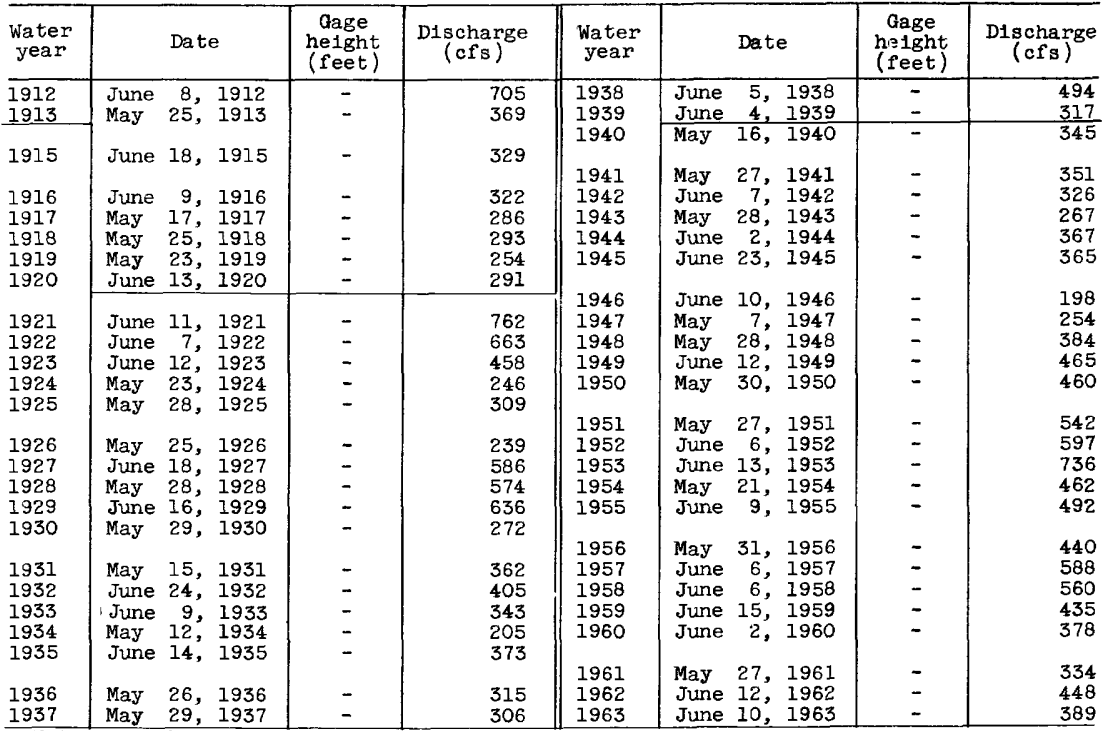

Note.--Discharges shown prior to 1947 are maximum dally means.

\section{Big Cottonwood Creek near Salt Lake City, Utah}

Location.--Lat $40^{\circ} 37^{\prime} 10^{\prime \prime}$, long $111^{\circ} 47^{\prime} 00^{\prime \prime}$, in SW $\frac{1}{4} \mathrm{NE} \frac{1}{4}$ sec.25, T.2 S., R.1 E., at mouth of canyon, about $80 \mathrm{ft}$ upstream from Wasatch Boulevard bridge, a quarter of a mile downstream from Utah Power \& Light Co.'s plant, and 12 miles southeast of Salt Lake City.

Drainage area. $--50 \mathrm{sq} \mathrm{mi}$.

Gage.--Nonrecording prior to 1908; recording and two Cippolett1 velrs thereafter. Altitude of gage is $4,880 \mathrm{ft}$ (from topographic map).

Stage-discharge relation.--Defined by current-meter measurements.

Remarks.--Records since 1913 furnished by Office of City Engineer of Salt Lake City. Only annual peaks are shown (maximum daily prior to 1951).

Peak stages and discharges

\begin{tabular}{|c|c|c|c|c|c|c|c|c|c|}
\hline $\begin{array}{l}\text { Water } \\
\text { year }\end{array}$ & & Date & $\begin{array}{c}\text { Gage } \\
\text { he1ght } \\
\text { (feet) }\end{array}$ & $\begin{array}{c}\text { Discharge } \\
\text { (cfs) }\end{array}$ & $\begin{array}{l}\text { Water } \\
\text { year }\end{array}$ & & Date & $\begin{array}{c}\text { Cage } \\
\text { helght } \\
\text { (feet) }\end{array}$ & $\begin{array}{c}\text { D1scharge } \\
(\text { efs) }\end{array}$ \\
\hline $\begin{array}{l}1901 \\
1902 \\
\end{array}$ & $\begin{array}{l}\text { May } \\
\text { May }\end{array}$ & $\begin{array}{ll}19, & 1901 \\
30, & 1902\end{array}$ & - & $\begin{array}{l}407 \\
370\end{array}$ & $\begin{array}{l}1921 \\
1922\end{array}$ & June & 14,1921 & - & $\begin{array}{l}721 \\
531\end{array}$ \\
\hline 1905 & June & 8, 1905 & - & 265 & $\begin{array}{l}1924 \\
1925\end{array}$ & May & $\begin{array}{ll}18, & 1924 \\
21, & 1925\end{array}$ & $=$ & $\begin{array}{l}276 \\
336\end{array}$ \\
\hline $\begin{array}{l}1907 \\
1908 \\
1909 \\
1910\end{array}$ & $\begin{array}{l}\text { June } \\
\text { June } \\
\text { June } \\
\text { June }\end{array}$ & 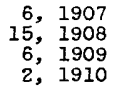 & $\begin{array}{l}- \\
-\end{array}$ & $\begin{array}{l}793 \\
520 \\
835 \\
390\end{array}$ & $\begin{array}{l}1926 \\
1927 \\
1928 \\
1929\end{array}$ & $\begin{array}{l}\text { May } \\
\text { May } \\
\text { May } \\
\text { May }\end{array}$ & $\begin{array}{rr}5, & 1926 \\
17, & 1927 \\
27, & 1928 \\
25, & 1929\end{array}$ & $\begin{array}{l}= \\
=\end{array}$ & $\begin{array}{l}352 \\
491 \\
402 \\
414\end{array}$ \\
\hline $\begin{array}{l}1911 \\
1912\end{array}$ & $\begin{array}{l}\text { June } \\
\text { June }\end{array}$ & $\begin{aligned} 13, & 1911 \\
7, & 1912\end{aligned}$ & $\overline{-}$ & $\begin{array}{l}387 \\
848\end{array}$ & 1930 & May & 29,1930 & - & 236 \\
\hline $\begin{array}{l}1913 \\
1914 \\
1915\end{array}$ & $\begin{array}{l}\text { May } \\
\text { May } \\
\text { June }\end{array}$ & $\begin{array}{rr}26, & 1913 \\
23, & 1914 \\
2, & 1915\end{array}$ & $\overline{-}$ & $\begin{array}{l}376 \\
438 \\
261\end{array}$ & $\begin{array}{l}1931 \\
1932 \\
1933 \\
1934\end{array}$ & $\begin{array}{l}\text { May } \\
\text { May } \\
\text { June } \\
\text { May }\end{array}$ & $\begin{array}{ll}17, & 1931 \\
21, & 1932 \\
12, & 1933 \\
12, & 1934\end{array}$ & $\begin{array}{l}z \\
z\end{array}$ & $\begin{array}{l}213 \\
414 \\
467 \\
123\end{array}$ \\
\hline $\begin{array}{l}1916 \\
1917 \\
1918 \\
1919 \\
1920\end{array}$ & $\begin{array}{l}\text { June } \\
\text { June } \\
\text { June } \\
\text { May } \\
\text { May }\end{array}$ & $\begin{array}{ll}10, & 1916 \\
18, & 1917 \\
12, & 1918 \\
23, & 1919 \\
23, & 1920\end{array}$ & $\begin{array}{l}- \\
- \\
-\end{array}$ & $\begin{array}{l}330 \\
499 \\
394 \\
343 \\
526\end{array}$ & $\begin{array}{l}1935 \\
1936 \\
1937 \\
1938\end{array}$ & $\begin{array}{l}\text { June } \\
\text { May } \\
\text { May } \\
\text { May }\end{array}$ & $\begin{array}{ll}13, & 1935 \\
15, & 1936 \\
18, & 1937 \\
29, & 1938\end{array}$ & $\begin{array}{l}- \\
-\end{array}$ & $\begin{array}{l}422 \\
370 \\
326 \\
406\end{array}$ \\
\hline
\end{tabular}


Peak stages and discharges of Big Cottonwood Creek near Salt Lake City, Utah--Con .

\begin{tabular}{|c|c|c|c|c|c|c|c|c|c|}
\hline $\begin{array}{l}\text { Water } \\
\text { year }\end{array}$ & & Date & $\begin{array}{c}\text { Gage } \\
\text { helght } \\
\text { (feet) }\end{array}$ & $\begin{array}{c}\text { Discharge } \\
\text { (cfs) }\end{array}$ & $\begin{array}{l}\text { Water } \\
\text { year }\end{array}$ & \multicolumn{2}{|r|}{ Date } & $\begin{array}{c}\text { Gage } \\
\text { helght } \\
\text { (feet) }\end{array}$ & $\begin{array}{c}\text { Discharge } \\
\text { (cfs) }\end{array}$ \\
\hline $\begin{array}{l}1939 \\
1940\end{array}$ & $\begin{array}{l}\text { May } \\
\text { May }\end{array}$ & $\begin{array}{ll}31, & 1939 \\
16, & 1940\end{array}$ & - & $\begin{array}{l}219 \\
266 \\
349\end{array}$ & $\begin{array}{l}1952 \\
1953 \\
1954 \\
1955\end{array}$ & $\begin{array}{l}\text { June } \\
\text { June } \\
\text { May } \\
\text { May }\end{array}$ & 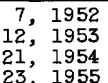 & $\begin{array}{l}- \\
- \\
-\end{array}$ & $\begin{array}{l}503 \\
503 \\
315 \\
308\end{array}$ \\
\hline $\begin{array}{l}1941 \\
1942 \\
1943 \\
1944 \\
1945\end{array}$ & $\begin{array}{l}\text { May } \\
\text { May } \\
\text { June } \\
\text { June } \\
\text { June }\end{array}$ & $\begin{array}{rr}13, & 1941 \\
26, & 1942 \\
1, & 1943 \\
3, & 1944 \\
24, & 1945\end{array}$ & $\begin{array}{l}- \\
- \\
- \\
-\end{array}$ & $\begin{array}{l}349 \\
444 \\
331 \\
432 \\
258\end{array}$ & $\begin{array}{l}1955 \\
1956 \\
1957 \\
1958 \\
1959\end{array}$ & $\begin{array}{l}\text { May } 2 \\
\text { May } 2 \\
\text { June } \\
\text { May } 2 \\
\text { June }\end{array}$ & $\begin{array}{rr}23, & 1955 \\
25, & 1956 \\
6, & 1957 \\
25, & 1958 \\
6, & 1959\end{array}$ & $\begin{array}{l}- \\
- \\
-\end{array}$ & $\begin{array}{l}508 \\
315 \\
536 \\
536 \\
298\end{array}$ \\
\hline $\begin{array}{l}1946 \\
1947 \\
1948 \\
1949 \\
1950\end{array}$ & $\begin{array}{l}\text { May } \\
\text { May } \\
\text { May } \\
\text { May } \\
\text { June }\end{array}$ & $\begin{array}{rr}6, & 1946 \\
8, & 1947 \\
28, & 1948 \\
29, & 1949 \\
1, & 1950\end{array}$ & $\begin{array}{l}- \\
- \\
- \\
-\end{array}$ & $\begin{array}{l}262 \\
348 \\
442 \\
320 \\
344\end{array}$ & $\begin{array}{l}1960 \\
1961 \\
1962 \\
1963\end{array}$ & $\begin{array}{ll}\text { May } & 1 \\
\text { May } & 2 \\
\text { June } & 1 \\
\text { June } & 1\end{array}$ & $\begin{array}{ll}12, & 1960 \\
24, & 1961 \\
12, & 1962 \\
10, & 1963\end{array}$ & $\begin{array}{l}- \\
- \\
-\end{array}$ & $\begin{array}{l}311 \\
173 \\
331 \\
294\end{array}$ \\
\hline 1951 & May & 29,1951 & - & 462 & & & & & \\
\hline
\end{tabular}

Note.--Maximum daily discharges are shown prior to 1951.

1700. Mill Creek near Salt Lake C1ty, Utah

Location.--Lat $40^{\circ} 41^{\prime} 20^{\prime \prime}$, long $111^{\circ} 46^{\prime} 55^{\prime \prime}$, in NW $\frac{1}{4} \mathrm{SE}_{\frac{1}{4}}$ sec.36, T.1 S., R.1 E., $1,000 \mathrm{ft}$ upstream from bridge at mouth of canyon, a quarter of a mile upstream from lower powerplant, and 7 miles southeast of Salt Lake Cit: .

Drainage area. $--21.7 \mathrm{sq} \mathrm{mi}$.

Gage.--Nonrecording and various types of weirs prior to 1930 , at or near pres-

ent site at unknown datums; recording gage and rating flume thereafter. Supplementary gage in tailrace of lower powerplant; recorder and weir a quarter of a mile downstream. Altitude of gage is 5,050 ft (from topographic map).

Stage-discharge relation.--Defined by current-meter measurements.

Remarks.--Records include flow through powerplant, and show natural runoff

since 1913; records furnished by Office of City Engineer of Salt Lake City.

Only annual maximum daily discharges are shown.

Maximum daily mean discharges

\begin{tabular}{|c|c|c|c|c|c|c|c|}
\hline $\begin{array}{l}\text { Water } \\
\text { year }\end{array}$ & Date & $\begin{array}{c}\text { Gage } \\
\text { helght } \\
\text { (feet) }\end{array}$ & $\begin{array}{l}\text { Discharge } \\
\text { (cfs) }\end{array}$ & $\begin{array}{l}\text { Water } \\
\text { year }\end{array}$ & Date & $\begin{array}{c}\text { Gage } \\
\text { helght } \\
\text { (feet) }\end{array}$ & $\begin{array}{c}\text { Discharge } \\
\text { (cfs) }\end{array}$ \\
\hline $\begin{array}{l}1899 \\
1900\end{array}$ & $\begin{array}{l}\text { June 1s99 } \\
\text { May 24, } 1900\end{array}$ & $\overline{-}$ & $\begin{array}{l}66 \\
31\end{array}$ & $\begin{array}{l}1927 \\
1928 \\
1929\end{array}$ & $\begin{array}{lll}\text { June } & 11, & 1927 \\
\text { May } 11, & 1928 \\
\text { May } 25, & 1929\end{array}$ & - & $\begin{array}{l}60 \\
67 \\
68 \\
\end{array}$ \\
\hline $\begin{array}{l}1901 \\
1902\end{array}$ & $\begin{array}{ll}\text { May } & 24,1901 \\
\text { May } 29,1902\end{array}$ & - & $\begin{array}{l}47 \\
39\end{array}$ & 1930 & May 31,1930 & - & 24 \\
\hline $\begin{array}{l}1903 \\
1904 \\
1905\end{array}$ & $\begin{array}{l}\text { June } 4-9,1903 \\
\text { May } 24,1904 \\
\text { May } 31,1905\end{array}$ & $\begin{array}{l}- \\
-\end{array}$ & $\begin{array}{l}34 \\
59 \\
38\end{array}$ & $\begin{array}{l}1931 \\
1932 \\
1933\end{array}$ & $\begin{array}{lll}\text { May } 16, & 1931 \\
\text { May } 21, & 1932 \\
\text { June } 2, & 1933\end{array}$ & $\begin{array}{l}- \\
-\end{array}$ & $\begin{array}{l}23 \\
55 \\
57\end{array}$ \\
\hline $\begin{array}{l}1906 \\
1907\end{array}$ & $\begin{array}{ll}\text { June } 11, & 1906 \\
\text { June } 4, & 1907\end{array}$ & - & $\begin{array}{l}59 \\
72\end{array}$ & $\begin{array}{l}1934 \\
1935\end{array}$ & $\begin{array}{l}\text { Oct.1-4, } 1933 \\
\text { June } 8,1935\end{array}$ & - & 42 \\
\hline $\begin{array}{l}1908 \\
1909 \\
1910\end{array}$ & $\begin{array}{l}\text { June } 13-16,1908 \\
\text { June } 17,1909 \\
\text { May } 12 \text {, June } 1 \text {, } \\
1910\end{array}$ & $\overline{-}$ & $\begin{array}{r}65 \\
112 \\
45\end{array}$ & $\begin{array}{l}1936 \\
1937 \\
1938 \\
1939 \\
1940\end{array}$ & $\begin{array}{l}\text { May } 16-20,1936 \\
\text { May } 19,1937 \\
\text { May } 28,1938 \\
\text { May } 11,1939 \\
\text { May } 16,1940\end{array}$ & $\begin{array}{l}- \\
\overline{-} \\
\overline{-}\end{array}$ & $\begin{array}{l}56 \\
51 \\
67 \\
29 \\
35\end{array}$ \\
\hline $\begin{array}{l}1911 \\
1912 \\
1913 \\
1914 \\
1915\end{array}$ & $\begin{array}{l}\text { June } 4-7,1911 \\
\text { May } 31,1912 \\
\text { May 25-30, } 1913 \\
\text { May } 25,1914 \\
\text { May } 18,1915\end{array}$ & $\begin{array}{l}- \\
\overline{-} \\
\overline{-}\end{array}$ & $\begin{array}{r}41 \\
121 \\
90 \\
74 \\
33\end{array}$ & $\begin{array}{l}1941 \\
1942 \\
1943 \\
1944 \\
1945\end{array}$ & $\begin{array}{ll}\text { May } 27, & 1941 \\
\text { May } 27, & 1942 \\
\text { June } 2,1943 \\
\text { June } 10,1944 \\
\text { June } 10,1945\end{array}$ & $\begin{array}{l}- \\
\overline{-} \\
-\end{array}$ & $\begin{array}{l}52 \\
87 \\
36 \\
57 \\
28\end{array}$ \\
\hline $\begin{array}{l}1916 \\
1917 \\
1918 \\
1919 \\
\end{array}$ & $\begin{array}{l}\text { May 6-9, } 1916 \\
\text { June 7, } 1917 \\
\text { June 6, } 1918 \\
\text { May } 19-25,1919\end{array}$ & $\begin{array}{l}- \\
-\end{array}$ & $\begin{array}{l}43 \\
54 \\
37 \\
45\end{array}$ & $\begin{array}{l}1946 \\
1947 \\
1948\end{array}$ & $\begin{array}{lrl}\text { May } & 6-8, & 1946 \\
\text { May } 23, & 1947 \\
\text { May } 25, & 1948\end{array}$ & - & $\begin{array}{l}47 \\
49 \\
84\end{array}$ \\
\hline $\begin{array}{l}1921 \\
1922 \\
\end{array}$ & $\begin{array}{l}\text { June } 12,1921 \\
\text { May } 24 \text {, June } 5 \text {, }\end{array}$ & - & $\begin{array}{r}104 \\
92\end{array}$ & 1950 & June 1,1950 & - & 83 \\
\hline $\begin{array}{l}1924 \\
1925\end{array}$ & $\begin{array}{l}1922 \\
\text { May } 17-22,1924 \\
\text { May } 23,1925\end{array}$ & - & $\begin{array}{l}33 \\
35\end{array}$ & $\begin{array}{l}1951 \\
1952 \\
1953 \\
1954 \\
1955\end{array}$ & $\begin{array}{lrl}\text { May } & 30, & 1951 \\
\text { June } 2, & 1952 \\
\text { June } 13, & 1953 \\
\text { May } 22, & 1954 \\
\text { May } 24, & 1955\end{array}$ & $\begin{array}{l}- \\
- \\
-\end{array}$ & $\begin{array}{r}72 \\
102 \\
77 \\
24 \\
40\end{array}$ \\
\hline 1926 & May 20,1926 & - & 35 & & & & \\
\hline
\end{tabular}


Maximum da1ly discharges of Mill Creek near Salt Lake City, Utah--Continued

\begin{tabular}{|c|c|c|c|c|c|c|c|c|c|}
\hline $\begin{array}{l}\text { Water } \\
\text { year }\end{array}$ & & Date & $\begin{array}{c}\text { Gage } \\
\text { helght } \\
\text { (feet) }\end{array}$ & $\begin{array}{c}\text { D1 scharge } \\
(\mathrm{cfs})\end{array}$ & $\begin{array}{l}\text { Water } \\
\text { year }\end{array}$ & & Date & $\begin{array}{c}\text { Qage } \\
\text { helght } \\
\text { (feet) }\end{array}$ & $\begin{array}{c}\text { Discharge } \\
(\mathrm{cfs})\end{array}$ \\
\hline $\begin{array}{l}1956 \\
1957 \\
1958 \\
1959 \\
1960 \\
\end{array}$ & $\begin{array}{l}\text { May } \\
\text { June } \\
\text { May } \\
\text { June } \\
\text { May }\end{array}$ & $\begin{array}{rr}25, & 1956 \\
6, & 1957 \\
27, & 1958 \\
7, & 1959 \\
17, & 1960 \\
\end{array}$ & $\begin{array}{l}- \\
- \\
- \\
- \\
-\end{array}$ & $\begin{array}{l}46 \\
80 \\
75 \\
26 \\
28 \\
\end{array}$ & $\begin{array}{l}1961 \\
1962 \\
1963\end{array}$ & $\begin{array}{l}\text { May } \\
\text { May } \\
\text { May }\end{array}$ & $\begin{array}{ll}26, & 1961 \\
12, & 1962 \\
23, & 1963\end{array}$ & $\begin{array}{l}- \\
-\end{array}$ & $\begin{array}{l}12 \\
30 \\
24\end{array}$ \\
\hline
\end{tabular}

\section{Surplus Canal at Salt Lake City, Utah}

Location.--Lat $40^{\circ} 43140^{\prime \prime}$, long $111^{\circ} 55^{\prime} 35^{\prime \prime}$, in SW $\frac{1}{4}$ SW $\frac{1}{4}$ sec.14, T.1 S., R.1 W., on right bank $400 \mathrm{ft}$ downstream from diversion dam at head of canal and an eighth of a mile downstream from highway bridge over Jordan R:ver on 2 lst South Street; auxiliary gage at diversion dam.

Gage.--Recording. Prior to 0ct. 22, 1952, at site $50 \mathrm{ft}$ upstream at same datum. Datum of gage is 4,219.02 ft above mean sea level, datum of 1929 .

Stage-discharge relation.--Defined by current-meter measurements below $1,590 \mathrm{cf}$.

Remarks.--Flow regulated at diversion structure $400 \mathrm{ft}$ above station. Canal was built to bypass floodwater of Jordan River around Salt Lake City residential and industrial area. Only annual peaks are shown.

\begin{tabular}{|c|c|c|c|c|c|c|c|c|c|}
\hline $\begin{array}{l}\text { Water } \\
\text { year }\end{array}$ & \multicolumn{2}{|r|}{ Date } & $\begin{array}{l}\text { Gage } \\
\text { helght } \\
\text { (feet) }\end{array}$ & $\begin{array}{c}\text { Discharge } \\
\text { (cfs) }\end{array}$ & $\begin{array}{l}\text { Water } \\
\text { year }\end{array}$ & \multicolumn{2}{|r|}{ Date } & $\begin{array}{c}\text { Gage } \\
\text { helght } \\
\text { (feet) }\end{array}$ & $\begin{array}{c}\text { Discharge } \\
\text { (cfs) }\end{array}$ \\
\hline $\begin{array}{l}1943 \\
1944 \\
1945\end{array}$ & $\begin{array}{l}\text { June } \\
\text { June } \\
\text { June }\end{array}$ & $\begin{array}{ll}2, & 1943 \\
3, & 1944 \\
5, & 1945\end{array}$ & $\begin{array}{l}5.78 \\
7.50 \\
4.82\end{array}$ & $\begin{array}{l}585 \\
965 \\
436\end{array}$ & $\begin{array}{l}1954 \\
1955\end{array}$ & $\begin{array}{l}\text { May } \\
\text { June }\end{array}$ & $\begin{array}{rr}22, & 1954 \\
9, & 1955\end{array}$ & $\begin{array}{l}5.98 \\
5.69\end{array}$ & $\begin{array}{l}439 \\
366\end{array}$ \\
\hline $\begin{array}{l}1946 \\
1947 \\
1948 \\
1949 \\
1950\end{array}$ & $\begin{array}{l}\text { May } \\
\text { June } \\
\text { June } \\
\text { May } \\
\text { June }\end{array}$ & $\begin{array}{rr}29, & 1946 \\
12, & 1947 \\
3, & 1948 \\
21, & 1949 \\
2, & 1950\end{array}$ & $\begin{array}{l}4.92 \\
5.84 \\
7.06 \\
6.42 \\
5.67\end{array}$ & $\begin{array}{l}429 \\
545 \\
814 \\
635 \\
434\end{array}$ & $\begin{array}{l}1956 \\
1957 \\
1958 \\
1959 \\
1960\end{array}$ & $\begin{array}{l}\text { May } \\
\text { June } \\
\text { May } \\
\text { June } \\
\text { May }\end{array}$ & $\begin{array}{rr}25, & 1956 \\
7, & 1957 \\
28, & 1958 \\
16, & 1959 \\
13, & 1960\end{array}$ & $\begin{array}{l}6.16 \\
6.88 \\
6.67 \\
6.39 \\
5.28\end{array}$ & $\begin{array}{l}633 \\
\text { s72 } \\
850 \\
418 \\
310\end{array}$ \\
\hline $\begin{array}{l}1951 \\
1952 \\
1953\end{array}$ & $\begin{array}{l}\text { May } \\
\text { June } \\
\text { June }\end{array}$ & 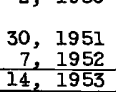 & $\begin{array}{l}6.22 \\
8.72 \\
6.97\end{array}$ & $\begin{array}{r}555 \\
1,700 \\
1,100\end{array}$ & $\begin{array}{l}1961 \\
1962 \\
1963\end{array}$ & $\begin{array}{l}\text { May } \\
\text { June } \\
\text { June }\end{array}$ & $\begin{array}{ll}16, & 1961 \\
13, & 1962 \\
11, & 1963\end{array}$ & $\begin{array}{l}4.86 \\
3.49 \\
1.77\end{array}$ & $\begin{array}{l}243 \\
491 \\
489\end{array}$ \\
\hline
\end{tabular}

\section{Jordan River at Salt Lake City, Utah}

Location.--Lat $40^{\circ} 43^{1} 40^{\prime \prime}$, long $111^{\circ} 55^{\prime} 25^{\prime \prime}$, in SW $\frac{1}{4} S W \frac{1}{4}$ sec.14, T.1 S., R.1 W., on lef't bank $800 \mathrm{ft}$ downstream from diversion structure at head of Surplus Canal, a quarter of a mile downstream from highway bridge on 2lst South Street, Salt Lake City, and 2 miles downstream from Mill Creel.

Drainage area.--3,420 sq $\mathrm{ml}$, approximately (Including $255 \mathrm{sq} \mathrm{mi}$ in closed basin in Cedar Valley, Utah).

Gage.--Recording. Datum of gage is $4,220.73 \mathrm{ft}$ above mean sea level, datum of 1929 .

Stage-discharge relation.--Defined by current-meter measurements below $338 \mathrm{cfs}$.

Remarks.--Flow completely regulated since construction of Surplus Canal di-

version dam $800 \mathrm{ft}$ upstream in May 1952. Many diversions above station for

irrigation and industrial and municipal water supplies. Only annual peaks

are shown. 
Peak stages and discharges of Jordan River at Salt Lake C1ty, Utah

\begin{tabular}{|c|c|c|c|c|c|c|c|c|}
\hline $\begin{array}{l}\text { Water } \\
\text { year }\end{array}$ & Date & $\begin{array}{c}\text { aage } \\
\text { helght } \\
\text { (feet) }\end{array}$ & $\begin{array}{c}\text { Discharge } \\
\text { (cfs) }\end{array}$ & $\begin{array}{l}\text { Water } \\
\text { year }\end{array}$ & & Date & $\begin{array}{c}\text { Gage } \\
\text { height } \\
\text { (feet) }\end{array}$ & $\begin{array}{c}\mathrm{D} \text { ischarge } \\
\text { (cfs) }\end{array}$ \\
\hline $\begin{array}{l}1943 \\
1944 \\
1945\end{array}$ & $\begin{array}{lll}\text { June } & 2,1943 \\
\text { June } & 3,1944 \\
\text { Aug. } & 6,1945\end{array}$ & $\begin{array}{l}5.03 \\
5.55 \\
4.50\end{array}$ & $\begin{array}{l}322 \\
384 \\
261\end{array}$ & $\begin{array}{l}1954 \\
1955\end{array}$ & $\begin{array}{l}\text { May } \\
\text { June }\end{array}$ & $\begin{array}{l}22,1954 \\
14,1955\end{array}$ & $\begin{array}{l}4.96 \\
4.39\end{array}$ & $\begin{array}{l}306 \\
233\end{array}$ \\
\hline $\begin{array}{l}1946 \\
1947 \\
1948 \\
1949 \\
1950\end{array}$ & $\begin{array}{l}\text { May 29, } 1946 \\
\text { June 9, } 1947 \\
\text { Sept.20, } 1948 \\
\text { Sept.11, } 1949 \\
\text { Sept.30, } 1950\end{array}$ & $\begin{array}{l}3.59 \\
4.43 \\
4.07 \\
5.00 \\
4.71\end{array}$ & $\begin{array}{l}265 \\
235 \\
219 \\
325 \\
283\end{array}$ & $\begin{array}{l}1956 \\
1957 \\
1958 \\
1959 \\
1960\end{array}$ & $\begin{array}{l}\text { May } \\
\text { May } \\
\text { Aug. } \\
\text { May } \\
\text { Mar. }\end{array}$ & $\begin{array}{ll}24, & 1956 \\
19, & 1957 \\
15, & 1958 \\
28, & 1959 \\
31, & 1960\end{array}$ & $\begin{array}{l}4.70 \\
4.00 \\
4.76 \\
4.27 \\
4.32\end{array}$ & $\begin{array}{l}279 \\
223 \\
279 \\
253 \\
228\end{array}$ \\
\hline $\begin{array}{l}1951 \\
1952 \\
1953\end{array}$ & $\begin{array}{l}\text { Oct. } 1,1950 \\
\text { June } 26,1952 \\
\text { Oct. } 17,1952\end{array}$ & $\begin{array}{l}4.71 \\
5.75 \\
5.21\end{array}$ & $\begin{array}{l}285 \\
367 \\
285\end{array}$ & $\begin{array}{l}1961 \\
1962 \\
1963\end{array}$ & $\begin{array}{l}\text { May } \\
\text { June } \\
\text { July } \\
\text { Jan. }\end{array}$ & $\begin{array}{ll}20, & 1961 \\
16, & 1961 \\
13, & 1962 \\
31, & 1963\end{array}$ & $\begin{array}{l}3.74 \\
3.82 \\
4.62 \\
4.73\end{array}$ & $\begin{array}{l}170 \\
170 \\
167 \\
218\end{array}$ \\
\hline
\end{tabular}

1715. Parleys Creek near Salt Lake City, Utah

Location.--Lat $40^{\circ} 43^{\prime} 00^{\prime \prime}$, long $111^{\circ} 47100^{\prime \prime}$, in SE $\frac{1}{4}$ sec.24, T.1 S., R.1 E., a quarter of a mile upstream from stillman highway bridge, three-quarters of a mile upstream from mouth of canyon, and $6 \frac{1}{2}$ miles southeast of Salt Lake City.

Drainage area. $--50.1 \mathrm{sq} \mathrm{mi}$.

Gage.--Nonrecording and two Cippoletti weirs prior to 1931 , at site about

three-quarters of a mile downstream at different datum; recording thereafter. Discharge is combined flow of creek and all diversions. Altitude of gage is $4,890 \mathrm{ft}$ (from topographic map).

Stage-discharge relation.--Defined by current-meter measurements.

Remarks.--Records since 1913 furnished by office of City Engineer of Salt Lake City. Flow regulated by Mountain Dell Reservoir (capacity, about 3,400 acre-ft) since September 1917. Only annual peaks are shown.

Peak stages and discharges

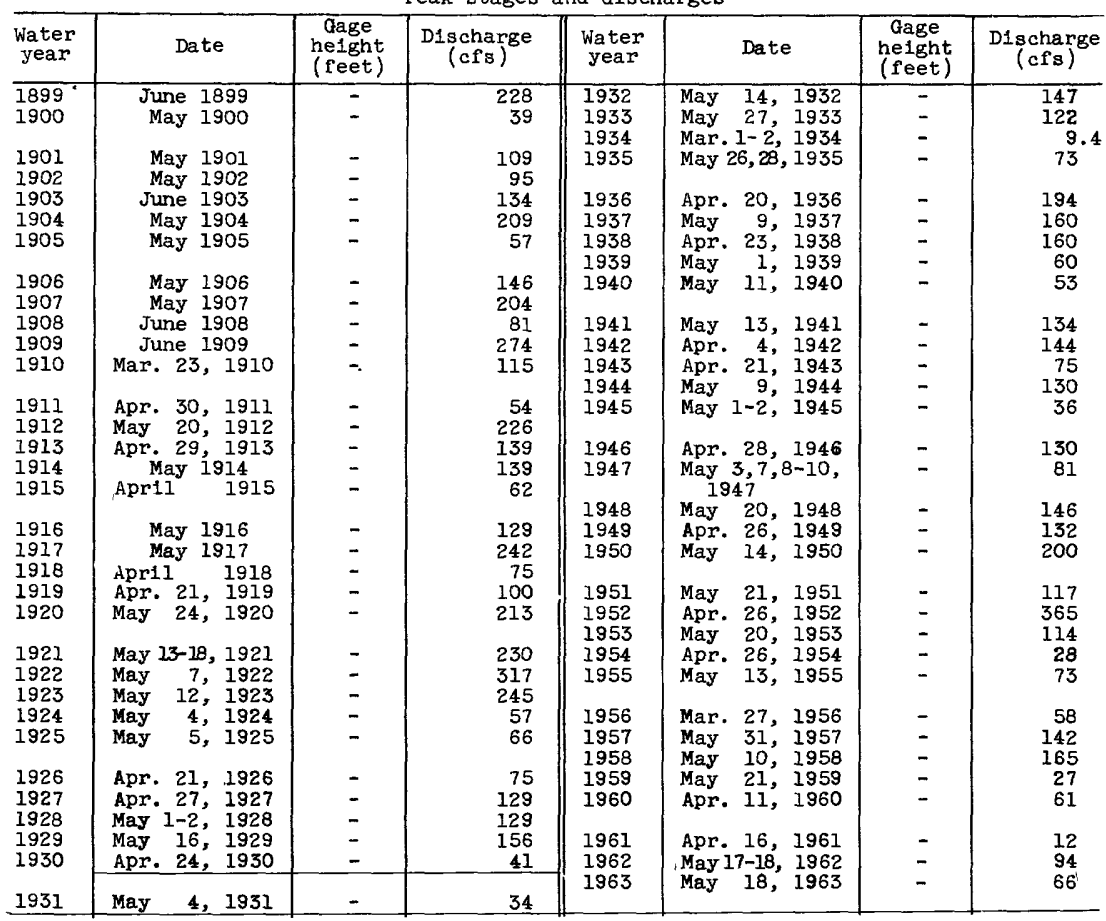


1720. Emigration Creek near Salt Lake City, Utah

Location.--Lat $40^{\circ} 45^{\prime} 00^{\prime \prime}$, long $111^{\circ} 48^{\prime} 45^{\prime \prime}$, in $\mathrm{SW} \frac{1}{4} \mathrm{NW} \frac{1}{4}$ sec.11, T.1 S., R.1 E., at east boundary of Hogle Zoo near mouth of canyon, 4 miles soutr east of sait Lake City.

Drainage area. --18 sq $\mathrm{mi}$, approximately.

Gage.--Nonrecording and Clppolett1 weirs prior to 1927; recording gage and

rating flume thereafter. Altitude of gage is 4,870 $\mathrm{ft}$ (from topographic map).

Stage-discharge relation.--Defined by current-meter measurements.

Remarks.--Records since 1913 furnished by office of City Engineer of Salt Lake City. Only annual maximum daily discharges are shown.

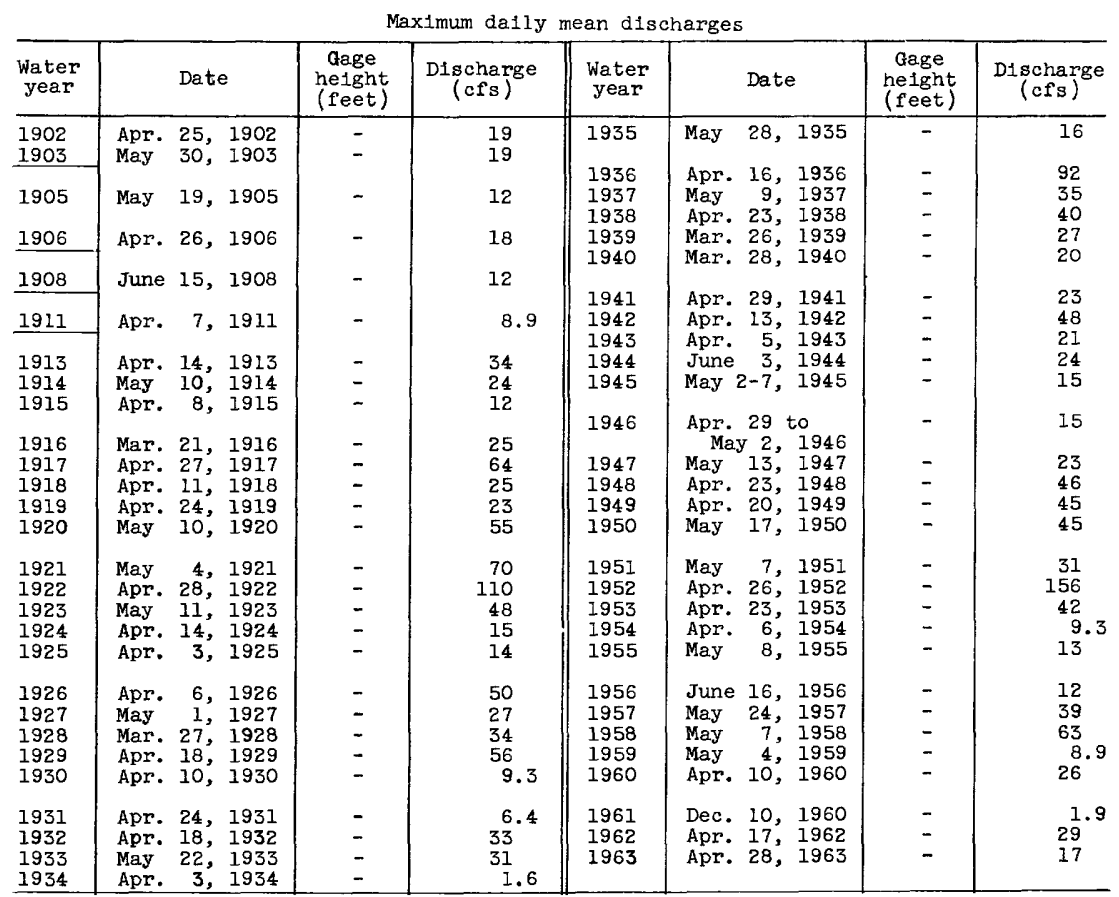

1725. C1ty Creek near Salt Lake C1ty, Utah

Location.--Lat $40^{\circ} 47^{\prime} 05^{\prime \prime}$, long $111^{\circ} 53^{\prime} 00^{\prime \prime}$, In SE $\frac{1}{4}$ SW $\frac{1}{4}$ sec.30, T.1 N. , R.I E., about $300 \mathrm{ft}$ downstream from abandoned stone bullding near mouth of canyon and 0.6 mile northeast of Utah State Capitol building.

Drainage area. $--19.2 \mathrm{sq} \mathrm{m}$.

Gage.--Nonrecording and two Clppoletti welrs prior to 1924 , at site $3 \frac{1}{2}$ miles upstream at different datum; recording gage and concrete flume thereafter.

Discharge is combined flow of creek and all diversions. Altitide of gage is $4,540 \mathrm{ft}$ (from topographic map).

Stage-discharge relation.--Defined by current-meter measurements.

Remarks.--Records since 1913 furnished by Office of City Engineer of Salt Lake city. Only annual maximum daily discharges are shown. 
Maximum dally mean discharges of City Creek near Salt Lake City, Utah

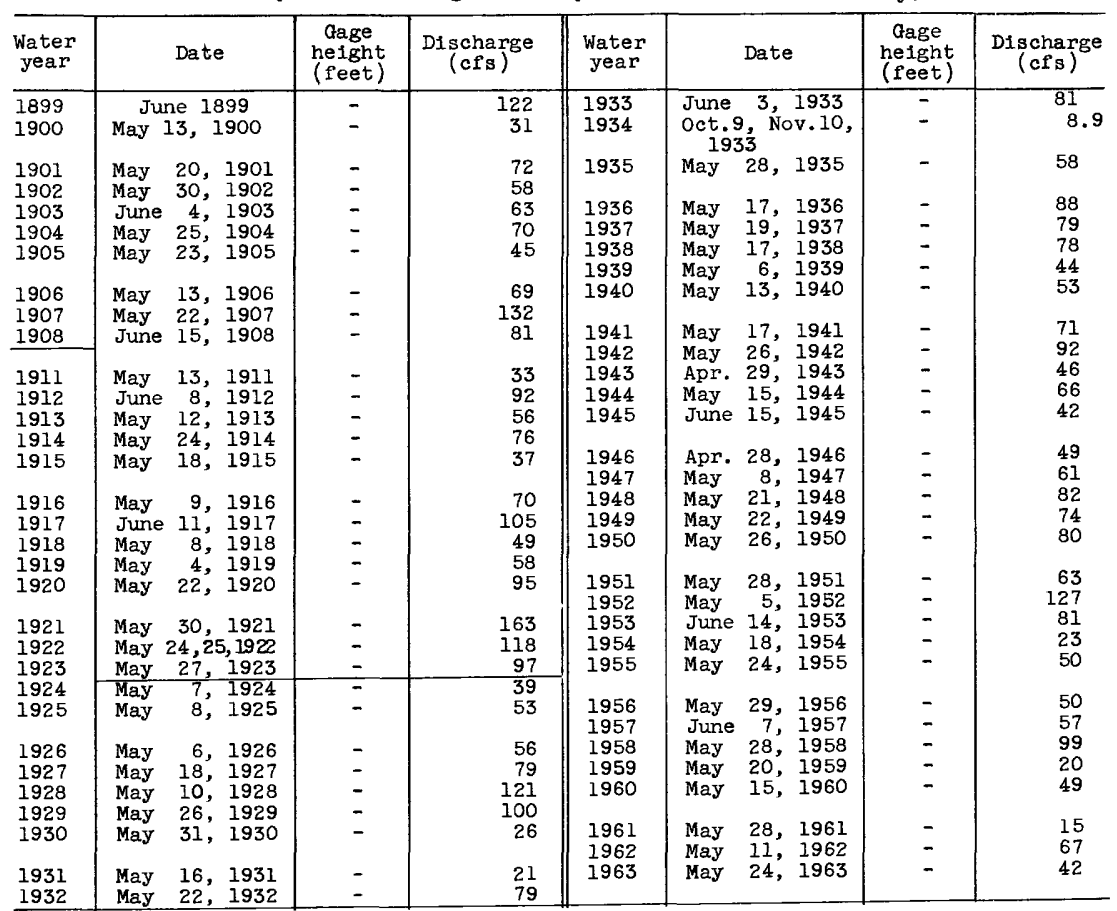

\section{RUSH VALLEY}

1727. Vernon Creek near Vernon, Utah

Location.--Lat $39^{\circ} 59^{\prime}$, long $112^{\circ} 23^{1}$, in W $\frac{1}{2}$ sec.2, T.10 S., R.5 W., on right bank 7 miles upstream from confluence with Dutch Creek forming Faust Creek and 8 miles southeast of Vermon.

Drainage area. $--25 \mathrm{sq} \mathrm{ml}$, approximateiy.

Gage.--Recording. Altitude of gage is 6,200 ft (from AMS topographic map). Stage-discharge relation.--Defined by current-meter measurements below $75 \mathrm{cf}$. Remarks.--Only annual peaks are shown.

Peak stages and discharges

\begin{tabular}{|c|c|c|c|c|c|c|c|}
\hline $\begin{array}{l}\text { Water } \\
\text { year }\end{array}$ & Date & $\begin{array}{l}\text { Gage } \\
\text { helght } \\
\text { (feet) }\end{array}$ & $\begin{array}{c}\text { Discharge } \\
(\text { cfs })\end{array}$ & $\begin{array}{l}\text { Water } \\
\text { year }\end{array}$ & Date & $\begin{array}{l}\text { Gage } \\
\text { height } \\
\text { (feet) }\end{array}$ & $\begin{array}{c}\text { D1scharge } \\
\text { (cfs) }\end{array}$ \\
\hline $\begin{array}{l}1958 \\
1959 \\
1960 \\
\end{array}$ & $\begin{array}{l}\text { June } 28 \text { to } \\
\text { July } 3,1958 \\
\text { Mar. } 23,1959 \\
\text { May } 15-18,1960\end{array}$ & 0.57 & $\begin{array}{r}a b 2.0 \\
1.9 \\
a 3.4\end{array}$ & $\begin{array}{l}1961 \\
1962 \\
1963\end{array}$ & $\begin{array}{l}\text { Sept.17, } 1961 \\
\text { Apr. 14, } 1962 \\
\text { Feb. 1, } 1963\end{array}$ & $\begin{array}{r}1.46 \\
1.82 \\
.80\end{array}$ & $\begin{array}{l}41 \\
78 \\
6.6\end{array}$ \\
\hline
\end{tabular}

a Maximum daily. 
1728.7. Trout Creek near Callao, Utah

Location.--Lat $39^{\circ} 44^{14} 0^{\prime \prime}$, long $113^{\circ} 53^{\prime} 20^{\prime \prime}$, in SW $\mathrm{w}_{4} \sec .28, \mathrm{~T} .12 \mathrm{~S} . \mathrm{R} .18 \mathrm{~W}$. , on left bank $2 \frac{1}{2}$ miles upstream from Birch Creek and 14 miles southwest of

Callao.

Drainage area. $--8.8 \mathrm{sq} \mathrm{ml}$, approximately.

Gage.--Recording. Altitude of gage is 6,200 ft (from topographic map).

Stage-discharge relation.--Defined by current-meter measurements below $44 \mathrm{cfs}$. Remarks.--Only annual peaks are shown.

\begin{tabular}{|c|c|c|c|c|c|c|c|c|}
\hline $\begin{array}{l}\text { Water } \\
\text { year }\end{array}$ & & Date & $\begin{array}{c}\text { Gage } \\
\text { heIght } \\
\text { (feet) }\end{array}$ & $\begin{array}{c}\text { Discharge } \\
(\mathrm{cfs})\end{array}$ & $\begin{array}{l}\text { Water } \\
\text { year }\end{array}$ & Date & $\begin{array}{c}\text { Gage } \\
\text { height } \\
\text { (feet) }\end{array}$ & $\begin{array}{c}\text { Discharge } \\
(\mathrm{cfs})\end{array}$ \\
\hline $\begin{array}{l}1959 \\
1960\end{array}$ & $\begin{array}{l}\text { May } \\
\text { May }\end{array}$ & $\begin{array}{ll}15, & 1959 \\
13, & 1960\end{array}$ & $\begin{array}{l}1.11 \\
1.44\end{array}$ & $21^{6.2}$ & $\begin{array}{l}1962 \\
1963\end{array}$ & $\begin{array}{lrl}\text { May } 9, & 1962 \\
\text { June } 20, & 1963\end{array}$ & $\begin{array}{l}1.92 \\
2.01\end{array}$ & $\begin{array}{l}45 \\
56\end{array}$ \\
\hline 1961 & May & $29, \quad 1961$ & 1.58 & 25 & & & & \\
\hline
\end{tabular}

\subsection{Deep Creek near Ibapah, Utah}

Location.--Lat $40^{\circ} 15^{\prime}$, long $113^{\circ} 59^{\prime}$, in T.6 S., R.19 W. (unsurveyed), half a mile upstream from Bar Creek and 15 miles north of Ibapah.

Drainage area. $--460 \mathrm{sq} \mathrm{mi}$, approximately.

Gage.--Crest-stage gage. Altitude of gage is 5,000 ft (from topographic map).

Stage discharge relation.--Defined by current-meter measurements below $23.2 \mathrm{cfs}$ and extended above on basis of logarithmic plotting and slope-area measurement at $1,250 \mathrm{cfs}$.

Remarks.--Only annual peaks are shown.

\begin{tabular}{|c|c|c|c|c|c|c|c|}
\hline $\begin{array}{l}\text { Water } \\
\text { year }\end{array}$ & Date & $\begin{array}{c}\text { Gage } \\
\text { height } \\
\text { (feet) }\end{array}$ & $\begin{array}{l}\text { Discharge } \\
\text { (cfs) }\end{array}$ & $\begin{array}{l}\text { Water } \\
\text { year }\end{array}$ & Date & $\begin{array}{c}\text { Gage } \\
\text { helght } \\
\text { (feet) }\end{array}$ & $\begin{array}{c}\text { D1scharge } \\
\text { (cfs) }\end{array}$ \\
\hline $\begin{array}{l}1959 \\
1960\end{array}$ & $\begin{array}{lll}\text { Aug. } & 20,1959 \\
\text { Apr. } 23, & 1960\end{array}$ & $\begin{array}{r}9.80 \\
10.66\end{array}$ & $\begin{array}{l}21 \\
81\end{array}$ & $\begin{array}{l}1962 \\
1963\end{array}$ & $\begin{array}{l}\text { Feb. } 14,1962 \\
\text { June } 10,1963\end{array}$ & $\begin{array}{l}11.55 \\
10.53\end{array}$ & $\begin{array}{r}175 \\
70\end{array}$ \\
\hline 1961 & Aug. 25,1961 & 17.14 & 1,250 & & & & \\
\hline
\end{tabular}

\section{Bar Creek near Ibapah, Utah}

Location. - - Lat $40^{\circ} 15^{1}$, long $113^{\circ} 59^{1}$, in T.6 S., R.19 W. (unsurveyed), half a mile upstream from mouth and 15 miles north of Ibapah.

Drainage area. - - $12 \mathrm{sq} \mathrm{ml}$, approximately.

Gage.--Crest-stage gage. Altitude of gage is 5,000 ft (from topngraphic map).

Stage-discharge relation.--Defined by zero flow and a slope-area measurement at 2,690 cfs.

Remarks.--Only annual peaks are shown.

Peak stages and discharges

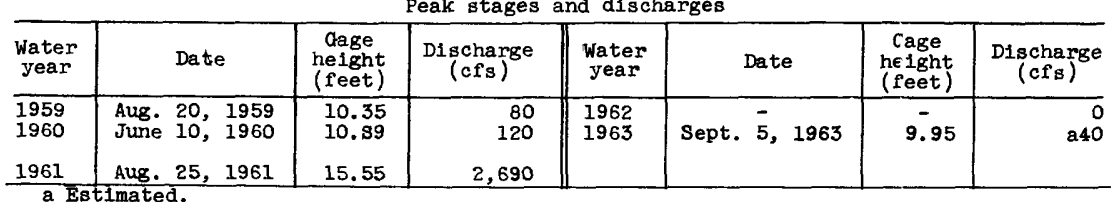




\subsection{Dove Creek near Park Valley, Utah}

Location. --Iat $41^{\circ} 47^{\prime}$, long $113^{\circ} 34^{\prime}$, in SE $\frac{1}{4}$ sec.4, T.12 N., R.15 W., on left bank 6 miles upstream from Black Hill Creek and 12 miles west of Park Valley.

Drainage area. $--35 \mathrm{sq} \mathrm{mi}$, approximately.

Gage.--Recording gage and timber welr. Altitude of gage is 5,600 ft (from topographic map).

Stage-discharge relation.--Defined by current-meter measurements below $72 \mathrm{cf}$, by slope-area measurement at $167 \mathrm{cfs}$, and extended to $275 \mathrm{cfs}$ on basis of logarithmic plotting.

Remarks.--Only annual peaks are shown.

Peak stages and discharges

\begin{tabular}{l|c|c|c||c|c|c|c}
\hline $\begin{array}{c}\text { Water } \\
\text { year }\end{array}$ & \multicolumn{2}{|c|}{ Date } & $\begin{array}{c}\text { Gage } \\
\text { height } \\
\text { (feet) }\end{array}$ & $\begin{array}{c}\text { Discharge } \\
\text { (cfs) }\end{array}$ & $\begin{array}{c}\text { Water } \\
\text { year }\end{array}$ & $\begin{array}{c}\text { Gage Date } \\
\text { height } \\
\text { (feet) }\end{array}$ & $\begin{array}{c}\text { Iischarge } \\
\text { (cfs) }\end{array}$ \\
\hline 1959 & May 23, 1959 & 1.07 & 1.8 & 1962 & Feb. 10, 1962 & 4.65 & 1.62 \\
1960 & Sept. 1, 1960 & 1.49 & 11 & 1963 & Aug. 30, 1963 & & \\
1961 & Aug. 25, 1961 & 3.91 & 167 & & \\
\hline
\end{tabular}

1729.6. West Fork Tenmlle Creek near Park Valley, Utah

Location.--Lat $41^{\circ} 50^{\prime}$, long $113^{\circ} 08^{\prime}$, in SW $\frac{1}{4}$ sec.19, T.13 N., R.11 W, at culvert on State Highway 70,2 miles downstream from Crystal Hollow, 10 miles east of Park Valley, and 23 miles southwest of Snowville.

Drainage area. $--5.93 \mathrm{sq} \mathrm{ml}$.

Gage.--Crest-stage gage. Alt1tude of gage 1s about 4,600 ft (from topographic map).

Stage-discharge relation.--Def'ined by zero f'low and culvert measurements at $151 \mathrm{cf}$ 's and $460 \mathrm{cf}$.

Remarks.--Only annual peaks are shown.

\begin{tabular}{c|c|c|c|c|c|c|c}
\hline $\begin{array}{c}\text { Water } \\
\text { year }\end{array}$ & Date & $\begin{array}{c}\text { Gage } \\
\text { height } \\
\text { (feet) }\end{array}$ & $\begin{array}{c}\text { Discharge } \\
\text { (cfs) }\end{array}$ & $\begin{array}{c}\text { Water } \\
\text { year }\end{array}$ & Date & $\begin{array}{c}\text { Gage } \\
\text { he1ght } \\
\text { (feet) }\end{array}$ & $\begin{array}{c}\text { Discharge } \\
\text { (cfs) }\end{array}$ \\
\hline 1959 & Sept.23, 1959 & 10.53 & -151 & 1962 & Feb. 12, 1962 & 10.25 & 90 \\
1960 & - & 0 & 1963 & Aug. 31, 1963 & 12.07 & \\
1961 & Sept.18, 1961 & 10.30 & 100 & & & \\
\hline
\end{tabular}

\subsection{Blue Spring Creek near Snowville, Utah}

Location.--Lat $41^{\circ} 51^{\prime}$, long $112^{\circ} 27^{\prime}$, in SW $\frac{1}{4}$ sec.17, T.13 N., R.5 W., at box culvert on U.S. Highway $30 S, 16$ miles southeast of Snowville and 24 miles upstream from Bear River Bay.

Dralnage area.--180 $\mathrm{sq} \mathrm{ml}$, approximately, of which about $78 \mathrm{sq} \mathrm{ml}$ contributes directly to surface runoff.

Gage.--Crest-stage gage. Altitude of gage is 4,700 ft (from topographic map). Remarks.--Only annual peaks are shown.

\begin{tabular}{l|c|c|c||c|c|c|r}
\hline $\begin{array}{c}\text { Water } \\
\text { year }\end{array}$ & Date & $\begin{array}{c}\text { Gage } \\
\text { helght } \\
\text { (feet) }\end{array}$ & $\begin{array}{c}\text { Discharge } \\
\text { (cfs) }\end{array}$ & $\begin{array}{c}\text { Water } \\
\text { year }\end{array}$ & Date & $\begin{array}{c}\text { Gage } \\
\text { height } \\
\text { (feet) }\end{array}$ & $\begin{array}{r}\text { Di scharge } \\
\text { (cfs) }\end{array}$ \\
\hline 1959 & Sept.23, 1959 & 13.15 & 282 & 1962 & Feb. 12, 1962 & 17.47 & 1,820 \\
1960 & Apr. 28, 1960 & 11.85 & 120 & 1963 & Feb. 1, 1963 & 10.06 & $\begin{array}{r}9 \\
1961\end{array}$ \\
\hline
\end{tabular}


1735. Mammoth Creek near Hatch, Utah

Location.--Lat $37^{\circ} 37^{\prime}$, long $112^{\circ} 28^{\prime}$, in sec.1, T.37 S., R.6 W., a quarter of a mile above flow line of former Hatchtown Reservolr, three-quarters of a mile east of east boundary of Sevier National Forest, and $3 \frac{3}{2}$ miles southwest of Hatch.

Drainage area. $--151 \mathrm{sq} \mathrm{ml}$.

Gage, --Recording.

Stage-discharge relation.--Defined by current-meter measurements below $480 \mathrm{cfs}$. Remarks.--Only annual peaks are shown.

Peak stages and discharges

\begin{tabular}{|c|c|c|c|c|c|c|c|c|c|}
\hline $\begin{array}{l}\text { Water } \\
\text { year }\end{array}$ & \multicolumn{2}{|r|}{ Date } & $\begin{array}{l}\text { Gage } \\
\text { height } \\
\text { (feet) }\end{array}$ & $\begin{array}{c}\text { Discharge } \\
\text { (cfs) }\end{array}$ & $\begin{array}{l}\text { Water } \\
\text { year }\end{array}$ & & Date & $\begin{array}{l}\text { Gage } \\
\text { helght } \\
\text { (feet) }\end{array}$ & $\begin{array}{c}\text { Discharge } \\
(\mathrm{cfs})\end{array}$ \\
\hline 1914 & \multirow{2}{*}{\multicolumn{2}{|c|}{$\begin{array}{l}\text { June } 1,1914 \\
\text { May } 12,1916 \\
\text { June } 10,1917\end{array}$}} & & & \multirow[t]{2}{*}{$\begin{array}{l}1918 \\
1919\end{array}$} & \multirow{2}{*}{\multicolumn{2}{|c|}{$\begin{array}{lrr}\text { May } & 16, & 1915 \\
\text { May } & 6, & 1919\end{array}$}} & \multirow[t]{2}{*}{$\begin{array}{l}3.32 \\
3.39\end{array}$} & \multirow[t]{2}{*}{$\begin{array}{l}366 \\
389\end{array}$} \\
\hline $\begin{array}{l}1916 \\
1917\end{array}$ & & & $\begin{array}{l}3.72 \\
4.32\end{array}$ & $\begin{array}{l}511 \\
795\end{array}$ & & & & & \\
\hline
\end{tabular}

1736. Midway Creek near Hatch, Utah

Location.--Lat $37^{\circ} 31^{\prime} 10^{\prime \prime}$, long $112^{\circ} 43^{\prime} 35^{\prime \prime}$, in SE $\frac{1}{4}$ sec.10, T.38 S., R. 8 W., on right bank $200 \mathrm{ft}$ south of State Highway $14,0.7$ mile east of Navajo Lake Resort turnoff, and 19 miles southwest of Hatch.

Dralnage area. $--25.7 \mathrm{sq} \mathrm{mi}$.

Gage.--Recording.

Stage-discharge relation.--Defined by current-meter measurements below $123 \mathrm{cf}$. Remarks.--Only annual peaks are shown.

\begin{tabular}{|c|c|c|c|c|c|c|c|c|c|}
\hline $\begin{array}{l}\text { Water } \\
\text { year }\end{array}$ & & Date & $\begin{array}{c}\text { Gage } \\
\text { height } \\
\text { (feet) }\end{array}$ & $\begin{array}{c}\text { Discharge } \\
(\mathrm{cfs})\end{array}$ & $\begin{array}{l}\text { Water } \\
\text { year }\end{array}$ & & Date & $\begin{array}{c}\text { Gage } \\
\text { he1ght } \\
\text { (feet) }\end{array}$ & $\begin{array}{c}\text { Discharge } \\
(\mathrm{cfs})\end{array}$ \\
\hline $\begin{array}{l}1958 \\
1959 \\
1960 \\
\end{array}$ & $\begin{array}{l}\text { June } \\
\text { May } \\
\text { May }\end{array}$ & $\begin{array}{rr}6, & 1958 \\
12, & 1959 \\
13, & 1960\end{array}$ & $\begin{array}{l}2.64 \\
1.53 \\
2.00\end{array}$ & $\begin{array}{r}153 \\
42 \\
78\end{array}$ & $\begin{array}{l}1961 \\
1962\end{array}$ & $\begin{array}{l}\text { May } \\
\text { May }\end{array}$ & $\begin{array}{rr}22, & 1961 \\
7, & 1962\end{array}$ & $\begin{array}{l}1.81 \\
2.34\end{array}$ & $\begin{array}{r}57 \\
114\end{array}$ \\
\hline
\end{tabular}

\section{Duck Creek near Hatch, Utah}

Location.--Lat $37^{\circ} 31^{\prime}$, long $112^{\circ} 42^{\prime}$, in SW $\frac{1}{4}$ sec.12, T.38 S., R. 8 W., on right bank $150 \mathrm{ft}$ north of State Highway $14,200 \mathrm{ft}$ east of Duck Lake dam, $400 \mathrm{ft}$ downstream from Duck Creek Spring, 3 miles east of Navajo Lake, and 18 miles southwest of Hatch.

Drainage area. $--38.3 \mathrm{sq} \mathrm{mi}$ (including $6.24 \mathrm{sq} \mathrm{mi}$ in closed basin for Navajo Lake).

Gage.--Recording. Altitude of gage is $8,530 \mathrm{ft}$ (by barometer).

Stage-discharge relation.--Defined by current-meter measurements below $135 \mathrm{cfs}$ and extended above on basis of logarithmic plotting.

Remarks.--Only annual peaks are shown.

\begin{tabular}{|c|c|c|c|c|c|c|c|c|}
\hline $\begin{array}{l}\text { Water } \\
\text { year }\end{array}$ & & Date & $\begin{array}{c}\text { Cage } \\
\text { helght } \\
\text { (feet) }\end{array}$ & $\begin{array}{c}\text { Discharge } \\
\text { (cfs) }\end{array}$ & $\begin{array}{l}\text { Water } \\
\text { year }\end{array}$ & Date & $\begin{array}{c}\text { Gage } \\
\text { height } \\
\text { (feet) }\end{array}$ & $\begin{array}{c}\text { Discharge } \\
\text { (cfs) }\end{array}$ \\
\hline $\begin{array}{l}1954 \\
1955\end{array}$ & $\begin{array}{l}\text { May } \\
\text { May }\end{array}$ & $\begin{array}{ll}20, & 1954 \\
14, & 1955\end{array}$ & $\begin{array}{l}3.04 \\
2.22\end{array}$ & $\begin{array}{r}140 \\
43\end{array}$ & $\begin{array}{l}1957 \\
1958\end{array}$ & $\begin{array}{lll}\text { June } & 6, & 1957 \\
\text { June } & 6, & 1958\end{array}$ & $\begin{array}{l}3.30 \\
3.61\end{array}$ & $\begin{array}{l}156 \\
226\end{array}$ \\
\hline 1956 & May & 24,1956 & 2.41 & 65 & & & & \\
\hline
\end{tabular}


1740. Asay Creek above West Fork, near Hatch, Utah

Location.--Lat $37^{\circ} 33^{\prime}$, Iong $112^{\circ} 31^{\prime}$, in sec.33, T.37 S., R.6 W., on right bank half a mile downstream from Asay Creek Spring, 2 miles upstream from West Fork Asay Creek, and 8 miles southwest of Hatch.

Drainage area $--105 \mathrm{sq} \mathrm{mi}$ (including $6.24 \mathrm{sq} \mathrm{mi}$ in closed basin for Navajo Lake).

Gage. --Recording.

Stage-discharge relation.--Defined by current-meter measurements below $269 \mathrm{cfs}$ and extended above on basis of logarithmic plotting.

Remarks.--Only annual peaks are shown.

Peak stages and discharges

\begin{tabular}{|c|c|c|c|c|c|c|c|c|}
\hline $\begin{array}{l}\text { Water } \\
\text { year }\end{array}$ & & Date & $\begin{array}{c}\text { Gage } \\
\text { helght } \\
\text { (feet) }\end{array}$ & $\begin{array}{c}\text { Discharge } \\
\text { (cfs) }\end{array}$ & $\begin{array}{l}\text { Water } \\
\text { year }\end{array}$ & Date & $\begin{array}{c}\text { Gage } \\
\text { height } \\
\text { (feet) }\end{array}$ & $\begin{array}{c}\text { Discharge } \\
\text { (cfs) }\end{array}$ \\
\hline $\begin{array}{l}1954 \\
1955 \\
1956 \\
\end{array}$ & $\begin{array}{l}\text { July } \\
\text { May } \\
\text { May }\end{array}$ & $\begin{array}{ll}25, & 1954 \\
23, & 1955 \\
25, & 1956 \\
\end{array}$ & $\begin{array}{l}1.89 \\
1.64 \\
1.74 \\
\end{array}$ & $\begin{array}{r}259 \\
36 \\
48\end{array}$ & $\begin{array}{l}1957 \\
1958 \\
1959\end{array}$ & 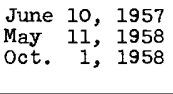 & $\begin{array}{l}2.39 \\
3.63 \\
-\end{array}$ & $\begin{array}{l}110 \\
419 \\
\text { b41 }\end{array}$ \\
\hline
\end{tabular}

a Maximum for period July to September.

b Maximum daily discharge for period october to January.

\section{Sevier River at Hatch, Utah \\ (Published as "near Hatch" 1912)}

Location.--Lat $37^{\circ} 39^{1} 00^{\prime \prime}$, long $112^{\circ} 25^{\prime} 30^{\prime \prime}$, in SW $\frac{1}{4} N W \frac{1}{4}$ sec.28, T.36 S., R.5 W., on left bank $300 \mathrm{ft}$ downstream from bridge, 0.2 mile east of Hatch, and 2.8 miles downstream from Mammoth Creek.

Drainage area.--340 sq $\mathrm{mi}$, approximately. Mean altitude, 8,480 ft.

Gage.--Nonrecording prior to 1915; recording thereafter. At several sites withIn 2 miles of present site at various datums prior to oct. 3, 1949. Altitude of gage is $6,870 \mathrm{ft}$ (from river-profile map).

Stage-discharge relation.--Defined by current-meter measurements below $1,400 \mathrm{cfs}$.

Historical data.--Maximum flood known sccurred May 25, 1914, when Hatchtown Dam, $1 \frac{1}{2}$ miles upstream falled, releasing 11,600 acre-ft of stored water. Discharge not determined.

Remarks. - No regulation since fallure of Hatchtown Dam. Base for partialduration series, 500 cfs. Only annual peaks are shown prior to 1948 .

\begin{tabular}{|c|c|c|c|c|c|c|c|c|}
\hline $\begin{array}{l}\text { Water } \\
\text { year }\end{array}$ & Date & $\begin{array}{c}\text { alge } \\
\text { height } \\
\text { (feet) }\end{array}$ & $\begin{array}{c}\text { Discharge } \\
\text { (cfs) }\end{array}$ & $\begin{array}{l}\text { Water } \\
\text { year }\end{array}$ & & Date & $\begin{array}{c}\text { Gage } \\
\text { neight } \\
\text { (feet) }\end{array}$ & $\begin{array}{c}\text { Discharge } \\
(\mathrm{cfs})\end{array}$ \\
\hline $\begin{array}{l}1912 \\
1913 \\
\end{array}$ & $\begin{array}{l}\text { June } 5,1912 \\
\text { May } 18,19,1913\end{array}$ & $\overline{-}$ & $\begin{array}{r}\text { al, } 210 \\
\text { a502 }\end{array}$ & $\begin{array}{l}1943 \\
1944 \\
1945\end{array}$ & $\begin{array}{l}\text { May } \\
\text { June } \\
\text { May }\end{array}$ & $\begin{array}{rr}3, & 1943 \\
9, & 1944 \\
14, & 1945\end{array}$ & $\overline{-}$ & $\begin{array}{l}524 \\
672 \\
480\end{array}$ \\
\hline 1915 & June 2,1915 & - & 770 & & Aug. & 15,1946 & & 366 \\
\hline $\begin{array}{l}1916 \\
1917\end{array}$ & $\begin{array}{ll}\text { May } 10, & 1916 \\
\text { June } 10, & 1917\end{array}$ & - & $\begin{array}{r}1,040 \\
952\end{array}$ & 1947 & May & 9,1947 & - & 607 \\
\hline $\begin{array}{l}1918 \\
1919\end{array}$ & $\begin{array}{ll}\text { May } & 6,1918 \\
\text { May } & 6,1919\end{array}$ & $\overline{-}$ & $\begin{array}{l}550 \\
504\end{array}$ & $194 \mathrm{~s}$ & May & 18,1948 & 2.89 & 458 \\
\hline 1920 & May 24,1920 & - & 1,130 & 1949 & $\begin{array}{l}\text { May } \\
\text { June }\end{array}$ & $\begin{array}{ll}30, & 1949 \\
11, & 1949 \\
\end{array}$ & 4.31 & $\begin{array}{r}568 \\
1,060 \\
\end{array}$ \\
\hline $\begin{array}{l}1921 \\
1922 \\
1923 \\
\end{array}$ & $\begin{array}{ll}\text { June } & 10,1921 \\
\text { May } 26,1922 \\
\text { May } 20,1923\end{array}$ & 5.25 & $\begin{array}{r}803 \\
1,490 \\
826\end{array}$ & 1950 & May & 21,1950 & & 317 \\
\hline 1925 & Sept. 5, 1925 & - & $6 \mathrm{~s} 9$ & 1951 & & 28,1951 & 2.17 & 248 \\
\hline 1926 & May 23, 1926 & - & 643 & 1952 & May & 15,1952 & $\begin{array}{l}3.92 \\
3.96\end{array}$ & $\begin{array}{l}812 \\
827\end{array}$ \\
\hline $\begin{array}{l}1939 \\
1940\end{array}$ & $\begin{array}{l}\text { Sept. 6, } 1939 \\
\text { Sept.17, } 1940\end{array}$ & - & $\begin{array}{l}614 \\
580\end{array}$ & & July & 28,1952 & 3.34 & 602 \\
\hline $\begin{array}{l}1941 \\
1942\end{array}$ & 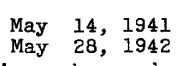 & - & $\begin{array}{r}1,140 \\
780\end{array}$ & 1954 & May & $\begin{array}{l}31,1953 \\
10,1954\end{array}$ & 2.70 & 410 \\
\hline
\end{tabular}


Peak stages and discharges of Sevier River at Hatch, Utah--Cortinued

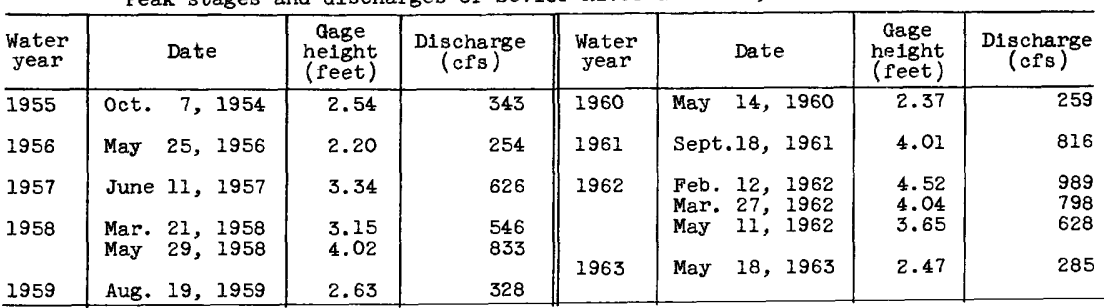

1748. Red Canyon tributary near Bryce Canyon, Utah

Location.--Lat $37^{\circ} 44^{\prime}$, long $112^{\circ} 17^{\prime}$, in sec.27, T.35 S., R. $4 \frac{1}{2}$ W. (unsurveyed), on right bank $500 \mathrm{ft}$ upstream from bridge, a quarter of a mile east of tunnel on State Highway 12 , and 10 miles southeast of Panguitch.

Drainage area. $--2.2 \mathrm{sq} \mathrm{mi}$, approximately.

Gage.--Crest-stage gage. Altitude of gage is 7,550 ft (from topographic map).

Stage-discharge relation.--Defined by current-meter measurements at $0.6 \mathrm{cfs}$ and slope-area measurement at $108 \mathrm{cfs}$.

Remarks.--Only annual peaks are shown.

Peak stages and discharges

\begin{tabular}{c|c|c|c||c|c|c|c}
\hline $\begin{array}{l}\text { Water } \\
\text { year }\end{array}$ & Date & $\begin{array}{c}\text { Gage } \\
\text { helght } \\
\text { (feet) }\end{array}$ & $\begin{array}{c}\text { Discharge } \\
\text { (cfs) }\end{array}$ & $\begin{array}{c}\text { Water } \\
\text { year }\end{array}$ & Date & $\begin{array}{c}\text { Gage } \\
\text { height } \\
\text { (feet) }\end{array}$ & $\begin{array}{c}\text { Discharge } \\
\text { (cfs) }\end{array}$ \\
\hline 1959 & Aug. 19, 1959 & 10.13 & 21 & 1962 & June 29, 1962 & 11.07 & \\
1960 & Apr. 28, 1960 & 10.48 & 50 & 1963 & Sept.18, 1963 & 10.20 & 95 \\
1961 & Aug. 4, 4961 & 11.21 & 108 & & & \\
\hline
\end{tabular}

1770. Panguitch Creek above canals, near Panguitch, Utah

Location.--Iat $37^{\circ} 48^{\prime}$, long $112^{\circ} 29^{\prime}$, in SW $\frac{1}{4} \sec .36$, T.34 S., R.6 W., and 3 miles southwest of Panguitch.

Drainage area. $--110 \mathrm{sq} \mathrm{mi}$, approximately.

Gage.--Recording.

Stage-discharge relation.--Defined by current-meter measurements below $130 \mathrm{cf}$.

Remarks.--Flow is regulated by storage in Panguitch Lake. Flow is diverted from Mammoth Creek to headwaters of Pangultch Creek for storag; in Panguitch Lake. Only annual peaks are shown.

Peak stages and discharges

\begin{tabular}{|c|c|c|c|c|c|c|c|c|c|}
\hline $\begin{array}{l}\text { Water } \\
\text { year }\end{array}$ & & Date & $\begin{array}{c}\text { Gage } \\
\text { neight } \\
(\text { feet) }\end{array}$ & $\begin{array}{c}\text { Discharge } \\
\text { (cfs) }\end{array}$ & $\begin{array}{l}\text { Water } \\
\text { year }\end{array}$ & & Date & $\begin{array}{c}\text { Gage } \\
\text { height } \\
\text { (feet) }\end{array}$ & $\begin{array}{c}\text { Discharge } \\
\text { (cfs) }\end{array}$ \\
\hline $\begin{array}{l}1916 \\
1917 \\
1915\end{array}$ & $\begin{array}{l}\text { May } \\
\text { June } \\
\text { May }\end{array}$ & $\begin{array}{ll}17, & 1916 \\
17, & 1917 \\
10, & 1918\end{array}$ & $\begin{array}{l}2.20 \\
3.75 \\
2.47\end{array}$ & $\begin{array}{l}125 \\
300 \\
164\end{array}$ & $\begin{array}{l}1919 \\
1920\end{array}$ & $\begin{array}{l}\text { May } \\
\text { May }\end{array}$ & $\begin{array}{rr}29, & 1919 \\
8, & 1920\end{array}$ & $\begin{array}{l}2.5 \mathrm{~s} \\
3.09\end{array}$ & $\begin{array}{r}180 \\
a 250\end{array}$ \\
\hline
\end{tabular}

a Maximum during period october 1919 to May 16, 1920. 
1800. Sevier River near Circleville, Utah

Location. --Lat $38^{\circ} 06^{\prime}$, long $112^{\circ} 19^{\prime}$, in SW $\frac{1}{4}$ sec.20, T.31 S., R.4 W., on left bank 2 miles upstream from Pine Creek and 6 miles southwest of Circleville.

Drainage area. $--950 \mathrm{sq} \mathrm{ml}$, approximately.

Gage.--Nonrecording May 10 to Sept. 19, 1912, at site $300 \mathrm{ft}$ upstream at different datum; recording thereafter. Apr. 23, 1914, to Sept. 30, 1927, and Nov. 21,1949 , to Aug. 6 , 1954 , at site 300 ft upstream at datum 0.2 ? $\mathrm{ft}$ higher. Altitude of gage is 6,240 $\mathrm{ft}$ (from river-profile map).

Stage-discharge relation.--Defined by current-meter measurements below $678 \mathrm{cfs}$ In 1912 , below 1,320 cfs from 1914 to 1954, and below 976 cfs since 1954.

Remarks.--Many diversions above station. Only annual peaks are shown.

\begin{tabular}{|c|c|c|c|c|c|c|c|}
\hline $\begin{array}{l}\text { Water } \\
\text { year }\end{array}$ & Date & $\begin{array}{c}\text { Gage } \\
\text { helght } \\
\text { (feet) }\end{array}$ & $\begin{array}{c}\text { D1scharge } \\
\text { (cfs) }\end{array}$ & $\begin{array}{l}\text { Water } \\
\text { year }\end{array}$ & Date & $\begin{array}{c}\text { Gage } \\
\text { he1ght } \\
\text { (feet) }\end{array}$ & $\begin{array}{c}\text { D1scharge } \\
\text { (cfs) }\end{array}$ \\
\hline 1912 & May 30,1912 & 3.7 & 2860 & 1950 & July 17,1950 & 3.45 & 258 \\
\hline $\begin{array}{l}1914 \\
1915\end{array}$ & May $\overrightarrow{18}, 1915$ & 5.6 & $\begin{array}{l}(\mathrm{b}) \\
786\end{array}$ & $\begin{array}{l}1951 \\
1952 \\
1953\end{array}$ & $\begin{array}{lrl}\text { July } & 22, & 1951 \\
\text { Aug. } & 30, & 1952 \\
\text { Aug. } 1, & 1953\end{array}$ & $\begin{array}{l}5.26 \\
7.05 \\
4.73\end{array}$ & $\begin{array}{r}709 \\
\mathrm{cl}, 380 \\
570\end{array}$ \\
\hline $\begin{array}{l}1916 \\
1917 \\
1918 \\
\end{array}$ & $\begin{array}{lr}\text { Aug. } 6,1916 \\
\text { May } 18,1917 \\
\text { Mar. 13, } 1918\end{array}$ & $\begin{array}{l}8.0 \\
6.37 \\
6.05\end{array}$ & $\begin{array}{l}1,600 \\
1,020 \\
1,000\end{array}$ & $\begin{array}{l}1954 \\
1955\end{array}$ & $\begin{array}{ll}\text { May } 11,1954 \\
\text { Aug. } & 6,1955\end{array}$ & $\frac{3.47}{2.69}$ & $\begin{array}{l}292 \\
297\end{array}$ \\
\hline 1920 & May 23,1920 & 0.05 & 1,110 & $\begin{array}{l}1956 \\
1957 \\
1958\end{array}$ & $\begin{array}{lll}\text { May } & 10,1956 \\
\text { June } & 11, & 1957 \\
\text { May } 13, & 1958\end{array}$ & $\begin{array}{l}2.07 \\
3.19 \\
4.08\end{array}$ & $\begin{array}{l}169 \\
426 \\
820\end{array}$ \\
\hline $\begin{array}{l}1921 \\
1922 \\
\end{array}$ & $\begin{array}{lr}\text { June } 8, & 1921 \\
\text { May } 21, & 1922\end{array}$ & $\begin{array}{l}4.80 \\
9.8\end{array}$ & $\begin{array}{r}622 \\
1,960\end{array}$ & $\begin{array}{l}1959 \\
1960\end{array}$ & $\begin{array}{lll}\text { Aug. } & 3,1959 \\
\text { Mar. } & 8,1960\end{array}$ & $\begin{array}{l}3.25 \\
2.26\end{array}$ & $\begin{array}{l}487 \\
223\end{array}$ \\
\hline $\begin{array}{l}1924 \\
1925\end{array}$ & $\begin{array}{l}\text { Sept. 6, } 1924 \\
\text { Sept.19, } 1925\end{array}$ & $\begin{array}{l}4.03 \\
5.20\end{array}$ & $\begin{array}{l}430 \\
770\end{array}$ & $\begin{array}{l}1961 \\
1962 \\
1963\end{array}$ & $\begin{array}{l}\text { Sept. 9, } 1961 \\
\text { Mar. 28, } 1962 \\
\text { Aug. 31, } 1963\end{array}$ & $\begin{array}{l}3.94 \\
5.00 \\
2.91\end{array}$ & $\begin{array}{r}740 \\
1,260 \\
390\end{array}$ \\
\hline 1926 & May 23,1926 & 4.45 & 465 & & & & \\
\hline
\end{tabular}

a Maximum observed during period May 10 to Sept. 19, 1912.

b Not determined, occurred May 25, when Hatchtown dam falled.

c Revised.

1835. Sevier River near Kingston, Utah

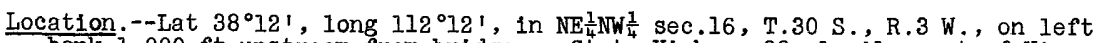
bank $1,000 \mathrm{ft}$ upstream from bridge on State Highway 22,1 mile west of Kingston, and 2 miles upstream from East Fork.

Drainage area. $--1,110 \mathrm{sq} \mathrm{mi}$, approximately. Mean altitude, 7,790 ft.

Gage.--Recording and concrete control. Prior to Sept. 20, 1918, at site about 1 mile downstream at different datum. Altitude of gage is 5,980 ft (from river-profile map).

Stage-discharge relation.--Defined by current-meter measurements below 1,300 cfs.

Remarks.--Many diversions above station for irrigation. Only annual peaks are shown.

\begin{tabular}{|c|c|c|c|c|c|c|c|}
\hline $\begin{array}{l}\text { Water } \\
\text { year }\end{array}$ & Date & $\begin{array}{c}\text { Gage } \\
\text { helght } \\
\text { (feet) }\end{array}$ & $\begin{array}{c}\text { D1scharge } \\
\text { (cfs) }\end{array}$ & $\begin{array}{l}\text { Water } \\
\text { year }\end{array}$ & Date & $\begin{array}{l}\text { Gage } \\
\text { helght } \\
\text { (feet) }\end{array}$ & $\begin{array}{c}\text { D1scharge } \\
\text { (cfs) }\end{array}$ \\
\hline 1916 & Aug. 6, 1916 & - & 900 & 1926 & \multirow{3}{*}{$\begin{array}{l}\text { Oct. } 6,1925 \\
\text { Mar. } 26,1928\end{array}$} & \multirow{3}{*}{-} & \multirow{3}{*}{$\begin{array}{r}536 \\
1,000\end{array}$} \\
\hline 1918 & $\begin{array}{l}\text { May } 19,1917 \\
\text { Mar. } 13,1918\end{array}$ & $\overline{-}$ & $\begin{array}{r}908 \\
1,000\end{array}$ & 1928 & & & \\
\hline $\begin{array}{l}1919 \\
1920\end{array}$ & $\begin{array}{l}\text { Apr. } 26,1919 \\
\text { May } 23,1920\end{array}$ & $\overline{-}$ & 1,260 & 1930 & & & \\
\hline \multirow{2}{*}{$\begin{array}{l}1921 \\
1922 \\
1923 \\
1924 \\
1925\end{array}$} & Sept. 1, 1921 & - & 890 & 1931 & \multirow{2}{*}{$\begin{array}{l}\text { Aug. } 15,1931 \\
\text { Aug, } 21 \text { ar } 2,1953 \\
\text { Feb. 4, } 1934 \\
\text { June s, } 1935\end{array}$} & - & 174 \\
\hline & $\begin{array}{l}\text { May } 18,1923 \\
\text { May } 18,1923 \\
\text { Sept. } 6,1924 \\
\text { Sept.19, } 1925\end{array}$ & - & $\begin{array}{r}a 1,460 \\
908 \\
500 \\
650\end{array}$ & $\begin{array}{l}1933 \\
1934 \\
1935\end{array}$ & & $\overline{-}$ & $\begin{array}{l}736 \\
184 \\
324\end{array}$ \\
\hline
\end{tabular}


Peak stages and discharges of Sevier River near KIngston, Utah--Continued

\begin{tabular}{|c|c|c|c|c|c|c|c|}
\hline $\begin{array}{l}\text { Water } \\
\text { year }\end{array}$ & Date & $\begin{array}{c}\text { Gage } \\
\text { helght } \\
\text { (feet) }\end{array}$ & $\begin{array}{c}\text { Discharge } \\
\text { (cfs) }\end{array}$ & $\begin{array}{l}\text { Water } \\
\text { year }\end{array}$ & Date & $\begin{array}{c}\text { orge } \\
\text { helght } \\
\text { (f iet) }\end{array}$ & $\begin{array}{c}\text { D1gcharge } \\
\text { (cfs) }\end{array}$ \\
\hline $\begin{array}{l}1936 \\
1937 \\
1938 \\
1939 \\
1940\end{array}$ & $\begin{array}{l}\text { Sept. 1, } 1936 \\
\text { May 18, } 1937 \\
\text { Mar. .4, } 1938 \\
\text { Sept. 7, } 1939 \\
\text { Sept.18, } 1940\end{array}$ & $\begin{array}{l}- \\
\overline{-} \\
- \\
-\end{array}$ & $\begin{array}{r}1,080 \\
2963 \\
\mathrm{c} 3,000 \\
1,000 \\
987\end{array}$ & $\begin{array}{l}1951 \\
1952 \\
1953 \\
1954 \\
1955\end{array}$ & $\begin{array}{lrr}\text { July } & 22, & 1951 \\
\text { May } & 6,1952 \\
\text { Aug. } & 1,1953 \\
\text { May } & 22, & 1954 \\
\text { Dec. } & 4, & 1954\end{array}$ & $\begin{array}{l}2.25 \\
2.62 \\
2.04 \\
1.65 \\
1.57\end{array}$ & $\begin{array}{l}549 \\
844 \\
424 \\
227 \\
227\end{array}$ \\
\hline $\begin{array}{l}1941 \\
1942 \\
1943 \\
1944 \\
1945\end{array}$ & $\begin{array}{l}\text { May } 14,1941 \\
\text { May } 28,1942 \\
\text { Aug. } 8,1943 \\
\text { June } 4,1944 \\
\text { Sept. } 3,1945\end{array}$ & $\begin{array}{l}- \\
- \\
- \\
-\end{array}$ & $\begin{array}{r}1,260 \\
790 \\
1,040 \\
604 \\
748\end{array}$ & $\begin{array}{l}1956 \\
1957 \\
1958 \\
1959 \\
1960\end{array}$ & $\begin{array}{l}\text { Nov. } 22,1955 \\
\text { June } 12,1957 \\
\text { May 13, } 1958 \\
\text { Aug. 3, } 1959 \\
\text { Mar. } 8,1960\end{array}$ & $\begin{array}{l}1.50 \\
2.14 \\
2.65 \\
1.84 \\
1.69\end{array}$ & $\begin{array}{l}184 \\
453 \\
694 \\
326 \\
239\end{array}$ \\
\hline $\begin{array}{l}1946 \\
1947 \\
1948 \\
1949 \\
1950\end{array}$ & $\begin{array}{l}\text { Feb. } 25,1946 \\
\text { May } 11,12,1947 \\
\text { Mar. 24, } 1948 \\
\text { June } 7,1949 \\
\text { Feb. } 7,1950\end{array}$ & $\begin{array}{l}- \\
- \\
2.10 \\
2.92 \\
1.66\end{array}$ & $\begin{array}{l}330 \\
576 \\
458 \\
928 \\
262\end{array}$ & $\begin{array}{l}1961 \\
1962 \\
1963\end{array}$ & $\begin{array}{l}\text { Sept.19, } 1961 \\
\text { Mar. 28, } 1962 \\
\text { Sept. 1, } 1963\end{array}$ & $\begin{array}{l}2.52 \\
3.40 \\
1.63\end{array}$ & $\begin{array}{r}682 \\
1,180 \\
247\end{array}$ \\
\hline
\end{tabular}

c Includes estimated flow of $360 \mathrm{cfs}$ in uverflow channel bypassing station.

1850. Antimony Creek near Antimony, Utah

Location.--Lat $38^{\circ} 06^{\prime}$, long $11^{\circ} 53^{\prime}$, in NW $\frac{1}{4}$ sec.22, T.31 S., R.1 W., on right bank 5 miles upstream from mouth and 5 miles southeast of Antimony.

Drainage area.--26 sq mi, approximately.

Gage.--Recording. October 1946 to September 1948 at datum $0.89 \mathrm{ft}$ lower. A1titude of gage is 7,000 ft (from topographic map).

Stage-discharge relation.--Defined by current-meter measurements below $136 \mathrm{cf} s$ prior to 1949. Defined by current-meter measurement below $235 \mathrm{cfs}$ and extended above on basis of 8lope-area measurement at $669 \mathrm{cfs}$ af'er 1957.

Remarks.--Base for partial-duration series, 170 cfs. Only annual peaks are shown.

\begin{tabular}{|c|c|c|c|c|c|c|c|c|}
\hline $\begin{array}{l}\text { Water } \\
\text { year }\end{array}$ & & Date & $\begin{array}{c}\text { Cage } \\
\text { helght } \\
\text { (feet) }\end{array}$ & $\begin{array}{c}\text { D1scharge } \\
\text { (cfs) }\end{array}$ & $\begin{array}{l}\text { Water } \\
\text { year }\end{array}$ & Date & $\begin{array}{c}\text { rage } \\
\text { helght } \\
\text { (feet) }\end{array}$ & $\begin{array}{c}\text { Discharge } \\
\text { (cfs) }\end{array}$ \\
\hline $\begin{array}{l}1947 \\
1948 \\
\end{array}$ & $\begin{array}{l}\text { May } \\
\text { May }\end{array}$ & $\begin{array}{ll}3, & 1947 \\
7, & 1948\end{array}$ & $\begin{array}{l}3.22 \\
3.80\end{array}$ & $\begin{array}{l}164 \\
215\end{array}$ & \multirow{2}{*}{$\begin{array}{l}1960 \\
1961 \\
1962 \\
1963\end{array}$} & \multirow{2}{*}{$\begin{array}{lrl}\text { July } & 31, & 1960 \\
& \\
\text { May } & 1,1961 \\
\text { Apr. } & 19,1962 \\
\text { May } & 3,1963\end{array}$} & \multirow{2}{*}{$\begin{array}{l}2.43 \\
3.25 \\
3.30 \\
3.05\end{array}$} & \multirow{2}{*}{$\begin{array}{l}181 \\
388 \\
314 \\
259\end{array}$} \\
\hline $\begin{array}{l}1958 \\
1959 \\
\end{array}$ & $\begin{array}{l}\text { May } \\
\text { Aug. }\end{array}$ & $\begin{array}{ll}9, & 1958 \\
3, & 1959 \\
\end{array}$ & $\begin{array}{l}3.20 \\
4.52\end{array}$ & $\begin{array}{l}331 \\
669\end{array}$ & & & & \\
\hline
\end{tabular}

1875. Otter Creek above reservoir, near Antimony, Utah (Published as "near Coyoto" 1915-20)

Location.--Lat $38^{\circ} 15^{\prime}$, long $111^{\circ} 58^{\prime}$, in SW $\frac{1}{4} S W \frac{1}{4}$ sec.25, T.29 S., F.2 W., on right bank $30 \mathrm{ft}$ upstream from county road bridge, half a mile east of Angle, and 10 miles north of Antimony.

Drainage area. $--330 \mathrm{sq} \mathrm{mi}$, approximately.

Gage.-Nonrecording at different datum prior to July 1 , 1920; recording thereafter. Altitude of gage is $6,400 \mathrm{ft}$ (from river-profile map).

Stage-discharge relation.--Defined by current-meter measurements below 50 cfs at present site and below $72 \mathrm{cfs}$ at former site.

Remarks. - Flow affected by storage in Koosharem Reservoir (storace of 900 acreft increased to 3,858 acre-ft in 1918). Diversions above station for irrigation. Only annual maximum observed discharges are shown. 
Maximum observed discharges of Otter Creek above reservoir, near Antimony, Utah

\begin{tabular}{|c|c|c|c|c|c|c|c|}
\hline $\begin{array}{l}\text { Water } \\
\text { year }\end{array}$ & Date & $\begin{array}{l}\text { Gage } \\
\text { height } \\
\text { (feet) }\end{array}$ & $\begin{array}{c}\text { Discharge } \\
\text { (cfs) }\end{array}$ & $\begin{array}{l}\text { Water } \\
\text { year }\end{array}$ & Date & $\begin{array}{c}\text { Gage } \\
\text { helght } \\
(\text { feet) }\end{array}$ & $\begin{array}{c}\text { D1scharge } \\
\text { (cfs) }\end{array}$ \\
\hline 1915 & Mar. 25, 1915 & 3.7 & 78 & $\begin{array}{l}1918 \\
1919\end{array}$ & \multirow{2}{*}{$\begin{array}{l}\text { Nov. 20, } 1917 \\
\text { Mar. } 20,1919 \\
\text { Mar. } 28,1962\end{array}$} & \multirow{2}{*}{$\begin{array}{l}2.20 \\
3.78 \\
2.19 \\
\end{array}$} & \multirow{2}{*}{$\begin{array}{r}38 \\
103 \\
95 \\
\end{array}$} \\
\hline $\begin{array}{l}1916 \\
1917\end{array}$ & $\begin{array}{l}\text { Mar. } 12,1916 \\
\text { Mar. } 27,1917\end{array}$ & $\begin{array}{l}4.08 \\
3.80\end{array}$ & $\begin{array}{l}87 \\
84\end{array}$ & 1962 & & & \\
\hline
\end{tabular}

1890. East Fork Sevier River near |Kingston, Utah

Location.--Lat $38^{\circ} 12^{\prime}$, long $112^{\circ} 09^{\prime}$, in SW $\frac{1}{4}$ NW $\frac{1}{4}$ sec.13, T.30 S., R.3 W., on right bank $1,000 \mathrm{ft}$ downstream from bridge on State Highway $22,3.7$ miles east of Kingston, 4.1 miles upstream from mouth, and $10 \frac{1}{2}$ miles downstream from Otter Creek.

Drainage area. $--1,260 \mathrm{sq} \mathrm{mi}$, approximately.

Gage.--Nonrecording prior to Apr. 29, 1914, at site 1 mile upstream at different datum; recording thereafter. Apr. 29, 1914, to June 2, 1939, at site $1,500 \mathrm{ft}$ downstream at different datum. Altitude of gage is $6,110 \mathrm{ft}$ (from river-profile map).

Stage-discharge relation.--Defined by current-meter measurements below 250 cfs prior to 1914, below 702 cf's from 1914 to 1939 , and below $1,410 \mathrm{cfs}$ thereafter.

Remarks.--Diversions for irrigation above and below station. Only annual peaks are shown.

Peak stages and discharges

\begin{tabular}{|c|c|c|c|c|c|c|c|c|}
\hline $\begin{array}{l}\text { Water } \\
\text { year }\end{array}$ & & Date & $\begin{array}{l}\text { Gage } \\
\text { helght } \\
\text { (feet) }\end{array}$ & $\begin{array}{l}\text { Discharge } \\
\text { (cfs) }\end{array}$ & $\begin{array}{l}\text { Water } \\
\text { year }\end{array}$ & Date & $\begin{array}{c}\text { Gage } \\
\text { nelght } \\
\text { (feet) }\end{array}$ & $\begin{array}{c}\text { Discharge } \\
\text { (cfs) }\end{array}$ \\
\hline $\begin{array}{l}1913 \\
1914 \\
1915\end{array}$ & $\begin{array}{l}\text { Apr. } \\
\text { May } \\
\text { May }\end{array}$ & $\begin{array}{rr}1, & 1913 \\
9, & 1914 \\
14, & 1915\end{array}$ & $\frac{-}{4.33}$ & $\begin{array}{r}a 518 \\
570 \\
578\end{array}$ & $\begin{array}{l}1939 \\
1940\end{array}$ & $\begin{array}{l}\text { July 15, } 1939 \\
\text { May 16-2l, } 1940\end{array}$ & $\begin{array}{l}2.45 \\
2.03\end{array}$ & $\begin{array}{r}316 \\
\mathrm{~b} 216\end{array}$ \\
\hline $\begin{array}{l}1916 \\
1917 \\
1918 \\
1919 \\
1920\end{array}$ & $\begin{array}{l}\text { Aug. } \\
\text { May } \\
\text { June } \\
\text { Aug. } \\
\text { June }\end{array}$ & $\begin{aligned} 1, & 1916 \\
18, & 1917 \\
20, & 1918 \\
8, & 1919 \\
28, & 1920\end{aligned}$ & $\begin{array}{l}4.40 \\
4.46 \\
4.01 \\
5.00 \\
4.10\end{array}$ & $\begin{array}{l}660 \\
946 \\
385 \\
900 \\
420\end{array}$ & $\begin{array}{l}1941 \\
1942 \\
1943 \\
1944 \\
1945\end{array}$ & $\begin{array}{l}\text { May } 12,1941 \\
\text { May 11, } 1942 \\
\text { July } 22 \text { to } \\
\quad \text { Aug. } 2,1943 \\
\text { May } 16,1944 \\
\text { Aug. } 12,1945\end{array}$ & $\begin{array}{l}5.05 \\
2.95 \\
- \\
4.00 \\
2.41\end{array}$ & $\begin{array}{r}2,030 \\
625 \\
b 321 \\
1, \frac{190}{342}\end{array}$ \\
\hline $\begin{array}{l}1921 \\
1922 \\
1923 \\
1924 \\
1925\end{array}$ & $\begin{array}{l}\text { July } \\
\text { May } \\
\text { Aug. } \\
\text { July } \\
\text { July }\end{array}$ & $\begin{array}{rr}20, & 1921 \\
8, & 1922 \\
20, & 1923 \\
23, & 1924 \\
23, & 1925\end{array}$ & $\begin{array}{l}4.15 \\
6.10 \\
3.79 \\
- \\
-\end{array}$ & $\begin{array}{r}406 \\
1,740 \\
\mathrm{~b} 339 \\
402 \\
331\end{array}$ & $\begin{array}{l}1946 \\
1947 \\
1948 \\
1949 \\
1950\end{array}$ & $\begin{array}{l}\text { Apr. } 20,1946 \\
\text { Oct. } 1,1946 \\
\text { Apr. } 23,1948 \\
\text { May } 17,1949 \\
\text { Sept. } 6,1950\end{array}$ & $\begin{array}{l}2.56 \\
1.93 \\
2.57 \\
2.46 \\
2.33\end{array}$ & $\begin{array}{l}397 \\
206 \\
401 \\
352 \\
305\end{array}$ \\
\hline $\begin{array}{l}1926 \\
1927 \\
1928 \\
1929 \\
1930\end{array}$ & $\begin{array}{l}\text { July } \\
\text { June } \\
\text { May } \\
\text { Aug. } \\
\text { Sept. }\end{array}$ & $\begin{array}{rr}6, & 1926 \\
6, & 1927 \\
6, & 1928 \\
27, & 1929 \\
23, & 1930\end{array}$ & $\begin{array}{l}- \\
- \\
7.35\end{array}$ & $\begin{array}{r}401 \\
b 265 \\
270 \\
2,000 \\
b 216\end{array}$ & $\begin{array}{l}1951 \\
1952 \\
1953 \\
1954 \\
1955\end{array}$ & $\begin{array}{lrl}\text { July } & 24, & 1951 \\
\text { May } 5, & 1952 \\
\text { July } 27, & 1953 \\
\text { May 22, } & 1954 \\
\text { Aug. } & 5, & 1955\end{array}$ & $\begin{array}{l}- \\
2.78 \\
3.60 \\
2.09 \\
1.71\end{array}$ & $\begin{array}{r}\mathrm{b} 242 \\
490 \\
920 \\
244 \\
154\end{array}$ \\
\hline $\begin{array}{l}1931 \\
1932 \\
1933 \\
1934 \\
1935\end{array}$ & $\begin{array}{l}\text { Oct. } \\
\text { Aug. } \\
\text { May } \\
\text { July } \\
\text { July }\end{array}$ & $\begin{array}{rr}1, & 1930 \\
22, & 1932 \\
21, & 1933 \\
20, & 1934 \\
15, & 1935\end{array}$ & $\begin{array}{l}3.64 \\
4.48 \\
3.90 \\
3.98 \\
4.23\end{array}$ & $\begin{array}{l}196 \\
585 \\
282 \\
242 \\
347\end{array}$ & $\begin{array}{l}1956 \\
1957 \\
1958 \\
1959 \\
1960\end{array}$ & 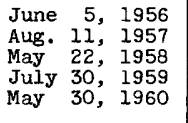 & $\begin{array}{l}2.03 \\
3.39 \\
3.18 \\
2.13 \\
2.18\end{array}$ & $\begin{array}{l}237 \\
354 \\
581 \\
226 \\
235\end{array}$ \\
\hline $\begin{array}{l}1936 \\
1937 \\
1938\end{array}$ & $\begin{array}{l}\text { July } \\
\text { Apr. } \\
\text { Apr. }\end{array}$ & $\begin{array}{ll}22, & 1936 \\
23, & 1937 \\
24, & 1938 \\
\end{array}$ & $\begin{array}{l}5.08 \\
4.65 \\
4.40 \\
\end{array}$ & $\begin{array}{l}646 \\
475 \\
331 \\
\end{array}$ & $\begin{array}{l}1961 \\
1962 \\
1963\end{array}$ & 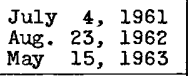 & $\begin{array}{l}2.45 \\
2.32 \\
2.06 \\
\end{array}$ & $\begin{array}{l}335 \\
300 \\
189 \\
\end{array}$ \\
\hline
\end{tabular}

Maximum observed.

b Maximum daily. 
1915. Sevier River below Piute Dam, near Marysvale, Utah

Location.--Lat $38^{\circ} 19^{\prime} 55^{\prime \prime}$, long $112^{\circ} 11^{\prime} 15^{\prime \prime}$, in NW $\frac{1}{4} S E \frac{1}{4} \sec .34$, T.28 S., R. 3 W., on left bank three-quarters of a mile downstream from Plute Dam and 8 miles south of Marysvale.

Drainage area. $--2,440 \mathrm{sq} \mathrm{mi}$, approximately.

Gage.--Recording. May 4, 1912, to Mar. 31, 1935, at site a quarter of a mile upstream at different datum. Apr. i, 1935, to Apr. 7, 1936, at datum $0.2 \mathrm{ft}$ higher than present datum. Altitude of gage is 5,870 ft (by barometer).

Stage-discharge relation.--Defined by current-meter measurements .

Remarks.--Flow regulated by Plute Reservoir. Only annual peaks are shown.

Peak stages and discharges

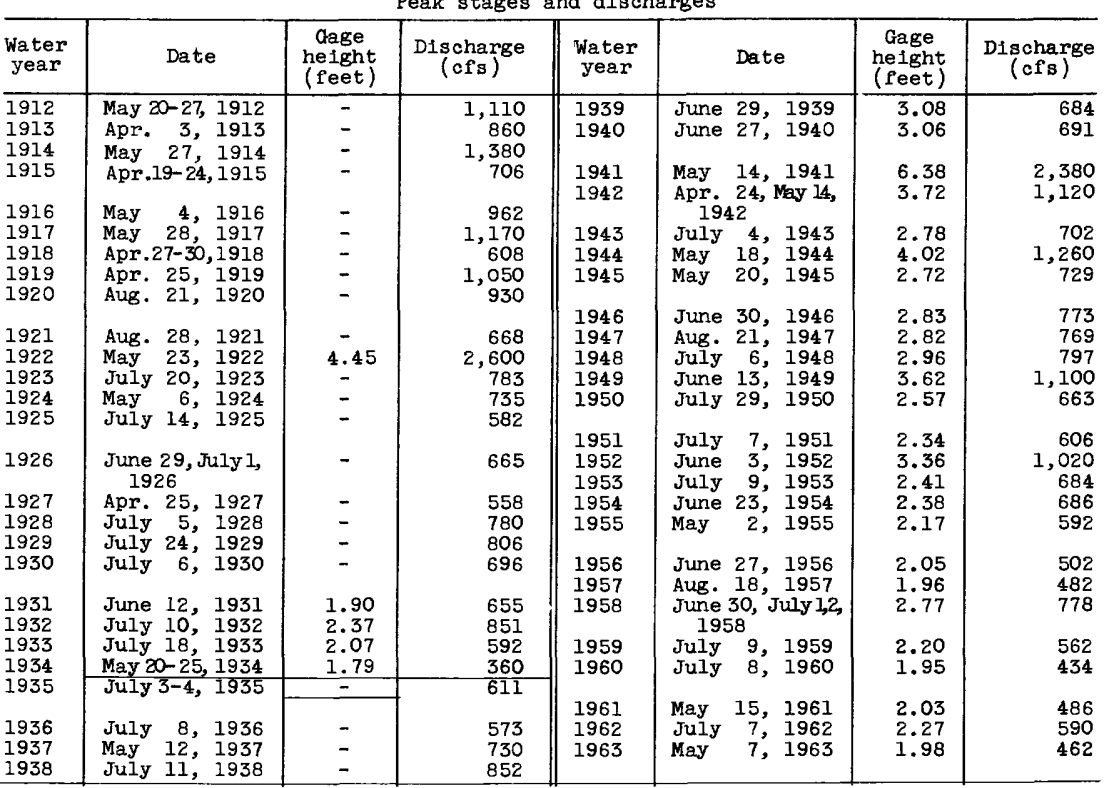

1940. Sevier River above Clear Creek, near Sevier, Utah

(Published as "Sevier River at Sevier" prior to 1917)

Location.--Lat $38^{\circ} 34^{\prime} 2^{\prime \prime}$, long $112^{\circ} 15^{\prime} 25^{\prime \prime}$, in NW $\frac{1}{4} \mathrm{NE} \frac{1}{4}$ sec.5, T.26 S., R.4 W., on right bank $0.6 \mathrm{mile}$ upstream from bridge on U.S. Highway $89,0.7 \mathrm{mile}$ upstream from Clear Creek, and 1 mile south of Sevier.

Drainage area.--2,700 sq $\mathrm{ml}$, approximately.

Gage.--Recording. Prior to Nov. 16, 1916, at site 0.8 mile dormstream at different datums. Altitude of gage is $5,560 \mathrm{ft}$ (by barometer).

Stage-discharge relation.--Defined by current-meter measurements.

Remarks.--Many diversions above station for irrigation. Flow regulated by Plute and otter Creek Reservolrs. Only annual peaks are shown. 
Peak stages and discharges of Sevier River above Clear Creek, near Sevier, Utah

\begin{tabular}{|c|c|c|c|c|c|c|c|c|}
\hline $\begin{array}{l}\text { Water } \\
\text { year }\end{array}$ & Date & $\begin{array}{l}\text { Gage } \\
\text { helght } \\
\text { (feet) }\end{array}$ & $\begin{array}{c}\text { Discharge } \\
\text { (cfs) }\end{array}$ & $\begin{array}{l}\text { Water } \\
\text { year }\end{array}$ & & Date & $\begin{array}{c}\text { Gage } \\
\text { height } \\
\text { (feet) }\end{array}$ & $\begin{array}{c}\text { Ifscharge } \\
(\mathrm{cfs})\end{array}$ \\
\hline $\begin{array}{l}1914 \\
1915 \\
1916 \\
\end{array}$ & $\begin{array}{lrr}\text { June } & 3, & 1914 \\
\text { May } & 19, & 1915 \\
\text { May } & 9, & 1916 \\
\end{array}$ & $\begin{array}{l}- \\
- \\
-\end{array}$ & $\begin{array}{r}1,570 \\
696 \\
1,120 \\
\end{array}$ & $\begin{array}{l}1947 \\
1948 \\
1949 \\
1950\end{array}$ & $\begin{array}{l}\text { Aug. } \\
\text { July } \\
\text { June } \\
\text { July }\end{array}$ & $\begin{array}{rr}22, & 1947 \\
9, & 1948 \\
14, & 1949 \\
18, & 1950\end{array}$ & $\begin{array}{l}3.05 \\
3.18 \\
3.73 \\
2.89\end{array}$ & $\begin{array}{r}768 \\
829 \\
1,210 \\
632\end{array}$ \\
\hline $\begin{array}{l}1939 \\
1940\end{array}$ & $\begin{array}{l}\text { June } 16,1939 \\
\text { June } 28,1940 \\
\begin{array}{l}\text { May } 16,1941 \\
\text { Apr. } 25,1942\end{array}\end{array}$ & $\begin{array}{l}3.04 \\
- \\
4.83\end{array}$ & $\begin{array}{r}664 \\
a 720 \\
2,270 \\
1,160\end{array}$ & $\begin{array}{l}1951 \\
1952 \\
1953 \\
1954 \\
1955 \\
\end{array}$ & $\begin{array}{l}\text { July } \\
\text { June } \\
\text { July } \\
\text { June } \\
\text { May }\end{array}$ & 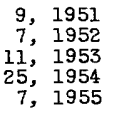 & $\begin{array}{l}2.79 \\
3.73 \\
2.91 \\
2.88 \\
2.61\end{array}$ & $\begin{array}{r}601 \\
1,240 \\
704 \\
687 \\
544\end{array}$ \\
\hline $\begin{array}{l}1943 \\
1944 \\
1945\end{array}$ & $\begin{array}{l}\text { July } 5,1943 \\
\text { May 19, } 1944 \\
\text { May 20, July } 20, \\
\quad 1945\end{array}$ & $\begin{array}{l}2.99 \\
3.64 \\
2.97\end{array}$ & $\begin{array}{r}718 \\
1,170 \\
732\end{array}$ & $\begin{array}{l}1961 \\
1962 \\
1963\end{array}$ & $\begin{array}{l}\text { May } \\
\text { July } \\
\text { May }\end{array}$ & $\begin{array}{rr}20, & 1961 \\
9, & 1962 \\
10, & 1963\end{array}$ & $\begin{array}{l}2.51 \\
2.78 \\
2.46\end{array}$ & $\begin{array}{l}467 \\
584 \\
462\end{array}$ \\
\hline 1946 & July 1,1946 & 3.07 & 792 & & & & & \\
\hline
\end{tabular}

a Maximum da1ly.

1942. Clear Creek above diversions, near Sevier, Utah

Location.--Iat $38^{\circ} 34^{1} 4^{\prime \prime}$, long $112^{\circ} 17^{1} 20^{\prime \prime}$, in NW $\frac{1}{4}$ SW $\frac{1}{4}$ sec. 31 , T.25 S., R.4 W., on left bank at south side of State Highway 13 , 1.8 miles west of Sevier,

2.3 miles upstream from mouth, and 17 miles southwest of Richfield.

Drainage area. $--164 \mathrm{sq} \mathrm{mi}$.

Gage.--Recording. Altitude of gage is 5,680 ft (from topographic map).

Stage-discharge relation.--Defined by current-meter measurements below $2.25 \mathrm{cfs}$. Remarks.--Only annual peaks are shown.

Peak stages and discharges

\begin{tabular}{l|cc|c|c||c|c|c|c}
\hline $\begin{array}{c}\text { Water } \\
\text { year }\end{array}$ & Date & $\begin{array}{c}\text { Gage } \\
\text { helght } \\
\text { (feet) }\end{array}$ & $\begin{array}{c}\text { Discharge } \\
\text { (cfs) }\end{array}$ & $\begin{array}{c}\text { Water } \\
\text { year }\end{array}$ & Date & $\begin{array}{c}\text { Gage } \\
\text { he 1ght } \\
\text { (feet) }\end{array}$ & $\begin{array}{c}\text { I.scharge } \\
\text { (cfs) }\end{array}$ \\
\hline 1958 & May 24, 1958 & 3.36 & 301 & 1961 & May 20, 1961 & 2.38 & \\
1959 & May 16, 1959 & 1.74 & 42 & 1962 & Feb. 9, 1962 & 2.87 & 230 \\
1960 & May 15, 1960 & 2.52 & 136 & 1963 & Aug. 2, 1963 & 2.60 & 170 \\
\hline
\end{tabular}

1950. Clear Creek at Sevier, Utah

Location.--Lat $38^{\circ} 34^{\prime} 5^{\prime \prime}$, long $12^{\circ} 15^{\prime} 30^{\prime \prime}$, in SW $\frac{1}{4} \mathrm{NE} \frac{1}{4} \sec .32, \mathrm{~T} .25 \mathrm{~S} ., \mathrm{R}_{4}$ W., on left bank $400 \mathrm{ft}$ upstream from bridge on U.S. Highway $89,1,000 \mathrm{ft}$ upstream from mouth, and 0.3 mile south of Sevier.

Drainage area. $--169 \mathrm{sq} \mathrm{mi}$.

Gage.--Nonrecording prior to Apr. 4, 1914; recording thereafter. Apr. 4, 1914 , to Sept. 30, 1919, and Apr. 1, 1934, to Sept. 30, 1940, at site 700 ft downstream at different datum. Oct. 1, 1940, to Sept. 24,1946 , at site $400 \mathrm{ft}$ downstream at different datum. Altitude of gage is 5,530 ft (from tcpographic map).

Stage-discharge relation.--Defined by current-meter measurements prior to 1946 and below 290 cfs thereafter.

Remarks.--Only annual peaks are shown.

Peak stages and discharges

\begin{tabular}{|c|c|c|c|c|c|c|c|c|c|}
\hline $\begin{array}{l}\text { Water } \\
\text { year }\end{array}$ & & Date & $\begin{array}{l}\text { Gage } \\
\text { height } \\
\text { (feet) }\end{array}$ & $\begin{array}{c}\text { Discharge } \\
(\text { cfs })\end{array}$ & $\begin{array}{l}\text { Water } \\
\text { year }\end{array}$ & & Date & $\begin{array}{c}\text { Gage } \\
\text { helght } \\
\text { (feet) }\end{array}$ & $\begin{array}{c}\text { I 1scharge } \\
\text { (cfs) }\end{array}$ \\
\hline $\begin{array}{l}1912 \\
1913 \\
1914\end{array}$ & $\begin{array}{l}\text { May } \\
\text { May } \\
\text { May }\end{array}$ & $\begin{array}{ll}30, & 1912 \\
27, & 1913 \\
24, & 1914\end{array}$ & $\begin{array}{c}3.0 \\
1.95 \\
-\end{array}$ & $\begin{array}{r}\text { a226 } \\
\text { a158 } \\
240\end{array}$ & $\begin{array}{l}1917 \\
1918 \\
1919 \\
\end{array}$ & \multirow{2}{*}{\multicolumn{2}{|c|}{$\begin{array}{ll}\text { June } 11, & 1917 \\
\text { June } 15, & 1918 \\
\text { May } 28,1919 \\
\text { June } 10,1935 \\
\text { June 10, } 1936\end{array}$}} & \multirow{2}{*}{$\begin{array}{l}2.74 \\
2.68 \\
2.38 \\
- \\
=\end{array}$} & \multirow{2}{*}{$\begin{array}{r}181 \\
110 \\
98 \\
\text { a208 } \\
\text { al } 70\end{array}$} \\
\hline 1916 & June & $\begin{array}{l}2,1915 \\
9,1916\end{array}$ & 2.26 & 153 & $\begin{array}{l}1935 \\
1936\end{array}$ & & & & \\
\hline
\end{tabular}


Peak stages and discharges of Clear Creek at Sev1er, Utah--Cont1nued

\begin{tabular}{|c|c|c|c|c|c|c|c|c|c|}
\hline $\begin{array}{l}\text { Water } \\
\text { year }\end{array}$ & & Date & $\begin{array}{c}\text { Gage } \\
\text { helght } \\
\text { (feet) }\end{array}$ & $\begin{array}{c}\text { Discharge } \\
(\mathrm{cfs})\end{array}$ & $\begin{array}{c}\text { Water } \\
\text { year }\end{array}$ & & Date & $\begin{array}{c}\text { Gage } \\
\text { helght } \\
\text { (feet) }\end{array}$ & $\begin{array}{c}\text { D1scharge } \\
\text { (cfs) }\end{array}$ \\
\hline $\begin{array}{l}1937 \\
1938 \\
1939 \\
1940\end{array}$ & $\begin{array}{l}\text { May } \\
\text { May } \\
\text { Mar. } \\
\text { Apr. }\end{array}$ & $\begin{array}{ll}19, & 1937 \\
27, & 1938 \\
25, & 1939 \\
24, & 1940 \\
\end{array}$ & $\begin{array}{l}- \\
-\end{array}$ & $\begin{array}{r}\text { a263 } \\
\text { a314 } \\
\text { a82 } \\
\text { al79 } \\
\end{array}$ & \multirow{2}{*}{$\begin{array}{l}1948 \\
1949 \\
1950 \\
1951 \\
1952 \\
1953 \\
1954 \\
1955\end{array}$} & \multicolumn{2}{|c|}{$\begin{array}{lr}\text { Apr. } 18, & 1948 \\
\text { June } 12, & 1949 \\
\text { June } 2, & 1950\end{array}$} & $\begin{array}{l}4.43 \\
2.89 \\
2.37\end{array}$ & $\begin{array}{l}400 \\
167 \\
100\end{array}$ \\
\hline $\begin{array}{l}1941 \\
1942 \\
1943 \\
1944 \\
1945\end{array}$ & $\begin{array}{l}\text { Aug. } \\
\text { May } \\
\text { Aug. } \\
\text { May } \\
\text { May }\end{array}$ & $\begin{array}{rr}7, & 1941 \\
27, & 1942 \\
10, & 1943 \\
10, & 1944 \\
4, & 1945\end{array}$ & $\begin{array}{l}4.05 \\
3.01 \\
2.27 \\
2.92 \\
2.71\end{array}$ & $\begin{array}{l}487 \\
275 \\
180 \\
281 \\
329\end{array}$ & & $\begin{array}{l}\text { May } \\
\text { May } \\
\text { July } \\
\text { May } \\
\text { Aug. }\end{array}$ & $\begin{array}{rr}29, & 1951 \\
5, & 1952 \\
15, & 1953 \\
22, & 1954 \\
17, & 1955\end{array}$ & $\begin{array}{l}2.17 \\
4.58 \\
3.83 \\
3.42 \\
5.97\end{array}$ & $\begin{array}{r}59 \\
337 \\
282 \\
156 \\
611\end{array}$ \\
\hline $\begin{array}{l}1946 \\
1947\end{array}$ & $\frac{\text { Apr. }}{\text { May }}$ & $\begin{array}{l}28,1946 \\
12, \\
\end{array}$ & $\frac{1.70}{3.38}$ & $\frac{135}{237}$ & $\begin{array}{l}1956 \\
1957 \\
1958\end{array}$ & $\begin{array}{l}\text { May } \\
\text { June } \\
\text { May }\end{array}$ & $\begin{array}{rr}27, & 1956 \\
5, & 1957 \\
27, & 1958\end{array}$ & $\begin{array}{l}2.47 \\
5.30 \\
4.40\end{array}$ & $\begin{array}{r}86 \\
484 \\
278\end{array}$ \\
\hline
\end{tabular}

a Maximum da1ly.

1955. Sevier River at Sevier, Utah

Location.--Iat $38^{\circ} 34^{\prime} 50^{\prime \prime}$, long $112^{\circ} 15^{\prime} 15^{\prime \prime}$, in $\mathrm{E}^{\frac{3}{2}}$ sec.32, T.25 S., R.4 W., at Sevier, just downstream from Clear Creek, and $300 \mathrm{ft}$ upstream from rallroad bridge.

Drainage area. $--2,850 \mathrm{sq} \mathrm{ml}$, approximately.

Gage.--Recording. Altitude of gage is $5,520 \mathrm{ft}$ (from topograpric map).

Stage-discharge relation.--Defined by current-meter measurements.

Remarks.--Flow regulated by Plute and Otter Creek Reservolrs. Many diversions for irrigation above station. Only annual peaks are shown.

Peak stages and discharges

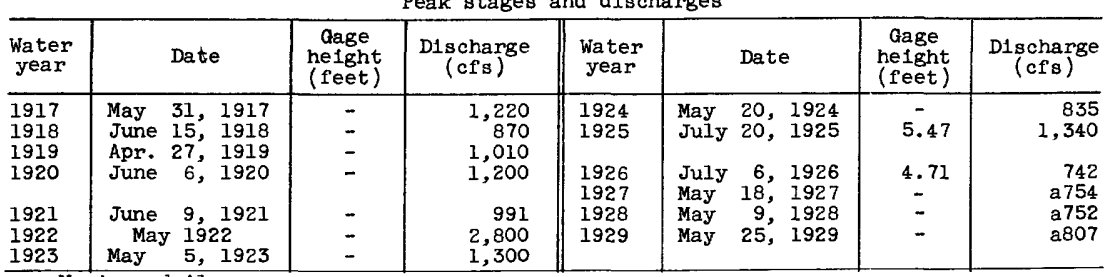

a Maximum da1ly.

2050. Sevier River near Sigurd, Utah

(Published as "near Vermilion" prior to 1939)

Location.--Lat $38^{\circ} 52^{\prime}$, long $111^{\circ} 57^{\prime}$, in SW $\frac{1}{4}$ sec.19, T.22 S., R.1 W., on left bank 200 ft downstream from bridge, half a mile downstream from Rockyford Dam, 2 miles northeast of Sigurd, and 5 miles upstream from Lost Creek.

Drainage area. $--3,340 \mathrm{sq} \mathrm{ml}$, approximately.

Gage.--Nonrecording prior to Apr. 20, 1917; recording thereafter. At datum $2.00 \mathrm{ft}$ higher prior to 0ct. 17, 1935. Altitude of gage is $5,180 \mathrm{ft}$ (by barometer).

Stage-discharge relation.--Defined by current-meter measurements below $600 \mathrm{cfs}$.

Remarks.--Flow regulated by reservoirs above station. During irrigation season practically entire flow through Rockyford Dam is diverted ak ove station for irrigation below. Only annual peaks are shown. 
Peak stages and discharges of Sevier River near Sigurd, Utah

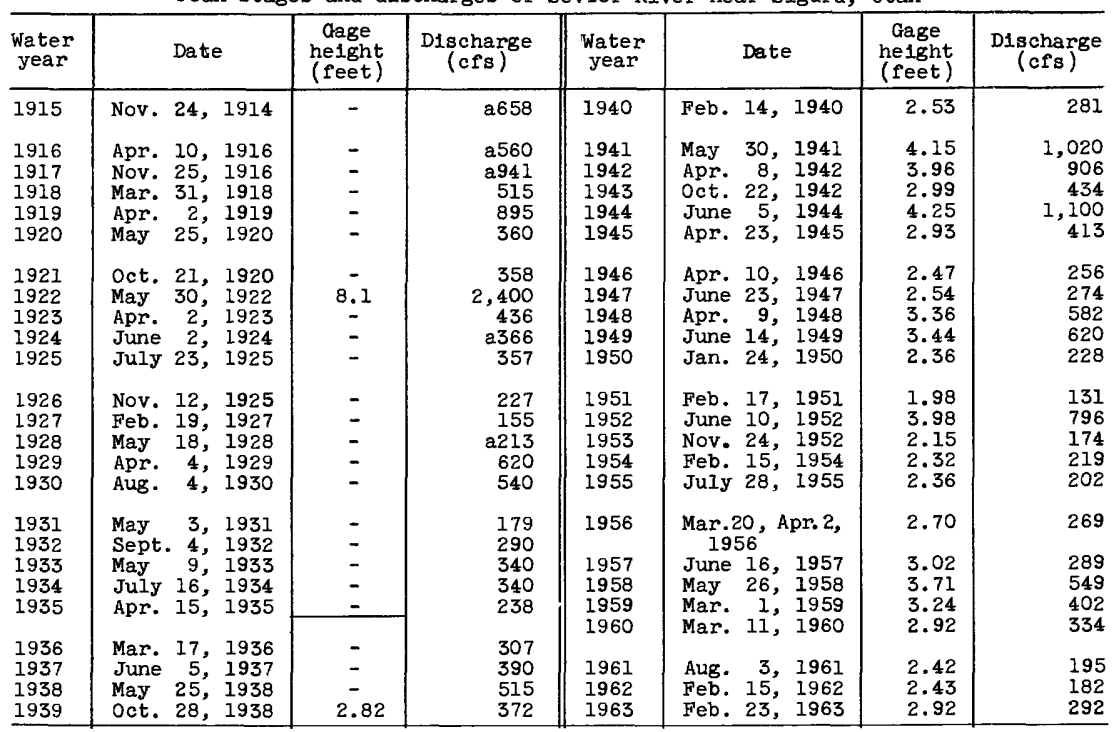

a Maximum observed.

2060. Salina Creek at Salina, Utah

Location.--Lat $38^{\circ} 57^{\prime}$, long $111^{\circ} 52^{\prime}$, in NW $\frac{1}{4}$ sec.25, T.21 S., R.1 W., on right bank $150 \mathrm{ft}$ upstream from bridge on U.S. Highway 89 in Salina and threequarters of a mile upstream from mouth.

Drainage area.--290 sq $\mathrm{ml}$, approximately. Mean altitude, 7,810 ft.

Gage.--Nonrecording prior to Oct. 17, 1917; recording thereafter. Prior to Mar. 23, 1915, at site $150 \mathrm{ft}$ downstream at different datum. Mar. 23, 1915, to Sept. 30,1919 , at site about a quarter of a mile upstream at different datum. Concrete control at present site. Altitude of gage is 5,140 ft (estimated on basis of nearby benchmark).

Stage-discharge relation.--Defined by current-meter measurements below $400 \mathrm{cfs}$ and extended above by logarithmic plotting.

Remariks.--Diversions above station for irrigation. Base for partial-duration serles, 120 cfs. Only annual peaks are shown except for 1948 and 1949.

Peak stages and discharges

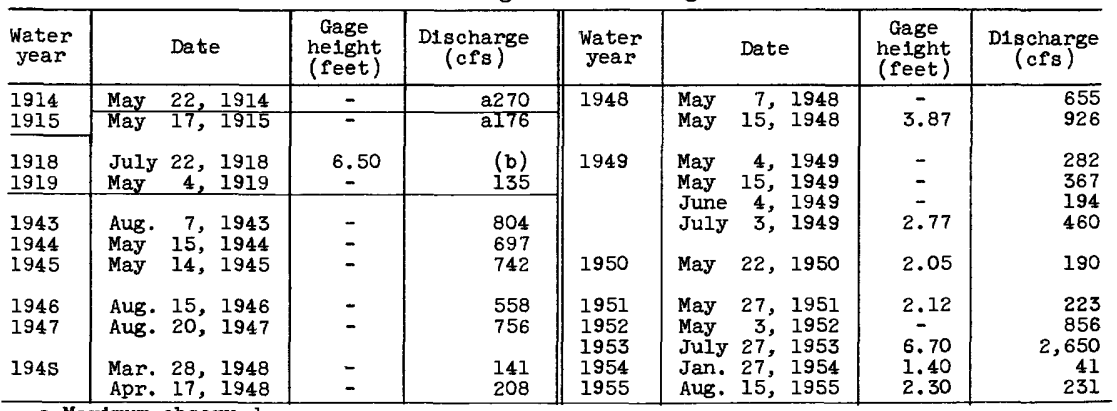

a Maximum observed.

$b$ Not determined. 
2080. Sevier River near Gunnison, Utah

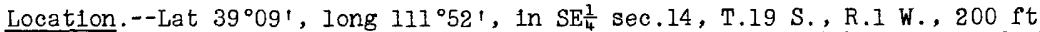
downstream from bridge, half a mile upstream from San Pitch River, and about 3 miles west of Gunnison.

Drainage area. $--3,990 \mathrm{sq} \mathrm{m} 1$, approximately.

Gage.--Nonrecording prior to May 19, 1914, at site $200 \mathrm{ft}$ upstream at different datums; recording thereafter. Altitude of gage is $4,910 \mathrm{ft}$.

Stage-discharge relation.--Defined by current-meter measurements below 1,770 cfs at former site, and below $1,490 \mathrm{cfs}$ thereafter.

Remarks.--Flow regulated by reservolrs upstream. Many diversions above station for irrigation. Only annual peaks are shown (maximum observed prior to 1914).

Peak stages and discharges

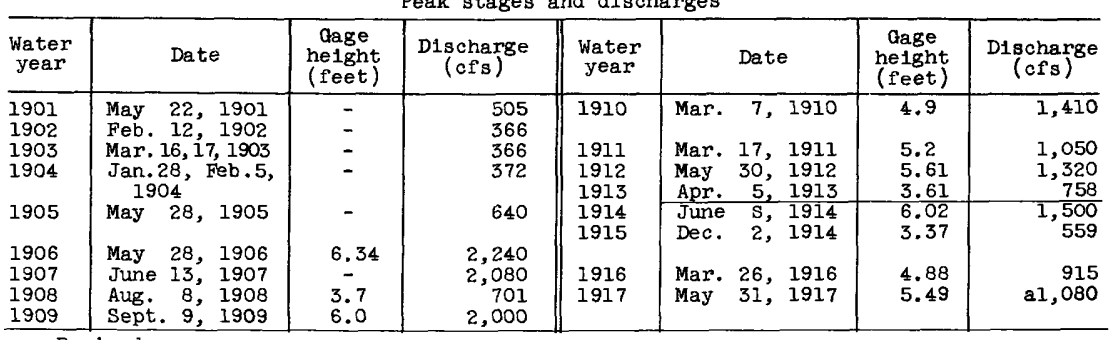

a Revised.

2100. Pleasant Creek near Mount Pleasant, Utah

Location. --Lat $39^{\circ} 32^{\prime} 30^{\prime \prime}$, long $111^{\circ} 23^{\prime} 30^{\prime \prime}$, in W $\frac{1}{2}$ sec. 5 , T.15 S., R.5 E., on lef't bank a quarter of a mile downstream from South Fork and 3.9 miles east of Mount Pleasant.

Drainage area.--16 sq $\mathrm{ml}$, approximately.

Gage.--Nonrecording prior to 1955; recording thereafter. Datum of gage is $6,759.67 \mathrm{ft}$ above mean sea level (levels by U.S. Soli Conservation Service).

Stage-discharge relation.--Defined by current-meter measurements below $183 \mathrm{cfs}$ and by computation of flow over dam at 445 and $2,060 \mathrm{cfs}$.

Remarks.--Base for partial-duration series, 50 cfs.

Peak stages and discharges

\begin{tabular}{|c|c|c|c|c|c|c|c|c|}
\hline $\begin{array}{c}\text { Water } \\
\text { year }\end{array}$ & & Date & $\begin{array}{c}\text { Gage } \\
\text { helght } \\
\text { (feet) }\end{array}$ & $\begin{array}{c}\text { D1scharge } \\
\text { (cfs) }\end{array}$ & $\begin{array}{l}\text { Water } \\
\text { year }\end{array}$ & Date & $\begin{array}{c}\text { Gage } \\
\text { height } \\
\text { (feet) }\end{array}$ & $\begin{array}{c}\text { Digcharge } \\
(\mathrm{cfs})\end{array}$ \\
\hline 1946 & July & 24,1946 & \multirow{2}{*}{$\begin{array}{c}- \\
8.6\end{array}$} & a2, 060 & \multirow{2}{*}{$\begin{array}{l}1960 \\
1961\end{array}$} & \multirow{2}{*}{$\begin{array}{lrl}\text { June } & 3,1960 \\
& & \\
\text { May } & 28, & 1961 \\
\text { Aug. } & 25, & 1961\end{array}$} & \multirow{2}{*}{$\begin{array}{l}6.92 \\
6.96 \\
7.0\end{array}$} & \multirow{2}{*}{$\begin{array}{r}s 8 \\
58 \\
\mathrm{~b} 200\end{array}$} \\
\hline 1955 & Aug. & 16,1955 & & 445 & & & & \\
\hline 1956 & May & 26,1956 & 8.72 & 93 & \multirow{2}{*}{1962} & \multirow{2}{*}{$\begin{array}{lll}\text { May } & \text { S, } & 1962 \\
\text { June } & 12, & 1962 \\
\text { June } 22, & 1962 \\
\text { July } 25, & 1962\end{array}$} & \multirow{2}{*}{$\begin{array}{l}6.16 \\
6.20 \\
6.09 \\
5.85\end{array}$} & \multirow{2}{*}{$\begin{array}{r}146 \\
168 \\
140 \\
62\end{array}$} \\
\hline 1957 & $\begin{array}{l}\text { June } \\
\text { July }\end{array}$ & $\begin{array}{ll}4, & 1957 \\
1, & 1957\end{array}$ & $\begin{array}{l}9.53 \\
\text { s. } 93\end{array}$ & $\begin{array}{l}178 \\
136\end{array}$ & & & & \\
\hline 1958 & May & 27,1958 & 7.04 & 209 & 1963 & May 31,1963 & 5.94 & 65 \\
\hline 1959 & June & 9, 1959 & 6.51 & 44 & & Sept. 5, 1963 & 6.01 & b 100 \\
\hline 1960 & May & 13,1960 & 6.62 & 58 & & & & \\
\hline
\end{tabular}

a Annual peak only.

b About. 
2110. Twin Creek near Mount Pleasant, Utah

Location.--Lat $39^{\circ} 29^{\prime} 30^{\prime \prime}$, long $11^{\circ} 24^{\prime} 25^{\prime \prime}$, in NW $\frac{1}{4} \sec .30$, T.15 S., R. 5 E., on right bank $3 \frac{1}{2}$ miles southeast of Mount Pleasant.

Drainage area. $--5.9 \mathrm{sq} \mathrm{mi}$, approximately .

Gage.--Recording and concrete control. Altitude of gage is $6,500 \mathrm{ft}$ (from topographic map).

Stage-discharge relation.--Defined by current-meter measurements below $70 \mathrm{cfs}$. Remarks.--Base for partial-duration series, $30 \mathrm{cfs}$.

\begin{tabular}{|c|c|c|c|c|c|c|c|c|}
\hline $\begin{array}{l}\text { Water } \\
\text { year }\end{array}$ & \multicolumn{2}{|r|}{ Date } & $\begin{array}{c}\text { Gage } \\
\text { he1ght } \\
\text { (feet) }\end{array}$ & $\begin{array}{c}\text { Discharge } \\
\text { (cfs) }\end{array}$ & $\begin{array}{l}\text { Water } \\
\text { year }\end{array}$ & Date & $\begin{array}{c}\text { Gage } \\
\text { helght } \\
\text { (feet) }\end{array}$ & $\begin{array}{c}\text { D1 scharge } \\
\text { (cfs) }\end{array}$ \\
\hline 1955 & $\begin{array}{l}\text { June } \\
\text { Aug. }\end{array}$ & $\begin{array}{ll}9, & 1955 \\
4, & 1955\end{array}$ & $\begin{array}{l}1.17 \\
1.14\end{array}$ & $\begin{array}{l}48 \\
43\end{array}$ & 1960 & $\begin{array}{lrl}\text { May } & 12, & 1960 \\
\text { June } & 8, & 1960\end{array}$ & $\begin{array}{l}1.55 \\
1.70\end{array}$ & $\begin{array}{l}32 \\
40\end{array}$ \\
\hline 1956 & $\begin{array}{l}\text { May } \\
\text { July }\end{array}$ & $\begin{array}{ll}31, & 1956 \\
30, & 1956\end{array}$ & $\begin{array}{l}1.24 \\
1.16\end{array}$ & $\begin{array}{l}45 \\
38\end{array}$ & 1961 & $\begin{array}{l}\text { Aug. 2, } 1961 \\
\text { Aug. } 25,1961\end{array}$ & $\begin{array}{l}1.99 \\
1.76\end{array}$ & $\begin{array}{l}96 \\
47\end{array}$ \\
\hline 1957 & $\begin{array}{l}\text { June } \\
\text { June }\end{array}$ & $\begin{array}{rr}9, & 1957 \\
22, & 1957\end{array}$ & $\begin{array}{l}1.55 \\
1.50\end{array}$ & $\begin{array}{l}90 \\
92\end{array}$ & 1962 & June 24,1962 & & so \\
\hline & June & $\begin{array}{ll}26, & 1957 \\
25, & 1957\end{array}$ & $\begin{array}{l}1.51 \\
1.54\end{array}$ & $\begin{array}{l}117 \\
113\end{array}$ & 1963 & $\begin{array}{l}\text { June } 2,1963 \\
\text { June 17, } 1963 \\
\text { Aug. } 25,1963\end{array}$ & $\begin{array}{l}1.44 \\
1.47 \\
1.53\end{array}$ & $\begin{array}{l}33 \\
35 \\
39\end{array}$ \\
\hline 1958 & June & $6, \quad 1958$ & $1.9 \mathrm{~s}$ & 111 & & Sept. 5,1963 & 1.60 & 51 \\
\hline 1959 & June & 9,1959 & 1.50 & 24 & & & & \\
\hline
\end{tabular}

2163. Sixmlle Creek near Sterling, Utah

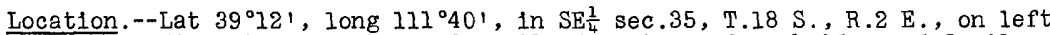
bank at diversion structure, $0.6 \mathrm{mile}$ downstream from bridge and 2 miles east of Sterling.

Drainage area. $--29 \mathrm{sq} \mathrm{mi}$, approximately.

Gage.--Crest-stage gage. Altitude of gage is 5,750 ft (from topographic map).

Stage-discharge relation.--Defined by current-meter measurements below $161 \mathrm{cfs}$ and extended above on basis of logarithmic plotting.

Remarks.--Only annual peaks are shown.

Peak stages and discharges

\begin{tabular}{l|c|c|c||c|c|c|c}
\hline $\begin{array}{l}\text { Water } \\
\text { year }\end{array}$ & Date & $\begin{array}{c}\text { Cage } \\
\text { height } \\
\text { (feet) }\end{array}$ & $\begin{array}{c}\text { Discharge } \\
\text { (cfs) }\end{array}$ & $\begin{array}{c}\text { Water } \\
\text { year }\end{array}$ & $\begin{array}{c}\text { Gage Date } \\
\text { height } \\
\text { (feet) }\end{array}$ & $\begin{array}{c}\text { Discharge } \\
\text { (cfs) }\end{array}$ \\
\hline 1959 & July 31, 1959 & 12.48 & 820 & 1962 & June 30, 1962 & 11.12 & 12 \\
1960 & May 15, 1960 & 11.00 & 185 & 1963 & Aug. 7, 1963 & 10.83 \\
1961 & July 4, 1961 & 10.69 & 100 & & & \\
\hline
\end{tabular}

2165. San Pitch River near Gunnison, Utah

Iocation.--Iat $39^{\circ} 09^{\prime}$, long $111^{\circ} 49^{\prime}$, in NW $\frac{1}{4} \mathrm{NW} \frac{1}{4}$ sec.20, T.19 S., R.1 E., at bridge on U.S. Highway 89 at Gunnison.

Drainage area. $--886 \mathrm{sq} \mathrm{ml}$.

Gage.--Nonrecording prior to May 1914; recording May 1914 to May 1918; ronrecording thereafter. At site 4 miles upstream at different datum prior to February 1912. At site 3 miles downstream at different datums February 1912 to May 1918. Altitude of gage is 5,190 ft (from topographic map).

Stage-discharge relation.--Defined by current-meter measurements below 116 cfs prior to 1906, below 554 cfs 1913 to 1917, and below $960 \mathrm{cfs}$ in 1952 and 1958 .

Remarks.--Flow regulated by Gunnison Reservo1r, 7 miles upstream. Only annual peaks are shown. 
Peak stages and discharges of San PItch River near Gunniscn, Utah

\begin{tabular}{|c|c|c|c|c|c|c|c|}
\hline $\begin{array}{l}\text { Water } \\
\text { year }\end{array}$ & Date & $\begin{array}{l}\text { Gage } \\
\text { helght } \\
\text { (feet) }\end{array}$ & $\begin{array}{c}\text { Discharge } \\
(\mathrm{cfs})\end{array}$ & $\begin{array}{l}\text { Water } \\
\text { year }\end{array}$ & Date & $\begin{array}{l}\text { Gage } \\
\text { helght } \\
\text { (feet) }\end{array}$ & $\begin{array}{l}\text { D1scharge } \\
\text { (cfs) }\end{array}$ \\
\hline \multirow[t]{2}{*}{$\begin{array}{l}1901 \\
1902 \\
1903 \\
1904 \\
1905 \\
\end{array}$} & \multirow[t]{2}{*}{$\begin{array}{l}\text { May } 20,28,29,1901 \\
\text { May } 14,1902 \\
\text { May } 31,1903 \\
\text { May } 18,24,1904 \\
\text { Aug. } 29,1905\end{array}$} & $\begin{array}{l}- \\
\overline{-} \\
-\end{array}$ & \multirow[t]{2}{*}{$\begin{array}{l}\text { a125 } \\
\text { a155 } \\
\text { a158 } \\
\text { a264 } \\
\text { a } 720 \\
\end{array}$} & $\begin{array}{l}1915 \\
1916 \\
1917 \\
\end{array}$ & $\begin{array}{l}\text { Mar. } 22,1915 \\
\text { Mar. 17, } 1916 \\
\text { June 18, } 1917 \\
\end{array}$ & $\begin{array}{c}3.85 \\
- \\
3.33 \\
\end{array}$ & $\begin{array}{r}608 \\
2466 \\
494 \\
\end{array}$ \\
\hline & & - & & 1952 & \multirow{2}{*}{$\begin{array}{l}\text { June } 5,1952 \\
\text { Feb. 27, } 1958\end{array}$} & \multirow{2}{*}{$\begin{array}{l}3.85 \\
7.23\end{array}$} & \multirow{2}{*}{$\begin{array}{r}\text { al, } 330 \\
2458\end{array}$} \\
\hline $\begin{array}{l}1912 \\
1913 \\
1914 \\
\end{array}$ & $\begin{array}{l}\text { June } 9,1912 \\
\text { Mar. 25, } 1913 \\
\text { June } 2,1914\end{array}$ & $\overline{-}$ & $\begin{array}{r}257 \\
2456 \\
591 \\
\end{array}$ & 1958 & & & \\
\hline
\end{tabular}

\section{Sevier River below San Pitch River, near Gunnison, Utah}

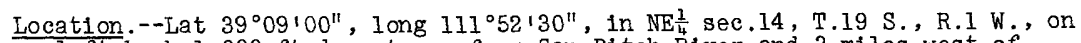
left bank 1,000 ft downstream from San Pitch River and 3 miles west of Gunnison.

Drainage area. $--4,880 \mathrm{sq} \mathrm{mi}$, approximately.

Gage.--Recording. Prior to 0ct. 28, 1938, at datum $0.36 \mathrm{ft}$ higher. Altitude of gage is $4,900 \mathrm{ft}$ (from topographic map).

Stage-discharge relation.--Defined by current-meter measurementi.

Remarks.--Flow regulated by reservoirs and many diversions abovo station for irrigation. Most of flow diverted above station during irrigation season. only annual peaks are shown.

\begin{tabular}{|c|c|c|c|c|c|c|c|c|c|}
\hline $\begin{array}{l}\text { Water } \\
\text { year }\end{array}$ & & Date & $\begin{array}{c}\text { Gage } \\
\text { helght } \\
\text { (feet) }\end{array}$ & $\begin{array}{c}\text { Discharge } \\
\text { (cfs) }\end{array}$ & $\begin{array}{l}\text { Water } \\
\text { year }\end{array}$ & \multicolumn{2}{|r|}{ Date } & $\begin{array}{l}\text { Gage } \\
\text { helght } \\
\text { (feet) }\end{array}$ & $\begin{array}{c}\text { Discharge } \\
(\mathrm{cfs})\end{array}$ \\
\hline $\begin{array}{l}1918 \\
1919 \\
1920\end{array}$ & $\begin{array}{l}\text { Mar. } \\
\text { Mar. } \\
\text { May }\end{array}$ & $\begin{array}{ll}12, & 1918 \\
25, & 1919 \\
22, & 1920\end{array}$ & $\begin{array}{l}- \\
-\end{array}$ & $\begin{array}{r}876 \\
979 \\
1,430\end{array}$ & $\begin{array}{l}1941 \\
1942 \\
1943 \\
1944\end{array}$ & $\begin{array}{l}\text { May } \\
\text { Apr. } \\
\text { Mar. } \\
\text { June }\end{array}$ & $\begin{array}{rr}24, & 1941 \\
15, & 1942 \\
10, & 1943 \\
8, & 1944\end{array}$ & $\begin{array}{l}4.61 \\
4.23 \\
2.83 \\
4.80\end{array}$ & $\begin{array}{r}1,480 \\
1,050 \\
434 \\
1,320\end{array}$ \\
\hline $\begin{array}{l}1921 \\
1922 \\
1923 \\
1924 \\
1925 \\
1926 \\
\end{array}$ & $\begin{array}{l}\text { June } \\
\text { June } \\
\text { Apr. } \\
\text { Mar. } \\
\text { Feb. } \\
\text { Sept. }\end{array}$ & $\begin{array}{rr}11, & 1921 \\
1, & 1922 \\
2, & 1923 \\
26, & 1924 \\
5, & 1925 \\
11, & 1926\end{array}$ & $\begin{array}{l}- \\
5.68 \\
- \\
2.45 \\
2.56\end{array}$ & $\begin{array}{r}1,420 \\
2,620 \\
1,100 \\
516 \\
510 \\
562\end{array}$ & $\begin{array}{l}1945 \\
1946 \\
1947 \\
1948 \\
1949 \\
1950\end{array}$ & $\begin{array}{l}\text { Apr. } \\
\text { Mar. } \\
\text { June } \\
\text { May } \\
\text { June } \\
\text { Nov. }\end{array}$ & $\begin{array}{rr}24, & 1945 \\
16, & 1946 \\
23, & 1947 \\
1, & 1948 \\
15, & 1949 \\
15, & 1949\end{array}$ & $\begin{array}{l}3.24 \\
3.12 \\
3.68 \\
4.28 \\
3.50 \\
2.79\end{array}$ & $\begin{array}{l}543 \\
495 \\
742 \\
905 \\
669 \\
455\end{array}$ \\
\hline $\begin{array}{l}1928 \\
1929 \\
1930\end{array}$ & $\begin{array}{l}\text { May } \\
\text { Apr. } \\
\text { Aug. }\end{array}$ & $\begin{array}{rr}26, & 1928 \\
6, & 1929 \\
5, & 1930\end{array}$ & $\begin{array}{l}- \\
2.70 \\
2.59\end{array}$ & $\begin{array}{l}491 \\
553 \\
511\end{array}$ & $\begin{array}{l}1951 \\
1952 \\
1953 \\
1954\end{array}$ & $\begin{array}{l}\text { Oct. } \\
\text { June } \\
\text { Feb. } \\
\text { Feb. }\end{array}$ & $\begin{array}{rr}25, & 1950 \\
10, & 1952 \\
9, & 1953 \\
17, & 1954\end{array}$ & $\begin{array}{l}2.65 \\
5.49 \\
3.48 \\
-\end{array}$ & $\begin{array}{r}396 \\
2,050 \\
563 \\
2360\end{array}$ \\
\hline $\begin{array}{l}1931 \\
1932 \\
1933 \\
1934 \\
1935\end{array}$ & $\begin{array}{l}\text { Feb. } \\
\text { Feb. } \\
\text { May } \\
\text { Jan. } \\
\text { June }\end{array}$ & $\begin{array}{rr}8, & 1931 \\
9, & 1932 \\
12, & 1933 \\
2, & 1934 \\
7, & 1935\end{array}$ & $\begin{array}{l}1.95 \\
2.53 \\
2.12 \\
1.73 \\
1.87\end{array}$ & $\begin{array}{l}283 \\
485 \\
424 \\
279 \\
286\end{array}$ & $\begin{array}{l}1955 \\
1956 \\
1957 \\
1958 \\
1959\end{array}$ & $\begin{array}{l}\text { Mar. } \\
\text { Mar. } \\
\text { June } \\
\text { May } \\
\text { Mar. }\end{array}$ & $\begin{array}{rr}11, & 1955 \\
13, & 1956 \\
11, & 1957 \\
29, & 1958 \\
2, & 1959\end{array}$ & $\begin{array}{l}- \\
2.81 \\
4.70 \\
4.61 \\
3.29\end{array}$ & $\begin{array}{r}2410 \\
365 \\
964 \\
932 \\
490\end{array}$ \\
\hline $\begin{array}{l}1936 \\
1937 \\
1938 \\
1939 \\
1940\end{array}$ & $\begin{array}{l}\text { June } \\
\text { May } \\
\text { May } \\
\text { Mar. } \\
\text { May }\end{array}$ & $\begin{array}{rr}6, & 1936 \\
20, & 1937 \\
28, & 1938 \\
24, & 1939 \\
15, & 1940\end{array}$ & $\begin{array}{l}2.72 \\
2.72 \\
3.22 \\
2.80 \\
2.72\end{array}$ & $\begin{array}{l}534 \\
508 \\
674 \\
454 \\
432\end{array}$ & $\begin{array}{l}1960 \\
1961 \\
1962 \\
1963 \\
\end{array}$ & $\begin{array}{l}\text { Mar. } \\
\text { Apr. } \\
\text { Feb. } \\
\text { Feb. }\end{array}$ & $\begin{array}{cc}9, & 1960 \\
16, & 1961 \\
10, & 1962 \\
24, & 1963\end{array}$ & $\begin{array}{l}2.78 \\
2.51 \\
5.40 \\
2.71\end{array}$ & $\begin{array}{r}371 \\
292 \\
1,290 \\
336 \\
\end{array}$ \\
\hline
\end{tabular}

a Maximum daily. 
2190. Sevier River near Juab, Utah

Location.--Lat $39^{\circ} 22^{\prime} 30^{\prime \prime}$, long $112^{\circ} 02^{\prime} 20^{\prime \prime}$, in $\mathrm{SE} \frac{1}{4}$ sec.35, T.16 S., R.2 W., on left bank half a mile downstream from Sevier Bridge Dam and 12 miles southwest of Juab.

Drainage area. $--5,120 \mathrm{sq} \mathrm{mi}$, approximately.

Gage.--Nonrecording prior to Apr. 16, 1914, $500 \mathrm{ft}$ upstream at differert datum; recording and rubble masonry control thereafter. Apr. 16, 1914, to Apr. 7, 1938, at present site and datum. Apr. 8, 1938, to Mar. 31, 1942, at site $1,300 \mathrm{ft}$ upstream at different datum. Altitude of gage is $4,940 \mathrm{ft}$ (by barometer).

Stage-discharge relation.--Defined by current-meter measurements.

Remarks.--No diversion between station near Gunnison and this station. Flow regulated by Sevier Bridge Reservoir. Only annual peaks are shown.

Peak stages and discharges

\begin{tabular}{|c|c|c|c|c|c|c|c|}
\hline $\begin{array}{l}\text { Water } \\
\text { year }\end{array}$ & Date & $\begin{array}{l}\text { Gage } \\
\text { helght } \\
\text { (feet) }\end{array}$ & $\begin{array}{c}\text { Discharge } \\
\text { (cfs) }\end{array}$ & $\begin{array}{l}\text { Water } \\
\text { year }\end{array}$ & Date & $\begin{array}{l}\text { Gage } \\
\text { height } \\
\text { (feet) }\end{array}$ & $\begin{array}{c}\text { Discharge } \\
\text { (cIs) }\end{array}$ \\
\hline $\begin{array}{l}1912 \\
1913 \\
1914 \\
1915\end{array}$ & $\begin{array}{lrr}\text { May } & 27,1912 \\
\text { Apr. } & 9,1913 \\
\text { June } & 5-10,1914 \\
\text { June } & 22,1915\end{array}$ & $\begin{array}{l}- \\
- \\
-\end{array}$ & $\begin{array}{r}\mathrm{a} 921 \\
\mathrm{al}, 310 \\
\mathrm{~b} 2,030 \\
1,080\end{array}$ & $\begin{array}{l}1938 \\
1939 \\
1940\end{array}$ & $\begin{array}{ll}\text { July } 15, & 1938 \\
\text { May } 11, & 1939 \\
\text { May } 7,8, & 1940\end{array}$ & $\begin{array}{l}3.70 \\
5.23 \\
5.15\end{array}$ & $\begin{array}{r}980 \\
1,190 \\
1,140\end{array}$ \\
\hline $\begin{array}{l}1916 \\
1917 \\
1918 \\
1919 \\
1920\end{array}$ & 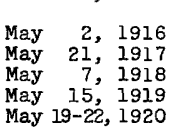 & $\begin{array}{l}- \\
- \\
\overline{-}\end{array}$ & $\begin{array}{l}1,100 \\
1,230 \\
1,450 \\
1,300 \\
1,090\end{array}$ & $\begin{array}{l}1941 \\
1942 \\
1943 \\
1944 \\
1945\end{array}$ & $\begin{array}{lrr}\text { May } 12-15, & 1941 \\
\text { July } & 15, & 1942 \\
\text { July } 2, & 1943 \\
\text { May } 17, & 1944 \\
\text { May } 7, & 1945\end{array}$ & $\begin{array}{l}3.71 \\
5.41 \\
4.97 \\
5.39 \\
4.61\end{array}$ & $\begin{array}{l}1,050 \\
1,190 \\
1,110 \\
1,320 \\
1,040\end{array}$ \\
\hline $\begin{array}{l}1921 \\
1922 \\
1923 \\
1924 \\
1925\end{array}$ & $\begin{array}{lrr}\text { May } & 15, & 1921 \\
\text { June } & 2, & 1922 \\
\text { May } 12, & 1923 \\
\text { May } & 7, & 1924 \\
\text { May } & 9, & 1925\end{array}$ & $\begin{array}{l}8.50 \\
- \\
-\end{array}$ & $\begin{array}{r}1,290 \\
2,140 \\
1,480 \\
1,600 \\
988\end{array}$ & $\begin{array}{l}1946 \\
1947 \\
1948 \\
1949 \\
1950\end{array}$ & $\begin{array}{lr}\text { Apr. } & 26,1946 \\
\text { May } 9,10, & 1947 \\
\text { May } 27, & 1948 \\
\text { May } 4,1949 \\
\text { May } 25, & 1950\end{array}$ & $\begin{array}{l}4.88 \\
4.95 \\
5.07 \\
5.22 \\
4.66\end{array}$ & $\begin{array}{r}1,150 \\
\mathrm{bl}, 200 \\
1,230 \\
1,290 \\
1,100\end{array}$ \\
\hline $\begin{array}{l}1926 \\
1927 \\
1928 \\
1929 \\
1930\end{array}$ & 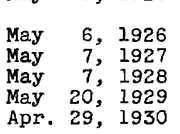 & $\begin{array}{l}- \\
- \\
-\end{array}$ & $\begin{array}{r}1,140 \\
1,140 \\
a 1,260 \\
1,270 \\
969\end{array}$ & $\begin{array}{l}1951 \\
1952 \\
1953 \\
1954 \\
1955\end{array}$ & $\begin{array}{lrl}\text { May } & 7, & 1951 \\
\text { June } & 21, & 1952 \\
\text { July } & 8, & 1953 \\
\text { May } & 6, & 1954 \\
\text { May } 14, & 1955\end{array}$ & $\begin{array}{l}4.82 \\
4.28 \\
4.70 \\
4.69 \\
4.83\end{array}$ & $\begin{array}{r}1,140 \\
944 \\
1,090 \\
1,100 \\
1,160\end{array}$ \\
\hline $\begin{array}{l}1931 \\
1932 \\
1933 \\
1934\end{array}$ & 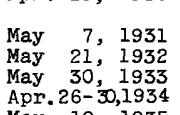 & $\begin{array}{l}- \\
4: 82 \\
4.74 \\
4.56\end{array}$ & $\begin{array}{r}988 \\
1,100 \\
1,110 \\
\mathrm{bl}, 030\end{array}$ & $\begin{array}{l}1956 \\
1957 \\
1958 \\
1959 \\
1960\end{array}$ & $\begin{array}{lrl}\text { May } & 17, & 1956 \\
\text { May } & 10,1957 \\
\text { May } & 8,1958 \\
\text { May } & 1,1959 \\
\text { May } & 9, & 1960\end{array}$ & $\begin{array}{l}4.27 \\
3.95 \\
5.19 \\
4.02 \\
3.95\end{array}$ & $\begin{array}{r}990 \\
911 \\
1,380 \\
938 \\
907\end{array}$ \\
\hline $\begin{array}{l}1936 \\
1937\end{array}$ & 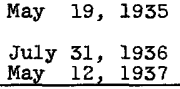 & $\begin{array}{l}4.95 \\
4.72 \\
\end{array}$ & $\begin{array}{r}1,050 \\
948 \\
\end{array}$ & $\begin{array}{l}1961 \\
1962 \\
1963\end{array}$ & $\begin{array}{lrr}\text { May } & 12, & 1961 \\
\text { May } & 6, & 1962 \\
\text { May } & 8, & 1963\end{array}$ & $\begin{array}{l}4.27 \\
4.79 \\
4.18\end{array}$ & $\begin{array}{r}1,010 \\
1,150 \\
968\end{array}$ \\
\hline
\end{tabular}

Maximum observed.

b Maximum daily.

2235. Sevier River at Leamington, Utah

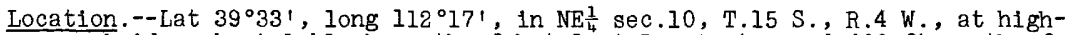
way bridge about 1 block north of hotel at Leamington and $400 \mathrm{ft}$ north of San Pedro, Los Angeles and Salt Lake Railroad (now Union Paciflc RR.).

Drainage area. $--5,860 \mathrm{sq} \mathrm{mi}$, approximately.

Gage.--Nonrecording. At site $1 \mathrm{mile}$ upstream at different datum 1890-93,

Stage-discharge relation.--Unkmown prior to 1894 , defined by current-mater! measurements below 1,720 cfs thereafter.

Remarks.--Flow affected by reservoirs upstream, particularly by Sevier Bridge Reservoir since about 1904. Many diversions for irrigation upstrean from station. Only annual maximum observed discharges are shown. 
Maximum observed discharges of Sevier River at Leamington, Utah

\begin{tabular}{|c|c|c|c|c|c|c|c|}
\hline $\begin{array}{l}\text { Water } \\
\text { year }\end{array}$ & Date & $\begin{array}{c}\text { Gage } \\
\text { helght } \\
\text { (feet) }\end{array}$ & $\begin{array}{c}\text { Discharge } \\
\text { (cfs) }\end{array}$ & $\begin{array}{l}\text { Water } \\
\text { year }\end{array}$ & Date & $\begin{array}{c}\text { Gage } \\
\text { helght } \\
\text { (feet) }\end{array}$ & $\begin{array}{c}\text { Discharge } \\
(\mathrm{cfs})\end{array}$ \\
\hline 1890 & May 30,1890 & - & 2,330 & $\begin{array}{l}1912 \\
1913\end{array}$ & $\begin{array}{l}\text { June 1, } 1912 \\
\text { Apr. 10, } 1913\end{array}$ & - & $\begin{array}{r}\mathrm{b} 882 \\
1,520\end{array}$ \\
\hline $\begin{array}{l}1891 \\
1892 \\
1893 \\
\end{array}$ & $\begin{array}{c}\text { May } 9,1891 \\
\text { June } 2-6,1892 \\
\text { (a) }\end{array}$ & - & $\begin{array}{l}1,390 \\
1,220 \\
1,300 \\
\end{array}$ & 1914 & June 9,10, 1914 & - & 1,820 \\
\hline
\end{tabular}

a Jan. 31, Feb. 1, July 27, 1893.

b Maximum observed during period May to September.

2240. Sevier River near Lynndyl, Utah

Location.--Lat $39^{\circ} 29^{\prime}$, long $112^{\circ} 24^{\prime}$, in SE $\frac{1}{4}$ sec.27, T.15 S., R.5 W., on right bank $i \frac{1}{2}$ miles downstream from highway bridge and $3 \frac{1}{2}$ miles southwest of Lynndy 1 .

Drainage area. $--6,270 \mathrm{sq} \mathrm{mi}$, approximately.

Gage.--Recording. Altitude of gage is $4,660 \mathrm{ft}$ (by barometer).

Stage-discharge relation.--Defined by current-meter measurements.

Remarks.--Flow regulated by Sevier Bridge Reservoir. Several diversions for irrlgation between reservolr and station. Only annual peaks are shown.

\begin{tabular}{|c|c|c|c|c|c|c|c|c|c|}
\hline $\begin{array}{l}\text { Water } \\
\text { year }\end{array}$ & \multicolumn{2}{|r|}{ Date } & $\begin{array}{c}\text { Gage } \\
\text { helght } \\
\text { (feet) }\end{array}$ & $\begin{array}{c}\text { Discharge } \\
\text { (cfs) }\end{array}$ & $\begin{array}{l}\text { Water } \\
\text { year }\end{array}$ & \multicolumn{2}{|r|}{ Date } & $\begin{array}{c}\text { Gage } \\
\text { relght } \\
\text { (feet) }\end{array}$ & $\begin{array}{c}\text { Discharge } \\
\text { (cfs) }\end{array}$ \\
\hline $\begin{array}{l}1914 \\
1915\end{array}$ & $\begin{array}{l}\text { June } \\
\text { June }\end{array}$ & $\begin{array}{rr}9, & 1914 \\
24, & 1915\end{array}$ & $\overline{-}$ & $\begin{array}{r}a 1,820 \\
923\end{array}$ & \multirow{5}{*}{$\begin{array}{l}1951 \\
1952 \\
1953 \\
1954 \\
1955 \\
1956 \\
1957 \\
1958 \\
1959 \\
1960\end{array}$} & \multirow{5}{*}{\multicolumn{2}{|c|}{$\begin{array}{lr}\text { May } 9, & 1951 \\
\text { May } 14, & 1952 \\
\text { July } 11, & 1953 \\
\text { May } 1, & 1954 \\
\text { Ju1y } 12, & 1955 \\
& \\
\text { May } 20, & 1956 \\
\text { May } 12,1957 \\
\text { May } 11,1958 \\
\text { Apr. } 27,1959 \\
\text { May } 11,1960\end{array}$}} & \multirow{5}{*}{$\begin{array}{l}6.15 \\
6.50 \\
6.31 \\
6.48 \\
6.26 \\
5.96 \\
5.88 \\
6.89 \\
6.04 \\
5.90\end{array}$} & \multirow{5}{*}{$\begin{array}{r}825 \\
912 \\
858 \\
882 \\
798 \\
\\
755 \\
707 \\
1,010 \\
765 \\
725\end{array}$} \\
\hline $\begin{array}{l}1916 \\
1917\end{array}$ & $\begin{array}{l}\text { May } \\
\text { May }\end{array}$ & $\begin{array}{l}16,1916 \\
23,1917\end{array}$ & - & $\begin{array}{r}930 \\
1,080\end{array}$ & & & & & \\
\hline 1918 & May & 9,1918 & - & 1,200 & & & & & \\
\hline 1919 & May & 11,1919 & - & 956 & & & & & \\
\hline $\begin{array}{l}1943 \\
1944 \\
1945\end{array}$ & $\begin{array}{l}\text { June } \\
\text { May } \\
\text { May }\end{array}$ & $\begin{array}{rr}3, & 1943 \\
19, & 1944 \\
8, & 1945\end{array}$ & $\begin{array}{l}5.96 \\
6.72 \\
5.94\end{array}$ & $\begin{array}{r}873 \\
1,030 \\
837\end{array}$ & & & & & \\
\hline $\begin{array}{l}1946 \\
1947 \\
1948 \\
1949 \\
1950\end{array}$ & $\begin{array}{l}\text { Apr. } \\
\text { May } \\
\text { June } \\
\text { May } \\
\text { May }\end{array}$ & $\begin{array}{rr}28, & 1946 \\
12, & 1947 \\
1, & 1948 \\
7, & 1949 \\
27, & 1950\end{array}$ & $\begin{array}{l}5.77 \\
6.14 \\
6.96 \\
6.50 \\
6.02\end{array}$ & $\begin{array}{r}748 \\
842 \\
1,080 \\
942 \\
771\end{array}$ & $\begin{array}{l}1961 \\
1962 \\
1963\end{array}$ & $\begin{array}{l}\text { May } \\
\text { Feb. } \\
\text { May }\end{array}$ & $\begin{array}{rr}15, & 1961 \\
10, & 1962 \\
9, & 1963\end{array}$ & $\begin{array}{r}6.07 \\
11.73 \\
6.01\end{array}$ & $\begin{array}{r}794 \\
2,980 \\
754\end{array}$ \\
\hline
\end{tabular}

a Maximum daily.

2280. Sevier River near Delta, Utah

Location. --Lat $39^{\circ} 24^{\prime} 10^{\prime \prime}$, long $112^{\circ} 30^{\prime} 15^{\prime \prime}$, in NW $\frac{1}{4}$ sec.27, T.16 S., R.6 W.,

$1 \frac{1}{2} \mathrm{miles}$ downstream from Delta and Melville Reservoir and $6 \frac{1}{2}$ miles northeast of Delta.

Drainage area $--7,380 \mathrm{sq} \mathrm{mi}$, approximately.

Gage. --Recording.

Stage-discharge relation.--Defined by current-meter measurements.

Remarks.--Many diversions above station for 1rrigation above and below station. Flow regulated by Delta and Melville Reservolr and by Sevier Eridge Reser-

voir. Only annual peaks are shown.

Peak stages and discharges

\begin{tabular}{|c|c|c|c|c|c|c|c|c|c|}
\hline $\begin{array}{l}\text { Water } \\
\text { year }\end{array}$ & & Date & $\begin{array}{l}\text { Gage } \\
\text { helght } \\
\text { (feet) }\end{array}$ & $\begin{array}{c}\text { Discharge } \\
(\text { cfs })\end{array}$ & $\begin{array}{c}\text { Water } \\
\text { year }\end{array}$ & & Date & $\begin{array}{l}\text { Gage } \\
\text { helght } \\
\text { (feet) }\end{array}$ & $\begin{array}{c}\text { Discharge } \\
\text { (cfs) }\end{array}$ \\
\hline $\begin{array}{l}1913 \\
1914 \\
1915\end{array}$ & $\begin{array}{ll}\text { Apr. } & 1 \\
\text { May } & 3 \\
\text { Mar. } & 3\end{array}$ & $\begin{array}{l}12,1913 \\
31,1914 \\
31,1915\end{array}$ & $\overline{-}$ & $\begin{array}{r}1,220 \\
1,470 \\
802\end{array}$ & $\begin{array}{l}1917 \\
1918 \\
1919\end{array}$ & $\begin{array}{l}\text { May } 2 \\
\text { May } 1 \\
\text { June }\end{array}$ & $\begin{array}{rr}27, & 1917 \\
12, & 1918 \\
6, & 1919\end{array}$ & - & $\begin{array}{l}504 \\
602 \\
525\end{array}$ \\
\hline 1916 & Apr. & 5,1916 & - & 880 & & & & & \\
\hline
\end{tabular}


2315. Sevier River at Oasis, Utah

(Pubilshed as "near Oasis" 1913)

Location.--Lat $39^{\circ} 18^{\prime}$, long $112^{\circ} 38^{\prime}$, in $\mathrm{E}^{\frac{1}{2}} \mathrm{sec} .33$, T.17 S., R.7 W., about threequarters of a mile northwest of Oasis and $1 \frac{1}{2}$ miles downstream from county bridge, locally known as Hinckley Bridge.

Drainage area. $--8,080 \mathrm{sq} \mathrm{mi}$, approximately.

Gage.--Nonrecording prior to Apr. 24, 1914, at site about $1 \frac{1}{2}$ miles upstream at different datum; recording thereafter.

Stage-discharge relation.--Defined by current-meter measurements .

Remarks.--Flow regulated by storage reservolrs and diversion dams upstream. Only annual peaks are shown.

Peak stages and discharges

\begin{tabular}{|c|c|c|c|c|c|c|c|c|}
\hline $\begin{array}{l}\text { Water } \\
\text { year }\end{array}$ & Date & $\begin{array}{l}\text { Gage } \\
\text { helght } \\
\text { (feet) }\end{array}$ & $\begin{array}{c}\text { Discharge } \\
\text { (cfs) }\end{array}$ & $\begin{array}{l}\text { Water } \\
\text { year }\end{array}$ & & Date & $\begin{array}{l}\text { Gage } \\
\text { helght } \\
\text { (feet) }\end{array}$ & $\begin{array}{c}\text { Discharge } \\
\text { (cfs) }\end{array}$ \\
\hline $\begin{array}{l}1913 \\
1914 \\
1915\end{array}$ & $\begin{array}{lll}\text { Apr. } 12, & 1913 \\
\text { June } 12, & 1914 \\
\text { Mar. } 24, & 1915\end{array}$ & $\frac{-}{-}$ & $\begin{array}{r}21,280 \\
1,580 \\
1,040\end{array}$ & \multirow{2}{*}{$\begin{array}{l}1921 \\
1922 \\
1923 \\
1924 \\
1925 \\
1926 \\
1927\end{array}$} & \multirow{2}{*}{$\begin{array}{l}\text { May } \\
\text { June } \\
\text { Apr. } \\
\text { oct. } \\
\text { May } \\
\text { May } \\
\text { May }\end{array}$} & \multirow{2}{*}{$\begin{aligned} 27, & 1921 \\
17, & 1922 \\
21, & 1923 \\
1, & 1923 \\
15, & 1925 \\
29, & 1926 \\
23, & 1927\end{aligned}$} & $\begin{array}{l}\bar{z} \\
\bar{z}\end{array}$ & \multirow{2}{*}{$\begin{array}{r}396 \\
1,570 \\
1,130 \\
a 145 \\
b 43 \\
27 \\
20\end{array}$} \\
\hline $\begin{array}{l}1916 \\
1917 \\
1918 \\
1919 \\
1920\end{array}$ & $\begin{array}{l}\text { Apr. } 6,1916 \\
\text { Feb. 27, } 1917 \\
\text { Nov. 22, } 1917 \\
\text { oct. 1, } 1918 \\
\text { Aug. 27, } 1920\end{array}$ & $\begin{array}{l}- \\
- \\
- \\
-\end{array}$ & $\begin{array}{r}720 \\
314 \\
327 \\
196 \\
77\end{array}$ & & & & - & \\
\hline
\end{tabular}

a Maximum observed.

b Maximum daily.

\section{PAVANT VALLEY}

2325. Chalk Creek near F1limore, Utah

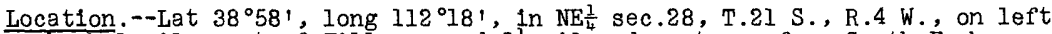
bank 1 mile east of Fillmore and $2 \frac{1}{4}$ miles downstream from South Fork.

Drainage area. $--60 \mathrm{sq} \mathrm{mi}$, approximately. Mean alt1tude, 8,020 ft.

Gage.--Nonrecording prior to August 1914, at site $1 \frac{1}{4}$ miles upstream at different datum; recording thereafter. Altitude of gage is $5,180 \mathrm{ft}$ (by

barometer).

Stage-discharge relation.--Defined by current-meter measurements.

Remarks.--Records include flow of Flllmore Canal whlch diverts on left bank at flood control dam $400 \mathrm{ft}$ upstream. Base for partlal-duration series, $130 \mathrm{cfs}$.

Peak stages and discharges

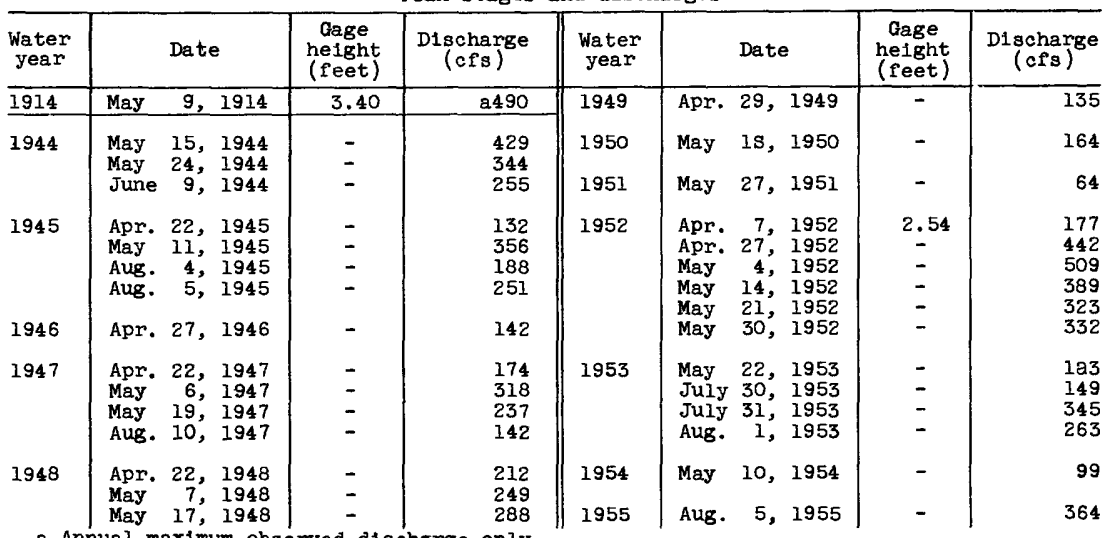

a Annual maximum observed discharge only. 
Peak stages and discharges of Chalk Creek near Fillmore, Utah--Continued

\begin{tabular}{|c|c|c|c|c|c|c|c|c|}
\hline $\begin{array}{l}\text { Water } \\
\text { year }\end{array}$ & & Date & $\begin{array}{l}\text { Gage } \\
\text { neight } \\
\text { (feet) }\end{array}$ & $\begin{array}{c}\text { Discharge } \\
\text { (cfs) }\end{array}$ & $\begin{array}{l}\text { Water } \\
\text { year }\end{array}$ & Date & $\begin{array}{c}\text { Gage } \\
\text { helght } \\
\text { (feet) }\end{array}$ & $\begin{array}{c}\text { Discharge } \\
\text { (cfs) }\end{array}$ \\
\hline 1956 & May & 5,1956 & - & 88 & 1960 & May 12,1960 & - & 162 \\
\hline 1957 & $\begin{array}{l}\text { May } \\
\text { May } \\
\text { June }\end{array}$ & $\begin{array}{rr}10, & 1957 \\
19, & 1957 \\
3, & 1957\end{array}$ & $\begin{array}{l}- \\
-\end{array}$ & $\begin{array}{l}244 \\
232 \\
359\end{array}$ & $\begin{array}{l}1961 \\
1962\end{array}$ & 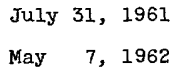 & - & $\begin{array}{r}1,850 \\
267\end{array}$ \\
\hline 1958 & May & 11,1958 & - & 258 & 1963 & Sept. 6, 1963 & - & 126 \\
\hline 1959 & July & 31,1959 & - & 308 & & & & \\
\hline
\end{tabular}

\section{BEAVER RIVER BASIN}

2340. Three Creeks near Beaver, Utah

Location.--Lat $38^{\circ} 17^{\prime} 40^{\prime \prime}$, long $112^{\circ} 25^{\prime} 40^{\prime \prime}$, in NW $\frac{1}{4} N W \frac{1}{4}$ sec.16, T. .9 S., R. 5 W. , on right bank half a mile downstream from Three Creeks Dam, i alf a mile upstream from Merchant Creek, and 16 miles east of Beaver.

Drainage area. $--19.5 \mathrm{sq} \mathrm{mi}$.

Gage.--Recording. Prior to Aug. 24, 1947, at site $500 \mathrm{ft}$ downstream at different datum. Aug. 24, 1947, to May II, 1950, at site $700 \mathrm{ft}$ upstream at different datum. Altitude of gage is $8,550 \mathrm{ft}$ (from topographic map).

Stage-discharge relation.--Defined by current-meter measurements below 19 cfs prior to 1948, below $60 \mathrm{cfs} 1948-49$, and below 161 cfs thereafter. Extended above on basis of slope-area measurement at $290 \mathrm{cfs}$.

Remarks.--Flow affected by storage in Puffer Lake and in Three Creeks Reservolr (capacity, 2,020 acre-ft) completed in 1950. Only annual pea'rs are shown.

Peak stages and discharges

\begin{tabular}{|c|c|c|c|c|c|c|c|c|}
\hline $\begin{array}{l}\text { Water } \\
\text { year }\end{array}$ & Date & $\begin{array}{c}\text { dage } \\
\text { height } \\
\text { (feet) }\end{array}$ & $\begin{array}{c}\text { Discharge } \\
\text { (cfs) }\end{array}$ & $\begin{array}{l}\text { Water } \\
\text { year }\end{array}$ & & Date & $\begin{array}{l}\text { Cage } \\
\text { hright } \\
\text { (feet) }\end{array}$ & $\begin{array}{c}\text { D1scharge } \\
\text { (cfs) }\end{array}$ \\
\hline 1947 & Aug. 9,1947 & 4.35 & 290 & \multirow{7}{*}{$\begin{array}{l}1955 \\
1956 \\
1957 \\
1958 \\
1959 \\
1960 \\
1961\end{array}$} & \multirow{7}{*}{$\begin{array}{l}\text { May } \\
\text { July } \\
\text { June } \\
\text { May } \\
\text { May } \\
\text { May } \\
\text { May }\end{array}$} & \multirow{2}{*}{27,1955} & & \multirow[t]{2}{*}{33} \\
\hline 1948 & May $17,194 \mathrm{~s}$ & $3.4 \mathrm{~S}$ & 153 & & & & & \\
\hline 1949 & June 12,1949 & 2.92 & 109 & & & 7,1956 & 2.48 & 57 \\
\hline 1950 & May 23,1950 & 2.16 & 30 & & & $\begin{array}{ll}10, & 1957 \\
31, & 1958\end{array}$ & $\begin{array}{l}3.40 \\
3.28\end{array}$ & $\begin{array}{l}147 \\
133\end{array}$ \\
\hline 1951 & June 7,1951 & 2.16 & 38 & & & 13,1959 & $\begin{array}{l}0.20 \\
1.95\end{array}$ & 22 \\
\hline 1952 & May 15,1952 & 3.58 & 219 & & & 19,1960 & 2.25 & 40 \\
\hline 1954 & June 8,1954 & 2.25 & 42 & & & 31,1961 & 2.58 & 63 \\
\hline
\end{tabular}

2345. Beaver River near Beaver, Utah

Location.--Lat $38^{\circ} 16^{\prime} 40^{\prime \prime}$, Iong $112^{\circ} 33^{\prime} 30^{\prime \prime}$, In NW $\frac{1}{4}$ sec.20, T.29 S., R.6 W. , on left bank $300 \mathrm{ft}$ downstream from Bakers Canyon and $4 \frac{1}{2}$ miles east of Beaver.

Drainage area.--82 sq $\mathrm{mi}$, approximately.

Gage.--Recording. Mar. 30, 1914, to 0ct. 15, 1937, at 81te 3,00 f't downstream at different datum. Oct. 16, 1937, to Mar. 20, 1959, at site 0.4 mile downstream at different datum. Altitude of gage is 6,500 ft (from topographic map).

Stage-discharge relation.--Defined by current-meter measurements below 581 cf's prior to 1938, below 712 cfs from 1938 to 1958 , and below 168 cfs thereafter.

Remarks.--Some regulation by powerplants and several smali reserrolrs. OnIy annual peaks are shown prior to 1948. Base for partial-duration serles, $250 \mathrm{cfs}$. 
Peak stages and discharges of Beaver River near Beaver, Utah

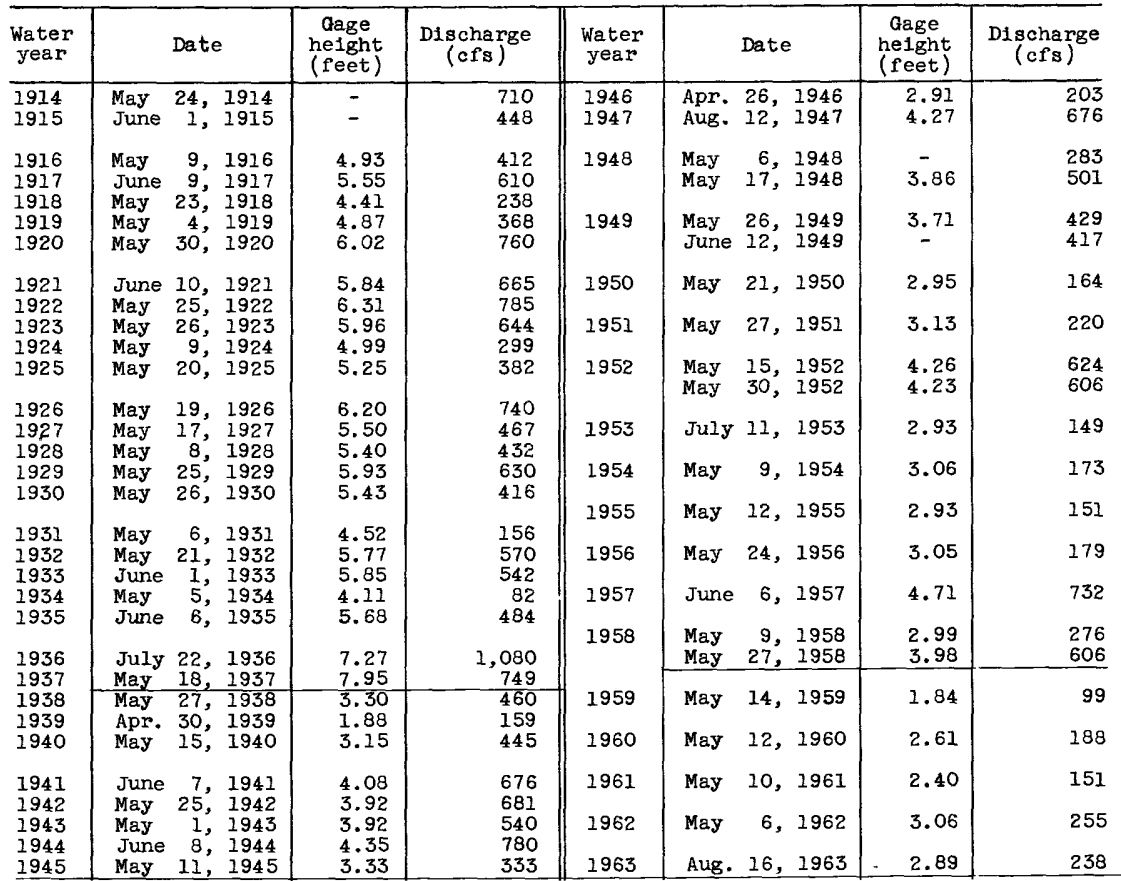

2370. Beaver River at Adamsvilie, Utah

Location.--Lat $38^{\circ} 15^{\prime} 05^{\prime \prime}$, long $112^{\circ} 47^{\prime} 25^{\prime \prime}$, in SE $\frac{1}{4}$ sec.30, T.29 S., R. E W., on left bank $600 \mathrm{ft}$ downstream from bridge on State Highway 21 , a quarter of a mile upstream from Indian Creek, and half a mile south of Adamsvili.e.

Drainage area. $--272 \mathrm{sq} \mathrm{m} 1$.

Gage.--Recording prior to Sept. 15, 1936, and nonrecording Sept. 15, 1936, to cct. 15, 1937, at site 225 ft upstream at different datum; recording thereafter. 0ct. 16, 1937, to May 28, 1946, at s1te $75 \mathrm{ft}$ downstream at datum $0.50 \mathrm{ft}$ higher. Altitude of gage is 5,500 ft (from topographic map).

Stage-discharge relation.--Defined by current-meter measurements below $747 \mathrm{cf}$ s prior to 1937, below 200 cfs during 1937, below 433 cf's f'rom 1938 to 1946 , and below 606 cf's thereafter.

Remarks.--Several ditches above station divert practically entire flow during Irrigation season to supply Adamsville and Beaver districts. Only annual peaks are shown.

Peak stages and discharges

\begin{tabular}{|c|c|c|c|c|c|c|c|}
\hline $\begin{array}{l}\text { Water } \\
\text { year }\end{array}$ & Date & $\begin{array}{l}\text { Cage } \\
\text { height } \\
\text { (feet) }\end{array}$ & $\begin{array}{c}\text { Discharge } \\
\text { (cfs) }\end{array}$ & $\begin{array}{l}\text { Water } \\
\text { year }\end{array}$ & Date & $\begin{array}{c}\text { Gage } \\
\text { helght } \\
\text { (feet) }\end{array}$ & $\begin{array}{c}\text { Discharge } \\
\text { (cfs) }\end{array}$ \\
\hline $\begin{array}{l}1914 \\
1915\end{array}$ & $\begin{array}{lr}\text { June } 3, & 1914 \\
\text { July } 26, & 1915\end{array}$ & $\begin{array}{l}4.27 \\
3.77\end{array}$ & $\begin{array}{l}544 \\
430\end{array}$ & $\begin{array}{l}1923 \\
1924 \\
1925\end{array}$ & $\begin{array}{cc}\text { July } 25, & 1923 \\
\text { Mar. } 26,1924 \\
\text { June 4, } 1925\end{array}$ & $\begin{array}{l}3.61 \\
2.11 \\
3.21\end{array}$ & $\begin{array}{r}373 \\
64 \\
268\end{array}$ \\
\hline $\begin{array}{l}1916 \\
1917 \\
1918 \\
1919 \\
1920\end{array}$ & 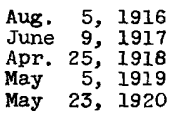 & $\begin{array}{l}4.00 \\
3.29 \\
2.14 \\
2.57 \\
4.85\end{array}$ & $\begin{array}{r}480 \\
275 \\
74 \\
147 \\
796\end{array}$ & $\begin{array}{l}1926 \\
1927 \\
1928 \\
1929 \\
1930\end{array}$ & $\begin{array}{l}\text { May } 20,1926 \\
\text { Feb. } 17,1927 \\
\text { May } 18,1928 \\
\text { Aug. } 5,1929 \\
\text { Feb. 19, } 1930\end{array}$ & $\begin{array}{l}3.70 \\
2.53 \\
2.45 \\
4.15 \\
2.78\end{array}$ & $\begin{array}{l}395 \\
122 \\
109 \\
494 \\
171\end{array}$ \\
\hline $\begin{array}{l}1921 \\
1922\end{array}$ & $\begin{array}{ll}\text { July } 14, & 1921 \\
\text { May } 31, & 1922\end{array}$ & $\begin{array}{l}4.96 \\
4.38\end{array}$ & $\begin{array}{r}a 836 \\
583\end{array}$ & 1931 & Feb. 6,1931 & 2.10 & 72 \\
\hline
\end{tabular}

a. May have been exceeded by flood of Aug. 23,1921 . 
Peak stages and discharges of Beaver R1ver at Adamsville, Utah--Cont1nued

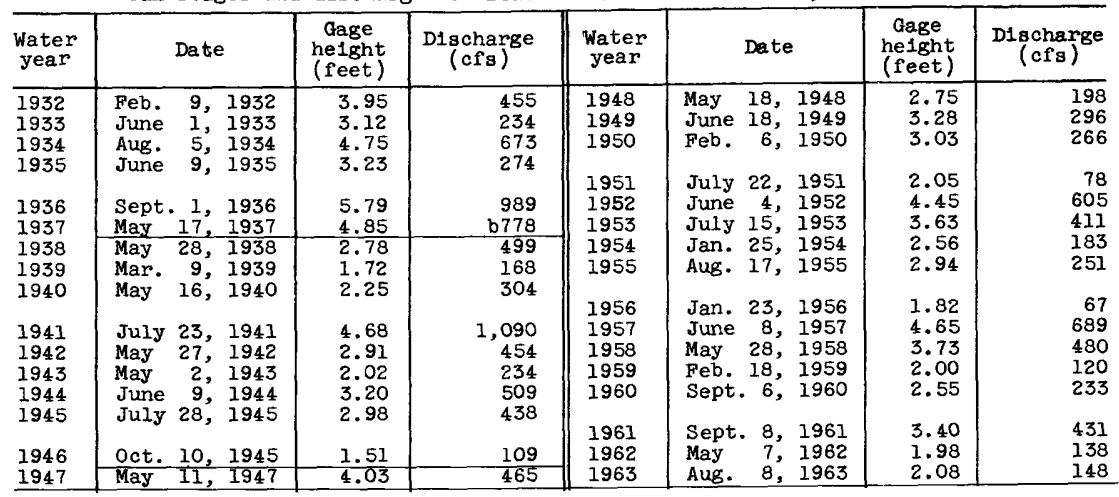

b Maximum observed.

2390. Beaver River at Rockyford Dam, near Minersville, Utah

Location.--Lat $38^{\circ} 14^{\prime}$, long $112^{\circ} 50^{\prime}$, in NW $\frac{1}{4}$ sec.11, T.30 S., R.9 W., on right bank half a mile downstream from Rockyford Dam and $4 \frac{3}{4}$ miles east of Minersville.

Drainage area. $--512 \mathrm{sq} \mathrm{mi}$.

Gage.--Recording except nonrecording May 29, 1927, to Apr. 21, 1.937. Prior to June 1, 1916, at site $1,500 \mathrm{ft}$ upstream at different datum. Concrete control at both sites. Altitude of gage is $5,400 \mathrm{ft}$ (by barometer).

Stage-discharge relation.--Defined by current-meter measurements below 172 cfs prior to June 1916, and below 495 cfs thereafter.

Remarks.--Flow regulated by Rockyford Reservoir (capacity, 23,260 acre-ft).

Numerous diversions for irrigation and municipal use above reservoir. only annual peaks are shown.

Peak stages and discharges

\begin{tabular}{|c|c|c|c|c|c|c|c|}
\hline $\begin{array}{l}\text { Water } \\
\text { year }\end{array}$ & Date & $\begin{array}{l}\text { Gage } \\
\text { helght } \\
\text { (feet) }\end{array}$ & $\begin{array}{c}\text { Discharge } \\
(\text { cfs })\end{array}$ & $\begin{array}{l}\text { Water } \\
\text { year }\end{array}$ & Date & $\begin{array}{c}\text { Gage } \\
\text { height } \\
\text { (feet) }\end{array}$ & $\begin{array}{c}\text { D1scharge } \\
\text { (cfs) }\end{array}$ \\
\hline $\begin{array}{l}1914 \\
1915\end{array}$ & $\begin{array}{l}\text { June } 9, \\
\text { July } 12,1914 \\
\end{array}$ & 4.49 & $\begin{array}{r}a 344 \\
202 \\
\end{array}$ & $\begin{array}{l}1939 \\
1940\end{array}$ & $\begin{array}{lrl}\text { May } & 3, & 1939 \\
\text { May } & 21, & 1940\end{array}$ & $\begin{array}{l}1.70 \\
1.54\end{array}$ & $\begin{array}{r}128 \\
91\end{array}$ \\
\hline $\begin{array}{l}1916 \\
1917 \\
1918 \\
1919 \\
1920\end{array}$ & $\begin{array}{l}\text { Aug. } 23,1916 \\
\text { June } 26,1917 \\
\text { May } 10,1918 \\
\text { May 13, } 1919 \\
\text { June 1, } 1920\end{array}$ & $\begin{array}{l}1.66 \\
- \\
1.91 \\
1.72 \\
3.12\end{array}$ & $\begin{array}{r}168 \\
\text { al } 62 \\
\text { al26 } \\
108 \\
548\end{array}$ & $\begin{array}{l}1941 \\
1942 \\
1943 \\
1944 \\
1945\end{array}$ & $\begin{array}{lr}\text { June } 8, & 1941 \\
\text { May } 29, & 1942 \\
\text { May } 7, & 1943 \\
\text { June } 10,1944 \\
\text { July } 13,16,1945\end{array}$ & $\begin{array}{l}3.02 \\
2.43 \\
1.66 \\
3.15 \\
1.79\end{array}$ & $\begin{array}{l}507 \\
309 \\
109 \\
561 \\
116\end{array}$ \\
\hline $\begin{array}{l}1921 \\
1922 \\
\\
1923 \\
1924 \\
1925\end{array}$ & $\begin{array}{l}\text { June } 10,1921 \\
\text { May } 29-31, \\
\text { June } 1,2,1922 \\
\text { May } 22,1923 \\
\text { May 24, } 1924 \\
\text { May 30, } 1925\end{array}$ & $\begin{array}{l}3.53 \\
3.14 \\
2.25 \\
1.69 \\
1.67\end{array}$ & $\begin{array}{r}727 \\
\text { a } 564 \\
\\
\text { a236 } \\
\text { a107 } \\
\text { a103 }\end{array}$ & $\begin{array}{l}1946 \\
1947 \\
1948 \\
1949 \\
1950\end{array}$ & $\begin{array}{l}\text { July } 13,1946 \\
\text { July } 10,1947 \\
\text { May } 23-31,1948 \\
\text { June } 23-25,27 \text {, } \\
1949 \\
\text { May } 19,1950\end{array}$ & $\begin{array}{l}- \\
2.05 \\
1.71 \\
- \\
1.62\end{array}$ & $\begin{array}{l}\text { al } 05 \\
\text { al24 } \\
\text { al28 } \\
\text { al } 49 \\
\text { al20 }\end{array}$ \\
\hline $\begin{array}{l}1926 \\
1927 \\
1928 \\
1929 \\
1930\end{array}$ & $\begin{array}{l}\text { June } 26-30,1926 \\
\text { May } 7,1927 \\
\text { May } 4,1928 \\
\text { May } 7-13,1929 \\
\text { June } 2-4,1930, \\
\text { July } 10-12,1930\end{array}$ & $\begin{array}{l}1.67 \\
1.68 \\
1.76 \\
1.76 \\
1.78\end{array}$ & $\begin{array}{l}\text { al05 } \\
\text { alo7 } \\
\text { al21 } \\
\text { al21 } \\
\text { al24 }\end{array}$ & $\begin{array}{l}1951 \\
1952 \\
1953 \\
1954 \\
1955\end{array}$ & $\begin{array}{l}\text { June } 23,1951 \\
\text { June } 7,1952 \\
\text { July } 20,1953 \\
\text { May } 17,1954 \\
\text { May 11-14, } 1955\end{array}$ & $\begin{array}{l}1.62 \\
3.05 \\
1.95 \\
1.64 \\
1.47\end{array}$ & $\begin{array}{r}\text { a65 } \\
\text { a513 } \\
\text { a116 } \\
\text { a100 } \\
\text { a86 }\end{array}$ \\
\hline $\begin{array}{l}1931 \\
1932 \\
1933 \\
1934 \\
1935\end{array}$ & 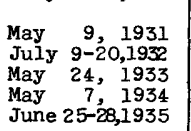 & $\begin{array}{l}1.65 \\
1.63 \\
1.67 \\
1.68 \\
-\end{array}$ & $\begin{array}{r}\text { alo7 } \\
\text { alog } \\
121 \\
\text { al11 } \\
\text { alo7 }\end{array}$ & $\begin{array}{l}1956 \\
1957 \\
1958 \\
1959 \\
1960\end{array}$ & $\begin{array}{ll}\text { June } 25, & 1956 \\
\text { July } 17, & 1957 \\
\text { May 29, } & 1958 \\
\text { July 2, } & 1959 \\
\text { May 9-18, } 1960\end{array}$ & $\begin{array}{l}- \\
2.14 \\
2.20\end{array}$ & $\begin{array}{r}\text { a } 176 \\
\text { a124 } \\
\text { a212 } \\
\text { a152 } \\
\text { a33 }\end{array}$ \\
\hline $\begin{array}{l}1936 \\
1937 \\
1938 \\
\end{array}$ & $\begin{array}{l}\text { Aug. 25-31, } 1936 \\
\text { May 18, } 1937 \\
\text { Nov. 1, } 1937\end{array}$ & $\begin{array}{l}1.67 \\
3.34 \\
2.04\end{array}$ & $\begin{array}{r}a 114 \\
a 668 \\
205\end{array}$ & $\begin{array}{l}1961 \\
1962 \\
1963\end{array}$ & $\begin{array}{l}\text { July } 6-10,1961 \\
\text { July } 9-13,1962 \\
\text { July } 9-13,1963\end{array}$ & $\bar{z}$ & $\begin{array}{l}242 \\
286 \\
a 57\end{array}$ \\
\hline
\end{tabular}


2400. Beaver River at Minersville, Utah

Location.--Lat $38^{\circ} 13^{1} 10^{\prime \prime}$, long $112^{\circ} 55^{\prime} 35^{\prime \prime}$, in NE⿺ sec.12, T.30 S., R.1C W., on right bank at Minersville.

Drainage area.--560 sq $\mathrm{mi}$, approximately.

Gage.--Nonrecording Apr. 13, 1909, to Dec. 20, 1913, at site three-quarters of mile downstream at different datum; recording and concrete control. thereafter. Altitude of gage is $5,250 \mathrm{ft}$ (from topographic map).

Stage-discharge relation.--Defined by current-meter measurements below $343 \mathrm{cfs}$ prior to 1914 and below 263 cfs thereafter.

Remarks.--Diversions above station for irrigation. Flow regulated by Fockyford Reservoix (capacity, 23,260 acre-ft). Only annual peaks are shown (maximum observed 1909-13).

Peak stages and discharges

\begin{tabular}{|c|c|c|c|c|c|c|c|}
\hline $\begin{array}{l}\text { Water } \\
\text { year }\end{array}$ & Date & $\begin{array}{c}\text { Cage } \\
\text { height } \\
\text { (feet) }\end{array}$ & $\begin{array}{c}\text { D1 scharge } \\
\text { (cfs) }\end{array}$ & $\begin{array}{l}\text { Water } \\
\text { year }\end{array}$ & Date & $\begin{array}{c}\text { Gage } \\
\text { height } \\
\text { (feet) }\end{array}$ & $\begin{array}{c}\text { Discharge } \\
\text { (cfs) }\end{array}$ \\
\hline $\begin{array}{l}1909 \\
1910 \\
1911 \\
1912 \\
1913 \\
\end{array}$ & $\begin{array}{l}\text { Sept. 6, } 1909 \\
\text { Jan. } 2,1910 \\
\text { Jan.10,11, } 1911 \\
\text { July 31, } 1912 \\
\text { Sept. 2, } 1913 \\
\end{array}$ & $\begin{array}{l}4.6 \\
- \\
3.25 \\
6.0 \\
4.0 \\
\end{array}$ & $\begin{array}{r}2565 \\
1,000 \\
164 \\
1,200 \\
406 \\
\end{array}$ & $\begin{array}{l}1951 \\
1952 \\
1953 \\
1954 \\
1955\end{array}$ & $\begin{array}{lll}\text { July } & 5, & 1951 \\
\text { June } 6, & 1952 \\
\text { July } 14, & 1953 \\
\text { May } 21, & 1954 \\
\text { Aug. } 23, & 1955\end{array}$ & $\begin{array}{l}1.00 \\
2.43 \\
1.92 \\
1.07 \\
2.50\end{array}$ & $\begin{array}{r}\mathrm{b} 41 \\
433 \\
243 \\
49 \\
447\end{array}$ \\
\hline
\end{tabular}

a Maximum observed during period April to September

b Maximum during period June 29 through September.

2406. Big Wash near Milford, Utah

Location.--Lat $38^{\circ} 29^{\prime}$, long $113^{\circ} 071^{\prime}$, in $\mathrm{NE} \frac{1}{4} \mathrm{sec} .26$, T.27 S., R.12 W., on left bank 8.2 miles northwest of Milford on State Highway 21 .

Drainage area. $--51 \mathrm{sq} \mathrm{mi}$, approximately.

Gage.--Crest-stage gage. Altitude of gage is 5,600 ft (from topographic map).

Stage-discharge relation.--Defined by zero flow, slope-area measurement at $107 \mathrm{cf}$, culvert measurement at $400 \mathrm{cfs}$, and extended above by logarithmic plotting.

Remarks.--Only annual peaks are shown.

Peak stages and discharges

\begin{tabular}{l|c|c|c||c|c|c|c}
\hline $\begin{array}{c}\text { Water } \\
\text { year }\end{array}$ & Date & $\begin{array}{c}\text { Gage } \\
\text { he1ght } \\
\text { (feet) }\end{array}$ & $\begin{array}{c}\text { Discharge } \\
\text { (cfs) }\end{array}$ & $\begin{array}{c}\text { Water } \\
\text { year }\end{array}$ & Date & $\begin{array}{c}\text { Gage } \\
\text { height } \\
\text { (feet) }\end{array}$ & $\begin{array}{c}\text { Discharge } \\
\text { (cfs) }\end{array}$ \\
\hline 1959 & Sept.17, 1959 & 11.00 & 158 & 1962 & Sept.28, 1962 & 12.00 & 350 \\
1960 & July 9, 1960 & 10.10 & 42 & 1963 & Sept.18,1963 & 12.80 & 520 \\
1961 & Sept.17, 1961 & 12.22 & 400 & & & & \\
\hline
\end{tabular}

\section{PAROWAN VALLEY}

2413. Fremont Wash near Paragonah, Utah

Location.--Lat $38^{\circ} 05^{\prime}$, long $112^{\circ} 41^{\prime}$, in SE⿺ $\frac{1}{4} \sec .30$, T. 31 S., R.7 W., on right bank $50 \mathrm{ft}$ upstream from bridge on old U.S. Highway 91 , and 14.5 miles north of Paragonah.

Drainage area. $--120 \mathrm{sq} \mathrm{mi}$, approximately.

Gage.--Crest-stage gage. Altitude of gage is $5,926.82 \mathrm{ft}$ (based on U.S. Coast and Geologic Survey bench mark).

Stage-discharge relation.--Defined by zero flow, float measurement at $78 \mathrm{cfs}$, and slope-area measurements at 82 and $205 \mathrm{cfs}$.

Remarks,--Only annual peaks are shown. 
Peak stages and djscharges of Fremont Wash near Paragonah, Utah

\begin{tabular}{l|c|c|c||c|c|c|c}
\hline $\begin{array}{c}\text { Water } \\
\text { year }\end{array}$ & Date & $\begin{array}{c}\text { Gage } \\
\text { hejght } \\
\text { (feet) }\end{array}$ & $\begin{array}{c}\text { D1scharge } \\
\text { (cfs) }\end{array}$ & $\begin{array}{c}\text { Water } \\
\text { year }\end{array}$ & $\begin{array}{c}\text { Gage Date } \\
\text { hejght } \\
\text { (feet) }\end{array}$ & $\begin{array}{c}\text { D1scharge } \\
\text { (cts) }\end{array}$ \\
\hline 1959 & Aug. 2, 1959 & 10.21 & 45 & 1962 & Mar. 23, 1962 & 11.07 & 12.01 \\
1960 & Sept. 5, 1960 & 10.25 & 50 & 1963 & Aug. 7, 1963 & 1200 \\
1961 & Aug. 29, 1961 & 11.01 & 82 & & \\
\hline
\end{tabular}

2415. Center Creek near Parowan, Utah

Location.--Lat $37^{\circ} 50^{\prime}$, long $112^{\circ} 49^{\prime}$, in SE $\frac{1}{4}$ sec.24, T.34 S., R.9 W., 600 ft downstream from Parowan municipai powerplant, $1 \frac{1}{2}$ miles south of Parowan, and $2 \frac{1}{2}$ miles downstream from Left Fork.

Drainage area. $--60 \mathrm{sq} \mathrm{mi}$. Mean altitude, $8,680 \mathrm{ft}$.

Gage.--Recording. Altitude of gage is $6,250 \mathrm{ft}$ (from topographic map).

Stage-discharge relation.--Defined by current-meter measurements below $52 \mathrm{cfs}$.

Remarks.--Only annual peaks are shown.

\begin{tabular}{|c|c|c|c|c|c|c|c|c|}
\hline $\begin{array}{l}\text { Water } \\
\text { year }\end{array}$ & Date & $\begin{array}{c}\text { Cage } \\
\text { helght } \\
\text { (feet) }\end{array}$ & $\begin{array}{c}\text { Discharge } \\
(\mathrm{cfs})\end{array}$ & $\begin{array}{l}\text { Water } \\
\text { year }\end{array}$ & & Date & $\begin{array}{c}\text { Gage } \\
\text { hejght } \\
\text { (feet) }\end{array}$ & $\begin{array}{c}\text { DJscharge } \\
\text { (cfs) }\end{array}$ \\
\hline $\begin{array}{l}1943 \\
1944 \\
1945\end{array}$ & $\begin{array}{l}\text { Aug. } 17,1943 \\
\text { May } 30,1944 \\
\text { Aug. } 5,1945 \\
\text { oct. }\end{array}$ & $\begin{array}{l}- \\
4.59\end{array}$ & $\begin{array}{l}143 \\
115 \\
386 \\
115\end{array}$ & $\begin{array}{l}1947 \\
1948 \\
1949 \\
1950\end{array}$ & $\begin{array}{l}\text { May } \\
\text { May } \\
\text { July } \\
\text { May }\end{array}$ & $\begin{array}{rr}4, & 1947 \\
15, & 1948 \\
2, & 1949 \\
17, & 1950\end{array}$ & $\begin{array}{l}- \\
3.32 \\
2.72 \\
1.99\end{array}$ & $\begin{array}{r}136 \\
194 \\
114 \\
32\end{array}$ \\
\hline
\end{tabular}

\section{CEDAR CITY VALIEY}

2418. Ashdown Creek near Cedar City, Utah

Location.--Lat $37^{\circ} 38^{\prime} 15^{\prime \prime}$, long $112^{\circ} 54^{\prime} 15^{\prime \prime}$, in SW $\frac{1}{4}$ sec.29, T.36 S., R.9 W., on right bank 1 mile upstream from East Fork Coal Creek and 8 miles southeast of Cedar City.

Drainage area. $--13.1 \mathrm{sq} \mathrm{m} 1$.

Gage.--Recording. Alt1tude of gage is 7,540 ft (from topographic map).

Stage-discharge relation.--Defined by current-meter measurements below $83 \mathrm{cfs}$, and extended to $1,000 \mathrm{cfs}$ on basis of a slope-area measurement 8 miles downstream on Coal Creek and a field determination that most of the floodwaters were from Ashdown Creek.

Remarks.--Only annual peaks are shown.

Peak stages and discharges

\begin{tabular}{|c|c|c|c|c|c|c|c|}
\hline $\begin{array}{l}\text { Water } \\
\text { year }\end{array}$ & Date & $\begin{array}{l}\text { Gage } \\
\text { height } \\
\text { (feet) }\end{array}$ & $\begin{array}{c}\text { Discharge } \\
(\mathrm{cfs})\end{array}$ & $\begin{array}{l}\text { Water } \\
\text { year }\end{array}$ & Date & $\begin{array}{l}\text { Gage } \\
\text { hes.ght } \\
\text { (feet) }\end{array}$ & $\begin{array}{c}\text { Discharge } \\
\text { (cfs) }\end{array}$ \\
\hline $\begin{array}{l}1957 \\
1958 \\
1959\end{array}$ & $\begin{array}{l}\text { Aug. 23, } 1957 \\
\text { Sept.12, } 1958 \\
\text { Aug. 3, } 1959\end{array}$ & $\begin{array}{l}1.79 \\
2.59 \\
4.95\end{array}$ & $\begin{array}{r}a 131 \\
228 \\
b 1,000\end{array}$ & $\begin{array}{l}1960 \\
1961\end{array}$ & $\begin{array}{l}\text { Sept. 5, } 1960 \\
\text { Aug. } 3,1961\end{array}$ & $\begin{array}{r}2.61 \\
4.69\end{array}$ & $\begin{array}{r}116 \\
b 850\end{array}$ \\
\hline
\end{tabular}

a Maximum during period January to September.

b About. 
2419. Coal Creek above Right Hand Creek, near Cedar City, Utah

Location.--Lat $37^{\circ} 39^{\prime} 10^{\prime \prime}$, long $112^{\circ} 59^{1} 05^{\prime \prime}$, in SE $\frac{1}{4}$ sec.21, T.36 S., R.10 W., on right bank $600 \mathrm{ft}$ upstream from Right Hand Creek, at county road aboit $500 \mathrm{ft}$ from junction with State Highway 14, and 5 miles southeast of Cedar City.

Drainage area $--54.2 \mathrm{sq} \mathrm{mi}$.

Gage.--Crest-stage gage. Altitude of gage is $6,500 \mathrm{ft}$ (from topographic map).

Stage-discharge relation.--Defined by current-meter measurements below $140 \mathrm{cfs}$ and a slope-area measurement at $1,210 \mathrm{cfs}$. The stage-discharge relation is subject to considerable shifting.

Remarks.--Only annual peaks are shown.

Peak stages and discharges

\begin{tabular}{|c|c|c|c|c|c|c|c|}
\hline $\begin{array}{l}\text { Water } \\
\text { year }\end{array}$ & Date & $\begin{array}{c}\text { Gage } \\
\text { helght } \\
\text { (feet) }\end{array}$ & $\begin{array}{l}\text { Discharge } \\
\text { (cfs) }\end{array}$ & $\begin{array}{c}\text { Water } \\
\text { year }\end{array}$ & Date & $\begin{array}{c}\text { Gage } \\
\text { height } \\
\text { (feet) }\end{array}$ & $\begin{array}{c}\text { D1scharge } \\
\text { (cfs) }\end{array}$ \\
\hline $\begin{array}{l}1959 \\
1960\end{array}$ & $\begin{array}{ll}\text { Aug. } 3, & 1959 \\
\text { Sept. } & 6,1960\end{array}$ & $\begin{array}{l}12.40 \\
10.03\end{array}$ & $\begin{array}{r}1,210 \\
220\end{array}$ & $\begin{array}{l}1962 \\
1963\end{array}$ & $\begin{array}{l}\text { Sept.28, } 1962 \\
\text { Aug. 19, } 1963\end{array}$ & $\begin{array}{l}11.60 \\
11.6 \mathrm{~s}\end{array}$ & $\begin{array}{l}388 \\
410\end{array}$ \\
\hline 1961 & Aug. 3,1961 & 14.15 & 1,470 & & & & \\
\hline
\end{tabular}

\section{Coal Creek near Cedar City, Utah}

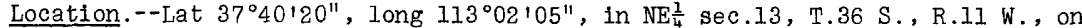
right bank $300 \mathrm{ft}$ downstream from powerplant, 1.3 miles east of Cedar City, and 4 miles downstream from South Creek.

Drainage area. $--80.9 \mathrm{sq} \mathrm{mi}$. Mean altitude, $8,640 \mathrm{ft}$.

Gage.--Nonrecording prior to Mar. 30, 1939; recording thereafter. Prior to May 15,1945 , at several sites about 0.5 mile upstream at various datums. May 15, 1945, to 0ct. 10, 1951, and May 4 to July 2, 1952, at site 2 miles upstream at different datum. Concrete control at present site. Altitude of gage is 6,000 ft (from topographic map).

Stage-discharge relation.--Defined by current-meter measurements below 330 cfs and extended above by weir formula and logarithmic plotting.

Remarks.--Base for partial-duration serles, $350 \mathrm{cfs}$. Only annual peaks are shown prior to 1948 .

Peak stages and discharges

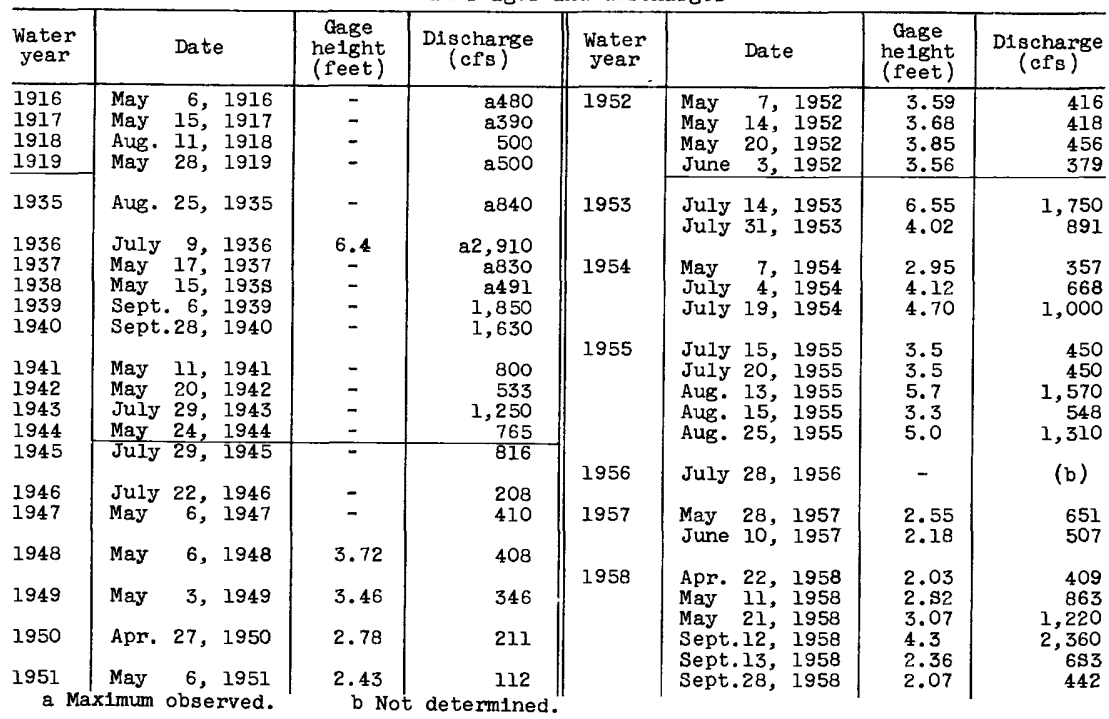


Peak stages and discharges of Coal Creek near Cedar C1ty, Utar--Continued

\begin{tabular}{|c|c|c|c|c|c|c|c|}
\hline $\begin{array}{l}\text { Water } \\
\text { year }\end{array}$ & Date & $\begin{array}{l}\text { Gage } \\
\text { height } \\
\text { (feet) }\end{array}$ & $\begin{array}{c}\text { Discharge } \\
\text { (cfs) }\end{array}$ & $\begin{array}{l}\text { Water } \\
\text { year }\end{array}$ & Date & $\begin{array}{c}\text { Gage } \\
\text { helght } \\
\text { (feet) }\end{array}$ & $\begin{array}{c}\text { Discharge } \\
(\text { cfs })\end{array}$ \\
\hline 1959 & $\begin{array}{lrr}\text { Aug. } & 3, & 1959 \\
\text { Aug. } & 8, & 1959 \\
\text { Aug. } & 19, & 1959\end{array}$ & $\begin{array}{l}5.45 \\
2.97 \\
3.05\end{array}$ & $\left\{\begin{array}{l}210 \\
b \\
b\end{array}\right)$ & 1961 & $\begin{array}{l}\text { Aug. } 22,1961 \\
\text { Sept. } 8,1961 \\
\text { Sept.17, } 1961\end{array}$ & $\begin{array}{l}4.28 \\
5.50 \\
4.05\end{array}$ & $\begin{array}{l}1,500 \\
1,750 \\
1,400\end{array}$ \\
\hline 1960 & Sept. 6, 1960 & 2.20 & 477 & 1962 & 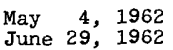 & $\begin{array}{l}2.82 \\
4.00\end{array}$ & $\begin{array}{r}468 \\
1,040\end{array}$ \\
\hline 1961 & $\begin{array}{lrl}\text { July } & 30, & 1961 \\
\text { Aug. } & 3, & 1961 \\
\text { Aug. } 5, & 1961 \\
\text { Aug. } 10, & 1961 \\
\text { Aug. } 20, & 1961 \\
\text { Aug. } 21, & 1961\end{array}$ & $\begin{array}{l}2.18 \\
3.60 \\
2.30 \\
6.50 \\
2.53 \\
2.08\end{array}$ & $\begin{array}{r}469 \\
1,250 \\
570 \\
2,000 \\
767 \\
388\end{array}$ & 1963 & $\begin{array}{l}\text { Sept.28, } 1962 \\
\text { Aug. 17, } 1963 \\
\text { Aug. 31, } 1963 \\
\text { Sept.18, } 1963\end{array}$ & $\begin{array}{l}2.69 \\
3.07 \\
3.10 \\
5.33\end{array}$ & $\begin{array}{r}417 \\
627 \\
642 \\
1,600\end{array}$ \\
\hline
\end{tabular}

b Not determined.

\section{Shurtz Creek near Cedar City, Utah}

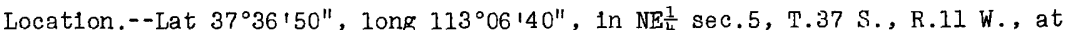
bridge on county road I.I miles south of junction with U.S. Highway 91 and 5.3 miles southwest of Cedar City.

Drainage area. $--12.8 \mathrm{sq} \mathrm{ml}$.

Gage.--Crest-stage gage. Alt1tude of gage is 5,870 ft (from tcpographic map).

Stage-discharge relation.--Defined by current-meter measurements below 94 cfs and culvert measurements at 416 and $1,230 \mathrm{cfs}$.

Remarks.--Only annual peaks are shown.

Peak stages and discharges

\begin{tabular}{l|c|c|c||c|c|c|c}
\hline $\begin{array}{c}\text { Water } \\
\text { year }\end{array}$ & Date & $\begin{array}{c}\text { Gage } \\
\text { helght } \\
\text { (feet) }\end{array}$ & $\begin{array}{c}\text { D1scharge } \\
\text { (cfs) }\end{array}$ & $\begin{array}{c}\text { Water } \\
\text { year }\end{array}$ & Date & $\begin{array}{c}\text { Gage } \\
\text { height } \\
\text { (feet) }\end{array}$ & $\begin{array}{c}\text { Discharge } \\
\text { (cfs) }\end{array}$ \\
\hline 1959 & July 24, 1959 & 11.20 & 110 & 1962 & Sept.28, 1962 & 14.28 & 13.23 \\
1960 & Sept. 1, 1960 & 11.70 & 140 & 1963 & Aug. 1, 1963 & 130 \\
1961 & Sept. S, 1961 & 15.20 & 416 & & & \\
\hline
\end{tabular}

\section{Duncan Creek near Cedar C1ty, Utah}

Location. - -Lat $37^{\circ} 38^{\prime} 0^{\prime \prime}$, long $113^{\circ} 16^{\prime} 20^{\prime \prime}$, in SE $\frac{1}{4} \sec .26$, T.36 S., R.13 W., on right bank $65 \mathrm{ft}$ upstream from ford at junction with State Highway 56 and 13 miles west of Cedar C1ty.

Drainage area. $--11.9 \mathrm{sq} \mathrm{ml}$.

Gage.--Crest-stage gage. Altitude of gage is 5,840 $\mathrm{ft}^{\mathrm{t}}$ (from tonographic map).

Stage-discharge relation.--Defined by slope-area measurement at $363 \mathrm{cfs}$ and estimates based on fleld surveys at 1,240 and $3,880 \mathrm{cfs}$.

Remarks.--Only annual peaks are shown.

Peak stages and discharges

\begin{tabular}{|c|c|c|c|c|c|c|c|}
\hline $\begin{array}{l}\text { Water } \\
\text { year }\end{array}$ & Date & $\begin{array}{l}\text { Cage } \\
\text { helght } \\
\text { (feet) }\end{array}$ & $\begin{array}{c}\text { Discharge } \\
(\text { cfs })\end{array}$ & $\begin{array}{c}\text { Water } \\
\text { year }\end{array}$ & Date & $\begin{array}{c}\text { Gage } \\
\text { helght } \\
\text { (feet) }\end{array}$ & $\begin{array}{c}\text { Discharge } \\
\text { (cfs) }\end{array}$ \\
\hline $\begin{array}{l}1959 \\
1960\end{array}$ & $\begin{array}{lll}\text { Aug. } & 3, & 1959 \\
\text { Sept. } & 6, & 1960\end{array}$ & $\begin{array}{l}12.62 \\
12.00\end{array}$ & $\begin{array}{l}363 \\
250\end{array}$ & $\begin{array}{l}1962 \\
1963\end{array}$ & $\begin{array}{l}\text { Apr. } 27,1962 \\
\text { Aug. } 19,1963\end{array}$ & $\begin{array}{l}10.07 \\
16.5\end{array}$ & $\begin{array}{r}250 \\
23,880\end{array}$ \\
\hline 1961 & Nov. 6,1960 & 11.34 & 150 & & & & \\
\hline
\end{tabular}


2432.4. Baker Creek at narrows, near Baker, Nev.

Location.--Lat $38^{\circ} 59^{\prime} 25^{\prime \prime}$, long $114^{\circ} 12^{\prime} 35^{\prime \prime}$, in $\mathrm{NE} \frac{1}{4} \sec .22, \mathrm{~T} .13 \mathrm{~N} ., \mathrm{R}_{\mathrm{i}} 69 \mathrm{E}$., on left bank, at narrows, 1,200 ft downstream from Pole Canyon and $5 \frac{1}{4}$ miles southwest of Baker.

Drainage area. $--16.4 \mathrm{sq} \mathrm{mi}$.

Gage.--Recording. Altitude of gage is 6,800 ft (from topographic map).

Stage-discharge relation.--Defined by current-meter measurements below an cfs and extended above by logarithmic plotting.

Remarks.--Base for partial-duration series, $20 \mathrm{cfs}$. Only annual peaks are shown since 1955 .

Peak stages and discharges

\begin{tabular}{|c|c|c|c|c|c|c|c|c|}
\hline $\begin{array}{l}\text { Water } \\
\text { year }\end{array}$ & \multicolumn{2}{|r|}{ Date } & $\begin{array}{l}\text { Cage } \\
\text { helght } \\
\text { (feet) }\end{array}$ & $\begin{array}{c}\text { Discharge } \\
\text { (cfs) }\end{array}$ & $\begin{array}{l}\text { Water } \\
\text { year }\end{array}$ & Date & $\begin{array}{c}\text { Gage } \\
\text { helght } \\
\text { (feet) }\end{array}$ & $\begin{array}{c}\text { Discharge } \\
(\mathrm{cfs})\end{array}$ \\
\hline 1948 & $\begin{array}{l}\text { May } \\
\text { May } \\
\text { June } \\
\text { June } \\
\text { June }\end{array}$ & $\begin{array}{rr}19, & 1948 \\
29, & 1948 \\
2, & 1945 \\
10, & 1948 \\
21, & 1948\end{array}$ & $\begin{array}{l}1.56 \\
1.65 \\
1.76 \\
1.78 \\
1.56\end{array}$ & $\begin{array}{l}21 \\
27 \\
37 \\
42 \\
21\end{array}$ & $\begin{array}{l}1952 \\
1953 \\
1954\end{array}$ & \multirow{3}{*}{$\begin{array}{ll}\text { June } & 7,1952 \\
\text { June } & 15,1953 \\
\text { May } 22, & 1954 \\
\text { June } 9, & 1955 \\
\text { Sept. } 3, & 1960\end{array}$} & $\begin{array}{l}2.72 \\
1.45 \\
2.50\end{array}$ & $\begin{array}{r}178 \\
23 \\
86\end{array}$ \\
\hline \multirow[t]{2}{*}{1949} & \multirow{2}{*}{$\begin{array}{l}\text { May } \\
\text { May } \\
\text { June }\end{array}$} & \multirow{2}{*}{$\begin{array}{ll}18, & 1949 \\
28, & 1949 \\
16, & 1949\end{array}$} & \multirow{2}{*}{$\begin{array}{l}1.61 \\
2.03 \\
2.43\end{array}$} & \multirow{2}{*}{$\begin{array}{r}28 \\
72 \\
146\end{array}$} & 1955 & & 2.43 & 75 \\
\hline & & & & & 1960 & & 2.36 & 92 \\
\hline 1950 & May & 31,1950 & 1.84 & 54 & 1961 & $\begin{array}{lll}\text { May } 29, & 1961 \\
\text { June } & 22, & 1962\end{array}$ & $\frac{1.81}{2.26}$ & $\begin{array}{l}28 \\
75\end{array}$ \\
\hline 1951 & May & 28,1951 & 2.10 & 84 & 1963 & June 21,1963 & 2.28 & 79 \\
\hline 1952 & May & 14,1952 & 2.10 & 96 & & & & \\
\hline
\end{tabular}

2432.6. Lehman Creek near Baker, Nev.

Location.--Lat $39^{\circ} 01{ }^{\prime}$, long $114^{\circ} \mathrm{I} 3^{\prime}$, in sec.10, T.13 N., R.69 E., on left bank $4 \frac{3}{4}$ miles west of Baker.

Drainage area.--11 sq mi, approximately. Mean altitude, 9,130 ft.

Gage.--Recording. Prior to Oct. 3, 1953, at site $45 \mathrm{ft}$ downstream. Altitude of gage is $6,730 \mathrm{ft}$ (by barometer).

Stage-discharge relation.--Defined by current-meter measurements.

Remarks.--Base for partial-duration series, $10 \mathrm{cfs}$.

Peak stages and discharges

\begin{tabular}{|c|c|c|c|c|c|c|c|c|}
\hline $\begin{array}{l}\text { Water } \\
\text { year }\end{array}$ & & Date & $\begin{array}{c}\text { Gage } \\
\text { helght } \\
\text { (feet) }\end{array}$ & $\begin{array}{c}\text { Discharge } \\
\text { (cfs) }\end{array}$ & $\begin{array}{l}\text { Water } \\
\text { year }\end{array}$ & Date & $\begin{array}{c}\text { Gage } \\
\text { helght } \\
\text { (feet) }\end{array}$ & $\begin{array}{c}\text { Discharge } \\
\text { (cfs) }\end{array}$ \\
\hline 1948 & & (a) & 1.31 & 15 & 1952 & June 2,1952 & 1.49 & 45 \\
\hline 1949 & June & 19,1949 & 1.38 & 34 & 1953 & June 25,1953 & .85 & 6.5 \\
\hline 1950 & June & 7,1950 & 1.13 & 16 & 1954 & $\begin{array}{lll}\text { May } & 22, & 1954 \\
\text { July } & 13, & 1954\end{array}$ & $\begin{array}{l}3.82 \\
3.69\end{array}$ & $\begin{array}{l}21 \\
14\end{array}$ \\
\hline 1951 & May & 29,1951 & 1.14 & 16 & 1955 & June 13, 1955 & 3.88 & 27 \\
\hline
\end{tabular}

a At times during June 1948 . 
2510. Big Dip Creek near Stoveplpe Wells, Calif.

Location.--Lat $36^{\circ} 55^{\prime} 05^{\prime \prime}$, long $117^{\circ} 17^{\prime} 35^{\prime \prime}$, in sec.16, T.12 S., R.43 E., in

Death Valley, on Scotty's Castle Road, 21 miles northwest of Stovepipe Wells.

Drainage area. $--0.95 \mathrm{sq} \mathrm{mi}$.

Gage.--Nonrecording. Altitude of gage is $1,640 \mathrm{ft}$ (from topographic map).

Stage-discharge relation.--Defined by indirect measurement.

Remarks.--On1y annual peaks are shown.

Peak stages and discharges

\begin{tabular}{l|c|c|c||c|c|c|c}
\hline $\begin{array}{l}\text { Water } \\
\text { year }\end{array}$ & Date & $\begin{array}{c}\text { Gage } \\
\text { helght } \\
\text { (feet) }\end{array}$ & $\begin{array}{c}\text { Discharge } \\
\text { (cfs) }\end{array}$ & $\begin{array}{c}\text { Water } \\
\text { year }\end{array}$ & $\begin{array}{c}\text { Gage Date } \\
\text { height } \\
\text { (feet) }\end{array}$ & $\begin{array}{c}\text { Discharge } \\
\text { (cfs) }\end{array}$ \\
\hline 1959 & Nov. I1, 1958 & 11.39 & 15 & 1962 & Feb. 19, 1962 & 10.41 & 11.62 \\
1960 & Sept. 3, 1960 & 12.55 & 32 & 1963 & Aug. 7, 1963 & 18 \\
1961 & Aug. 22, 1961 & 13.58 & 46 & & \\
\hline
\end{tabular}

2512. Spring Creek at Furnace Creek Inn, Calif.

Location.--Lat $36^{\circ} 26140^{\prime \prime}$, long $116^{\circ} 50^{\prime} 15^{\prime \prime}$, in $\mathrm{S} \frac{1}{2} \sec .23$, T.27 N., R.1 E., at

culvert on State Highway $190,0.8$ mlle southeast of Furnace Creek Inn.

Drainage area. $--0.21 \mathrm{sq} \mathrm{ml}$.

Gage.--Nonrecording. Altitude of gage is $200 \mathrm{ft}$ (from topographic map).

Stage-discharge relation.--Defined by indirect measurements below $10 \mathrm{cfs}$. Subject to changes, owing to unstable channel conditions.

Remarks.--Only annual peaks are shown.

Peak stages and discharges

\begin{tabular}{|c|c|c|c|c|c|c|c|}
\hline $\begin{array}{l}\text { Water } \\
\text { year }\end{array}$ & Date & $\begin{array}{c}\text { Gage } \\
\text { helght } \\
\text { (feet) }\end{array}$ & $\begin{array}{c}\text { D1scharge } \\
(\mathrm{cfs})\end{array}$ & $\begin{array}{l}\text { Water } \\
\text { year }\end{array}$ & Date & $\begin{array}{c}\text { Gage } \\
\text { helght } \\
\text { (feet) }\end{array}$ & $\begin{array}{l}\text { Discharge } \\
\text { (cfs) }\end{array}$ \\
\hline $\begin{array}{l}1959 \\
1960\end{array}$ & Sept.12, 1959 & 10.30 & $\begin{array}{l}0.5 \\
0\end{array}$ & $\begin{array}{l}1962 \\
1963\end{array}$ & $\begin{array}{l}\text { Sept.26, } 1962 \\
\text { Sept.18, } 1963\end{array}$ & $\begin{array}{l}10.35 \\
13.93\end{array}$ & $\begin{array}{l}0.9 \\
14\end{array}$ \\
\hline 1961 & Nov. $\quad 6,1960$ & 11.21 & 5.5 & & & & \\
\hline
\end{tabular}

2514. Ibex Creek near Tecopa, Calif'.

Location.--Lat $35^{\circ} 47^{\prime} 15^{\prime \prime}$, long $116^{\circ} 20^{100}$ ", in sec.33, T.20 N., R.6 E., at culvert on State Highway 127, 7.5 miles southwest of Tecopa.

Drainage area, $--0.20 \mathrm{sq} \mathrm{mi}$.

Gage.--Nonrecording. Altitude of gage is $1,720 \mathrm{ft}$ (from topographic map).

Stage-discharge relation.--Tentative definition by indirect mes surements below $45 \mathrm{cfs}$.

Remarks.--Only annual peaks are shown.

\begin{tabular}{|c|c|c|c|c|c|c|c|}
\hline $\begin{array}{l}\text { Water } \\
\text { year }\end{array}$ & Date & $\begin{array}{c}\text { Gage } \\
\text { helght } \\
\text { (feet) }\end{array}$ & $\begin{array}{c}\text { Discharge } \\
\text { (cfs) }\end{array}$ & $\begin{array}{l}\text { Water } \\
\text { year }\end{array}$ & Date & $\begin{array}{c}\text { Gage } \\
\text { height } \\
\text { (feet) }\end{array}$ & $\begin{array}{c}\text { Discharge } \\
\text { (cfs) }\end{array}$ \\
\hline $\begin{array}{l}1959 \\
1960\end{array}$ & $\begin{array}{l}\text { Sept.13, } 1959 \\
\text { Nov. } 1,1959\end{array}$ & 10.21 & $\begin{array}{r}\mathrm{a} 0.1 \\
3.8\end{array}$ & $\begin{array}{l}1962 \\
1963\end{array}$ & $\begin{array}{ll}\text { Sept.26, } 1962 \\
\text { Feb. 10, } 1963\end{array}$ & 12.20 & $\begin{array}{l}45 \\
8.0\end{array}$ \\
\hline 1961 & - & - & 0 & & & & \\
\hline
\end{tabular}

\footnotetext{
a Greater peak discharge may have occurred during period Oct. 1, 1958, to Jan. 15, 1959.
} 
2515. Yucca Creek near Yucca Grove, Calif.

Location.--Lat $35^{\circ} 24^{\prime} 30^{\prime \prime}$, Iong $115^{\circ} 46^{\prime} 20^{\prime \prime}$, in SE $\frac{1}{4}$ sec.2, T.15 N., R.II E., at culvert on U.S. Highway 91 and $466,2.5$ miles northeast of Yucca Grove.

Drainage area. $-0.034 \mathrm{sq} \mathrm{mi}$.

Gage.--Nonrecording. Prior to May 1I, 1961, at different datum. Altitude of gage is $3,990 \mathrm{ft}$ (from topographic map).

Stage-discharge relation.--Tentative definition by current-meter and indirect measurements, at old site. Defined by indirect measurements at $7.1 \mathrm{cfs}$ at present site.

Remarks.,--Only annual peaks are shown.

Peak stages and discharges

\begin{tabular}{|c|c|c|c|c|c|c|c|}
\hline $\begin{array}{l}\text { Water } \\
\text { year }\end{array}$ & Date & $\begin{array}{c}\text { Gage } \\
\text { he1ght } \\
\text { (feet) }\end{array}$ & $\begin{array}{c}\text { D1scharge } \\
\text { (cfs) }\end{array}$ & $\begin{array}{l}\text { Water } \\
\text { year }\end{array}$ & Date & $\begin{array}{c}\text { Gage } \\
\text { he1ght } \\
\text { (feet) }\end{array}$ & $\begin{array}{c}\text { D'scharge } \\
\text { (cfs) }\end{array}$ \\
\hline $\begin{array}{l}1959 \\
1960\end{array}$ & $\begin{array}{lll}\text { Aug. } & 7,1959 \\
\text { Sept. } 9, & 1960\end{array}$ & $\begin{array}{l}10.66 \\
10.35\end{array}$ & $\begin{array}{r}24.6 \\
2.8\end{array}$ & $\begin{array}{l}1962 \\
1963\end{array}$ & $\begin{array}{ll}\text { Mar. 6, } & 1962 \\
\text { Sept.18, } & 1963\end{array}$ & $\begin{array}{l}1.29 \\
1.80\end{array}$ & $\begin{array}{l}0.2 \\
7.1\end{array}$ \\
\hline 1961 & Sept.12, 1961 & 1.53 & .3 & & & & \\
\hline
\end{tabular}

2516. Salsberry Creek near Shoshone, Calif.

Location.--Lat $35^{\circ} 55^{\prime} 10^{\prime \prime}$, long $116^{\circ} 26^{\prime} 05^{\prime \prime}$, in sec.15, T.21 N., R.5 E., at culvert on Shoshone-Death Valley Road 10 miles southwest of Shoshone.

Drainage area. $--0.008 \mathrm{sq} \mathrm{mi}$.

Gage.--Nonrecording. Altitude of gage is 3,150 ft (from topographic maf). Stage-discharge relation.--Partly defined by indirect measurement below 2 cfs. Remarks.--Only annual peaks are shown.

Peak stages and discharges

\begin{tabular}{|c|c|c|c|c|c|c|c|}
\hline $\begin{array}{l}\text { Water } \\
\text { year }\end{array}$ & Date & $\begin{array}{c}\text { Gage } \\
\text { height } \\
\text { (feet) }\end{array}$ & $\begin{array}{l}\text { D1scharge } \\
(\mathrm{cfs})\end{array}$ & $\begin{array}{l}\text { Water } \\
\text { year }\end{array}$ & Date & $\begin{array}{c}\text { Cage } \\
\text { helght } \\
\text { (feet) }\end{array}$ & $\begin{array}{c}\text { Ifscharge } \\
\text { (efs) }\end{array}$ \\
\hline $\begin{array}{l}1959 \\
1960\end{array}$ & Sept. $\overline{2}, 1960$ & 10.82 & 2.2 & $\begin{array}{l}1962 \\
1963\end{array}$ & $\begin{array}{l}\text { Sept.26, } 1962 \\
\text { Sept.19, } 1963\end{array}$ & $\begin{array}{l}10.20 \\
10.80\end{array}$ & $\begin{array}{l}0.2 \\
2.2\end{array}$ \\
\hline 1961 & Sept.16, 1961 & 10.10 & .1 & & & & \\
\hline
\end{tabular}

\section{BRISTOL LAKE BASIN}

2527. Creosote Creek near Cadiz, Calif.

Location.--Lat $34^{\circ} 34^{\prime} 15^{\prime \prime}$, long $115^{\circ} 28^{\prime} 55^{\prime \prime}$, in $\mathrm{NE} \frac{1}{4}$ sec. 35 , T.6 N., R.14 E., at culvert on U.S. Highway 66,4 miles northeast of Cadiz.

Drainage area. $-0.023 \mathrm{sq} \mathrm{mi}$.

Gage.--Nonrecording. Altitude of gage is $1,280 \mathrm{ft}$ (from topographic mar). Stage-discharge relation.--Defined by indirect measurement.

Remarks.--only annual peaks are shown.

Peak stages and discharges

\begin{tabular}{l|c|c|c||c|c|c|c}
\hline $\begin{array}{l}\text { Water } \\
\text { year }\end{array}$ & \multicolumn{2}{|c|}{ Date } & $\begin{array}{c}\text { Gage } \\
\text { he1ght } \\
\text { (feet) }\end{array}$ & $\begin{array}{c}\text { D1scharge } \\
\text { (cfs) }\end{array}$ & $\begin{array}{c}\text { Water } \\
\text { year }\end{array}$ & $\begin{array}{c}\text { dage } \\
\text { he1ght } \\
\text { (feet) }\end{array}$ & $\begin{array}{c}\text { D1scharge } \\
\text { (cfs) }\end{array}$ \\
\hline 1959 & Aug. 17, 1959 & 10.99 & 9.2 & 1962 & Sept.18, 1963 & 10.70 & 0 \\
1960 & Mar. 2,1960 & 11.10 & 12 & 1963 & 5.3 & & \\
1961 & Nov. 5, 1960 & 5.33 & 5.5 & \\
\hline
\end{tabular}


2530. Gourd Creek near Ludlow, Callf.

Location.--Lat $34^{\circ} 40135^{\prime \prime}$, long $116^{\circ} 01120^{\prime \prime}$, in SW $\frac{1}{4}$ sec.23, T.7 N., R.9 E., at culvert on U.S. Highway $66,8.5$ miles southeast of Ludlow.

Drainage area. $--0.30 \mathrm{sq} \mathrm{mi}$.

Gage.--Nonrecording. Altitude of gage is $1,710 \mathrm{ft}$ (from topographic map).

Stage-discharge relation.--Partiy defined by indirect measurements at 65 and $106 \mathrm{c}$ 's.

Remarks.--Only annual peaks are shown.

Peak stages and discharges

\begin{tabular}{|c|c|c|c|c|c|c|c|}
\hline $\begin{array}{l}\text { Water } \\
\text { year }\end{array}$ & Date & $\begin{array}{l}\text { Gage } \\
\text { helght } \\
\text { (feet) }\end{array}$ & $\begin{array}{c}\text { D1scharge } \\
\text { (cfs) }\end{array}$ & $\begin{array}{l}\text { Water } \\
\text { year }\end{array}$ & Date & $\begin{array}{c}\text { Gage } \\
\text { height } \\
\text { (feet) }\end{array}$ & $\begin{array}{c}\text { Discharge } \\
(\mathrm{cfs})\end{array}$ \\
\hline $\begin{array}{l}1959 \\
1960\end{array}$ & Nov. $\overline{1}, 1959$ & 13.78 & $\begin{array}{l}20 \\
65\end{array}$ & $\begin{array}{l}1962 \\
1963\end{array}$ & Sept.1 $\overline{8}, 1963$ & 13.01 & $\begin{array}{r}0 \\
49\end{array}$ \\
\hline 1961 & Sept. 12, 1961 & 16.19 & 106 & & & & \\
\hline
\end{tabular}

a Flow may have occurred during period oct. 1,1958 , to Jan, 13, 1959.

\section{SALTON SEA BASIN}

2557. San Fellpe Creek near Jullan, Calif.

Location.--Lat $33^{\circ} 07^{\prime} 07^{\prime \prime}$, long $116^{\circ} 26^{\prime} 04^{\prime \prime}$, in Anza Borrego State Park, on left bank at bridge on State Highway 78, in Sentenac Canyon 1.0 mile upstream from Grapevine Canyon and 10 miles northeast of Julian, San Diego County.

Drainage area. $--89.3 \mathrm{sq} \mathrm{mi}$.

Gage.--Recording and concrete low-water control. Datum of gag? is 1,872.69 ft above mean sea level (datum of 1929).

Stage-discharge relation.--Defined by current-meter measurements below $12 \mathrm{cfs}$. Bankfull stage.--Not subject to overflow.

Remarks.--Only annual peaks are shown.

\begin{tabular}{l|c|c|c||c|c|c|c}
\hline $\begin{array}{c}\text { Water } \\
\text { year }\end{array}$ & Date & $\begin{array}{c}\text { Gage } \\
\text { ne1ght } \\
\text { (feet) }\end{array}$ & $\begin{array}{c}\text { Discharge } \\
\text { (cfs) }\end{array}$ & $\begin{array}{c}\text { Water } \\
\text { year }\end{array}$ & Date & $\begin{array}{c}\text { Gage } \\
\text { he1ght } \\
\text { (feet) }\end{array}$ & $\begin{array}{c}\text { D1scharge } \\
\text { (cfs) }\end{array}$ \\
\hline 1959 & feb. 16, 1959 & 1.68 & 7.1 & 1962 & Jan. 24, 1962 & 1.62 & 5.5 \\
1960 & Dec. 24, 1959 & 1.66 & 6.2 & 1963 & Mar. 17, 1963 & 1.63 & 5.8 \\
1961 & Sept.13,1961 & 1.85 & 16 & & \\
\hline
\end{tabular}

2558. Coyote Creek near Borrego Springs, Calif.

Location.--Lat $33^{\circ} 22^{\prime} 30^{\prime \prime}$, long $116^{\circ} 25^{\prime} 25^{\prime \prime}$, in $\mathrm{SE} \frac{1}{4} \sec .23$, T.9 S., R. 5 E., on right bank $500 \mathrm{ft}$ upstream from Box Canyon and 9 miles nortrwest of Borrego Springs.

Drainage area.--144 sq mi. Mean altitude, 3,700 ft.

Gage.--Recording. Altitude of gage is 1,250 ft (from topograpric map).

Stage-discharge relation.--Defined by current-meter measurements below $4 \mathrm{cfs}$ and by slope-area measurements at $3,800 \mathrm{cfs}$.

Remarks.--Base for partial-duration series, $50 \mathrm{cfs}$. 
Peak stages and discharges of Coyote Creek near Borrego Springs, Calif.

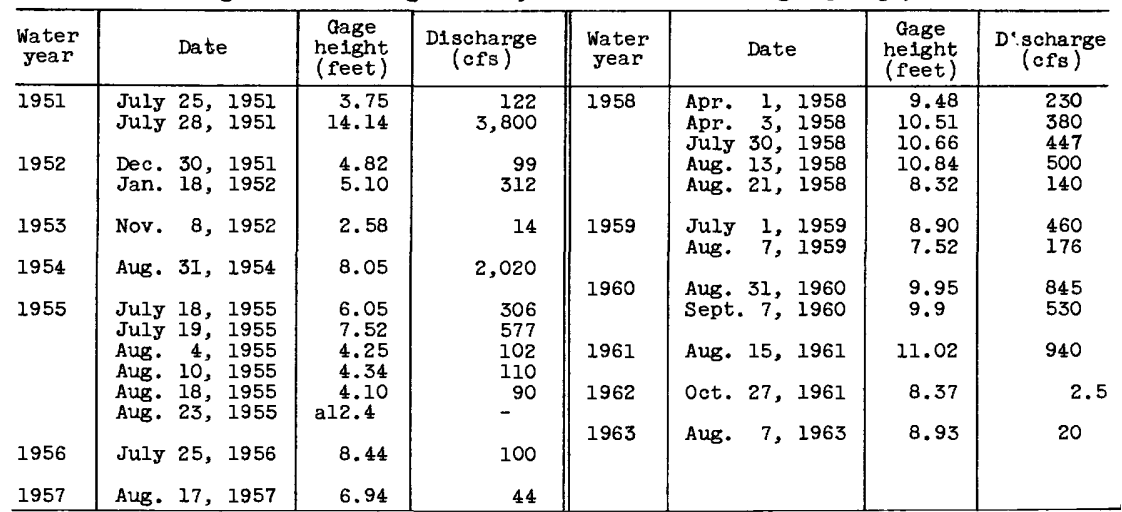

a Backwater from debris cone at mouth of Box Canyon 500 ft downstream.

2558.1. Borrego Palm Creek near Borrego Springs, Calif.

(Published as "Palm Canyon Creek" prior to 1961)

Location.--Lat $33^{\circ} 16^{\prime} 44^{\prime \prime}$, Iong $116^{\circ} 25^{\prime} 45^{\prime \prime}$, In Anza-Borrego State Park on left bank 3.3 miles northwest of Borrego Springs, San Diego County.

Drainage area,$--21.7 \mathrm{sq} \mathrm{m} 1$. Mean alt1tude, $4,480 \mathrm{ft}$.

Gage.--Recording. Altitude of gage is 1,200 ft (from topographic map).

Stage-discharge relation.--Defined by current-meter and slope-area measurements below $500 \mathrm{cfs}$ and by velocity-area study at $2,000 \mathrm{cfs}$.

Remarks.--Base for partial-duration series, 15 cfs.

Peak stages and discharges

\begin{tabular}{|c|c|c|c|c|c|c|c|}
\hline $\begin{array}{l}\text { Water } \\
\text { year }\end{array}$ & Date & $\begin{array}{c}\text { Gage } \\
\text { helght } \\
\text { (feet) }\end{array}$ & $\begin{array}{l}\text { Discharge } \\
\text { (cfs) }\end{array}$ & $\begin{array}{l}\text { Water } \\
\text { year }\end{array}$ & Date & $\begin{array}{c}\text { Gage } \\
\text { height } \\
\text { (feet) }\end{array}$ & $\begin{array}{c}\text { D scharge } \\
\text { (cfs) }\end{array}$ \\
\hline $\begin{array}{l}1951 \\
1952\end{array}$ & $\begin{array}{l}\text { July 28, } 1951 \\
\text { Dec. 30, } 1951 \\
\text { Jan. 18, } 1952 \\
\text { Mar. 11, } 1952\end{array}$ & $\begin{array}{l}2.60 \\
2.51 \\
2.68 \\
2.01\end{array}$ & $\begin{array}{l}45 \\
40 \\
50 \\
18\end{array}$ & 1958 & $\begin{array}{l}\text { Mar. 16, } 1958 \\
\text { Mar. 22, } 1958 \\
\text { Apr. 3, } 1958 \\
\text { Apr. } 7,1958\end{array}$ & $\begin{array}{l}2.90 \\
3.17 \\
3.53 \\
2.89\end{array}$ & $\begin{array}{r}66 \\
88 \\
123 \\
57\end{array}$ \\
\hline 1953 & Dec. 17,1952 & 1.81 & 14 & $\begin{array}{l}1959 \\
1960\end{array}$ & $\begin{array}{l}\text { July } 23,1959 \\
\text { Feb. } 10,1960\end{array}$ & $\begin{array}{l}4.44 \\
1.97\end{array}$ & 5.1 \\
\hline 1954 & Mar. 22, 1954 & 1.91 & 15 & 1961 & Jan. 27, 1961 & 1.62 & \\
\hline 1955 & $\begin{array}{l}\text { Aug. } 4,1955 \\
\text { Aug. 23, } 1955\end{array}$ & $\begin{array}{l}3.1 \\
9.9\end{array}$ & 2,000 & 1962 & Feb. 20, 1962 & 1.86 & 1.9 \\
\hline 1956 & Feb. 1,1956 & 2.12 & 8.0 & 1963 & Feb. 10, 1963 & 2.10 & 3.5 \\
\hline 1957 & Jan. 7,1957 & 1.85 & 3.4 & & & & \\
\hline
\end{tabular}


2560. Whitewater River at White Water, Calif.

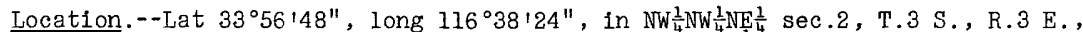
on right bank 1.5 miles north of White Water and $3 \frac{1}{2}$ miles upstream from San Gorgonio River.

Drainage area. $--57.4 \mathrm{sq} \mathrm{mi}$. Mean altitude, 5,530 ft.

Gage.--Recording, except nonrecording Feb. 24, 1950, to Sept. 30, 1952. Datum of gage is $1,610.98 \mathrm{ft}$ above mean sea level, adjustment of 1934 .

Stage-discharge relation.--Defined by current-meter measurements below 680 cfs and extended above by logarithmic plotting.

Historical data.--Maximum flood known occurred Mar. 2, 1938; 42,000 cfs, from slope-area measurement at site 2.5 miles upstream.

Remarks.--Water is diverted out of the basin about 15 miles upstream to powerplants in San Gorgonio River basin and thence to an area north of Banning for irrigation. Base for partial-duration series, $100 \mathrm{cfs}$.

Peak stages and discharges

\begin{tabular}{|c|c|c|c|c|c|c|c|}
\hline $\begin{array}{l}\text { Water } \\
\text { year }\end{array}$ & Date & $\begin{array}{l}\text { Gage } \\
\text { height } \\
\text { (feet) }\end{array}$ & $\begin{array}{c}\text { Discharge } \\
\text { (cfs) }\end{array}$ & $\begin{array}{l}\text { Water } \\
\text { year }\end{array}$ & Date & $\begin{array}{c}\text { Gage } \\
\text { height } \\
\text { (feet) }\end{array}$ & $\begin{array}{l}\text { D1scharge } \\
(\mathrm{cfs})\end{array}$ \\
\hline 1949 & $\begin{array}{ll}\text { Oct. } 18, & 1948 \\
\text { Jan. } 20, & 1949\end{array}$ & - & $\left(\begin{array}{l}a \\
a\end{array}\right)$ & 1957 & $\begin{array}{ll}\text { Jan. } 13, & 1957 \\
\text { Feb. } 23, & 1957\end{array}$ & $\begin{array}{l}8.68 \\
7.20\end{array}$ & $\begin{array}{r}\mathrm{b} 750 \\
134\end{array}$ \\
\hline 1950 & $\begin{array}{l}\text { Nov. } 10,1949 \\
\text { Sept. } 6,1950\end{array}$ & $\begin{array}{l}7.4 \\
8.08\end{array}$ & $\begin{array}{l}225 \\
450\end{array}$ & 1958 & $\begin{array}{l}\text { Dec. } 15,1957 \\
\text { Jan. } 26,1958 \\
\text { Feb. }\end{array}$ & $\begin{array}{r}8.00 \\
8.25 \\
10.55\end{array}$ & $\begin{array}{l}343 \\
304 \\
250\end{array}$ \\
\hline 1951 & Jan. 29, 1951 & 6.93 & 102 & & $\begin{array}{l}\text { Mar. } 16,1958 \\
\text { Apr. } 1,1958\end{array}$ & $\begin{array}{l}9.95 \\
8.22\end{array}$ & $\begin{array}{l}646 \\
607\end{array}$ \\
\hline 1952 & $\begin{array}{l}\text { Dec. } 5,1951 \\
\text { Dec. } 30,1951 \\
\text { Jan. } 16,1952 \\
\text { Jan. } 18,1952\end{array}$ & $\begin{array}{l}7.72 \\
7.42 \\
7.12 \\
7.24\end{array}$ & $\begin{array}{l}265 \\
149 \\
219 \\
180\end{array}$ & & $\begin{array}{ll}\text { Apr. } 3, & 1958 \\
\text { Apr. } 22, & 1958 \\
\text { July } 29, & 1958 \\
\text { Sept. } 7, & 1958\end{array}$ & $\begin{array}{l}8.35 \\
8.20 \\
7.08 \\
6.45\end{array}$ & $\begin{array}{r}b 1,500 \\
299 \\
140 \\
132\end{array}$ \\
\hline 1953 & Apr. 28, 1953 & 6.52 & 98 & 1959 & $\begin{array}{ll}\text { Feb. } 11, & 1959 \\
\text { Feb. } 16, & 1959\end{array}$ & $\begin{array}{l}6.60 \\
7.20\end{array}$ & $\begin{array}{r}132 \\
1,300\end{array}$ \\
\hline 1954 & $\begin{array}{l}\text { Jan. } 19,1954 \\
\text { Jan. } 25,1954 \\
\text { Feb. } 13,1954 \\
\text { Mar. } 22,1954 \\
\text { June } 25,1954\end{array}$ & $\begin{array}{l}6.47 \\
7.40 \\
7.14 \\
7.13 \\
7.52\end{array}$ & $\begin{array}{l}137 \\
592 \\
421 \\
415 \\
686\end{array}$ & 1960 & $\begin{array}{l}\text { Aug. 2, } 1959 \\
\text { Sept.13, } 1959 \\
\text { Dec. 25, } 1959 \\
\text { Feb. 2, } 1960\end{array}$ & $\begin{array}{l}6.13 \\
6.02 \\
5.84 \\
6.79\end{array}$ & $\begin{array}{l}101 \\
170 \\
104 \\
140\end{array}$ \\
\hline 1955 & $\begin{array}{ll}\text { Nov. } 11, & 1954 \\
\text { Dec. } 10, & 1954 \\
\text { Jan. } 2, & 1955\end{array}$ & $\begin{array}{l}6.73 \\
6.76 \\
6.61\end{array}$ & $\begin{array}{l}157 \\
148 \\
129\end{array}$ & $\begin{array}{l}1961 \\
1962\end{array}$ & $\begin{array}{ll}\text { Jan. } 26, & 1961 \\
\text { Dec. } & 2,1961\end{array}$ & $\begin{array}{l}5.34 \\
7.04\end{array}$ & $\begin{array}{r}62 \\
185\end{array}$ \\
\hline 1956 & Jan. 27, 1956 & 6.86 & 578 & 1963 & $\begin{array}{l}\text { Feb. } 10,1963 \\
\text { Sept.18, } 1963\end{array}$ & $\begin{array}{l}6.83 \\
7.80\end{array}$ & $\begin{array}{l}109 \\
660\end{array}$ \\
\hline 1957 & Jan. 7,1957 & 7.10 & 397 & & & & \\
\hline
\end{tabular}

a Momentary maximum may have exceeded base; dally discharge estimated on basis of diversion records.

b Approximate.

2580. Tahquitz Creek near Palm Springs, Calif'.

Location. --Lat $33^{\circ} 48^{1} 18^{\prime \prime}$, long $116^{\circ} 33^{1} 30^{\prime \prime}$, in NE $\frac{1}{4} \mathrm{SW} \frac{1}{4} \mathrm{SW} \frac{1}{4} \sec .22$, T.4 S., R.4 E., on left bank 2.2 miles southwest of Palm Springs and 7 miles upstream from mouth.

Drainage area. $--16.7 \mathrm{sq} \mathrm{mi}$. Mean altitude, 6,920 ft.

Gage.--Recording. Datum of gage is $764.5 \mathrm{ft}$ above mean sea lerel (levels by Riverside County Flood Control and Water Conservation Distr:ct).

Stage-discharge relation.--Defined by current-meter measurements below $60 \mathrm{cfs}$ and by slope-area measurements at $1,570 \mathrm{cfs}$.

Remarks.--Base for partial-duration series, $20 \mathrm{cfs}$. 
Peak stages and discharges of Tahquitz Creek near Palm Springis, Calif.

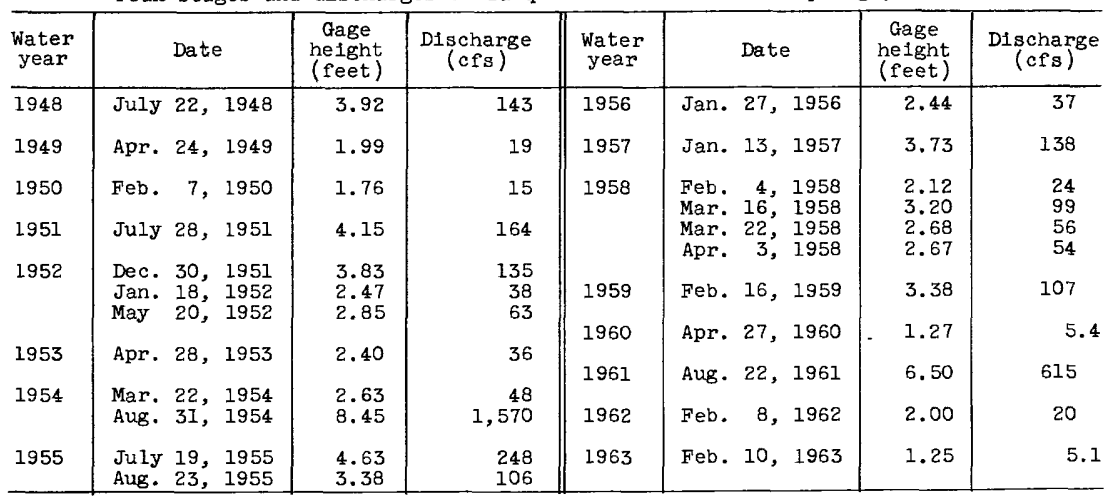

2585. Palm Canyon Creek near Palm Springs, Calff.

Location.--Lat $33^{\circ} 44^{\prime} 55^{\prime \prime}$, long $116^{\circ} 32^{\prime} 15^{\prime \prime}$, in S $\frac{1}{2} \sec .11$, T.5 S., R.4 E., on right bank three-quarters of a mile upstream from Murray Canyon Cree's and 6 miles south of Palm Springs.

Drainage area. $--94.0 \mathrm{sq} \mathrm{mi}$. Mean altitude, 3,950 ft.

Gage.--Recording. Prior to Jan. 14, 1942, at datum $0.2 \mathrm{ft}$ higher. Alt1tude of gage is $700 \mathrm{ft}$ (from topographlc map).

Stage-discharge relation.--Defined by current-meter measurements below $120 \mathrm{cfs}$ and extended to $3,850 \mathrm{cfs}$ on basis of veloclty-area study.

Remarks. --Base for partial-duration series, $100 \mathrm{cfs}$.

Peak stages and discharges

\begin{tabular}{|c|c|c|c|c|c|c|c|}
\hline $\begin{array}{l}\text { Water } \\
\text { year }\end{array}$ & Date & $\begin{array}{l}\text { Gage } \\
\text { height } \\
\text { (feet) }\end{array}$ & $\begin{array}{c}\text { Discharge } \\
\text { (cfs) }\end{array}$ & $\begin{array}{c}\text { Water } \\
\text { year }\end{array}$ & Date & $\begin{array}{c}\text { Gage } \\
\text { helght } \\
\text { (feet) }\end{array}$ & $\begin{array}{c}\text { Discharge } \\
\text { (cfs) }\end{array}$ \\
\hline 1933 & $\begin{array}{l}\text { Feb. 14, } 1931 \\
\text { oct. 1, } 1931 \\
\text { Dec. 9, } 1931 \\
\text { Dec. 28, } 1931 \\
\text { Feb. } 2,1932 \\
\text { Feb. 9, } 1932 \\
\text { Feb. 18, } 1932 \\
\text { Oct. 9, } 1932\end{array}$ & $\begin{array}{l}1.09 \\
3.34 \\
1.83 \\
3.02 \\
1.73 \\
3.42 \\
1.87 \\
2.17\end{array}$ & $\begin{array}{r}31 \\
1,780 \\
338 \\
1,380 \\
282 \\
1,870 \\
362 \\
514\end{array}$ & 1941 & $\begin{array}{l}\text { Dec. } 24,1940 \\
\text { Jan. } 28,1941 \\
\text { Feb. 12, } 1941 \\
\text { Feb. 14, } 1941 \\
\text { Feb. 22, } 1941 \\
\text { Mar. 1, } 1941 \\
\text { Mar. 4, } 1941 \\
\text { Mar. 14, } 1941 \\
\text { Apr. 2, } 1941 \\
\text { Apr. 11, } 1941\end{array}$ & $\begin{array}{l}4.85 \\
2.10 \\
1.88 \\
1.47 \\
2.15 \\
2.55 \\
2.28 \\
1.95 \\
1.72 \\
1.59 \\
\end{array}$ & $\begin{array}{r}2,900 \\
402 \\
235 \\
110 \\
380 \\
623 \\
454 \\
298 \\
188 \\
140\end{array}$ \\
\hline 1934 & 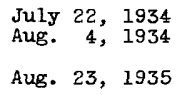 & $\begin{array}{l}2.30 \\
5.20 \\
-\end{array}$ & $\begin{array}{r}650 \\
a 700 \\
2300\end{array}$ & $\begin{array}{l}1948 \\
1949\end{array}$ & $\begin{array}{l}\text { July } 23,1948 \\
\text { Jan. } 21 \text { or } 23 \text {, } \\
1949\end{array}$ & $\begin{array}{l}2.81 \\
2.59\end{array}$ & $\begin{array}{r}150 \\
16\end{array}$ \\
\hline 1936 & $\begin{array}{l}\text { Feb. 15, } 1936 \\
\text { Feb. 1s, } 1936 \\
\text { Apr. 4, } 1936 \\
\text { July 26, } 1936\end{array}$ & $\begin{array}{l}3.25 \\
3.12 \\
2.72 \\
3.25\end{array}$ & $\begin{array}{r}2350 \\
250 \\
150 \\
300\end{array}$ & $\begin{array}{l}1950 \\
1951 \\
1952\end{array}$ & $\begin{array}{l}\text { Jan. 29, } 1950 \\
\text { July 28, } 1951\end{array}$ & $\begin{array}{l}2.17 \\
4.88 \\
4.60\end{array}$ & $\begin{array}{r}16 \\
850\end{array}$ \\
\hline 1.937 & $\begin{array}{l}\text { Dec. } 28,1936 \\
\text { Feb. 6, } 1937 \\
\text { Mar. 13, } 1937 \\
\text { Mar. 16, } 1937\end{array}$ & $\begin{array}{l}3.25 \\
5.60 \\
2.12 \\
2.22\end{array}$ & $\begin{array}{r}1,110 \\
3,850 \\
258 \\
295\end{array}$ & 1956 & $\begin{array}{l}\text { Jan. 18, } 1952 \\
\text { Mar. 11, } 1952 \\
\text { Mar. 16, } 1952 \\
\text { July } 30,1952\end{array}$ & $\begin{array}{l}4.60 \\
5.10 \\
3.22 \\
3.24 \\
3.02\end{array}$ & $\begin{array}{r}1,010 \\
282 \\
288 \\
222\end{array}$ \\
\hline 1938 & $\begin{array}{lr}\text { Mar. 2, } 1938 \\
\text { Mar. 12, } 1938\end{array}$ & $\begin{array}{l}4.43 \\
1.83\end{array}$ & $\begin{array}{r}2,380 \\
258\end{array}$ & 1953 & Dec. 17, 1952 & 3.25 & 272 \\
\hline 1939 & $\begin{array}{ll}\text { Jan. 9, } & 1939 \\
\text { Sept.24, } & 1939\end{array}$ & $\begin{array}{l}1.50 \\
2.00\end{array}$ & $\begin{array}{l}138 \\
223\end{array}$ & 1954 & $\begin{array}{l}\text { Feb. 14, } 1954 \\
\text { Mar. 22, } 1954 \\
\text { Mar. 25, } 1954\end{array}$ & $\begin{array}{l}2.62 \\
3.44 \\
2.67\end{array}$ & $\begin{array}{l}114 \\
358 \\
124\end{array}$ \\
\hline 1940 & $\begin{array}{l}\text { Jan. } 8,1940 \\
\text { Feb. } 3,1940 \\
\text { Dec. } 18,1940\end{array}$ & $\begin{array}{l}2.40 \\
1.48 \\
1.38\end{array}$ & $\begin{array}{l}358 \\
133 \\
131\end{array}$ & 1955 & $\begin{array}{ll}\text { July } 18, & 1955 \\
\text { Aug. } 10, & 1955 \\
\text { Aug. } 15, & 1955\end{array}$ & $\begin{array}{l}3.60 \\
3.25 \\
2.93\end{array}$ & $\begin{array}{l}263 \\
17 \mathrm{~s} \\
110\end{array}$ \\
\hline
\end{tabular}

785-975 O-66-11 
Peak stages and discharges of Palm Canyon Creek near Palm Springs, Calif.--Continued

\begin{tabular}{|c|c|c|c|c|c|c|c|}
\hline $\begin{array}{l}\text { Water } \\
\text { year }\end{array}$ & Date & $\begin{array}{c}\text { Gage } \\
\text { helght } \\
\text { (feet) }\end{array}$ & $\begin{array}{c}\text { Discharge } \\
\text { (cfs) }\end{array}$ & $\begin{array}{l}\text { Water } \\
\text { year }\end{array}$ & Date & $\begin{array}{c}\text { Gage } \\
\text { helght } \\
\text { (feet) }\end{array}$ & $\begin{array}{c}\text { Discharge } \\
\text { (cfs) }\end{array}$ \\
\hline 1956 & July 26, 1956 & 1.72 & 0.4 & 1959 & Feb. 16, 1959 & 2.40 & 82 \\
\hline 1957 & Jan. 13, 1957 & 1.92 & 4.2 & 1960 & Sept.10, 1960 & 2.52 & 76 \\
\hline 1958 & $\begin{array}{l}\text { Feb. } 4,1958 \\
\text { Mar. } 16,1958 \\
\text { Mar. } 22,1958 \\
\text { Apr. } 1,1958 \\
\text { Apr. } 3,1958 \\
\text { Aug. } 16,1958\end{array}$ & $\begin{array}{l}3.52 \\
3.93 \\
3.12 \\
4.55 \\
4.90 \\
4.50\end{array}$ & $\begin{array}{r}332 \\
504 \\
216 \\
890 \\
1,130 \\
860 \\
\end{array}$ & $\begin{array}{l}1961 \\
1962 \\
1963\end{array}$ & $\begin{array}{l}\text { Aug. 23, } 1961 \\
\text { Mar. 9, } 1962 \\
\text { Aug. } \quad 7,1963\end{array}$ & $\begin{array}{l}1.98 \\
1.63 \\
2.98\end{array}$ & $\begin{array}{l}\begin{array}{l}25 \\
4.8\end{array} \\
100\end{array}$ \\
\hline
\end{tabular}

2590. Andreas Creek near Palm Springs, Calif.

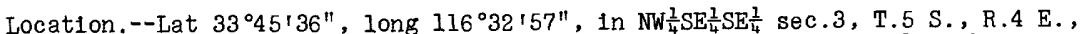
on left bank at Bureau of Indian Affairs diversion dam, 1.1 miles above mouth and 5.1 miles south of Palm Springs.

Drainage area. $--8.78 \mathrm{sq} \mathrm{ml}$. Mean altitude, 4,500 ft.

Gage.--Recording gage and concrete control. Altitude of gage is $800 \mathrm{ft}$ (from topographic map).

Stage-discharge relation.--Defined by current-meter measurements below $80 \mathrm{cfs}$ and by slope-area measurements at 1,960 cfs.

Remarks.--Base for partial-duration series, $30 \mathrm{cfs}$.

Peak stages and discharges

\begin{tabular}{|c|c|c|c|c|c|c|c|}
\hline $\begin{array}{l}\text { Water } \\
\text { year }\end{array}$ & Date & $\begin{array}{c}\text { Gage } \\
\text { helght } \\
\text { (feet) }\end{array}$ & $\begin{array}{l}\text { Discharge } \\
\text { (cfs) }\end{array}$ & $\begin{array}{l}\text { Water } \\
\text { year }\end{array}$ & Date & $\begin{array}{c}\text { Gage } \\
\text { helght } \\
\text { (feet) }\end{array}$ & $\begin{array}{c}\text { Discharge } \\
\text { (cfs) }\end{array}$ \\
\hline 1950 & Feb. 6,1950 & 2.22 & 21 & 1956 & Jan. 27, 1956 & 2.43 & 53 \\
\hline 1951 & $\begin{array}{ll}\text { July } 28, & 1951 \\
\text { Aug. } 30, & 1951\end{array}$ & $\begin{array}{l}2.41 \\
2.40\end{array}$ & $\begin{array}{l}50 \\
47\end{array}$ & 1957 & $\begin{array}{l}\text { Jan. } 7,1957 \\
\text { Jan. } 13,1957\end{array}$ & $\begin{array}{l}2.33 \\
2.55\end{array}$ & $\begin{array}{l}43 \\
64\end{array}$ \\
\hline 1952 & $\begin{array}{l}\text { Dec. } 5,1951 \\
\text { Dec. } 30,1951 \\
\text { Jan. } 16,1952 \\
\text { Jan. } 18,1952\end{array}$ & $\begin{array}{l}2.27 \\
2.44 \\
2.47 \\
2.57\end{array}$ & $\begin{array}{l}30 \\
96 \\
54 \\
31\end{array}$ & $195 \mathrm{~s}$ & 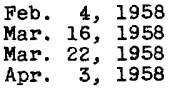 & $\begin{array}{l}2.35 \\
2.67 \\
2.50 \\
2.65\end{array}$ & $\begin{array}{l}48 \\
75 \\
55 \\
68\end{array}$ \\
\hline 1953 & Dec. 17,1952 & 2.23 & 31 & 1959 & Feb. 16,1959 & 2.50 & 57 \\
\hline 1954 & $\begin{array}{l}\text { Jan. } 25,1954 \\
\text { Feb. 13, } 1954 \\
\text { Mar. 22, } 1954 \\
\text { Aug. 31, } 1954\end{array}$ & $\begin{array}{l}2.19 \\
2.36 \\
2.70 \\
7.11\end{array}$ & $\begin{array}{r}32 \\
46 \\
77 \\
1,960\end{array}$ & $\begin{array}{l}1960 \\
1961\end{array}$ & $\begin{array}{l}\text { July } 22,1960 \\
\text { Aug. 23, } 1961\end{array}$ & $\begin{array}{l}2.40 \\
2.12\end{array}$ & $\begin{array}{l}48 \\
28\end{array}$ \\
\hline 1955 & $\begin{array}{ll}\text { July } 19, & 1955 \\
\text { Aug. } 23, & 1955\end{array}$ & $\begin{array}{l}2.55 \\
3.10\end{array}$ & $\begin{array}{r}60 \\
130\end{array}$ & 1962 & Feb. 10,1963 & 2.03 & 21 \\
\hline
\end{tabular}


2605. Deep Creek near Hesperia, Calif

Location.--Lat $34^{\circ} 20^{\prime} 30^{\prime \prime}$, long $117^{\circ} 13^{\prime} 40^{\prime \prime}$, In SE $\frac{1}{4}$ sec. 18 , T. 3 N., R. 3 W. , on right bank 0.5 mile upstream from confluence with West Fork Mojave River and 7 miles southeast of Hesperia.

Drainage area. $--137 \mathrm{sq} \mathrm{ml}$. Mean altitude, 5,760 ft.

Gage.--Recording. Concrete control since 1938. Prior to Sept. 30, 1922, and from December 1929 to Apr. 20, 1938, at different datums. Apr. 21 to Dec. 10, 1938, at site 0.25 mile downstream at different datum. Altitude of gage is $3,050 \mathrm{ft}$ (from topographic map).

Stage-discharge relation.--Defined by current-meter measurements below 4,000 cf's and by slope-area measurement at $46,600 \mathrm{cfs}$.

Historical data.--From investigations made by Corps of Engineers in 1938 and shown in report on Forks flood-control reservolr site, floods occurred in $1859,1862,1867,1884,1886,1889,1891,1903,1905,1907,1910,1914,1916$, 1921, 1922, and 1927, and none of these floods exceeded that of 1938; however, records of flood discharge prior to 1930 are incomplete.

Remarks.--S1ight regulation by Lake Arrowhead (capacity, 48,000 acre-ft). Hesperia Water Co.'s canal diverts water about $2 \frac{1}{2}$ miles above station for irrigation of about 1,500 acres and domestic use below station. Records prior to Sept. 30,1922 , furnished by Califormia Department of Water Resources. Base for partial-duration series, $400 \mathrm{cfs}$.

Peak stages and discharges

\begin{tabular}{|c|c|c|c|c|c|c|c|}
\hline $\begin{array}{l}\text { Water } \\
\text { year }\end{array}$ & Date & $\begin{array}{l}\text { Gage } \\
\text { helght } \\
\text { (feet) }\end{array}$ & $\begin{array}{c}\text { Discharge } \\
(\mathrm{cfs})\end{array}$ & $\begin{array}{l}\text { Water } \\
\text { year }\end{array}$ & Date & $\begin{array}{l}\text { Gage } \\
\text { he1ght } \\
\text { (feet) }\end{array}$ & $\begin{array}{c}\text { Discharge } \\
(\mathrm{cfs})\end{array}$ \\
\hline $\begin{array}{l}1906 \\
1907\end{array}$ & $\begin{array}{l}\text { Mar. } 12,1906 \\
\text { Dec. } 12,1906 \\
\text { Jan. } 9,1907 \\
\text { Mar. } 5,1907\end{array}$ & $\begin{array}{l}- \\
- \\
-\end{array}$ & $\begin{array}{r}10,800 \\
5,190 \\
2,200 \\
6,920\end{array}$ & 1937 & $\begin{array}{ll}\text { Feb. } 6, & 1937 \\
\text { Feb. 14, } 1937 \\
\text { Mar. } 12,1937 \\
\text { Mar. } 16,1937 \\
\text { Apr. } 14,1937 \\
\text { Apr. } 15,1937\end{array}$ & $\begin{array}{l}9.45 \\
9.50 \\
5.62 \\
7.74 \\
4.20 \\
4.22 \\
\end{array}$ & $\begin{array}{r}6,700 \\
6,800 \\
1,710 \\
4,010 \\
740 \\
750 \\
\end{array}$ \\
\hline 1909 & Jan. 22, 1909 & - & 6,290 & 1938 & Mar. 2,1938 & - & $\mathrm{a} 46,600$ \\
\hline 1911 & $\begin{array}{ll}\text { Dec. } & 9,1909 \\
\text { Jan. } & 1,1910 \\
\text { Mar. } & 9,1911\end{array}$ & - & $\begin{array}{r}3,680 \\
37,900 \\
6,250\end{array}$ & 1939 & $\begin{array}{ll}\text { Apr. 2, } & 1939 \\
\text { Sept. 25, } & 1939\end{array}$ & $\begin{array}{l}3.54 \\
4.38\end{array}$ & $\begin{array}{r}916 \\
1,850\end{array}$ \\
\hline 1914 & $\begin{array}{l}\text { Jan. } 25,1914 \\
\text { Feb. } 20,1914\end{array}$ & - & $\begin{array}{l}6,700 \\
9,350\end{array}$ & 1940 & $\begin{array}{l}\text { Jan. } 8,1940 \\
\text { Feb. 26, } 1940 \\
\text { Mar. } 31,1940\end{array}$ & $\begin{array}{l}4.58 \\
4.06 \\
3.00\end{array}$ & $\begin{array}{r}2,610 \\
1,790 \\
600\end{array}$ \\
\hline 1915 & Feb. 10,1915 & - & 7,160 & 1941 & $\begin{array}{l}\text { Dec. } 17,1940 \\
\text { Dec. } 24,1940\end{array}$ & $\begin{array}{l}3.30 \\
5.85\end{array}$ & $\begin{array}{r}880 \\
5,500\end{array}$ \\
\hline 1916 & Jan. 17,1916 & & 23,000 & & $\begin{array}{l}\text { Feb. 11, } 1941 \\
\text { Feb. } 15,1941\end{array}$ & $\begin{array}{l}2.90 \\
3.08\end{array}$ & $\begin{array}{l}520 \\
672\end{array}$ \\
\hline 1918 & & & 11,000 & & Feb. 20, 1941 & $\begin{array}{l}5.50 \\
4.05\end{array}$ & \\
\hline $\begin{array}{l}1920 \\
1921 \\
\end{array}$ & $\begin{array}{l}\text { Feb. 22, } 1920 \\
\text { Mar. 14, } 1921\end{array}$ & - & $\begin{array}{l}4,760 \\
2,200\end{array}$ & & $\begin{array}{l}\text { Mar. } 4,1941 \\
\text { Mar. 14, } 1941 \\
\text { Apr. } 5,1941\end{array}$ & $\begin{array}{l}3.02 \\
4.00 \\
4.43\end{array}$ & $\begin{array}{l}1,220 \\
1,540 \\
2,280\end{array}$ \\
\hline 1930 & Mar. 5,1930 & 3.55 & 340 & 1942 & Apr. 4,1942 & 2.74 & 395 \\
\hline 1931 & $\begin{array}{l}\text { Feb. } 4,1931 \\
\text { Apr. 26, } 1931\end{array}$ & $\begin{array}{l}4.55 \\
5.65\end{array}$ & $\begin{array}{r}900 \\
1,600\end{array}$ & 1943 & $\begin{array}{l}\text { Jan. 23, } 1943 \\
\text { Feb. 22, } 1943 \\
\text { Max. 4, } 1943\end{array}$ & $\begin{array}{r}11.30 \\
5.40 \\
5.40\end{array}$ & $\begin{array}{r}19,000 \\
3,690 \\
3,260\end{array}$ \\
\hline 1932 & $\begin{array}{l}\text { Dec. 28, } 1931 \\
\text { Feb. } 9,1932\end{array}$ & $\begin{array}{r}6.50 \\
11.30\end{array}$ & $\begin{array}{l}2,260 \\
7,900\end{array}$ & 1944 & $\begin{array}{l}\text { Dec. 19, } 1943 \\
\text { Mar. } 11,1944\end{array}$ & $\begin{array}{l}2.77 \\
2.88\end{array}$ & $\begin{array}{l}402 \\
490\end{array}$ \\
\hline $\begin{array}{l}1933 \\
1934\end{array}$ & $\begin{array}{l}\text { Apr. } 4,1933 \\
\text { Dec. 13, } 1933 \\
\text { Dec. 31, } 1933\end{array}$ & $\begin{array}{l}2.52 \\
4.28 \\
6.60\end{array}$ & $\begin{array}{r}812 \\
2,340\end{array}$ & 1945 & $\begin{array}{l}\text { Nov. } 12,1944 \\
\text { Feb. } 2,1945 \\
\text { Mar. } 15,1945\end{array}$ & $\begin{array}{l}5.38 \\
6.80 \\
3.25\end{array}$ & $\begin{array}{r}3,650 \\
6,350 \\
735\end{array}$ \\
\hline 1935 & $\begin{array}{l}\text { Oct. } 18,1934 \\
\text { Dec. } 14,1934 \\
\text { Jan. } 9,1935 \\
\text { Feb. } 6,1935\end{array}$ & $\begin{array}{l}4.40 \\
4.80 \\
4.70 \\
5.30\end{array}$ & $\begin{array}{r}877 \\
I, 130 \\
1,070 \\
I, 510\end{array}$ & 1946 & $\begin{array}{l}\text { Dec. } 23,1945 \\
\text { Mar. } 30,1946 \\
\text { Apr. } 7,1946\end{array}$ & $\begin{array}{l}6.53 \\
6.27 \\
2.93\end{array}$ & $\begin{array}{r}5,800 \\
5,300 \\
480\end{array}$ \\
\hline 1936 & $\begin{array}{l}\text { Apr. } 8,1935 \\
\text { Feb. } 2,1936 \\
\text { Feb. } 12,1936 \\
\text { Feb. 23, } 1936\end{array}$ & $\begin{array}{l}6.60 \\
5.20 \\
6.10 \\
3.94\end{array}$ & $\begin{array}{r}2,760 \\
1,430 \\
2,170 \\
625\end{array}$ & 1947 & $\begin{array}{l}\text { Nov. } 13,1946 \\
\text { Nov. } 20,1946 \\
\text { Nov. } 23,1946 \\
\text { Dec. } 26,1946 \\
\text { Dec. } 27,1946\end{array}$ & $\begin{array}{l}3.54 \\
3.62 \\
4.83 \\
3.37 \\
3.37\end{array}$ & $\begin{array}{r}1,020 \\
1,110 \\
2,740 \\
850 \\
850\end{array}$ \\
\hline 1937 & Dec. 16,1936 & 3.98 & 631 & 1948 & 4,1948 & 3.36 & 840 \\
\hline
\end{tabular}


Peak stages and discharges of Deep Creek near Hesperla, Calif.--Continued

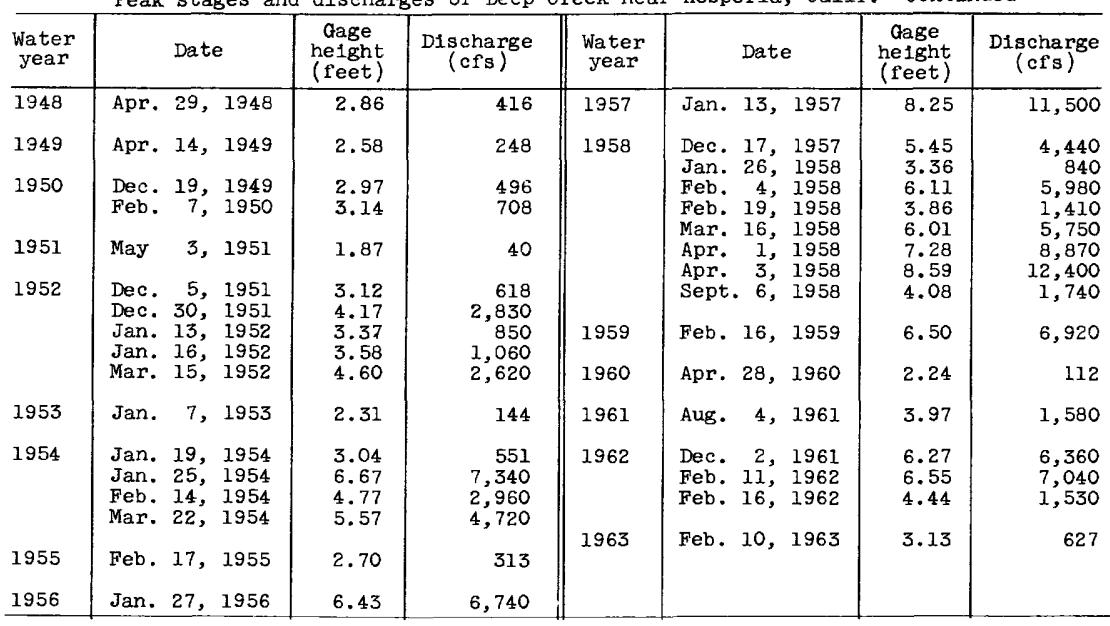

2610. West Fork Mojave River near Hesperia, Calif.

Location.--Lat $34^{\circ} 20127^{\prime \prime}$, Iong $117^{\circ} 14124^{\prime \prime}$, in SW $\frac{1}{4} \mathrm{SW} \frac{1}{4}$ sec.18, T.3 N., R.4 W., on left bank at highway bridge, 0.5 mile upstream from confluence with Deep Creek and 6.5 miles southeast of Hesperia.

Drainage area. $--74.8 \mathrm{sq} \mathrm{mi}$. Mean altitude, 4,080 ft.

Gage.--Recording. Prior to June 30, 1922 , several hundred feet downstream at different datum. Altitude of gage is $3,050 \mathrm{ft}$ (from topographic map).

Stage-discharge relation.--Defined by slope-area measurement at $26,100 \mathrm{cfs}$.

Historical data.--According to Federal and local agencies other moderate to large floods occurred in the years $1859,1862,1867,1884,1886,1889,1891$, 1903, 1905, 1921, 1922, and 1927. On the basis of estimates made by Corps of Engineers, U.S. Army, none of these floods exceeded that of 1938.

Remarks.--Records prior to July 1, 1922, furmished by California Department of Water Resources. Base for partial-duration series, $500 \mathrm{cfs}$.

Peak stages and discharges

\begin{tabular}{|c|c|c|c|c|c|c|c|}
\hline $\begin{array}{l}\text { Water } \\
\text { year }\end{array}$ & Date & $\begin{array}{c}\text { Cage } \\
\text { height } \\
\text { (feet) }\end{array}$ & $\begin{array}{c}\text { Discharge } \\
\text { (cfs) }\end{array}$ & $\begin{array}{c}\text { Water } \\
\text { year }\end{array}$ & Date & $\begin{array}{l}\text { Gage } \\
\text { helght } \\
\text { (feet) }\end{array}$ & $\begin{array}{c}\text { Discharge } \\
\text { (cfs) }\end{array}$ \\
\hline 1907 & $\begin{array}{lr}\text { Dec. } & 12,1906 \\
\text { Jan. } & 9,1907 \\
\text { Mar. } & 5,1907\end{array}$ & $\begin{array}{l}- \\
- \\
-\end{array}$ & $\begin{array}{r}5,100 \\
7,750 \\
12,300\end{array}$ & $\begin{array}{l}1931 \\
1932\end{array}$ & $\begin{array}{l}\text { Apr. } 26,1931 \\
\text { Dec. } 28,1931\end{array}$ & $\begin{array}{r}3.75 \\
4.70 \\
3.8 ?\end{array}$ & $\begin{array}{l}712 \\
912 \\
541\end{array}$ \\
\hline 1909 & $\begin{array}{l}\text { Jan. 21, } 1909 \\
\text { Feb. } 7,1909\end{array}$ & - & $\begin{array}{l}2,540 \\
4,710\end{array}$ & & Feb. 8,1932 & 10.00 & 8,500 \\
\hline 1910 & Jan. 1,1910 & - & 23,700 & $\begin{array}{l}1933 \\
1934\end{array}$ & $\begin{array}{l}\text { Jan. } 19,1933 \\
\text { Jan. } 1,1934\end{array}$ & $\begin{array}{l}3.28 \\
5.25\end{array}$ & $\begin{array}{r}464 \\
1,380\end{array}$ \\
\hline 1911 & $\begin{array}{ll}\text { Feb. } & 4,1911 \\
\text { Mar. } & 9,1911\end{array}$ & - & $\begin{array}{l}3,140 \\
5,050\end{array}$ & 1935 & $\begin{array}{lll}\text { Jan. } & 9,1935 \\
\text { Apr. } & 8,1935\end{array}$ & $\begin{array}{l}3.50 \\
4.90\end{array}$ & $\begin{array}{r}600 \\
1,280\end{array}$ \\
\hline 1914 & Feb. 20, 1914 & - & 16,600 & 1936 & Feb. 11,1936 & 2.98 & 418 \\
\hline 1915 & Feb. 2, 1915 & - & $a 2,520$ & 1937 & Dec. 28,1936 & 3.26 & 614 \\
\hline 1916 & Jan. 18,1916 & - & 12,600 & & $\begin{array}{l}\text { Dec. } 31,1936 \\
\text { Jan. } 30,1937\end{array}$ & $\begin{array}{l}5.65 \\
3.45\end{array}$ & $\begin{array}{r}2,080 \\
695\end{array}$ \\
\hline 1920 & Mar. 2, 1920 & - & $\mathrm{bl}, 160$ & & Feb. $\quad 6,1937$ & 6.37 & 2,720 \\
\hline 1930 & $\begin{array}{lrl}\text { Mar. } & 14, & 1930 \\
\text { May } & 4, & 1930\end{array}$ & $\begin{array}{l}4.20 \\
3.70\end{array}$ & $\begin{array}{l}800 \\
530\end{array}$ & & $\begin{array}{l}\text { Mar. 13, } 1937 \\
\text { Mar. 16, } 1937\end{array}$ & $\begin{array}{l}7.70 \\
6.34\end{array}$ & $\begin{array}{l}4,100 \\
2,690\end{array}$ \\
\hline
\end{tabular}

a May have been exceeded by a peak of unknown magnitude on Feb. 10 .

b Supplemental peak; yearly maximum on or about Mar. 21 , not available. 
Peak stages and discharges of West Fork Mojave River near Hesperia, Calif.--Ccnt1nued

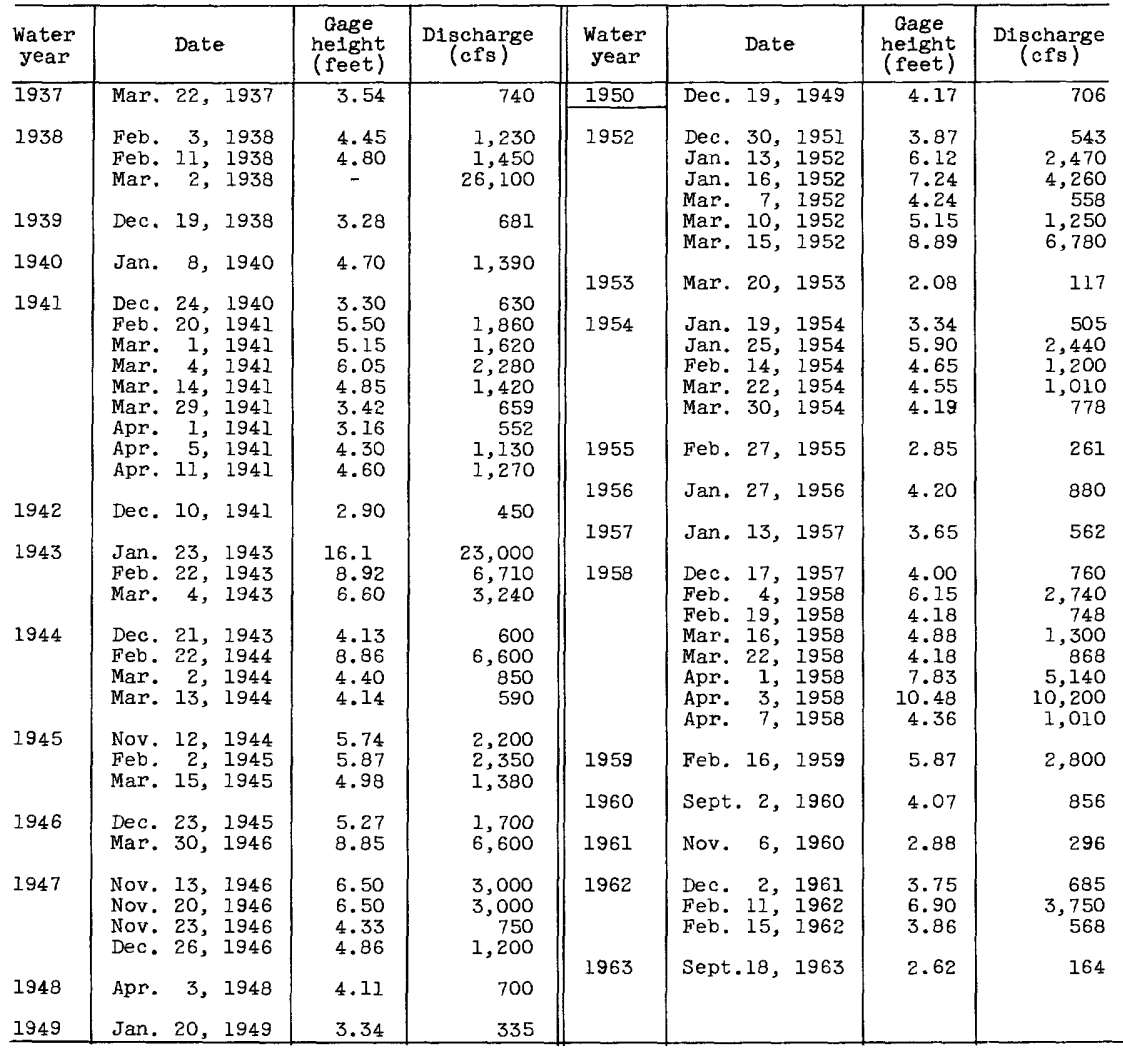

2615. Mojave River at lower narrows, near Victorville, Calif.

(Published as "at Victorville" prior to 1937 and as "near Victorville" in 1937)

Location.--Lat $34^{\circ} 34^{\prime} 22^{\prime \prime}$, long $117^{\circ} 19^{\prime} 08^{\prime \prime}$, in SW $\frac{1}{4} \operatorname{SW} \frac{1}{4} \operatorname{SE} \frac{1}{4}$ sec. 29 , T.6 N., R.4 W., on left bank $1,000 \mathrm{ft}$ upstream from bridge on county road (formerly U.S.

Highway 66), 2,500 ft downstream from The Atchison, Topeka and Santa Fe Railway $C o$. bridge, and 3 miles northwest of victorvilie.

Drainage area. $-530 \mathrm{sq} \mathrm{mi}$. Mean altitude, 4,000 ft.

Gage.--Recording. Nov. 12, 1930, to Dec. 8, 1936, at site 3.8 miles upatream at different datum. Dec. 9, 1936, to Mar. 28, 1938, at datum $2.00 \mathrm{ft}$ higher. Altitude of gage is $2,650^{\circ} \mathrm{ft}$ (from topographic map).

Stage-discharge relation.--Defined by slope-area measurement at 70,600 cfs.

Historical data.--According to various sources, other moderate to large floods occurred in the years 1859, 1862, 1867, 1884, 1886, 1889, 1891, 190\%, 1905, $1907,1910,1914,1916,1921,1922$, and 1927. The earliest flood mea surement, 13,400 cf's, was made by float method at upper narrows on Mar. 31, 1503. The only reported overtopping of the Santa Fe Railway bridge at upper nerrows took place in 1938. 'This conflirms the Corps of Engineers' estimate of the 1938 peak as the maximum since 1856.

Remarks.--Perlodic regulation by Lake Arrowhead (capacity, 48,000 acre-ft, used principally for recreation). Diversions and pumping for irrigation of about 5,000 acres above station. Base for partial-duration series, $200 \mathrm{cfs}$. Only annual peaks are shown prior to 1940 . 
Peak stages and discharges of Mojave River at lower narrows, near Victorville, Calif.

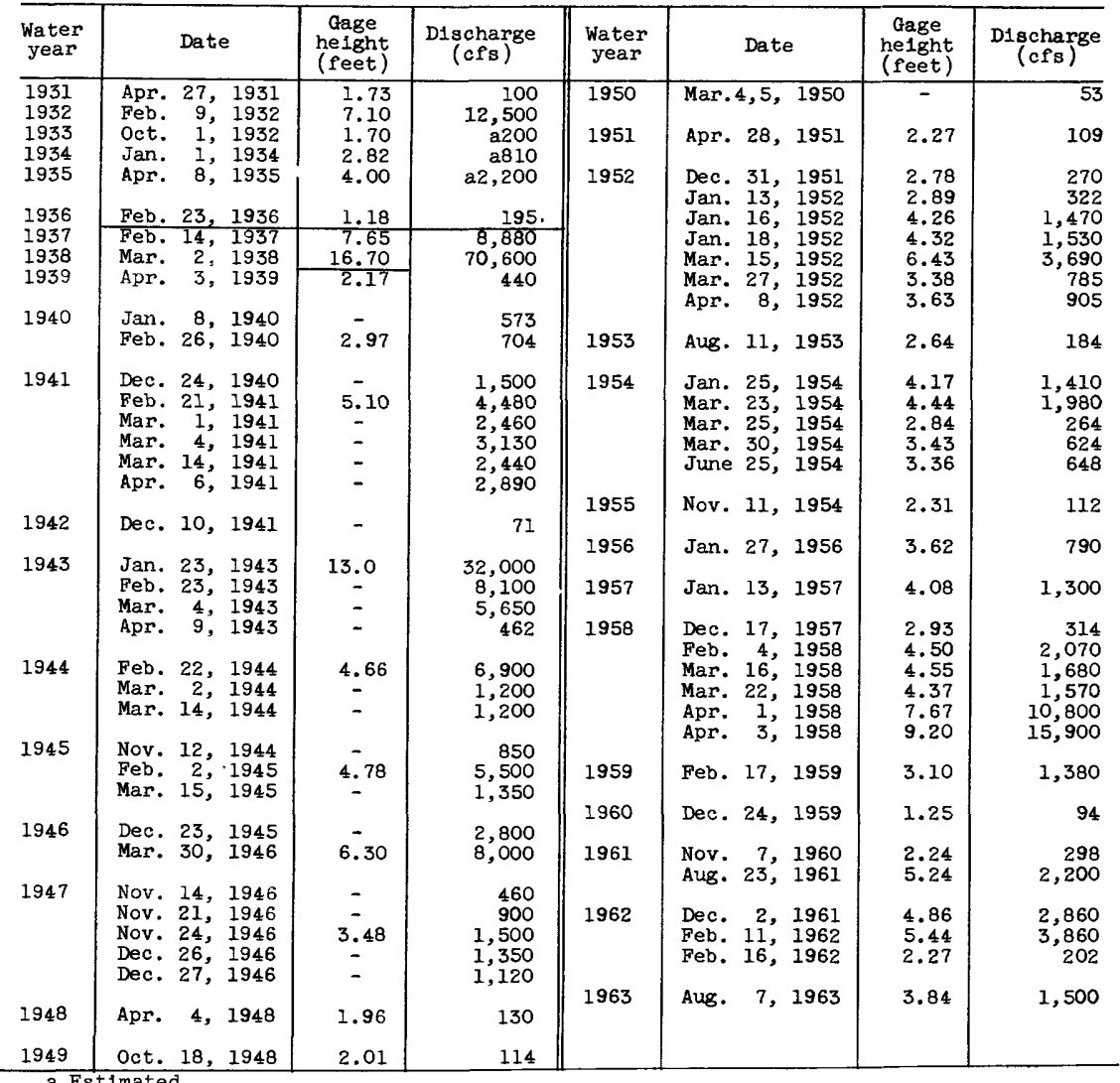

a Estimated.

2625. Mojave River at Barstow, Calif.

Location.--Lat $34^{\circ} 54^{\prime} 25^{\prime \prime}$, long $17^{\circ} 01^{\prime} 20^{\prime \prime}$, in SE $\frac{1}{4} \operatorname{SW} \frac{1}{4} \sec .31$, T. 10 N., R.1 W., on left bank $75 \mathrm{ft}$ upstream from bridge on U.S. Highway 91 at Barstow.

Gage--Nonrecording. Altitude of gage is 2,090 ft (from topographic map). Stage-discharge relation.--Defined by current-meter measurementis below 25,000
cfs and extended above on basis of slope-area measurement at $64,300 \mathrm{cfs}$.

Subject to changes owing to unstable channel conditions.

Bankfull stage. $--5 \mathrm{ft}$.

Historical data.--Flood of Mar. 3, 1938, is belleved to be the greatest since 1885.

Remarks.--Slight regulation by Lake Arrowhead (capacity, 48,000 acre-ft, used principally for recreation). Diversions and pumping for irrigation of about 15,000 acres above station. Base for partial-duration series, $100 \mathrm{cfs}$. 
Peak stages and discharges of Mojave River at Barstow, Calif.

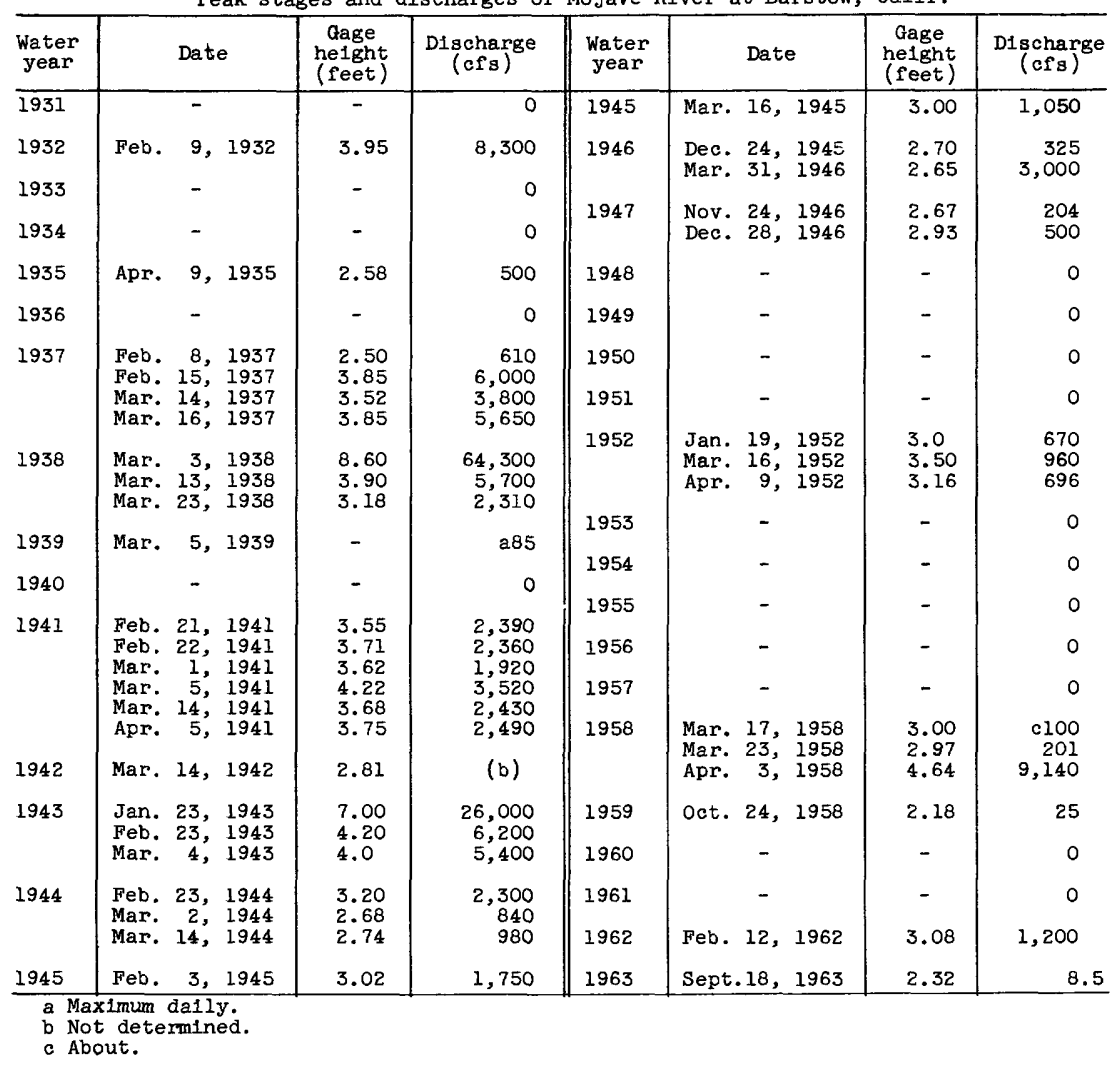

2631. Zzyzx Creek near Baker, Cal1f.

Location.--Lat $35^{\circ} 11^{140^{\prime \prime}}$, long $116^{\circ} 09^{\prime} 05^{\prime \prime}$, in sec.20, T.13 N., R.8 E., at culvert on U.S. Highways 91 and $466,6.5$ miles southwest of Baker.

Drainage area. $--0.23 \mathrm{sq} \mathrm{ml}$.

Gage.--Nonrecording. Altitude of gage is 1,270 ft (from topographic map). Stage-discharge relation.--Defined by indirect measurements below $2 \mathrm{cfs}$. Remarks.--Only annual peaks are shown.

Peak stages and discharges

\begin{tabular}{l|c|c|c||c|c|c|c}
\hline $\begin{array}{c}\text { Water } \\
\text { year }\end{array}$ & Date & $\begin{array}{c}\text { Gage } \\
\text { helght } \\
\text { (feet) }\end{array}$ & $\begin{array}{c}\text { Digcharge } \\
\text { (cfs) }\end{array}$ & $\begin{array}{c}\text { Water } \\
\text { year }\end{array}$ & $\begin{array}{c}\text { Gage Date } \\
\text { he1ght } \\
\text { (feet) }\end{array}$ & $\begin{array}{c}\text { Discharge } \\
\text { (cfs) }\end{array}$ \\
\hline 1959 & - & - & a0 & 1962 & Aug. 16, 1962 & 10.48 \\
1960 & - & - & 0 & 1963 & Sept.19, 1963 & 10.28 \\
1961 & July 13,1961 & 10.28 & 1.0 & & & \\
\hline
\end{tabular}


2635. Big Rock Creek near Valyermo, Calif.

(Published as Rock Creek prior to October 1954)

Location.--Lat $34^{\circ} 25^{\prime} 15^{\prime \prime}$, long $117^{\circ} 50^{\prime 1} 19^{\prime \prime}$, in NW $\frac{1}{4} \mathrm{SE} \frac{1}{4} \mathrm{NE} \frac{1}{4}$ sec.20, T.4 N., R.9 W., on left bank 0.1 mile upstream from Punchbowl Canyon and 1 . . miles southwest of Valyermo.

Drainage area. $--23.0 \mathrm{sq} \mathrm{mi}$.

Gage.--Recording. Prior to May 4, 1938, at different datums. May 4, 1938, to Jan. 26, 1939, at site 0.2 mile downstream (below Punchbow1 Canyon) at different datum. Altitude of gage is 4,050 ft (from topographic map).

Stage-discharge relation.--Defined by current-meter measurements below 500 cfs and extended above on basis of slope-area measurements at 1,100 and 3,000

cfs for perlods January 1923 to May 3, 1938, Jan. 26, 1939, and thereafter.

Defined by current-meter measurements below 100 cfs and extended on basis of

slope-area measurement at 8,300 cfs for perlod May 4, 1938, to Jan. 26, 1939

Subject to changes owing to unstable channel conditions.

Bankfull stage.--Not subject to overflow.

Remarks.--Only annual peaks are shown prior to 1948. Base for partial-duration series, 50 cfs.

Peak stages and discharges

\begin{tabular}{|c|c|c|c|c|c|c|c|}
\hline $\begin{array}{l}\text { Water } \\
\text { year }\end{array}$ & Date & $\begin{array}{c}\text { Gage } \\
\text { helght } \\
(\text { feet) }\end{array}$ & $\begin{array}{c}\text { Discharge } \\
\text { (cfs) }\end{array}$ & $\begin{array}{l}\text { Water } \\
\text { year }\end{array}$ & Date & $\begin{array}{c}\text { Gage } \\
\text { helght } \\
\text { (feet) }\end{array}$ & $\begin{array}{c}\text { Discharge } \\
(\text { cfs })\end{array}$ \\
\hline $\begin{array}{l}1923 \\
1924\end{array}$ & $\begin{array}{l}\text { Apr. } 10,1923 \\
\text { Apr. } 14,1924\end{array}$ & $\begin{array}{l}1.4 \\
1.35\end{array}$ & $\begin{array}{l}27 \\
19\end{array}$ & 1951 & Apr. 28, 1951 & 2.02 & 4.3 \\
\hline 1925 & Apr. 4, 1925 & 1.41 & 16 & 1952 & $\begin{array}{l}\text { Dec. } 30,1951 \\
\text { Jan. } 12,1952\end{array}$ & $\begin{array}{l}3.00 \\
2.54\end{array}$ & $\begin{array}{r}224 \\
67\end{array}$ \\
\hline $\begin{array}{l}1926 \\
1927 \\
1928\end{array}$ & $\begin{array}{l}\text { Apr. } 7,1926 \\
\text { Feb. } 16,1927 \\
\text { Feb. } \\
1,1928\end{array}$ & $\begin{array}{l}3.38 \\
3.70 \\
2.00\end{array}$ & $\begin{array}{r}416 \\
510 \\
86\end{array}$ & & $\begin{array}{ll}\text { Jan. } 16, & 1952 \\
\text { Mar. 15, } 1952\end{array}$ & $\begin{array}{l}2.63 \\
2.67\end{array}$ & $\begin{array}{l}84 \\
86\end{array}$ \\
\hline $\begin{array}{l}1929 \\
1930\end{array}$ & $\begin{array}{l}\text { Mar. } 10,1929 \\
\text { Mar. } 25,1930\end{array}$ & $\begin{array}{l}2.25 \\
1.94\end{array}$ & $\begin{array}{r}136 \\
56\end{array}$ & 1953 & Dec. 1, 1952 & 2.24 & 17 \\
\hline $\begin{array}{l}1931 \\
1932\end{array}$ & $\begin{array}{l}\text { Apr. } 26,1931 \\
\text { Feb. } 8,1932\end{array}$ & $\begin{array}{l}2.20 \\
4.15\end{array}$ & $\begin{array}{r}98 \\
800\end{array}$ & 1954 & $\begin{array}{l}\text { Jan. 25, } 1954 \\
\text { Feb. } 13,1954\end{array}$ & $\begin{array}{l}3.39 \\
2.58\end{array}$ & $\begin{array}{r}320 \\
73\end{array}$ \\
\hline $\begin{array}{l}1933 \\
1934\end{array}$ & $\begin{array}{lll}\text { Apr. } & 4,1933 \\
\text { Jan. } & 1,1934\end{array}$ & $\begin{array}{l}1.82 \\
2.97\end{array}$ & $\begin{array}{r}24 \\
246\end{array}$ & 1955 & Nov. 11, 1954 & 2.45 & 48 \\
\hline 1935 & Dec. 14,1934 & 3.10 & 338 & 1956 & Jan. 26, 1956 & 3.52 & 380 \\
\hline $\begin{array}{l}1936 \\
1937\end{array}$ & $\begin{array}{l}\text { Feb. } 23,1936 \\
\text { Feb. } \quad 6,1937\end{array}$ & $\begin{array}{l}1.85 \\
3.25\end{array}$ & $\begin{array}{r}70 \\
360\end{array}$ & 1957 & Jan. 13, 1957 & 3.87 & 362 \\
\hline 1938 & Mar. 2, 1938 & & 8,300 & 1958 & Dec. 15,1957 & 4.05 & 399 \\
\hline 1939 & Dec. 18,1938 & 9.70 & 450 & & Feb. 4,1958 & 3.65 & 295 \\
\hline 1940 & Feb. 25,1940 & $\overline{3.28}$ & 150 & & $\begin{array}{l}\text { Feb. } 19,1958 \\
\text { Mar. } 16,1958\end{array}$ & $\begin{array}{l}3.42 \\
3.60\end{array}$ & $\begin{array}{l}210 \\
264\end{array}$ \\
\hline $\begin{array}{l}1941 \\
1942\end{array}$ & $\begin{array}{l}\text { Feb. } 21,1941 \\
\text { Aug. } 10,1942\end{array}$ & $\begin{array}{l}4.10 \\
2.90\end{array}$ & $\begin{array}{l}512 \\
175\end{array}$ & & Apr. 3,1958 & 3.52 & 242 \\
\hline $\begin{array}{l}1943 \\
1944\end{array}$ & $\begin{array}{l}\text { Jan. } 23,1943 \\
\text { Dec. } 19,1943\end{array}$ & $\begin{array}{l}7.03 \\
2.98\end{array}$ & $\begin{array}{r}3,040 \\
180\end{array}$ & 1959 & Feb. 16,1959 & 3.28 & 215 \\
\hline 1945 & Nov. 11,1944 & 3.88 & 513 & 1960 & Feb. 1,1960 & 1.85 & 6.5 \\
\hline $\begin{array}{l}1946 \\
1947\end{array}$ & $\begin{array}{ll}\text { Dec. } 21, & 1945 \\
\text { Dec. } 26, & 1946\end{array}$ & $\begin{array}{l}4.17 \\
4.58\end{array}$ & $\begin{array}{l}650 \\
900\end{array}$ & 1961 & Nov. 5,1960 & 2.32 & 34 \\
\hline 1948 & Apr. 29,1948 & 2.63 & 84 & 1962 & $\begin{array}{l}\text { Dec. } 2,1961 \\
\text { Feb. } 11,1962\end{array}$ & $\begin{array}{l}3.13 \\
5.68\end{array}$ & $\begin{array}{r}140 \\
1,090\end{array}$ \\
\hline 1949 & Apr. 23, 1949 & 2.32 & 26 & 1963 & Feb. 9,1963 & 2.56 & 80 \\
\hline 1950 & 6,1950 & 2.47 & 48 & & & & \\
\hline
\end{tabular}


2640. Little Rock Creek near Little Rock, Calif.

Location.--Lat $34^{\circ} 27^{\prime} 50^{\prime \prime}$, long $118^{\circ} 01^{\prime} 05^{\prime \prime}$, in SW $\frac{1}{4} \operatorname{SW} \frac{1}{4} \mathrm{NE} \frac{1}{4} \sec .3$, T.4 N., R.11 W. on right bank 0.3 mile upstream from Santiago Creek, 1.65 miles upstream from Little Rock Palmdale Irrigation District's dam, and 5 miles south of Little Rock.

Drainage area. $--49.0 \mathrm{sq} \mathrm{mi}$. Mean altitude, 5,470 ft.

Gage.--Recording. Prior to May 1943, at site $500 \mathrm{ft}$ downstream at different datums (datum changed in March 1939). Altitude of gage is $3,290 \mathrm{ft}$ (from topographic map).

Stage-discharge relation.--Defined by current-meter measurements.

Remarks.--Base for partial-duration series, 75 cfs. Records furnished by Los Angeles County Flood Control District.

Peak stages and discharges

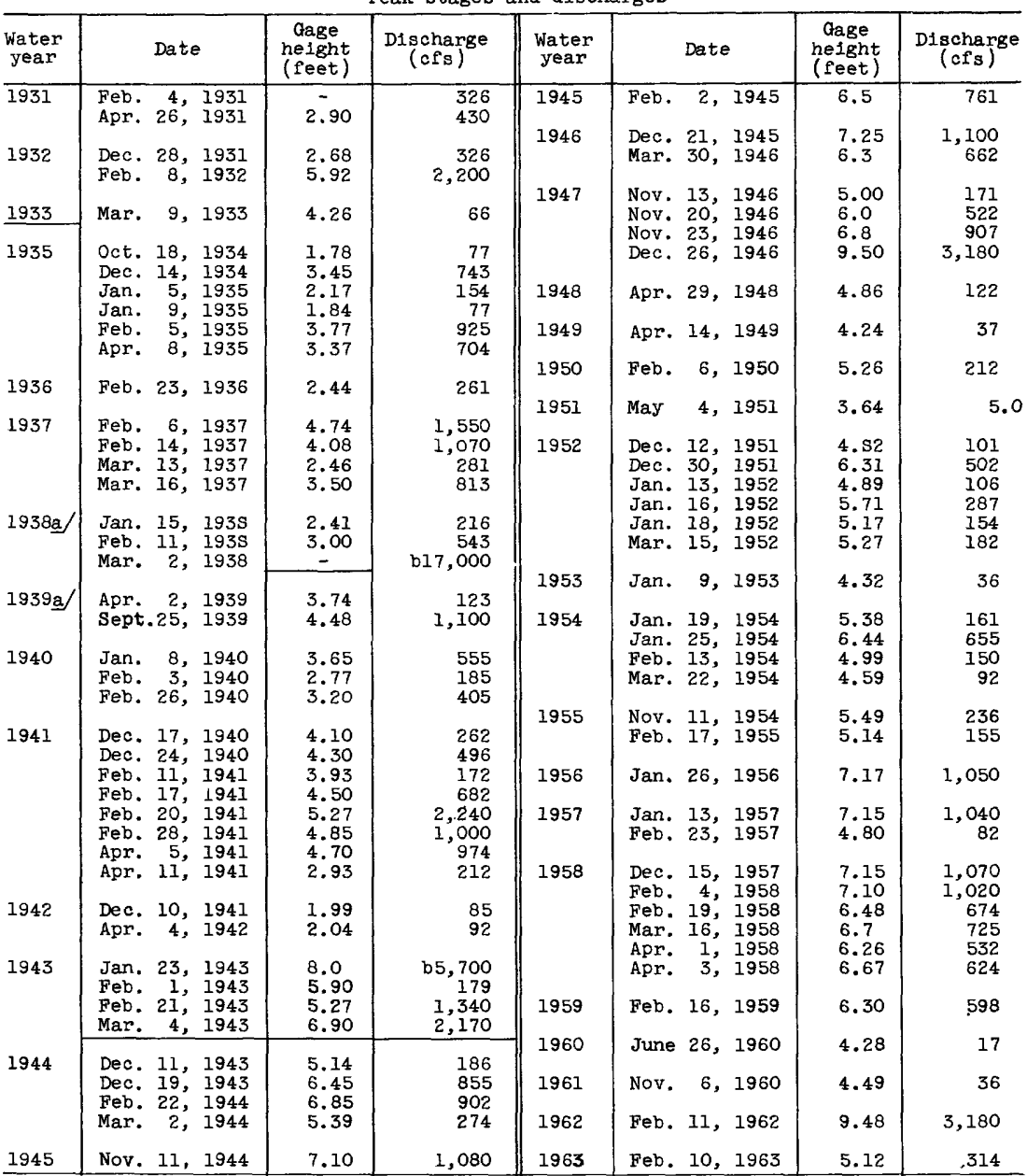


2645.2. Amargosa Creek tributary near Palmdale, Calif.

Location.--Lat $34^{\circ} 37^{\prime} 51^{\prime \prime}$, long $118^{\circ} 19^{\prime} 32^{\prime \prime}$, in SE $\frac{1}{4}$ sec.2, T.6 N., R.14 W., at culvert on Pine Canyon Road, San Bermardino National Forest, 12.5 miles northwest of Palmdale.

Drainage area $--0.048 \mathrm{sq} \mathrm{mi}$.

Gage.--Nonrecording. Altitude of gage is 3,200 ft (from topographic map).

Stage-discharge relation. - Tentatively defined by indirect measirements below 6 cfs.

Remarks.--Only annual peaks are shown.

\begin{tabular}{|c|c|c|c|c|c|c|c|}
\hline $\begin{array}{l}\text { Water } \\
\text { year }\end{array}$ & Date & $\begin{array}{c}\text { aage } \\
\text { height } \\
\text { (feet) }\end{array}$ & $\begin{array}{c}\text { Discharge } \\
(\text { cfs })\end{array}$ & $\begin{array}{l}\text { Water } \\
\text { year }\end{array}$ & Date & $\begin{array}{c}\text { Gage } \\
\text { height } \\
\text { (feet) }\end{array}$ & $\begin{array}{c}\text { Discharge } \\
(\mathrm{cfs})\end{array}$ \\
\hline $\begin{array}{l}1959 \\
1960 \\
1961 \\
\end{array}$ & $\begin{array}{cc}\text { Feb. } & 11, \\
\text { Dec. } 24, & 1959 \\
- & \end{array}$ & $\begin{array}{c}10.72 \\
10.34 \\
-\end{array}$ & $\begin{array}{r}2.7 \\
.7 \\
0\end{array}$ & $\begin{array}{l}1962 \\
1963\end{array}$ & $\begin{array}{ll}\text { Dec. } 2, & 1961 \\
\text { Apr. } 13, & 1963\end{array}$ & $\begin{array}{c}11.11 \\
10.82\end{array}$ & $\begin{array}{l}6.6 \\
3.6\end{array}$ \\
\hline
\end{tabular}

2645.3. Pine Creek near Palmdale, Calif .

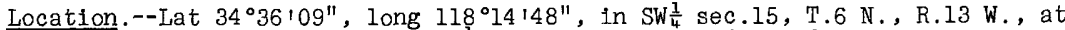
culvert on Pine Canyon Road, $7 \frac{1}{2}$ miles northwest of Palmdale.

Drainage area $--0.25 \mathrm{sq} \mathrm{mi}$.

Gage.--Nonrecording. Altitude of gage is $2,990 \mathrm{ft}$ (from topogrephic map). Stage-discharge relation.--Defined by indirect measurements belcw $58 \mathrm{cfs}$. Remarks.--Only annual peaks are shown.

Peak stages and discharges

\begin{tabular}{|c|c|c|c|c|c|c|c|}
\hline $\begin{array}{l}\text { Water } \\
\text { year }\end{array}$ & Date & $\begin{array}{c}\text { Gage } \\
\text { helght } \\
\text { (feet) }\end{array}$ & $\begin{array}{l}\text { Discharge } \\
\text { (cfs) }\end{array}$ & $\begin{array}{l}\text { Water } \\
\text { year }\end{array}$ & Date & $\begin{array}{c}\text { Gage } \\
\text { hoight } \\
\text { (feet) }\end{array}$ & $\begin{array}{c}\text { Discharge } \\
\text { (cfs) }\end{array}$ \\
\hline $\begin{array}{l}1959 \\
1960\end{array}$ & $\begin{array}{lr}\text { Jan. } & 6,1959 \\
\text { Apr. } 28, & 1960\end{array}$ & $\begin{array}{l}10.41 \\
10.32\end{array}$ & $\begin{array}{r}0.8 \\
.5\end{array}$ & $\begin{array}{l}1962 \\
1963\end{array}$ & $\begin{array}{l}\text { Feb. } 10,1962 \\
\text { June } 12,1963\end{array}$ & $\begin{array}{l}14.88 \\
10.92\end{array}$ & $\begin{array}{r}58 \\
3.5\end{array}$ \\
\hline 1961 & Aug. 5,1961 & 10.69 & 2.0 & & & & \\
\hline
\end{tabular}

2645.6. Spencer Canyon Creek near Fairmont, Calif.

Location.--Lat $34^{\circ} 46^{\prime} 33^{\prime \prime}$, long $118^{\circ} 34^{\prime} 08^{\prime \prime}$, in SW $\frac{1}{4}$ sec.15, T.8 N., R.16 W., at culvert on State Highway $138,8.5$ miles northwest of Fairmont.

Drainage area. $--3.51 \mathrm{sq} \mathrm{mi}$.

Gage.--Nonrecording. Altitude of gage is 2,950 ft (from topogrephic map).

Stage-discharge relation.--Defined by indirect measurements between 100 and 300 cfs.

Remarks.--Only annual peaks are shown.

Peak stages and discharges

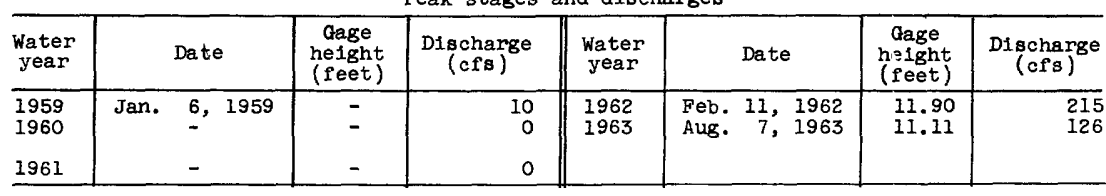


2646. Oak Creek near Mojave, Calif.

Location.--Lat $35^{\circ} 03^{100^{\prime \prime}}$, long $118^{\circ} 21^{\prime} 25^{\prime \prime}$, in NW/ sec.15, T.11 N., R. 14 W., on upstream right wingwaII of culvert, $100 \mathrm{ft}$ downstream from unnamed tributary, 0.1 mile west of junction of Oak Creek and Willow Springs Roads, and 10.5 miles west of Mojave.

Drainage area. $--15.8 \mathrm{sq} \mathrm{ml}$.

Gage.--Recording and concrete control. Altitude of gage is 4,100 ft (from topographic map).

Stage-discharge relation.--Defined by current-meter measurements below $15 \mathrm{cfs}$. BankfulI stage. - Not subject to overflow.

Remarks.--Only annual peaks are shown.

\begin{tabular}{|c|c|c|c|c|c|c|c|}
\hline $\begin{array}{l}\text { Water } \\
\text { year }\end{array}$ & Date & $\begin{array}{l}\text { Cage } \\
\text { helght } \\
\text { (feet) }\end{array}$ & $\begin{array}{c}\text { Discharge } \\
(\mathrm{cfs})\end{array}$ & $\begin{array}{l}\text { Water } \\
\text { year }\end{array}$ & Date & $\begin{array}{c}\text { Gage } \\
\text { neight } \\
\text { (feet) }\end{array}$ & $\begin{array}{c}\text { Discharge } \\
(\mathrm{cfs})\end{array}$ \\
\hline $\begin{array}{l}1958 \\
1959 \\
1960 \\
\end{array}$ & $\begin{array}{rrr}\text { Apr. } & 18,1958 \\
\text { Jan. } & 6,1959 \\
\text { Feb. } & 1,1960 \\
\end{array}$ & $\begin{array}{r}1.51 \\
1.19 \\
.97\end{array}$ & $\begin{array}{r}22 \\
9.2 \\
4.0\end{array}$ & $\begin{array}{l}1961 \\
1962 \\
1963\end{array}$ & $\begin{array}{l}\text { Aug. 23, } 1961 \\
\text { Feb. 11, } 1962 \\
\text { Feb. 9, } 1963\end{array}$ & $\begin{array}{r}0.98 \\
1.55 \\
.97\end{array}$ & $\begin{array}{r}3.0 \\
29 \\
3.6 \\
\end{array}$ \\
\hline
\end{tabular}

2646.05. Joshua Creek near Mojave, Calif.

Location.--Lat $35^{\circ} 00^{\prime} 4^{\prime \prime}$, Iong $118^{\circ} 20^{14} 0^{\prime \prime}$, in SW $\frac{1}{4}$ sec.26, T.11 N., R.14 W., at

culvert on Willow Springs Road, 10 miles southwest of Mojave.

Drainage area. $--3.86 \mathrm{sq} \mathrm{mi}$.

Gage.--Nonrecording. Altitude of gage is $3,850 \mathrm{ft}$ (from topographic map).

Stage-discharge relation.--Defined by indirect measurements below $4 \mathrm{cfs}$.

Remarks.--Only annual peaks are shown.

Peak stages and discharges

\begin{tabular}{l|c|c|c||c|c|c|c}
\hline $\begin{array}{c}\text { Water } \\
\text { year }\end{array}$ & \multicolumn{2}{|c|}{ Date } & $\begin{array}{c}\text { Gage } \\
\text { he1ght } \\
\text { (feet) }\end{array}$ & $\begin{array}{c}\text { Discharge } \\
\text { (cfs) }\end{array}$ & $\begin{array}{c}\text { Water } \\
\text { year }\end{array}$ & $\begin{array}{c}\text { Gage } \\
\text { he1ght } \\
\text { (feet) }\end{array}$ & $\begin{array}{c}\text { Discharge } \\
\text { (cfs) }\end{array}$ \\
\hline 1959 & Jan. 6,1959 & 10.63 & 3 & 1962 & Dec. 2, 1961 & 10.59 & 0.72 \\
1960 & Feb. 29, 1960 & 10.41 & 1 & 1963 & Aug. 8, 1963 & 10.72 \\
1961 & Nov. 5, 1960 & 10.43 & .2 & & \\
\hline
\end{tabular}

\section{KOEHN LAKE BASIN}

2647. Peewee Creek near Randsburg, Calif.

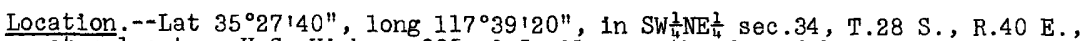
at culvert on U.S. Highway $395,6.5$ miles north of Randsburg.

Drainage area. $-0.14 \mathrm{sq} \mathrm{mi}$.

Gage.-Nonrecording. Altitude of gage is $3,500 \mathrm{ft}$ (from topographic map). Stage-discharge relation.--Defined by indirect measurements below $0.8 \mathrm{cfs}$. Remarks.--Only annual peaks are shown.

Peak stages and discharges

\begin{tabular}{l|c|c|c||c|c|c|c}
\hline $\begin{array}{c}\text { Water } \\
\text { year }\end{array}$ & Date & $\begin{array}{c}\text { Gage } \\
\text { helght } \\
\text { (feet) }\end{array}$ & $\begin{array}{c}\text { Discharge } \\
\text { (cfs) }\end{array}$ & $\begin{array}{c}\text { Water } \\
\text { year }\end{array}$ & $\begin{array}{c}\text { Gage Date } \\
\text { he1ght } \\
\text { (feet) }\end{array}$ & $\begin{array}{c}\text { D1scharge } \\
\text { (cfs) }\end{array}$ \\
\hline 1959 & - & - & - & 0 & 1962 & Mar. 9, 1962 & 10.25 \\
1960 & - & -1963 & Sept.19, 1963 & 0.65 \\
1961 & Nov. 5, 1960 & 10.26 & .2 & & \\
\hline
\end{tabular}

a Flow may have occurred during period Oct. 1, 1958, to Jan. 20, 1959. 
2649. Salt Wells Creek near Westend, Calif.

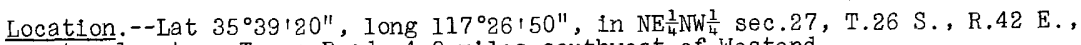
at culvert on Trona Road, 4.8 miles southwest of Westend.

Drainage area. $--61.6 \mathrm{sq} \mathrm{mi}$.

Gage.- -Nonrecording. Altitude of gage is $1,860 \mathrm{ft}$ (from topographic map).

Stage-discharge relation.--Defined by indirect measurements below $167 \mathrm{cfs}$.

Remarks.--Only annual peaks are shown.

Peak stages and discharges

\begin{tabular}{|c|c|c|c|c|c|c|c|}
\hline $\begin{array}{l}\text { Water } \\
\text { year }\end{array}$ & Date & $\begin{array}{l}\text { Cage } \\
\text { helght } \\
\text { (feet) }\end{array}$ & $\begin{array}{c}\text { Discharge } \\
\text { (cf } \mathrm{s})\end{array}$ & $\begin{array}{l}\text { Water } \\
\text { year }\end{array}$ & Date & $\begin{array}{c}\text { Gage } \\
\text { helght } \\
\text { (feet) }\end{array}$ & $\begin{array}{c}\text { D1scharge } \\
\text { (efs) }\end{array}$ \\
\hline $\begin{array}{l}1959 \\
1960\end{array}$ & $\begin{array}{ll}\text { Feb. } 16, & 1959 \\
\text { Dec. } 25, & 1959\end{array}$ & $\begin{array}{l}10.36 \\
10.22\end{array}$ & $\begin{array}{r}\text { a10 } \\
7\end{array}$ & $\begin{array}{l}1962 \\
1963\end{array}$ & $\begin{array}{lll}\text { Mar. } & 9,1962 \\
\text { Aug. } & 8,1963\end{array}$ & $\begin{array}{l}10.62 \\
12.48\end{array}$ & $\begin{array}{r}25 \\
167\end{array}$ \\
\hline 1961 & Nov. 5,1960 & 11.04 & 49 & & & & \\
\hline
\end{tabular}

a Greater peak discharge may have occurred dur1ng period |Oct.1, 1958, to Jan. 20, 1959.

2649.15. Crust Creek near Westend, Calif.

Location. --Lat $35^{\circ} 41^{\prime} 25^{\prime \prime}$, long $117^{\circ} 22^{\prime} 50^{\prime \prime}$, in NW $\frac{1}{4}$ sec.8, T.26 S., R.43 E., at culvert on Trona Rallroad, 1.2 miles southeast of Westend.

Drainage area. $--0.13 \mathrm{sq} \mathrm{mi}$.

Gage.--Nonrecording. Altitude of gage is 1,610 ft (from topographic map). Stage-discharge relation.--Poorly defined.

Remarks.--only annual peaks are shown.

\begin{tabular}{|c|c|c|c|c|c|c|c|}
\hline $\begin{array}{l}\text { Water } \\
\text { year }\end{array}$ & Date & $\begin{array}{c}\text { Gage } \\
\text { he1ght } \\
\text { (feet) }\end{array}$ & $\begin{array}{c}\text { Discharge } \\
(\text { cfs })\end{array}$ & $\begin{array}{l}\text { Water } \\
\text { year }\end{array}$ & Date & $\begin{array}{c}\text { Gage } \\
\text { he1ght } \\
\text { (feet) }\end{array}$ & $\begin{array}{c}\text { Discharge } \\
(\text { cfs })\end{array}$ \\
\hline $\begin{array}{l}1959 \\
1960\end{array}$ & Sept.13, 1959 & - & $\mathrm{aO}_{0} \mathrm{.}$ & $\begin{array}{l}1962 \\
1963\end{array}$ & $\overline{8}, 1963$ & 9.94 & 0.3 \\
\hline 1961 & Aug. 22,1961 & 9.93 & .3 & & & & \\
\hline
\end{tabular}

a Greater peak discharge may have occurred during period oct.1,1958, to Jan. 20 , 1959.

\section{OWENS LAKE BASIN}

2652. Convict Creek near Mammoth Lakes, Calif.

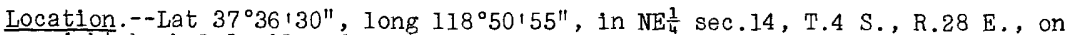
right bank 1.1 miles downstream from Convict Lake, 2.0 miles ups tream from U.S. Highway 395 , and 7.0 miles southeast of Mammoth Lakes (ranger station).

Drainage area. $--18.7 \mathrm{sq} \mathrm{mi}$.

Gage.--Nonrecording prior to Nov. 15, 1926; recording gage and woden contro1 thereafter. Altitude of gage is $7,450 \mathrm{ft}$ (from topographic map).

Stage-d1scharge relation.--Defined by current-meter measurements below $220 \mathrm{cfs}$. Remarks.--Records furnished by city of Los Angeles, Department of Water and Power. Only annual peaks are shown. 
Peak stages and discharges of Conv1ct Creek near Mammoth Lakes, Calif.

\begin{tabular}{|c|c|c|c|c|c|c|c|c|c|}
\hline $\begin{array}{c}\text { Water } \\
\text { year }\end{array}$ & & Date & $\begin{array}{c}\text { Cage } \\
\text { helght } \\
\text { (feet) }\end{array}$ & $\begin{array}{c}\text { Discharge } \\
\text { (cfs) }\end{array}$ & $\begin{array}{l}\text { Water } \\
\text { year }\end{array}$ & \multicolumn{2}{|r|}{ Date } & $\begin{array}{c}\text { aage } \\
\text { he1ght } \\
\text { (feet) }\end{array}$ & $\begin{array}{c}\text { D1scharge } \\
\text { (cfs) }\end{array}$ \\
\hline $\begin{array}{l}1926 \\
1927 \\
1928 \\
1929 \\
1930\end{array}$ & $\begin{array}{l}\text { May } \\
\text { June } \\
\text { May } \\
\text { June } \\
\text { June }\end{array}$ & $\begin{array}{ll}21, & 1926 \\
17, & 1927 \\
29, & 1928 \\
30, & 1929 \\
15, & 1930\end{array}$ & $\begin{array}{l}- \\
- \\
- \\
-\end{array}$ & $\begin{array}{r}\text { a95 } \\
172 \\
114 \\
77 \\
101\end{array}$ & $\begin{array}{l}1946 \\
1947 \\
1948 \\
1949 \\
1950\end{array}$ & $\begin{array}{l}\text { June } \\
\text { May } \\
\text { June } \\
\text { June } \\
\text { June }\end{array}$ & $\begin{array}{rr}6, & 1946 \\
26, & 1947 \\
29, & 1948 \\
12, & 1949 \\
4, & 1950\end{array}$ & $\begin{array}{l}- \\
- \\
- \\
-\end{array}$ & $\begin{array}{r}87 \\
75 \\
75 \\
110 \\
81\end{array}$ \\
\hline $\begin{array}{l}1931 \\
1932 \\
1933 \\
1934 \\
1935\end{array}$ & $\begin{array}{l}\text { Oct. } \\
\text { June } \\
\text { June } \\
\text { May } \\
\text { June }\end{array}$ & $\begin{array}{ll}21, & 1930 \\
29, & 1932 \\
17, & 1933 \\
16, & 1934 \\
13, & 1935\end{array}$ & $\begin{array}{l}- \\
\overline{-} \\
- \\
-\end{array}$ & $\begin{array}{r}50 \\
290 \\
96 \\
44 \\
108\end{array}$ & $\begin{array}{l}1951 \\
1952 \\
1953 \\
1954 \\
1955\end{array}$ & $\begin{array}{l}\text { June } \\
\text { June } \\
\text { July } \\
\text { June } \\
\text { June }\end{array}$ & $\begin{array}{rr}27, & 1951 \\
9, & 1952 \\
10, & 1953 \\
26, & 1954 \\
10, & 1955\end{array}$ & $\begin{array}{l}- \\
- \\
-\end{array}$ & $\begin{array}{r}82 \\
117 \\
83 \\
92 \\
126\end{array}$ \\
\hline $\begin{array}{l}1936 \\
1937 \\
1938 \\
1939 \\
1940\end{array}$ & $\begin{array}{l}\text { June } \\
\text { June } \\
\text { June } \\
\text { June } \\
\text { June }\end{array}$ & $\begin{array}{r}25,1936 \\
23,1937 \\
28,1938 \\
2,1939 \\
18,1940\end{array}$ & $\begin{array}{l}- \\
- \\
-\end{array}$ & $\begin{array}{r}131 \\
156 \\
231 \\
55 \\
110\end{array}$ & $\begin{array}{l}1956 \\
1957 \\
1958 \\
1959 \\
1960\end{array}$ & $\begin{array}{l}\text { June } \\
\text { June } \\
\text { June } \\
\text { June } \\
\text { June }\end{array}$ & $\begin{array}{rr}30, & 1956 \\
28, & 1957 \\
24, & 1958 \\
14, & 1959 \\
5, & 1960\end{array}$ & $\begin{array}{l}\overline{-} \\
\overline{-} \\
\overline{-}\end{array}$ & $\begin{array}{r}168 \\
136 \\
201 \\
58 \\
42\end{array}$ \\
\hline $\begin{array}{l}1941 \\
1942 \\
1943 \\
1944 \\
1945\end{array}$ & $\begin{array}{l}\text { June } \\
\text { July } \\
\text { May } \\
\text { July } \\
\text { June }\end{array}$ & $\begin{array}{rr}17, & 1941 \\
7, & 1942 \\
30, & 1943 \\
3, & 1944 \\
22, & 1945\end{array}$ & $\begin{array}{l}- \\
- \\
- \\
-\end{array}$ & $\begin{array}{r}145 \\
134 \\
100 \\
82 \\
148\end{array}$ & $\begin{array}{l}1961 \\
1962 \\
1963\end{array}$ & $\begin{array}{l}\text { Oct. } \\
\text { June } \\
\text { June }\end{array}$ & $\begin{array}{ll}26, & 1960 \\
25, & 1962 \\
21, & 1963\end{array}$ & $\begin{array}{l}- \\
3.53\end{array}$ & $\begin{array}{r}25 \\
157 \\
223\end{array}$ \\
\hline
\end{tabular}

a Maximum da1ly.

2655. Owens River near Round Valley, Calif.

Location.--Lat $37^{\circ} 26^{\prime} 25^{\prime \prime}$, long $118^{\circ} 33^{1} 20^{\prime \prime}$, in SE $\frac{1}{4}$ sec.10, T.6 S., R.31 E., just downstream from Sheep Bringe, $700 \mathrm{ft}$ upstream from Rock Creek and 2 miles north of town of Round Valley.

Drainage area. $--450 \mathrm{sq} \mathrm{mi}$, approximately.

Gage.--Nonrecording prior to Nov. 21, 1920, at site $100 \mathrm{ft}$ downstream at different datum; recording thereafter. Altitude of gage is $4,400 \mathrm{ft}$ (from topo-

graphic map).

Stage-discharge relation.--Defined by current-meter measurements below $920 \mathrm{cfs}$.

Bankfull stage. - -Not subject to overflow.

Remarks.--Diversions for irrigation above station. Records for 1927-40 fur-

nished by city of Los Angeles, Department of Water and Power. Only annual peaks are shown (maximum observed prior to 1921 ).

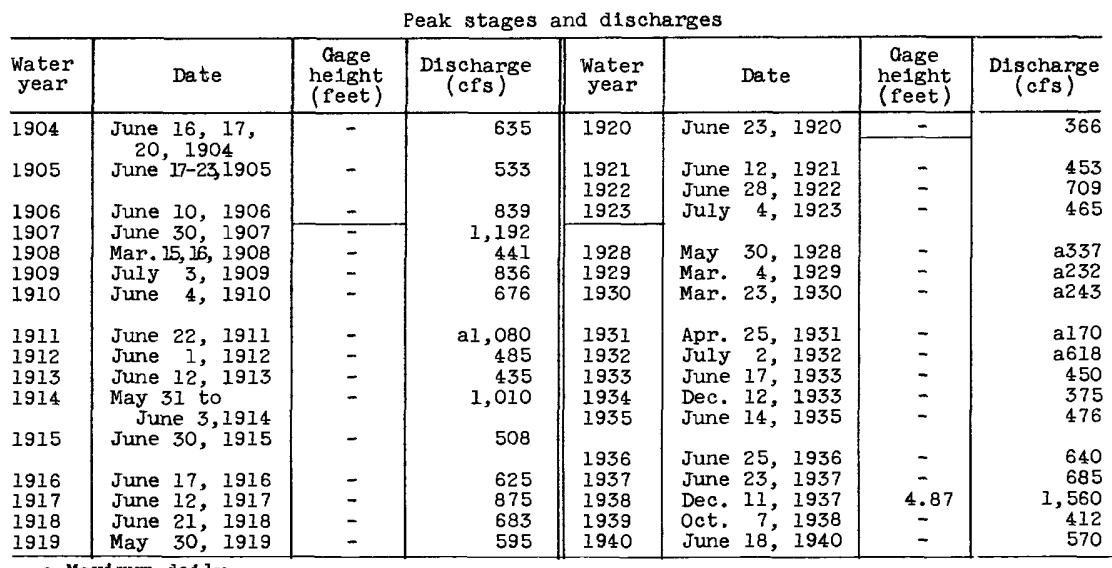

a Maximum daily.

Note.-D1scharges are maximum observed prior to 1921. 
2657. Rock Creek at Iittle Round Valley, near Blshop, Calif.

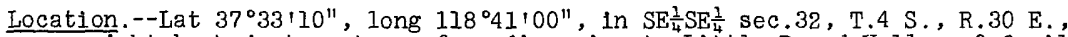
on right bank just upstream from diversion to Little Round valley, 0.6 mile south of Toms Place and 20 miles northwest of Blshop, Mono Crunty.

Drainage area. $--35.8 \mathrm{sq} \mathrm{ml}$.

Gage.--Recording. May 24, 1926, to May 28, 1953, at different datums. Since May 1953, 6-foot Parshall flume. Altitude of gage is 7,450 ft (from topographic map).

Stage-discharge relation.--Defined by current-meter measurements below $250 \mathrm{cf}$ 's.

Remarks.--Records furnished by city of Los Angeles, Department of Water and

Power. Only annual peaks are shown.

Peak stages and discharges

\begin{tabular}{|c|c|c|c|c|c|c|c|c|c|}
\hline $\begin{array}{l}\text { Water } \\
\text { year }\end{array}$ & \multicolumn{2}{|r|}{ Date } & $\begin{array}{c}\text { Gage } \\
\text { helght } \\
\text { (feet) }\end{array}$ & $\begin{array}{c}\text { Discharge } \\
\text { (cfs) }\end{array}$ & $\begin{array}{l}\text { Water } \\
\text { year }\end{array}$ & & Date & $\begin{array}{c}\text { Gage } \\
\text { reight } \\
\text { (feet) }\end{array}$ & $\begin{array}{c}\text { Discharge } \\
\text { (cfs) }\end{array}$ \\
\hline $\begin{array}{l}1927 \\
1928 \\
1929 \\
1930\end{array}$ & $\begin{array}{l}\text { June } \\
\text { May } \\
\text { June } \\
\text { June }\end{array}$ & $\begin{array}{ll}14, & 1927 \\
29, & 1928 \\
30, & 1929 \\
16, & 1930\end{array}$ & $\begin{array}{l}- \\
- \\
-\end{array}$ & $\begin{array}{r}205 \\
130 \\
75 \\
90\end{array}$ & $\begin{array}{l}1946 \\
1947 \\
1948 \\
1949 \\
1950\end{array}$ & $\begin{array}{l}\text { July } \\
\text { May } \\
\text { June } \\
\text { June } \\
\text { June }\end{array}$ & $\begin{array}{rr}26, & 1946 \\
25, & 1947 \\
30, & 1948 \\
12, & 1949 \\
3, & 1950\end{array}$ & $\begin{array}{l}- \\
- \\
-\end{array}$ & $\begin{array}{r}119 \\
89 \\
77 \\
141 \\
121\end{array}$ \\
\hline $\begin{array}{l}1931 \\
1932 \\
1933\end{array}$ & $\begin{array}{l}\text { June } \\
\text { June } \\
\text { June }\end{array}$ & $\begin{array}{rr}6, & 1931 \\
27, & 1932 \\
16, & 1933\end{array}$ & $\overline{-}$ & $\begin{array}{r}30 \\
168 \\
112\end{array}$ & $\begin{array}{l}1951 \\
1952\end{array}$ & $\begin{array}{l}\text { June } \\
\text { July }\end{array}$ & $\begin{array}{ll}22, & 1951 \\
26, & 1952\end{array}$ & 2.93 & $\begin{array}{l}117 \\
270\end{array}$ \\
\hline $\begin{array}{l}1934 \\
1935\end{array}$ & $\begin{array}{l}\text { Dec. } \\
\text { June }\end{array}$ & $\begin{array}{ll}17, & 1933 \\
13, & 1935\end{array}$ & - & $\begin{array}{r}70 \\
107\end{array}$ & $\begin{array}{l}1953 \\
1954 \\
1955\end{array}$ & $\begin{array}{l}\text { July } \\
\text { May } \\
\text { June }\end{array}$ & $\begin{array}{ll}18, & 1953 \\
21, & 1954 \\
11, & 1955\end{array}$ & $\overline{-}$ & $\begin{array}{r}135 \\
98 \\
153\end{array}$ \\
\hline $\begin{array}{l}1936 \\
1937 \\
1935 \\
1939 \\
1940\end{array}$ & $\begin{array}{l}\text { June } \\
\text { June } \\
\text { June } \\
\text { May } \\
\text { June }\end{array}$ & $\begin{array}{ll}24, & 1936 \\
22, & 1937 \\
27, & 1938 \\
31, & 1939 \\
15, & 1940\end{array}$ & $\begin{array}{l}\overline{-} \\
\overline{-} \\
\bar{z}\end{array}$ & $\begin{array}{r}142 \\
151 \\
257 \\
78 \\
118\end{array}$ & $\begin{array}{l}1956 \\
1957 \\
1958 \\
1959 \\
1960\end{array}$ & $\begin{array}{l}\text { June } \\
\text { June } \\
\text { June } \\
\text { June } \\
\text { June }\end{array}$ & $\begin{array}{rr}30, & 1956 \\
5, & 1957 \\
24, & 1958 \\
13, & 1959 \\
5, & 1960\end{array}$ & $\begin{array}{l}- \\
\overline{-} \\
-\end{array}$ & $\begin{array}{r}193 \\
147 \\
159 \\
54 \\
55\end{array}$ \\
\hline $\begin{array}{l}1941 \\
1942 \\
1943 \\
1944 \\
1945 \\
\end{array}$ & $\begin{array}{l}\text { June } \\
\text { July } \\
\text { May } \\
\text { July } \\
\text { July }\end{array}$ & 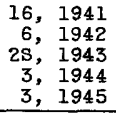 & $\begin{array}{l}- \\
\overline{-} \\
\overline{-}\end{array}$ & $\begin{array}{r}145 \\
120 \\
116 \\
79 \\
143\end{array}$ & $\begin{array}{l}1961 \\
1962 \\
1963\end{array}$ & $\begin{array}{l}\text { June } \\
\text { June } \\
\text { June }\end{array}$ & $\begin{array}{ll}20, & 1961 \\
24, & 1962 \\
20, & 1963\end{array}$ & $\overline{-}$ & $\begin{array}{r}58 \\
144 \\
207\end{array}$ \\
\hline
\end{tabular}

2660. Rock Creek at Sherwin Hill, near Blshop, Calif.

Location.--Lat $37^{\circ} 28^{1} 45^{\prime \prime}$, long $118^{\circ} 36^{\prime} 05^{\prime \prime}$, in SW $\frac{1}{4}$ sec.29, T.5 S., R.31 E., at Sherwin Hill, 3 miles upstream from Plne Creek and $14 \mathrm{mlles}$ northwest of Bishop.

Dralnage area. $--51.7 \mathrm{sq} \mathrm{mi}$.

Gage.--Nonrecording prior to Apr. 5, 1924; recording thereafter and, since 1933, Parshall flume. Altitude of gage is 4,900 ft (from topographic map).

Stage-discharge relation.--Defined by current-meter measurements below $150 \mathrm{cfs}$.

Bankfull stage.--Not subject to overflow.

Remarks.--Diversions above station for irrigation in Little Rouni Valley or for discharge into Owens River at lower end of Long Valley. Records furnished by city of Los Angeles, Department of Water and Power. Only annual peaks are shown (maximum daliy prior to 1933).

Peak stages and discharges

\begin{tabular}{|c|c|c|c|c|c|c|c|}
\hline $\begin{array}{l}\text { Water } \\
\text { year }\end{array}$ & Date & $\begin{array}{l}\text { Gage } \\
\text { height } \\
\text { (feet) }\end{array}$ & $\begin{array}{c}\text { Discharge } \\
(\mathrm{cfs})\end{array}$ & $\begin{array}{l}\text { Water } \\
\text { year }\end{array}$ & Date & $\begin{array}{c}\text { Cage } \\
\text { helght } \\
\text { (feet) }\end{array}$ & $\begin{array}{c}\text { Discharge } \\
\text { (cfs) }\end{array}$ \\
\hline $\begin{array}{l}1923 \\
1924 \\
1925\end{array}$ & $\begin{array}{l}\text { July } 5,1923 \\
\text { Mar. } 22, \\
\text { May } 22,1924 \\
\text { June } 26, \text { Jily 3, } \\
\text { 1925 }\end{array}$ & $\begin{array}{l}- \\
-\end{array}$ & $\begin{array}{r}104 \\
34 \\
73\end{array}$ & $\begin{array}{l}1931 \\
1932 \\
1933 \\
1934 \\
1935\end{array}$ & $\begin{array}{l}\text { June } 6,1931 \\
\text { June } 27,1932 \\
\text { June } 15,1933 \\
\text { Apr. } 22,23,1934 \\
\text { June } 12,13,1935\end{array}$ & $\begin{array}{l}\overline{-} \\
\overline{-} \\
-\end{array}$ & $\begin{array}{r}27 \\
142 \\
79 \\
22 \\
77\end{array}$ \\
\hline $\begin{array}{l}1926 \\
1927 \\
1928 \\
1929 \\
1930\end{array}$ & $\begin{array}{l}\text { June } 9,1926 \\
\text { June } 17,1927 \\
\text { May } 28,29,1928 \\
\text { June } 30,1929 \\
\text { June } 16,19,1930\end{array}$ & $\begin{array}{l}- \\
\overline{-} \\
-\end{array}$ & $\begin{array}{r}134 \\
162 \\
108 \\
58 \\
71\end{array}$ & $\begin{array}{l}1936 \\
1937 \\
1938 \\
1939 \\
1940\end{array}$ & $\begin{array}{l}\text { June } 24,1936 \\
\text { June } 22,1937 \\
\text { June } 27,1938 \\
\text { May 1, } 1939 \\
\text { June } 18,1940\end{array}$ & $\begin{array}{l}- \\
4.12 \\
=\end{array}$ & $\begin{array}{r}117 \\
113 \\
229 \\
47 \\
98 \\
\end{array}$ \\
\hline
\end{tabular}

Note.--Maximum daily mean discharges are shown prior to 1933. 
2665. Rock Creek near Round Valley, Callf.

Location.--Lat $37^{\circ} 26^{1}{ }^{2} 5^{\prime \prime}$, long $118^{\circ} 34^{1} 15^{\prime \prime}$, in SE $\frac{1}{4}$ sec.9, T.6 S., R.31 F., $0.1 \mathrm{mile}$ upstream from Pine Creek and 2 miles northwest of town of Pound Valley.

Drainage area.--96 sq mi, approximately.

Gage.--Nonrecording prior to July 1906, at site $600 \mathrm{ft}$ upstream at different datum, and July 1906 to November 1923, at described site and datum; recording thereafter. Altitude of gage is 4,450 ft (from topographic map).

Stage-discharge relation.--Defined by current-meter measurements below $100 \mathrm{cfs}$ prior to July 1906; below $180 \mathrm{cfs}$ thereafter.

Bankfull stage. - -Not subject to overflow.

Remarks.--Diversions above station for irrigation; at times flow diverted from Rock Creek to Owens River at elevation of about 7,300 ft. Records furnished by city of Los Angeles, Department of Water and Power. Only annual peaks are shown (maxlmum dally prior to 1933).

Peak stages and discharges

\begin{tabular}{|c|c|c|c|c|c|c|c|c|}
\hline $\begin{array}{l}\text { Water } \\
\text { year }\end{array}$ & Date & $\begin{array}{l}\text { Gage } \\
\text { helght } \\
\text { (feet) }\end{array}$ & $\begin{array}{c}\text { Discharge } \\
\text { (cfs) }\end{array}$ & $\begin{array}{l}\text { Water } \\
\text { year }\end{array}$ & & Date & $\begin{array}{l}\text { Gage } \\
\text { height } \\
\text { (feet) }\end{array}$ & $\begin{array}{c}\text { Discharge } \\
\text { (cfs) }\end{array}$ \\
\hline $\begin{array}{l}1904 \\
1905\end{array}$ & $\begin{array}{l}\text { June 16,17, } 1904 \\
\text { June } 19,1905\end{array}$ & $\overline{-}$ & $\begin{array}{r}109 \\
\mathrm{~s} 1\end{array}$ & & \multirow{7}{*}{\multicolumn{2}{|c|}{$\begin{array}{lr}\text { May } 30,1920 \\
\text { June } 11,1921 \\
\text { June } 6,1922 \\
\text { July } 5,1923 \\
\text { June } 19,1930 \\
\\
\text { Jan. } 31,1931 \\
\text { June } 28,1932 \\
\text { June } 15,1933 \\
\text { Jan. } 1,1934 \\
\text { June } 11,1935 \\
\text { June } 24,1936 \\
\text { June } 22,1937 \\
\text { June } 28,1938 \\
\text { Oct. } 6,1938 \\
\text { June } 18,1940\end{array}$}} & \multirow{7}{*}{$\begin{array}{l}- \\
= \\
- \\
- \\
- \\
= \\
- \\
- \\
- \\
-\end{array}$} & \multirow{7}{*}{$\begin{array}{r}84 \\
184 \\
137 \\
95 \\
60 \\
30 \\
143 \\
92 \\
110 \\
84 \\
107 \\
108 \\
274 \\
52 \\
94\end{array}$} \\
\hline 1906 & June $25,26,1906$ & - & 215 & $\begin{array}{l}1921 \\
1922\end{array}$ & & & & \\
\hline 1907 & June 30,1907 & $=$ & 195 & 1923 & & & & \\
\hline $\begin{array}{l}1908 \\
1909 \\
1910\end{array}$ & $\begin{array}{lrl}\text { Aug. } & 13, & 1908 \\
\text { July } & 3, & 1909 \\
\text { June } & 4, & 1910\end{array}$ & $\begin{array}{l}- \\
-\end{array}$ & $\begin{array}{r}80 \\
172 \\
94\end{array}$ & 1930 & & & & \\
\hline $\begin{array}{l}1911 \\
1912 \\
1913\end{array}$ & $\begin{array}{l}\text { June } 22,1911 \\
\text { June 11, } 1912 \\
\text { July 30 to } \\
\text { Aug. 1, } 1913\end{array}$ & $\overline{-}$ & $\begin{array}{r}225 \\
64 \\
61\end{array}$ & $\begin{array}{l}1931 \\
1932 \\
1933 \\
1934 \\
1935\end{array}$ & & & & \\
\hline $\begin{array}{l}1914 \\
1915\end{array}$ & $\begin{array}{l}\text { Jan. } 25,1914 \\
\text { June } 23,1915\end{array}$ & 5.0 & $\begin{array}{l}360 \\
111\end{array}$ & $\begin{array}{l}1936 \\
1937\end{array}$ & & & & \\
\hline $\begin{array}{l}1916 \\
1917 \\
1918 \\
1919\end{array}$ & $\begin{array}{lr}\text { June } 19, & 1916 \\
\text { July } 4, & 1917 \\
\text { June } 21, & 1918 \\
\text { May } 30, & 1919\end{array}$ & $\begin{array}{l}- \\
- \\
-\end{array}$ & $\begin{array}{l}157 \\
170 \\
185 \\
159\end{array}$ & $\begin{array}{l}1938 \\
1939 \\
1940\end{array}$ & & & & \\
\hline
\end{tabular}

Note.--Maximum dally mean discharges are shown prior to 1933.

2670. Pine Creek at division box, near Bishop, Calif.

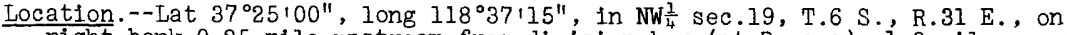
right bank 0.25 mile upstream from division box (at Rovana), 1.9 miles west of Round Valley schoolhouse, and 13 miles northwest of Bishop.

Drainage area. $--37.9 \mathrm{sq} \mathrm{mi}$. Mean altitude, $10,270 \mathrm{ft}$.

Gage.--Nonrecording prior to November 1938; recording and Parshall flume thereafter. Altitude of gage is $5,280 \mathrm{ft}$ (from topographic map).

Stage-discharge relation.--Unknown.

Remarks.--Records furnished by city of Los Angeles. Only annual peaks are shown.

Peak stages and discharges

\begin{tabular}{|c|c|c|c|c|c|c|c|c|c|}
\hline $\begin{array}{l}\text { Water } \\
\text { year }\end{array}$ & & Date & $\begin{array}{c}\text { Gage } \\
\text { height } \\
\text { (feet) }\end{array}$ & $\begin{array}{c}\text { Discharge } \\
\text { (cf's) }\end{array}$ & $\begin{array}{l}\text { Water } \\
\text { year }\end{array}$ & & Date & $\begin{array}{l}\text { Gage } \\
\text { helght } \\
\text { (feet) }\end{array}$ & $\begin{array}{c}\text { Discharge } \\
\text { (cfs) }\end{array}$ \\
\hline $\begin{array}{l}1922 \\
1923 \\
1924 \\
1925\end{array}$ & $\begin{array}{l}\text { June } \\
\text { July } \\
\text { May } \\
\text { June } \\
\text { July }\end{array}$ & $\begin{array}{r}26,1922 \\
2,1923 \\
9,1924 \\
28,1925 \\
18,1925\end{array}$ & $\begin{array}{l}3.62 \\
2.78 \\
2.14 \\
2.78 \\
2.78\end{array}$ & $\begin{array}{r}310 \\
201 \\
90 \\
153 \\
153\end{array}$ & $\begin{array}{l}1930 \\
1931 \\
1932 \\
1933 \\
1934\end{array}$ & $\begin{array}{l}\text { June } \\
\text { May } \\
\text { June } \\
\text { June } \\
\text { May }\end{array}$ & $\begin{array}{ll}12, & 1930 \\
18, & 1931 \\
25, & 1932 \\
14, & 1933 \\
13, & 1934\end{array}$ & $\begin{array}{l}2.78 \\
2.12 \\
3.62 \\
3.00 \\
2.32\end{array}$ & $\begin{array}{r}125 \\
61 \\
325 \\
195 \\
71\end{array}$ \\
\hline $\begin{array}{l}1926 \\
1927 \\
1925 \\
1929\end{array}$ & $\begin{array}{l}\text { May } \\
\text { June } \\
\text { May } \\
\text { June }\end{array}$ & $\begin{array}{ll}19, & 1926 \\
16, & 1927 \\
28, & 1928 \\
29, & 1929\end{array}$ & $\begin{array}{l}2.90 \\
3.93 \\
3.30 \\
2.68\end{array}$ & $\begin{array}{l}167 \\
295 \\
186 \\
127\end{array}$ & $\begin{array}{l}1935 \\
\\
1936 \\
1937\end{array}$ & $\begin{array}{l}\text { June } \\
\text { July } \\
\text { June }\end{array}$ & $\begin{array}{rr}5, & 1935 \\
21, & 1936 \\
21, & 1937\end{array}$ & $\begin{array}{l}3.07 \\
3.58 \\
3.56\end{array}$ & $\begin{array}{l}228 \\
350 \\
274\end{array}$ \\
\hline
\end{tabular}


Peak stages and discharges of Pine Creek at division box, near Blshop, Calff.--Continued

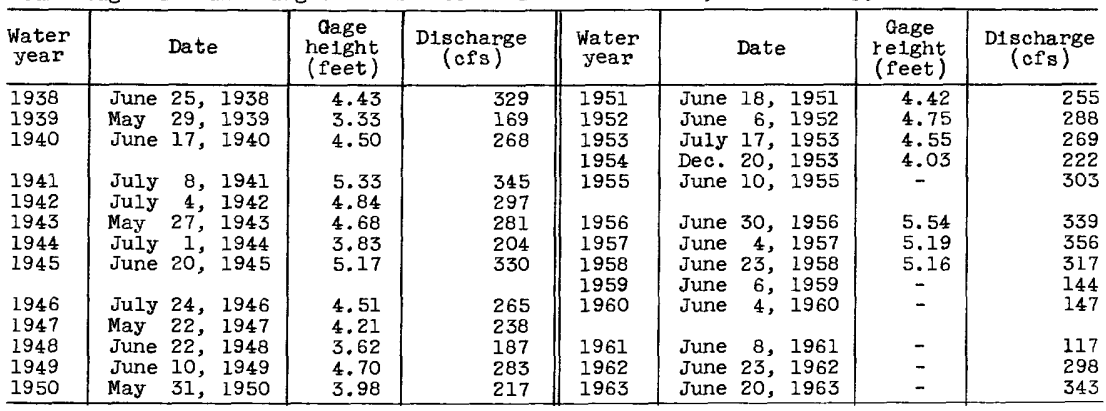

2675. Pine Creek near Round Valley, Calif.

Location. --Lat $37^{\circ} 26^{\prime} 10^{\prime \prime}$, long $118^{\circ} 34^{\prime} 10^{\prime \prime}$, in SE $\frac{1}{4}$ sec.9, T.6 S., R.31 E., $600 \mathrm{ft}$ upstream from mouth and 2 miles northwest of town of Round Valiey.

Drainage area. $--37.0 \mathrm{sq} \mathrm{m} 1$.

Gage.--Nonrecording prior to Nov. 11, 1923; recording thereafter, and since 1930, 6-foot Cippolett1 we1r. Prior to Aug. 23, 1906, at site $450 \mathrm{ft}$ downstream at different datum. Aug. 23, 1906, to May 13, 1908, at site $300 \mathrm{ft}$ downstream at different datum. May 13, 1908, to July 9, 1922 , at site $20 \mathrm{ft}$ upstream at same datum. Altitude of gage is $4,450 \mathrm{ft}$ (from topographic map).

Stage-discharge relation.--Def'ined by current-meter measurements below 92 cfs prior to Aug. 23, 1906; be1ow 210 cfs for period Aug. 23, 1903, to May 13, 1908; and below 250 cf's thereafter.

Bankfull stage. - Not subject to overflow.

Remarks.--Diversions for irrigation above station. Records for 1930-40 furnished by clty of Los Angeles, Department of Water and Power. Only annual peaks are shown.

Peak stages and discharges

\begin{tabular}{|c|c|c|c|c|c|c|c|c|}
\hline $\begin{array}{l}\text { Water } \\
\text { year }\end{array}$ & Date & $\begin{array}{c}\text { Cage } \\
\text { helght } \\
\text { (feet) }\end{array}$ & $\begin{array}{c}\text { Discharge } \\
\text { (cfs) }\end{array}$ & $\begin{array}{l}\text { Water } \\
\text { year }\end{array}$ & & Date & $\begin{array}{c}\text { Cage } \\
\text { helght } \\
\text { (feet) }\end{array}$ & $\begin{array}{c}\text { Discharge } \\
\text { (cfs) }\end{array}$ \\
\hline $\begin{array}{l}1904 \\
1905 \\
\end{array}$ & $\begin{array}{l}\text { June } 3,1904 \\
\text { June 13-16,1905 }\end{array}$ & - & $\begin{array}{l}\text { a213 } \\
\text { al19 }\end{array}$ & $\begin{array}{l}1919 \\
1920\end{array}$ & \multirow{4}{*}{\multicolumn{2}{|c|}{$\begin{array}{l}\text { May } 28,1919 \\
\text { June } 9,1920 \\
\text { June } 12,1921 \\
\text { June } 28,1922 \\
\text { June } 11, \text { July2, } \\
1923\end{array}$}} & \multirow{4}{*}{$\begin{array}{l}- \\
- \\
-\end{array}$} & \multirow{4}{*}{$\begin{array}{r}211 \\
\text { a110 } \\
\\
287 \\
\text { b300 } \\
\text { a85 }\end{array}$} \\
\hline 1907 & June 30,1907 & - & a.262 & 1921 & & & & \\
\hline 1908 & $\begin{array}{l}\text { July } 13,14, \\
16,1908\end{array}$ & - & a104 & $\begin{array}{l}1922 \\
1923 \\
\end{array}$ & & & & \\
\hline $\begin{array}{l}1909 \\
1910\end{array}$ & $\begin{array}{lll}\text { July } & 3, & 1909 \\
\text { June } & 4, & 1916\end{array}$ & - & $\begin{array}{l}\text { a318 } \\
\text { a277 }\end{array}$ & & & & & \\
\hline $\begin{array}{l}1911 \\
1912 \\
1913 \\
1914 \\
1915\end{array}$ & $\begin{array}{l}\text { June 22, } 1911 \\
\text { June 1, } 1912 \\
\text { July 22, } 1913 \\
\text { Jan. 25, } 1914 \\
\text { June 27, 30, }\end{array}$ & $\begin{array}{l}- \\
- \\
- \\
-\end{array}$ & $\begin{array}{l}\text { a370 } \\
\text { a118 } \\
\text { al93 } \\
\text { a251 } \\
\text { al40 }\end{array}$ & $\begin{array}{l}1931 \\
1932 \\
1933 \\
1934 \\
1935\end{array}$ & $\begin{array}{l}\text { Jan. } \\
\text { June } \\
\text { June } \\
\text { May } \\
\text { June }\end{array}$ & $\begin{array}{ll}31, & 1931 \\
26, & 1932 \\
16, & 1933 \\
17, & 1934 \\
12, & 1935\end{array}$ & $\begin{array}{l}- \\
- \\
- \\
-\end{array}$ & $\begin{array}{l}a 6.5 \\
a 264 \\
a 96 \\
a 40 \\
146\end{array}$ \\
\hline $\begin{array}{l}1916 \\
1917 \\
1918\end{array}$ & $\begin{array}{l}\text { July 1, } 1915 \\
\text { June 19, } 1916 \\
\text { June 16, } 1917 \\
\text { June 21,22,1918 }\end{array}$ & $\begin{array}{l}- \\
-\end{array}$ & $\begin{array}{l}a 244 \\
\text { a283 } \\
\text { a220 }\end{array}$ & $\begin{array}{l}1936 \\
1937 \\
1938 \\
1939 \\
1940\end{array}$ & $\begin{array}{l}\text { July } \\
\text { June } \\
\text { June } \\
\text { May } \\
\text { June }\end{array}$ & $\begin{array}{ll}22, & 1936 \\
21, & 1937 \\
27, & 1938 \\
30, & 1939 \\
13, & 1940\end{array}$ & $\begin{array}{l}- \\
\overline{-} \\
\overline{-}\end{array}$ & $\begin{array}{l}300 \\
293 \\
442 \\
114 \\
223\end{array}$ \\
\hline
\end{tabular}

a Maximum da.11y.

b About. 
2680. Owens River at Pleasant Valley, near Bishop, Calif.

Location.--Lat $37^{\circ} 25^{1} 00^{\prime \prime}$, long $118^{\circ} 31^{14} 0^{\prime \prime}$, in NW $\frac{1}{4} \sec .24$, T.6 S., R.31 E.,

$1,000 \mathrm{ft}$ upstream from Owens River canal intake, $2.2 \mathrm{miles}$ downstream from

Rock Creek, and 8 miles northwest of Blshop.

Drainage area. $--596 \mathrm{sq} \mathrm{mi}$.

Gage.--Recording. Altitude of gage is 4,350 ft (from topographic map).

Stage-discharge relation.--Defined by current-meter measurements below $1,200 \mathrm{cfs}$.

Bankfull stage.--Not subject to overflow.

Remarks.--Diversions for irrigation above station. Records fumished $k$ city

of Los Angeles, Department of Water and Power. Only annual peaks are shown.

Peak stages and discharges

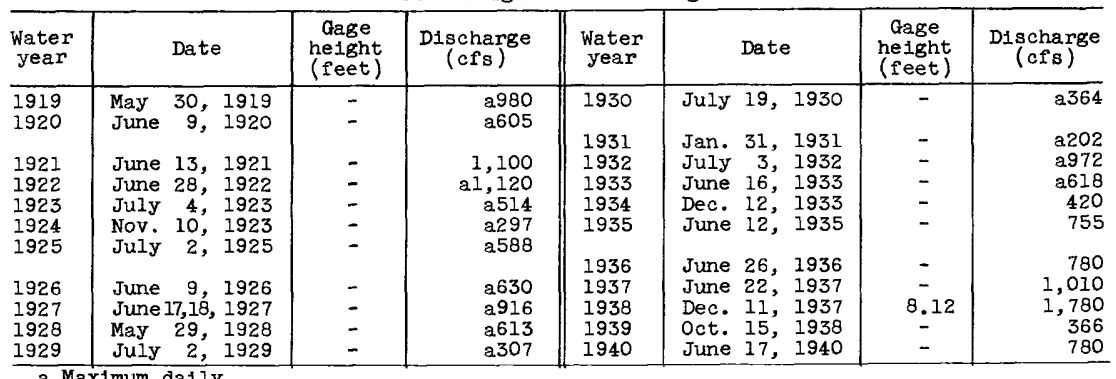

a Maximum daily.

2687. Silver Canyon Creek near Laws, Calif.

Location. --Lat $37^{\circ} 24^{\prime} 15^{\prime \prime}$, long $118^{\circ} 18^{13} 30^{\prime \prime}$, in NW $\frac{1}{4}$ sec.25, T.6 S., R.33 E., on right bank at mouth of canyon, 2.0 miles east of Laws.

Drainage area. $--22.4 \mathrm{sq} \mathrm{mi}$.

Gage.--Nonrecording and 2-foot Cippoletti weir prior to Feb. 24, 1943, at site $1 \frac{1}{2}$ miles downstream at different datum; recording and 1-foot Parshall

flume thereafter. Altitude of gage is 4,600 ft (from topographic mao).

Stage-discharge relation.--Discharge is determined from a standard rating for i-foot Parshall f'lume.

Remarks.--Records furnished by city of Los Angeles, Department of Water and Power. Only annual peaks are shown (maximum daily prior to 1944).

Peak stages and discharges

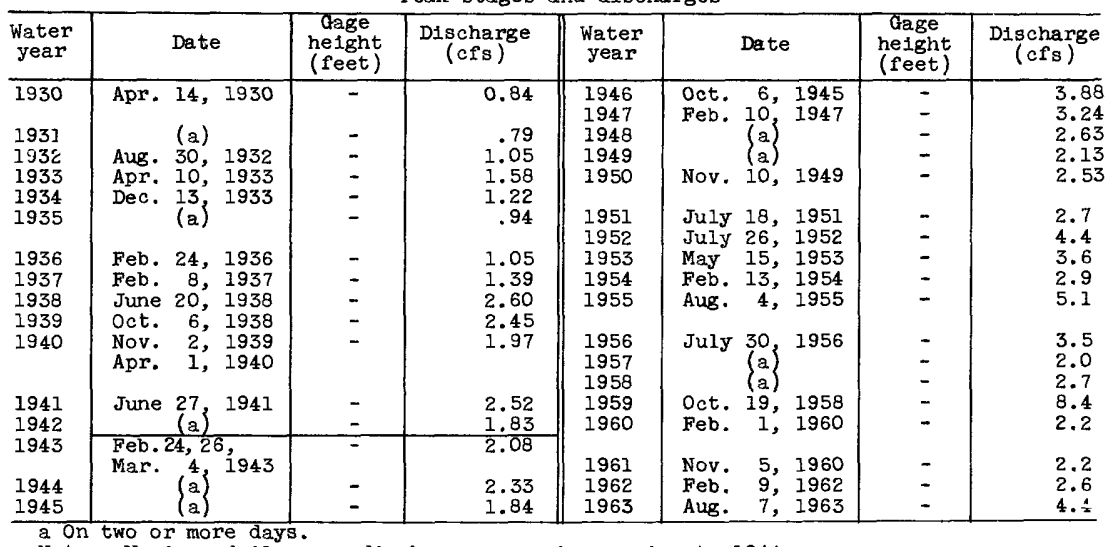

Note.--Maximum daily mean discharges are shown prior to 1944 .

$785-975$ O- $66-12$ 
2720. Bishop Creek near Bishop, Cal1f.

Location.--Lat $37^{\circ} 21^{\prime} 00^{\prime \prime}$, long $118^{\circ} 27^{\prime} 40^{\prime \prime}$, in SE $\frac{1}{4}$ sec.9, T.7 S., R.32 E., at

highway bridge, 4 miles west of Bishop.

Drainage area. $-105 \mathrm{sq} \mathrm{ml}$.

Gage.--Nonrecording. Altitude of gage is 4,450 ft (from topographic map).

Stage-discharge relation.--Defined by current-meter measurements below $400 \mathrm{cfs}$. Remarks.--Only annual maximum observed discharges are shown.

\begin{tabular}{|c|c|c|c|c|c|c|c|}
\hline $\begin{array}{l}\text { Water } \\
\text { year }\end{array}$ & Date & $\begin{array}{c}\text { Gage } \\
\text { he1ght } \\
\text { (feet) }\end{array}$ & $\begin{array}{c}\text { Discharge } \\
\text { (cfs) }\end{array}$ & $\begin{array}{l}\text { Water } \\
\text { year }\end{array}$ & Date & $\begin{array}{l}\text { Gage } \\
\text { helght } \\
\text { (feet) }\end{array}$ & $\begin{array}{c}\text { D1scharge } \\
\text { (efs) }\end{array}$ \\
\hline $\begin{array}{l}1904 \\
1905 \\
1906\end{array}$ & $\begin{array}{l}\text { June } 16-19,1904 \\
\text { June } 16-22,1905 \\
\text { July } 6,1906\end{array}$ & $\begin{array}{l}4.1 \\
3.8 \\
5.6\end{array}$ & $\begin{array}{l}479 \\
391 \\
822\end{array}$ & $\begin{array}{l}1907 \\
1908 \\
1909 \\
1910\end{array}$ & $\begin{array}{l}\text { June } 1907 \\
\text { Aug. 4, } 1908 \\
\text { June 26, } 1909 \\
\text { July } 22,1910\end{array}$ & $\begin{array}{l}- \\
3.7 \\
4.4 \\
4.0\end{array}$ & $\begin{array}{r}a 450 \\
370 \\
713 \\
477\end{array}$ \\
\hline
\end{tabular}

a About.

2760. Big Pine Creek near Big Pine, Calif.

Location.--Lat $37^{\circ} 08^{14} 0^{\prime \prime}$, long $118^{\circ} 18^{\prime} 55^{\prime \prime}$, in $\mathrm{NW} \frac{1}{4} \sec .25$, T.9 S., R.33 E., on left bank $0.3 \mathrm{mlle}$ downstream from Little Plne Creek, $0.5 \mathrm{mlle}$ downstream from powerhouse No. 3 , and 2.2 miles southwest of B1g Pine.

Drainage area. $--39.0 \mathrm{sq} \mathrm{ml}$. Mean altitude, 9,660 ft.

Gage.--Nonrecording prior to January 1923; recording and Parshall flume thereafter. Altitude of gage is $4,550 \mathrm{ft}$ (from topographic map).

Stage-discharge relation.--Unknown.

Remarks.--Records since Mar. 19, 1920, furnished by city of Los Angeles. Only annual peaks are shown.

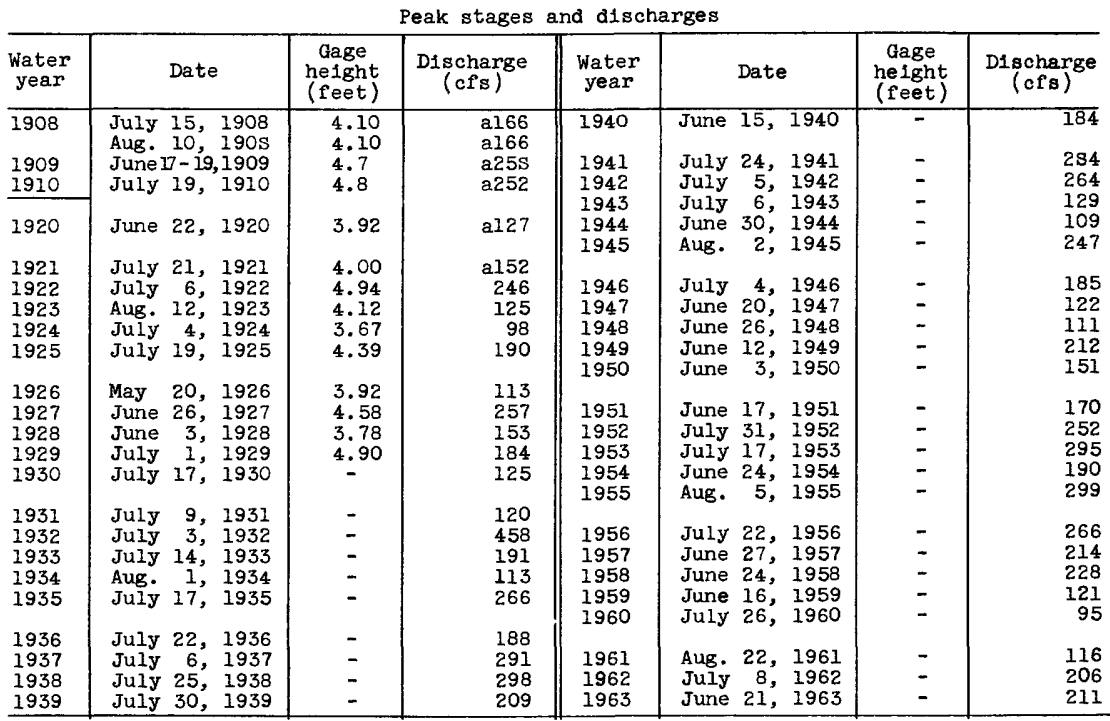

a Maximum observed. 
2775. Owens River near Big Pine, Calif.

(Published as "near Tinemaha" prior to 19i2)

Location.--Lat $37^{\circ} 00155^{\prime \prime}$, long $118^{\circ} 13^{\prime} 30^{\prime \prime}$, in SE $\frac{1}{4}$ sec.2, T.11 S., R. 34 E., on left bank 0.1 mile downstream from Little Seeley Spring, $0.15 \mathrm{mile}$ downstream from Charlies Butte, and 10.8 miles southeast of Big Pine.

Drainage area. $--1,930 \mathrm{sq} \mathrm{m}$, approximately.

Gage.--Nonrecording prior to Oct. 8, 1922; recording thereafter and roc's artificial control since October 1958. Altitude of gage is $3,800 \mathrm{ft}$ (from topographic map).

Stage-discharge relation.--Defined by current-meter measurements below 1,700 cf's.

Bankfull stage. $--8 \mathrm{ft}$.

Remarks:--Diversions from both main stream and tributaries. Flow regulated by Sabrina Reservoir and South Lake since 1911 (combined capacity, 20,970 acre-ft); Tinemaha Reservolr since 1929 (capacity, 16,000 acre-ft); Lake Crowley since 1941 (capacity, 183,500 acre-ft); and Pleasant Valley Reservoir since 1955 (capacity, 3,900 acre-ft). Water imported from Mono Iake basin since 1941 for diversion to Los Angeles aqueduct which diverts 4 miles downstream. Records furnished by city of Los Angeles, Department of Water and Power. Only annual peaks are shown.

Peak stages and discharges

\begin{tabular}{|c|c|c|c|c|c|c|c|c|}
\hline $\begin{array}{l}\text { Water } \\
\text { year }\end{array}$ & & Date & $\begin{array}{c}\text { Gage } \\
\text { height } \\
\text { (feet) }\end{array}$ & $\begin{array}{c}\text { Discharge } \\
(\mathrm{cfs})\end{array}$ & $\begin{array}{l}\text { Water } \\
\text { year }\end{array}$ & Date & $\begin{array}{c}\text { Gage } \\
\text { height } \\
\text { (feet) }\end{array}$ & $\begin{array}{c}\text { Discharge } \\
(\text { cfs })\end{array}$ \\
\hline $\begin{array}{l}1906 \\
1907 \\
1908 \\
1909 \\
1910\end{array}$ & $\begin{array}{l}\text { July } \\
\text { July } \\
\text { Feb. } \\
\text { July } \\
\text { Jan. }\end{array}$ & $\begin{array}{rr}29, & 1906 \\
8, & 1907 \\
5, & 1908 \\
6, & 1909 \\
3, & 1910\end{array}$ & $\begin{array}{l}- \\
7.35 \\
3.55 \\
6.9 \\
5.75\end{array}$ & $\begin{array}{r}\text { a2, } 610 \\
\text { al, } 710 \\
\text { a } 744 \\
\text { a1, } 680 \\
\text { al, } 320\end{array}$ & $\begin{array}{l}1936 \\
1937 \\
1938 \\
1939 \\
1940\end{array}$ & $\begin{array}{lrr}\text { June } & 3, & 1936 \\
\text { Feb. } 18, & 1937 \\
\text { July } 4, & 1938 \\
\text { Oct. } 19, & 1938 \\
\text { Nov. } & 9, & 1939\end{array}$ & $\begin{array}{l}4.08 \\
6.26 \\
7.75 \\
4.97 \\
4.60\end{array}$ & $\begin{array}{r}579 \\
970 \\
1,320 \\
768 \\
713\end{array}$ \\
\hline $\begin{array}{l}1911 \\
1912 \\
1913 \\
1914 \\
1915\end{array}$ & $\begin{array}{l}\text { July } \\
\text { Jan. } \\
\text { Feb. } \\
\text { Jan. } \\
\text { July }\end{array}$ & $\begin{array}{ll}20, & 1911 \\
16, & 1912 \\
28, & 1913 \\
26, & 1914 \\
7, & 1915\end{array}$ & $\begin{array}{l}7.85 \\
3.1 \\
3.2 \\
11.2 \\
4.2\end{array}$ & $\begin{array}{r}a 2,000 \\
a 517 \\
a 540 \\
b 3,220 \\
a 805\end{array}$ & $\begin{array}{l}1941 \\
1942 \\
1943 \\
1944 \\
1945\end{array}$ & $\begin{array}{lll}\text { Oct. } & 2, & 1940 \\
\text { Apr. } & 2, & 1942 \\
\text { Nov. } & 5, & 1942 \\
\text { Jan. } 4, & 1944 \\
\text { Aug. } 19, & 1945\end{array}$ & $\begin{array}{l}- \\
\overline{-} \\
\overline{-}\end{array}$ & $\begin{array}{l}\text { a } 640 \\
\text { a } 716 \\
\text { a } 696 \\
\text { a } 621 \\
\text { a } 671\end{array}$ \\
\hline $\begin{array}{l}1916 \\
1917 \\
1918 \\
1919 \\
1920\end{array}$ & $\begin{array}{l}\text { Jan. } \\
\text { Feb. } \\
\text { June } \\
\text { May } \\
\text { Dec. }\end{array}$ & $\begin{array}{ll}10, & 1916 \\
26, & 1917 \\
23, & 1918 \\
31, & 1919 \\
12, & 1919\end{array}$ & $\begin{array}{l}7.0 \\
4.75 \\
6.25 \\
4.8 \\
3.35\end{array}$ & $\begin{array}{r}\text { al, } 700 \\
\text { a980 } \\
\text { a. }, 250 \\
\text { a980 } \\
\text { a } 524\end{array}$ & $\begin{array}{l}1946 \\
1947 \\
1948 \\
1949 \\
1950\end{array}$ & $\begin{array}{l}\text { July } 30,1946 \\
\text { Aug. 17, } 1947 \\
\text { Apr. } 27,1948 \\
\text { Sept. 1, } 1949 \\
\text { Oct. } 13,1949\end{array}$ & $\begin{array}{l}- \\
- \\
-\end{array}$ & $\begin{array}{l}\text { a732 } \\
\text { a7s9 } \\
\text { a642 } \\
\text { a646 } \\
\text { a651 }\end{array}$ \\
\hline $\begin{array}{l}1921 \\
1922 \\
1923 \\
1924 \\
1925\end{array}$ & $\begin{array}{l}\text { June } \\
\text { Dec. } \\
\text { Dec. } \\
\text { Feb. } \\
\text { July }\end{array}$ & $\begin{aligned} 13, & 1921 \\
22, & 1921 \\
14, & 1922 \\
10, & 1924 \\
4, & 1925\end{aligned}$ & $\begin{array}{l}3.45 \\
6.50 \\
4.10 \\
3.30 \\
-\end{array}$ & $\begin{array}{r}a 524 \\
a 1,220 \\
651 \\
454 \\
a 456\end{array}$ & $\begin{array}{l}1951 \\
1952 \\
1953 \\
1954 \\
1955\end{array}$ & $\begin{array}{l}\text { July 13, } 1951 \\
\text { Mar. 27, } 1952 \\
\text { Dec. 31, } 1952 \\
\text { Sept. 8, } 1954 \\
\text { Oct. 10, } 1954\end{array}$ & $\begin{array}{l}- \\
\overline{-} \\
\overline{-}\end{array}$ & $\begin{array}{l}634 \\
663 \\
676 \\
61.0 \\
687\end{array}$ \\
\hline $\begin{array}{l}1926 \\
1927 \\
1928 \\
1929 \\
1930\end{array}$ & $\begin{array}{l}\text { June } \\
\text { Nov. } \\
\text { Nov. } \\
\text { Mar. } \\
\text { Feb. }\end{array}$ & $\begin{aligned} 11, & 1926 \\
28, & 1926 \\
12, & 1927 \\
7, & 1929 \\
24, & 1930\end{aligned}$ & $\begin{array}{l}- \\
- \\
- \\
-\end{array}$ & $\begin{array}{r}\text { a521 } \\
\text { a1, } 150 \\
\text { a } 516 \\
\text { a388 } \\
\text { a478 }\end{array}$ & $\begin{array}{l}1956 \\
1957 \\
1958 \\
1959 \\
1960\end{array}$ & $\begin{array}{l}\text { Aug. } 16,1956 \\
\text { Oct. } 23,1956 \\
\text { Jan. } 11,1958 \\
\text { Nov. } 18,1958 \\
\text { Oct. } 25,1959\end{array}$ & $\begin{array}{l}- \\
\overline{-} \\
\overline{-}\end{array}$ & $\begin{array}{l}726 \\
662 \\
676 \\
669 \\
665\end{array}$ \\
\hline $\begin{array}{l}1931 \\
1932 \\
1933 \\
1934 \\
1935 \\
\end{array}$ & $\begin{array}{l}\text { Mar. } \\
\text { July } \\
\text { June } \\
\text { Dec. } \\
\text { Nov. }\end{array}$ & $\begin{array}{rr}27, & 1931 \\
12, & 1932 \\
24, & 1933 \\
7, & 1933 \\
27, & 1934 \\
\end{array}$ & $\begin{array}{l}- \\
- \\
4.41 \\
4.08 \\
4.10\end{array}$ & $\begin{array}{r}2506 \\
a 721 \\
555 \\
650 \\
592 \\
\end{array}$ & $\begin{array}{l}1961 \\
1962 \\
1963\end{array}$ & $\begin{array}{lll}\text { Aug. } 25, & 1961 \\
\text { Oct. } 17, & 1961 \\
\text { July } 21, & 1963\end{array}$ & $\overline{6.31}$ & $\begin{array}{l}590 \\
636 \\
7 \mathrm{~S} 4\end{array}$ \\
\hline
\end{tabular}

a Maximum daily.

b About. 
2780. Taboose Creek near Aberdeen, Calif.

Location.--Lat $36^{\circ} 59^{\prime} 55^{\prime \prime}$, long $118^{\circ} 15120^{\prime \prime}$, in $\mathrm{NE}_{\frac{1}{4}} \mathrm{NE} \frac{1}{4} \mathrm{sec} .16$, T.11 S., R.34 E., 1.4 miles north of Aberdeen and 2.5 miles northwest of Aberdeen railway station.

Drainage area. $--13.9 \mathrm{sq} \mathrm{mi}$.

Gage.-Nonrecording. Prior to Feb. 25, 1907, at site about 2 miles downstream at different datum. Feb. 25, 1907, to Dec. 31, 1909, at datum 1.0 ft higher. Altitude of gage is $3,950^{\circ} \mathrm{ft}$ (from topographic map).

Stage-discharge relation.--Defined by current-meter measurements below 56 cfs prior to Feb. 25, 1907; below 32 cfs thereafter. Subject to changes owing to unstable channel conditions.

Remarks.--Only annual maximum observed discharges are shown.

\begin{tabular}{|c|c|c|c|c|c|c|c|}
\hline $\begin{array}{l}\text { Water } \\
\text { year }\end{array}$ & Date & $\begin{array}{l}\text { Cage } \\
\text { helght } \\
\text { (feet) }\end{array}$ & $\begin{array}{c}\text { Discharge } \\
\text { (cfs) }\end{array}$ & $\begin{array}{l}\text { Water } \\
\text { year }\end{array}$ & Date & $\begin{array}{l}\text { Gage } \\
\text { he1ght } \\
\text { (feet) }\end{array}$ & $\begin{array}{c}\text { Discharge } \\
(\text { cfs })\end{array}$ \\
\hline $\begin{array}{l}1906 \\
1907 \\
1908 \\
\end{array}$ & $\begin{array}{lrr}\text { July } & 14, & 1906 \\
\text { July } & 5, & 1907 \\
\text { July } 12-15, & 1908\end{array}$ & $\begin{array}{r}- \\
0.9 \\
.7 \\
\end{array}$ & $\begin{array}{l}56 \\
28 \\
14 \\
\end{array}$ & $\begin{array}{l}1909 \\
1910\end{array}$ & $\begin{array}{lrl}\text { July } & 2, & 1909 \\
\text { May } & 30, & 1910\end{array}$ & $\frac{-}{1.4}$ & $\begin{array}{l}39 \\
15\end{array}$ \\
\hline
\end{tabular}

2785. Goodale Creek near Aberdeen, Calif.

Location.--Lat $36^{\circ} 59^{\prime} 10^{\prime \prime}$, 1ong $118^{\circ} 15^{\prime} 50^{\prime \prime}$, in NE $\frac{1}{4} N W^{\frac{1}{4}}$ sec.21, T.11 S., R.34 E.,

$0.8 \mathrm{mile}$ northwest of Aberdeen and 3 miles west of Aberdeen railway section.

Drainage area. $--11.2 \mathrm{sq} \mathrm{mi}$.

Gage.--Nonrecording. Prior to Mar. 7, 1910, at datum 1.00 ft higher. Altitude of gage is $3,950 \mathrm{ft}$ (from topographic map).

Stage-discharge relation.--Defined by current-meter measurements.

Remarks.--Only annual maximum observed discharges are shown.

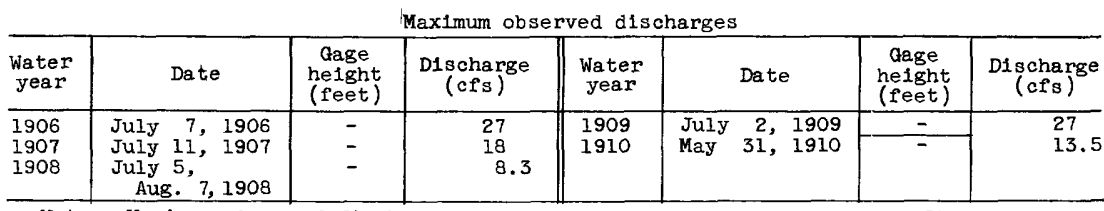

Note. --Maximum observed discharge usualiy occurs on several days; only first day of occurence is shown.

2815. Oak Creek near Independence, Calıf.

Location.--Lat $36^{\circ} 50^{\prime} 00^{\prime \prime}$, long $118^{\circ} 14^{\prime} 35^{\prime \prime}$, in $\mathrm{SE}_{\frac{1}{4}}$ sec.2, T.13 S., R.34 E., three-quarters of a mile west of Bell's flour mill and 3.2 miles northwest of Independence.

Drainage area. $--26.9 \mathrm{sq} \mathrm{m} 1$.

Gage.--Nonrecording. Prior to Apr. 19, 1907, at two sites witrin a mile downstream at different datums. Altitude of gage is $4,250 \mathrm{ft}$ (from topographic map).

Stage-discharge relation.--Defined by current-meter measurements below 36 ef's prior to Apr. 19, 1907; below 95 ef's thereafter.

Remarks.--only annual maximum observed discharges are shown. 
Maximum observed stages and djscharges of Oak Creek near Independence, Calif.

\begin{tabular}{l|c|c|c||c|c|c|c}
\hline $\begin{array}{c}\text { Water } \\
\text { year }\end{array}$ & Date & $\begin{array}{c}\text { Cage } \\
\text { he1ght } \\
\text { (feet) }\end{array}$ & $\begin{array}{c}\text { Discharge } \\
\text { (cfs) }\end{array}$ & $\begin{array}{c}\text { Water } \\
\text { year }\end{array}$ & Date & $\begin{array}{c}\text { Gage } \\
\text { he1ght } \\
\text { (feet) }\end{array}$ & $\begin{array}{c}\text { Discharge } \\
\text { (cfs) }\end{array}$ \\
\hline 1906 & July 7, 1906 & - & 162 & 1909 & July 3, 1909 & 1.7 & \\
1907 & July 4, 1907 & 1.0 & 88 & 1910 & July 18, 1910 & 1.15 & \\
\hline 1908 & July 4-12,1908 & .65 & 32 & & \\
\hline
\end{tabular}

2818. Independence Creek below Pinyon Creek, near Independence, Calif.

Location. --Lat $36^{\circ} 46^{\prime} 45^{\prime \prime}$, long $118^{\circ} 15^{\prime} 45^{\prime \prime}$, in NE $\frac{1}{4} \sec .27$, T.13 S., R. 34 E., on right bank 0.2 mile downstream from Pinyon Creek and 4.0 miles southrest of Independence.

Drainage area. $--18.2 \mathrm{sq} \mathrm{mi}$.

Gage.--Recording. Sept. 12, 1934, to Dec. 13, 1936, Cippoletti weir (renoved during high water); 4-foot Parshall flume thereafter. Altitude of gage is 5,300 ft (from topographic map).

Stage-discharge relation.--Defined by current-meter measurements below $81 \mathrm{cfs}$.

Remarks.--Records fumished by city of Los Angeles, Department of Water and

Power. Only annual peaks are shown (maximum daily prior to 1952).

Peak stages and discharges

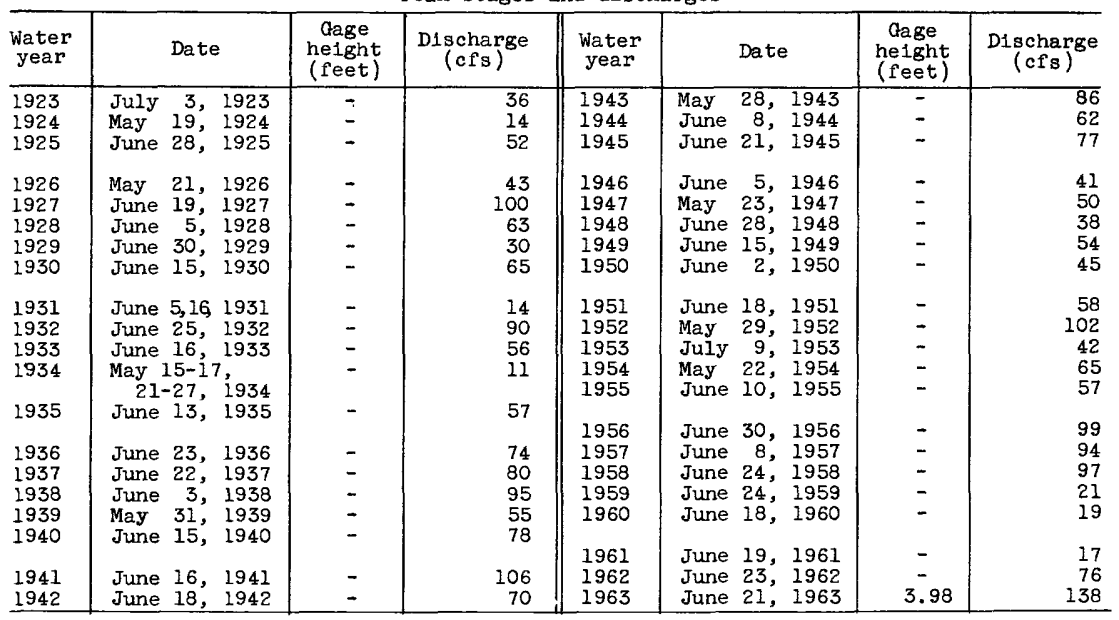

Note.--Maximum da1ly mean discharges are shown prior to 1952 .

2820. Independence Creek near Independence, Calif.

(Published in annual Water Supply Papers as "Little Pine Creek")

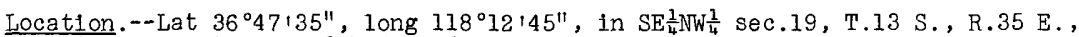
1.0 mile southwest of Independence.

Drainage area. $--21.4 \mathrm{sq} \mathrm{mi}$.

Gage.--Nonrecording. Prior to Aug. 20, 1906, at site $300 \mathrm{ft}$ downstream at dif-

ferent datum. Altitude of gage is $4,150 \mathrm{ft}$ (from topographic map).

Stage-discharge relation.--Defined by current-meter measurements below 144 cfs prior to Aug. 20, 1906; below 130 cfs thereafter.

Remarks.--Only annual maximum observed discharges are shown. 
Maximum observed discharges of Independence Creek near Indepenjence, Calif.

\begin{tabular}{|c|c|c|c|c|c|c|c|}
\hline $\begin{array}{l}\text { Water } \\
\text { year }\end{array}$ & Date & $\begin{array}{c}\text { Cage } \\
\text { height } \\
\text { (feet) }\end{array}$ & $\begin{array}{c}\text { Discharge } \\
\text { (cfs) }\end{array}$ & $\begin{array}{l}\text { Water } \\
\text { year }\end{array}$ & Date & $\begin{array}{c}\text { Gage } \\
\text { height } \\
\text { (feet) }\end{array}$ & $\begin{array}{c}\text { Discharge } \\
(\mathrm{cfs})\end{array}$ \\
\hline 1905 & June 15,1905 & 1.10 & a47 & $\begin{array}{l}1908 \\
1909\end{array}$ & $\begin{array}{l}\text { July } 2-6,1908 \\
\text { June } 25-27,1909\end{array}$ & $\overline{-}$ & $\begin{array}{r}35 \\
140\end{array}$ \\
\hline $\begin{array}{l}1906 \\
1907\end{array}$ & $\begin{array}{lll}\text { July } & 9, & 1906 \\
\text { July } & 5 & 1907\end{array}$ & $=$ & $\frac{144}{137}$ & 1910 & July 18, 1910 & - & 71 \\
\hline
\end{tabular}

a Maximum observed during period June 15 to Sept. 31, 1905.

2845. Owens River near Lone Pine, Calif .

Location.--Lat $36^{\circ} 37^{\prime} 10^{\prime \prime}$, long $118^{\circ} 02^{\prime} 05^{\prime \prime}$, in NW $\frac{1}{4}$ sec.23, T.15 S., R.36 E., at Mount Whitney Highway bridge and 2 miles northeast of Lone Pine.

Gage.--Nonrecording. Prior to February 1914, at datum $1.83 \mathrm{ft}$ lower. Altitude of gage is $3,650 \mathrm{ft}$ (from topographic map).

Stage-discharge relation.--Defined by current-meter measurements below 2,000 cfs.

Remarks.--Many diversions above station. Only annual maximum observed discharges are shown.

Maximum observed discharges

\begin{tabular}{|c|c|c|c|c|c|c|c|}
\hline $\begin{array}{l}\text { Water } \\
\text { year }\end{array}$ & Date & $\begin{array}{c}\text { Gage } \\
\text { height } \\
\text { (feet) }\end{array}$ & $\begin{array}{l}\text { Discharge } \\
\text { (cfs) }\end{array}$ & $\begin{array}{l}\text { Water } \\
\text { year }\end{array}$ & Date & $\begin{array}{l}\text { Gage } \\
\text { he1ght } \\
\text { (feet) }\end{array}$ & $\begin{array}{c}\text { Discharge } \\
\text { (cfs) }\end{array}$ \\
\hline $\begin{array}{l}1909 \\
1910\end{array}$ & $\begin{array}{lll}\text { July } & 7, & 1909 \\
\text { Jan. } & 5, & 1910\end{array}$ & $\begin{array}{l}10.6 \\
10.2\end{array}$ & $\begin{array}{l}2,050 \\
1,770\end{array}$ & $\begin{array}{l}1914 \\
1915\end{array}$ & $\begin{array}{lr}\text { Jan. } & 28,1914 \\
\text { Feb. } & 3,1915\end{array}$ & $\frac{11.8}{6.1}$ & $\begin{array}{r}1,920 \\
729\end{array}$ \\
\hline $\begin{array}{l}1911 \\
1912 \\
1913 \\
\end{array}$ & $\begin{array}{l}\text { July } 22,1911 \\
\text { Jan. } 17-20,1912 \\
\text { Jan. } 28,1913\end{array}$ & $\begin{array}{l}- \\
6.6 \\
6.7\end{array}$ & $\begin{array}{r}1,660 \\
564 \\
560 \\
\end{array}$ & $\begin{array}{l}1916 \\
1917 \\
1918\end{array}$ & $\begin{array}{l}\text { Feb. } 25,1916 \\
\text { Feb. } 27,1917 \\
\text { June } 25,1918\end{array}$ & $\begin{array}{l}- \\
7.0 \\
6.65\end{array}$ & $\begin{array}{r}1,400 \\
906 \\
810 \\
\end{array}$ \\
\hline
\end{tabular}

2850. Lone Pine Creek near Lone Pine, Calif.

Location.--Lat $36^{\circ} 36^{\prime} 1^{\prime \prime}$, long $118^{\circ} 04^{14} 0^{\prime \prime}$, in SE $\frac{1}{4}$ sec.29, T.15 S., R. 36 E.,

about $1,000 \mathrm{ft}$ upstream from division box and 1 mile west of Lone Pine.

Drainage area. $--33.4 \mathrm{sq} \mathrm{mi}$.

Gage.--Nonrecording. Altitude of gage is 5,850 ft (from topographic map).

Stage-discharge relation.--Defined by current-meter measurements below $139 \mathrm{cfs}$.

Remarks.--Only annual maximum observed discharges are shown.

Maximum observed discharges

\begin{tabular}{|c|c|c|c|c|c|c|c|}
\hline $\begin{array}{l}\text { Water } \\
\text { year }\end{array}$ & Date & $\begin{array}{c}\text { Gage } \\
\text { height } \\
\text { (feet) }\end{array}$ & $\begin{array}{c}\text { Discharge } \\
\text { (cfs) }\end{array}$ & $\begin{array}{l}\text { Water } \\
\text { year }\end{array}$ & Date & $\begin{array}{l}\text { Gage } \\
\text { nelght } \\
\text { (feet) }\end{array}$ & $\begin{array}{c}\text { Discharge } \\
\text { (cfs) }\end{array}$ \\
\hline $\begin{array}{l}1906 \\
1907 \\
1908 \\
\end{array}$ & $\begin{array}{ll}\text { July } 25, & 1906 \\
\text { July } 4-7, & 1907 \\
\text { Aug. } 3-6, & 1908\end{array}$ & - & $\begin{array}{r}139 \\
80 \\
110\end{array}$ & $\begin{array}{l}1909 \\
1910\end{array}$ & $\begin{array}{l}\text { June 29, } 1909 \\
\text { May } 30,1910\end{array}$ & 3.1 & $\begin{array}{r}118 \\
47\end{array}$ \\
\hline
\end{tabular}

2855. Tuttle Creek near Lone Pine, Calif.

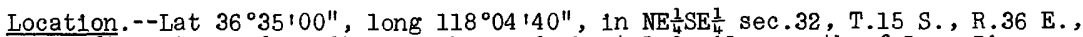
$50 \mathrm{ft}$ upstream from division box and about $1.8 \mathrm{miles}$ south of Lone pine.

Dralnage area. $--14.0 \mathrm{sq} \mathrm{mi}$.

Gage.--Nonrecording. Altitude of gage is 3,900 ft (from topographic map).

Stage-discharge relation.--Defined by current-meter measurements below $85 \mathrm{cfs}$. Remarks.--Only annual naximum observed discharges are shown. 
Maximum observed discharges of Tuttle Creek near Lone P1ne, Cal1f.

\begin{tabular}{l|c|c|c||c|c|c|c}
\hline $\begin{array}{c}\text { Water } \\
\text { year }\end{array}$ & Date & $\begin{array}{c}\text { Gage } \\
\text { height } \\
\text { (feet) }\end{array}$ & $\begin{array}{c}\text { Digcharge } \\
\text { (cfs) }\end{array}$ & $\begin{array}{c}\text { Water } \\
\text { year }\end{array}$ & Date & $\begin{array}{c}\text { Gage } \\
\text { height } \\
\text { (feet) }\end{array}$ & $\begin{array}{c}\text { Discharge } \\
\text { (cfs) }\end{array}$ \\
\hline 1906 & July 25, 1906 & - & 67 & 1909 & July 1, 1909 & - & \\
1907 & May 21, 1907 & 1.10 & 85 & 1910 & Dec.7-11, 1909 & - & \\
1908 & Aug. 7, 1908 & 1.32 & 21 & & \\
\hline
\end{tabular}

2857. Owens River at Keeler Bridge, near Lone Plne, Calif.

Location.--Lat $36^{\circ} 34^{\prime} 30^{\prime \prime}$, long $118^{\circ} 00^{\prime} 45^{\prime \prime}$, in NW/ sec.1, T.16 S., R.36 E., on left bank under old itimber bridge, 0.5 mile upstream from bridge on state Highway 190 and 3.4 miles southeast of Lone Pine.

Gage.--Nonrecording prior to Feb. 15, 1935, and 3-foot Cippoletti weir Oct. 20, 1930 , to Feb. 14, 1935, at present site at different datums; recording and 10-foot Cippoletti weir thereafter.' Altitude of gage is $3,600 \mathrm{ft}$ (from topographic map).

Stage-discharge relation.--Defined by current-meter measurements.

Remarks. - Natural flow affected by storage in several reservoirs, many natural lakes, diversions for irrigation, and return flow from irrigated areas.

Records furmished by city of Los Angeles, Department of Water and Power.

only annual peaks are shown (maximum daily prior to 1951).

Peak stages and discharges

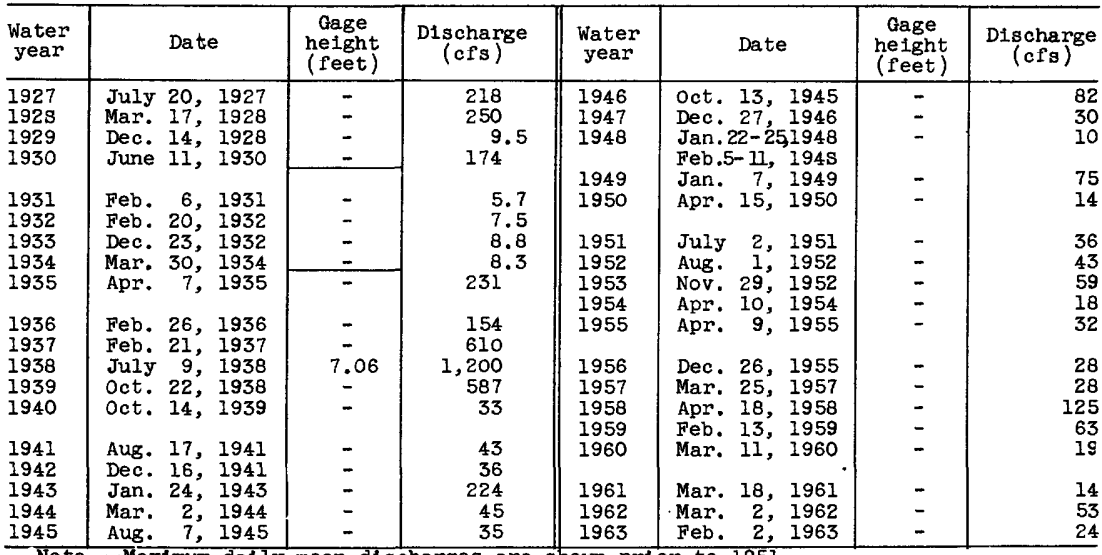

Note. - Maximum da1ly mean discharges are shown prior to 1951.

2860. Cottonwood Creek near Olancha, Calif.

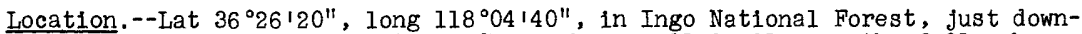
stream from intake to Cottonwood'powerhouse, 11.2 miles north of olancha.

Drainage area. $--39.9 \mathrm{sq} \mathrm{mi}$. Mean altitude, 9,960 ft.

Gage.--Nonrecording prior to Mar. 7, 1921; recording thereafter. Parshall fiume since October 1938. Prior to Sept. 9, 1908, at site about 2 miles downstream at different datum. Sept. 9, 1908, to Mar. 31, 1911, and Jan. 1, 1914 , to Oct. 31, 1938, at site just upstream from intake to Cottonw rod powerhouse at different aatum.

Stage-discharge relation.--Unknown.

Remarks.--Records since June 1, 1914, furnished by city of Los Angeles. Only annual peaks are shown. 
Peak stages and discharges of Cottonwood Creek near Olancha, Calif.

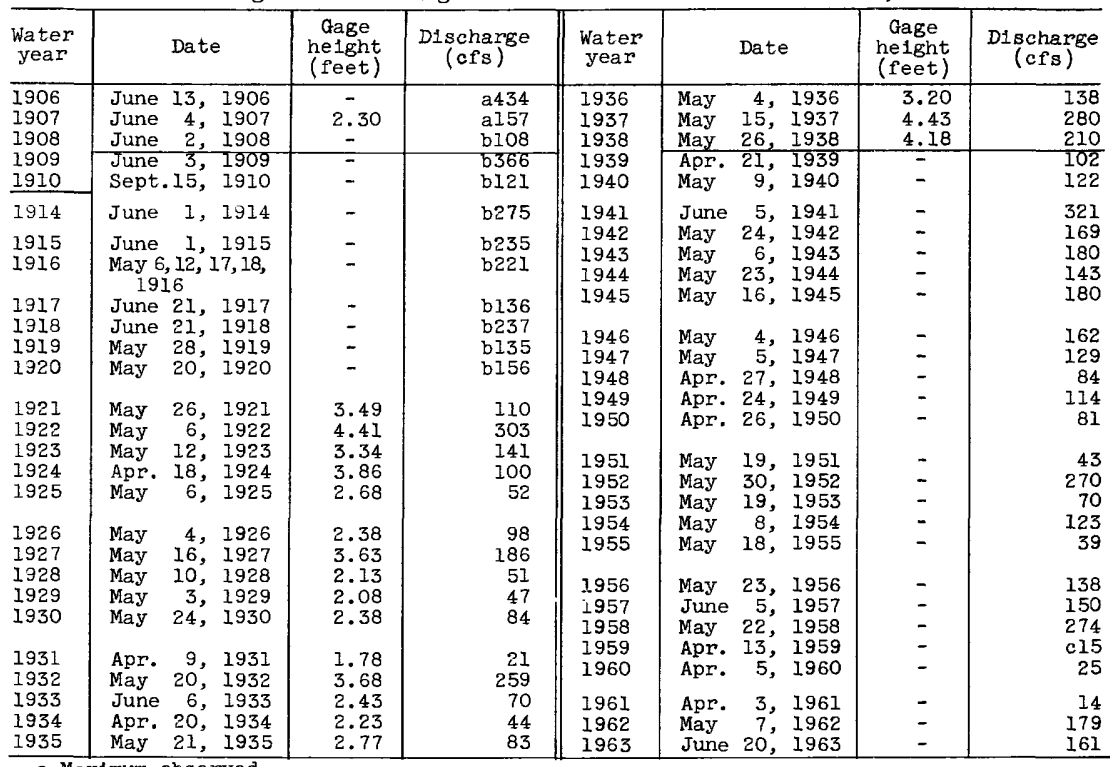

a Maximum observed.

b Maximum dally discharge at site below Cottonwood powerhouse intake.

c Does not include diversion to powerhouse.

\section{MONO LAKE BASIN}

2874. Rush Creek above Grant Lake, near June Lake, Calif.

Location. --Lat $37^{\circ} 48120^{\prime \prime}$, long $119^{\circ} 06^{1} 30^{\prime \prime}$, In NE $\frac{1}{4}$ sec.4, T.2 S., R.26 E., on left bank in narrows, 0.6 mile upstream from Grant Lake and 2.7 miles northwest of town of June Lake.

Drainage area. $--51.2 \mathrm{sq} \mathrm{mi}$.

Gage.--Recording and 15-foot Parshall flume. Alt1tude of gage is 7,200 ft (from topographic map).

Stage-discharge relation.--Defined by current-meter measurements.

Remarks. - Flow regulated by Gem Lake, Lake Agnew, and Waugh Lake (combined capacity, 23,400 acre-ft), and by many natural lakes. Records fumished by city of Los Angeles, Department of Water and Power. Only annual peaks are shown (maximum daily prior to 1951).

Peak stages and discharges

\begin{tabular}{|c|c|c|c|c|c|c|c|c|}
\hline $\begin{array}{l}\text { Water } \\
\text { year }\end{array}$ & \multicolumn{2}{|r|}{ Date } & $\begin{array}{c}\text { Gage } \\
\text { helght } \\
\text { (feet) }\end{array}$ & $\begin{array}{c}\text { D1scharge } \\
\text { (cfs) }\end{array}$ & $\begin{array}{l}\text { Water } \\
\text { year }\end{array}$ & Date & $\begin{array}{l}\text { Gage } \\
\text { helght } \\
\text { (feet) }\end{array}$ & $\begin{array}{c}\text { Discharge } \\
\text { (cfs) }\end{array}$ \\
\hline $\begin{array}{l}1937 \\
1938\end{array}$ & $\begin{array}{l}\text { May } \\
\text { June }\end{array}$ & $\begin{array}{l}29,1937 \\
28,1938\end{array}$ & - & $\begin{array}{l}200 \\
711\end{array}$ & $\begin{array}{l}1951 \\
1952\end{array}$ & $\begin{array}{lrl}\text { Nov, } 19, & 1950 \\
\text { July } & 8, & 1952\end{array}$ & - & $\begin{array}{l}219 \\
457\end{array}$ \\
\hline $\begin{array}{l}1939 \\
1940\end{array}$ & $\begin{array}{l}\text { Apr. } \\
\text { May }\end{array}$ & $\begin{array}{ll}23, & 1939 \\
24, & 1940\end{array}$ & $\ddot{-}$ & $\begin{array}{l}134 \\
185\end{array}$ & $\begin{array}{l}1954 \\
1955\end{array}$ & $\begin{array}{lll}\text { May } 21, & 1954 \\
\text { June } 10, & 1955\end{array}$ & $\overline{-}$ & $\begin{array}{l}201 \\
260\end{array}$ \\
\hline $\begin{array}{l}1941 \\
1942 \\
1943 \\
1944 \\
1945\end{array}$ & $\begin{array}{l}\text { July } \\
\text { July } \\
\text { May } \\
\text { June } \\
\text { July }\end{array}$ & $\begin{array}{rr}8, & 1941 \\
17, & 1942 \\
27, & 1943 \\
8, & 1944 \\
1, & 1945\end{array}$ & $\begin{array}{l}- \\
- \\
-\end{array}$ & $\begin{array}{l}485 \\
265 \\
233 \\
194 \\
344\end{array}$ & $\begin{array}{l}1956 \\
1957 \\
1958 \\
1959 \\
1960\end{array}$ & 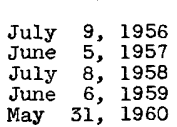 & $\begin{array}{l}- \\
- \\
-\end{array}$ & $\begin{array}{l}394 \\
227 \\
455 \\
126 \\
148\end{array}$ \\
\hline $\begin{array}{l}1946 \\
1947 \\
1948 \\
1949 \\
1950 \\
\end{array}$ & $\begin{array}{l}\text { June } \\
\text { Nov. } \\
\text { June } \\
\text { June } \\
\text { June }\end{array}$ & $\begin{array}{rr}6, & 1946 \\
23, & 1946 \\
26, & 1948 \\
11, & 1949 \\
1,2, & 1950\end{array}$ & $\begin{array}{l}- \\
- \\
- \\
-\end{array}$ & $\begin{array}{l}207 \\
136 \\
366 \\
206 \\
185\end{array}$ & $\begin{array}{l}1961 \\
1962 \\
1963\end{array}$ & $\begin{array}{l}\text { June } 12,1961 \\
\text { June 23, } 1962 \\
\text { June 20, } 1963\end{array}$ & $\overline{-}$ & $\begin{array}{l}128 \\
250 \\
307\end{array}$ \\
\hline
\end{tabular}

Note.--Maximum da1ly mean discharges are shown prior to 1951. 
2879. Lee Vining Creek near Lee Vining, Calif.

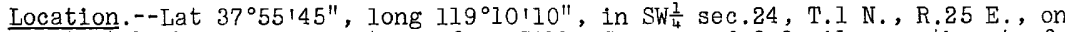
right bank $0.8 \mathrm{mile}$ upstream from Gibbs Canyon and 3.3 miles southwest of Lee Vining.

Drainage area. $--35.2 \mathrm{sq} \mathrm{mi}$.

Gage.--Nonrecording prior to Aug. 6, 1944; recording thereafter. At different datum prior to oct. 17, 1955; concrete control at present datum thereafter. Altitude of gage is $7,400 \mathrm{ft}$ (from topographic map).

Stage-discharge relation.--Defined by current-meter measurements.

Remarks.--Flow regulated by Ellery, Saddlebag, and Tioga Lakes, and several small natural lakes. Records furnished by city of Los Angeles, Department of Water and Power. Only annual peaks are shown (maximum daily prior to 1951).

Peak stages and discharges

\begin{tabular}{|c|c|c|c|c|c|c|c|c|}
\hline $\begin{array}{l}\text { Water } \\
\text { year }\end{array}$ & & Date & $\begin{array}{c}\text { Cage } \\
\text { nelght } \\
\text { (feet) }\end{array}$ & $\begin{array}{c}\text { Discharge } \\
\text { (cfs) }\end{array}$ & $\begin{array}{c}\text { Water } \\
\text { year }\end{array}$ & Date & $\begin{array}{l}\text { Gage } \\
\text { he1ght } \\
\text { (feet) }\end{array}$ & $\begin{array}{c}\text { Discharge } \\
\text { (cfs) }\end{array}$ \\
\hline 1935 & June & 7, 1935 & - & 391 & 1950 & June $2,6,1950$ & - & 237 \\
\hline $\begin{array}{l}1936 \\
1937 \\
1938 \\
1939 \\
1940\end{array}$ & $\begin{array}{l}\text { June } \\
\text { June } \\
\text { June } \\
\text { May } \\
\text { June }\end{array}$ & $\begin{array}{r}22,1936 \\
7,1937 \\
9,1938 \\
31,1939 \\
13-17,1940\end{array}$ & $\begin{array}{l}- \\
- \\
- \\
-\end{array}$ & $\begin{array}{l}310 \\
304 \\
503 \\
157 \\
294\end{array}$ & $\begin{array}{l}1951 \\
1952 \\
1953 \\
1954 \\
1955\end{array}$ & $\begin{array}{lr}\text { June } 17,1951 \\
\text { June } 8,1952 \\
\text { June } 19,1953 \\
\text { May } 20,1954 \\
\text { June } 8,1955\end{array}$ & $\begin{array}{l}- \\
- \\
-\end{array}$ & $\begin{array}{l}385 \\
400 \\
391 \\
254 \\
278\end{array}$ \\
\hline $\begin{array}{l}1941 \\
1942 \\
1943 \\
1944 \\
1945\end{array}$ & $\begin{array}{l}\text { June } \\
\text { June } \\
\text { June } \\
\text { June } \\
\text { June }\end{array}$ & 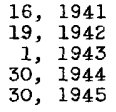 & $\begin{array}{l}- \\
\overline{-} \\
\overline{-}\end{array}$ & $\begin{array}{l}389 \\
345 \\
501 \\
152 \\
293\end{array}$ & $\begin{array}{l}1956 \\
1957 \\
1958 \\
1959 \\
1960\end{array}$ & $\begin{array}{ll}\text { June } 29, & 1956 \\
\text { June 5, } & 1957 \\
\text { June 24, } & 1958 \\
\text { May 12, 13, } & 1959 \\
\text { June 2, } & 1960\end{array}$ & $\begin{array}{l}- \\
\overline{-} \\
\overline{-}\end{array}$ & $\begin{array}{l}391 \\
378 \\
335 \\
165 \\
216\end{array}$ \\
\hline $\begin{array}{l}1946 \\
1947 \\
1948 \\
1949 \\
\end{array}$ & $\begin{array}{l}\text { May } \\
\text { May } \\
\text { June } \\
\text { June }\end{array}$ & $\begin{array}{ll}20, & 1946 \\
24, & 1947 \\
26, & 1948 \\
13, & 1949 \\
\end{array}$ & $\begin{array}{l}- \\
- \\
-\end{array}$ & $\begin{array}{l}221 \\
223 \\
237 \\
167\end{array}$ & $\begin{array}{l}1961 \\
1962 \\
1963\end{array}$ & $\begin{array}{l}\text { June } 8,11,1961 \\
\text { June } 23,1962 \\
\text { June } 18,1963\end{array}$ & $\begin{array}{l}- \\
3.89\end{array}$ & $\begin{array}{l}157 \\
265 \\
424\end{array}$ \\
\hline
\end{tabular}

Note.--Maximum daily mean discharges are shown prior to 1951.

\section{WALKER LAKE BASIN}

2890. Virginia Creek near Bridgeport, Calif.

Location. --Lat $38^{\circ} 11^{\prime} 30^{\prime \prime}$, long $119^{\circ} 12^{\prime} 30^{\prime \prime}$, near center of W $\frac{1}{2}$ sec.22, T.4 N., R.25 E., on right bank $1 \frac{1}{4}$ miles downstream from Clearwater Creek, 3 miles upstream from mouth, and $4 \frac{1}{2}$ miles southeast of Bridgeport.

Drainage area. --64 sq mi, approximately. Mean altitude, 8,390 ft.

Gage.--Recording. Altitude of gage is 6,700 ft (from topographic map).

Stage-discharge relation.--Defined by current-meter measurements below 170 cfs and by slope-area measurements at $1,300 \mathrm{cf}$.

Remarks.--Diversions for irrigation of about 3,000 acres above station. Base for partial-duration series, $50 \mathrm{cfs}$.

Peak stages and discharges

\begin{tabular}{|c|c|c|c|c|c|c|c|}
\hline $\begin{array}{l}\text { Water } \\
\text { year }\end{array}$ & Date & $\begin{array}{l}\text { Cage } \\
\text { hefght } \\
\text { (feet) }\end{array}$ & $\begin{array}{l}\text { Discharge } \\
\text { (cfs) }\end{array}$ & $\begin{array}{c}\text { Water } \\
\text { year }\end{array}$ & Date & $\begin{array}{c}\text { Gage } \\
\text { helght } \\
\text { (feet) }\end{array}$ & $\begin{array}{c}\text { D1scharge } \\
\text { (cIs) }\end{array}$ \\
\hline 1955 & $\begin{array}{l}\text { Mar. 9, } 1954 \\
\text { Apr. } 14,1954 \\
\text { June } 9,1955\end{array}$ & $\begin{array}{l}3.07 \\
3.13 \\
2.76\end{array}$ & $\begin{array}{l}67 \\
74 \\
45\end{array}$ & 1956 & $\begin{array}{lll}\text { June } & 14, & 1956 \\
\text { June } 29, & 1956 \\
\text { July } 22, & 1956 \\
\text { July } 24, & 1956\end{array}$ & $\begin{array}{l}3.50 \\
3.48 \\
3.78 \\
3.49\end{array}$ & $\begin{array}{r}94 \\
94 \\
134 \\
96\end{array}$ \\
\hline 1956 & $\begin{array}{lr}\text { Dec. } & 23,1955 \\
\text { Mar. } 24, & 1956 \\
\text { Apr. } 18, & 1956 \\
\text { May } 4, & 1956 \\
\text { May } 19, & 1956 \\
\text { May } 24, & 1956\end{array}$ & $\begin{array}{l}8.40 \\
3.54 \\
3.84 \\
3.43 \\
3.70 \\
3.65\end{array}$ & $\begin{array}{r}1,300 \\
74 \\
143 \\
70 \\
105 \\
98\end{array}$ & $\begin{array}{l}1957 \\
1958\end{array}$ & $\begin{array}{lrl}\text { June } & 4,1957 \\
& \\
\text { Apr. } & 20,1958 \\
\text { May } & 5,1958 \\
\text { May } & 18,1958 \\
\text { June } & 13,1958\end{array}$ & $\begin{array}{l}3.06 \\
5.61 \\
5.43 \\
4.30 \\
4.08\end{array}$ & $\begin{array}{r}54 \\
375 \\
287 \\
87 \\
61\end{array}$ \\
\hline
\end{tabular}


Peak stages and discharges of V1rginia Creek near Bridgeport, Calif.--Continued

\begin{tabular}{|c|c|c|c|c|c|c|c|}
\hline $\begin{array}{l}\text { Water } \\
\text { year }\end{array}$ & Date & $\begin{array}{l}\text { Gage } \\
\text { helght } \\
\text { (feet) }\end{array}$ & $\begin{array}{c}\text { D1scharge } \\
\text { (cfs) }\end{array}$ & $\begin{array}{l}\text { Water } \\
\text { year }\end{array}$ & Date & $\begin{array}{l}\text { Gage } \\
\text { helght } \\
\text { (feet) }\end{array}$ & $\begin{array}{c}\text { Discharge } \\
\text { (cfs) }\end{array}$ \\
\hline 1958 & $\begin{array}{ll}\text { June } 18, & 1958 \\
\text { July } 23, & 1958 \\
\text { Aug. 16, } 1958\end{array}$ & $\begin{array}{l}4.12 \\
4.08 \\
5.59\end{array}$ & $\begin{array}{r}61 \\
61 \\
328\end{array}$ & 1962 & $\begin{array}{ll}\text { Apr. } 8, & 1962 \\
\text { June 15, } & 1962\end{array}$ & $\begin{array}{l}4.34 \\
3.16\end{array}$ & $\begin{array}{l}94 \\
54\end{array}$ \\
\hline 1959 & Apr. $\quad 4,1959$ & 4.30 & 76 & 1963 & $\begin{array}{l}\text { Peb. } 1,1963 \\
\text { Apr. } 6,1963 \\
\text { May }\end{array}$ & $\begin{array}{l}6.13 \\
3.48 \\
3.52\end{array}$ & $\begin{array}{r}652 \\
54 \\
58\end{array}$ \\
\hline 1960 & Mar. 25, 1960 & 3.90 & 39 & & $\begin{array}{lll}\text { May } & 31,1963 \\
\text { June } & 11, & 1963\end{array}$ & $\begin{array}{l}4.52 \\
3.66\end{array}$ & $\begin{array}{r}199 \\
74\end{array}$ \\
\hline 1961 & $\begin{array}{l}\text { Jan. } 5,1961 \\
\text { Aug. } 21,1961\end{array}$ & $\begin{array}{r}\text { a3. } 74 \\
3.67\end{array}$ & $\overline{26}$ & & June 19,1963 & 3.88 & 99 \\
\hline
\end{tabular}

a Backwater from $1 \mathrm{ce}$.

2895. Green Creek near Bridgeport, Cal1f.

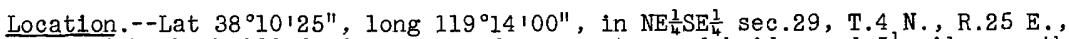
on right bank 130 ft downstream from county road bridge and $5 \frac{1}{2}$ miles south of Bridgeport.

Drainage area. $--19.4 \mathrm{sq} \mathrm{mi}$.

Gage.--Recording. Altitude of gage is 6,850 ft (from topographic map).

Stage-discharge relation.--Defined by current-meter measurements below $220 \mathrm{cfs}$ and extended above on basis of slope-area measurement at $307 \mathrm{cfs}$.

Remarks.--Flow regulated by West, Green, East, Summit, and other lakes. Only annual peaks are shown.

Peak stages and discharges

\begin{tabular}{l|c|c|c||c|r|r|r}
\hline $\begin{array}{l}\text { Water } \\
\text { year }\end{array}$ & Date & $\begin{array}{c}\text { Gage } \\
\text { he1ght } \\
\text { (feet) }\end{array}$ & $\begin{array}{c}\text { Discharge } \\
\text { (cfs) }\end{array}$ & $\begin{array}{l}\text { Water } \\
\text { year }\end{array}$ & Date & $\begin{array}{r}\text { Gage } \\
\text { height } \\
\text { (feet) }\end{array}$ & $\begin{array}{r}\text { Discharge } \\
\text { (cfs) }\end{array}$ \\
\hline 1954 & May 20, 1954 & 2.62 & 135 & 1959 & June 14, 1959 & 2.42 & 73 \\
1955 & June 10, 1955 & 2.90 & 237 & 1960 & June 5, 1960 & 2.64 & 109 \\
1956 & Dec. 23, 1955 & - & 307 & 1961 & June 8, 1961 & 2.50 & 2.87 \\
1957 & June 3, 1957 & 2.78 & 184 & 1962 & June 22, 1962 & 160 \\
1958 & June 24, 1958 & 3.13 & 233 & 1963 & Feb. 1, 1963 & 3.03 \\
\hline
\end{tabular}

2900. Summers Creek near Bridgeport, Calif.

Location.--Lat $38^{\circ} 09^{\prime} 15^{\prime \prime}$, long $119^{\circ} 15^{\prime} 30^{\prime \prime}$, in NW $\frac{1}{4} \mathrm{NE} \frac{1}{4} \sec .6$, T. 3 N., R.25 E., $7 \frac{1}{2}$ miles southwest of Bridgeport.

Drainage area. $--12.6 \mathrm{sq} \mathrm{mi}$. Mean altitude, $9,210 \mathrm{ft}$.

Gage.--Recording. Altitude of gage is 7,100 ft (from topographic map).

Stage-discharge relation.--Defined by current-meter measurementa below 58 cfs and by slope-area measurements at $690 \mathrm{cfs}$.

Remarks.--Base for partial-duration series, $20 \mathrm{cfs}$.

Peak stages and discharges

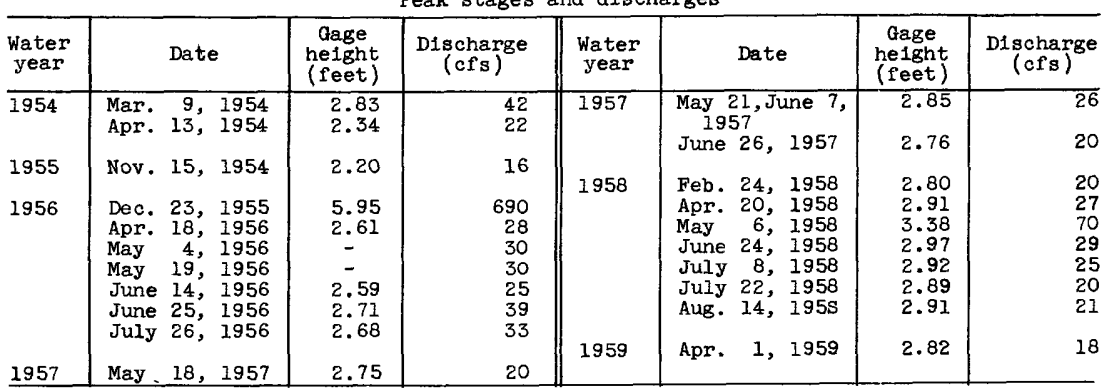


2905. Robinson Creek at Twin Lakes Outlet, near Bridgeport, Calif.

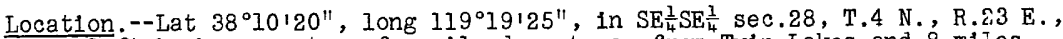
on left bank a quarter of a mile downstream from Twin Lakes and 8 miJes southwest of Bridgeport.

Drainage area. $--34.7 \mathrm{sq} \mathrm{ml}$.

Gage.--Recording. Altitude of gage is 7,050 ft (from topographic map).

Stage-discharge relation.--Defined by current-meter measurements below $400 \mathrm{cfs}$. Bankfull stage.--Not subject to overflow.

Historical data.--Maximum discharge known, that of June 21, 1911.

Remarks.--Flow regulated by Twin Lakes. Only annual peaks are shown.

Peak stages and discharges

\begin{tabular}{|c|c|c|c|c|c|c|c|}
\hline $\begin{array}{l}\text { Water } \\
\text { year }\end{array}$ & Date & $\begin{array}{c}\text { Qage } \\
\text { helght } \\
\text { (feet) }\end{array}$ & $\begin{array}{c}\text { D1scharge } \\
\text { (cfs) }\end{array}$ & $\begin{array}{l}\text { Water } \\
\text { year }\end{array}$ & Date & $\begin{array}{c}\text { Gage } \\
\text { he1ght } \\
\text { (feet) }\end{array}$ & $\begin{array}{c}\text { Discharge } \\
\text { (cfs) }\end{array}$ \\
\hline 1911 & June 21,1911 & a.5.2 & $a 660$ & \multirow{2}{*}{$\begin{array}{l}1958 \\
1959 \\
1960\end{array}$} & \multirow{2}{*}{$\begin{array}{lll}\text { June } 25, & 1958 \\
\text { June } 15, & 1959 \\
\text { June } 16, & 1960\end{array}$} & \multirow{2}{*}{$\begin{array}{l}4.22 \\
2.96 \\
3.00\end{array}$} & \multirow{2}{*}{$\begin{array}{l}383 \\
136 \\
141\end{array}$} \\
\hline $\begin{array}{l}1954 \\
1955\end{array}$ & $\begin{array}{lll}\text { May } 21, & 1954 \\
\text { June } 14, & 1955\end{array}$ & $\begin{array}{l}3.56 \\
3.45\end{array}$ & $\begin{array}{l}225 \\
216\end{array}$ & & & & \\
\hline $\begin{array}{l}1956 \\
1957 \\
\end{array}$ & $\begin{array}{ll}\text { June } 29, & 1956 \\
\text { June } 7, & 1957\end{array}$ & $\begin{array}{l}4.35 \\
3.71\end{array}$ & $\begin{array}{l}445 \\
270 \\
\end{array}$ & $\begin{array}{l}1961 \\
1962 \\
1963\end{array}$ & $\begin{array}{ll}\text { June } 21, & 1961 \\
\text { June } 23, & 1962 \\
\text { June } 20, & 1963 \\
\end{array}$ & $\begin{array}{l}3.12 \\
3.90 \\
4.49 \\
\end{array}$ & $\begin{array}{l}157 \\
307 \\
492 \\
\end{array}$ \\
\hline
\end{tabular}

a At site $2 \frac{1}{2}$ miles downstream.

2915. Buckeye Creek near Bridgeport, Calif.

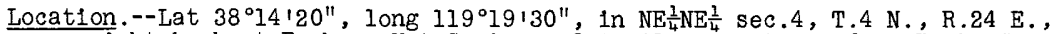
on right bank at Buckeye Hot Springs, 0.6 mile downstream from Eagle Creek and $5 \frac{\pi}{2}$ miles southwest of Bridgeport.

Drainage area.--45 sq $\mathrm{ml}$, approximately. Mean altitude, 9,200 ft.

Gage.--Recording. Altitude of gage is 6,900 ft (from topographic map).

Stage-discharge relation.--Defined by current-meter measurements below 360 cfs and by slope-area measurements at $700 \mathrm{cfs}$.

Remarks.--Base for partial-duration serles, $100 \mathrm{cfs}$.

Peak stages and discharges

\begin{tabular}{|c|c|c|c|c|c|c|c|c|}
\hline $\begin{array}{l}\text { Water } \\
\text { year }\end{array}$ & \multicolumn{2}{|r|}{ Date } & $\begin{array}{c}\text { Cage } \\
\text { height } \\
\text { (feet) }\end{array}$ & $\begin{array}{c}\text { Discharge } \\
\text { (cfs) }\end{array}$ & $\begin{array}{l}\text { Water } \\
\text { year }\end{array}$ & Date & $\begin{array}{c}\text { Gage } \\
\text { height } \\
\text { (feet) }\end{array}$ & $\begin{array}{c}\text { D1scharge } \\
(\mathrm{cfs})\end{array}$ \\
\hline 1954 & $\begin{array}{l}\text { Mar. } \\
\text { Apr. } \\
\text { May } \\
\text { June } \\
\text { July }\end{array}$ & $\begin{array}{ll}9, & 1954 \\
25, & 1954 \\
20, & 1954 \\
23, & 1954 \\
15, & 1954\end{array}$ & $\begin{array}{l}2.50 \\
2.63 \\
3.33 \\
2.77 \\
2.50\end{array}$ & $\begin{array}{l}122 \\
155 \\
404 \\
201 \\
129\end{array}$ & 1958 & $\begin{array}{lr}\text { July } 6, & 1958 \\
\text { July } 23, & 1958 \\
\text { July } 31, & 1958 \\
\text { Aug. } 5, & 1958 \\
\text { Aug. } 14, & 195 s\end{array}$ & $\begin{array}{l}3.25 \\
3.01 \\
2.82 \\
2.84 \\
2.53\end{array}$ & $\begin{array}{l}340 \\
242 \\
186 \\
191 \\
188\end{array}$ \\
\hline 1955 & $\begin{array}{l}\text { May } \\
\text { May } \\
\text { May } \\
\text { June }\end{array}$ & $\begin{array}{ll}13, & 1955 \\
23, & 1955 \\
29, & 1955 \\
7, & 1955\end{array}$ & $\begin{array}{l}2.49 \\
2.94 \\
3.10 \\
3.43\end{array}$ & $\begin{array}{l}122 \\
250 \\
305 \\
438\end{array}$ & 1959 & $\begin{array}{ll}\text { May } 1, & 1959 \\
\text { May 13, } & 1959 \\
\text { June } 6, & 1959 \\
\text { Sept.19, } & 1959\end{array}$ & $\begin{array}{l}2.59 \\
2.79 \\
2.88 \\
2.42\end{array}$ & $\begin{array}{l}141 \\
188 \\
201 \\
101\end{array}$ \\
\hline 1956 & $\begin{array}{l}\text { Dec. } \\
\text { Jan. } \\
\text { Apr. } \\
\text { May } \\
\text { June } \\
\text { June } \\
\text { July }\end{array}$ & $\begin{array}{rr}23, & 1955 \\
16, & 1956 \\
24, & 1956 \\
4, & 1956 \\
11, & 1956 \\
29, & 1956 \\
22, & 1956\end{array}$ & $\begin{array}{l}4.00 \\
2.46 \\
2.56 \\
2.78 \\
3.63 \\
3.79 \\
3.59\end{array}$ & $\begin{array}{l}700 \\
117 \\
135 \\
183 \\
510 \\
590 \\
490\end{array}$ & $\begin{array}{l}1960 \\
1961\end{array}$ & $\begin{array}{lrl}\text { May 12, } & 1960 \\
\text { June } 2, & 1960 \\
& \\
\text { May 25, } 1961 \\
\text { June 8, } 1961 \\
\text { Aug. 22, } 1961\end{array}$ & $\begin{array}{l}2.78 \\
3.05 \\
2.70 \\
2.69 \\
3.76\end{array}$ & $\begin{array}{r}183 \\
261 \\
\cdot \\
169 \\
169 \\
526\end{array}$ \\
\hline 1957 & $\begin{array}{l}\text { May } \\
\text { May } \\
\text { June }\end{array}$ & 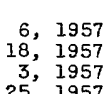 & $\begin{array}{l}2.64 \\
2.77 \\
3.43 \\
3\end{array}$ & $\begin{array}{l}151 \\
181 \\
414\end{array}$ & 1962 & $\begin{array}{lrl}\text { May } & 6, & 1962 \\
\text { June 9, } & 1962 \\
\text { June } 22, & 1962\end{array}$ & $\begin{array}{l}2.98 \\
3.24 \\
3.37\end{array}$ & $\begin{array}{l}242 \\
336 \\
3 \mathrm{SS}\end{array}$ \\
\hline 1958 & $\begin{array}{l}\text { June } \\
\text { Apr. } \\
\text { May } \\
\text { May } \\
\text { June }\end{array}$ & $\begin{array}{ll}25, & 1957 \\
21, & 1958 \\
10, & 1955 \\
19, & 1958 \\
23, & 1955\end{array}$ & $\begin{array}{l}3.19 \\
2.42 \\
3.02 \\
3.32 \\
3.69\end{array}$ & $\begin{array}{l}316 \\
107 \\
255 \\
368 \\
540\end{array}$ & 1963 & 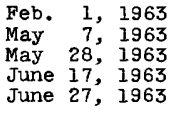 & $\begin{array}{l}4.41 \\
2.41 \\
3.22 \\
3.79 \\
3.30\end{array}$ & $\begin{array}{l}947 \\
122 \\
336 \\
590 \\
360\end{array}$ \\
\hline
\end{tabular}




\section{Swager Creek near Bridgeport, Calif.}

Location.--Lat $38^{\circ} 17^{\prime} 00^{\prime \prime}$, long $119^{\circ} 17^{\prime} 50^{\prime \prime}$, in $\mathrm{SE} \frac{1}{4} \mathrm{NW} \frac{1}{4}$ sec.23, T.5 N., R.24 E., on right bank three-quarters of a mile downstream from Yaney Canyon and

4 miles northwest of Bridgeport.

Drainage area.--53 sq mi, approximately. Mean altitude, 8,390 ft.

Gage.--Recording. Altitude of gage is 6,620 ft (from topographic map).

Stage-discharge relation.--Defined by current-meter measurements below 175 cfs and by slope-area measurements at $585 \mathrm{cfs}$.

Remarks.--Diversions for irrigation of about 1,000 acres above station. Base for partial-duration series, $25 \mathrm{cfs}$.

\begin{tabular}{|c|c|c|c|c|c|c|c|}
\hline $\begin{array}{l}\text { Water } \\
\text { year }\end{array}$ & Date & $\begin{array}{l}\text { Gage } \\
\text { helght } \\
\text { (feet) }\end{array}$ & $\begin{array}{c}\text { Discharge } \\
\text { (cfs) }\end{array}$ & $\begin{array}{l}\text { Water } \\
\text { year }\end{array}$ & Date & $\begin{array}{l}\text { Gage } \\
\text { nelght } \\
\text { (feet) }\end{array}$ & $\begin{array}{l}\text { Discharge } \\
\text { (cfs) }\end{array}$ \\
\hline 1954 & $\begin{array}{l}\text { Mar. 9, } 1954 \\
\text { Apr. 18, } 1954\end{array}$ & $\begin{array}{l}2.74 \\
2.62\end{array}$ & $\begin{array}{l}77 \\
54\end{array}$ & 1958 & $\begin{array}{ll}\text { May } 17, & 1958 \\
\text { June } 13, & 1958 \\
\text { Aug. } 14, & 1958\end{array}$ & $\begin{array}{l}3.47 \\
2.78 \\
5.20\end{array}$ & $\begin{array}{r}145 \\
66 \\
361\end{array}$ \\
\hline 1955 & Mar. 11, 1955 & 2.22 & 24 & & Aug. 18,1958 & 2.39 & 31 \\
\hline \multirow[t]{5}{*}{1956} & $\begin{array}{l}\text { Dec. } 23,1955 \\
\text { Jan. } 15,1956\end{array}$ & $\begin{array}{l}6.24 \\
2.54\end{array}$ & $\begin{array}{r}585 \\
34\end{array}$ & 1959 & Mar. 30, 1959 & 2.46 & 35 \\
\hline & $\begin{array}{l}\text { Mar. } 24,1956 \\
\text { Apr. } 9,1956\end{array}$ & $\begin{array}{l}2.84 \\
2.77\end{array}$ & $\begin{array}{l}54 \\
49\end{array}$ & 1960 & Mar. 7,1960 & 2.26 & 20 \\
\hline & $\begin{array}{l}\text { Apr. } 24,1956 \\
\text { May } 4,1956\end{array}$ & $\begin{array}{l}3.37 \\
3.43\end{array}$ & $\begin{array}{l}103 \\
106\end{array}$ & 1961 & $\begin{array}{l}\text { Aug. 20, } 1961 \\
\text { Aug. 21, } 1961\end{array}$ & $\begin{array}{l}3.33 \\
2.51\end{array}$ & $\begin{array}{r}114 \\
38\end{array}$ \\
\hline & May 24,1956 & 3.38 & 99 & & & & \\
\hline & $\begin{array}{l}\text { July } 20,1956 \\
\text { July } 26,1956\end{array}$ & $\begin{array}{l}2.62 \\
2.75\end{array}$ & $\begin{array}{l}30 \\
38\end{array}$ & 1962 & Apr. 14,1962 & $\begin{array}{l}3.63 \\
2.57\end{array}$ & $\begin{array}{r}136 \\
35 \\
36\end{array}$ \\
\hline \multirow[t]{2}{*}{1957} & Feb. 16, 1957 & 2.59 & 29 & & June 16,1962 & 2.55 & 30 \\
\hline & $\begin{array}{lll}\text { May } 18, & 1957 \\
\text { June } & 3, & 1957\end{array}$ & $\begin{array}{l}2.02 \\
2.95 \\
2.72\end{array}$ & $\begin{array}{l}2 \\
51 \\
35\end{array}$ & 1963 & $\begin{array}{l}\text { Feb. } 1,1963 \\
\text { Apr. } \\
\text { Apr. } 30,1963 \\
1963\end{array}$ & $\begin{array}{l}5.57 \\
2.70 \\
2.79\end{array}$ & $\begin{array}{r}443 \\
29 \\
33\end{array}$ \\
\hline 1958 & $\begin{array}{lll}\text { Feb. } 24, & 1958 \\
\text { Apr. } & 20, & 1958 \\
\text { May } & 4, & 1958\end{array}$ & $\begin{array}{l}3.01 \\
4.70 \\
3.92\end{array}$ & $\begin{array}{r}54 \\
265 \\
181\end{array}$ & & $\begin{array}{ll}\text { May } & 24, \\
\text { May } & 1963 \\
& 1963\end{array}$ & $\begin{array}{l}3.30 \\
3.18\end{array}$ & $\begin{array}{l}71 \\
61\end{array}$ \\
\hline
\end{tabular}

2930. East Walker River near Bridgeport, Calif.

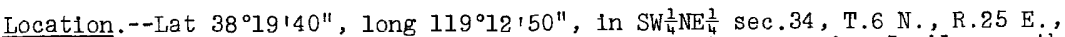
on right bank $1,500 \mathrm{ft}$ downstream from Bridgeport Reservoir, 5 miles north of Bridgeport, and 10 miles upstream from Sweetwater Creek.

Drainage area. $--362 \mathrm{sq} \mathrm{mi}$.

Gage.--Recording prior to Oct. 1, 1931, and since May 25, 1939; nonrecording oct. 1, 1931, to May 25, 1939. Prior to Feb. 22, 1924 , at site 1 mile downstream at different datum. Feb. 22, 1924, to May 25, 1939, at datum $2.34 \mathrm{ft}$ lower. Altitude of gage is $6,400 \mathrm{ft}$ (from topographic map).

Stage-discharge relation.--Defined by current-meter measurements.

Remarks.--Diversion for irrigation of meadow pasture lands near Bridgeport.

Flow regulated by Bridgeport Reservoir. Only annual peaks are shown.

\begin{tabular}{|c|c|c|c|c|c|c|c|}
\hline $\begin{array}{l}\text { Water } \\
\text { year }\end{array}$ & Date & $\begin{array}{l}\text { Gage } \\
\text { helght } \\
\text { (feet) }\end{array}$ & $\begin{array}{c}\text { D1scharge } \\
\text { (cfs) }\end{array}$ & $\begin{array}{l}\text { Water } \\
\text { year }\end{array}$ & Date & $\begin{array}{c}\text { Gage } \\
\text { nelght } \\
\text { (feet) }\end{array}$ & $\begin{array}{l}\text { Discharge } \\
\text { (cfs) }\end{array}$ \\
\hline \multirow{2}{*}{$\begin{array}{l}1923 \\
1924 \\
1925\end{array}$} & May 22,1923 & - & a714 & 1932 & May 21,1932 & - & a.363 \\
\hline & $\begin{array}{l}\text { July } 22,1924 \\
\text { July } 25,1925\end{array}$ & $\overline{-}$ & $\begin{array}{l}550 \\
513\end{array}$ & $\begin{array}{l}1933 \\
1934\end{array}$ & Aug. 2, 1933 & $\overline{-}$ & $\begin{array}{l}\text { a408 } \\
\text { a221 }\end{array}$ \\
\hline $\begin{array}{l}1926 \\
1927\end{array}$ & $\begin{array}{l}\text { June } 27,28,1926 \\
\text { July } 1,1927\end{array}$ & $\overline{-}$ & $\begin{array}{l}\text { a334 } \\
\text { a491 }\end{array}$ & 1935 & Aug. 2,1935 & - & 2287 \\
\hline 1928 & July 11, 1928 & - & a 326 & 1936 & July 1,1936 & - & 510 \\
\hline $\begin{array}{l}1929 \\
1930\end{array}$ & $\begin{array}{ll}\text { July } 12, & 1929 \\
\text { June } 17, & 1930\end{array}$ & $\overline{-}$ & $\begin{array}{l}\text { a255 } \\
\text { a304 }\end{array}$ & $\begin{array}{l}1937 \\
1938\end{array}$ & $\begin{array}{l}\text { June } 12-151937 \\
\text { June } 12,1938\end{array}$ & - & $\begin{array}{r}a 452 \\
a 1,220\end{array}$ \\
\hline 1931 & May 21,1931 & - & al69 & $\begin{array}{l}1939 \\
1940\end{array}$ & $\begin{array}{l}\text { Mar. 24-28, } 1939 \\
\text { June } 27-30,1940\end{array}$ & 1.76 & $\begin{array}{l}\text { a297 } \\
2289\end{array}$ \\
\hline
\end{tabular}


Peak stages and discharges of East Walker River near Bridgeport, Calif.--Continued

\begin{tabular}{|c|c|c|c|c|c|c|c|}
\hline $\begin{array}{l}\text { Water } \\
\text { year }\end{array}$ & Date & $\begin{array}{l}\text { Gage } \\
\text { height } \\
\text { (feet) }\end{array}$ & $\begin{array}{c}\text { Discharge } \\
\text { (cfs) }\end{array}$ & $\begin{array}{l}\text { Water } \\
\text { year }\end{array}$ & Date & $\begin{array}{l}\text { Gage } \\
\text { helght } \\
\text { (feet) }\end{array}$ & $\begin{array}{c}\text { Iischarge } \\
(\mathrm{cfs})\end{array}$ \\
\hline $\begin{array}{l}1941 \\
1942 \\
1943 \\
1944\end{array}$ & $\begin{array}{lr}\text { July } 7, & 1941 \\
\text { June } 18, & 1942 \\
\text { Jan. } 22, & 1943 \\
\text { Apr. } 8, & 1944\end{array}$ & $\stackrel{-}{-}$ & $\begin{array}{r}652 \\
674 \\
1,240 \\
368\end{array}$ & $\begin{array}{l}1953 \\
1954 \\
1955\end{array}$ & $\begin{array}{ll}\text { July } 16, & 1953 \\
\text { June 4, } & 1954 \\
\text { June 12-zl, } & 1955\end{array}$ & $\begin{array}{l}2.36 \\
1.91 \\
1.61\end{array}$ & $\begin{array}{r}475 \\
328 \\
a 242\end{array}$ \\
\hline 1945 & July 11,1945 & - & 856 & $\begin{array}{l}1956 \\
1957\end{array}$ & $\begin{array}{l}\text { July } 1,1956 \\
\text { July } 19-21,1957\end{array}$ & $\begin{array}{l}3.77 \\
2.08\end{array}$ & $\begin{array}{r}981 \\
\text { a385 }\end{array}$ \\
\hline $\begin{array}{l}1946 \\
1947 \\
1948\end{array}$ & $\begin{array}{lr}\text { May } \quad 5, & 1946 \\
\text { May } 7, & 1947 \\
\text { June } 19,20,1948\end{array}$ & - & $\begin{array}{l}\text { a325 } \\
\text { a2 } 79 \\
\text { a249 }\end{array}$ & $\begin{array}{l}1958 \\
1959 \\
1960\end{array}$ & $\begin{array}{lr}\text { June } & 26,1958 \\
\text { Oct. } 1, & 1958 \\
\text { June } & 7,1960\end{array}$ & $\begin{array}{l}3.51 \\
1.69 \\
1.69\end{array}$ & $\begin{array}{r}882 \\
259 \\
\mathrm{a} 265\end{array}$ \\
\hline 1949 & June 9, 1949 & - & a297 & & & & 191 \\
\hline 1950 & July 25,1950 & 1.86 & 282 & $\begin{array}{l}1961 \\
1962\end{array}$ & $\begin{array}{ll}\text { June } 23, & 1961 \\
\text { June } 23, & 1962\end{array}$ & $\begin{array}{l}1.43 \\
2.52\end{array}$ & $\begin{array}{l}191 \\
487\end{array}$ \\
\hline $\begin{array}{l}1951 \\
1952\end{array}$ & $\begin{array}{ll}\text { June } 24, & 1951 \\
\text { July } 31, & 1952\end{array}$ & $\begin{array}{l}3.02 \\
3.78\end{array}$ & $\begin{array}{l}714 \\
985\end{array}$ & 1963 & June 19,1963 & 4.64 & 1,390 \\
\hline
\end{tabular}

a Maximum daily.

2935. East Walker River above Strosnider ditch, near Mason, Nev.

Location.--Lat $38^{\circ} 48^{\prime} 50^{\prime \prime}$, long $119^{\circ} 02^{\prime} 50^{\prime \prime}$, in NW $\frac{1}{4} S W \frac{1}{4}$ sec.14, T.11 N., R.26 E., on right bank 0.8 mile upstream from head of Strosnider ditch, $12 \mathrm{miles}$ southeast of Mason, and $13 \frac{1}{2}$ miles southeast of Yerington.

Drainage area. $--1,100 \mathrm{sq} \mathrm{ml}$, approximately.

Gage.--Recording. Prior to 0ct. 24, 1957, at site $400 \mathrm{ft}$ upstream at datum $0.56 \mathrm{ft}$ higher. Datum of gage is $4,574.10 \mathrm{ft}$ above mean sea level, datum of 1929.

Stage-discharge relation.--Defined by current-meter measurements below 1,100 cfs and extended above by logarithmic plotting.

Remarks.--Flow regulated by Brldgeport Reservolr. Only annual peaks are shown.

\begin{tabular}{|c|c|c|c|c|c|c|c|c|}
\hline $\begin{array}{l}\text { Water } \\
\text { year }\end{array}$ & & Date & $\begin{array}{l}\text { Qage } \\
\text { helght } \\
\text { (feet) }\end{array}$ & $\begin{array}{c}\text { Discharge } \\
\text { (cfs) }\end{array}$ & $\begin{array}{l}\text { Water } \\
\text { year }\end{array}$ & Date & $\begin{array}{l}\text { Gage } \\
\text { height } \\
\text { (feet) }\end{array}$ & $\begin{array}{c}\text { Discharge } \\
\text { (cfs) }\end{array}$ \\
\hline $\begin{array}{l}1947 \\
1948 \\
1949 \\
1950\end{array}$ & $\begin{array}{l}\text { May } \\
\text { June } \\
\text { June } \\
\text { May }\end{array}$ & $\begin{array}{ll}28, & 1947 \\
21, & 1948 \\
10, & 1949 \\
31, & 1950\end{array}$ & $\begin{array}{l}2.30 \\
2.08 \\
2.37 \\
2.16\end{array}$ & $\begin{array}{l}246 \\
197 \\
239 \\
226\end{array}$ & $\begin{array}{l}1956 \\
1957 \\
1958 \\
1959 \\
1960\end{array}$ & $\begin{array}{lr}\text { Dec. } 24, & 1955 \\
\text { July } 21, & 1957 \\
\text { Aug. } & 17,1958 \\
\text { July } 24, & 1959 \\
\text { June } 9, & 1960\end{array}$ & $\begin{array}{l}6.87 \\
2.55 \\
4.96 \\
2.78 \\
2.38\end{array}$ & $\begin{array}{r}1,640 \\
318 \\
935 \\
372 \\
179\end{array}$ \\
\hline $\begin{array}{l}1951 \\
1952 \\
1953 \\
1954 \\
1955 \\
\end{array}$ & $\begin{array}{l}\text { June } \\
\text { July } \\
\text { July } \\
\text { June } \\
\text { July }\end{array}$ & 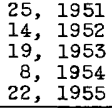 & $\begin{array}{l}3.40 \\
6.21 \\
3.07 \\
2.38 \\
2.35\end{array}$ & $\begin{array}{r}489 \\
1,400 \\
409 \\
259 \\
243\end{array}$ & $\begin{array}{l}1961 \\
1962 \\
1963\end{array}$ & $\begin{array}{l}\text { Aug. } 25,1961 \\
\text { June 26, } 1962 \\
\text { Feb. 1, } 1963\end{array}$ & $\begin{array}{l}4.3 \\
4.06 \\
7.60\end{array}$ & $\begin{array}{r}750 \\
468 \\
2,380\end{array}$ \\
\hline
\end{tabular}

2945. East Walker River near Yerington, Nev.

(Published as "Walker River (East Fork) at Ross Ranch" 1902 , as "East Fork of Walker River" 1903, and as "Walker River (East Fork)" 1904)

Location.--Lat $38^{\circ} 51^{\prime}$, 1ong $119^{\circ} 06^{\prime}$, in sec.5, T.11 N., R.26 E., at Rosa Ranch, 6 miles upstream from confluence with West walker River and $10 \mathrm{mlles}$ southeast of Yerington.

Drainage area. $--1,180 \mathrm{sq} \mathrm{ml}$, approximately.

Gage.--Nonrecording. Alt1tude of gage is 4,530 ft (from topographic map).

Stage-discharge relation. --Defined by current-meter measurements below $1,100 \mathrm{cfs}$.

Remarks.--Diversions for 1rrigation above station. Only annual maximum observed discharges are shown. 
Maximum observed discharges of East Walker River near Yerington, Nev.

\begin{tabular}{c|c|c|c||c|c|c|c}
\hline $\begin{array}{c}\text { Water } \\
\text { year }\end{array}$ & Date & $\begin{array}{c}\text { Gage } \\
\text { nelght } \\
\text { (feet) }\end{array}$ & $\begin{array}{c}\text { Discharge } \\
\text { (cfs) }\end{array}$ & $\begin{array}{c}\text { Water } \\
\text { year }\end{array}$ & Date & $\begin{array}{c}\text { Gage } \\
\text { height } \\
\text { (feet) }\end{array}$ & $\begin{array}{c}\text { Discharge } \\
\text { (cfs) }\end{array}$ \\
\hline 1903 & June 12, 1903 & - & 510 & 1906 & July 8, 1906 & - & 1,230 \\
1904 & June 23, 1904 & - & 696 & 1907 & Mar. 19, 1907 & 6.0 & 1,700 \\
1905 & June 21, 1905 & - & 321 & 1908 & Mar. 19, 1908 & - \\
\hline
\end{tabular}

2950. East Walker River near Mason, Nev.

Location. - - Lat $38^{\circ} 52^{1} 30^{\prime \prime}$, long $119^{\circ} 08^{1} 30^{\prime \prime}$, in sec.26, T.12 N., R.25 E., $50 \mathrm{ft}^{\prime}$ downstream from highway bridge, $2 \frac{1}{2}$ miles above confluence with west walker River, and 8 miles south of Mason.

Drainage area. $-1,230 \mathrm{sq} \mathrm{mi}$, approximately.

Gage.--Nonrecording. Prior to July 1, 1914, at site $50 \mathrm{ft}$ downstream at unknown datum. Altitude of gage is $4,480 \mathrm{ft}$ (from topographic map).

Stage-discharge relation.--Defined by current-meter measurements below 1,300 cfs.

Remarks.--Only annual maximum observed discharges are shown.

Maximum observed discharges

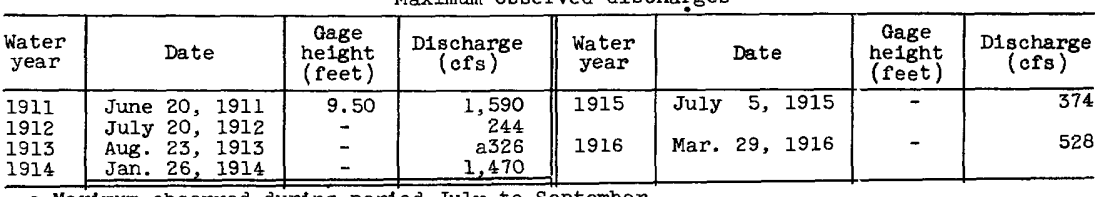

a Maximum observed during period July to September.

2952. West Walker River at Leavitt Meadows, near Coleville, Calif.

Location.--Lat $38^{\circ} 19^{1} 50^{\prime \prime}$, long $119^{\circ} 33^{1} 05^{\prime \prime}$, in NW $\frac{1}{4} \mathrm{NW} \frac{1}{4} \sec .34$, T. 6 N., R. 22 E., on left bank at Leavitt Meadows Lodge, $500 \mathrm{ft}$ upstream from Brownie Creek, $0.9 \mathrm{mile}$ downstream from Leavitt Creek, and $16 \frac{1}{2}$ miles south of Coleville.

Drainage area. $--73 \mathrm{sq} \mathrm{mi}$, approximately.

Gage.--Recording. Prior to Oct. 1, 1957, 0.2 mile upstream at different datum. Datum of gage is $7,111.32 \mathrm{ft}$ above mean sea level (levels by Bureau of Reclamation).

Stage-discharge relation.--Defined by current-meter measurements at present site; records prior to October 1957 furnished by Sierra Pacific Power Co.

Bankful1 stage.--In canyon; not subject to overflow.

Remarks.--Base for partial-duration series, 600 cfs. Only annial peaks are shown prior to 1958 .

Peak stages and discharges

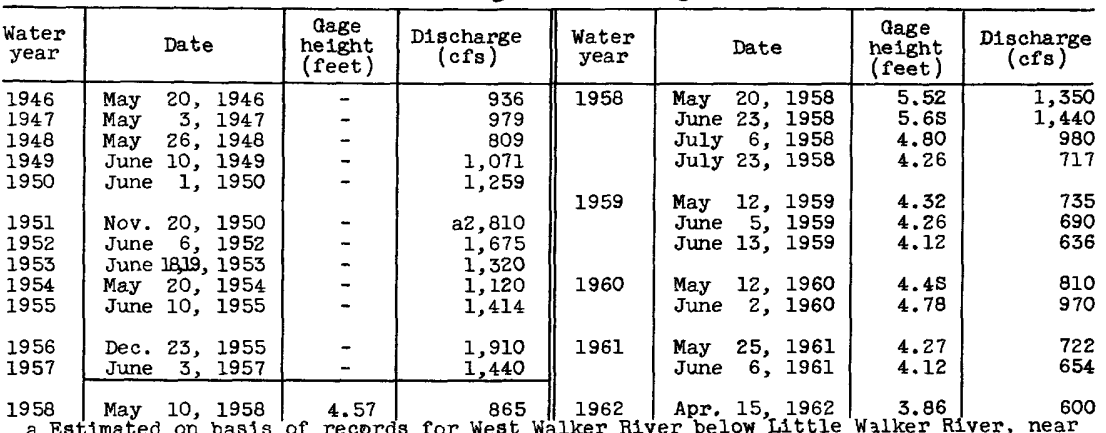

a Estimated on basis of records for West Walker River below'Little Walker River, near Coleville. 
Peak stages and discharges of West Walker River at Leavitt Meadows, near Coleville, Calif.--Continued

\begin{tabular}{|c|c|c|c|c|c|c|c|}
\hline $\begin{array}{l}\text { Water } \\
\text { year }\end{array}$ & Date & $\begin{array}{c}\text { Gage } \\
\text { helght } \\
\text { (feet) }\end{array}$ & $\begin{array}{c}\text { D1scharge } \\
\text { (cfs) }\end{array}$ & $\begin{array}{l}\text { Water } \\
\text { year }\end{array}$ & Date & $\begin{array}{c}\text { Gage } \\
\text { helght } \\
\text { (feet) }\end{array}$ & $\begin{array}{c}I^{+} \text {scharge } \\
\text { (cfs) }\end{array}$ \\
\hline 1962 & $\begin{array}{l}\text { Apr. . 23, } 1962 \\
\text { May 5, } 1962 \\
\text { June 2, } 1962 \\
\text { June 11, } 1962 \\
\text { June 19, } 1962\end{array}$ & $\begin{array}{l}3.87 \\
4.05 \\
4.79 \\
4.86 \\
4.93\end{array}$ & $\begin{array}{r}609 \\
686 \\
985 \\
1,060 \\
1,100\end{array}$ & 1963 & $\begin{array}{ll}\text { Feb. } 1,1963 \\
\text { June } 2,1963 \\
\text { June 16, } 1963 \\
\text { June } 27,1963 \\
\text { July } 7,1963\end{array}$ & $\begin{array}{l}5.55 \\
4.94 \\
5.70 \\
4.15 \\
4.47\end{array}$ & $\begin{array}{r}1,370 \\
1,060 \\
1,460 \\
658 \\
805\end{array}$ \\
\hline
\end{tabular}

2955. Little Walker River near Bridgeport, Calif.

(Published as "East Fork West Walker River" prior to October 1958)

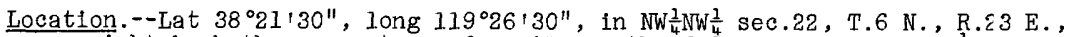
on right bank three-quarters of a mile north of Sonora Junction, $1 \frac{1}{2}$ miles upstream from mouth, and 14 miles northwest of.Bridgeport.

Drainage area. $--63 \mathrm{sq} \mathrm{mi}$, approximately. Mean altitude, 8,780 ft.

Gage--Recording. Alt1tude of gate is 6,790 ft (from topographic map).

Stage-discharge relation.--Defined by current-meter measurements below $₹ 70$ cfs and by slope-area measurements at $994 \mathrm{cfs}$ and logarithmic plotting.

Remarks.--Base for partial-duration series, $200 \mathrm{cfs}$.

Peak stages and discharges

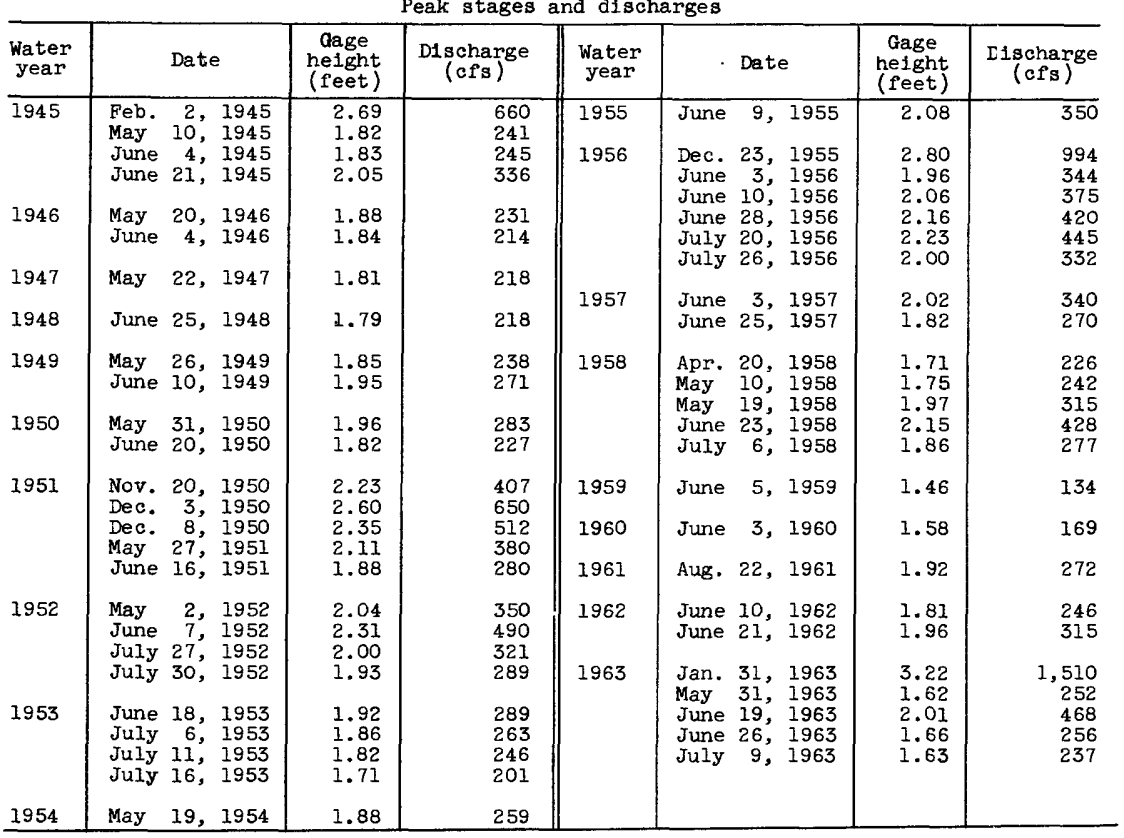


2960. West Walker River below Little Walker River, near Coleville, Calif. (Published as "below East Fork" prior to October 1958)

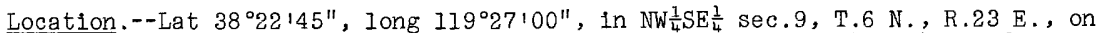
left bank $75 \mathrm{ft}$ downstream from Little Walker River, 200 ft upstream from bridge on U.S. Highway 395 , and 13 miles southeast of Colevilie.

Drainage area.--182 sq $\mathrm{ml}$. Mean altitude, 8,830 ft.

Gage.--Recording. Prior to 0ct. 1, 1939, at site $125 \mathrm{ft}$ downstream at datum $1.00 \mathrm{ft}$ higher. Altitude of gage is $6,650 \mathrm{ft}$ (from topograshic map).

Stage-discharge relation.--Defined by current-meter measurements below 1,900 $\mathrm{cfs}$ and by slope-area measurements at $6,220 \mathrm{cfs}$.

Remarks.--Base for partial-duration series, $1,120 \mathrm{cfs}$.

Peak stages and discharges

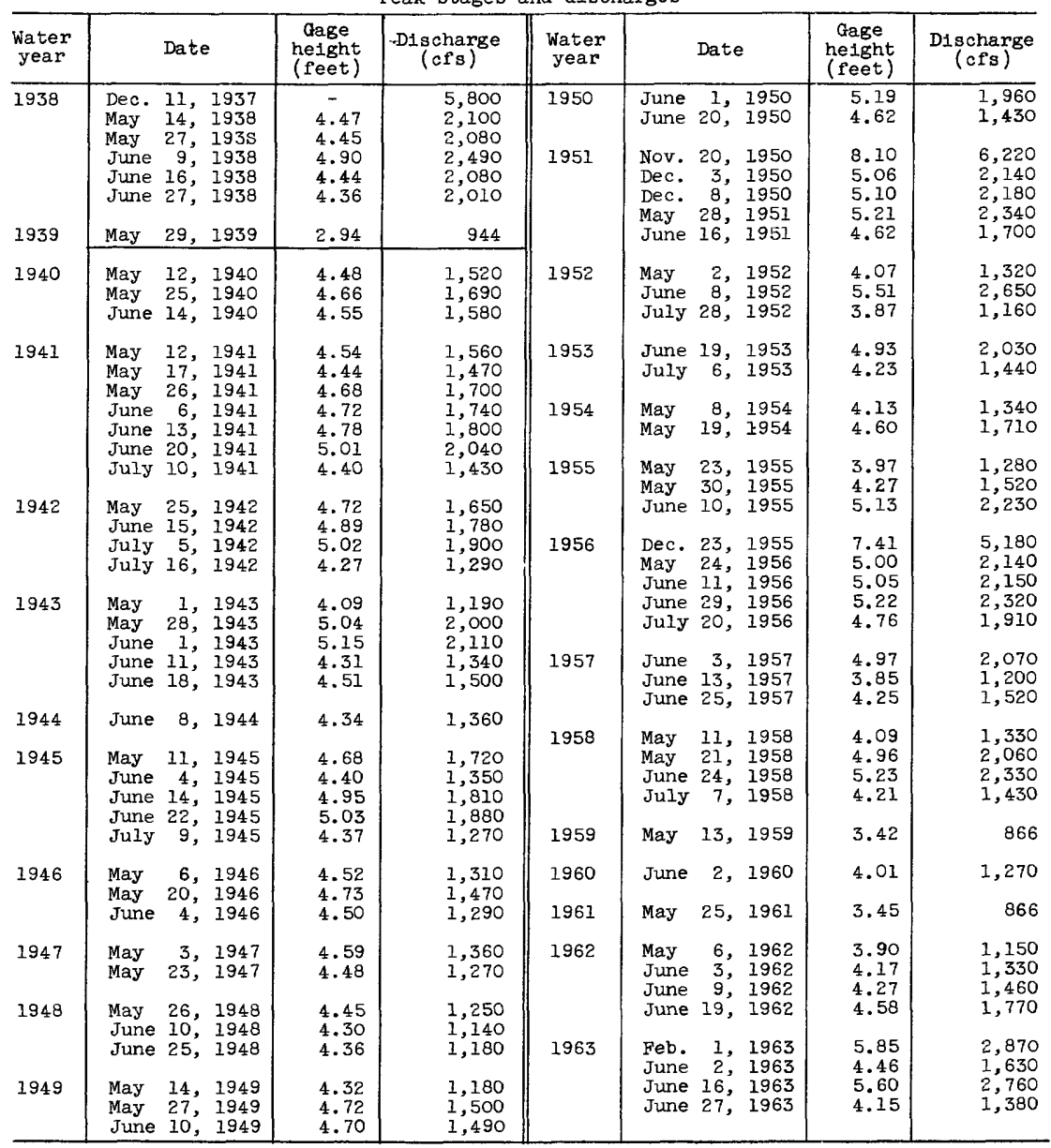


2965. West Walker River near Coleville, Calif.

(Published as "West Fork of Walker RIver" 1903, 1905-8, and as "Walker River ((West Fork)" 1904)

Location.--Lat $38^{\circ} 30155^{\prime \prime}$, long $119^{\circ} 27^{\prime} 15^{\prime \prime}$, in NW $\frac{1}{4} \mathrm{NE} \frac{1}{4}$ sec.28, T.8 N., R.23 E., on left bank a quarter of a mile downstream from Rock Creek and 5 miles southeast of Coleville.

Drainage area. $--245 \mathrm{sq} \mathrm{m} 1$.

Gage.--Nonrecording prior to Sept. 1, 1910; recording thereafter. Prior to July 31, 1908, at site half a mile upstream at different datum. Mar. 1, 1909, to Aug. 15, 1919, near present site at different datums. Aug. 16, 1919, to Mar. 31, 1938, at site 1,000 ft upstream at different datum. Altituce of gage. is $5,520 \mathrm{ft}$ (from topographic map).

Stage-discharge relation.--Defined by slope-area measurements at 6,500 efs.

Remarks.--Flow very slightly regulated by Poor Lake Reservolr (capacity unknown) $17 \mathrm{miles}$ upstream. Base for partial-duration series, $1,120 \mathrm{cfs}$. Onj.y annual peaks are shown prlor to 1916 .

Peak stages and discharges

\begin{tabular}{|c|c|c|c|c|c|c|c|c|c|}
\hline $\begin{array}{l}\text { Water } \\
\text { year }\end{array}$ & \multicolumn{2}{|r|}{ Date } & \multirow{2}{*}{$\begin{array}{r}\begin{array}{c}\text { Cage } \\
\text { helght } \\
\text { (feet) }\end{array} \\
4.10 \\
4.90 \\
3.90\end{array}$} & \multirow{2}{*}{$\begin{array}{r}\begin{array}{c}\text { Discharge } \\
(\mathrm{cfs})\end{array} \\
2,030 \\
2,100 \\
1,160\end{array}$} & \multirow{2}{*}{$\begin{array}{c}\begin{array}{c}\text { Water } \\
\text { year }\end{array} \\
1929\end{array}$} & \multicolumn{2}{|r|}{ Date } & \multirow{2}{*}{$\begin{array}{c}\begin{array}{c}\text { Gage } \\
\text { height } \\
\text { (feet) }\end{array} \\
\begin{array}{c}4.49 \\
4.60\end{array}\end{array}$} & \multirow{2}{*}{ 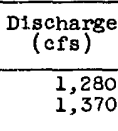 } \\
\hline $\begin{array}{l}1903 \\
1904 \\
1905\end{array}$ & $\begin{array}{l}\text { June } \\
\text { May } \\
\text { June }\end{array}$ & $\begin{aligned} 1, & 1903 \\
25, & 1904 \\
13,14, & 20,1906\end{aligned}$ & & & & $\begin{array}{l}\text { May } \\
\text { June }\end{array}$ & $\begin{array}{ll}24, & 1929 \\
16, & 1929\end{array}$ & & \\
\hline $\begin{array}{l}1906 \\
1907 \\
1908\end{array}$ & $\begin{array}{l}\text { July } \\
\text { July } \\
\text { June }\end{array}$ & $\begin{array}{r}3,4,1906 \\
3,1907 \\
13,1908 \\
\end{array}$ & $\begin{array}{l}5.45 \\
5.9 \\
3.6 \\
\end{array}$ & $\begin{array}{l}3,300 \\
4,170 \\
1,050\end{array}$ & 1931 & $\begin{array}{l}\text { June } \\
\text { May }\end{array}$ & $\begin{array}{r}12,1930 \\
7,1931\end{array}$ & $\begin{array}{l}4.70 \\
3.93\end{array}$ & 870 \\
\hline $\begin{array}{l}1909 \\
1910\end{array}$ & $\begin{array}{l}\text { June } \\
\text { May } \\
191\end{array}$ & $\begin{array}{l}4,5,1909 \\
25, \text { June } 1 \text {, } \\
10\end{array}$ & $\overline{-}$ & $\begin{array}{l}2,220 \\
1,680\end{array}$ & 1932 & $\begin{array}{l}\text { May } \\
\text { May } \\
\text { June }\end{array}$ & $\begin{array}{ll}1 S, & 1932 \\
28, & 1932 \\
26, & 1932\end{array}$ & $\begin{array}{l}4.65 \\
4.60 \\
5.60\end{array}$ & $\begin{array}{l}1,300 \\
1,260 \\
2,020\end{array}$ \\
\hline 1916 & $\begin{array}{l}\text { May } \\
\text { June } \\
\text { June }\end{array}$ & $\begin{array}{r}6,1916 \\
17,1916 \\
27,1916\end{array}$ & $\begin{array}{l}4.75 \\
5.40 \\
5.05\end{array}$ & $\begin{array}{l}1,260 \\
1,830 \\
1,520\end{array}$ & 1933 & $\begin{array}{l}\text { May } \\
\text { June }\end{array}$ & $\begin{array}{ll}31, & 1933 \\
14, & 1933\end{array}$ & $\begin{array}{l}4.49 \\
5.45\end{array}$ & $\begin{array}{l}1,280 \\
2,120\end{array}$ \\
\hline 1917 & $\begin{array}{l}\text { June } \\
\text { June }\end{array}$ & $\begin{array}{ll}10, & 1917 \\
17, & 1917\end{array}$ & $\begin{array}{l}5.65 \\
5.75\end{array}$ & $\begin{array}{l}2,260 \\
2,400\end{array}$ & 1934 & $\begin{array}{l}\text { June } \\
\text { May }\end{array}$ & $\begin{array}{ll}18, & 1934 \\
27, & 1935\end{array}$ & $\begin{array}{l}3.80 \\
4.59\end{array}$ & $\begin{array}{r}750 \\
1,670\end{array}$ \\
\hline 1918 & $\begin{array}{l}\text { June } \\
\text { June }\end{array}$ & $\begin{array}{ll}14, & 1918 \\
20, & 1918\end{array}$ & $\begin{array}{l}5.77 \\
5.42\end{array}$ & $\begin{array}{l}2,250 \\
1,890\end{array}$ & & $\begin{array}{l}\text { June } \\
\text { June } \\
\text { June }\end{array}$ & $\begin{array}{rr}6, & 1935 \\
13, & 1935 \\
20, & 1935\end{array}$ & $\begin{array}{l}5.10 \\
5.17 \\
4.83\end{array}$ & $\begin{array}{l}1,980 \\
1,950 \\
1,620\end{array}$ \\
\hline 1919 & May & 29,1919 & 5.60 & 2,180 & 1936 & May & 26,1936 & 4.40 & 1,250 \\
\hline 1920 & $\begin{array}{l}\text { May } \\
\text { May }\end{array}$ & $\begin{array}{ll}18, & 1920 \\
30, & 1920\end{array}$ & $\begin{array}{l}4.62 \\
4.55\end{array}$ & $\begin{array}{l}1,500 \\
1,440\end{array}$ & & $\begin{array}{l}\text { June } \\
\text { June }\end{array}$ & $\begin{array}{l}13,1936 \\
23,1936\end{array}$ & $\begin{array}{l}4.53 \\
4.75\end{array}$ & $\begin{array}{l}1,350 \\
1,540\end{array}$ \\
\hline & June & 20,1920 & 4.36 & 1,260 & 1937 & $\begin{array}{l}\text { May } \\
\text { May }\end{array}$ & $\begin{array}{ll}15, & 1937 \\
25, & 1937\end{array}$ & $\begin{array}{l}5.08 \\
4.89\end{array}$ & $\begin{array}{l}1,860 \\
1,670\end{array}$ \\
\hline 1921 & $\begin{array}{l}\text { May } \\
\text { May } \\
\text { June } \\
\text { June }\end{array}$ & $\begin{array}{ll}16, & 1921 \\
27, & 1921 \\
12, & 1921 \\
24, & 1921\end{array}$ & $\begin{array}{l}4.60 \\
4.62 \\
5.74 \\
4.77\end{array}$ & $\begin{array}{l}1,480 \\
1,500 \\
2,710 \\
1,650\end{array}$ & & $\begin{array}{l}\text { May } \\
\text { June } \\
\text { June } \\
\text { June }\end{array}$ & $\begin{array}{r}29,1937 \\
5,1937 \\
16,1937 \\
22,1937\end{array}$ & $\begin{array}{l}5.40 \\
5.08 \\
4.45 \\
4.95\end{array}$ & $\begin{array}{l}1,200 \\
1,860 \\
1,290 \\
1,730\end{array}$ \\
\hline 1922 & May & 6, 1922 & 4.68 & 1,330 & 1938 & Dec. & 11,1937 & - & 6,500 \\
\hline & $\begin{array}{l}\text { May } \\
\text { June } \\
\text { June }\end{array}$ & $\begin{array}{rr}25, & 1922 \\
5, & 1922 \\
26, & 1922\end{array}$ & $\begin{array}{l}5.18 \\
5.95 \\
5.70\end{array}$ & $\begin{array}{l}1,820 \\
2,640 \\
2,440\end{array}$ & 1957 & $\begin{array}{l}\text { June } \\
\text { June } \\
\text { June }\end{array}$ & $\begin{aligned} 4, & 1957 \\
13, & 1957 \\
25, & 1957\end{aligned}$ & $\begin{array}{l}3.87 \\
3.05 \\
3.29\end{array}$ & $\begin{array}{l}2,000 \\
1,230 \\
1,470\end{array}$ \\
\hline 1923 & $\begin{array}{l}\text { May } \\
\text { May } \\
\text { June } \\
\text { July }\end{array}$ & $\begin{array}{rr}17, & 1923 \\
25, & 1923 \\
11, & 1923 \\
2, & 1923\end{array}$ & $\begin{array}{l}4.85 \\
4.73 \\
5.10 \\
4.69\end{array}$ & $\begin{array}{l}1,540 \\
1,440 \\
1,770 \\
1,400\end{array}$ & 1958 & $\begin{array}{l}\text { May } \\
\text { May } \\
\text { June } \\
\text { July }\end{array}$ & 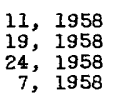 & $\begin{array}{l}3.40 \\
4.10 \\
4.21 \\
3.41\end{array}$ & $\begin{array}{l}1,440 \\
2,100 \\
2,230 \\
1,370\end{array}$ \\
\hline 1924 & May & 9,1924 & 3.92 & 856 & 1959 & May & 13,1959 & 2.76 & 884 \\
\hline 1925 & $\begin{array}{l}\text { May } \\
\text { May } \\
\text { June } \\
\text { June }\end{array}$ & $\begin{array}{rr}6, & 1925 \\
27, & 1925 \\
13, & 1925 \\
27, & 1925\end{array}$ & $\begin{array}{l}4.71 \\
4.95 \\
4.62 \\
4.90\end{array}$ & $\begin{array}{l}1,460 \\
1,660 \\
1,390 \\
1,610\end{array}$ & $\begin{array}{l}1960 \\
1961\end{array}$ & $\begin{array}{l}\text { June } \\
\text { May }\end{array}$ & $\begin{array}{r}2,1960 \\
26,1961\end{array}$ & $\begin{array}{l}3.15 \\
2.75\end{array}$ & $\begin{array}{r}1,270 \\
869\end{array}$ \\
\hline 1926 & $\begin{array}{l}\text { May } \\
\text { May } \\
\text { June }\end{array}$ & $\begin{array}{rr}4, & 1926 \\
20, & 1926 \\
8, & 1926\end{array}$ & $\begin{array}{l}4.45 \\
4.67 \\
4.64\end{array}$ & $\begin{array}{l}1,250 \\
1,430 \\
1,400\end{array}$ & 1962 & $\begin{array}{l}\text { May } \\
\text { June } \\
\text { June } \\
\text { June }\end{array}$ & $\begin{array}{rr}6, & 1962 \\
3, & 1962 \\
10, & 1962 \\
22, & 1962\end{array}$ & $\begin{array}{l}3.13 \\
3.20 \\
3.37 \\
3.55\end{array}$ & $\begin{array}{l}1,120 \\
1,180 \\
1,330 \\
1,500\end{array}$ \\
\hline 1927 & $\begin{array}{l}\text { May } \\
\text { May } \\
\text { June } \\
\text { June } \\
\text { July }\end{array}$ & 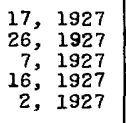 & $\begin{array}{l}5.40 \\
4.44 \\
5.20 \\
5.7 \\
4.48\end{array}$ & $\begin{array}{l}2,070 \\
1,240 \\
1,890 \\
2,350 \\
1,270\end{array}$ & 1963 & $\begin{array}{l}\text { Feb. } \\
\text { June } \\
\text { June } \\
\text { June } \\
\text { July }\end{array}$ & $\begin{array}{r}1,1963 \\
2,1963 \\
17,1963 \\
28,1963 \\
8,1963\end{array}$ & $\begin{array}{l}4.44 \\
3.52 \\
4.32 \\
3.36 \\
3.15\end{array}$ & $\begin{array}{l}2,510 \\
1,550 \\
2,470 \\
1,410 \\
1,230\end{array}$ \\
\hline 1928 & May & 26,1928 & 4.74 & 1,480 & & & & & \\
\hline
\end{tabular}

$785-975$ O-66-13, 
2975. West Walker River at Hoye Bridge, near Wellington, Nev.

Location.--Lat $38^{\circ} 43^{14} 0^{\prime \prime}$, long $119^{\circ} 25^{14} 0^{\prime \prime}$, in $\mathrm{NE} \frac{1}{4} \mathrm{SE} \frac{1}{4} \mathrm{sec} .17$, T.10 N., R.23 E., on left bank $20 \mathrm{ft}$ upstream from Hoye Bridge, 2 miles upstream from head of

Saroni Canal, and 4 miles southwest of Wellington.

Drainage area. $--504 \mathrm{sq} \mathrm{mi}$.

Gage.--Recording. July 1, 1920, to Sept. 30, 1923, at site 3 miles downstream (i mile downstream from Saroni Canal) at different datum ard supplemental staff gage on Saroni Canal 1 mile downstream from head. Altitude of gage is $4,980 \mathrm{ft}$ (from topographic map).

Stage-discharge relation.--Defined by current-meter measuremerts.

Remarks.--Flow regulated by off-channel storage in Topaz Reservoir since Jan. 30,1922 . Diversions for irrigation of about 10,500 acres above station. Records include releases from Topaz Reservolr and all return flow from Antelope Valley. Base for partial-duration series, $700 \mathrm{cfs}$. Only annual peaks are shown prior to 1958.

Peak stages and discharges

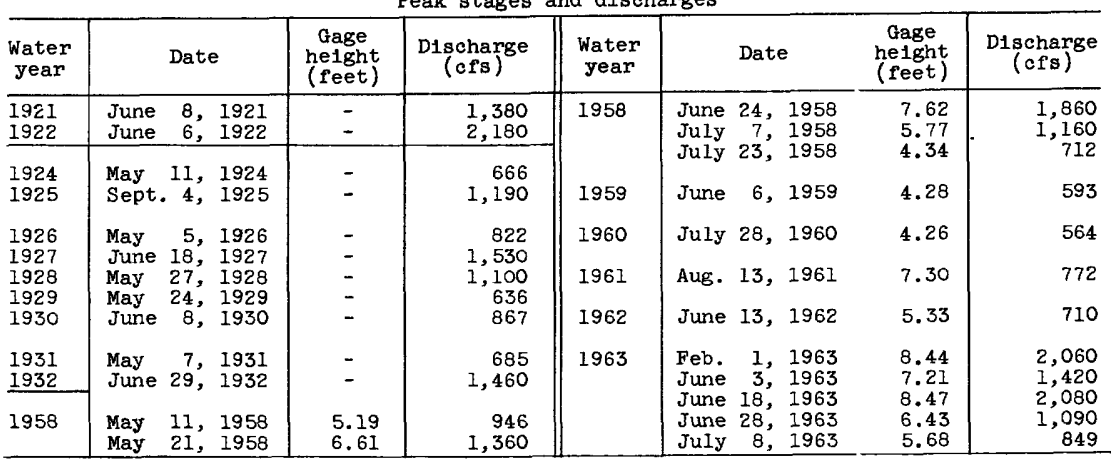

2985. West Walker River near Wellington, Nev.

Location.--Lat $38^{\circ} 45^{\prime}$, long $119^{\circ} 24^{\prime}$, in sec.10, T.10 N., R.23 E., in canyon between Antelope and Smith Valleys, a quarter of a mile upstream from Plymouth and Colony Canals, 1 mile downstream from Saroni Canal, threequarters of a mile upstream from county line, and 1 mile southwest of Wellington.

Drainage area. $--521 \mathrm{sq} \mathrm{mi}$.

Gage.--Recording. Altitude of gage is 4,850 ft (from topograplic map).

Stage-discharge relation.--Defined by current-meter measurements below $1,500 \mathrm{cf}$ 's.

Remarks.--Flow partly regulated by storage in Poor Lake and Topaz Reservolrs. only annual peaks are shown.

Peak stages and discharges

\begin{tabular}{l|c|c|c||c|c|c|c}
\hline $\begin{array}{l}\text { Water } \\
\text { year }\end{array}$ & Date & $\begin{array}{c}\text { Gage } \\
\text { helght } \\
\text { (feet) }\end{array}$ & $\begin{array}{c}\text { Discharge } \\
\text { (cfs) }\end{array}$ & $\begin{array}{c}\text { Water } \\
\text { year }\end{array}$ & Date & $\begin{array}{c}\text { Gage } \\
\text { height } \\
\text { (feet) }\end{array}$ & $\begin{array}{c}\text { Discharge } \\
\text { (cfs) }\end{array}$ \\
\hline 1918 & June 15, 1918 & - & 1,900 & 1921 & June 8,1921 & - & 1,300 \\
1919 & May 30, 1919 & - & 1,940 & 1922 & June 6, 1922 & 5.32 & 2,110 \\
1920 & May 30, 1920 & - & 1,030 & 1923 & July 3, 1923 & - & 1,370 \\
\hline
\end{tabular}


3000. West Walker River near Hudson, Nev.

(Published as "at Hudson" prior to June 1921)

Location.--Lat $38^{\circ} 48^{\prime} 35^{\prime \prime}$, long $119^{\circ} 13^{\prime} 35^{\prime \prime}$, in SE $\frac{1}{4} \mathrm{SW} \frac{1}{4}$ sec.18, T.11 N., R.25 E., on left bank half a mile upstream from wilson Canyon and 3 miles southeast of Hudson.

Drainage area. $--964 \mathrm{sq} \mathrm{mi}$.

Gage.--Nonrecording prior to May 1921, at site $2 \frac{1}{2}$ miles upstream at different datum; recording thereafter. May 1921 to March 1925 at approximately same site at different datum. Altitude of gage is $4,670 \mathrm{ft}$ (from topographic map).

Stage-discharge relation.--Defined by current-meter measurements below $1,700 \mathrm{cfs}$.

Remarks.--Flow regulated by off-channel storage in Topaz Reservoir since Jan. 30, 1922. Many diversions above station for irrigation. Station is below return flow from Irrigated areas in Smith Valley. Base for partialduration series, $500 \mathrm{cf}$. Only annual peaks are shown prior to 1951 .

Peak stages and discharges

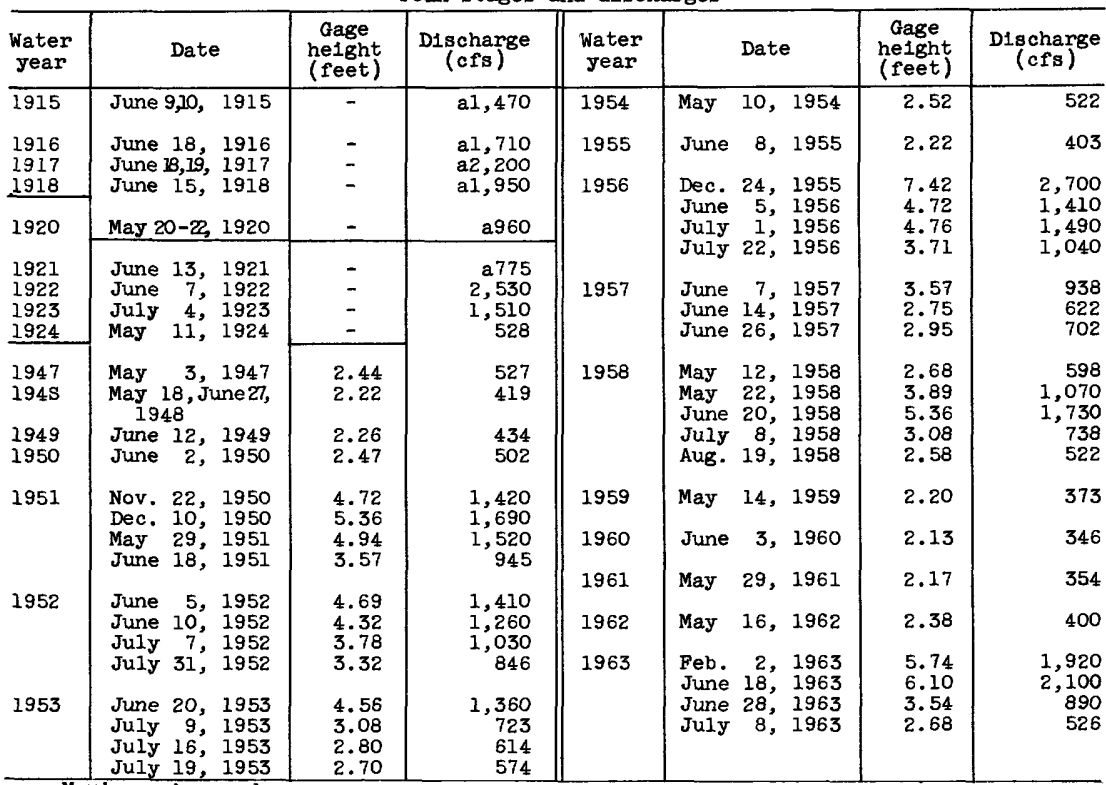

a Maximum observed.

3010. Walker River at Mason, Nev.

Location.--Lat $38^{\circ} 56^{\prime} 55^{\prime \prime}$, long $119^{\circ} 11^{\prime} 10^{\prime \prime}$, in NE $\frac{1}{4}$ sec.33, T.13 N., R.25 E., $600 \mathrm{f} t$ upstream from highway bridge at Mason.

Gage:--Nonrecording prior to May 15, 1921, on bridge pier $600 \mathrm{ft}$ downstream at different datum; recording thereafter. Altitude of gage is $4,400 \mathrm{ft}$ (from topographic map).

Stage-discharge relation.--Defined by current-meter measurements below $3,900 \mathrm{cfs}$.

Remarks.--Flow regulated by off-channel storage in Topaz Reservoir sinc? January 1922. Slight regulation by storage in Poor Lake and Twin Lakes Reservoirs. Only annual peaks are shown. 
Peak stages and discharges of Walker River at Mason, Nev.

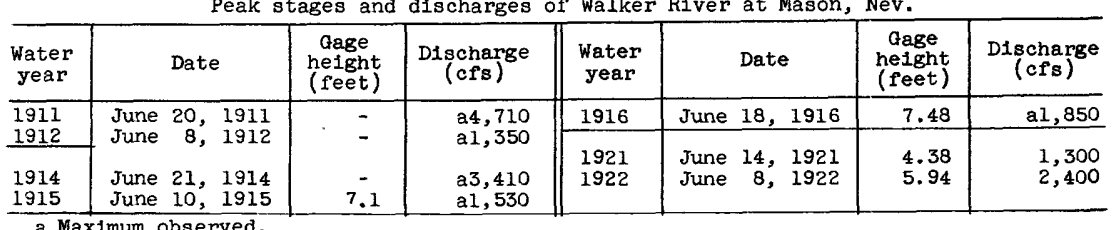

a Maximum observed.

3015. Walker River near Wabuska, Nev.

Location.--Iat $39^{\circ} 09^{\prime} 10^{\prime \prime}$, long $119^{\circ} 05^{\prime} 50^{\prime \prime}$, in $\mathrm{SE} \frac{1}{4} \mathrm{NW} \frac{1}{4} \sec .20$, T. $15 \mathrm{~N} ., \mathrm{R} .26$ E., on left bank $600 \mathrm{ft}$ upstream from timber bridge at Julian Rench, $1 \frac{3}{4}$ miles downstream from Southerm Pacific Railroad bridge, 4.6 miles east of Wabuska, and 16 miles upstream from Weber Dam.

Drainage area. $--2,600 \mathrm{sq} \mathrm{mi}$, approximately.

Gage.--Nonrecording prior to July 28, 1920; recording thereafter, except nonrecording Aug. 30 to Oct. 13, 1922, Oct. 1, 1924, to Sept. 50,1929 , and January 1939 to September 1958 . Prior to 1908 at site $2 \frac{1}{2}$ miles upstream at different datum. Jan. 15, 1920, to Sept. 30, 1929, at sites near present gage at different datums. Oct. 1, 1929, to Sept. 30,1935 , at site $1 \frac{1}{2}$ miles downstream at different datum. January 1939 to September $1 \$ 58,300 \mathrm{ft}$ downstream at datum $1.19 \mathrm{ft}$ higher. Altitude of gage is $4,280 \mathrm{ft}$ (from topographic map).

Stage-discharge relation. --Defined by current-meter measurements.

Remarks.--Records for 1934-35 furnished by Bureau of Indian Affairs, and those for 1939-58 by Walker River Irrigation District. Many diversions for irrigation above station. Flow regulated by Bridgeport and Topaz Reservoirs. only annual maximum daily or maximum observed discharges are shown except for 1959.

Peak stages and discharges

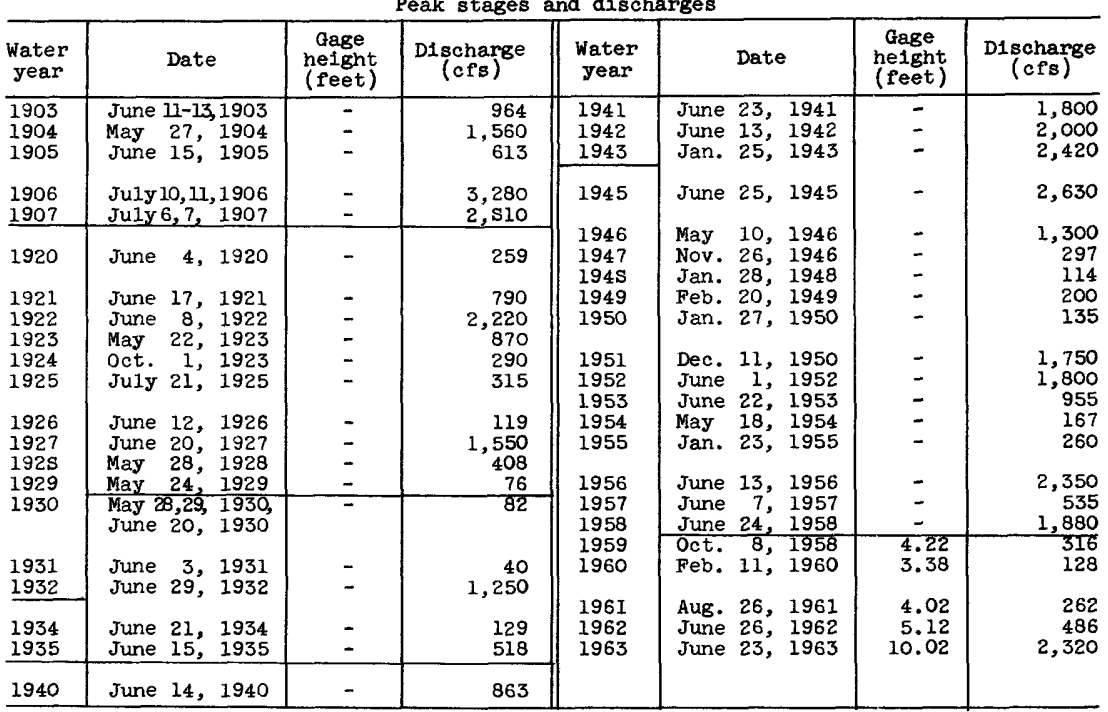


3020. Walker River at Schurz, Nev.

Location.--Lat $38^{\circ} 57^{\prime}$, long $118^{\circ} 48^{\prime}$, in sec. 36 , T.13 N., R.28 E, at rall road bridge at Schurz, 3 miles upstream from Walker Lake and 6 miles downstream from Walker River Indian Reservation diversion dam.

Drainage area. $--2,850 \mathrm{sq} \mathrm{mi}$, approximately.

Gage.-Nonrecording. Prior to Aug. 4, 1914, at site about 2,300 ft upstream at different datum. Aug. 4, 1914, to Nov. 14, 1916, at site 1,000 ft unstream at different datum. Altitude of gage is $4,120 \mathrm{ft}$ (from topographic map).

Stage-discharge relation.--Defined by current-meter measurements.

Remarks.--Many diversions for irrigation above station. Flow regulated by Topaz Reservoir since 1922 and by Bridgeport Reservoir since 1923. Only annual maximum observed discharges are shown.

Maximum observed stages and discharges

\begin{tabular}{|c|c|c|c|c|c|c|c|}
\hline $\begin{array}{l}\text { Water } \\
\text { year }\end{array}$ & Date & $\begin{array}{c}\text { Gage } \\
\text { helght } \\
\text { (feet) }\end{array}$ & $\begin{array}{c}\text { D1scharge } \\
\text { (cfs) }\end{array}$ & $\begin{array}{l}\text { Water } \\
\text { year }\end{array}$ & Date & $\begin{array}{c}\text { Gage } \\
\text { helght } \\
\text { (feet) }\end{array}$ & $\begin{array}{l}\text { D1scharge } \\
\text { (cfs) }\end{array}$ \\
\hline $\begin{array}{l}1914 \\
1915\end{array}$ & $\begin{array}{l}\text { June } 8,1914 \\
\text { June } 12,1915\end{array}$ & $\frac{11.0}{6.85}$ & $\frac{2,530}{1,180}$ & $\begin{array}{l}1924 \\
1925\end{array}$ & $\begin{array}{ll}\text { Oct. } 1, & 1923 \\
\text { July } 22, & 1925\end{array}$ & $\begin{array}{l}2.75 \\
2.8\end{array}$ & $\begin{array}{l}301 \\
315\end{array}$ \\
\hline $\begin{array}{l}1916 \\
1917 \\
1918 \\
1919\end{array}$ & $\begin{array}{l}\text { June 20, } 1916 \\
\text { June } 21,1917 \\
\text { June 1s, } 1918 \\
\text { May 31, June 1, } \\
1919\end{array}$ & $\begin{array}{l}7.50 \\
7.3 \\
7.00 \\
6.50\end{array}$ & $\begin{array}{l}1,500 \\
1,860 \\
2,100 \\
1,970\end{array}$ & $\begin{array}{l}1926 \\
1927 \\
1928 \\
1929 \\
1930\end{array}$ & 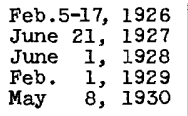 & $\begin{array}{l}1.98 \\
5.70 \\
2.82 \\
1.60 \\
1.60\end{array}$ & $\begin{array}{r}125 \\
1,530 \\
350 \\
61 \\
61\end{array}$ \\
\hline $\begin{array}{l}1920 \\
1921 \\
1922 \\
1923\end{array}$ & $\begin{array}{ll}\text { May } 25, & 1920 \\
& \\
\text { June } 15, & 1921 \\
\text { July 1, } 1922 \\
\text { May 24, } 1923\end{array}$ & $\begin{array}{l}2.20 \\
4.00 \\
6.40 \\
4.20\end{array}$ & $\begin{array}{r}187 \\
640 \\
2,050 \\
\$ 25\end{array}$ & $\begin{array}{l}1931 \\
1932 \\
1933 \\
\end{array}$ & $\begin{array}{l}\text { Jan.31, Feb.1, } \\
1931 \\
\text { June 30, } 1932 \\
\text { Mar. 1, } 1933\end{array}$ & $\begin{array}{l}1.50 \\
6.00 \\
1.90 \\
\end{array}$ & $\begin{array}{r}91 \\
1,250 \\
139 \\
\end{array}$ \\
\hline
\end{tabular}

\section{CARSON RIVER BASIN}

3025. East Fork Carson River above Soda Springs ranger station, near Markleeville, Calif.

Location.--Lat $38^{\circ} 30^{\prime}$, long $119^{\circ} 41^{\prime}$, in sec. 28, T. 8 N., R.21 E., on lef': bank half a mile downstream from Murray Canyon Creek, 2 miles southwest of Soda Springs ranger station, and 14 miles southeast of Markleeville.

Drainage area. $--30 \mathrm{sq} \mathrm{mi}$, approximately. Mean altitude, 8,790 ft.

Gage.--Recording. Altitude of gage is 6,820 ft (from topographic map).

Stage-discharge relation.--Defined by current-meter measurements below $320 \mathrm{cfs}$ and by slope-area measurements at $3,570 \mathrm{cfs}$.

Remarks.--Base for partial-duration series, $300 \mathrm{cfs}$.

Peak stages and discharges

\begin{tabular}{|c|c|c|c|c|c|c|c|c|c|}
\hline $\begin{array}{l}\text { Water } \\
\text { year }\end{array}$ & \multicolumn{2}{|r|}{ Date } & $\begin{array}{c}\text { Gage } \\
\text { height } \\
\text { (feet) }\end{array}$ & $\begin{array}{c}\text { D1scharge } \\
\text { (cfs) }\end{array}$ & $\begin{array}{l}\text { Water } \\
\text { year }\end{array}$ & \multicolumn{2}{|r|}{ Date } & $\begin{array}{c}\text { Gage } \\
\text { helght } \\
\text { (feet) }\end{array}$ & $\begin{array}{c}\text { D1scharge } \\
\text { (cfs) }\end{array}$ \\
\hline 1947 & $\begin{array}{l}\text { May } \\
\text { May } \\
\text { June }\end{array}$ & $\begin{array}{rr}2, & 1947 \\
22, & 1947 \\
7, & 1947\end{array}$ & $\begin{array}{l}3.80 \\
3.59 \\
3.35\end{array}$ & $\begin{array}{l}447 \\
356 \\
322\end{array}$ & 1949 & $\begin{array}{l}\text { May } \\
\text { June } \\
\text { May }\end{array}$ & $\begin{array}{ll}26, & 1949 \\
10, & 1949 \\
31, & 1950\end{array}$ & $\begin{array}{l}3.91 \\
3.89\end{array}$ & $\begin{array}{l}480 \\
474\end{array}$ \\
\hline 1948 & $\begin{array}{l}\text { May } \\
\text { May } \\
\text { June } \\
\text { June }\end{array}$ & 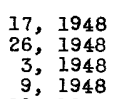 & $\begin{array}{l}3.60 \\
4.06 \\
3.44 \\
3.74\end{array}$ & $\begin{array}{l}359 \\
528 \\
345 \\
429\end{array}$ & 1950 & $\begin{array}{l}\text { May } \\
\text { June } \\
\text { June } \\
\text { June }\end{array}$ & $\begin{array}{r}31,1950 \\
5,1950 \\
10,1950 \\
20,1950\end{array}$ & $\begin{array}{l}4.27 \\
4.18 \\
3.32 \\
3.99\end{array}$ & $\begin{array}{l}652 \\
813 \\
311 \\
533\end{array}$ \\
\hline 1949 & $\begin{array}{l}\text { June } \\
\text { Apr. } \\
\text { May } \\
\text { May }\end{array}$ & $\begin{array}{l}29,1948 \\
24,1949 \\
12,1949 \\
16,1949\end{array}$ & $\begin{array}{l}3.76 \\
3.41 \\
3.38 \\
3.35\end{array}$ & $\begin{array}{l}435 \\
338 \\
330 \\
322\end{array}$ & 1951 & $\begin{array}{l}\text { Nov. } \\
\text { Dec. } \\
\text { Dec. } \\
\text { May }\end{array}$ & $\begin{array}{rr}20, & 1950 \\
3, & 1950 \\
8, & 1950 \\
27, & 1951\end{array}$ & $\begin{array}{l}7.62 \\
4.44 \\
4.52 \\
4.46\end{array}$ & $\begin{array}{r}3,570 \\
733 \\
934 \\
744\end{array}$ \\
\hline
\end{tabular}


3030. Silver King Creek near Coleville, Callf.

Location.--Lat $38^{\circ} 31^{\prime}$, long $119^{\circ} 36^{\prime}$, in sec.30, T.8 N., R.22 E., on left bank a quarter of a mile downstream from Poison Valley, $2 \frac{1}{2}$ miles east of Soda

Springs ranger station, and $6 \frac{1}{2}$ miles southwest of Coleville.

Drainage area. $--30 \mathrm{sq} \mathrm{ml}$, approximately. Mean altitude, 8,840 ft.

Gage.--Recording. Altitude of gage is 7,650 ft (from topograpl ic map).

Stage-discharge relation.--Defined by current-meter measurements.

Remarks.--Base for partial-duration series, $100 \mathrm{cfs}$.

\begin{tabular}{|c|c|c|c|c|c|c|c|c|c|}
\hline $\begin{array}{l}\text { Water } \\
\text { year }\end{array}$ & & Date & $\begin{array}{c}\text { Gage } \\
\text { helght } \\
\text { (feet) }\end{array}$ & $\begin{array}{c}\text { Discharge } \\
\text { (cfs) }\end{array}$ & $\begin{array}{l}\text { Water } \\
\text { year }\end{array}$ & & Date & $\begin{array}{c}\text { Gage } \\
\text { helght } \\
\text { (feet) }\end{array}$ & $\begin{array}{c}\text { Discharge } \\
\text { (cfs) }\end{array}$ \\
\hline 1947 & $\begin{array}{l}\text { Apr. } \\
\text { May } \\
\text { May } \\
\text { May }\end{array}$ & $\begin{array}{rr}19, & 1947 \\
2, & 1947 \\
5, & 1947 \\
22, & 1947\end{array}$ & $\begin{array}{c}- \\
2.39 \\
-\end{array}$ & $\begin{array}{l}140 \\
172 \\
170 \\
138\end{array}$ & $\begin{array}{l}1949 \\
1950\end{array}$ & $\begin{array}{l}\text { May } \\
\text { June } \\
\text { Apr. } \\
\text { May }\end{array}$ & $\begin{array}{l}26,1949 \\
10,1949 \\
27,1950 \\
31,1950\end{array}$ & $\begin{array}{c}- \\
- \\
2.62\end{array}$ & $\begin{array}{l}169 \\
158 \\
186 \\
220\end{array}$ \\
\hline 1948 & $\begin{array}{l}\text { May } \\
\text { May } \\
\text { May }\end{array}$ & $\begin{array}{rr}5, & 1948 \\
15, & 1948 \\
26, & 1948\end{array}$ & $\begin{array}{c}2.33 \\
-\end{array}$ & $\begin{array}{l}160 \\
151 \\
149\end{array}$ & 1951 & $\begin{array}{l}\text { June } \\
\text { Nov. } \\
\text { Dec. }\end{array}$ & $\begin{aligned} 20, & 1950 \\
20, & 1950 \\
3, & 1950\end{aligned}$ & $\begin{array}{c}- \\
5.47 \\
4.35\end{array}$ & $\begin{array}{l}159 \\
748 \\
520\end{array}$ \\
\hline 1949 & $\begin{array}{l}\text { Apr. } \\
\text { May } \\
\text { May }\end{array}$ & $\begin{array}{rr}24, & 1949 \\
1, & 1949 \\
16, & 1949 \\
\end{array}$ & $\begin{array}{l}2.61 \\
- \\
-\end{array}$ & $\begin{array}{l}214 \\
163 \\
199\end{array}$ & & $\begin{array}{l}\text { Dec. } \\
\text { May }\end{array}$ & $\begin{array}{rr}8, & 1950 \\
27, & 1951\end{array}$ & $\begin{array}{l}4.07 \\
2.87\end{array}$ & $\begin{array}{l}464 \\
230\end{array}$ \\
\hline
\end{tabular}

3040. Wolf Creek near Markleeville, Calif.

Location.--Lat $38^{\circ} 32^{\prime}$, long $119^{\circ} 43^{\prime}$, in sec. 24 , T.8 N., R.20 E., on left bank three-quarters of a mile downstream from Bull Canyon Creek and 12 miles southwest of Markleeville.

Drainage area. $--9.8 \mathrm{sq} \mathrm{m}$, approximately. Mean altitude, $8,700 \mathrm{ft}$.

Gage.--Recording. Altitude of gage is 7,350 ft (from topographic map).

Stage-discharge relation.--Defined by current-meter measurements below $150 \mathrm{cfs}$ and by slope-area measurements at $1,480 \mathrm{cfs}$.

Remarks. --Base for partial-duration series, $150 \mathrm{cfs}$.

Peak stages and d1scharges

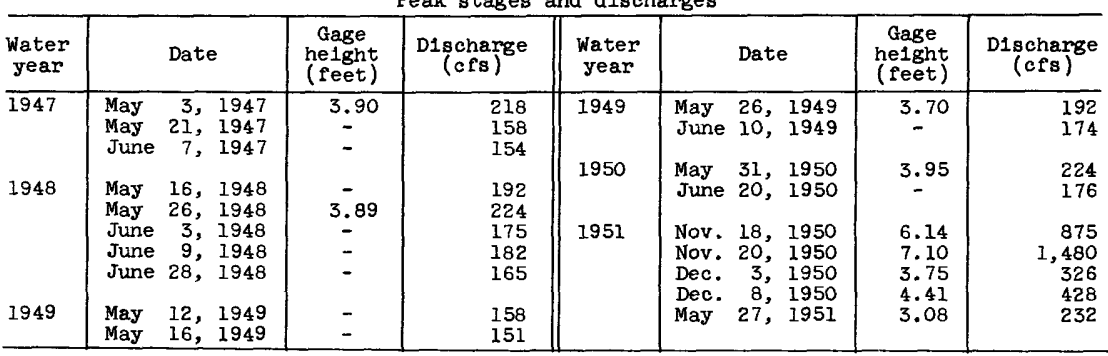


3045. Silver Creek below Pennsylvania Creek, near Markleeville, Calif.

Location. - -Lat $38^{\circ} 36^{1} 00^{\prime \prime}$, long $119^{\circ} 46^{\prime} 30^{\prime \prime}$, in $\mathrm{SE} \frac{1}{4} \mathrm{NE} \frac{1}{4}$ sec. 28 , T.9 N., R.20 E., on left bank a quarter of a mile downstream from Pennsylvania Creek and $6 \frac{1}{2}$ miles south of Markleeville.

Drainage area. $--20 \mathrm{sq} \mathrm{mi}$, approximately. Mean altitude, 8,200 ft.

Gage.--Recording. Prior to Aug. 3, 1954, at site $180 \mathrm{ft}$ upstream at datum $5.20 \mathrm{ft}$ higher. Aug. 3, 1954 , to Sept. 16, 1957, at site $30 \mathrm{ft}$ upstream at datum $3.00 \mathrm{ft}$ h1gher. Sept. 17, 1957, to Aug. 22, 1963, at present site at datum $2.00 \mathrm{ft}$ higher. Altitude of gage is $6,500 \mathrm{ft}$ (from topographic map).

Stage-discharge relation.--Defined by current-meter measurements below $450 \mathrm{cfs}$ and by slope-area measurements at 1,520 and $2,220 \mathrm{cfs}$.

Remarks.--Base for partial-duration series, $190 \mathrm{cfs}$.

Peak stages and discharges

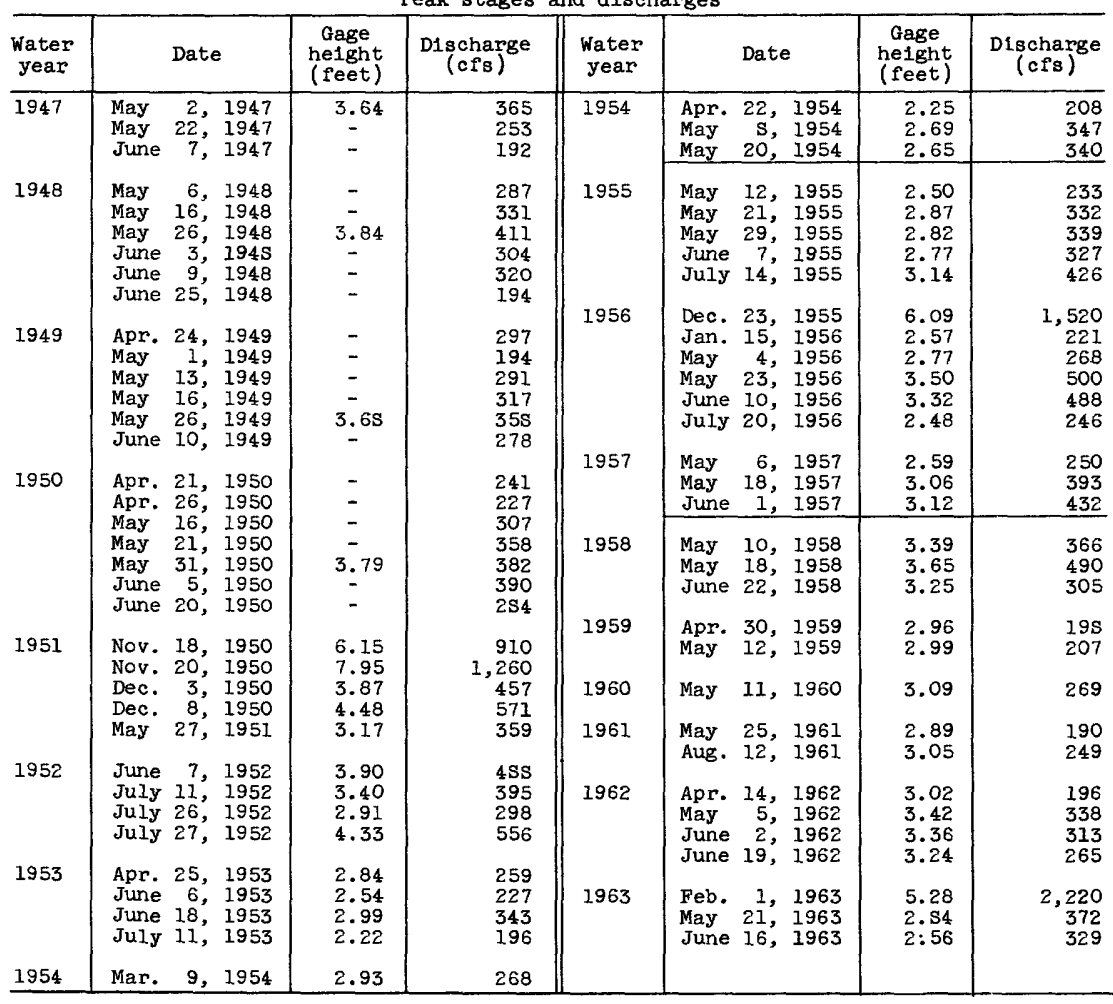


3060. Hot Springs Creek near Markleeville, Calif.

(Published as "Markleeville Creek above Grover Hot Springs, near Markleeville" prior to 1956)

Location.--Lat $38^{\circ} 42^{\prime}$, long $119^{\circ} 51^{\prime}$, in SE $\frac{1}{4} \mathrm{NE} \frac{1}{4}$ Sec.23, T.10 N., R.19 E., on right bank half a mile upstream from Buck Creek, 4 miles upstream from mouth, and 4 miles west of Markleeville.

Drainage area.--14 sq mi, approximately. Mean altitude, 8,170 ft.

Gage.--Recording. Prior to July 31, 1953, at site $25 \mathrm{ft}$ upstream at datum $0.05 \mathrm{ft}$ higher. Altitude of gage is 5,880 ft (from river-profile map, extended).

Stage-discharge relation.---Defined by current-meter measurements below $330 \mathrm{cfs}$ and by slope-area measurements at $1,740 \mathrm{cfs}$.

Remarks.--Base for partial-duration series, $175 \mathrm{cfs}$.

\begin{tabular}{|c|c|c|c|c|c|c|c|c|c|}
\hline $\begin{array}{l}\text { Water } \\
\text { year }\end{array}$ & \multicolumn{2}{|r|}{ Date } & $\begin{array}{l}\text { Gage } \\
\text { helght } \\
\text { (feet) }\end{array}$ & $\begin{array}{c}\text { D1scharge } \\
\text { (cfs) }\end{array}$ & $\begin{array}{l}\text { Water } \\
\text { year }\end{array}$ & \multicolumn{2}{|r|}{ Date } & $\begin{array}{c}\text { Gage } \\
\text { helght } \\
\text { (feet) }\end{array}$ & \multirow{2}{*}{$\begin{array}{r}\begin{array}{c}\text { Discharge } \\
\text { (cfs) }\end{array} \\
203 \\
205 \\
247 \\
255 \\
\end{array}$} \\
\hline \multirow[t]{2}{*}{1948} & $\begin{array}{l}\text { May } \\
\text { May } \\
\text { May }\end{array}$ & $\begin{array}{rr}2, & 1947 \\
6, & 1948 \\
16, & 1948\end{array}$ & $\begin{array}{l}4.73 \\
4.14 \\
4.75\end{array}$ & $\begin{array}{l}316 \\
185 \\
302\end{array}$ & 1953 & $\begin{array}{l}\text { Apr. } \\
\text { May } \\
\text { June } \\
\text { June }\end{array}$ & $\begin{array}{rr}26, & 1953 \\
19, & 1953 \\
6, & 1953 \\
18, & 1953 \\
\end{array}$ & $\begin{array}{l}4.40 \\
4.34 \\
4.52 \\
4.56 \\
\end{array}$ & \\
\hline & $\begin{array}{l}\text { May } \\
\text { June }\end{array}$ & $\begin{array}{r}26,1948 \\
2,1948\end{array}$ & $\begin{array}{l}5.17 \\
4.57\end{array}$ & $\begin{array}{l}399 \\
270\end{array}$ & 1954 & Apr. & $\begin{array}{rr}24, & 1954 \\
8, & 1954\end{array}$ & $\begin{array}{l}4.55 \\
5.21\end{array}$ & $\begin{array}{l}189 \\
302\end{array}$ \\
\hline 1949 & $\begin{array}{l}\text { Apr. } \\
\text { May } \\
\text { May }\end{array}$ & $\begin{array}{ll}24, & 1949 \\
13, & 1949 \\
26, & 1949\end{array}$ & $\begin{array}{l}4.40 \\
4.93 \\
4.38\end{array}$ & $\begin{array}{l}211 \\
318 \\
208\end{array}$ & 1955 & $\begin{array}{l}\text { May } \\
\text { May } \\
\text { May }\end{array}$ & $\begin{array}{ll}20, & 1954 \\
12, & 1955 \\
23, & 1955\end{array}$ & $\begin{array}{l}4.62 \\
4.52 \\
5.02\end{array}$ & $\begin{array}{l}198 \\
205 \\
292\end{array}$ \\
\hline 1950 & May & 27,1950 & 5.03 & 338 & & $\begin{array}{l}\text { May } \\
\text { June }\end{array}$ & $\begin{array}{rr}29, & 1955 \\
7, & 1955\end{array}$ & $\begin{array}{l}5.05 \\
4.50\end{array}$ & $\begin{array}{l}297 \\
202\end{array}$ \\
\hline 1951 & $\begin{array}{l}\text { Nov. } \\
\text { Nov. } \\
\text { Dec. } \\
\text { Dec. } \\
\text { May }\end{array}$ & $\begin{array}{rr}15, & 1950 \\
20, & 1950 \\
3, & 1950 \\
8, & 1950 \\
27, & 1951\end{array}$ & $\begin{array}{l}7.43 \\
8.49 \\
5.86 \\
6.50 \\
4.16\end{array}$ & $\begin{array}{r}1,200 \\
1,740 \\
558 \\
810 \\
186\end{array}$ & 1956 & $\begin{array}{l}\text { Dec. } \\
\text { May } \\
\text { May }\end{array}$ & $\begin{array}{rr}23, & 1955 \\
3, & 1956 \\
23, & 1956\end{array}$ & $\begin{array}{l}7.36 \\
4.73 \\
6.14\end{array}$ & $\begin{array}{l}900 \\
267 \\
523\end{array}$ \\
\hline 1952 & $\begin{array}{l}\text { May } \\
\text { July }\end{array}$ & $\begin{array}{ll}31, & 1952 \\
25, & 1952 \\
\end{array}$ & $\begin{array}{l}5.75 \\
4.27 \\
\end{array}$ & $\begin{array}{l}513 \\
187 \\
\end{array}$ & 1957 & $\begin{array}{l}\text { May } \\
\text { May } \\
\text { June }\end{array}$ & $\begin{array}{rr}7, & 1957 \\
18, & 1957 \\
1, & 1957 \\
\end{array}$ & $\begin{array}{l}4.37 \\
5.02 \\
5.07 \\
\end{array}$ & $\begin{array}{l}214 \\
313 \\
341 \\
\end{array}$ \\
\hline
\end{tabular}

3090. East Fork Carson River near Gardnerville, Nev.

(Published as "at Rodenbahs" 1890-93, and as "at Rodenbah's ranch near Gardnervilie" 1950)

Location,--Lat $38^{\circ} 50150^{\prime \prime}$, long $119^{\circ} 42^{\prime} 10^{\prime \prime}$, in SW $\frac{1}{4} \mathrm{NE} \frac{1}{4} \sec .2$, T.11 N., R.20 E., on left bank 2 miles east of Mud Lake Reservolr, $4 \frac{1}{2}$ miles dornstream from Bryant Creek, and 7 miles southeast of Gardnerville.

Drainage area.--344 sq $\mathrm{ml}$. Mean altitude, 7,620 ft.

Gage.--Nonrecording prior to May 19, 1939, at several sites witrin 2 miles of present site at various datums; recording thereafter. Datum of gage is $4,985.11 \mathrm{ft}$ above mean sea level (levels by Bureau of Reclametion).

Stage-discharge relation.--Defined by current-meter measurements below 6,000 cf's and by slope-area measurements at $17,600 \mathrm{cfs}$.

Remarks.--Station is above all diversions in Carson Valley. Diversions for $1 \mathrm{r}-$ rigation above station. Flow slightly regulated by several small reservolrs (total capacity, about 5,000 acre-ft). Base for partial-duration series, $1,300 \mathrm{cfs}$. Only annual peaks are shown prior to 1948 .

Peak stages and discharges

\begin{tabular}{|c|c|c|c|c|c|c|c|}
\hline $\begin{array}{l}\text { Water } \\
\text { year }\end{array}$ & Date & $\begin{array}{c}\text { Gage } \\
\text { height } \\
\text { (feet) }\end{array}$ & $\begin{array}{c}\text { Discharge } \\
\text { (cfs) }\end{array}$ & $\begin{array}{l}\text { Water } \\
\text { year }\end{array}$ & Date & $\begin{array}{c}\text { Gage } \\
\text { helght } \\
\text { (feet) }\end{array}$ & $\begin{array}{c}\text { D1scharge } \\
(\mathrm{cfs})\end{array}$ \\
\hline $\begin{array}{l}1890 \\
1891 \\
1892 \\
1893 \\
\end{array}$ & $\begin{array}{ll}\text { May } 28, & 1890 \\
& \left\{\begin{array}{l}a \\
b\end{array}\right) \\
\text { Dec. } & 25,1892\end{array}$ & $\begin{array}{l}- \\
- \\
-\end{array}$ & $\begin{array}{l}4,260 \\
1,880 \\
2,590 \\
5,540\end{array}$ & $\begin{array}{l}1901 \\
1902 \\
1903 \\
1904\end{array}$ & $\begin{array}{l}\text { May } 17,1901 \\
\text { May 2S, June } \mathrm{S}, \\
\quad 1902 \\
\text { May } 14,1903 \\
\text { Feb. } 24,1904\end{array}$ & $\begin{array}{l}- \\
- \\
-\end{array}$ & $\begin{array}{l}3,162 \\
1,800 \\
2,900 \\
4,100\end{array}$ \\
\hline
\end{tabular}


Peak stages and discharges of East Fork Carson River near Gardnerville, Nev,--Con.

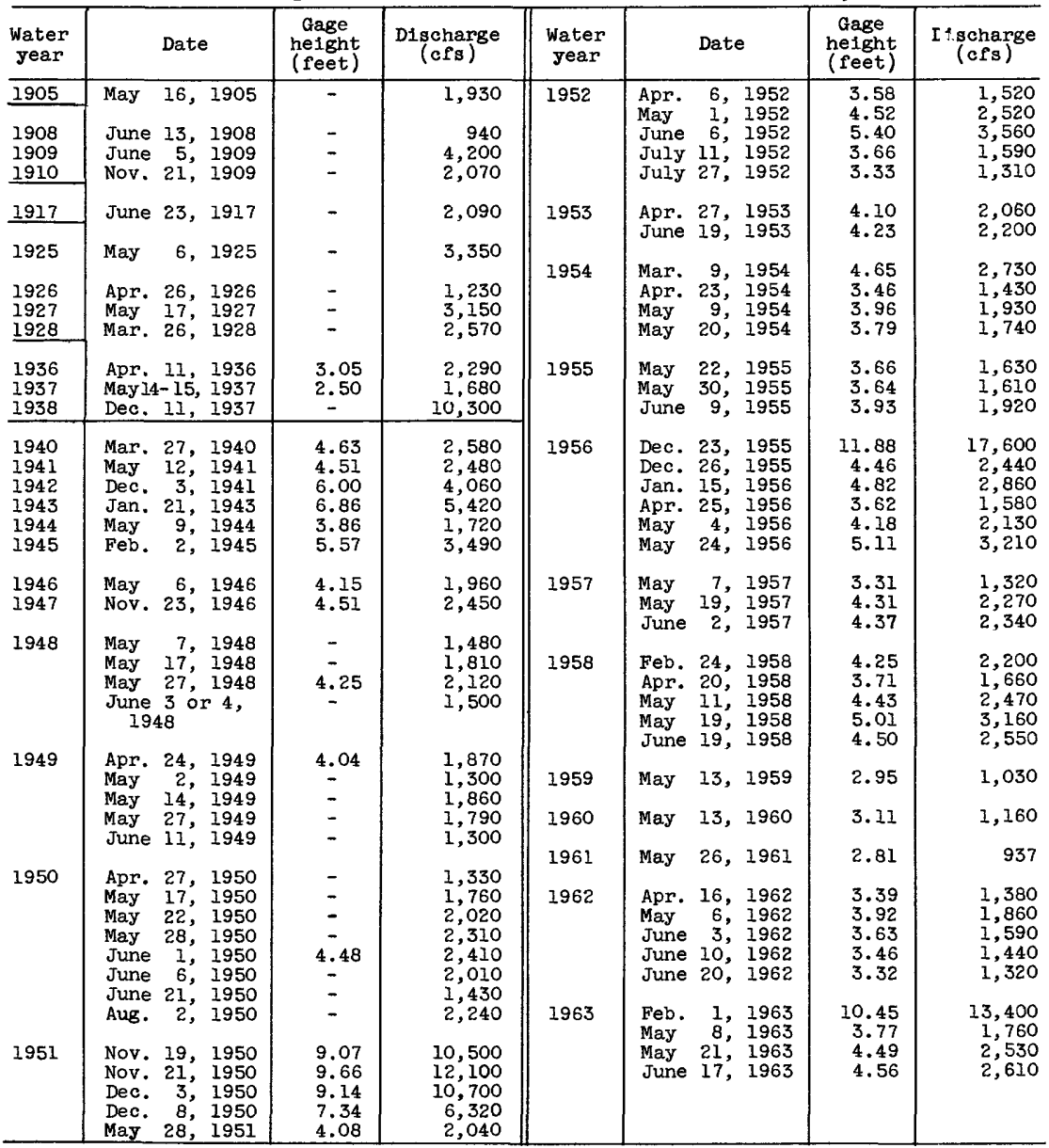

3095. West Fork Carson River above Woodfords, Calif.

Location.--Lat $38^{\circ} 47^{\prime}$, long $119^{\circ} 54^{\prime}$, in sec.31, T.11 N., R. 19 E., on right bank 1 mile above Horsethief Canyon Creek and 4 miles west of Woodfords.

Drainage area. $--53 \mathrm{sq} \mathrm{ml}$, approximately.

Gage.--Recording. Altitude of gage is 6,860 ft (from river-profile map).

Stage-discharge relation.--Defined by current-meter measurements below $630 \mathrm{cfs}$ and extended on basis of slope-area measurements and areal-yield studi to peak of $4,600 \mathrm{cfs}$.

Bankfull stage.--In canyon; not subject to overflow.

Remarks.--Base for partial-duration series, $450 \mathrm{cfs}$. 
Peak stages and discharges of West Fork Carson River above Woodfords, Calif.

\begin{tabular}{|c|c|c|c|c|c|c|c|c|}
\hline $\begin{array}{l}\text { Water } \\
\text { year }\end{array}$ & \multicolumn{2}{|r|}{ Date } & $\begin{array}{c}\text { Gage } \\
\text { height } \\
\text { (feet) }\end{array}$ & $\begin{array}{c}\text { Digcharge } \\
(\mathrm{cfs})\end{array}$ & $\begin{array}{l}\text { Water } \\
\text { year }\end{array}$ & Date & $\begin{array}{c}\text { Gage } \\
\text { height } \\
\text { (feet) }\end{array}$ & $\begin{array}{l}\text { Discharge } \\
\text { (cfs) }\end{array}$ \\
\hline 1947 & & $2, \quad 1947$ & 4.75 & 602 & 1950 & $\begin{array}{lll}\text { Apr. } & 27, & 1950 \\
\text { May } & 15, & 1950\end{array}$ & $\begin{array}{l}5.05 \\
5.06\end{array}$ & $\begin{array}{l}698 \\
701\end{array}$ \\
\hline 1948 & $\begin{array}{l}\text { May } \\
\text { May } \\
\text { May }\end{array}$ & $\begin{array}{rr}6, & 1948 \\
16, & 1948 \\
26, & 1948\end{array}$ & $\begin{array}{l}4.84 \\
5.00 \\
4.74\end{array}$ & $\begin{array}{l}627 \\
674 \\
599\end{array}$ & 1951 & 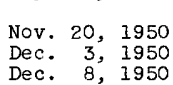 & $\begin{array}{l}9.82 \\
8.59 \\
7.33\end{array}$ & $\begin{array}{l}4,600 \\
3,190 \\
2,010\end{array}$ \\
\hline 1949 & $\begin{array}{l}\text { Apr. } \\
\text { May }\end{array}$ & $\begin{array}{ll}24, & 1949 \\
14, & 1949 \\
\end{array}$ & $\begin{array}{l}5.39 \\
5.06\end{array}$ & $\begin{array}{l}793 \\
692\end{array}$ & & & & \\
\hline
\end{tabular}

3100. West Fork Carson River at Woodfords, Calif.

Location. - -Lat $38^{\circ} 46^{\prime} 10^{\prime \prime}$, long $119^{\circ} 49^{\prime} 55^{\prime \prime}$, in NW $\frac{1}{4} S E \frac{1}{4} \sec .34$, T.11 N., R.19 E., on left bank 0.3 mile downstream from bridge on State Highways 88 and 89 ,

0.6 mile southwest of Woodfords, and $3 \frac{3}{4}$ miles downstream from W11low Creek.

Drainage area. $--66 \mathrm{sq} \mathrm{mi}$, approximately. Mean altitude, 8,060 ft.

Gage.--Nonrecording prior to Oct. 1, 1938, at different datum; recording thereafter. Oct. 1, 1938, to Nov. 11, 1958, at present site at datum $1.02 \mathrm{ft}$

lower. Nov. 13, 1958 , to Jan. 30,1963 , at site $150 \mathrm{ft}$ downstream at datum

$3.06 \mathrm{ft}$ lower. Altitude of gage is 5,760 ft (from river-profile map).

Stage-discharge relation.--Defined by current-meter measurements below 1,000 cfs and by slope-area measurements at $4,810 \mathrm{cfs}$.

Remarks.--Base for partial-duration series, $500 \mathrm{cfs}$. Only annual peaks are shown prior to 1948 ( $1891,1901-20$, maximum dally discharge).

\begin{tabular}{|c|c|c|c|c|c|c|c|c|}
\hline $\begin{array}{l}\text { Water } \\
\text { year }\end{array}$ & Date & $\begin{array}{l}\text { Gage } \\
\text { helght } \\
\text { (feet) }\end{array}$ & $\begin{array}{c}\text { Discharge } \\
\text { (cfs) }\end{array}$ & $\begin{array}{l}\text { Water } \\
\text { year }\end{array}$ & & Date & $\begin{array}{l}\text { Gage } \\
\text { height } \\
\text { (feet) }\end{array}$ & $\begin{array}{l}\text { Discharge } \\
\text { (cfs) }\end{array}$ \\
\hline $\begin{array}{l}1890 \\
1891 \\
\end{array}$ & $\begin{array}{lll}\text { June } & 9, & 1890 \\
\text { May } & 5, & 1891\end{array}$ & - & $\begin{array}{r}1,280 \\
740\end{array}$ & 1948 & $\begin{array}{l}\text { May } \\
\text { May }\end{array}$ & $\begin{array}{ll}16, & 1948 \\
26, & 1948\end{array}$ & 4.65 & $\begin{array}{l}708 \\
621\end{array}$ \\
\hline $\begin{array}{l}1901 \\
1902 \\
1903 \\
1904 \\
1905\end{array}$ & $\begin{array}{l}\text { May } 12,1901 \\
\text { May } 26,28,1902 \\
\text { May } 10-13,1903 \\
\text { May } 12,1904 \\
\text { May } 18,1925\end{array}$ & $\begin{array}{l}- \\
\overline{-} \\
-\end{array}$ & $\begin{array}{r}596 \\
448 \\
502 \\
1,055 \\
370\end{array}$ & 1950 & $\begin{array}{l}\text { Apr. } \\
\text { May }\end{array}$ & $\begin{array}{ll}24, & 1949 \\
14, & 1949 \\
27, & 1950 \\
16, & 1950\end{array}$ & $\begin{array}{l}4.98 \\
- \\
- \\
4.77\end{array}$ & $\begin{array}{l}824 \\
735 \\
731 \\
747\end{array}$ \\
\hline $\begin{array}{l}1906 \\
1907 \\
1908 \\
1909\end{array}$ & $\begin{array}{lr}\text { May } 9,10, & 1906 \\
\text { May } 17, & 1907 \\
\text { Aug. } & 1,1908 \\
\text { May } & 5,1909\end{array}$ & $\begin{array}{c}6.8 \\
- \\
-\end{array}$ & $\begin{array}{r}1,570 \\
1,450 \\
643 \\
1,230\end{array}$ & 1951 & $\begin{array}{l}\text { Nov. } \\
\text { Dec. } \\
\text { Dec. }\end{array}$ & $\begin{array}{rr}20, & 1950 \\
3, & 1950 \\
8, & 1950\end{array}$ & $\begin{array}{l}8.35 \\
7.45 \\
6.23\end{array}$ & $\begin{array}{l}4,730 \\
3,400 \\
2,070\end{array}$ \\
\hline 1910 & Dec. 1, 1909 & - & 818 & 1952 & $\begin{array}{l}\text { May } \\
\text { July }\end{array}$ & $\begin{array}{ll}20, & 1952 \\
29, & 1952\end{array}$ & $\begin{array}{l}5.29 \\
3.81\end{array}$ & $\begin{array}{r}1,100 \\
543\end{array}$ \\
\hline $\begin{array}{l}1911 \\
1912 \\
1913 \\
1914 \\
1915\end{array}$ & $\begin{array}{l}\text { May } 23,1911 \\
\text { May 15, } 1912 \\
\text { Apr. } 26,1913 \\
\text { May 21, } 1914 \\
\text { May } 11, \text { June } 6.7\end{array}$ & $\begin{array}{l}- \\
- \\
-\end{array}$ & $\begin{array}{r}1,300 \\
710 \\
647 \\
1,050 \\
672\end{array}$ & 1953 & $\begin{array}{l}\text { Apr. } \\
\text { May } \\
\text { June }\end{array}$ & $\begin{array}{ll}25, & 1953 \\
19, & 1953 \\
19, & 1953\end{array}$ & $\begin{array}{l}4.09 \\
3.75 \\
3.52\end{array}$ & $\begin{array}{l}813 \\
662 \\
572\end{array}$ \\
\hline & 7075 & & & 1954 & $\begin{array}{l}\text { Apr. } \\
\text { May }\end{array}$ & $\begin{array}{rr}22, & 1954 \\
8, & 1954\end{array}$ & $\begin{array}{l}3.88 \\
3.65\end{array}$ & $\begin{array}{l}701 \\
600\end{array}$ \\
\hline $\begin{array}{l}1916 \\
1917 \\
1918 \\
1919\end{array}$ & $\begin{array}{lr}\text { May } 7, & 1916 \\
\text { June } 13, & 1917 \\
\text { May 5, } 1918 \\
\text { Apr. 29,30, } 1919\end{array}$ & $\begin{array}{l}- \\
- \\
-\end{array}$ & $\begin{array}{r}1,180 \\
944 \\
618 \\
958\end{array}$ & 1955 & $\begin{array}{l}\text { May } \\
\text { May }\end{array}$ & $\begin{array}{ll}12, & 1955 \\
21, & 1955\end{array}$ & $\begin{array}{l}3.59 \\
3.58\end{array}$ & $\begin{array}{l}596 \\
592\end{array}$ \\
\hline 1920 & May 12,1920 & - & 742 & 1956 & Dec. & $\begin{array}{l}23,1955 \\
24,1956\end{array}$ & $\begin{array}{l}8.86 \\
4.78\end{array}$ & $\begin{array}{r}4,810 \\
685\end{array}$ \\
\hline $\begin{array}{l}1938 \\
1939 \\
1940\end{array}$ & $\begin{array}{lr}\text { Dec. } & 11,1937 \\
\text { Apr. } & 7,1939 \\
\text { May } & 2,1940\end{array}$ & $\begin{array}{l}9.00 \\
3.72 \\
5.21\end{array}$ & $\begin{array}{r}3,500 \\
354 \\
895\end{array}$ & & $\begin{array}{l}\text { May } \\
\text { May }\end{array}$ & $\begin{aligned} 4, & 1956 \\
23, & 1956\end{aligned}$ & $\begin{array}{l}5.08 \\
5.60\end{array}$ & $\begin{array}{r}856 \\
1,210\end{array}$ \\
\hline $\begin{array}{l}1941 \\
1942 \\
1943\end{array}$ & $\begin{array}{lrl}\text { May } & 5, & 1941 \\
\text { May } & 22, & 1942 \\
\text { Apr. } & 28, & 1943\end{array}$ & $\begin{array}{l}6.00 \\
5.80 \\
5.93\end{array}$ & $\begin{array}{l}1,330 \\
1,210 \\
1,290\end{array}$ & 1957 & $\begin{array}{l}\text { May } \\
\text { May } \\
\text { June }\end{array}$ & $\begin{array}{rr}6, & 1957 \\
18, & 1957 \\
2, & 1957\end{array}$ & $\begin{array}{l}4.40 \\
5.10 \\
4.50\end{array}$ & $\begin{array}{l}516 \\
880 \\
560\end{array}$ \\
\hline $\begin{array}{l}1944 \\
1945\end{array}$ & $\begin{array}{lrl}\text { May } & 7, & 3944 \\
\text { May } & 10, & 1945\end{array}$ & $\begin{array}{l}4.11 \\
5.26\end{array}$ & $\begin{array}{l}497 \\
975\end{array}$ & 1958 & $\begin{array}{l}\text { May } \\
\text { May } \\
\text { May }\end{array}$ & $\begin{aligned} 5, & 1958 \\
18, & 1958 \\
23, & 1958\end{aligned}$ & $\begin{array}{l}5.15 \\
5.64 \\
5.12\end{array}$ & $\begin{array}{l}1,020 \\
1,650 \\
1,250\end{array}$ \\
\hline 1946 & Apr. 25, 1946 & 5.01 & 860 & & June & 19,1958 & 4.39 & $\begin{array}{r}654 \\
\end{array}$ \\
\hline 1948 & May 6,3948 & - & 678 & 1959 & Apr. & 5,1959 & 3.60 & 320 \\
\hline
\end{tabular}


Peak stages and discharges of West Fork Carson River at Woodfords, Calif.--Continued

\begin{tabular}{|c|c|c|c|c|c|c|c|}
\hline $\begin{array}{c}\text { Water } \\
\text { year }\end{array}$ & Date & $\begin{array}{c}\text { Gage } \\
\text { he1ght } \\
\text { (feet) }\end{array}$ & $\begin{array}{c}\text { D1scharge } \\
(\mathrm{cfs})\end{array}$ & $\begin{array}{l}\text { Water } \\
\text { year }\end{array}$ & Date & $\begin{array}{c}\text { Gage } \\
\text { height } \\
\text { (feet) }\end{array}$ & $\begin{array}{c}\text { D'scharge } \\
\text { (cfs) }\end{array}$ \\
\hline 1960 & $\begin{array}{l}\text { Apr. 9, } 1960 \\
\text { Apr. 17, } 1961 \\
\text { Apr. 24, } 1962\end{array}$ & $\begin{array}{l}3.70 \\
3.39\end{array}$ & $\begin{array}{l}350 \\
237\end{array}$ & 1963 & $\begin{array}{lrl}\text { Feb. } & 1,1963 \\
\text { May } & 8,1963 \\
\text { May } & 23,1963 \\
\text { June } & 17,1963\end{array}$ & $\begin{array}{l}9.0 \\
4.4 \\
4.8 \\
4.7\end{array}$ & $\begin{array}{r}4,890 \\
\text { a800 } \\
\text { a1, 000 } \\
\text { al, } 000\end{array}$ \\
\hline 1962 & $\begin{array}{rr}\text { Apr. } 24, & 1962 \\
\text { May } & 4,1962 \\
\end{array}$ & $\begin{array}{l}4.64 \\
4.93 \\
\end{array}$ & $\begin{array}{l}581 \\
677 \\
\end{array}$ & & & & \\
\hline
\end{tabular}

3105. Clear Creek near Carson City, Nev.

Location.--Lat $39^{\circ} 06^{\prime} 50^{\prime \prime}$, long $119^{\circ} 47150^{\prime \prime}$, in $\mathrm{NE} \frac{1}{4} \mathrm{NW} \frac{1}{4}$ sec.1, T.14 N., R.19 E., on left bank 3 miles upstream from mouth and $3 \frac{1}{2}$ miles southwest of Cerson.
City.

Drainage area. - - $15 \mathrm{sq} \mathrm{ml}$, approximately.

Gage.--Recording and sharp-crested welr prior to October 1962; crest-stage gage thereafter. Altitude of gage is $5,000 \mathrm{ft}$ (from topographic map).

Stage-discharge relation.--Defined by current-meter measurements below $100 \mathrm{cfs}$ and extended above on basis of logarithmic plotting.

Bankfull stage.--In canyon; not subject to overflow.

Remarks.--Base for partial-duration series, $15 \mathrm{cfs}$.

Peak stages and discharges

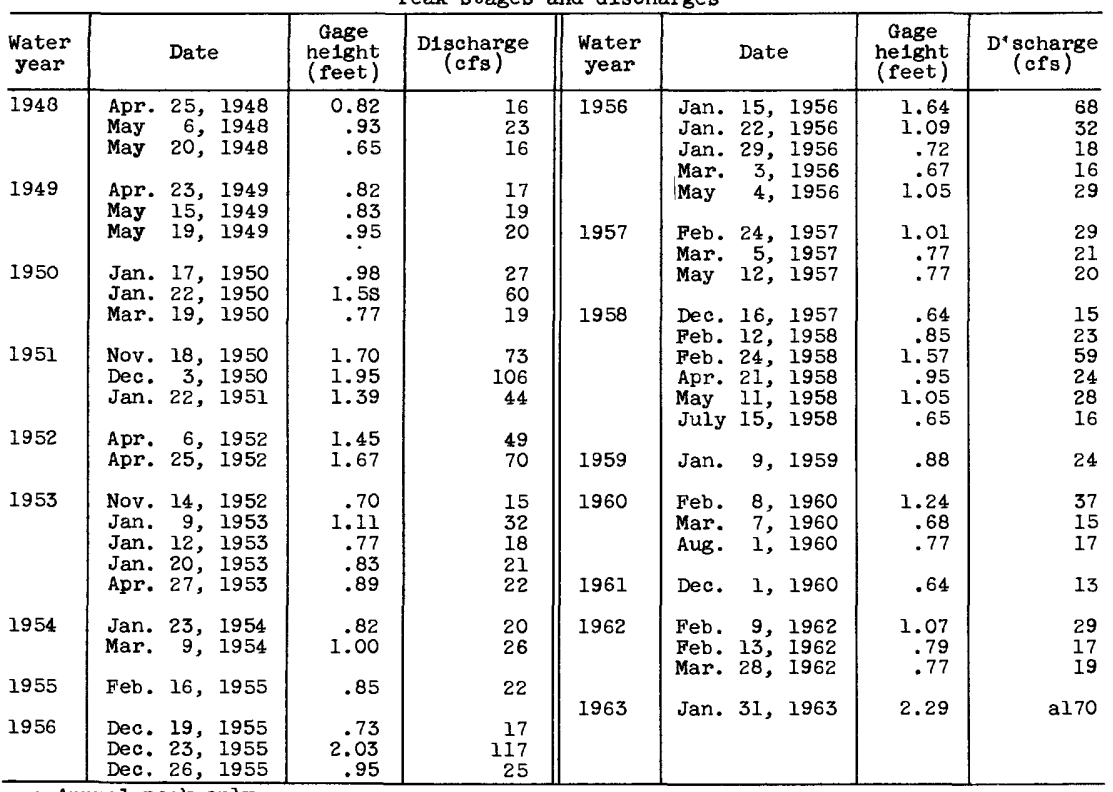

a Annual peak only. 
3110. Carson River near Carson City, Nev.

Location. --Lat $39^{\circ} 06^{1} 30^{\prime \prime}$, long $119^{\circ} 42^{14} 40^{\prime \prime}$, in SW $\frac{1}{4} N W \frac{1}{4}$ sec.2, T.14 N. , R.20 E., on left bank 2 miles downstream from Clear Creek, 3 miles unstream from bridge on road to Mexican Dam, and 5 miles southeast of Carson City.

Drainage area. $--876 \mathrm{sq} \mathrm{mi}$.

Gage.--Recording, except nonrecording Dec. 23, 1955, to Mar. 13, 1956. Datum of gage is $4,621.48 \mathrm{ft}$ above mean sea level, datum of 1929 .

Stage-discharge relation.--Defined by current-meter measurements below 6,000 cfs and by slope-area measurements at $30,000 \mathrm{cfs}$.

Remarks.--Many diversions above station for irrigation. Flow slightly regulated by several small reservoirs on tributaries. Base for partial-duration series, $1,600 \mathrm{cfs}$.

Peak stages and discharges

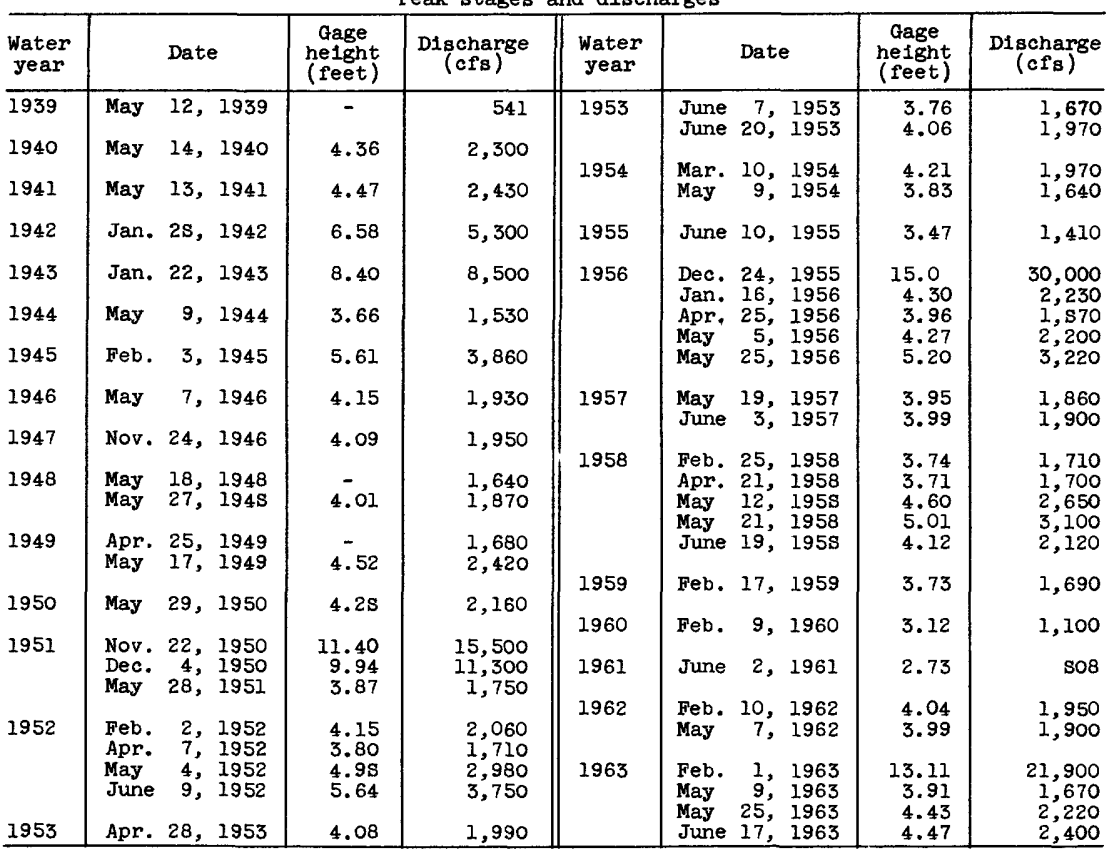


3115. Carson River near Empire, Nev.

Location.--Lat $39^{\circ} 10^{\prime}$, Iong $119^{\circ} 41^{\prime}$, in sec.12, T.15 N., R.20 E. , just downstream from tailrace of Brunswick Mill power canal, a quarter of a mile downstream from highway bridge and 2 miles east of Empire.

Drainage area. $--988 \mathrm{sq} \mathrm{mi}$.

Gage.--Nonrecording. Prior to Feb. 24, 1911, at several sites within threequarters of a mile at different datums. Altitude of gage is $4,560 \mathrm{ft}$ (from river-profile map).

Stage-discharge relation.--Defined by current-meter measurements below 2,400 cfs at sites used prior to April 1907, defined by current-meter measurements at sites used after April 1907.

Bankfull stage.--In canyon; not subject to overflow.

Remarks.--Brunswick Mill power canal began diverting above station Apr. 12 , 1907; records herein adjusted for this diversion until Feb. 23, 1911, when station was moved below canal tailrace. Only annual maximum observed discharges are shown.

Maximum observed stages and discharges

\begin{tabular}{|c|c|c|c|c|c|c|c|c|}
\hline $\begin{array}{l}\text { Water } \\
\text { year }\end{array}$ & Date & $\begin{array}{c}\text { Gage } \\
\text { helght } \\
\text { ( feet) }\end{array}$ & $\begin{array}{c}\text { D1scharge } \\
\text { (cfs) }\end{array}$ & $\begin{array}{l}\text { Water } \\
\text { year }\end{array}$ & & Date & $\begin{array}{c}\text { Gage } \\
\text { nelght } \\
\text { (feet) }\end{array}$ & $\begin{array}{c}\text { Discharge } \\
\text { (cfs) }\end{array}$ \\
\hline $\begin{array}{l}1901 \\
1902 \\
1903 \\
1904 \\
1905\end{array}$ & $\begin{array}{lll}\text { May } & 18, & 1901 \\
\text { May } & 30,1902 \\
\text { May } & 15,1903 \\
\text { Feb. } & 25,1904 \\
\text { May } 19, & 1905\end{array}$ & $\begin{array}{l}5.25 \\
4.0 \\
4.4 \\
6.9 \\
5.0\end{array}$ & $\begin{array}{l}3,300 \\
1,710 \\
2,060 \\
3,250 \\
1,430\end{array}$ & \multirow{4}{*}{$\begin{array}{l}1912 \\
1913 \\
1914 \\
1915 \\
1916 \\
1917 \\
1918 \\
1919 \\
1920 \\
1921 \\
1922\end{array}$} & \multirow{4}{*}{\multicolumn{2}{|c|}{ 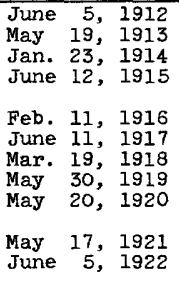 }} & \multirow{4}{*}{$\begin{array}{l}6.0 \\
6.05 \\
\text { s.0 } \\
6.8 \\
6.9 \\
6.9 \\
5.6 \\
6.8 \\
5.5 \\
6.2 \\
7.4\end{array}$} & \multirow{4}{*}{$\begin{array}{l}2,030 \\
2,090 \\
5,160 \\
3,100 \\
3,100 \\
3,250 \\
1,440 \\
2,630 \\
1,350\end{array}$} \\
\hline $\begin{array}{l}1906 \\
1907 \\
1908\end{array}$ & $\begin{array}{l}\text { June 14, } 1906 \\
\text { Mar. 18, } 1907 \\
\text { Apr.21, May 2, } \\
1908\end{array}$ & $\begin{array}{c}7.2 \\
- \\
5.6\end{array}$ & $\begin{array}{r}3,020 \\
4,000 \\
750\end{array}$ & & & & & \\
\hline $\begin{array}{l}1909 \\
1910\end{array}$ & $\begin{array}{ll}\text { Jan. } 15, & 1909 \\
\text { Apr. } 29, & 1910 \\
\end{array}$ & $\begin{array}{l}8.1 \\
6.7 \\
\end{array}$ & $\begin{array}{l}2,930 \\
1,700 \\
\end{array}$ & & & & & \\
\hline 1911 & June 19,1911 & 7.6 & 4,440 & & & & & \\
\hline
\end{tabular}

3120. Carson River near Fort Churchill, Nev.

Location.--Lat $39^{\circ} 17^{\prime} 30^{\prime \prime}$, long $119^{\circ} 18^{1} 40^{\prime \prime}$, in SW $\frac{1}{4} \mathrm{SE} \frac{1}{4}$ sec.32, T.17 N., R.24 E., on right bank $400 \mathrm{ft}$ downstream from Buckland ditch, 2 miles west' of Fort Churchill, and $4 \frac{1}{2}$ miles upstream from Weeks bridge on U.S. Highway $9^{-}$ alternate.

Drainage area. $--1,450 \mathrm{sq} \mathrm{mi}$, approximately.

Gage.--Nonrecording prior to Apr. 25, 1924, at site $7 \frac{3}{4}$ miles upstream at different datum; recording thereafter. Apr. 25, 1924, to Dec. 31, 1933, at site 8 miles upstream at different datum. Jan. 1, 1934, to Sept. 30, 1957, at datum $1.36 \mathrm{ft}$ higher (levels by Truckee-Carson Irrigation District). Datum of gage is $4,214.70 \mathrm{ft}$ above mean sea level, datum of 1929 , supplementary

Stage-discharge relation.--Defined by current-meter measurements.

Remarks.--Records for 1911-31 furmished by Bureau of Reclamation and those for 1932-59 furmished by Truckee-Carson Irrigation District. Many diversions for irrigation above station, including diversions for irrigation of $720^{\circ}$ acres between present site and sites used prior to Jan. 1, 1934. Buckland ditch diverts $400 \mathrm{ft}$ upstream for irrigation below station. Oniy annual maximum daily discharges are shown prior to 1958 , unless otherwise noted. Base for partial-duration series, $1,400 \mathrm{cfs}$. 
Peak stages and discharges of Carson R1ver near Fort Churchill, Nev.

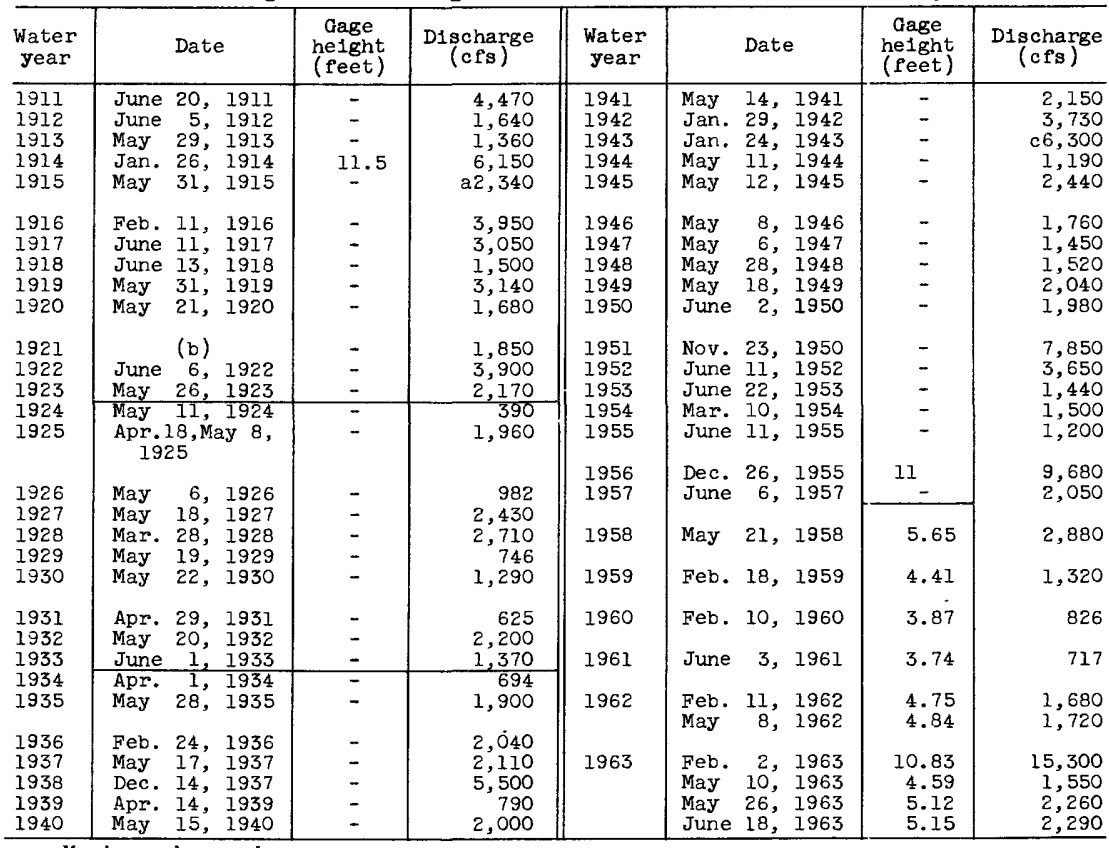

a Maximum observed.

b May 16, June 9, 10, 1921.

c Momentary maximum.

Note.--Maximum dally mean discharges are shown prior to 1958 except for 1915 and 1943.

\section{HUMBOLDT RIVER BASIN}

3130. Starr Creek near Deeth, Nev.

Location.--Lat $41^{\circ} 01^{\prime}$, long $115^{\circ} 16^{\prime}$, in $\mathrm{NE} \frac{1}{4}$ sec.12, T. 36 N., R.59 E., 2 miles upstream from mouth and 3 miles southeast of Deeth.

Gage.--Nonrecording. Prior to Oct. 1, 1916, at datum 2.14 ft lower and oct. 1, 1916 , to Nov. 6,1917 , at datum $1.14 \mathrm{ft}$ lower. Altitude of gage is 5,450 ft (from topographic map).

Stage-discharge relation.--Defined by current-meter measurements below $210 \mathrm{cf}$. Remarks.--Orily annual maximum observed discharges are shown.

Maximum observed discharges

\begin{tabular}{|c|c|c|c|c|c|c|c|c|c|}
\hline $\begin{array}{l}\text { Water } \\
\text { year }\end{array}$ & & Date & $\begin{array}{c}\text { Gage } \\
\text { helght } \\
\text { (feet) }\end{array}$ & $\begin{array}{c}\text { Discharge } \\
(\mathrm{cfs})\end{array}$ & $\begin{array}{l}\text { Water } \\
\text { year }\end{array}$ & & Date & $\begin{array}{c}\text { Gage } \\
\text { he1ght } \\
\text { (feet) }\end{array}$ & $\begin{array}{c}\text { Discharge } \\
(\mathrm{cfs})\end{array}$ \\
\hline $\begin{array}{l}1913 \\
1914 \\
1915\end{array}$ & $\begin{array}{l}\text { June } \\
\text { June } \\
\text { June }\end{array}$ & $\begin{array}{rr}11, & 1913 \\
4, & 1914 \\
1, & 1915\end{array}$ & $\begin{array}{l}- \\
-\end{array}$ & $\begin{array}{r}a 273 \\
372 \\
62\end{array}$ & $\begin{array}{l}1919 \\
1920\end{array}$ & $\begin{array}{l}\text { Mar. } \\
\text { June }\end{array}$ & $\begin{array}{rr}23, & 1919 \\
9, & 1920\end{array}$ & - & $\begin{array}{l}184 \\
167\end{array}$ \\
\hline $\begin{array}{l}1916 \\
1917 \\
1918 \\
\end{array}$ & $\begin{array}{l}\text { June } \\
\text { June } \\
\text { Mar. }\end{array}$ & $\begin{array}{ll}17, & 1916 \\
27, & 1917 \\
11, & 1918 \\
\end{array}$ & $\begin{array}{l}- \\
-\end{array}$ & $\begin{array}{r}126 \\
383 \\
83 \\
\end{array}$ & $\begin{array}{l}1921 \\
1922 \\
1923 \\
1924\end{array}$ & $\begin{array}{l}\text { June } \\
\text { June } \\
\text { June } \\
\text { May }\end{array}$ & $\begin{array}{rr}9, & 1921 \\
14, & 1922 \\
12, & 1923 \\
19, & 1924\end{array}$ & $\begin{array}{l}4.65 \\
- \\
-\end{array}$ & $\begin{array}{r}391 \\
253 \\
218 \\
99\end{array}$ \\
\hline
\end{tabular}

a Maximum observed during period June to September. 
3150. Marys River near Deeth, Nev.

Location.--Lat $41^{\circ} 19^{\prime}$, long $115^{\circ} 16^{\prime}$, in NW $\frac{1}{4} \mathrm{sec} .31$, T.40 N., R.60 E., $300 \mathrm{ft}$ east of Malo Vista ranchhouse and 19 miles north of Deeth.

Drainage area. $--355 \mathrm{sq} \mathrm{mi}$.

Gage.--Nonrecording at different datums. Altitude of gage is 5,757 ft (from river-profile map).

Stage-discharge relation.--Defined by current-meter measurements below $410 \mathrm{cf}$. Remarks.--Only annual maximum observed discharges are shown.

Maximum observed stages and discharges

\begin{tabular}{|c|c|c|c|c|c|c|c|c|}
\hline $\begin{array}{c}\text { Water } \\
\text { year }\end{array}$ & Date & $\begin{array}{c}\text { Gage } \\
\text { helght } \\
\text { (feet) }\end{array}$ & $\begin{array}{c}\text { Discharge } \\
\text { (cfs) }\end{array}$ & $\begin{array}{c}\text { Water } \\
\text { year }\end{array}$ & & Date & $\begin{array}{c}\text { Gage } \\
\text { helght } \\
\text { (feet) }\end{array}$ & $\begin{array}{c}\text { Discharge } \\
(\text { cfs })\end{array}$ \\
\hline $\begin{array}{l}1912 \\
1913 \\
1914 \\
1915\end{array}$ & $\begin{array}{ll} & (\mathrm{a}) \\
\text { Apr. } & 30,1913 \\
(\mathrm{~b}) & \\
\text { Mar. } 30,1915 & \end{array}$ & $\begin{array}{l}6.3 \\
- \\
3.7\end{array}$ & $\begin{array}{r}439 \\
205 \\
402 \\
94\end{array}$ & $\begin{array}{l}1921 \\
1922 \\
1923 \\
1924 \\
1925\end{array}$ & $\begin{array}{l}\text { May } \\
\text { May } \\
\text { May } \\
\text { Apr. } \\
\text { May }\end{array}$ & 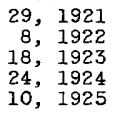 & $\begin{array}{l}7.1 \\
7.78 \\
4.90 \\
3.60 \\
6.30\end{array}$ & $\begin{array}{l}530 \\
616 \\
223 \\
102 \\
410\end{array}$ \\
\hline $\begin{array}{l}1916 \\
1917 \\
1918 \\
1919 \\
1920 \\
\end{array}$ & $\begin{array}{l}\text { Apr. } 14,1916 \\
\text { May 16, } 1917 \\
\text { May 6-9, } 1918 \\
\text { Apr. 30, } 1919 \\
\text { May 22, } 1920\end{array}$ & $\begin{array}{l}6.0 \\
- \\
4.0 \\
5.24 \\
4.90\end{array}$ & $\begin{array}{l}381 \\
420 \\
130 \\
286 \\
239\end{array}$ & $\begin{array}{l}1926 \\
1927 \\
1928\end{array}$ & $\begin{array}{l}\text { May } \\
\text { May }\end{array}$ & $\begin{array}{ll}\text { (c) } & \\
21, & 1927 \\
13, & 1928\end{array}$ & $\begin{array}{l}4.10 \\
6.55 \\
6.10\end{array}$ & $\begin{array}{l}136 \\
428 \\
350\end{array}$ \\
\hline
\end{tabular}

a May 19 , June $3-7,1912$.

o Apr. 10-23, May 11-13, 1914

c Apr. 15, 21-23, May 5, 1926.

3155. Marys River above Hot Springs Creek, near Deeth, Nev

(Published as "below Hot Springs Creek" prior to October 1950)

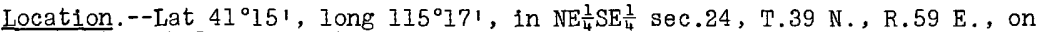
right bank 1 mile upstream from Hot Springs Creek, 7 miles north of Cross Ranch, and 13 miles north of Deeth.

Drainage area. $--415 \mathrm{sq} \mathrm{mi}$. Mean altitude, 6,610 ft.

Gage.--Recording. Prior to Nov. 3, 1950, at site $1 \frac{1}{4}$ miles downstream at dif-

ferent datum. Altitude of gage is 5,500 ft (from river-profile map).

Stage-discharge relation.--Defined by current-meter measurements below 1,000

$\mathrm{cf} s$ and extended above on basis of slope-area measurement at $4,210 \mathrm{cf}$.

Remarks.--Base for partial-duration series, $200 \mathrm{cfs}$.

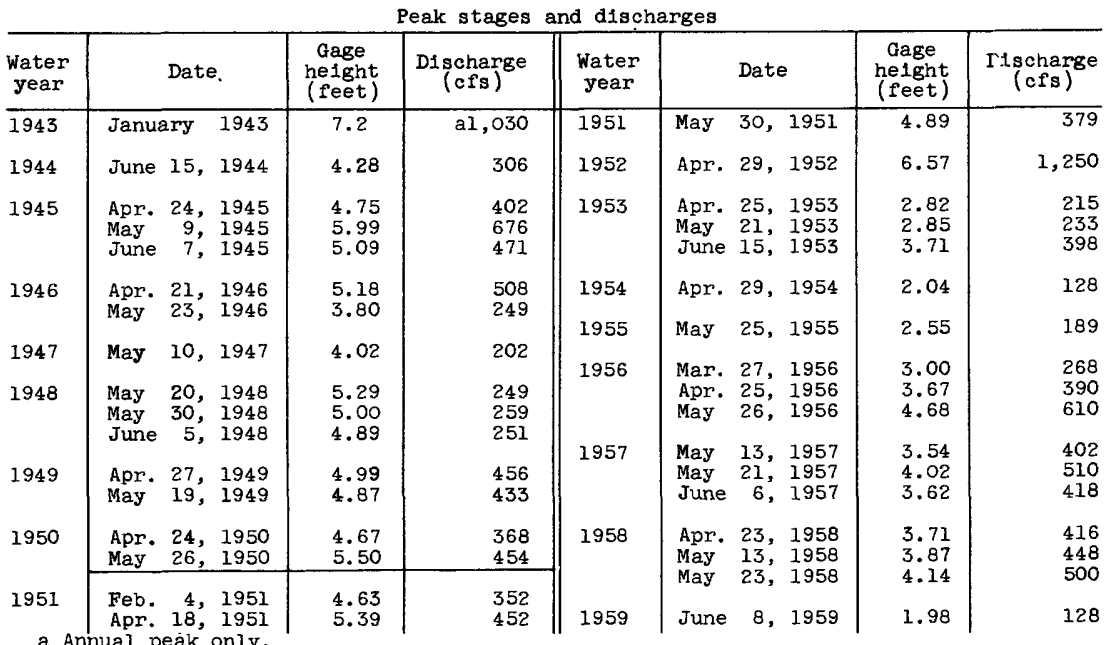


Peak stages and discharges of Marys River above Hot Springs Creek, near Deeth, Nev.--Con.

\begin{tabular}{|c|c|c|c|c|c|c|c|c|c|}
\hline $\begin{array}{l}\text { Water } \\
\text { year }\end{array}$ & & Date & $\begin{array}{c}\text { Gage } \\
\text { helght } \\
\text { (feet) }\end{array}$ & $\begin{array}{c}\text { Discharge } \\
\text { (cfs) }\end{array}$ & $\begin{array}{l}\text { Water } \\
\text { year }\end{array}$ & & Date & $\begin{array}{c}\text { Gage } \\
\text { helght } \\
\text { (feet) }\end{array}$ & $\begin{array}{c}\text { D1scharge } \\
\text { (cfs) }\end{array}$ \\
\hline 1960 & $\begin{array}{l}\text { Apr. } \\
\text { May } \\
\text { May }\end{array}$ & $\begin{array}{ll}12, & 1960 \\
14, & 1960 \\
26, & 1961\end{array}$ & $\begin{array}{l}2.93 \\
2.88 \\
1.82\end{array}$ & $\begin{array}{l}276 \\
272 \\
113\end{array}$ & 1962 & $\begin{array}{l}\text { Apr. } \\
\text { May } \\
\text { June } \\
\text { June }\end{array}$ & $\begin{array}{rr}22, & 1962 \\
16, & 1962 \\
5, & 1962 \\
16, & 1962\end{array}$ & $\begin{array}{l}3.56 \\
3.22 \\
2.98 \\
2.85\end{array}$ & $\begin{array}{l}423 \\
365 \\
316 \\
289\end{array}$ \\
\hline 1962 & $\begin{array}{l}\text { Feb. } \\
\text { Nar. } \\
\text { Apr. }\end{array}$ & $\begin{array}{rr}12, & 1962 \\
29, & 1962 \\
9, & 1962 \\
\end{array}$ & $\begin{array}{l}7.63 \\
3.01 \\
3.21 \\
\end{array}$ & $\begin{array}{r}4,210 \\
281 \\
329 \\
\end{array}$ & 1963 & $\begin{array}{l}\text { May } \\
\text { June } \\
\text { June }\end{array}$ & $\begin{array}{rr}25, & 1963 \\
6, & 1963 \\
16, & 1963 \\
\end{array}$ & $\begin{array}{l}2.66 \\
2.79 \\
2.83 \\
\end{array}$ & $\begin{array}{l}267 \\
293 \\
301 \\
\end{array}$ \\
\hline
\end{tabular}

3160. Secret Creek near Halleck, Nev.

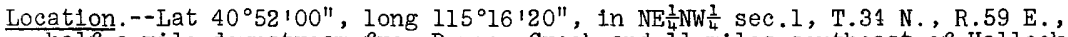
half a mile downstream from Dorsey Creek and 11 miles southesst of Halleck.

Drainage area. $--35 \mathrm{sq} \mathrm{ml}$, approximately.

Gage.--Nonrecording. Prior to June 16, 1921, at datum $0.33 \mathrm{ft}$ lower. Altitude of gage is $5,700 \mathrm{ft}$ (from topographic map).

Stage-discharge relation.--Defined by current-meter measurements below 76 cfs prior to November 1918, and below $130 \mathrm{cfs}$ thereafter. Frequent changes in high-water rating reduce accuracy of peak discharges.

Remarks.--Only annual maximum observed discharges are shown.

Maximum observed stages and discharges

\begin{tabular}{|c|c|c|c|c|c|c|c|c|}
\hline $\begin{array}{l}\text { Water } \\
\text { year }\end{array}$ & & Date & $\begin{array}{c}\text { Gage } \\
\text { height } \\
\text { (feet) }\end{array}$ & $\begin{array}{c}\text { Discharge } \\
\text { (cfs) }\end{array}$ & $\begin{array}{c}\text { Water } \\
\text { year }\end{array}$ & Date & $\begin{array}{c}\text { Gage } \\
\text { helght } \\
\text { (feet) }\end{array}$ & $\begin{array}{c}\text { Discharge } \\
\text { (cfs) }\end{array}$ \\
\hline $\begin{array}{l}1917 \\
1918 \\
1919 \\
1920 \\
\end{array}$ & $\begin{array}{l}\text { June } \\
\text { Apr. } \\
\text { Apr. } \\
\text { May } 1\end{array}$ & $\begin{array}{rr}4, & 1917 \\
1, & 1918 \\
3, & 1919 \\
10, & 1920 \\
\end{array}$ & $\begin{array}{l}2.71 \\
1.57 \\
1.82 \\
2.09\end{array}$ & $\begin{array}{r}170 \\
32 \\
76 \\
112 \\
\end{array}$ & $\begin{array}{l}1921 \\
1922 \\
1923 \\
1924 \\
\end{array}$ & $\begin{array}{l}\text { Apr. 23, } 1921 \\
\text { Apr. 29, } 1922 \\
\text { June 21, } 1923 \\
\text { Apr. } 7,1924 \\
\end{array}$ & $\begin{array}{l}3.65 \\
- \\
1.70 \\
1.6\end{array}$ & $\begin{array}{r}375 \\
\mathrm{a} 300 \\
105 \\
122 \\
\end{array}$ \\
\hline
\end{tabular}

a Maximum daily.

3165. Lamoille Creek near Lamoille, Nev.

Location.--Lat $40^{\circ} 4 I^{\prime} 30^{\prime \prime}$, long $115^{\circ} 28^{\prime} 30^{\prime \prime}$, in NE $\frac{1}{4}$ sec.6, T.32 N., R.58 E., on left bank at Lamollle Creek Bridge at mouth of canyon, $300 \mathrm{f}$ ': downstream from Elko-Lamoille powerplant and 3 miles south of Lamoille.

Drainage area. $--25 \mathrm{sq} \mathrm{mi}$, approximately. Mean altitude, 9,040 ft.

Gage.--Nonrecording prior to 0ct. 1, 1943, at various sites nearby at different datums; recording thereafter. Concrete control since 1950. Altitude of gage is $6,240 \mathrm{ft}$ (from topographic map).

Stage-discharge relation.--Defined by current-meter measurements.

Historical data.--June 1917 flood may have exceeded that of Juns 4, 1957.

Remarks.--Base for partial-duration series, $310 \mathrm{cfs}$. Only annual peaks are shown prior to 1948 .

Peak stages and discharges

\begin{tabular}{|c|c|c|c|c|c|c|c|c|}
\hline $\begin{array}{l}\text { Water } \\
\text { year }\end{array}$ & Date & $\begin{array}{l}\text { Gagie } \\
\text { he1ght } \\
\text { (feet) }\end{array}$ & $\begin{array}{c}\text { D1scharge } \\
\text { (cfs) }\end{array}$ & $\begin{array}{l}\text { Water } \\
\text { year }\end{array}$ & & Date & $\begin{array}{c}\text { Gage } \\
\text { helght } \\
\text { (feet) }\end{array}$ & $\begin{array}{c}\text { Discharge } \\
\text { (cfs) }\end{array}$ \\
\hline $\begin{array}{l}1915 \\
1916 \\
\end{array}$ & \multirow{3}{*}{$\begin{array}{l}\text { June } 9,1915 \\
\text { June } 17,1916 \\
\text { June } 12,1918 \\
\text { May } 28,1919 \\
\text { May 28,29, } \\
\text { June } 7,8,9,1920 \\
\text { June } 7,1922 \\
\end{array}$} & \multirow{3}{*}{$\begin{array}{l}- \\
- \\
- \\
- \\
-\end{array}$} & \multirow{2}{*}{$\begin{array}{l}315 \\
330 \\
\\
300 \\
360 \\
377\end{array}$} & $\begin{array}{l}1945 \\
1946 \\
1947\end{array}$ & \multicolumn{2}{|c|}{$\begin{array}{lrr}\text { June } & 23, & 1945 \\
\text { June } & 5,1946 \\
\text { May } & 6, & 1947\end{array}$} & $\begin{array}{l}\overline{-} \\
\bar{z}\end{array}$ & $\begin{array}{l}486 \\
299 \\
326\end{array}$ \\
\hline $\begin{array}{l}1918 \\
1919 \\
1920\end{array}$ & & & & 1948 & $\begin{array}{l}\text { May } \\
\text { May } \\
\text { June }\end{array}$ & $\begin{array}{r}6,1947 \\
27, \quad 1948 \\
12,1948\end{array}$ & $\overline{-}$ & $\begin{array}{l}326 \\
383 \\
332\end{array}$ \\
\hline 1922 & & & 416 & 1949 & $\begin{array}{l}\text { May } \\
\text { June }\end{array}$ & $\begin{array}{ll}28, & 1949 \\
11, & 1949\end{array}$ & - & $\begin{array}{l}317 \\
330\end{array}$ \\
\hline 1944 & June 26,1944 & - & 341 & 1950 & May & 30,1950 & - & 571 \\
\hline
\end{tabular}


Peak stages and discharges of Lamo11le Creek near Lamo1lle, Nev.--Cont1nued

\begin{tabular}{|c|c|c|c|c|c|c|c|c|c|}
\hline $\begin{array}{l}\text { Water } \\
\text { year }\end{array}$ & & Date & $\begin{array}{c}\text { Gage } \\
\text { hejght } \\
\text { (feet) }\end{array}$ & $\begin{array}{c}\text { Discharge } \\
\text { (cf's) }\end{array}$ & $\begin{array}{l}\text { Water } \\
\text { year }\end{array}$ & & Date & $\begin{array}{c}\text { aage } \\
\text { hejght } \\
\text { (feet) }\end{array}$ & $\begin{array}{c}\text { Discharge } \\
\text { (cfs) }\end{array}$ \\
\hline 1950 & July & 6,1950 & - & 588 & 1957 & June 2 & $27, \quad 1957$ & - & 416 \\
\hline 1951 & $\begin{array}{l}\text { May } \\
\text { June }\end{array}$ & $\begin{array}{ll}26, & 1951 \\
16, & 1951\end{array}$ & $\overline{-}$ & $\begin{array}{l}505 \\
363\end{array}$ & 1958 & $\begin{array}{l}\text { May } \\
\text { June }\end{array}$ & $\begin{array}{ll}24, & 1958 \\
19, & 1958\end{array}$ & - & $\begin{array}{l}457 \\
309\end{array}$ \\
\hline 1952 & June & 5,1952 & - & 415 & 1959 & June & 6, 1959 & - & 238 \\
\hline 1953 & June & 18,1953 & - & 311 & 1960 & June & 2,1960 & - & 348 \\
\hline 1954 & May & 19,1954 & - & 235 & 1961 & May & 25,1961 & - & 340 \\
\hline 1955 & June & 9,1955 & - & 323 & 1962 & June & $20, \quad 1962$ & - & 415 \\
\hline 1956 & May & 24,1956 & - & 447 & 1963 & $\begin{array}{l}\text { May } \\
\text { June }\end{array}$ & $\begin{array}{ll}27, & 1963 \\
20, & 1963\end{array}$ & - & $\begin{array}{l}362 \\
570\end{array}$ \\
\hline 1957 & June & 4, 1957 & - & 794 & & & & & \\
\hline
\end{tabular}

3170. Lamoille Creek near Halleck, Nev.

Location.--Lat $40^{\circ} 55^{1} 40^{\prime \prime}$, long $115^{\circ} 26120^{\prime \prime}$, in SW $\frac{1}{4}$ sec.9, T.35 N., R.58 E., $1 \frac{1}{2}$ miles southeast of Halleck and 2 miles upstream from mouth.'

Drainage area. $--245 \mathrm{sq} \mathrm{mi}$.

Gage.--Nonrecording. Prior to Aug. 19, 1915, at datum $1.0 \mathrm{ft}$ lower and Aug. 19, 1915 , to Sept. 26 , 1917, at datum $2.5 \mathrm{ft}$ lower. Altitude of gage is 5,240 ft (from topographic map).

Stage-discharge relation.--Defined by current-meter measurements.

Remarks.--Only annual peaks are shown.

\begin{tabular}{|c|c|c|c|c|c|c|c|c|}
\hline $\begin{array}{l}\text { Water } \\
\text { year }\end{array}$ & Date & $\begin{array}{c}\text { Gage } \\
\text { helght } \\
\text { (feet) }\end{array}$ & $\begin{array}{c}\text { Discharge } \\
\text { (cfs) }\end{array}$ & $\begin{array}{l}\text { Water } \\
\text { year }\end{array}$ & & Date & $\begin{array}{c}\text { Gage } \\
\text { nelght } \\
\text { (feet) }\end{array}$ & $\begin{array}{c}\text { Discharge } \\
\text { (cfs) }\end{array}$ \\
\hline $\begin{array}{l}1913 \\
1914 \\
1915\end{array}$ & $\begin{array}{ll}\text { June } 13, & 1913 \\
\text { June } 5, & 1914 \\
& (\mathrm{a})\end{array}$ & $\begin{array}{l}- \\
6.7 \\
4.2 \\
\end{array}$ & $\begin{array}{l}452 \\
556 \\
113\end{array}$ & $\begin{array}{l}1917 \\
1918 \\
1919\end{array}$ & $\begin{array}{l}\text { June } \\
\text { June } \\
\text { May }\end{array}$ & $\begin{array}{ll}22, & 1917 \\
24, & 1918 \\
31, & 1919\end{array}$ & $\frac{7.1}{2.70}$ & $\begin{array}{l}420 \\
115 \\
204\end{array}$ \\
\hline 1916 & Mar. 8,1916 & 5.92 & 201 & & & & & \\
\hline
\end{tabular}

3175. North Fork Humboldt River at Devils Gate, near Halleck, Nev.

Location.--Lat $41^{\circ} 11^{\prime}$, long $115^{\circ} 29^{\prime}$, in $\mathrm{SE}_{\frac{1}{4}}^{\frac{1}{4}}$ sec.13, T.38 N., R. 57 E., on right bank 16 miles north of Halleck and 26 miles upstream from mouth.

Drainage area. $--830 \mathrm{sq} \mathrm{ml}$, approximately. Mean altitude, 6,090 ft.

Gage.--Recording. November 1913 to September 1921, at site a quarter of a mile upstream at different datum. Datum of gage is $5,368 \mathrm{ft}$ above mean sea level (Geological Survey planetable bench mark).

Stage-discharge relation.--Defined by current-meter measurements below 2,000 cfs and extended above on basis of slope-area measurement at $10,40 \mathrm{C}$ fs.

Remarks.--Many diversions for irrigation above station. Base for partialduration series, $170 \mathrm{cfs}$.

Peak stages and discharges

\begin{tabular}{|c|c|c|c|c|c|c|c|}
\hline $\begin{array}{l}\text { Water } \\
\text { year }\end{array}$ & Date & $\begin{array}{c}\text { gage } \\
\text { helght } \\
\text { (feet) }\end{array}$ & $\begin{array}{c}\text { Discharge } \\
\text { (cfs) }\end{array}$ & $\begin{array}{l}\text { Water } \\
\text { year }\end{array}$ & Date & $\begin{array}{c}\text { Gage } \\
\text { hejght } \\
\text { (feet) }\end{array}$ & $\begin{array}{c}\text { Discharge } \\
\text { (cfs) }\end{array}$ \\
\hline 1914 & $\begin{array}{l}\text { Mar. 8, } 1914 \\
\text { Mar. 19, } 1914 \\
\text { Apr. 7, } 1914 \\
\text { Apr. 23, } 1914 \\
\text { June 4, } 1914\end{array}$ & $\begin{array}{l}5.8 \\
6.2 \\
7.24 \\
5.71 \\
4.55\end{array}$ & $\begin{array}{l}500 \\
558 \\
726 \\
487 \\
325\end{array}$ & 1916 & $\begin{array}{l}\text { Mar. 24, } 1916 \\
\text { Mar. } 29,1916 \\
\text { Apr. } 3,1916 \\
\text { Apr. } 12,1916 \\
\text { May } 27,1916\end{array}$ & $\begin{array}{l}5.92 \\
6.24 \\
7.05 \\
6.99 \\
3.77\end{array}$ & $\begin{array}{l}486 \\
527 \\
632 \\
625 \\
225\end{array}$ \\
\hline 1915 & Mar. 26, 1915 & 3.44 & 194 & 1917 & Apr. 9,1917 & 9.0 & 1,260 \\
\hline
\end{tabular}

785-975 O-66-14 
Peak stages and discharges of North Fork Humboldt R1ver at Dev1ls Gate, near Halleck, Nev.--Cont1nued

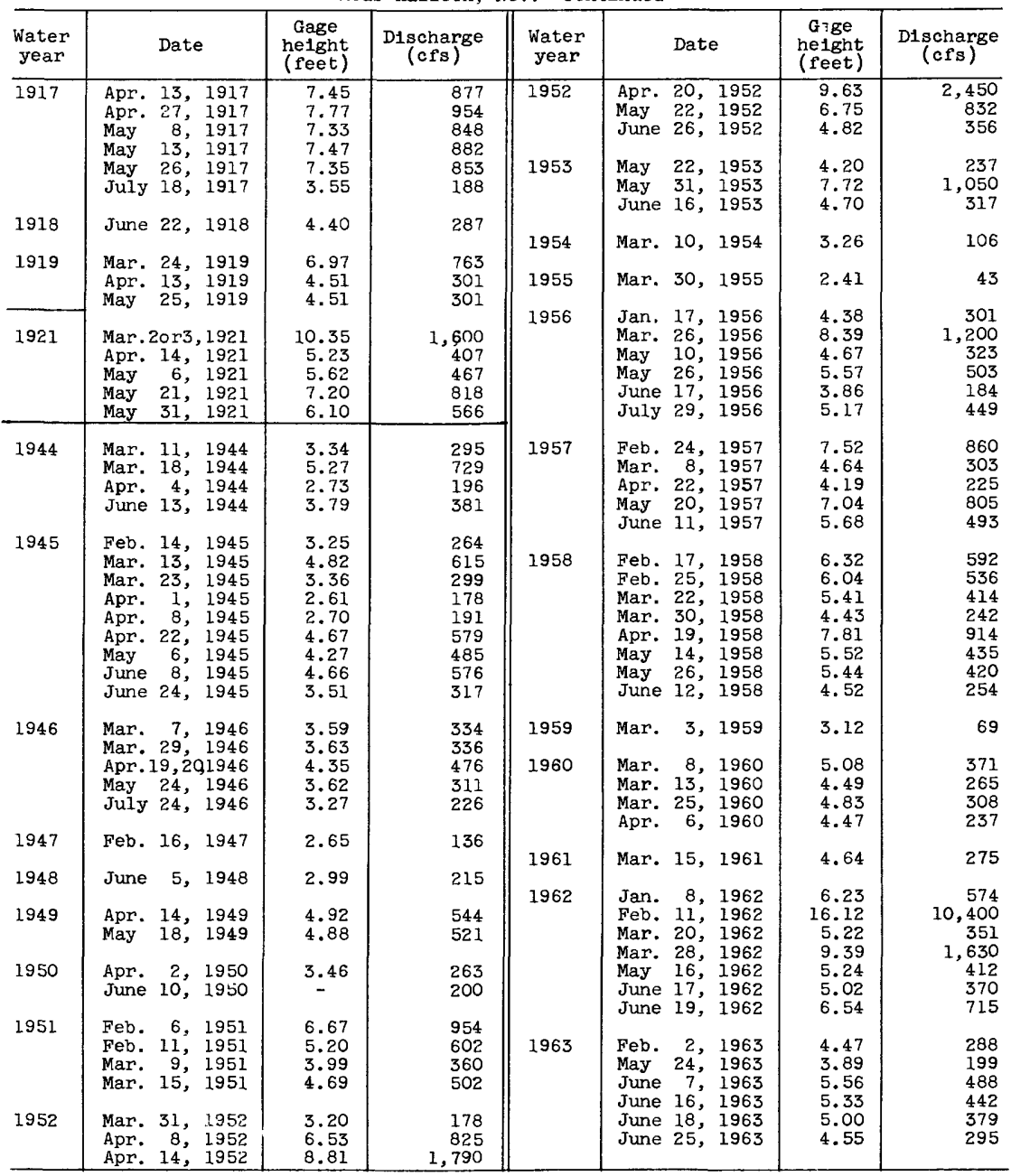

3180. North Fork Humboldt River near Halleck, Nev.

(Published as "at Peko" 1898-1900, and as "near Elburz" 1903-6)

Location.--Lat $40^{\circ} 56^{1}$, long $115^{\circ} 33^{1}$, in $\mathrm{SE} \frac{1}{4}$ sec.9, T.35 N., R.57 E., $150 \mathrm{ft}$ downstream from Southern Pacific Railroad bridge, a quarter of a mile upstream from mouth, and 6 miles west of Halleck.

Drainage area. $--1,020 \mathrm{sq} \mathrm{mi}$, approximately.

Gage.--Nonrecording. Prior to 0ct. 10, 1902 , at site $150 \mathrm{ft}$ upstream at different datum. Altitude of gage is $5,170 \mathrm{ft}$ (from river-profile map).

Stage-discharge relation.--Unknown.

Remarks.--Many diversions for irrigation above station. Only annual maximum observed discharges are shown. 
Maximum observed discharges of North Fork Humboldt River near Halleck, Nev.

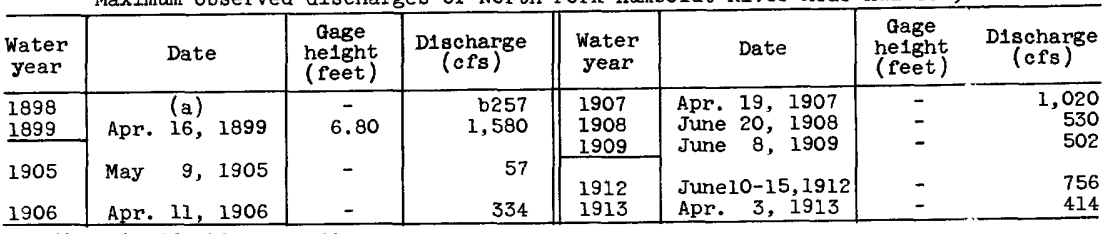

a May 10, 17, 18, 25, 1898 .

b Maximum observed during period April to september.

3185. Humboldt River near Elko, Nev.

Iocation. - - Lat $40^{\circ} 56^{\prime}$, long $115^{\circ} 38^{\prime}$, in $\mathrm{NE} \frac{1}{4} \mathrm{NE} \frac{1}{4} \sec .11$, T. $35 \mathrm{~N} ., \mathrm{R} .56 \mathrm{E}$, on right bank 1 mile southwest of Ryndon, 5 miles downstream from North Fork, and 10 miles northeast of Elko.

Drainage area. $--2,800 \mathrm{sq} \mathrm{mi}$, approximately.

Gage.--Nonrecording prior to October 1902 at site 11 miles downstream at different datum; recording thereafter. Datum of gage is $5,142.32 \mathrm{ft}$ above mean sea level, datum of 1929.

Stage-discharge relation.--Defined by current-meter measurements.

Remarks.--Diversions for irrigation above station. Only annual peaks are shown (maximum observed 1896-1902).

Peak stages and discharges

\begin{tabular}{|c|c|c|c|c|c|c|c|c|}
\hline $\begin{array}{l}\text { Water } \\
\text { year }\end{array}$ & Date & $\begin{array}{c}\text { Gage } \\
\text { he1ght } \\
\text { (feet) }\end{array}$ & $\begin{array}{c}\text { D1scharge } \\
(\mathrm{cfs})\end{array}$ & $\begin{array}{l}\text { Water } \\
\text { year }\end{array}$ & & Date & $\begin{array}{l}\text { Gage } \\
\text { helght } \\
\text { (feet) }\end{array}$ & $\begin{array}{c}\text { Discharge } \\
\text { (cfs) }\end{array}$ \\
\hline $\begin{array}{l}1896 \\
1897 \\
1898 \\
1899 \\
1900\end{array}$ & $\begin{array}{l}\text { June } 7,1896 \\
\text { May } 28,1897 \\
\text { Feb. } 28, \text { Mar. } 4, \\
1898 \\
\text { June } 23-25,1899 \\
\text { June } 10,1900\end{array}$ & $\begin{array}{l}- \\
- \\
-\end{array}$ & $\begin{array}{r}1,850 \\
2,400 \\
565 \\
2,340 \\
945\end{array}$ & \multirow{3}{*}{$\begin{array}{l}1951 \\
1952 \\
1953 \\
1954 \\
1955 \\
1956 \\
1957 \\
1958 \\
1959 \\
1960 \\
1961 \\
1962 \\
1963\end{array}$} & \multirow{3}{*}{\multicolumn{2}{|c|}{ 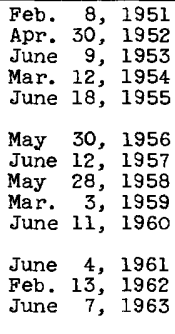 }} & \multirow{3}{*}{$\begin{array}{c}6.92 \\
9.60 \\
5.06 \\
3.07 \\
3.71 \\
7.55 \\
7.79 \\
6.47 \\
2.27 \\
3.66 \\
3.65 \\
12.3 \\
7.25\end{array}$} & \multirow{3}{*}{$\begin{array}{r}1,650 \\
3,860 \\
1,020 \\
337 \\
414 \\
\\
2,180 \\
2,250 \\
1,620 \\
142 \\
453 \\
\\
309 \\
7,070 \\
1,910\end{array}$} \\
\hline $\begin{array}{l}1901 \\
1902 \\
\end{array}$ & $\begin{array}{ll}\text { Feb. } 24, & 1901 \\
\text { June } 21, & 1902 \\
\end{array}$ & - & $\begin{array}{l}2,340 \\
1,140 \\
\end{array}$ & & & & & \\
\hline $\begin{array}{l}1945 \\
1946 \\
1947 \\
1948 \\
1949 \\
1950\end{array}$ & $\begin{array}{lr}\text { June } & 9,1945 \\
\text { Apr. } & 23,1946 \\
\text { June } 3, & 1947 \\
\text { June } 7, & 1948 \\
\text { May } 21, & 1949 \\
\text { June } 10, & 1950\end{array}$ & $\begin{array}{l}8.96 \\
6.53 \\
4.74 \\
5.68 \\
6.44 \\
6.13\end{array}$ & $\begin{array}{r}2,530 \\
1,370 \\
692 \\
1,020 \\
1,380 \\
1,240\end{array}$ & & & & & \\
\hline
\end{tabular}

3190. South Fork Humboldt River near Lee, Nev.

Location. - Iat $40^{\circ} 34^{\prime}$, long $115^{\circ} 33^{\prime}$, in $\mathrm{SE} \frac{1}{4}$ sec.16, T.31 N., R.57 E., on left

bank $400 \mathrm{ft}$ downstream from Kleckner Creek and $2 \frac{1}{2}$ miles east of Les.

Drainage area. $--54 \mathrm{sq} \mathrm{mi}$, approximately. Mean altitude, 8,570 ft.

Gage--Recording. Altitude of gage is 5,970 ft (from topographic map).

Stage-discharge relation.--Defined by current-meter measurements.

Remarks.--Base for partial-duration series, $450 \mathrm{cfs}$.

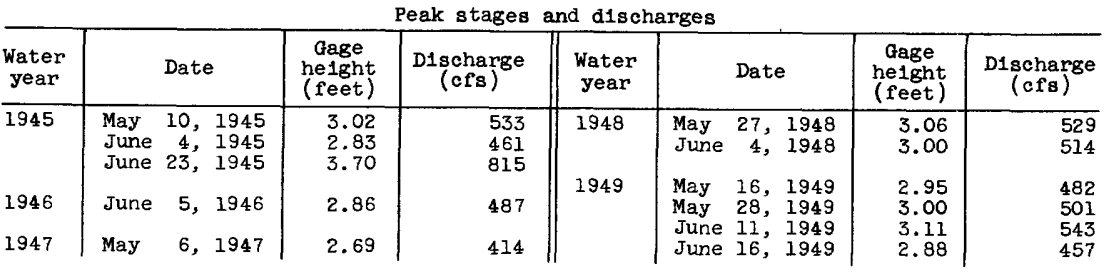


Peak stages and discharges of South Fork Humboldt River near Lee, Nev.--Continued

\begin{tabular}{|c|c|c|c|c|c|c|c|c|c|}
\hline $\begin{array}{l}\text { Water } \\
\text { year }\end{array}$ & \multicolumn{2}{|r|}{ Date } & $\begin{array}{c}\text { Gage } \\
\text { helght } \\
\text { (feet) }\end{array}$ & $\begin{array}{c}\text { Discharge } \\
\text { (cfs) }\end{array}$ & $\begin{array}{l}\text { Water } \\
\text { year }\end{array}$ & \multicolumn{2}{|r|}{ Date } & $\begin{array}{c}\text { Gage } \\
\text { he1ght } \\
\text { (feet) }\end{array}$ & $\begin{array}{c}\text { D1scharge } \\
\text { (cfs) }\end{array}$ \\
\hline 1950 & $\begin{array}{l}\text { May } \\
\text { June }\end{array}$ & $\begin{array}{ll}30, & 1950 \\
22, & 1950\end{array}$ & $\begin{array}{l}3.45 \\
2.87\end{array}$ & $\begin{array}{l}762 \\
457\end{array}$ & 1953 & $\begin{array}{l}\text { June } \\
\text { June }\end{array}$ & $\begin{array}{ll}12, & 1953 \\
18, & 1953\end{array}$ & $\begin{array}{l}3.47 \\
3.35\end{array}$ & $\begin{array}{l}664 \\
610\end{array}$ \\
\hline 1951 & $\begin{array}{l}\text { May } \\
\text { June }\end{array}$ & $\begin{array}{ll}27, & 1951 \\
17, & 1951\end{array}$ & $\begin{array}{l}3.81 \\
3.03\end{array}$ & $\begin{array}{l}935 \\
560\end{array}$ & 1954 & & 19,1954 & 2.64 & 357 \\
\hline 1952 & & 5,1952 & 3.48 & 687 & 1955 & une & , 1 & 3.51 & 592 \\
\hline
\end{tabular}

3195. Huntington Creek near Lee, Nev.

Location.--Lat $40^{\circ} 33^{\prime}$, long $115^{\circ} 43^{\prime}$, in SW $\frac{1}{4}$ sec.19, T. 31 N., R.56 E., on right

bank $5 \frac{1}{2}$ miles upstream from mouth and 6 miles west of Lee.

Drainage area. $--770 \mathrm{sq} \mathrm{mi}$, approximately. Mean altitude, 6,410 ft.

Gage.--Recording. Altitude of gage is 5,315 ft (from river-prof:.le map).

Stage-discharge relation.--Defined by current-meter measurements below 530 cfs and extended above on basis of slope-area measurement at $2,160 \mathrm{cfs}$.

Remarks.--Diversions for irrigation of 17,700 acres above station. Only annual peaks are shown prior to 1962 (peaks above base of $200 \mathrm{cf}$ thereafter).

\begin{tabular}{|c|c|c|c|c|c|c|c|c|c|}
\hline $\begin{array}{l}\text { Water } \\
\text { year }\end{array}$ & & Date & $\begin{array}{c}\text { Gage } \\
\text { helght } \\
\text { (feet) }\end{array}$ & $\begin{array}{c}\text { Discharge } \\
\text { (cfs) }\end{array}$ & $\begin{array}{l}\text { Water } \\
\text { year }\end{array}$ & & Date & $\begin{array}{c}\text { Cage } \\
\text { helght } \\
\text { (feet) }\end{array}$ & $\begin{array}{c}\text { Discharge } \\
\text { (cfs) }\end{array}$ \\
\hline $\begin{array}{l}1949 \\
1950\end{array}$ & $\begin{array}{l}\text { May } \\
\text { June }\end{array}$ & $\begin{array}{rr}16, & 1949 \\
8, & 1950\end{array}$ & $\begin{array}{l}4.52 \\
3.47\end{array}$ & $\begin{array}{l}532 \\
242\end{array}$ & $\begin{array}{l}1959 \\
1960\end{array}$ & $\begin{array}{l}\text { Feb. } \\
\text { May }\end{array}$ & $\begin{array}{rr}19, & 1959 \\
7, & 1960\end{array}$ & $\begin{array}{l}1.38 \\
2.19\end{array}$ & $\begin{array}{l}23 \\
72\end{array}$ \\
\hline $\begin{array}{l}1951 \\
1952 \\
1953 \\
1954 \\
1955\end{array}$ & $\begin{array}{l}\text { Feb. } \\
\text { Apr. } \\
\text { June } \\
\text { Mar. } \\
\text { June }\end{array}$ & $\begin{array}{rr}5, & 1951 \\
29, & 1952 \\
15, & 1953 \\
25, & 1954 \\
11, & 1955\end{array}$ & $\begin{array}{l}3.78 \\
6.54 \\
2.51 \\
1.67 \\
2.54\end{array}$ & $\begin{array}{r}382 \\
1,210 \\
129 \\
37 \\
104\end{array}$ & $\begin{array}{l}1961 \\
1962\end{array}$ & $\begin{array}{l}\text { May } \\
\text { Feb. } \\
\text { May } \\
\text { May } \\
\text { May } \\
\text { June }\end{array}$ & $\begin{array}{ll}31, & 1961 \\
10, & 1962 \\
17, & 1962 \\
24, & 1962 \\
28, & 1962 \\
16, & 1962\end{array}$ & $\begin{array}{l}3.13 \\
7.99 \\
3.42 \\
3.76 \\
3.85 \\
3.96\end{array}$ & $\begin{array}{r}126 \\
160 \\
302 \\
381 \\
404 \\
432\end{array}$ \\
\hline $\begin{array}{l}1956 \\
1957 \\
1958 \\
\end{array}$ & $\begin{array}{l}\text { May } \\
\text { June } \\
\text { May }\end{array}$ & $\begin{array}{rr}25, & 1956 \\
6, & 1957 \\
26, & 1955\end{array}$ & $\begin{array}{l}3.98 \\
3.91 \\
3.29\end{array}$ & $\begin{array}{l}422 \\
388 \\
257\end{array}$ & 1963 & $\begin{array}{l}\text { June } \\
\text { June } \\
\text { June }\end{array}$ & $\begin{array}{rr}5, & 1963 \\
11, & 1963 \\
19, & 1963\end{array}$ & $\begin{array}{l}4.00 \\
3.43 \\
3.37\end{array}$ & $\begin{array}{l}369 \\
257 \\
246 \\
\end{array}$ \\
\hline
\end{tabular}

3200. South Fork Humboldt River above Dixie Creek, near Elko, Nev.

Location.--Iat $40^{\circ} 41^{\prime} 05^{\prime \prime}$, long $115^{\circ} 48^{\prime 4} 45^{\prime \prime}$, in NW $\frac{1}{4} \mathrm{SW} \frac{1}{4}$ sec.5, T. $32 \mathrm{~N}$, , R. 55 E., on left bank $1 \frac{1}{2}$ miles upstream from Dixie Creek and $10 \frac{1}{2}$ miles south of Eiko.

Drainage area. $--1,150 \mathrm{sq} \mathrm{mi}$, approximately.

Gage.--Recording. Altitude of gage is 5,140 ft (from topographic map).

Stage-discharge relation.--Defined by current-meter measurements below 2,000

cf's and extended above on basis of slope-area measurement at $₹, 760 \mathrm{cfs}$.

Bankfull stage. $-5 \mathrm{ft}$.

Remarks.--Diversions for irrigation of 32,900 acres above statior. Only annual peaks are shown.

Peak stages and discharges

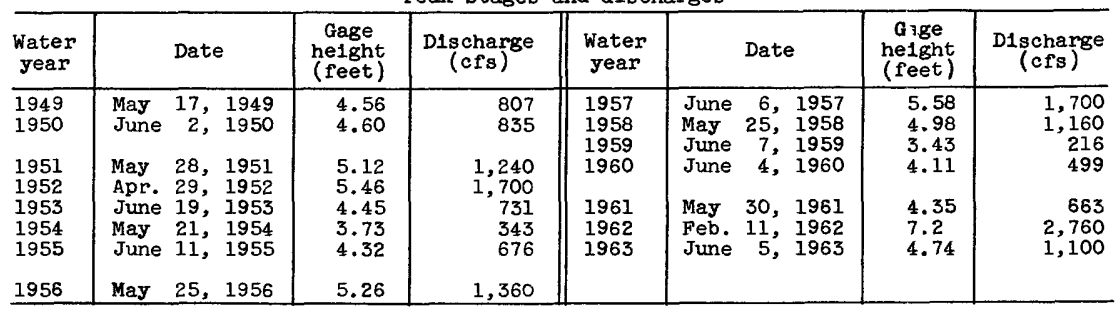


3205. South Fork Humboldt River near Elko, Nev.

(Published as "at Mason's ranch" 1896-1902)

Location.--Lat $40^{\circ} 43^{\prime} 2^{\prime \prime}$, long $115^{\circ} 49^{\prime} 45^{\prime \prime}$, in $\mathrm{NE} \frac{1}{4} \mathrm{NW} \frac{1}{4}$ sec. 30 , T. 33 N., R. 55 E., on $\mathrm{r}^{\prime}$ ght bank $0.1 \mathrm{mile}$ upstream from head of canyon, $1.7 \mathrm{miles}$ downstream from highway bridge, 8.8 miles upstream from mouth, and 10 miles southwest of Elko.

Drainage area.--1,310 sq $\mathrm{m1}$, approximately. Mean altitude, 6,330 ft.

Gage.--Nonrecording prior to November 1913 at several sites about 1 mile upstream at various datums. Recording November 1913 to February 1927 near present site at different datums. Nonrecording March 1927 to September 1932 at site 1 mile upstream at different datum; recording thereafter. 0ctober 1932 to oct. $12,1955,900 \mathrm{ft}$ upstream at datum $1.97 \mathrm{ft}$ higher. Altitude of gage is $5,100 \mathrm{ft}$ (from topographic map).

Stage-discharge relation.--Defined by current-meter measurements below 1,500 $c$ f's and by slope-area measurement at $2,830 \mathrm{cfs}$.

Remarks. - Many diversions for irrigation above station. Station is below all diversions except those of Hunter \& Banks Ranch 3 miles downstream. Only annual peaks are shown prior to 1961 (peaks above base of $410 \mathrm{cfs}$ thereafter)

Peak stages and discharges

\begin{tabular}{|c|c|c|c|c|c|c|c|c|}
\hline $\begin{array}{l}\text { Water } \\
\text { year }\end{array}$ & Date & $\begin{array}{l}\text { Gage } \\
\text { nelght } \\
\text { (feet) }\end{array}$ & $\begin{array}{c}\text { D1scharge } \\
(\mathrm{cfs})\end{array}$ & $\begin{array}{l}\text { Water } \\
\text { year }\end{array}$ & & Date & $\begin{array}{c}\text { Gage } \\
\text { helght } \\
\text { (feet) }\end{array}$ & $\begin{array}{c}\text { D1scharge } \\
\text { (cfs) }\end{array}$ \\
\hline $\begin{array}{l}1897 \\
1898 \\
1899 \\
1900\end{array}$ & $\begin{array}{lll}\text { May } 25,1897 \\
\text { June } 18,1898 \\
\text { June } 21,1899 \\
\text { June } 10,1900\end{array}$ & $\begin{array}{l}- \\
- \\
-\end{array}$ & $\begin{array}{r}1,330 \\
473 \\
1,370 \\
740\end{array}$ & $\begin{array}{l}1937 \\
1938 \\
1939 \\
1940\end{array}$ & $\begin{array}{l}\text { June } \\
\text { June } \\
\text { Mar. } \\
\text { May }\end{array}$ & $\begin{array}{r}1,1937 \\
6,1938 \\
28,1939 \\
16,1940\end{array}$ & $\begin{array}{l}4.00 \\
3.84 \\
3.19 \\
3.80\end{array}$ & $\begin{array}{l}800 \\
770 \\
476 \\
750\end{array}$ \\
\hline $\begin{array}{l}1901 \\
1902 \\
1903 \\
1904 \\
1905\end{array}$ & $\begin{array}{l}\text { Feb. } 18-20,1901 \\
\text { June } 13,14,1902 \\
\text { June } 11-13,1903 \\
\text { May } 26,1904 \\
\text { June 17, } 1905\end{array}$ & $\begin{array}{l}- \\
\overline{-} \\
\overline{-}\end{array}$ & $\begin{array}{r}1,480 \\
1,380 \\
1,170 \\
1,180 \\
816\end{array}$ & $\begin{array}{l}1941 \\
1942 \\
1943 \\
1944 \\
1945\end{array}$ & $\begin{array}{l}\text { Aug. } \\
\text { May } \\
\text { June } \\
\text { June } \\
\text { May }\end{array}$ & $\begin{array}{r}8,1941 \\
27,1942 \\
2,1943 \\
10,1944 \\
11,1945\end{array}$ & $\begin{array}{l}5.25 \\
5.15 \\
4.55 \\
4.31 \\
5.33\end{array}$ & $\begin{array}{r}1,560 \\
1,410 \\
1,080 \\
975 \\
1,440\end{array}$ \\
\hline $\begin{array}{l}1906 \\
1907 \\
1908 \\
1909 \\
\end{array}$ & $\begin{array}{l}\text { June16-24, } 1906 \\
\text { June 8, } 1907 \\
\text { June 17, } 1908 \\
\text { June 7,8, } 1909\end{array}$ & $\begin{array}{l}- \\
- \\
-\end{array}$ & $\begin{array}{r}1,010 \\
1,260 \\
850 \\
1,090\end{array}$ & $\begin{array}{l}1946 \\
1947 \\
1948 \\
1949\end{array}$ & $\begin{array}{l}\text { Apr. } \\
\text { June } \\
\text { June } \\
\text { May }\end{array}$ & $\begin{array}{rr}20 ; & 1946 \\
1, & 1947 \\
5, & 1948 \\
17, & 1949\end{array}$ & $\begin{array}{l}3.83 \\
3.50 \\
3.80 \\
4.20\end{array}$ & $\begin{array}{l}740 \\
608 \\
736 \\
910\end{array}$ \\
\hline $\begin{array}{l}1911 \\
1912 \\
1913\end{array}$ & $\begin{array}{l}\text { June } 14,1911 \\
\text { June } 9,14,1912 \\
\text { May } 26-30,1913\end{array}$ & - & $\begin{array}{r}856 \\
1,470 \\
632 \\
\end{array}$ & $\begin{array}{l}1950 \\
1951 \\
1952\end{array}$ & $\begin{array}{l}\text { May } \\
\text { May } \\
\text { Apr. }\end{array}$ & $\begin{array}{l}31,1950 \\
29,1951 \\
29,1952\end{array}$ & $\begin{array}{l}0.71 \\
4.50 \\
5.37\end{array}$ & $\begin{array}{r}1,120 \\
1,700\end{array}$ \\
\hline $\begin{array}{l}1914 \\
1915\end{array}$ & $\begin{array}{l}\text { Jan. } 26,1914 \\
\text { June } 10,1915\end{array}$ & $\overline{-}$ & $\begin{array}{r}a 2,400 \\
372\end{array}$ & $\begin{array}{l}1953 \\
1954 \\
1955\end{array}$ & $\begin{array}{l}\text { June } \\
\text { May } \\
\text { June }\end{array}$ & 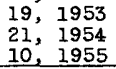 & $\begin{array}{l}3.63 \\
2.65 \\
3.51 \\
\end{array}$ & $\begin{array}{r}742 \\
358 \\
688 \\
\end{array}$ \\
\hline $\begin{array}{l}1916 \\
1917 \\
1918 \\
\end{array}$ & $\begin{array}{c}\text { June } 18,1916 \\
\text { Mar. } 28,1917 \\
\text { June } 21,1918\end{array}$ & $\begin{array}{l}- \\
-\end{array}$ & $\begin{array}{r}438 \\
1,700 \\
1,300\end{array}$ & $\begin{array}{l}1956 \\
1957\end{array}$ & $\begin{array}{l}\text { May } \\
\text { June }\end{array}$ & 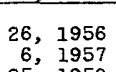 & $\begin{array}{l}5.42 \\
5.77\end{array}$ & $\begin{array}{l}1,270 \\
1,590\end{array}$ \\
\hline 1922 & May 24, 1921 & - & 2,070 & $\begin{array}{l}1950 \\
1959 \\
1960\end{array}$ & $\begin{array}{l}\text { Juy } \\
\text { June }\end{array}$ & $\begin{array}{r}7,1959 \\
4,1960\end{array}$ & $\begin{array}{l}0.10 \\
3.21 \\
4.03\end{array}$ & $\begin{array}{r}1,110 \\
221 \\
488\end{array}$ \\
\hline $\begin{array}{l}1924 \\
1925\end{array}$ & $\begin{array}{lr}\text { May } 18,1924 \\
\text { July } \quad 4, .1925\end{array}$ & $\overline{-}$ & $\begin{array}{r}470 \\
1,470\end{array}$ & 1961 & May & 30,1961 & 4.34 & 624 \\
\hline 1926 & May 21,1926 & - & 244 & & July & 3,1961 & 4.82 & 882 \\
\hline $\begin{array}{l}1927 \\
1928 \\
1929 \\
1930\end{array}$ & $\begin{array}{l}\text { May } 20,1927 \\
\text { May } 27,1928 \\
\text { June } 17,1929 \\
\text { May } 29,30,1930, \\
\text { June } 12,14,1930\end{array}$ & $\begin{array}{l}- \\
- \\
-\end{array}$ & $\begin{array}{l}885 \\
957 \\
990 \\
475\end{array}$ & 1962 & $\begin{array}{l}\text { Feb. } \\
\text { May } \\
\text { May } \\
\text { June } \\
\text { June }\end{array}$ & $\begin{array}{l}11,1962 \\
17,1962 \\
25,1962 \\
16,1962 \\
23,1962\end{array}$ & $\begin{array}{l}8.00 \\
4.70 \\
4.89 \\
5.28 \\
4.72\end{array}$ & $\begin{array}{r}2,830 \\
772 \\
888 \\
1,150 \\
804\end{array}$ \\
\hline $\begin{array}{l}1931 \\
1932 \\
\end{array}$ & $\begin{array}{ll}\text { Mar. } 10,1931 \\
\text { June } 16,1932\end{array}$ & - & $\begin{array}{r}51 \\
1,490 \\
\end{array}$ & & June & 19,1963 & & 1,000 \\
\hline
\end{tabular}

\section{a Maximum daily.}

Note.--Maximum observed prior to 1914 and for 1932. 
3210. Humboldt River near Carlin, Nev.

Location.--Lat $40^{\circ} 43^{1} 40^{\prime \prime}$, long $116^{\circ} 00^{\prime} 30^{\prime \prime}$, in sec.21, T.33 N., R.53 E., on right bank $4 \frac{1}{2}$ miles southwest of Moleen, 5 miles upstream fron Susie Creek, $5 \frac{1}{2}$ miles east of Carlin, and 15 miles southwest of Elko.

Drainage area. $--4,310 \mathrm{sq} \mathrm{mi}$, approximately.

Gage.--Recording. Datum of gage is $4,931.91 \mathrm{ft}$ above mean sea level (levels by State Highway Department).

Stage-discharge relation.--Defined by slope-area measurement at 5,900 cfs.

Remarks.--Many diversions for irrigation above station. Only annual peaks are shown.

Peak stages and discharges

\begin{tabular}{|c|c|c|c|c|c|c|c|c|}
\hline $\begin{array}{l}\text { Water } \\
\text { year }\end{array}$ & Date & $\begin{array}{c}\text { Gage } \\
\text { he1ght } \\
\text { (feet) }\end{array}$ & $\begin{array}{c}\text { Discharge } \\
\text { (cfs) }\end{array}$ & $\begin{array}{l}\text { Water } \\
\text { year }\end{array}$ & & Date & $\begin{array}{l}\text { Gage } \\
\text { helght } \\
\text { (feet) }\end{array}$ & $\begin{array}{c}\text { D1scharge } \\
\text { (cfs) }\end{array}$ \\
\hline $\begin{array}{l}1944 \\
1945\end{array}$ & $\begin{array}{l}\text { June } 15,1944 \\
\text { June } 10,1945\end{array}$ & $\begin{array}{l}5.66 \\
7.78\end{array}$ & $\begin{array}{l}1,930 \\
3,640\end{array}$ & $\begin{array}{l}1954 \\
1955\end{array}$ & $\begin{array}{l}\text { Mar. } \\
\text { June }\end{array}$ & $\begin{array}{ll}28, & 1954 \\
16, & 1955\end{array}$ & $\begin{array}{l}2.37 \\
3.49\end{array}$ & $\begin{array}{l}308 \\
741\end{array}$ \\
\hline $\begin{array}{l}1946 \\
1947 \\
1948 \\
1949 \\
1950\end{array}$ & $\begin{array}{ll}\text { Apr. } 26,27, & 1946 \\
\text { June 2, } & 1947 \\
\text { June 10, } 1948 \\
\text { May 22, } 1949 \\
\text { June 8, } 1950\end{array}$ & $\begin{array}{l}5.61 \\
4.29 \\
4.84 \\
5.51 \\
5.24\end{array}$ & $\begin{array}{l}1,870 \\
1,080 \\
1,370 \\
1,800 \\
1,730\end{array}$ & $\begin{array}{l}1956 \\
1957 \\
1958 \\
1959 \\
1960\end{array}$ & $\begin{array}{l}\text { May } \\
\text { June } \\
\text { May } \\
\text { June } \\
\text { June }\end{array}$ & 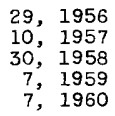 & $\begin{array}{l}6.83 \\
7.22 \\
5.98 \\
2.08 \\
3.37\end{array}$ & $\begin{array}{r}2,960 \\
3,340 \\
2,260 \\
225 \\
679\end{array}$ \\
\hline $\begin{array}{l}1951 \\
1952 \\
1953 \\
\end{array}$ & $\begin{array}{l}\text { June } 1,2,1951 \\
\text { May 1, } 1952 \\
\text { June 20, } 1953\end{array}$ & $\begin{array}{l}5.57 \\
9.35 \\
4.83\end{array}$ & $\begin{array}{l}2,000 \\
5,220 \\
1,440\end{array}$ & $\begin{array}{l}1961 \\
1962 \\
1963 \\
\end{array}$ & $\begin{array}{l}\text { June } \\
\text { Feb. } \\
\text { June }\end{array}$ & $\begin{array}{rr}9, & 1961 \\
14, & 1962 \\
9, & 1963\end{array}$ & $\begin{array}{r}3.20 \\
10.21 \\
6.39\end{array}$ & $\begin{array}{r}630 \\
6,160 \\
2,630\end{array}$ \\
\hline
\end{tabular}

3220. Maggie Creek at Carlin, Nev.

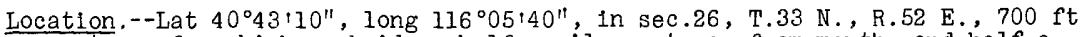
upstream from highway bridge, half a mile upstream from mouth, and half a mile east of Carlin.

Gage.--Nonrecording. Prior to Jan. 20, 1924, at several sites from $100 \mathrm{ft}$ upstream to $600 \mathrm{ft}$ downstream from described site at different datums. Altitude of gage is $4,910 \mathrm{ft}$ (from topographic map).

Stage-discharge relation.--Defined by current-meter measurements below $250 \mathrm{cfs}$ prior to 1922 , below 300 cfs thereafter.

Bankfull stage.--Not subject to overflow.

Remarks.--Only annual maximum observed discharges are shown.

Maximum observed stages and discharges

\begin{tabular}{|c|c|c|c|c|c|c|c|c|}
\hline $\begin{array}{l}\text { Water } \\
\text { year }\end{array}$ & Date & $\begin{array}{l}\text { Gage } \\
\text { he1ght } \\
\text { (feet) }\end{array}$ & $\begin{array}{c}\text { Discharge } \\
\text { (cfs) }\end{array}$ & $\begin{array}{l}\text { Water } \\
\text { year }\end{array}$ & & Date & $\begin{array}{c}\text { Gage } \\
\text { he1ght } \\
\text { (feet) }\end{array}$ & $\begin{array}{l}\text { Discharge } \\
\text { (cfs) }\end{array}$ \\
\hline $\begin{array}{l}1914 \\
1915\end{array}$ & $\begin{array}{ll}\text { Apr. } 28, & 1914 \\
\text { Mar. } 29, & 1915\end{array}$ & $\begin{array}{l}4.5 \\
2.1\end{array}$ & $\begin{array}{r}394 \\
29\end{array}$ & 1920 & May & 3,1920 & 2.08 & 85 \\
\hline $\begin{array}{l}1916 \\
1917 \\
1918 \\
1919\end{array}$ & $\begin{array}{l}\text { Apr. } 11,1916 \\
\text { Apr. } 27,1917 \\
\text { Apr. } 11,1918 \\
\text { Apr. } 6,1919\end{array}$ & $\begin{array}{l}3.09 \\
- \\
1.68 \\
2.65\end{array}$ & $\begin{array}{r}183 \\
300 \\
31 \\
160 \\
\end{array}$ & $\begin{array}{l}1921 \\
1922 \\
1923 \\
1924\end{array}$ & $\begin{array}{l}\text { Mar. } \\
\text { May } \\
\text { May } \\
\text { Apr. }\end{array}$ & $\begin{array}{rr}5, & 1921 \\
7, & 1922 \\
22, & 1923 \\
17, & 1924\end{array}$ & $\begin{array}{l}4.12 \\
4.3 \\
2.08 \\
1.46\end{array}$ & $\begin{array}{r}416 \\
800 \\
a 73 \\
36\end{array}$ \\
\hline
\end{tabular}

a Maximum observed during period April to September. 
3225. Humboldt River at Palisade, Nev.

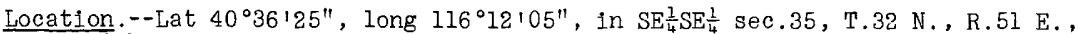
on right bank a quarter of a mile downstream from Southern Pacific Railroad bridge, half a mile downstream from Palisade, and three-quarters of a mile upstream from Pine Creek.

Drainage area. $--5,010 \mathrm{sq} \mathrm{mi}$, approximately.

Gage.--Nonrecording prior to Apr. 1, 1939, at several sites within half a mile of present site at various datums; recording thereafter. Datum of gage is $4,825.55 \mathrm{ft}$ above mean sea level, datum of 1929 .

Stage-discharge relation.--Defined by current-meter measurements.

Historical data.--Maximum stage known, about $17 \mathrm{ft}$ (present datum), about Feb. 28, 1910, from old photographs and statement of local resident (discharge, about $17,000 \mathrm{cf}$ ) .

Remarks.--Diversion for irrigation of about 150,000 acres of hay and fasture land above station. Only annual peaks are shown.

Peak stages and discharges

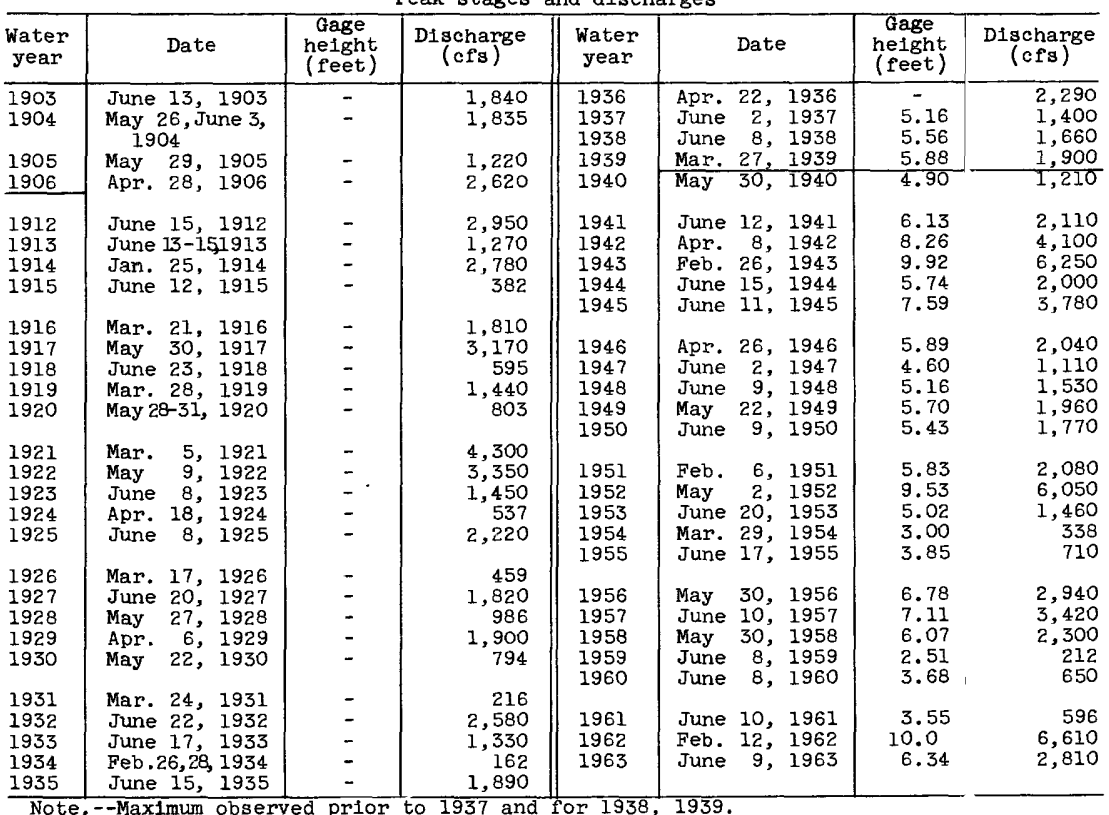

Note. --Maximum observed prior to 1937 and for 1938, 1939.

3230. Pine Creek near Palisade, Nev.

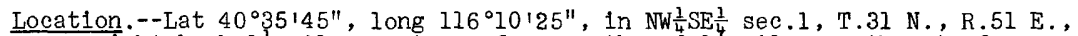
on right bank $1 \frac{1}{4}$ miles upstream from mouth and $1 \frac{4}{2}$ miles southeast of Palisade.

Drainage area. --999 sq mi. Mean altitude, 6,210 ft.

Gage.--Nonrecording prior to Jan. I, 1946, at site half a mile downstream at different datums; recording thereafter. Jan. 1 to July 18, 1946, at site $1,000 \mathrm{ft}$ downstream at different datum. Altitude of gage is $4,900 \mathrm{ft}$ (from topographic map).

Stage-discharge relation.--Defined by current-meter measurements below 330 cfs and by slope-area measurement at 1,010 and $3,140 \mathrm{cf}$.

Remarks.--Diversions above station for irrigation. Only annual peaks are shown. 
Peak stages and discharges of Pine Creek near Palisade, Nev.

\begin{tabular}{|c|c|c|c|c|c|c|c|}
\hline $\begin{array}{l}\text { Water } \\
\text { year }\end{array}$ & Date & $\begin{array}{c}\text { Gage } \\
\text { helght } \\
\text { (feet) }\end{array}$ & $\begin{array}{c}\text { Discharge } \\
(\mathrm{cfs})\end{array}$ & $\begin{array}{l}\text { Water } \\
\text { year }\end{array}$ & Date & $\begin{array}{l}\text { Gage } \\
\text { height } \\
\text { (feet) }\end{array}$ & $\begin{array}{c}\text { D1scharge } \\
\text { (cfs) }\end{array}$ \\
\hline $\begin{array}{l}1912 \\
1913 \\
1914 \\
\end{array}$ & $\begin{array}{l}\text { Apr. 26, } 1912 \\
\text { Dec. 3, } 1912 \\
\text { Jan.25, 26, } 1914 \\
\end{array}$ & $\begin{array}{l}- \\
-\end{array}$ & $\begin{array}{r}a 82 \\
a 28 \\
a 1,000 \\
\end{array}$ & $\begin{array}{l}1952 \\
1953 \\
1954 \\
1955\end{array}$ & $\begin{array}{l}\text { Mar. } 27,1952 \\
\text { Jan. } 18,1953 \\
\text { Feb. } 14,1954 \\
\text { Aug. } 13,1955\end{array}$ & $\begin{array}{l}4.69 \\
1.46 \\
1.56 \\
4.54\end{array}$ & $\begin{array}{r}1,010 \\
24 \\
23 \\
788\end{array}$ \\
\hline \multirow{2}{*}{$\begin{array}{l}1946 \\
1947 \\
1948 \\
1949 \\
1950\end{array}$} & $\begin{array}{l}\text { Feb. } 24,1946 \\
\text { Feb. } 10,1947 \\
\text { Jan. } 9,1948 \\
\text { Mar. 19, } 1949\end{array}$ & $\begin{array}{l}4.0 \\
2.01 \\
1.54 \\
2.47\end{array}$ & $\begin{array}{r}600 \\
76 \\
28 \\
146\end{array}$ & $\begin{array}{l}1956 \\
1957 \\
1958 \\
\end{array}$ & $\begin{array}{lr}\text { Mar. } 4, & 1956 \\
\text { May 19, } & 1957 \\
\text { Jan. } 25, & 1958\end{array}$ & $\begin{array}{l}2.57 \\
2.85 \\
2.92\end{array}$ & $\begin{array}{r}190 \\
60 \\
67\end{array}$ \\
\hline & $\begin{array}{l}\text { Apr. } 18,1950 \\
\text { Feb. } 5,1951\end{array}$ & $\begin{array}{l}1.84 \\
3.62\end{array}$ & 358 & 1962 & Feb. 11,1962 & 9.16 & 3,140 \\
\hline
\end{tabular}

a Maximum observed.

3235. Humboldt River near Argenta, Nev.

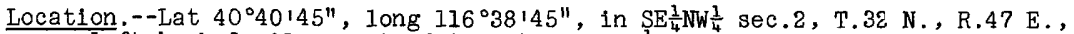
on left bank 3 miles east of Argenta and $15 \frac{1}{2}$ miles east of Battle Mountain. Drainage area. $--7,490 \mathrm{sq} \mathrm{ml}$, approximately.

Gage.--Recording. Altitude of gage is 4,580 ft (from topographic map).

Stage-discharge relation.--Defined by current-meter measurements below 3,000 cfs.

Remarks.--Many diversions above station for irrigation. Records do not include flow in secondary channels or ditches, much of which is used for irrigation. only annual peaks are shown.

\begin{tabular}{|c|c|c|c|c|c|c|c|}
\hline $\begin{array}{l}\text { Water } \\
\text { year }\end{array}$ & Date & $\begin{array}{c}\text { Gage } \\
\text { helght } \\
\text { (feet) }\end{array}$ & $\begin{array}{c}\text { Discharge } \\
\text { (cfs) }\end{array}$ & $\begin{array}{l}\text { Water } \\
\text { year }\end{array}$ & Date & $\begin{array}{c}\text { Gage } \\
\text { helght } \\
\text { (feet) }\end{array}$ & $\begin{array}{c}\text { D1scharge } \\
\text { (cfs) }\end{array}$ \\
\hline $\begin{array}{l}1946 \\
1947 \\
1948 \\
1949 \\
1950\end{array}$ & $\begin{array}{ll}\text { Apr.27,28, } & 1946 \\
\text { June 3, } & 1947 \\
\text { June 12, } & 1948 \\
\text { May } 24, & 1949 \\
\text { June 11, } & 1950\end{array}$ & $\begin{array}{l}8.58 \\
6.02 \\
6.62 \\
7.86 \\
7.58\end{array}$ & $\begin{array}{r}1,780 \\
797 \\
974 \\
1,450 \\
1,330\end{array}$ & $\begin{array}{l}1956 \\
1957 \\
1955 \\
1959 \\
1960\end{array}$ & $\begin{array}{l}\text { June } 3,1956 \\
\text { June } 13,1957 \\
\text { June 3, } 1958 \\
\text { Mar. 9, } 1959 \\
\text { Jan. 10, } 1960\end{array}$ & $\begin{array}{l}9.41 \\
9.64 \\
7.80 \\
3.42 \\
4.72\end{array}$ & $\begin{array}{r}2,430 \\
2,680 \\
1,810 \\
153 \\
462\end{array}$ \\
\hline $\begin{array}{l}1951 \\
1952 \\
1953 \\
1954 \\
1955 \\
\end{array}$ & $\begin{array}{l}\text { Feb. 12, } 1951 \\
\text { May 2, } 1952 \\
\text { June 23, } 1953 \\
\text { Mar. 29, } 1954 \\
\text { June 18, } 1955\end{array}$ & $\begin{array}{l}8.16 \\
- \\
6.80 \\
4.14 \\
4.91 \\
\end{array}$ & $\begin{array}{r}1,630 \\
a 5,700 \\
1,120 \\
315 \\
523 \\
\end{array}$ & $\begin{array}{l}1961 \\
1962 \\
1963\end{array}$ & $\begin{array}{l}\text { June } 11,1961 \\
\text { Feb. } 15,1962 \\
\text { June } 24,1963\end{array}$ & $\begin{array}{r}4.69 \\
10.78 \\
8.73\end{array}$ & $\begin{array}{r}436 \\
6,000 \\
2,200\end{array}$ \\
\hline
\end{tabular}

a Maximum da1ly.

3245. Rock Creek near Battle Mountain, Nev.

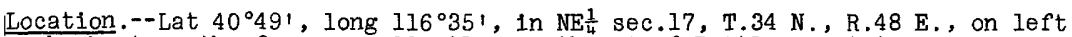
bank at mouth of canyon, 22 miles northeast of Battle Mountain.

Drainage area. $--875 \mathrm{sq} \mathrm{mi}$, approximately. Mean altitude, 5,730 ft.

Gage.--Nonrecording prior to Mar. 26, 1918, at site about 11 miles upstream at different datum; recording thereafter. Mar. 26, 1918, to Jan. 3, 1946, at present site at idifferent datum; Altitude of gage is $4,600 \mathrm{ft}$ (estimated from nearby U.S. Coast and Geodétic Survey bench mark).

Stage-discharge relation.--Defined by current-meter measurements below 2,500 $\mathrm{cf}$ 's and extended above on basis of slope-area measurement at $4,800 \mathrm{cfs}$.

Remarks.--Several diversions for irrigation in valleys upstream. Station is above all diversions in Boulder flat and below all tributaries. Flow slightly affected by small reservolr in Squaw Valley, 30 miles upstream. only annual peaks are shown. 
Peak stages and discharges of Rock Creek near Battle Mountain, Nev.

\begin{tabular}{|c|c|c|c|c|c|c|c|}
\hline $\begin{array}{l}\text { Water } \\
\text { year }\end{array}$ & Date & $\begin{array}{l}\text { Gage } \\
\text { he1ght } \\
\text { (feet) }\end{array}$ & $\begin{array}{c}\text { D1scharge } \\
\text { (cfs) }\end{array}$ & $\begin{array}{l}\text { Water } \\
\text { year }\end{array}$ & Date & $\begin{array}{c}\text { Gage } \\
\text { helght } \\
\text { (feet) }\end{array}$ & $\begin{array}{c}\text { Discharge } \\
\text { (cfs) }\end{array}$ \\
\hline 1896 & May 31,1896 & - & $\mathrm{a} 1,130$ & \multirow{2}{*}{$\begin{array}{l}1951 \\
1952 \\
1953 \\
1954 \\
1955\end{array}$} & \multirow{2}{*}{$\begin{array}{l}\text { Feb. } 4,1951 \\
\text { Apr. 7, } 1952 \\
\text { June 4, 8, } 1953 \\
\text { Mar. 11, } 1954 \\
\text { Mar. II, } 1955\end{array}$} & \multirow{2}{*}{$\begin{array}{l}4.08 \\
5.60 \\
1.59 \\
1.21 \\
1.91\end{array}$} & \multirow{2}{*}{$\begin{array}{r}1,200 \\
3,000 \\
73 \\
38 \\
141\end{array}$} \\
\hline $\begin{array}{l}1318 \\
1919 \\
1920\end{array}$ & $\begin{array}{l}\text { June 19-25, } 1918 \\
\text { Mar. 21, } 1919 \\
\text { Apr. 20, } 1920\end{array}$ & $\begin{array}{l}- \\
-\end{array}$ & $\begin{array}{l}350 \\
700 \\
212\end{array}$ & & & & \\
\hline $\begin{array}{l}1921 \\
1922 \\
1923 \\
\end{array}$ & $\begin{array}{l}\text { Feb. 11, } 1921 \\
\text { Apr. 24, } 1922 \\
\text { Apr. } 7,1923\end{array}$ & $\begin{array}{l}- \\
- \\
\end{array}$ & $\begin{array}{c}2,750 \\
851 \\
292\end{array}$ & $\begin{array}{l}1956 \\
1957 \\
1958\end{array}$ & $\begin{array}{ll}\text { Jan. } 15, & 1956 \\
\text { May } 20, & 1957 \\
\text { Apr. } 23, & 1958\end{array}$ & $\begin{array}{l}2.99 \\
3.50 \\
2.88\end{array}$ & $\begin{array}{l}500 \\
785 \\
445\end{array}$ \\
\hline $\begin{array}{l}1946 \\
1947 \\
1948 \\
1949 \\
1350 \\
\end{array}$ & $\begin{array}{l}\text { Mar. 24, } 1946 \\
\text { Feb. } 11,1947 \\
\text { Mar. 25, } 1948 \\
\text { Apr. 9, } 1949 \\
\text { Mar. 31, } 1950\end{array}$ & $\begin{array}{l}2.37 \\
2.32 \\
2.00 \\
2.27 \\
2.74\end{array}$ & $\begin{array}{l}230 \\
213 \\
134 \\
194 \\
363\end{array}$ & $\begin{array}{l}1961 \\
1962 \\
1963\end{array}$ & $\begin{array}{l}\text { Feb. } 1,1959 \\
\text { Mar. } \\
\text { Mar. } 31,1960 \\
\text { Feb. } 11,1961 \\
\text { Feb. } 2,1962 \\
\end{array}$ & $\begin{array}{l}1.47 \\
6.89 \\
3.69\end{array}$ & $\begin{array}{r}68 \\
4,800 \\
1,070 \\
\end{array}$ \\
\hline
\end{tabular}

a Maximum daily.

3250. Humboldt River at Battle Mountain, Nev.

Location.--Lat $40^{\circ} 39^{\prime} 15^{\prime \prime}$, long $116^{\circ} 55^{\prime} 10^{\prime \prime}$, in $\mathrm{NE} \frac{1}{4} \mathrm{NE} \frac{1}{4} \sec .17$, T. 32 N., R.45 E., on left bank 1 mile northeast of Battle Mountain. Reese River enters

Humboldt River several miles below station.

Drainage area. $--8,870 \mathrm{sq} \mathrm{mi}$, approximately.

Gage.--Nonrecording prior to Mar. 1, 1921, 1,500 ft upstream and Mar. 1, 1921, to Apr. 19, $1924,900 \mathrm{ft}$ downstream, both at different datums; recording thereafter. Altitude of gage is 4,500 ft (from topographic map).

Stage-discharge relation.--Determined by current-meter measurements.

Remarks.--Records do not Include flow in secondary channels or ditches, much of which is used for irrigation. Many diversions above station for irrigation. only annual peaks are shown.

Peak stages and discharges

\begin{tabular}{|c|c|c|c|c|c|c|c|}
\hline $\begin{array}{l}\text { Water } \\
\text { year }\end{array}$ & Date & $\begin{array}{l}\text { Gage } \\
\text { height } \\
\text { (feet) }\end{array}$ & $\begin{array}{c}\text { Discharge } \\
\text { (cfs) }\end{array}$ & $\begin{array}{l}\text { Water } \\
\text { year }\end{array}$ & Date & $\begin{array}{c}\text { Gage } \\
\text { helght } \\
\text { (feet) }\end{array}$ & $\begin{array}{c}\text { Discharge } \\
\text { (cfs) }\end{array}$ \\
\hline $\begin{array}{l}1896 \\
1897 \\
\end{array}$ & $\begin{array}{l}\text { June } 21, \\
\text { June } 2,1896 \\
\end{array}$ & $\begin{array}{r}8.40 \\
8.80 \\
\end{array}$ & $\begin{array}{l}3,001 \\
3,130 \\
\end{array}$ & \multirow{3}{*}{$\begin{array}{l}1952 \\
1953 \\
1954 \\
1955 \\
1956 \\
1957 \\
1955 \\
1959 \\
1960 \\
1961 \\
1962 \\
1963\end{array}$} & \multirow{3}{*}{ 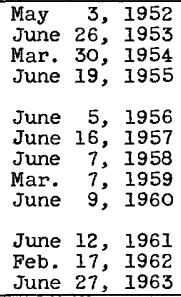 } & \multirow{3}{*}{$\begin{array}{l}- \\
6.65 \\
3.85 \\
4.30 \\
9.15 \\
9.50 \\
\text { 5.59 } \\
3.18 \\
4.56\end{array}$} & \multirow{3}{*}{$\begin{array}{r}25,800 \\
896 \\
304 \\
403 \\
1,560 \\
1,580 \\
1,400 \\
155 \\
396 \\
\\
643 \\
4,600 \\
4,500 \\
\end{array}$} \\
\hline $\begin{array}{l}1921 \\
1922 \\
1923 \\
\end{array}$ & $\begin{array}{ll}\text { June } 19, & 1921 \\
\text { May } 10-13, & 1922 \\
\text { June } 23, & 1923 \\
\end{array}$ & $\begin{array}{l}9.58 \\
9.15 \\
7.53 \\
\end{array}$ & $\begin{array}{l}1,560 \\
1,560 \\
1,070 \\
\end{array}$ & & & & \\
\hline $\begin{array}{l}1946 \\
1947 \\
1948 \\
1949 \\
1950\end{array}$ & $\begin{array}{lr}\text { Apr. } & 24,1946 \\
\text { June } & 2,1947 \\
\text { June } 15, & 1948 \\
\text { May } 30, & 1949 \\
\text { June } 14, & 1950 \\
\text { Feb. } 15, & 1951\end{array}$ & $\begin{array}{l}5.90 \\
5.65 \\
6.62 \\
7.83 \\
7.54 \\
\text { s. } 16\end{array}$ & $\begin{array}{r}1,500 \\
675 \\
909 \\
1,180 \\
1,170 \\
1,370\end{array}$ & & & & \\
\hline
\end{tabular}

a Maximum da11y.

Note.--Maximum observed discharges prior to 1946. 
3255. Reese River near Ione, Nev.

Location.--Lat $38^{\circ} 51^{\prime}$, long $117^{\circ} 28^{\prime}$, in $\mathrm{NE} \frac{1}{4}$ sec.3, T.11 N., R.40 E., on right bank $2 \frac{1}{2}$ miles upstream from Indian Creek, 8 miles southeast of Ione, and 58 miles southwest of Austin.

Drainage area. $--44 \mathrm{sq} \mathrm{m}$, approximately. Mean altitude, 8,820 ft.

Gage.--Recording, and since 0ct. 3, 1956, concrete control. Prior to Sept. 9, 1955, at site $200 \mathrm{ft}$ upstream at datum $2.85 \mathrm{ft}$ higher. Altitude of gage is $7,350 \mathrm{ft}$ (from topographic map).

Stage-discharge relation.--Defined by current-meter measurements below $45 \mathrm{cfs}$ and by slope-area measurements at $512 \mathrm{cfs}$.

Remarks.--No diversion above'station. Base for partial-duratior series, 130 cfs.

\begin{tabular}{|c|c|c|c|c|c|c|c|c|}
\hline $\begin{array}{l}\text { Water } \\
\text { year }\end{array}$ & Date & $\begin{array}{c}\text { Gage } \\
\text { height } \\
\text { (feet) }\end{array}$ & $\begin{array}{c}\text { Discharge } \\
\text { (cfs) }\end{array}$ & $\begin{array}{c}\text { Water } \\
\text { year }\end{array}$ & & Date & $\begin{array}{c}\text { Gage } \\
\text { reight } \\
\text { (feet) }\end{array}$ & $\begin{array}{c}\text { Discharge } \\
\text { (cfs) }\end{array}$ \\
\hline 1952 & $\begin{array}{lrl}\text { Apr. } & 6, & 1952 \\
\text { Apr. } 25, & 1952 \\
\text { Apr. } 28, & 1952 \\
\text { May } & 3, & 1952\end{array}$ & $\begin{array}{l}2.42 \\
2.76 \\
3.07 \\
2.85\end{array}$ & $\begin{array}{l}160 \\
213 \\
266 \\
222\end{array}$ & $\begin{array}{l}1958 \\
1959\end{array}$ & $\begin{array}{l}\text { May } \\
\text { May } \\
\text { Nov. }\end{array}$ & $\begin{array}{ll}11, & 1958 \\
24, & 1958 \\
23, & 1958\end{array}$ & $\begin{array}{r}2.02 \\
2.08 \\
.72\end{array}$ & $\begin{array}{r}210 \\
223 \\
12\end{array}$ \\
\hline 1953 & July 9,1953 & 1.17 & 28 & 1960 & May & 15,1960 & .76 & 12 \\
\hline 1954 & Apr. $\quad 5,1954$ & 1.20 & 27 & 1961 & Aug. & 12,1961 & 2.07 & 221 \\
\hline 1955 & June 16,1955 & 1.01 & 18 & 1962 & Feb. & 11,1962 & 2.02 & 210 \\
\hline 1956 & July 27, 1956 & 4.86 & 512 & & $\begin{array}{l}\text { Apr. } \\
\text { May }\end{array}$ & $\begin{array}{rr}19, & 1962 \\
9, & 1962\end{array}$ & $\begin{array}{l}1.69 \\
1.72\end{array}$ & $\begin{array}{l}137 \\
143\end{array}$ \\
\hline $\begin{array}{l}1957 \\
1958\end{array}$ & $\begin{array}{l}\text { June } 5,1957 \\
\text { Apr. } 20,1958 \\
\end{array}$ & $\begin{array}{l}1.43 \\
2.29\end{array}$ & $\begin{array}{r}80 \\
274 \\
\end{array}$ & 1963 & Apr. & 30,1963 & .88 & 22 \\
\hline
\end{tabular}

3270. Humboldt River near Valmy, Nev.

Location.--Lat $40^{\circ} 48^{\prime}$, long $117^{\circ} 04^{\prime}$, in NE $\frac{1}{4} \mathrm{NW} \frac{1}{4}$ sec. 30 , T.34 N., R.44 E., on left bank $3 \frac{1}{2}$ miles east of Valmy and 13 miles northwest of Battle Mountain. Drainage area. $--11,400 \mathrm{sq} \mathrm{ml}$, approximately.

Gage.--Recording. Altitude of gage is $4,440 \mathrm{ft}$ (from topographic map).

Stage-discharge relation.--Defined by current-meter measurements.

Remarks.--Diversions above station for irrigation. Flow bypassing station at high stages not included in this report. Only annual peaks are shown.

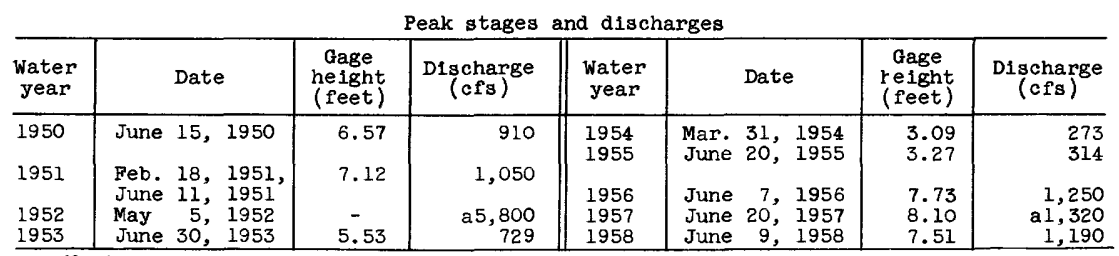

a Maximum da11y. 
3275. Humboldt River at Comus, Nev.

(Published as "near Golconda" prior to 1918)

Location.--Lat $41^{\circ} 00^{\prime \prime}$, long $117^{\circ} 19^{\prime}$, in $\mathrm{SE}_{\frac{1}{4}}$ sec.14, T.36 N., R.41 E., on left bank at Comus siding of Southern Pacific Rallroad, 9 miles northeast of Golconda and 32 miles northwest of Battle Mountain.

Drainage area. $--12,100 \mathrm{sq} \mathrm{mi}$, approximately.

Gage.--Nonrecording prior to Sept. 25, 1917, at several sites about 10 miles downstream at different datums, and Sept. 25, 1917, to June 30, 192 May 23, 1925, to May 31,1926 , at several sites within half a mile if present site at different datum; recording thereafter. Datum of gage is 4,359.9 $f^{\prime} t$ above mean sea level (from Soll Conservation Service reference merk).

Stage-discharge relation.--Defined by current-meter measurements.

Remarks.--Diversions above station for irrigation. Only annual peaks ere shown

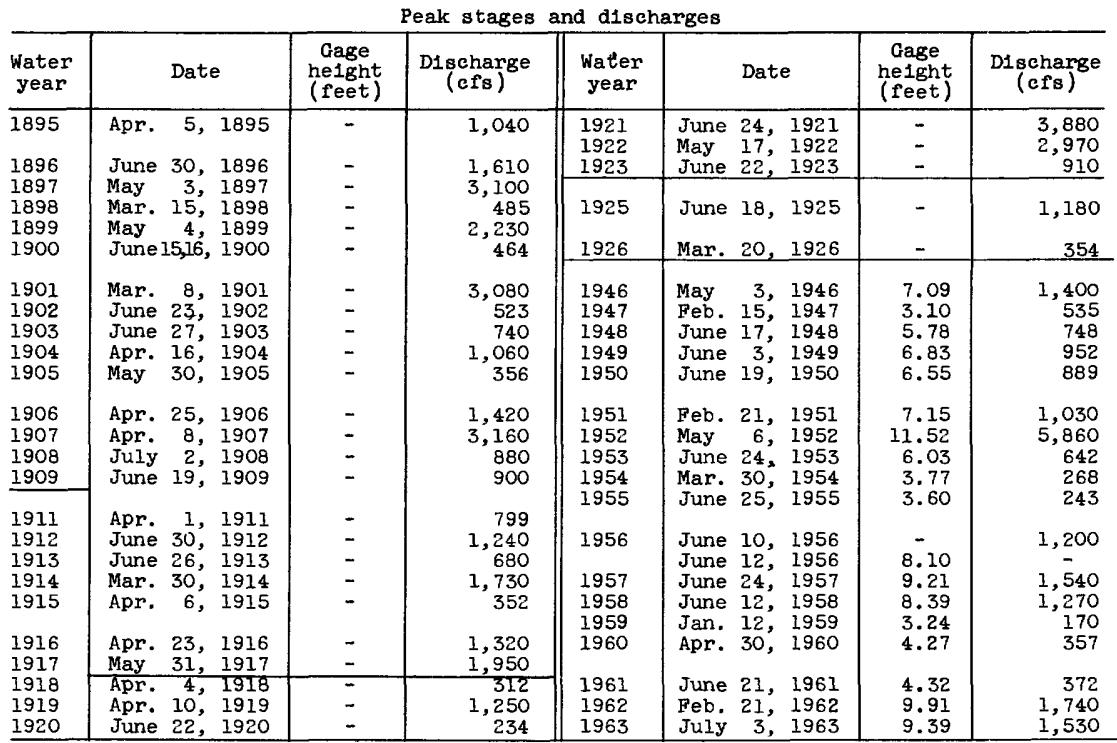

Note. --Maximum observed prior to 1946. Maximum discharge frequently occurs on several days during year. Only date of first occurence is shown.

3285. Little Humboldt River at Chimney damsite, near Paradise Valley, Nev.

Location.--Lat $41^{\circ} 24^{\prime}$, long $117^{\circ} 11^{\prime}$, in NE $\frac{1}{4}$ sec.36, T.41 N., R.42 E., at

Chimney damsite, $300 \mathrm{ft}$ downstream from confluence of North and South Forks and 25 miles east of Paradise Valley.

Drainage area.--715 sq mi, approximately. Mean altitude, 5,770 ft.

Gage.--Recording. Altitude of gage is 4,580 ft (from river-profile mar).

Stage-discharge relation.--Defined by current-meter measurements below 360 cfs and by slope-area measurement at 4,000 cfs.

Remarks.--Only annual peaks are shown. 
Peak stages and discharges of Little Humboldt River at Chimney damsite,

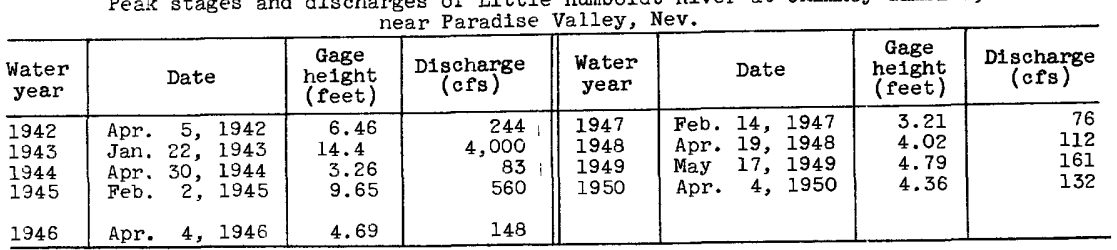

3290. Little Humboldt River near Paradise Valley, Nev.

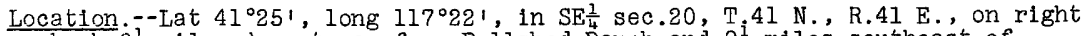
bank $3 \frac{1}{2}$ miles downstream from Bullshed Ranch and $9 \frac{1}{2}$ miles southeast of Paradise valley.

Drainage area. $--1,030 \mathrm{sq} \mathrm{mi}$, approximately.

Gage.--Recording. Prior to Nov. 21, 1946, at site 1 mile downstream at different datum. Altitude of gage is 4,470 ft (from river-profile map).

Stage-discharge relation.--1922-28: Defined by current-meter measurements below 150 cfs.

1944-46: Defined by current-meter measurements throughout range.

1946-63: Defined by current-meter measurements below 390 cfs and by float measurement at $852 \mathrm{cfs}$.

Bankfull stage.--In canyon; not subject to overflow.

Remarks.--Only annual peaks are shown.

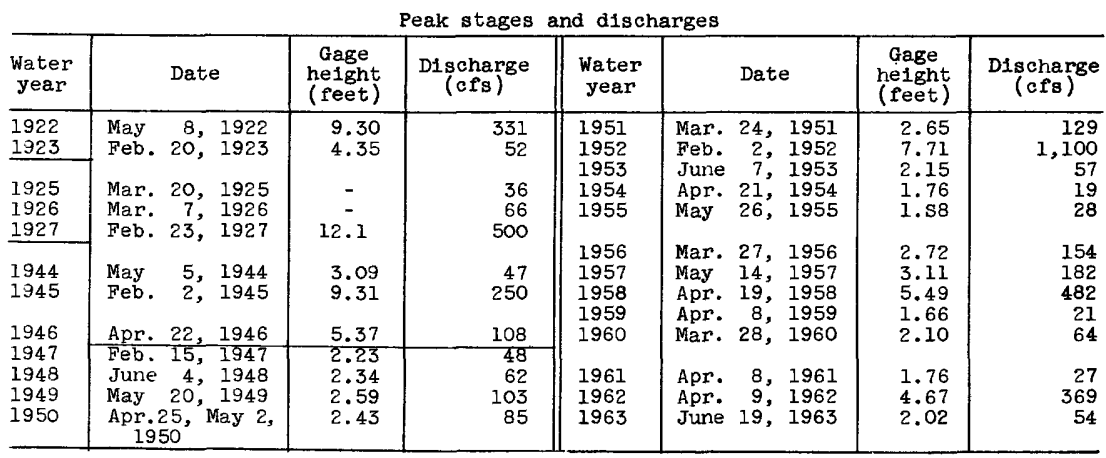

3295. Martin Creek near Paradise Valley, Nev.

Location.--Lat $41^{\circ} 32^{\prime} 00^{\prime \prime}$, long $17^{\circ} 25^{\prime} 40^{\prime \prime}$, In NW $\frac{1}{4}$ SW $\frac{1}{4}$ sec. 12 , T.42 N., R.40 E., on left bank 0.6 mile upstream from Humboldt County Recreation Park and

7 miles northeast of Paradise Valley.

Drainage area.--172 sq mi. Mean altitude, 6,210 ft.

Gage.--Recording. Prior to Oct. 22, 1946, at several sites within $400 \mathrm{ft}$ of present site at different datums. Altitude of gage is $4,700 \mathrm{ft}$ (from extension of river-profile map).

Stage-discharge relation.--Defined by slope-area measurement at 9,000 cfs. Remarks.--Only annual peaks are shown prior to 1962 ; peaks above $100 \mathrm{cfs}$ thereafter. 
Peak stages and discharges of Martin Creek near Paradise Valley, Nev.

\begin{tabular}{|c|c|c|c|c|c|c|c|}
\hline $\begin{array}{l}\text { Water } \\
\text { year }\end{array}$ & Date & $\begin{array}{c}\text { Gage } \\
\text { height } \\
\text { (feet) }\end{array}$ & $\begin{array}{c}\text { D1scharge } \\
\text { (cfs) }\end{array}$ & $\begin{array}{l}\text { Water } \\
\text { year }\end{array}$ & Date & $\begin{array}{l}\text { Gage } \\
\text { helght } \\
\text { (feet) }\end{array}$ & $\begin{array}{c}\text { Discharge } \\
(\mathrm{cfs})\end{array}$ \\
\hline $\begin{array}{l}1922 \\
1923 \\
1924 \\
1925 \\
1926\end{array}$ & 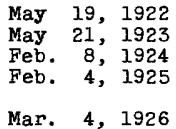 & $\begin{array}{l}- \\
\overline{-}\end{array}$ & $\begin{array}{r}275 \\
101 \\
74 \\
550\end{array}$ & $\begin{array}{l}1946 \\
1947 \\
1948 \\
1949 \\
1950\end{array}$ & $\begin{array}{l}\text { Dec. } 28,1945 \\
\text { Feb. } 12,1947 \\
\text { Jan. } 7 \text { or } 8,1948 \\
\text { Apr. } 12,1949 \\
\text { Mar. 19, } 1950\end{array}$ & $\begin{array}{l}1.99 \\
2.67 \\
2.50 \\
2.57 \\
3.17\end{array}$ & $\begin{array}{l}269 \\
296 \\
201 \\
209 \\
262\end{array}$ \\
\hline $\begin{array}{l}1926 \\
1927 \\
\end{array}$ & Feb.21,22, 1927 & & & $\begin{array}{l}1951 \\
1952\end{array}$ & Feb. 7,1951 & & $\begin{array}{l}470 \\
955\end{array}$ \\
\hline $\begin{array}{l}1929 \\
1930\end{array}$ & $\begin{array}{c}\text { May } 24,1929 \\
\text { May } 1930\end{array}$ & - & $\begin{array}{l}82 \\
85\end{array}$ & $\begin{array}{l}1953 \\
1954 \\
1955\end{array}$ & $\begin{array}{lr}\text { May } & 29,1953 \\
\text { Mar. } & 9,1954 \\
\text { Mar. } & 7,1955\end{array}$ & $\begin{array}{l}2.81 \\
2.71 \\
2.27\end{array}$ & $\begin{array}{r}174 \\
177 \\
87\end{array}$ \\
\hline $\begin{array}{l}1931 \\
1932 \\
1933 \\
\end{array}$ & $\begin{array}{l}\text { Mar. 18, } 1931 \\
\text { Mar. 19, } 1932 \\
\text { Aug. 18, } 1933\end{array}$ & $\begin{array}{l}- \\
- \\
-\end{array}$ & $\begin{array}{l}106 \\
420 \\
570\end{array}$ & $\begin{array}{l}1956 \\
1957 \\
1958\end{array}$ & $\begin{array}{ll}\text { Jan. } 15, & 1956 \\
\text { Feb. } 25, & 1957\end{array}$ & $\begin{array}{l}5.49 \\
4.21 \\
7.30\end{array}$ & $\begin{array}{r}1,200 \\
684 \\
1,940\end{array}$ \\
\hline 1935 & May 31,1935 & - & 242 & $\begin{array}{l}1959 \\
1960\end{array}$ & $\begin{array}{lll}\text { Apr. } & 4,1959 \\
\text { Mar. } & 7,1960\end{array}$ & $\begin{array}{l}1.92 \\
3.01\end{array}$ & $\begin{array}{r}71 \\
265\end{array}$ \\
\hline $\begin{array}{l}1936 \\
1937 \\
1938 \\
1939 \\
1940\end{array}$ & $\begin{array}{l}\text { Apr. } 23,1936 \\
\text { Apr. 15, } 1937 \\
\text { Apr. 19, } 1938 \\
\text { Mar. 20, } 1939 \\
\text { Feb. } 27,1940\end{array}$ & $\begin{array}{c}- \\
- \\
11.0 \\
3.90 \\
4.09\end{array}$ & $\begin{array}{r}200 \\
247 \\
1,000 \\
330 \\
441\end{array}$ & $\begin{array}{l}1961 \\
1962\end{array}$ & $\begin{array}{l}\text { Aug. } 6,1961 \\
\text { Feb. 10, } 1962 \\
\text { Mar. 19, } 1962 \\
\text { Mar. 27, } 1962 \\
\text { Apr. } 7,1962\end{array}$ & $\begin{array}{l}4.44 \\
4.21 \\
2.62 \\
4.50 \\
4.25\end{array}$ & $\begin{array}{l}780 \\
672 \\
182 \\
808 \\
708\end{array}$ \\
\hline $\begin{array}{l}1941 \\
1942 \\
1943 \\
1944 \\
1945\end{array}$ & $\begin{array}{l}\text { Mar. } 1,1941 \\
\text { Mar. } 31,1942 \\
\text { Jan. } 21,1943 \\
\text { May } 10,1944 \\
\text { Feb. } 2,1945\end{array}$ & $\begin{array}{l}3.73 \\
3.90 \\
11.1 \\
1.36 \\
5.00\end{array}$ & $\begin{array}{r}361 \\
400 \\
9,000 \\
145 \\
1,500\end{array}$ & 1963 & $\begin{array}{l}\text { Jan. } 31,1963 \\
\text { Apr. } 6,1963 \\
\text { Apr. } 30,1963 \\
\text { June 14, } 1963 \\
\text { June } 17,1963\end{array}$ & $\begin{array}{l}7.40 \\
1.83 \\
2.04 \\
1.79 \\
2.33\end{array}$ & $\begin{array}{r}3,770 \\
115 \\
151 \\
108 \\
210 \\
\end{array}$ \\
\hline
\end{tabular}

3300. Cottonwood Creek near Paradise Valley, Nev.

Location.--Lat $41^{\circ} 33^{\prime}$, long $117^{\circ} 35^{\prime}$, in SW $\frac{1}{4}$ sec.3, T.42 N., R.39 E., 5 miles northwest of Paradise Valley.

Gage.--Nonrecording. Prior to Apr. 7, 1927, at site $75 \mathrm{ft}$ downstream at different datum.

Stage-discharge relation.--Defined by current-meter measurements below $51 \mathrm{cfs}$.

Remarks.--Records for Mar. 12 to June 23, 1934, furnished by Little Humboldt River water commissioner. Only maximum observed discharges are shown.

\begin{tabular}{|c|c|c|c|c|c|c|c|c|}
\hline $\begin{array}{l}\text { Water } \\
\text { year }\end{array}$ & & Date & $\begin{array}{l}\text { Gage } \\
\text { height } \\
\text { (feet) }\end{array}$ & $\begin{array}{c}\text { Discharge } \\
\text { (cfs) }\end{array}$ & $\begin{array}{l}\text { Water } \\
\text { year }\end{array}$ & Date & $\begin{array}{c}\text { Gage } \\
\text { height } \\
\text { (feet) }\end{array}$ & $\begin{array}{c}\text { Discharge } \\
\text { (cfs) }\end{array}$ \\
\hline $\begin{array}{l}1926 \\
1927 \\
1928 \\
1929 \\
1930\end{array}$ & $\begin{array}{l}\text { May } \\
\text { Apr. } \\
\text { Mar. } \\
\text { May }\end{array}$ & $\begin{array}{ll}4, & 1926 \\
26, & 1927 \\
25, & 1928 \\
23, & 1929 \\
\text { (a) } & \end{array}$ & $\begin{array}{l}- \\
- \\
- \\
-\end{array}$ & $\begin{array}{r}22 \\
75 \\
120 \\
21 \\
18\end{array}$ & $\begin{array}{l}1931 \\
1932 \\
1933 \\
1934\end{array}$ & $\begin{array}{l}\text { Nov. 16, } 1930 \\
\text { Mar. 19, } 1932 \\
\text { June 2, } 1933 \\
\text { Mar. } 30,1934\end{array}$ & $\begin{array}{l}4.45 \\
5.80 \\
4.55 \\
-\end{array}$ & $\begin{array}{r}18 \\
183 \\
22 \\
22\end{array}$ \\
\hline
\end{tabular}

a May 27, 29, Aug. 6, 7, 1930.

3305. Cottonwood Creek at Paradise Valley, Nev.

Location.--Lat $41^{\circ} 31^{\prime} 00^{\prime \prime}$, long $117^{\circ} 32^{1} 30^{\prime \prime}$, in NW $\frac{1}{4} \sec .25$, T.42 N., R.39 E., on

right bank at highway bridge, $300 \mathrm{ft}$ west of Paradise Vailey Post office.

Drainage area. $--57.4 \mathrm{sq} \mathrm{mi}$, approximately. Mean altitude, 5,940 ft.

Gage.--Recording.

Stage-discharge relation.--Defined by current-meter measurements.

Remarks.--Only annual peaks are shown. 
Peak stages and discharges of Cottonwood Creek at Parad1se Valley, Nev.

\begin{tabular}{|c|c|c|c|c|c|c|c|}
\hline $\begin{array}{l}\text { Water } \\
\text { year }\end{array}$ & Date & $\begin{array}{l}\text { Gage } \\
\text { helght } \\
\text { (feet) }\end{array}$ & $\begin{array}{c}\text { D1scharge } \\
\text { (cfs) }\end{array}$ & $\begin{array}{l}\text { Water } \\
\text { year }\end{array}$ & Date & $\begin{array}{l}\text { Gage } \\
\text { helght } \\
(\text { feet })\end{array}$ & $\begin{array}{c}\text { D1 scharge } \\
(\mathrm{cfs})\end{array}$ \\
\hline $\begin{array}{l}1945 \\
1946 \\
1947 \\
1948 \\
\end{array}$ & $\begin{array}{lr}\text { Feb. } 14,1945 \\
\text { Dec. } 28,1945 \\
\text { Apr. } 16,1947 \\
\text { Jan. } 8,1948\end{array}$ & $\begin{array}{r}2.16 \\
2.14 \\
.74 \\
1.52 \\
\end{array}$ & $\begin{array}{r}253 \\
264 \\
16 \\
88\end{array}$ & $\begin{array}{l}1949 \\
1950 \\
1951\end{array}$ & $\begin{array}{l}\text { Mar. 15, } 1949 \\
\text { Mar. 19, } 1950 \\
\text { Feb. } 7,1951\end{array}$ & $\begin{array}{l}1.56 \\
3.16 \\
3.06\end{array}$ & $\begin{array}{r}73 \\
794 \\
720\end{array}$ \\
\hline
\end{tabular}

3315. Humboldt River near Rose Creek, Nev.

Location.--Lat $40^{\circ} 52^{\prime} 05^{\prime \prime}$, long $117^{\circ} 59^{\prime} 45^{\prime \prime}$, in SE $\frac{1}{4} N W \frac{1}{4}$ sec 36, IT.35 N., R.35 E., on right bank $5 \frac{1}{2}$ mlles southwest of Rose Creek and $15 \frac{1}{2}$ miles southwest of Winnemucca.

Drainage area. $--15,200 \mathrm{sq} \mathrm{ml}$, approximately.

Gage.--Recording. Altitude of gage is 4,200 ft (from U.S. Department of Agriculture Soll Conservation Service levels).

Stage-discharge relation.--Defined by current-meter measurements.

Remarks.--Many diversions above station for 1rrigation. Only annual peaks are shown.

\begin{tabular}{|c|c|c|c|c|c|c|c|c|}
\hline $\begin{array}{l}\text { Water } \\
\text { year }\end{array}$ & Date & $\begin{array}{c}\text { Gage } \\
\text { helght } \\
\text { (feet) }\end{array}$ & $\begin{array}{c}\text { D1scharge } \\
\text { (cfs) }\end{array}$ & $\begin{array}{l}\text { Water } \\
\text { year }\end{array}$ & & Date & $\begin{array}{l}\text { Gage } \\
\text { helght } \\
\text { (feet) }\end{array}$ & $\begin{array}{c}\text { D1scharge } \\
\text { (cfs) }\end{array}$ \\
\hline $\begin{array}{l}1948 \\
1949 \\
1950\end{array}$ & $\begin{array}{l}\text { June } 24,1948 \\
\text { June } 2,1949 \\
\text { June } 26,27,1950\end{array}$ & $\begin{array}{l}4.86 \\
4.66 \\
4.75\end{array}$ & $\begin{array}{l}708 \\
639 \\
684\end{array}$ & \multirow{2}{*}{$\begin{array}{l}1956 \\
1957 \\
1958 \\
1959 \\
1960 \\
1961 \\
1962 \\
1963\end{array}$} & \multirow{2}{*}{\multicolumn{2}{|c|}{$\begin{array}{lrr}\text { June } & 26, & 1956 \\
\text { July } & 1, & 1957 \\
\text { May } & 2, & 1958 \\
\text { Mar. } 21, & 1959 \\
\text { May } 2, & 1960 \\
& \\
\text { June } 14, & 1961 \\
\text { June } 18, & 1962 \\
\text { July } 10, & 1963\end{array}$}} & \multirow{2}{*}{$\begin{array}{l}5.06 \\
5.52 \\
5.59 \\
2.65 \\
2.48 \\
2.47 \\
5.62 \\
5.73\end{array}$} & \multirow{2}{*}{$\begin{array}{r}950 \\
1,140 \\
1,170 \\
230 \\
203 \\
\\
205 \\
1,160 \\
1,710\end{array}$} \\
\hline $\begin{array}{l}1951 \\
1952 \\
1953 \\
1954 \\
1955 \\
\end{array}$ & $\begin{array}{lrl}\text { Mar. } & 2, & 1951 \\
\text { May } 8, & 1952 \\
\text { Mar. } 27, & 1953 \\
\text { Apr. } 3, & 1954 \\
\text { June } 27, & 1955\end{array}$ & $\begin{array}{r}4.90 \\
11.41 \\
4.18 \\
2.79 \\
2.50\end{array}$ & $\begin{array}{r}747 \\
5,510 \\
644 \\
278 \\
214\end{array}$ & & & & & \\
\hline
\end{tabular}

3330. Humboldt River near Imlay, Nev.

Location.--Lat $40^{\circ} 41^{\prime} 30^{\prime \prime}$, long $118^{\circ} 12^{\prime} 10^{\prime \prime}$, in SW $\frac{1}{4} \mathrm{SE} \frac{1}{4}$ sec.25, T.33 N., R. 33 E., on right bank 1 mile upstream from Old Calahan Dam and 4 miles northwest of Imlay.

Dra1nage area. $--15,700 \mathrm{sq} \mathrm{ml}$, approximately.

Gage.--Recording. Prior to Apr. 28, 1945, at site 1 mile downstream at different datum. Apr. 28, 1945, to Aug. 20, 1947, at datum 1 ft righer. Altitude of gage is $4,130^{\circ} \mathrm{ft}$ (from Geological Survey vertical-angle kench mark).

Stage-discharge relation.--Defined by current-meter measurements.

Remarks.--Humboldt-Lovelock Irrigation, Light \& Power Co.'s feeder canal diverts water from river above station to P1tt-Taylor Reservolrs. This water is ordinarily released during 1rrigation season through Rye Patch Reservolr to Humboldt River for irrigation in Lovelock district. Flon affected by many other diversions above station for 1rrigation. Only arnual peaks are shown.

Peak stages and discharges

\begin{tabular}{|c|c|c|c|c|c|c|c|c|c|}
\hline $\begin{array}{l}\text { Water } \\
\text { year }\end{array}$ & & Date & $\begin{array}{c}\text { Gage } \\
\text { helght } \\
\text { (feet) }\end{array}$ & $\begin{array}{c}\text { D1scharge } \\
\text { (cfs) }\end{array}$ & $\begin{array}{l}\text { Water } \\
\text { year }\end{array}$ & & Date & $\begin{array}{c}\text { Gage } \\
\text { helght } \\
\text { (feet) }\end{array}$ & $\begin{array}{c}\text { Discharge } \\
(\mathrm{cfs})\end{array}$ \\
\hline $\begin{array}{l}1936 \\
1937 \\
1938 \\
1939 \\
1940 \\
1941 \\
\end{array}$ & $\begin{array}{l}\text { June } \\
\text { Apr. } \\
\text { June } \\
\text { Apr. } 2 \\
\text { June } 1 \\
\text { July }\end{array}$ & $\begin{array}{rr}4, & 1936 \\
6, & 1937 \\
9, & 1935 \\
21, & 1939 \\
18, & 1940 \\
8, & 1941 \\
\end{array}$ & $\begin{array}{l}- \\
\overline{-} \\
\overline{-}\end{array}$ & $\begin{array}{l}564 \\
405 \\
480 \\
497 \\
363 \\
558 \\
\end{array}$ & $\begin{array}{l}1945 \\
1946 \\
1947 \\
1948 \\
1949 \\
1950\end{array}$ & $\begin{array}{l}\text { May } \\
\text { May } \\
\text { June } \\
\text { June } \\
\text { June } \\
\text { July }\end{array}$ & $\begin{array}{r}31,1945 \\
15,1946 \\
20,1947 \\
25,1948 \\
6,1949 \\
2,1950\end{array}$ & $\begin{array}{l}9.49 \\
- \\
4.52 \\
4.25 \\
5.46 \\
5.49\end{array}$ & $\begin{array}{r}a 2,220 \\
a 1,210 \\
382 \\
430 \\
644 \\
648\end{array}$ \\
\hline
\end{tabular}

a Maximum da11y. 
Peak stages and discharges of Humboldt River near Imlay, Nev,--Continued

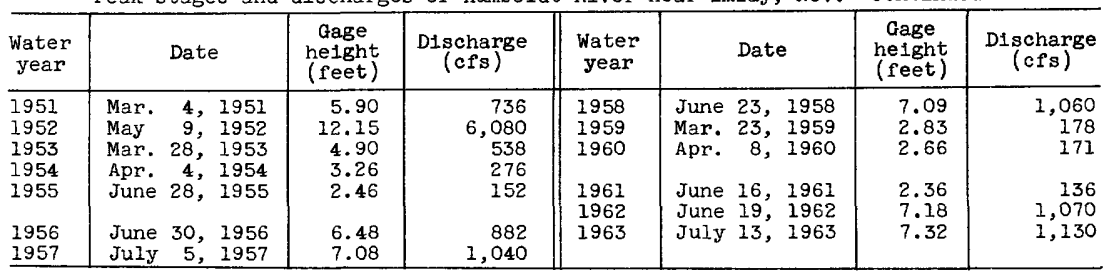

3350. Humboldt River near Rye Patch, Nev.

(Published as "near Oreana" prior to 1935)

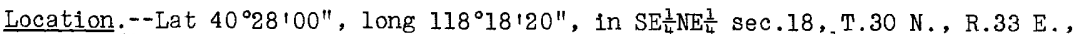
on left bank 1,000 ft downstream from Rye Patch Dam and $1 \frac{1}{2}$ miles northwest of Rye Patch.

Drainage area. $--16,100 \mathrm{sq} \mathrm{mi}$, approximately.

Gage.--Recording or nonrecording prior to oct. 1, 1935, at several sites about 7 miles downstream at different datums; recording thereafter. oct. ]., 1935 , to 0ct. 13, 1945, at site half a mile downstream at different datum. Datum of gage is $4,068.53 \mathrm{ft}$ above mean sea level (levels by Bureau of Reclamation).

Stage-discharge relation.--Defined by current-meter measurements.

Bankfull stage.--Not subject to overflow.

Remarks.--Flow regulated by Rye Patch Reservoir. Only annual peaks are shown (maximum observed prior to 1914).

Peak stages and discharges

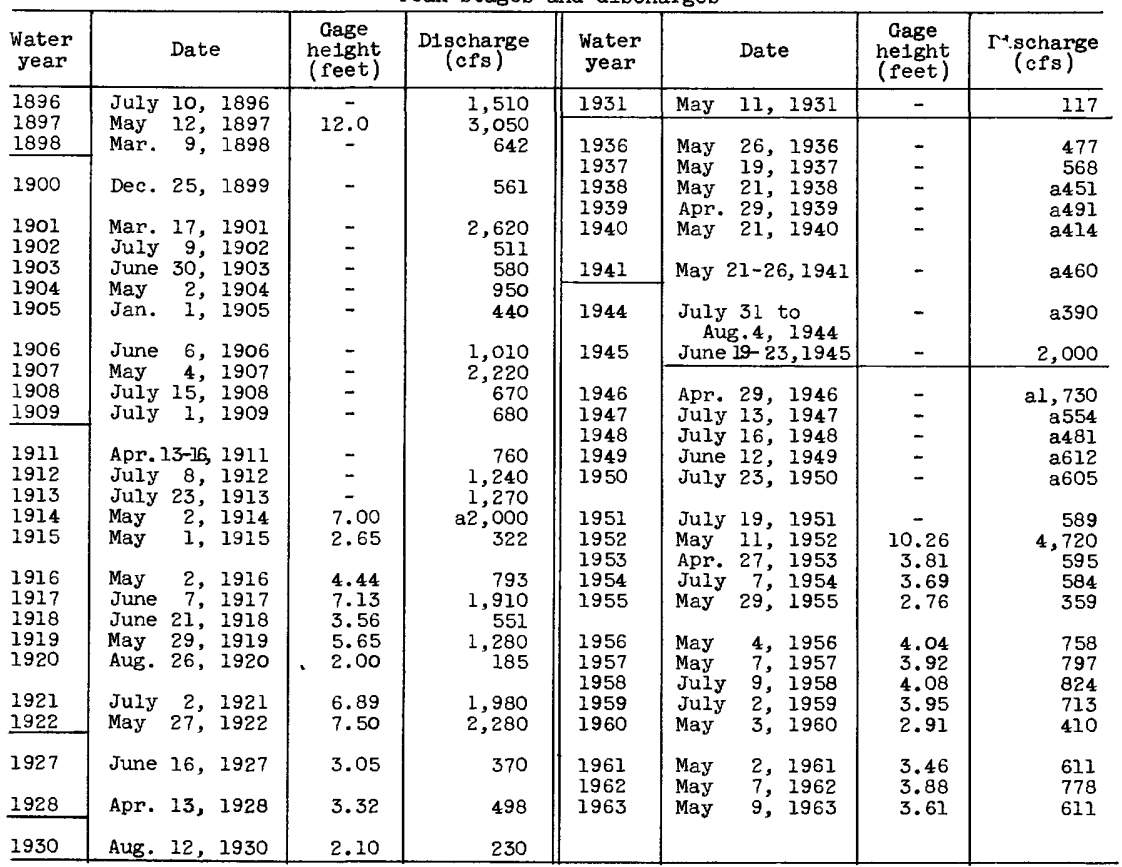

a Maximum daily. 
3360. Humboldt River near Lovelock, Nev.

Location.--Lat $40^{\circ} 03^{\prime} 05^{\prime \prime}$, long $118^{\circ} 28^{1} 05^{\prime \prime}$, in $\mathrm{SE}_{\frac{1}{4}} \mathrm{NW} \frac{1}{4}$ sec.11, T.25 N., R. 31 E., on right bank $900 \mathrm{ft}$ downstream from breached dam of Loveloc's Land and Development Co. and 9 miles south of Lovelock.

Drainage area.--16,600 sq $\mathrm{ml}$, approximately.

Gage.--Recording. Prior to September 1927, $600 \mathrm{ft}$ downstream at different

datum; 1950-51, $300 \mathrm{ft}$ upstream at same datum. Alt1tude of gage 1s $3,900 \mathrm{ft}$ (from topographic map).

Stage-discharge relation.--Defined by current-meter measurements.

Bankfull stage. $--8 \mathrm{ft}^{\prime}$.

Remarks.--Peak flow affected by 1rrigation in Lovelock Valley and regulation by Rye Patch Reservolr since Feb. 20, 1936. Only annual peaks are shown.

\begin{tabular}{|c|c|c|c|c|c|c|c|c|}
\hline $\begin{array}{l}\text { Water } \\
\text { year }\end{array}$ & & Date & $\begin{array}{c}\text { aage } \\
\text { helght } \\
\text { (feet) }\end{array}$ & $\begin{array}{c}\text { D1scharge } \\
(\text { cfs })\end{array}$ & $\begin{array}{l}\text { Water } \\
\text { year }\end{array}$ & Date & $\begin{array}{c}\text { Cage } \\
\text { helght } \\
\text { (feet) }\end{array}$ & $\begin{array}{c}\text { Discharge } \\
(\mathrm{cfs})\end{array}$ \\
\hline \multirow{2}{*}{$\begin{array}{l}1912 \\
1913 \\
1314 \\
1915\end{array}$} & \multirow{2}{*}{$\begin{array}{l}\text { July } \\
\text { June } \\
\text { May } \\
\text { Mar. }\end{array}$} & \multirow{2}{*}{$\begin{array}{cc}12, & 1912 \\
13, & 1913 \\
4, & 1914 \\
5, & 1915\end{array}$} & \multirow{2}{*}{$\begin{array}{l}- \\
- \\
5.15 \\
1.34\end{array}$} & \multirow{2}{*}{$\begin{array}{r}640 \\
323 \\
1,450 \\
270\end{array}$} & 1927 & - & - & 0 \\
\hline & & & & & \multirow[b]{2}{*}{$\begin{array}{l}1950 \\
1951 \\
1952 \\
1953 \\
1954 \\
1955\end{array}$} & July 26, 1950 & \multirow[b]{2}{*}{$\begin{array}{l}3.92 \\
4.27 \\
9.36 \\
2.69 \\
3.28 \\
1.38\end{array}$} & $\mathrm{~b} 50$ \\
\hline $\begin{array}{l}1916 \\
1917 \\
1918 \\
1919 \\
1920\end{array}$ & $\begin{array}{l}\text { Mar. } \\
\text { June } \\
\text { Feb. }\end{array}$ & $\begin{array}{ll}17, & 1916 \\
19, & 1917 \\
24, & 1918 \\
- & \\
- & \end{array}$ & $\begin{array}{l}1.29 \\
5.40 \\
1.74 \\
- \\
-\end{array}$ & $\begin{array}{r}257 \\
a 1,170 \\
255 \\
0 \\
0\end{array}$ & & $\begin{array}{lll}\text { July } & 24, & 1951 \\
\text { May } & 19, & 1952 \\
\text { Mar. } 19, & 1953 \\
\text { Aug. } 24, & 1954 \\
\text { June } 20, & 1955\end{array}$ & & \multirow{3}{*}{$\begin{array}{c}60 \\
3,540 \\
109 \\
188 \\
6.3 \\
64 \\
130 \\
119 \\
104\end{array}$} \\
\hline $\begin{array}{l}1921 \\
1922 \\
\end{array}$ & \multirow[t]{2}{*}{$\begin{array}{l}\text { July } \\
\text { May }\end{array}$} & \multirow[t]{2}{*}{$\begin{array}{rr}6, & 1921 \\
29, & 1922\end{array}$} & $\begin{array}{l}5.51 \\
5.90\end{array}$ & \multirow{2}{*}{$\begin{array}{r}1,540 \\
1,700 \\
0\end{array}$} & \multirow{2}{*}{$\begin{array}{l}1956 \\
1957 \\
1958 \\
1959\end{array}$} & \multirow{2}{*}{ 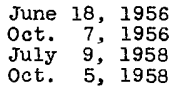 } & \multirow{2}{*}{$\begin{array}{l}3.16 \\
3.47 \\
3.78 \\
3.17\end{array}$} & \\
\hline 1925 & & & & & & & & \\
\hline 1926 & Feb. & 19,1926 & - & al72 & & & & \\
\hline
\end{tabular}

a Maximum observed.

b Maximum discharge during period June to September.

PYRAMID AND WINNEMUCCA LAKES BASIN

3375. Truckee River at Tahoe City, Calif.

(Published as at "Tahoe, Calif." prior to 1962 )

Location.--Lat $39^{\circ} 10^{\prime} 00^{\prime \prime}$, long $120^{\circ} 08^{\prime} 40^{\prime \prime}$, in $\mathrm{NE} \frac{1}{4} \mathrm{NW} \frac{1}{4}$ sec.7, T.15 N., R.17 E., at Tahoe City, on left bank $510 \mathrm{ft}$ downstream from dam at outlet of Lake Tahoe.

Drainage area. $--507 \mathrm{sq} \mathrm{mi}$.

Gage.--Nonrecording prior to Oct. 1, 1937; recording thereafter. Prior to Nov. 12,1912 , at site $370 \mathrm{ft}$ upstream at different datum. Nov. 12,1912 , to Aug. 21, 1957, at datum $2.26 \mathrm{ft}$ higher, and Aug. 22,1957 , to July 10 , 1960 , at datum $2.42 \mathrm{ft}$ higher, both at site $270 \mathrm{ft}$ upstream. Datum of gage is $6,216.75 \mathrm{ft}$ above mean sea level, datum of 1929 .

Stage-discharge relation.--Defined by current-meter measurements.

Remarks.--Flow regulated by Lake Tahoe. Records for January 1944 to August 1957 furnished by Truckee-Carson Irrigation District and Federal Court

Watermaster. Only annual peaks are shown (maximum daily prior to 1958 ).

\begin{tabular}{|c|c|c|c|c|c|c|c|}
\hline $\begin{array}{l}\text { Water } \\
\text { year }\end{array}$ & Date & $\begin{array}{c}\text { Gage } \\
\text { helght } \\
\text { (feet) }\end{array}$ & $\begin{array}{c}\text { Discharge } \\
\text { (cfs) }\end{array}$ & $\begin{array}{l}\text { Water } \\
\text { year }\end{array}$ & Date & $\begin{array}{c}\text { Gage } \\
\text { helght } \\
\text { (feet) }\end{array}$ & $\begin{array}{c}\text { Discharge } \\
\text { (cfs) }\end{array}$ \\
\hline $\begin{array}{l}1901 \\
1902 \\
1903 \\
1904 \\
1905\end{array}$ & $\begin{array}{l}\text { Aug. 11, } 1901 \\
\text { Aug. 14, } 1902 \\
\text { Sept. 3, } 1903 \\
\text { June 19, } 1904 \\
\text { Oet. 20, } 1904\end{array}$ & $\begin{array}{l}- \\
- \\
- \\
-\end{array}$ & $\begin{array}{l}555 \\
445 \\
426 \\
931 \\
790\end{array}$ & $\begin{array}{l}1908 \\
1909 \\
1910 \\
1911 \\
1912\end{array}$ & $\begin{array}{lr}\text { Oct. } & 1,1907 \\
\text { June } 20, & 1909 \\
\text { Jan. } 2, & 1910 \\
\text { July } 20, & 1911 \\
\text { Dec. 29, } 1911 \\
\end{array}$ & $\begin{array}{l}\overline{-} \\
\overline{-} \\
\overline{-}\end{array}$ & $\begin{array}{r}1,210 \\
869 \\
898 \\
\\
861 \\
617 \\
\end{array}$ \\
\hline $\begin{array}{l}1906 \\
1907\end{array}$ & $\begin{array}{l}\text { Aug. } 18,1906 \\
\text { July 13, } 1907\end{array}$ & - & $\begin{array}{r}831 \\
1,340\end{array}$ & $\begin{array}{l}1913 \\
1914\end{array}$ & $\begin{array}{lll}\text { Aug. } & 25, & 1913 \\
\text { July } & 4, & 1914\end{array}$ & $\overline{-}$ & $\begin{array}{l}520 \\
618\end{array}$ \\
\hline
\end{tabular}


Peak stages and discharges of Truckee River at Tahoe C1ty, Cal1f.--Continied

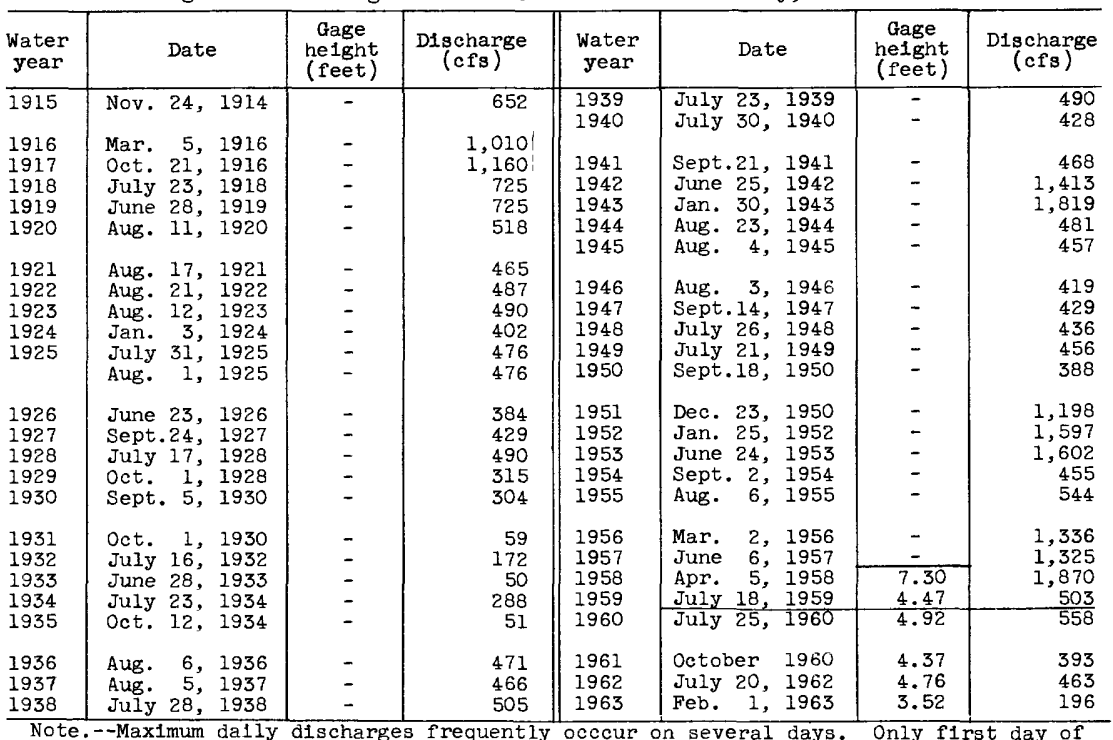

Note.--Maximum dally discharges frequently occcur on several days. Only flrst day of occurence is show.

3380. Truckee River near Truckee, Calif.

Location.--Lat $39^{\circ} 17^{\prime} 30^{\prime \prime}$, long $120^{\circ} 12^{\prime} 30^{\prime \prime}$, in $\mathrm{SW}_{\frac{1}{4}} \mathrm{NE} \frac{1}{4} \sec .28, \mathrm{~T} .17 \mathrm{~N} ., \mathrm{R} .16$ E., on left bank 1.4 miles upstream from Donner Creek and 2.5 miles southwest of Truckee.

Drainage area. $--552 \mathrm{sq} \mathrm{m}_{\perp}$

Gage.--Recording prior to 1962 ; crest-stage gage thereafter. Altitude of gage is 5,860 ft (from topographic map).

Stage-discharge relation.--Defined by current-meter measurements below 2,400 cfs and extended above on basis of slope-area measurements at 6,480 cfs and 8,140 cfs.

Bankfull stage. $--7 \mathrm{ft}$.

Remarks.--Flow regulated by Lake Tahoe (operating capacity, 744,600 acre-ft). OnIy annual peaks are shown.

Peak stages and discharges

\begin{tabular}{|c|c|c|c|c|c|c|c|}
\hline $\begin{array}{l}\text { Water } \\
\text { year }\end{array}$ & Date & $\begin{array}{c}\text { Gage } \\
\text { helght } \\
\text { (feet) }\end{array}$ & $\begin{array}{c}\text { Discharge } \\
\text { (cfs) }\end{array}$ & $\begin{array}{l}\text { Water } \\
\text { year }\end{array}$ & Date & $\begin{array}{c}\text { Gage } \\
\text { helght } \\
\text { (feet) }\end{array}$ & $\begin{array}{l}\text { E1scharge } \\
\text { (cfs) }\end{array}$ \\
\hline 1945 & Feb. 2,1945 & 3.34 & 1,110 & $\begin{array}{l}1954 \\
1955\end{array}$ & $\begin{array}{lll}\text { Mar. } & 9,1954 \\
\text { Aug. } & 8,1955\end{array}$ & $\begin{array}{l}3.88 \\
2.51\end{array}$ & $\begin{array}{r}1,540 \\
552\end{array}$ \\
\hline $\begin{array}{l}1946 \\
1947 \\
1948 \\
1949 \\
1950\end{array}$ & $\begin{array}{ll}\text { Apr. } 25, & 1946 \\
\text { Nov. } 23,1946 \\
\text { Oct. } 16,1947 \\
\text { May } 14,1949 \\
\text { Jan. } 22,1950\end{array}$ & $\begin{array}{c}2.95 \\
2.70 \\
2.75 \\
- \\
a 5.00\end{array}$ & $\begin{array}{l}838 \\
677 \\
708 \\
671 \\
700\end{array}$ & $\begin{array}{l}1956 \\
1957 \\
1958 \\
1959 \\
1960\end{array}$ & $\begin{array}{l}\text { Dec. } 23,1955 \\
\text { June } 5,1957 \\
\text { May 18, } 1958 \\
\text { Sept.18, } 1959 \\
\text { Feb. 8, } 1960\end{array}$ & $\begin{array}{l}7.92 \\
4.24 \\
5.31 \\
2.58 \\
3.38\end{array}$ & $\begin{array}{r}7,760 \\
2,040 \\
2,920 \\
576 \\
1,190\end{array}$ \\
\hline $\begin{array}{l}1951 \\
1952 \\
1953\end{array}$ & $\begin{array}{l}\text { Nov. } 20,1950 \\
\text { June } 5,1952 \\
\text { June } 23,1953\end{array}$ & $\begin{array}{l}7.62 \\
5.08 \\
4.40\end{array}$ & $\begin{array}{l}6,480 \\
2,640 \\
1,990\end{array}$ & $\frac{1961}{1963}$ & $\begin{array}{l}\text { Oct. } 1,1960 \\
\text { Feb. } 1,1963\end{array}$ & $\begin{array}{l}2.25 \\
9.25\end{array}$ & $\begin{array}{r}390 \\
11,000\end{array}$ \\
\hline
\end{tabular}

a Backwater from 1ce.

785-975 O-66-15 
3385. Donner Creek at Donner Lake, near Truckee, Cal1f.

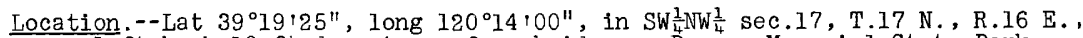
on left bank $10 \mathrm{ft}$ downstream from bridge on Donner Memorial State Park road, $0.2 \mathrm{mile}$ downstream from Donner Lake outlet, 0.7 mile upstream from Cold Creek, and $2 \frac{1}{2}$ miles west of Truckee.

Drainage area. $--14.5 \mathrm{sq} \mathrm{mi}$.

Gage.--Nonrecording Nov. 1, 1909, to Aug. 31, 1910, at different datum; recording thereafter. January 1929 to December 1957, at same site at unknown datum. Altitude of gage is $5,930 \mathrm{ft}$ (from topographic map).

Stage-discharge relation.--Defined by current-meter measurements at present site and datum.

Remarks. --Records prior to October 1958 fumished by Federal Court Watermaster in cooperation with Truckee-Carson Irrigation District. Flow regulated by dam at outlet of Donner Lake (usable capacity, 9,500 acre-f';). Only annual peaks are shown.

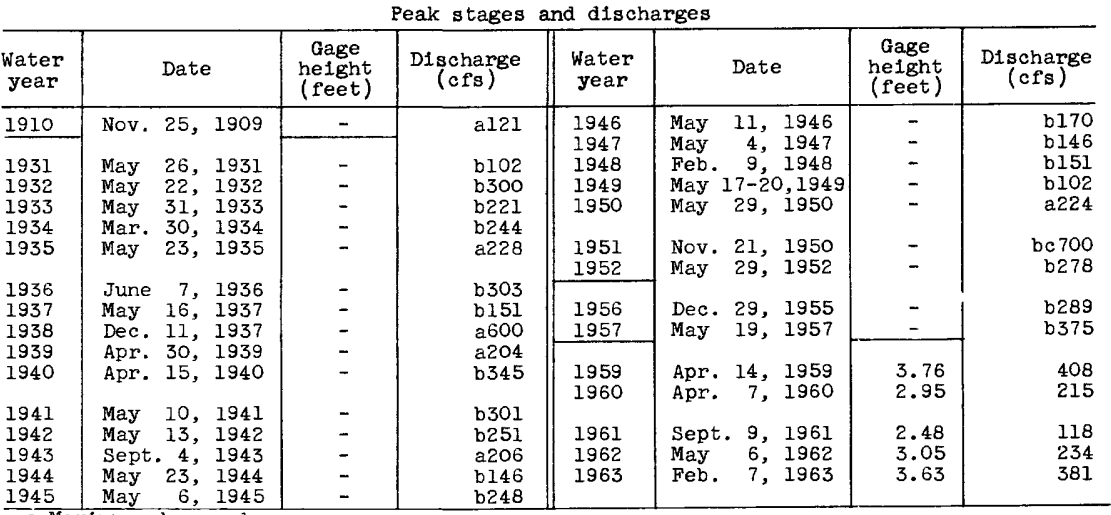

a Maximum observed.

b Maximum daily.

c Estimated.

3390. Donner Creek near Truckee, Calif.

Location.--Lat $39^{\circ} 19^{\prime} 15^{\prime \prime}$, long $120^{\circ} 12^{\prime} 10^{\prime \prime}$, in SE $\frac{1}{4}$ sec.16, T.17 N., R.16 E., 1 mile downstream from Cold Creek, 1.5 miles southwest of Truckee, and

2 miles downstream from Donner lake.

Drainage area. - -30 sq mi, approximately.

Gage.--Nonrecording prior to Sept. 30, 1915; recording thereaf ser. Prior to Sept. 12, 1909, at site $40 \mathrm{ft}$ upstream at different datum. Altitude of gage is $5,850 \mathrm{ft}$ (from topographic map).

Stage-discharge relation.--Defined by current-meter measurements.

Remarks.--Flow regulated by Donner Lake. Records for 1928-43, furnished by Truckee-Carson Irrigation District and Federal Court Watermaster. Only annual peaks are shown.

\begin{tabular}{|c|c|c|c|c|c|c|c|c|}
\hline $\begin{array}{l}\text { Water } \\
\text { year }\end{array}$ & & Date & $\begin{array}{c}\text { Gage } \\
\text { helght } \\
\text { (feet) }\end{array}$ & $\begin{array}{c}\text { Discharge } \\
\text { (cfs) }\end{array}$ & $\begin{array}{c}\text { Water } \\
\text { year }\end{array}$ & Date & $\begin{array}{c}\text { Gage } \\
\text { helght } \\
\text { (feet) }\end{array}$ & $\begin{array}{c}\text { Discharge } \\
(\mathrm{cfs})\end{array}$ \\
\hline $\begin{array}{l}1903 \\
1904\end{array}$ & May & $\begin{array}{ll}13, & 1903 \\
22, & 1904\end{array}$ & $\overline{-}$ & $\begin{array}{l}2478 \\
a 709\end{array}$ & 1910 & \multirow{4}{*}{$\begin{array}{lr}\text { Dec. } 1, & 1909 \\
\text { June 13, } 1911 \\
\text { June 3, } 1912 \\
\text { Aug. 12, } 1913 \\
\text { June 2, } 1914 \\
\text { May 13, } 1915\end{array}$} & \multirow{4}{*}{$\begin{array}{l}- \\
- \\
- \\
- \\
-\end{array}$} & \multirow{4}{*}{$\begin{array}{l}\text { a.862 } \\
\text { a.670 } \\
\text { a350 } \\
\text { a } 278 \\
\text { b } 510 \\
\text { b } 518\end{array}$} \\
\hline 1905 & Apr. & 27,1905 & - & a290 & $\begin{array}{l}1911 \\
1912\end{array}$ & & & \\
\hline $\begin{array}{l}1906 \\
1907\end{array}$ & $\begin{array}{l}\text { May } \\
\text { Mar. }\end{array}$ & $\begin{array}{ll}21, & 1906 \\
18, & 1907\end{array}$ & 5.5 & $\begin{array}{l}\text { a } 698 \\
\text { b } 980\end{array}$ & $\begin{array}{l}1913 \\
1914\end{array}$ & & & \\
\hline $\begin{array}{l}1908 \\
1909\end{array}$ & $\begin{array}{l}\text { Apr. } \\
\text { Jan. }\end{array}$ & $\begin{array}{ll}20, & 1908 \\
16, & 1909\end{array}$ & - & $\begin{array}{l}\text { a224 } \\
\text { a812 }\end{array}$ & 1915 & & & \\
\hline
\end{tabular}


Peak stages and discharges of Donner Creek near Truckee, Cal1f.--Continued

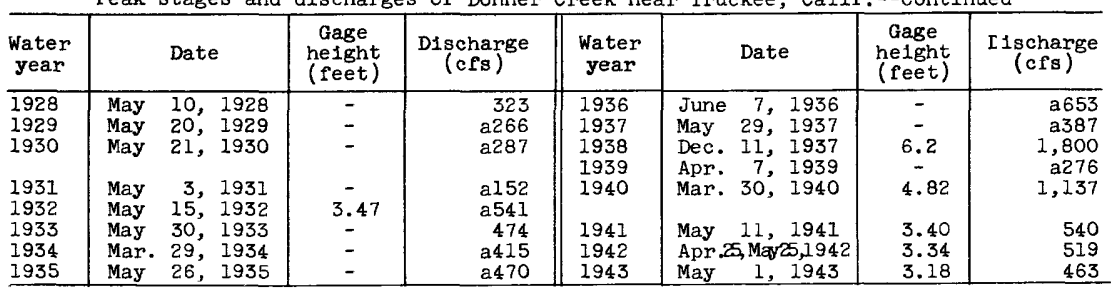

a Maximum daily.

3394. Martis Creek near Truckee, Calif.

Location.--Lat $39^{\circ} 20^{\prime} 20^{\prime \prime}$, long $120^{\circ} 07^{1} 00^{\prime \prime}$, in $\mathrm{SE}_{\frac{1}{4}} \mathrm{NW} \frac{1}{4}$ sec.8, T.17 N, R.17 E., on left bank three-quarters of a mile upstream from mouth and $3 \frac{i}{2}$ 'miles northeast of Truckee.

Drainage area. $--40.8 \mathrm{sq} \mathrm{mi}$.

Gage.--Recording. Altitude of gage is 5,700 ft (from topographic map).

Stage-discharge relation.--Defined by current-meter measurements below 500 cfs and extended above on basis of slope-area measurement at $1,880 \mathrm{cfs}$.

Bankfull stage.--Not subject to overflow.

Remarks.--Base for partial-duration series, $170 \mathrm{cfs}$.

Peak stages and discharges

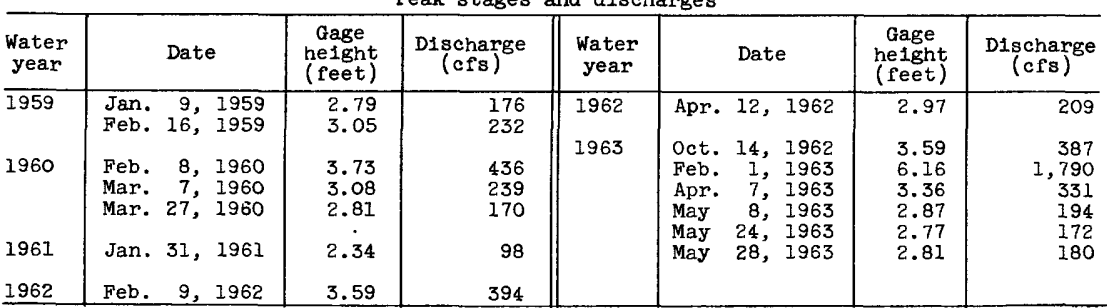

3397. Prosser Creek at Hobart Mills, Calif.

Location.--Lat $39^{\circ} 24^{1} 00^{\prime \prime}$, long $120^{\circ} 12^{10} 00^{\prime \prime}$, in $\mathrm{NE} \frac{1}{4} \mathrm{NE} \frac{1}{4}$ sec.21, T.18 N., R.16 E., on left bank $0.8 \mathrm{mile}$ west of Hobart Mills, 3 miles upstream from Alder Creek, and 5 miles north of Truckee.

Drainage area. $--27.4 \mathrm{sq} \mathrm{mi}$.

Gage.--Recording prior to Jan. 5, 1963, $40 \mathrm{ft}$ upstream at different datum; nonrecording read monthly thereafter. Altitude of gage is $5,840 \mathrm{ft}$ (fron topographic map).

Stage-discharge relation.--Defined by current-meter measurements below $240 \mathrm{cfs}$ and extended above on basis of slope-area measurements at $1,880 \mathrm{cfs}$ and 4,920 cfs.

Bankfull stage.--Not subject to overflow.

Remarks.--Base for partial-duration series, $200 \mathrm{cfs}$. 
Peak stages and discharges of Prosser Creek at Hobart Mills, Calif.

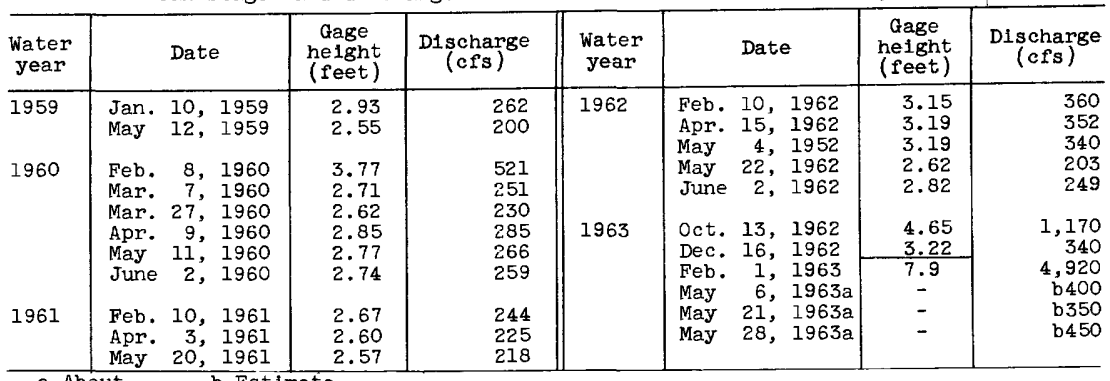

a. About. b Estimate.

3399. Alder Creek near Truckee, Calif.

Location.--Lat $39^{\circ} 22^{\prime} 10^{\prime \prime}$, Iong $120^{\circ} 10^{\prime} 50^{\prime \prime}$, in $\mathrm{SE}_{\frac{1}{4}} \mathrm{NE}_{\frac{1}{4}}$ sec.34, T.18 N., R.16 E., on right bank 2 miles upstream from mouth and $2 \frac{1}{2}$ miles nortr of Truckee.

Drainage area. $--7.36 \mathrm{sq} \mathrm{mi}$.

Gage.--Recording. Altitude of gage is 5,800 ft (from topograpric map).

Stage-discharge relation.--Defined by current-meter measurements below 36 cfs and extended above on basis of culvert measurement at $730 \mathrm{cfs}$.

Bankfull stage. $--6 \mathrm{ft}$.

Remarks.--Base for partial-duration series, $25 \mathrm{cfs}$.

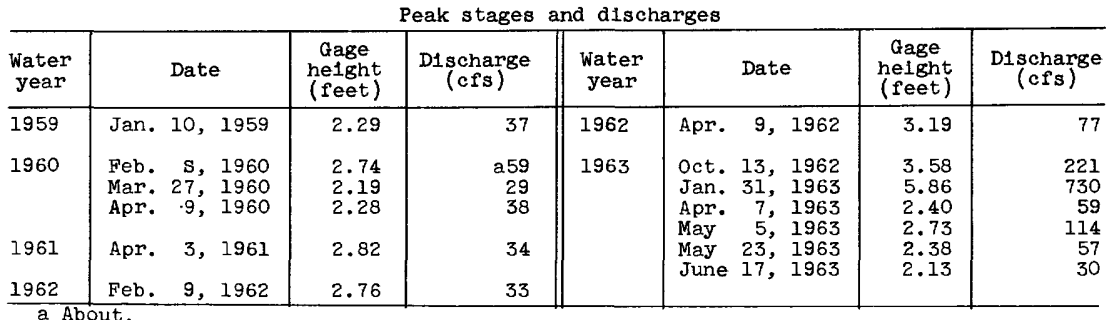

3400. Prosser Creek near Truckee, Calif.

(Published as "near Hobart Mills" prior to igll)

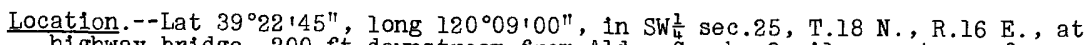
highway bridge, $200 \mathrm{ft}$ downstream from Alder Creek, 2 miles upstream from mouth, and 4 miles north of Truckee.

Drainage area. $--48 \mathrm{sq} \mathrm{mi}$, approximately.

Gage:--Nonrecording. Prior to June 1, 1911, in vicinity of described site at different datums. Altitude of gage is 5,650 ft (from topographic map).

Stage-discharge relation.--Unknown.

Remarks.--Only annual peaks are shown.

Peak stages and discharges

\begin{tabular}{c|c|c|c||c|c|c|c}
\hline $\begin{array}{c}\text { Water } \\
\text { year }\end{array}$ & Date & $\begin{array}{c}\text { Gage } \\
\text { helght } \\
\text { (feet) }\end{array}$ & $\begin{array}{c}\text { D1scharge } \\
\text { (cfs) }\end{array}$ & $\begin{array}{c}\text { Water } \\
\text { year }\end{array}$ & Date & $\begin{array}{c}\text { Gage } \\
\text { helght } \\
\text { (feet) }\end{array}$ & $\begin{array}{c}\text { D1scharge } \\
\text { (cfs) }\end{array}$ \\
\hline 1904 & Feb. 24, 1904 & 5.1 & al,100 & 1910 & Nov. 21, 1909 & 5.3 & b900 \\
\hline 1908 & June 12, 1908 & 4.1 & b221 & 1911 & June 5, 1911 & 4.9 & b675 \\
1909 & Jan. 16, 1909 & 5.8 & al,360 & 1912 & May 12, 1912 & 3.2 & c123 \\
\hline
\end{tabular}

a Maximum observed.

b Maximum da1ly.

c Maximum observed prior to June 1, 1912 . 
3405. Prosser Creek near Boca, Cal1f.

Location.--Lat $39^{\circ} 22^{\prime} 10^{\prime \prime}$, long $120^{\circ} 07110^{\prime \prime}$, in SW $\frac{1}{4} \mathrm{NW} \frac{1}{4} \mathrm{sec} .32$, T.18 N., R.17 E., on left bank a quarter of a mile upstream from mouth and 2 miles southwest' of Boca.

Drainage area. $--53.5 \mathrm{sq} \mathrm{ml}$. Mean altitude, 6,670 ft.

Gage.--Recording. October 1942 to December 1950 at different datum. June 1951 to September 1956 at datum $2.00 \mathrm{ft}$ higher. Datum of gage is $5,572.66 \mathrm{ft}$ above mean sea level (levels by Bureau of Reclamation).

Stage-discharge relation.--Defined by current-meter measurements below $910 \mathrm{cfs}$ and by slope-area measurement at 4,560 cfs.

Remarks.--Records for October 1942 to December 1950, not published by Geological Survey prior to listing in WSP 1734, furnished by Federal Court Watermaster in cooperation with Bureau of Reclamation, for "Prosser Creek near confluence with Truckee River." Base for partial-duration series, $300 \mathrm{cfs}$. Only annual peaks are shown prior to 1951.

Peak stages and discharges

\begin{tabular}{|c|c|c|c|c|c|c|c|}
\hline $\begin{array}{l}\text { Water } \\
\text { year }\end{array}$ & Date & $\begin{array}{l}\text { Gage } \\
\text { height } \\
\text { (feet) }\end{array}$ & $\begin{array}{c}\text { Discharge } \\
\text { (cfs) }\end{array}$ & $\begin{array}{l}\text { Water } \\
\text { year }\end{array}$ & Date & $\begin{array}{c}\text { Gage } \\
\text { helght } \\
\text { (feet) }\end{array}$ & $\begin{array}{c}\text { Discharge } \\
(\text { cfs })\end{array}$ \\
\hline $\begin{array}{l}1943 \\
1944 \\
1945\end{array}$ & 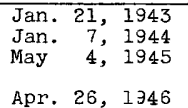 & $\begin{array}{l}- \\
- \\
-\end{array}$ & $\begin{array}{r}\mathrm{a} 472 \\
433 \\
635 \\
\\
\mathrm{a} 467\end{array}$ & 1956 & $\begin{array}{lrr}\text { Jan. } & 16, & 1956 \\
\text { Apr. } & 9, & 1956 \\
\text { Apr. } & 24, & 1956 \\
\text { May } & 4, & 1956 \\
\text { May } & 23, & 1956\end{array}$ & $\begin{array}{l}2.31 \\
1.39 \\
1.33 \\
2.35 \\
2.54\end{array}$ & $\begin{array}{l}800 \\
345 \\
506 \\
765 \\
860\end{array}$ \\
\hline 1947 & May 3,1947 & - & a228 & & May 23,1500 & & \\
\hline 1948 & Apr. 17, 1948 & - & a290 & 1957 & Feb. 25, 1957 & - & 360 \\
\hline 1950 & May $25,28,1950$ & - & a 420 & & May 18,1957 & 5.29 & 1,300 \\
\hline 1951 & Nov. 20,1950 & $\mathrm{~b} 11.0$ & 4,320 & & 2,1957 & 3.60 & 430 \\
\hline 1952 & $\begin{array}{lrl}\text { Apr. } & 7, & 1352 \\
\text { May } & 2, & 1952 \\
\text { May } & 20, & 1952 \\
\text { June } & 24, & 1952\end{array}$ & $\begin{array}{l}3.26 \\
5.14 \\
4.66 \\
3.56\end{array}$ & $\begin{array}{r}325 \\
1,130 \\
872 \\
412\end{array}$ & 1958 & $\begin{array}{ll}\text { Feb. } 25,1958 \\
\text { Apr. } 21,1958 \\
\text { May 10, } 1958 \\
\text { May 18, } 1958 \\
\text { June 19, } 1958\end{array}$ & $\begin{array}{l}3.86 \\
3.94 \\
4.48 \\
4.74 \\
3.57\end{array}$ & $\begin{array}{l}515 \\
580 \\
850 \\
950 \\
420\end{array}$ \\
\hline 1953 & $\begin{array}{l}\text { Jan. 10, } 1953 \\
\text { Apr. } 27,1953\end{array}$ & $\begin{array}{l}3.96 \\
4.72\end{array}$ & $\begin{array}{l}557 \\
903\end{array}$ & 1959 & Jan. 12,1959 & 3.11 & 264 \\
\hline & $\begin{array}{lll}\text { May 19, } 1953 \\
\text { June } 7, & 1953 \\
\text { June } 19, & 1953\end{array}$ & $\begin{array}{l}3.86 \\
3.41 \\
3.71\end{array}$ & $\begin{array}{l}518 \\
366 \\
463\end{array}$ & 1960 & 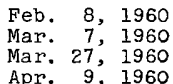 & $\begin{array}{l}- \\
3.43 \\
3.53 \\
3.43\end{array}$ & $\begin{array}{l}860 \\
360 \\
396 \\
360\end{array}$ \\
\hline 1954 & $\begin{array}{l}\text { Mar. } 9,1954 \\
\text { Apr. } 22,1954 \\
\text { May } 9,1954\end{array}$ & $\begin{array}{l}5.18 \\
3.46 \\
3.47\end{array}$ & $\begin{array}{r}1,150 \\
381 \\
384\end{array}$ & 1961 & Feb. 10, 1961 & 3.26 & 312 \\
\hline & May 19,1954 & 3.24 & 319 & 1962 & $\begin{array}{l}\text { Apr. } 15,1962 \\
\text { Apr. } 27,1962\end{array}$ & $\begin{array}{l}4.22 \\
3.78\end{array}$ & $\begin{array}{l}640 \\
431\end{array}$ \\
\hline 1955 & $\begin{array}{lll}\text { May } & 12, & 1955 \\
\text { May } & 22, & 1955\end{array}$ & $\begin{array}{l}3.36 \\
3.33\end{array}$ & $\begin{array}{l}357 \\
349\end{array}$ & & $\begin{array}{lll}\text { Mpr. } & \text { 5, } 1962\end{array}$ & 3.55 & 461 \\
\hline 1956 & $\begin{array}{l}\text { Dec. } 23,1955 \\
\text { Dec. } 26,1955\end{array}$ & $\frac{b 10.15}{2.18}$ & $\begin{array}{r}4,560 \\
700\end{array}$ & 1963 & $\begin{array}{l}\text { Jan. } 31,1963 \\
\text { Feb. } 6,1963\end{array}$ & $\begin{array}{r}c 6.59 \\
6.14\end{array}$ & $1, \overline{5} 20$ \\
\hline
\end{tabular}

a Maximum da1ly.

b Present datum.

c Backwater from ice.

3420. Little Truckee River near Hobart Mills, Calif.

Location.--Lat $39^{\circ} 30^{\prime} 0^{\prime \prime}$, long $120^{\circ} 16^{\prime} 35^{\prime \prime}$, in NE $\frac{1}{4} \mathrm{NE} \frac{1}{4} \sec .14$, T.19 N., R.15 E., on right bank half a mile upstream from Independence Creek and $7 \frac{1}{2}$ miles northwest of Hobart Mills.

Drainage area. $--36.6 \mathrm{sq} \mathrm{m}$. Mean altitude, 7,220 ftt.

Gage.--Recording. Prior to Nov. 9, 1962, at datum $0.15 \mathrm{ft}$ higher. Altitude of gage is $6,290 \mathrm{ft}$ (from topographic map).

Stage-discharge relation.--Defined by current-meter measurements below 1,100 cfs and by slope-area measurements at 7,010 and 7,910 cfs.

Remarks. --Base for partial-duration series, $500 \mathrm{cfs}$. 
Peak stages and discharges of Little Truckee RIver near Hobart M11ls, Cal1f.

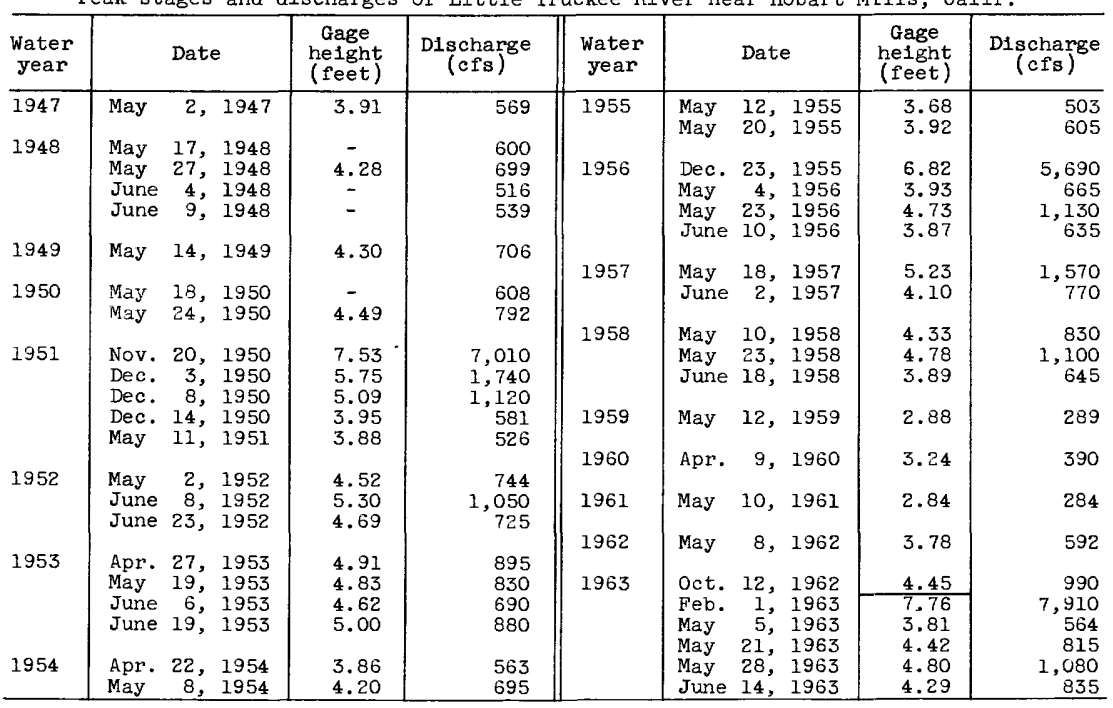

3430. Independence Creek near Truckee, Calif.

(Published as "below Independence Lake" 1902-7)

Location.--Lat $39^{\circ} 27^{\prime} 10^{\prime \prime}$, long $120^{\circ} 17^{\prime} 20^{\prime \prime}$, in SW $\frac{1}{4} \sec .35$, T.19 N., R.15 E., $75 \mathrm{ft}$ downstream from Independence Lake Outlet, $4 \frac{1}{2}$ miles upstream from mouth, and 10 miles northeast of Truckee.

Drainage area. $--8.4 \mathrm{sq} \mathrm{mi}$, approximately.

Gage.--Nonrecording. Prior to July 1, 1904, at site about $600 \mathrm{ft}$ downstream at approximately same datum. Altitude of gage is 6,940 ft (from topograhic map).

Stage-discharge relation. "-Unknown.

Remarks.--Flow regulated by Independence Lake (usable capacity, 17,300 acre-ft in 1950). Only annual maximum observed discharges are showr.

Maximum observed stages and discharges

\begin{tabular}{|c|c|c|c|c|c|c|c|}
\hline $\begin{array}{l}\text { Water } \\
\text { year }\end{array}$ & Date & $\begin{array}{c}\text { Gage } \\
\text { he1ght } \\
\text { (feet) }\end{array}$ & $\begin{array}{c}\text { Discharge } \\
\text { (cfs) }\end{array}$ & $\begin{array}{l}\text { Water } \\
\text { year }\end{array}$ & Date & $\begin{array}{c}\text { Gage } \\
\text { helght } \\
\text { (feet) }\end{array}$ & $\begin{array}{c}\text { Discharge } \\
(c f s)\end{array}$ \\
\hline 1903 & May 13,1903 & \multirow{3}{*}{$\begin{array}{l}3.10 \\
3.42 \\
3.5 \\
3.85\end{array}$} & 154 & 1907 & \multirow{3}{*}{$\begin{array}{l}\text { June } 23,1907 \\
\text { Nov. } 25,1909\end{array}$} & \multirow{3}{*}{$\begin{array}{c}3.9 \\
-\end{array}$} & \multirow{3}{*}{$\begin{array}{r}\text { a286 } \\
187\end{array}$} \\
\hline $\begin{array}{l}1904 \\
1905\end{array}$ & $\frac{\text { May }}{25,26,1904}$ & & $\frac{203}{232}$ & 1910 & & & \\
\hline 1906 & June 25,1906 & & 268 & & & & \\
\hline
\end{tabular}

a Maximum observed prior to June 31, 1907. 
3435. Sagehen Creek near Truckee, Calif.

Location.--Iat $39^{\circ} 25^{\prime} 50^{\prime \prime}$, long $120^{\circ} 14^{\prime} 10^{\prime \prime}$, in $\mathrm{NE} \frac{1}{4} \mathrm{NE} \frac{1}{4} \sec .7$, T.18 N., R.16 E., on left bank 2.2 miles upstream from bridge on State Highway 89 and

7.5 miles north of Truckee.

Drainage area. $--10.9 \mathrm{sq} \mathrm{ml}$. Mean altitude, 7,130 ft.

Gage.--Recording and concrete control. Altitude of gage is $6,320 \mathrm{ft}$ (f -om topographic map).

Stage-discharge relation.--Defined by current-meter measurements below $70 \mathrm{cfs}$ and by slope-area measurement at $495 \mathrm{cfs}$.

Remarks.--Base for partial-duration series, 50 cfs.

Peak stages and discharges

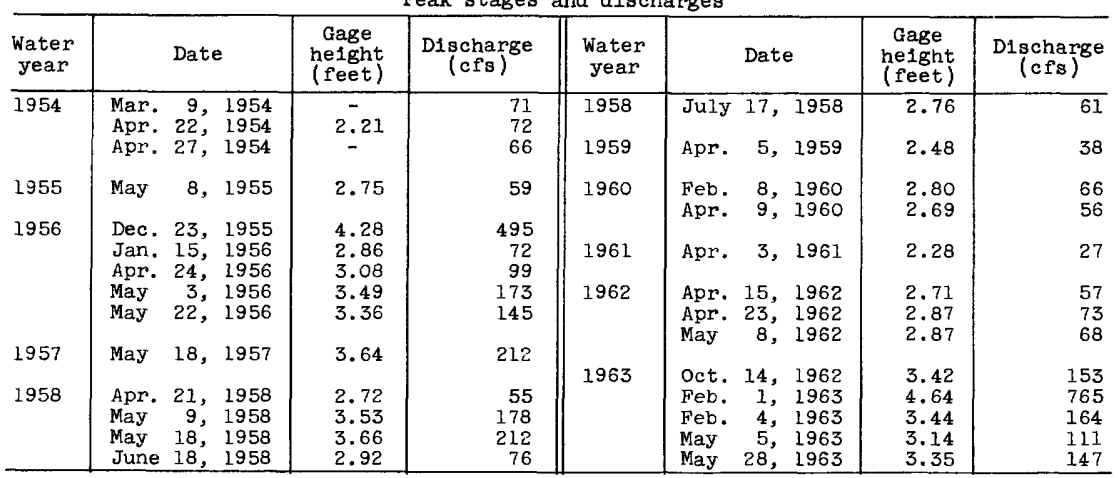

3444. Little Truckee River above Boca Reservoir, near Boca, Calif.

(Published as "at Pine Station" June 1903 to December 1907 and as "at Starr" January 1908 to October 1910)

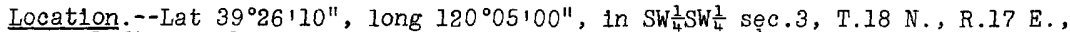
on left bank 1 mile upstream from Boca Reservolr, $1 \frac{1}{2}$ miles upstream from Dry Creek, and $3 \frac{1}{2}$ miles north of Boca.

Drainage area. $--146 \mathrm{sq} \mathrm{mi}$.

Gage.--Nonrecording June 1903 to October 1910, at different sites and datums; recording and concrete control thereafter. Datum of gage is $5,618.67 \mathrm{ft}^{t}$ above mean sea level (Bureau of Reclamation bench mark).

Stage-discharge. relation.--Defined by current-meter measurements below 1,600 cf's and extended above on basis of slope-area measurements at 4,170 and $13,300 \mathrm{cfs}$.

Bankfull stage.--Not subject to overflow.

Remarks.--Records prior to October 1957 furnished by Federal Court Watermaster In cooperation with Washoe County Conservation District. Only annual peaks are shown prior to 1958. Base for partial-duration series, $500 \mathrm{cfs}$.

Peak stages and discharges

\begin{tabular}{|c|c|c|c|c|c|c|c|c|}
\hline $\begin{array}{l}\text { Water } \\
\text { year }\end{array}$ & Date & $\begin{array}{l}\text { Gage } \\
\text { helght } \\
\text { (feet) }\end{array}$ & $\begin{array}{c}\text { Discharge } \\
\text { (cfs) }\end{array}$ & $\begin{array}{l}\text { Water } \\
\text { year }\end{array}$ & & Date & $\begin{array}{c}\text { Gage } \\
\text { netght } \\
\text { (feet) }\end{array}$ & $\begin{array}{c}\text { Discharge } \\
\text { (cfs) }\end{array}$ \\
\hline $\begin{array}{l}1904 \\
1905\end{array}$ & $\begin{array}{l}\text { Apr. } 14,1904 \\
\text { Apr. } 29,1905 \\
\text { May } 11,1906 \\
\text { Mar. } 18,1907\end{array}$ & $\begin{array}{l}4.56 \\
2.85 \\
3.69 \\
4.05\end{array}$ & $\begin{array}{r}a 1,809 \\
\text { a } 760 \\
\text { a1, } 350 \\
\text { a1, } 560\end{array}$ & \multirow{3}{*}{$\begin{array}{l}1941 \\
1942 \\
1943 \\
1944 \\
1945 \\
1946 \\
1947 \\
1948 \\
1949\end{array}$} & \multirow{3}{*}{$\begin{array}{l}\text { May } \\
\text { May } \\
\text { May } \\
\text { May } \\
\text { May } \\
\\
\text { Apr. } \\
\text { Feb. } \\
\text { June } \\
\text { May }\end{array}$} & $\begin{array}{ll}25, & 1941 \\
25, & 1942 \\
2, & 1943 \\
8, & 1944 \\
4, & 1945\end{array}$ & $\begin{array}{l}- \\
- \\
- \\
-\end{array}$ & $\begin{array}{r}\mathrm{bl}, 140 \\
\mathrm{bl}, 380 \\
\mathrm{~b} 960 \\
\mathrm{~b} 788 \\
\mathrm{~b} 1,000\end{array}$ \\
\hline $\begin{array}{l}1908 \\
1909 \\
1910 \\
\end{array}$ & $\begin{array}{l}\text { Apr. } 21,1908 \\
\text { Jan. } 15,16,1909 \\
\text { Mar. } 19,1910\end{array}$ & $\begin{array}{l}2.4 \\
4.8 \\
3.75 \\
\end{array}$ & $\begin{array}{r}a 573 \\
a 1,920 \\
a 1,240\end{array}$ & & & $\begin{array}{ll}18, & 1946 \\
12, & 1947\end{array}$ & - & $\begin{array}{l}\text { b } 935 \\
\text { b } 522\end{array}$ \\
\hline 1940 & May 12,1940 & - & $\mathrm{bl}, 440$ & & & 14,1949 & - & b 788 \\
\hline
\end{tabular}

a Maximum observed.

b Maximum da1ly. 
Peak stages and discharges of Little Truckee River above Boca Reservolr, near Boca, Calif.--Continued

\begin{tabular}{|c|c|c|c|c|c|c|c|c|}
\hline $\begin{array}{l}\text { Water } \\
\text { year }\end{array}$ & \multicolumn{2}{|r|}{ Date } & $\begin{array}{c}\text { Gage } \\
\text { height } \\
\text { (feet) }\end{array}$ & $\begin{array}{l}\text { Discharge } \\
\text { (cfs) }\end{array}$ & $\begin{array}{l}\text { Water } \\
\text { year }\end{array}$ & Date & $\begin{array}{c}\text { Qage } \\
\text { relght } \\
\text { (feet) }\end{array}$ & $\begin{array}{c}\text { Discharge } \\
\text { (cf's) }\end{array}$ \\
\hline 1950 & Apr. & 21,1950 & - & bl, 040 & 1960 & $\begin{array}{l}\text { Feb. } 8,1960 \\
\text { Mar. 27, } 1960\end{array}$ & $\begin{array}{l}3.02 \\
2.31\end{array}$ & $\begin{array}{r}1,430 \\
670\end{array}$ \\
\hline 1351 & Nov. & 20,1950 & - & $b 5,000$ & & Apr. 8, 1960 & 2.23 & 606 \\
\hline 1952 & May & 2,1952 & - & $b 2,200$ & & & & \\
\hline 1353 & May & 19,1953 & - & b698 & 1961 & June 6,1961 & 1.76 & 325 \\
\hline $\begin{array}{l}1954 \\
1955\end{array}$ & Apr. & $23, \quad 1954$ & - & b528 & & Anr $14.196 ?$ & 2.88 & \\
\hline 1955 & May & 8,1955 & - & Ł575 & 1962 & $\begin{array}{ll}\text { Apr. 14, } & 1962 \\
\text { May } & 6,1962\end{array}$ & $\begin{array}{l}2.88 \\
2.28\end{array}$ & $\begin{array}{r}1,290 \\
670\end{array}$ \\
\hline $\begin{array}{l}1956 \\
1957\end{array}$ & Dec. & 23,1955 & - & 9,500 & 1967 & Oct $13 \quad 1962$ & 4.33 & 4.100 \\
\hline & May & 10 , & - & $01,1<0$ & ה 150 & Feb. 1,1963 & 9.00 & 13,300 \\
\hline 1958 & Feb. & 24,1958 & 2.17 & 569 & & Feb. 5,1963 & 3.07 & 1,490 \\
\hline & Apr. & 21,1958 & 3.11 & 1,540 & & $\begin{array}{l}\text { Apr. } \quad 7,1963 \\
\text { Mav } 1963\end{array}$ & $\begin{array}{l}2.35 \\
2.66\end{array}$ & 1,020 \\
\hline & May & 19,1958 & 3.16 & 1,610 & & May 22,1963 & 2.80 & 1,160 \\
\hline & June & 19,1958 & 2.52 & 860 & & $\begin{array}{lll}\text { May } 29, & 1963 \\
\text { June } & 15, & 1963\end{array}$ & $\begin{array}{l}3.40 \\
2.62\end{array}$ & $\begin{array}{r}1,960 \\
962\end{array}$ \\
\hline 1959 & Jan. & 1959 & 1.88 & 390 & & & & \\
\hline
\end{tabular}

b Maximum da11y.

3445. Iittle Truckee River at Boca, Calif.

Location.--Lat $39^{\circ} 23^{\prime} 10^{\prime \prime}$, long $120^{\circ} 05^{14} 40^{\prime \prime}$, in $\mathrm{NE} \frac{1}{4} \mathrm{NW} \frac{1}{4}$ sec.28, T.18 N., R.17 E., on right bank $800 \mathrm{ft}$ upstream from mouth and $1,000 \mathrm{ft}$ downstream from Boca Dam, and a third of a mile northwest of Boca.

Drainage area. $--172 \mathrm{sq} \mathrm{ml}$.

Gage.--Nonrecording prior to Sept. 30, 1915, at site $650 \mathrm{ft}$ downstream at different datum. January 1939 to September 1957, records computed from dally $\log$ of rated settings of needle valve in dam, and from computed flow over spillway; recording thereafter. Altitude of gage is $5,500 \mathrm{ft}$ (from topograph1c map).

Stage-discharge relation.--Defined by current-meter measurements below 1,400 cf's and extended above by logarithmic plotting.

Remarks.--Records prior to October 1958 furmished by Federal Ccurt Watermaster in cooperation with Washoe County Conservation District. Flow regulated by Boca Reservolr (capacity, 40,900 acre-ft). Independence Lake (capac1ty, about 17,500 acre-ft), and one transmountain diversion to Sierra Valley. only annual peaks are shown (maximum observed prior to 1955 and for 1957).

\begin{tabular}{|c|c|c|c|c|c|c|c|}
\hline $\begin{array}{l}\text { Water } \\
\text { year }\end{array}$ & Date & $\begin{array}{l}\text { Gage } \\
\text { height } \\
\text { (feet) }\end{array}$ & $\begin{array}{c}\text { Discharge } \\
\text { (cfs) }\end{array}$ & $\begin{array}{l}\text { Water } \\
\text { year }\end{array}$ & Date & $\begin{array}{c}\text { Gage } \\
\text { helght } \\
\text { (feet) }\end{array}$ & $\begin{array}{c}\text { Discharge } \\
\text { (cfs) }\end{array}$ \\
\hline 1890 & May 6,1890 & & & $\begin{array}{l}1949 \\
1950\end{array}$ & $\begin{array}{l}\text { May } 6-8,1949 \\
\text { Apr. } 28,1950\end{array}$ & - & $\begin{array}{l}375 \\
850\end{array}$ \\
\hline $\begin{array}{l}1911 \\
1912 \\
1913 \\
1914 \\
1915 \\
\end{array}$ & $\begin{array}{l}\text { Apr. } 26,1911 \\
\text { June } 6,1912 \\
\text { May } 18,1913 \\
\text { Apr. 15, } 1914 \\
\text { May } 12,1915 \\
\end{array}$ & $\begin{array}{l}4.9 \\
2.55 \\
2.6 \\
4.9 \\
3.9 \\
\end{array}$ & $\begin{array}{r}2,260 \\
659 \\
688 \\
2,360 \\
1,600 \\
\end{array}$ & $\begin{array}{l}1951 \\
1952 \\
1953 \\
1954\end{array}$ & $\begin{array}{l}\text { Nov. } 20,1950 \\
\text { May } 4,1952 \\
\text { May } 8-26,1953 \\
\text { May } 10,1954\end{array}$ & $\begin{array}{l}- \\
-\end{array}$ & $\begin{array}{r}5,000 \\
2,516 \\
750 \\
450\end{array}$ \\
\hline $\begin{array}{l}1940 \\
1941 \\
1942 \\
1943 \\
1944 \\
1945\end{array}$ & $\begin{array}{l}\text { May } 13,1940 \\
\text { May } 27,28,1941 \\
\text { Apr. } 16-18,1942 \\
\text { Apr. } 21,1943 \\
\text { Aug. } 18,1944 \\
\text { May } 15,1945\end{array}$ & $\begin{array}{l}- \\
\overline{-} \\
\overline{-} \\
-\end{array}$ & $\begin{array}{r}1,330 \\
680 \\
1,100 \\
834 \\
457 \\
1,400\end{array}$ & $\begin{array}{l}1956 \\
1957 \\
1958 \\
1959 \\
1960\end{array}$ & $\begin{array}{lr}\text { Dune } & 3,1950 \\
\text { Dec. } 24, & 1955 \\
\text { June } 2, & 1957 \\
\text { May } 14, & 1958 \\
\text { July } 8, & 1959 \\
\text { July } 22, & 1960\end{array}$ & $\begin{array}{l}- \\
- \\
5.15 \\
3.29 \\
3.43\end{array}$ & $\begin{array}{r}8,800 \\
587 \\
1,590 \\
460 \\
526\end{array}$ \\
\hline $\begin{array}{l}1947 \\
1948 \\
\end{array}$ & $\begin{array}{l}\text { Apr. } 20 \text { to } \\
\text { May } 2,1946 \\
\text { Jan. } 17,18,1947 \\
\text { June } 10,1948\end{array}$ & $\begin{array}{l}- \\
-\end{array}$ & $\begin{array}{l}435 \\
595\end{array}$ & $\begin{array}{l}1961 \\
1962 \\
1963\end{array}$ & $\begin{array}{l}\text { Aug. 3, } 1961 \\
\text { May 5,9, } 1962 \\
\text { Feb. 2, } 1963\end{array}$ & $\begin{array}{l}2.73 \\
4.17 \\
6.16\end{array}$ & $\begin{array}{r}306 \\
877 \\
2,590\end{array}$ \\
\hline
\end{tabular}


3460. Truckee River at Farad, Calif.

(Published as "at or near Nevada-Califormia State line" 1899-1912 and as "at Iceland" 1913-37)

Location.--Lat $39^{\circ} 25^{\prime} 41^{\prime \prime}$, long $120^{\circ} 01^{\prime} 59^{\prime \prime}$, in $\mathrm{NE} \frac{1}{4} \sec .12, \mathrm{~T} .18 \mathrm{~N}$, , R.17 E., on left bank $0.7 \mathrm{mile}$ downstream from Farad powerplant, 2.5 miles north of Floristan, 3.5 miles downstream from Bronco Creek, and 3.5 miles upstream from California-Nevada State line.

Drainage area. $--932 \mathrm{sq} \mathrm{ml}$.

Gage.--Nonrecording prior to Aug. 1, 1912; recording thereafter. Sept. 7, 1899, to May 31, 1909, at approximately present site at different datum. June 1 , 1909 , to July 31,1912 , at site about $2 \frac{1}{2}$ miles downstream at different datum. Aug. 1, 1912, to Dec. 31, 1937, at site 4.1 miles upstream at different datum. Jan. 1, 1938, to Aug. 27, 1957, at approximately present site at datum $1.0 \mathrm{ft}$ higher. Datum of gage is $5,153.21 \mathrm{ft}$ above mean sea level (Bureau of Reclamation bench mark).

Stage-discharge relation.--Defined by current-meter measurements below 5,600 cf's and by slope-area measurement at 17,500 cfs.

Historical data.--Maximum flood known, that of Nov. 21, 1950.

Remarks.--Flow regulated by Lake Tahoe, Boca Reservoir, Donner and Inderendence Iakes, and by several powerplants. Records for January 1944 to August 1957, furnished by Federal Court Watermaster in cooperation with Truckee-Carson Irrigation District. Base for partial-duration series, 1,600 cfs. Only annual peaks are shown prior to 1958.

Peak stages and discharges

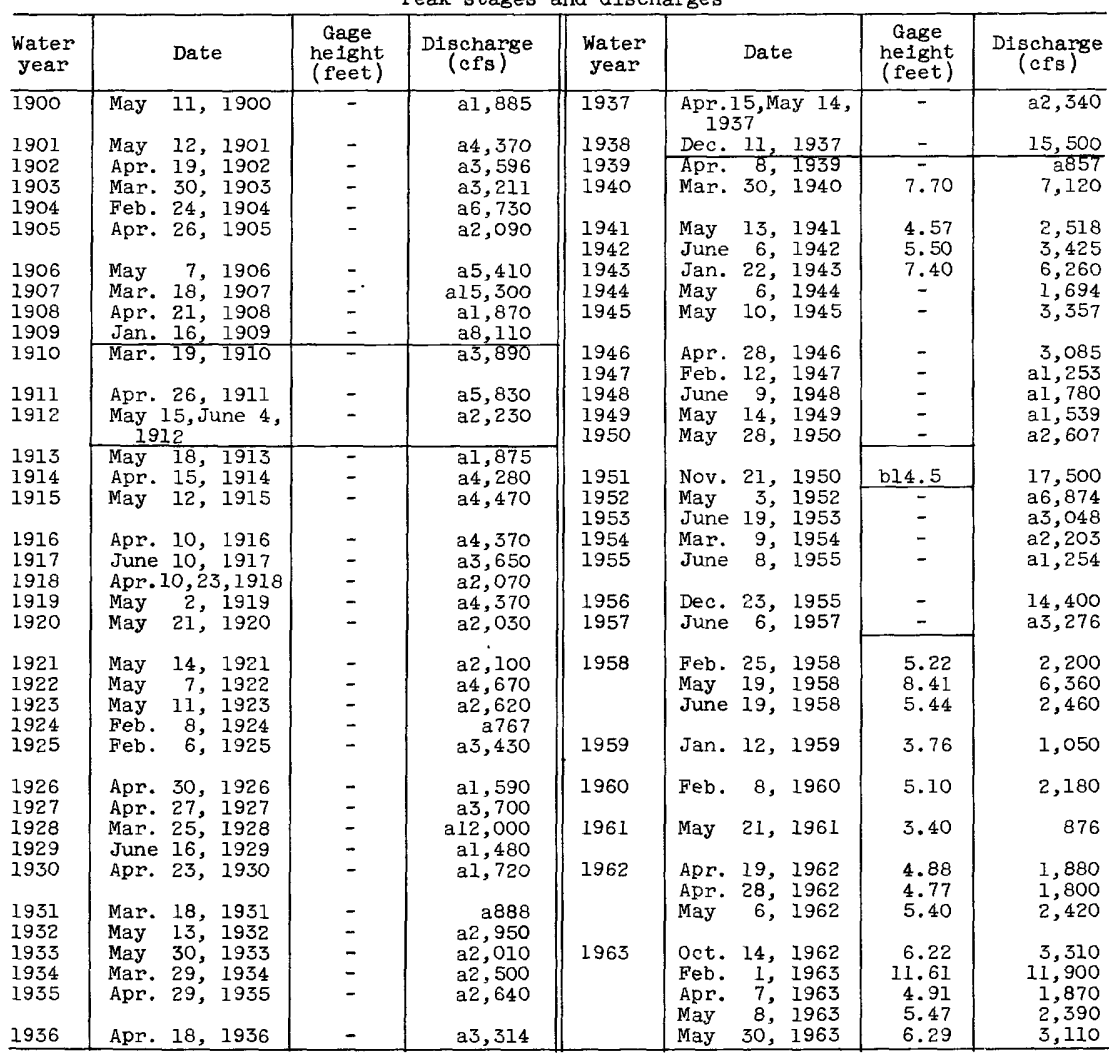

a Maximum da11y.

b At present datum. 
3473. Dog Creek near Verdi, Nev.

Location.--Lat $39^{\circ} 33^{\prime} 5^{\prime \prime}$, long $120^{\circ} 01^{\prime} 25^{\prime \prime}$, in SW $\frac{1}{4} \operatorname{SW} \frac{1}{4} \sec .30$, T.20 N., R.18 E., on left bank $3 \frac{1}{2}$ miles upstream from mouth and 4 miles northwest of Verdi.

Drainage area. $--16.2 \mathrm{sq} \mathrm{mi}$.

Gage.--Recording and concrete control. Altitude of gage is 5,660 ft (from topographic map).

Stage-discharge relation.--Defined by current-meter measurements below $250 \mathrm{cfs}$. Bankfull stage.--Not subject to overflow.

Remarks.--Base for partial-duration series, $40 \mathrm{cfs}$.

Peak stages and discharges

\begin{tabular}{|c|c|c|c|c|c|c|c|c|}
\hline $\begin{array}{l}\text { Water } \\
\text { year }\end{array}$ & & Date & $\begin{array}{c}\text { Gage } \\
\text { helght } \\
\text { (feet) }\end{array}$ & $\begin{array}{c}\text { D1scharge } \\
\text { (cfs) }\end{array}$ & $\begin{array}{l}\text { Water } \\
\text { year }\end{array}$ & Date & $\begin{array}{c}\text { Gage } \\
\text { helght } \\
\text { (feet) }\end{array}$ & $\begin{array}{c}\text { Discharge } \\
\text { (cfs) }\end{array}$ \\
\hline 1957 & $\begin{array}{l}\text { Feb. } \\
\text { May } \\
\text { May }\end{array}$ & $\begin{array}{ll}24, & 1957 \\
18, & 1957 \\
29, & 1957\end{array}$ & $\begin{array}{r}1.58 \\
.95 \\
1.32\end{array}$ & $\begin{array}{c}157 \\
41 \\
99\end{array}$ & 1960 & $\begin{array}{l}\text { Feb. } \quad \text { s, } 1960 \\
\text { Mar. } 7,1960 \\
\text { Mar. 13, } 1960 \\
\text { Mar. 27, } 1960\end{array}$ & $\begin{array}{r}1.92 \\
1.43 \\
1.00 \\
.95\end{array}$ & $\begin{array}{r}256 \\
122 \\
46 \\
40\end{array}$ \\
\hline 1958 & $\begin{array}{l}\text { Feb. } \\
\text { Apr. } \\
\text { May }\end{array}$ & $\begin{array}{rr}24, & 1958 \\
17, & 1958 \\
5, & 195 \mathrm{~s}\end{array}$ & $\begin{array}{l}2.75 \\
2.13 \\
1.22\end{array}$ & $\begin{array}{r}550 \\
322 \\
81\end{array}$ & 1961 & Feb. 2, 1961 & .70 & 16 \\
\hline 1959 & Mar. & 12,1959 & .92 & 35 & & & & \\
\hline
\end{tabular}

3480. Truckee River at Reno, Nev.

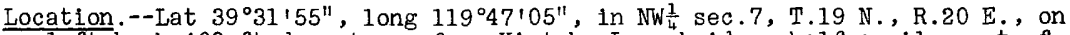
left bank $400 \mathrm{ft}$ downstream from Kietzke Lane bridge, half a mile east of Reno, and 5 miles upstream from Steamboat Creek.

Drainage area. $--1,067 \mathrm{sq} \mathrm{mi}$.

Gage.--Nonrecording prior to October 1946 , at sites 1 to $1 \frac{1}{2}$ miles upstream at different datums; recording thereafter. Datum of gage is $4,431.97 \mathrm{ft}$ above mean sea level (levels by Corps of Engineers).

Stage-discharge relation.--Defined by current-meter measurements below $14,000 \mathrm{cfs}$.

Remarks.--Flow regulated by Lake Tahoe, Boca Reservoir, Donner and Independence Lakes, and by several powerplants. Many diversions above station. Records for October 1919 to December 1946, partly furnished by Federa1 Court Watermaster in cooperation with U.S. Reclamation Service. Only annual peaks are shown (maximum observed prior to 1920, maximum daily 1920-31).

\begin{tabular}{|c|c|c|c|c|c|c|c|}
\hline $\begin{array}{l}\text { Water } \\
\text { year }\end{array}$ & Date & $\begin{array}{l}\text { Gage } \\
\text { helght } \\
\text { (feet) }\end{array}$ & $\begin{array}{c}\text { Discharge } \\
\text { (cfs) }\end{array}$ & $\begin{array}{l}\text { Water } \\
\text { year }\end{array}$ & Date & $\begin{array}{l}\text { Gage } \\
\text { helght } \\
\text { (feet) }\end{array}$ & $\begin{array}{c}\text { Discharge } \\
\text { (cfs) }\end{array}$ \\
\hline $\begin{array}{l}1907 \\
1908 \\
1909\end{array}$ & $\begin{array}{ll}\text { Mar. } 18,1907 \\
\text { Apr. } 13,1908 \\
\text { Jan. } 16,1909\end{array}$ & $\overline{-}$ & $\begin{array}{r}14,600 \\
1,660 \\
s, 540\end{array}$ & $\begin{array}{l}1925 \\
1926 \\
\end{array}$ & Apr. $\quad 6,1926$ & - & $\begin{array}{l}1,200 \\
1,647\end{array}$ \\
\hline $\begin{array}{l}1910 \\
1911 \\
1912\end{array}$ & $\begin{array}{l}\text { Mar. 19, } 1910 \\
\text { Apr. 26, } 1911 \\
\text { May 16, June 4, } \\
\text { 1912 }\end{array}$ & - & $\begin{array}{l}3,360 \\
6,060 \\
1,570\end{array}$ & $\begin{array}{l}1931 \\
1932 \\
1933 \\
1934 \\
\end{array}$ & $\begin{array}{lll}\text { Mar. } & 19, & 1931 \\
\text { May } 14, & 1932 \\
\text { May } & 31, & 1933 \\
\text { Mar. } 29, & 1934 \\
\end{array}$ & $\begin{array}{l}- \\
- \\
\end{array}$ & $\begin{array}{r}759 \\
2,590 \\
1,480 \\
1,790 \\
\end{array}$ \\
\hline $\begin{array}{l}1914 \\
1915\end{array}$ & $\begin{array}{l}\text { Apr.27, May } 18, \\
1913 \\
\text { Dec. 31, } 1913 \\
\text { May } 13,1915\end{array}$ & - & $\begin{array}{l}1,520 \\
7,520 \\
3,900\end{array}$ & $\begin{array}{l}1947 \\
1945 \\
1949 \\
1950\end{array}$ & 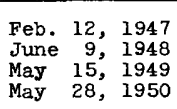 & $\begin{array}{l}4.58 \\
4.42 \\
4.20 \\
5.45\end{array}$ & $\begin{array}{l}1,840 \\
1,700 \\
1,510 \\
2,620\end{array}$ \\
\hline $\begin{array}{l}1916 \\
1917 \\
1918 \\
1919 \\
1920 \\
1921 \\
\end{array}$ & 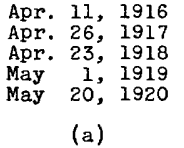 & $\begin{array}{l}- \\
- \\
-\end{array}$ & $\begin{array}{l}5,020 \\
3,680 \\
2,040 \\
4,060 \\
2,070 \\
2,200\end{array}$ & $\begin{array}{l}1951 \\
1952 \\
1953 \\
1954 \\
1955\end{array}$ & $\begin{array}{lrl}\text { Nov. } & 21, & 1950 \\
\text { May } & 3, & 1952 \\
\text { June } & 20, & 1953 \\
\text { Mar. } 9, & 1954 \\
\text { June } & 9, & 1955\end{array}$ & $\begin{array}{r}13.83 \\
9.38 \\
6.52 \\
6.74 \\
4.02\end{array}$ & $\begin{array}{r}19,900 \\
7,950 \\
3,430 \\
3,700 \\
1,020\end{array}$ \\
\hline
\end{tabular}

a Mar. 18, May 14, 15, sept. 7, 1921.

b May $17,22,27,1925$ 
Peak stages and discharges of Truckee River at Reno, Nev,--Continued

\begin{tabular}{|c|c|c|c|c|c|c|c|c|}
\hline $\begin{array}{l}\text { Water } \\
\text { year }\end{array}$ & & Date & $\begin{array}{l}\text { Gage } \\
\text { helght } \\
\text { (feet) }\end{array}$ & $\begin{array}{c}\text { Discharge } \\
\text { (cfs) }\end{array}$ & $\begin{array}{c}\text { Water } \\
\text { year }\end{array}$ & Date & $\begin{array}{l}\text { Gage } \\
\text { helght } \\
\text { (feet) }\end{array}$ & $\begin{array}{c}\text { Discharge } \\
(\mathrm{cfs})\end{array}$ \\
\hline $\begin{array}{l}1356 \\
1957 \\
1958 \\
1959 \\
1960\end{array}$ & $\begin{array}{l}\text { Dec. } \\
\text { May } \\
\text { May } \\
\text { Feb. } \\
\text { Feb. }\end{array}$ & $\begin{array}{rr}23, & 1955 \\
19, & 1957 \\
20, & 1958 \\
17, & 1959 \\
8, & 1960\end{array}$ & $\begin{array}{r}13.63 \\
6.97 \\
8.10 \\
3.89 \\
5.63\end{array}$ & $\begin{array}{r}20,800 \\
4,100 \\
6,090 \\
1,050 \\
2,620\end{array}$ & $\begin{array}{l}1961 \\
1962 \\
1963\end{array}$ & $\begin{array}{lll}\text { Apr. } & 4, & 1961 \\
\text { May } & 6,1962 \\
\text { Feb. } & 1,1963\end{array}$ & $\begin{array}{r}3.24 \\
5.08 \\
13.28\end{array}$ & $\begin{array}{r}661 \\
2,060 \\
18,400\end{array}$ \\
\hline
\end{tabular}

3485. Franktown Creek at Franktown, Nev.

Location.--Lat $39^{\circ} 16^{\prime}$, long $119^{\circ} 51^{\prime}$, in sec.9, T.16 N., R.19 E., on right bank a mile west of Franktown and 3 miles upstream from Washoe Lake.

Drainage area.--14 sq $\mathrm{mi}$, approximately. Mean altitude, 7,410 ft.

Gage.--Recording. Gage destroyed by flood Dec. 3 or 4, 1950; reestablished May 21 , 1951, at same site at different datum. Altitude of gage is $5,200 \mathrm{ft}$ (from topographic map).

Stage-discharge relation.--Defined by slope-area measurement at $800 \mathrm{cfs}$.

Remarks.--Base for partial-duration series, $50 \mathrm{cfs}$.

Peak stages and discharges

\begin{tabular}{|c|c|c|c|c|c|c|c|}
\hline $\begin{array}{l}\text { Water } \\
\text { year }\end{array}$ & Date & $\begin{array}{c}\text { Gage } \\
\text { nelght } \\
\text { (feet) }\end{array}$ & $\begin{array}{c}\text { D1scharge } \\
\text { (cfs) }\end{array}$ & $\begin{array}{l}\text { Water } \\
\text { year }\end{array}$ & Date & $\begin{array}{c}\text { Gage } \\
\text { helght } \\
\text { (feet) }\end{array}$ & $\underset{\text { (cfs) }}{\text { Mischarge }}$ \\
\hline 1948 & $\begin{array}{lrr}\text { Apr. } & 20, & 1948 \\
\text { Apr. } & 25, & 1948 \\
\text { Apr. } & 27, & 1948 \\
\text { May } & 6, & 1948\end{array}$ & $\begin{array}{l}- \\
- \\
2.37\end{array}$ & $\begin{array}{l}58 \\
59 \\
63 \\
65\end{array}$ & $\begin{array}{l}1951 \\
1952\end{array}$ & 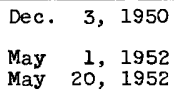 & $\begin{array}{l}- \\
3.22 \\
2.91\end{array}$ & $\begin{array}{l}800 \\
164 \\
117\end{array}$ \\
\hline 1949 & $\begin{array}{l}\text { Feb. } 7,1949 \\
\text { Apr. } 18,1949 \\
\text { Apr. } 23,1949 \\
\text { May } 14,1949\end{array}$ & $\overline{-}$ & $\begin{array}{l}61 \\
59 \\
81 \\
70\end{array}$ & 1953 & $\begin{array}{lrl}\text { Jan. } & 9,1953 \\
\text { Apr. } & 27,1953 \\
\text { May } 15, & 1953 \\
\text { May } 28, & 1953 \\
\text { June } 6,1953\end{array}$ & $\begin{array}{l}2.49 \\
3.33 \\
2.32 \\
2.29 \\
2.47\end{array}$ & $\begin{array}{r}76 \\
188 \\
55 \\
52 \\
67\end{array}$ \\
\hline 1950 & $\begin{array}{lr}\text { Jan. } 22,1950 \\
\text { Mar. } 19,1950 \\
\text { Apr. } 2,1950 \\
\text { Apr. } 22,1950 \\
\text { May } 16,1950 \\
\text { June } 15,1950\end{array}$ & $\begin{array}{l}- \\
- \\
- \\
- \\
3.55\end{array}$ & $\begin{array}{r}66 \\
62 \\
61 \\
93 \\
66 \\
165\end{array}$ & $\begin{array}{l}1954 \\
1955\end{array}$ & $\begin{array}{l}\text { Mar. 9, } 1954 \\
\text { Apr. 27, } 1954 \\
\text { Mar. 28, } 1955\end{array}$ & $\begin{array}{l}3.09 \\
2.52 \\
2.17\end{array}$ & $\begin{array}{r}130 \\
61\end{array}$ \\
\hline
\end{tabular}


3500. Truckee River at Vista, Nev.

Location.--Lat $39^{\circ} 31^{\prime} 05^{\prime \prime}$, long $119^{\circ} 40^{\prime} 58^{\prime \prime}$, in NW $\frac{1}{4} \mathrm{NE} \frac{1}{4}$ sec.13, T.19 N., R.20 E., on left bank $800 \mathrm{ft}$ downstream from Southern Pacific Railroed bridge,

$0.9 \mathrm{mile}$ southeast of Vista, $1 \frac{1}{2}$ miles downstream from Steamboat Creek, and

4 miles southeast of Sparks.

Drainage area $.-1,429 \mathrm{sq} \mathrm{ml}$.

Gage.--Nonrecording prior to Apr. 16, 1907, at several sites in vicinity of present site at various datums; recording thereafter. May to December 1907. reference point on rallroad bridge. January 1932 to December 1954, October 1958 to Aug. 17, 1959, at site 1,200 ft upstream at datum 5.89 ft higher. Datum of gage is $4,368.33$ ft above mean sea level, datum of 1929 , supplementary adjustment of 1956 .

Stage-discharge relation.--Defined by current-meter measurements below 5,000 $\mathrm{cfs}$ and extended above on basis of slope-area measurement of $21,300 \mathrm{cf}$.

Bankfull stage.--Not subject to overflow.

H1storical data.--Flood of Dec. 23, 1955, probably equaled or exceeded that of Mar. 18, 1907.

Remarks.--Records prior to January 1955 furmished by Federal Court Watermaster. Flow regulated by Lake Tahoe, Boca Reservoir, and other lakes (combined capacity, 800,000 acre-ft). Only annual peaks are shown prior to 1959 (maximum observed prior to 1907, maximum daily 1907-54). Base for partialduration series, $1,800 \mathrm{cf}$ 's.

Peak stages and discharges

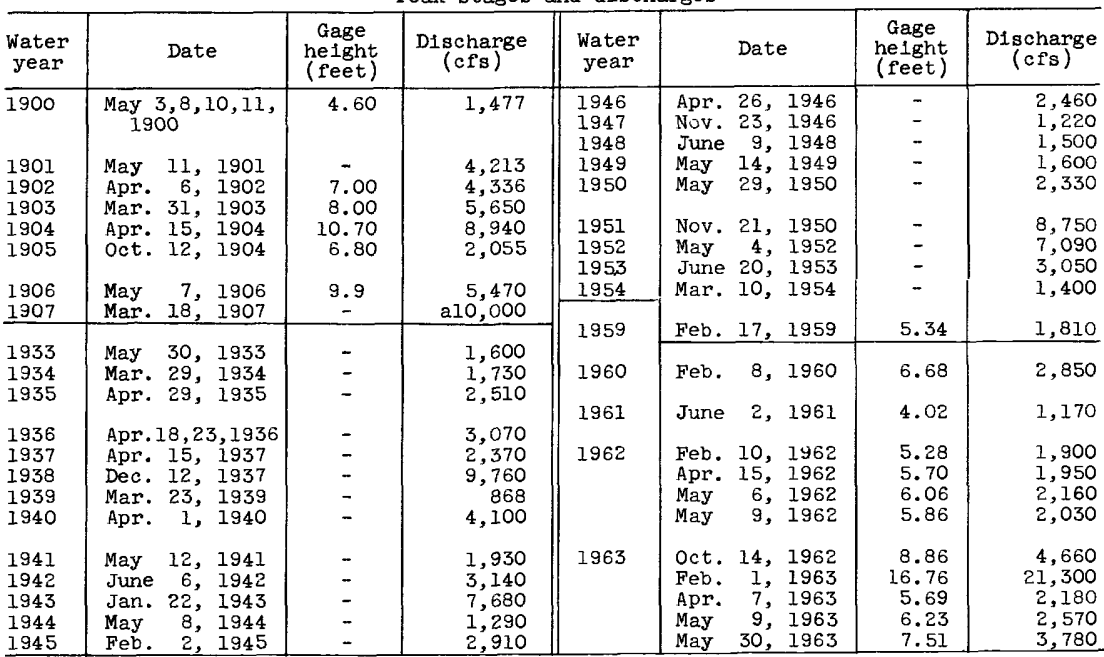

a About.

Note.--Discharges are maximum observed prior to 1907, maximum daily neans 1907-54.

3505. Truckee River at Clarks, Nev.

(Published as "at Derby Dam" prior to August 1910)

Location.--Lat $39^{\circ} 34^{\prime}$, long $119^{\circ} 30^{\prime}$, in SE $\frac{1}{4} \sec .26$, T.20 N., R.22 E., at highway bridge at Clarks and 18 miles east of Reno.

Drainage area. $--1,740 \mathrm{sq} \mathrm{mi}$, approximately.

Gage.--Nonrecording. Prior to Aug. 1, 1910, about 2 miles downstream at different datum. Altitude of gage is $4,270 \mathrm{ft}$ (from topographic map).

Stage-discharge relation.--Defined by current-meter measurements.

Remarks.--Flow regulated by Lake Tahoe, Boca Reservolr, Donner and Independence Lakes, and by several powerplants. Records furnished by Bureau of Reclama-

tion, 1915. Only annual maximum observed discharges are shovin. 
Maximum observed stages and discharges of Truckee River at Clarks, Nev.

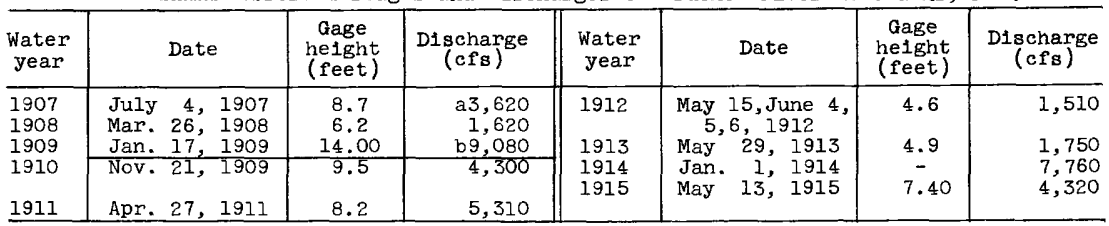

a Maximum observed during period July to September.

b Corrected.

3516. Truckee River below Derby Dam, near Wadsworth, Nev.

Location.--Lat $39^{\circ} 35^{1} 05^{\prime \prime}$, long $119^{\circ} 26^{\prime} 25^{\prime \prime}$, in NW $\frac{1}{4} \mathrm{SE} \frac{1}{4}$ sec.19, T.20 N., F.23 E., on right bank $1,500 \mathrm{ft}$ downstream from Derby Dam, $3 \frac{1}{4}$ miles downstream from Clark, and 9 miles southwest of Wadsworth.

Drainage area $--1,670 \mathrm{sq} \mathrm{mi}$.

Gage.--Recording. Altitude of gage is 4,200 $\mathrm{ft}$ (from topographic map).

Stage-discharge relation.--Defined by current-meter measurements below 3,700

$\mathrm{cfs}$ and extended above on basis of slope-area measurement at $18,400 \mathrm{cfs}$.

Bankfull stage. $--10 \mathrm{ft}$.

Remarks.--Records prior to October 1958 furnished by Truckee-Carson Irrigation

District in cooperation with Sierra Pacific Power Co. Flow regulated by

Lake Tahoe, Boca Reservoir, other lakes, powerplants, and by Derby Dam.

Truckee Canal diverts water at Derby Dam out of basin to Lohontan Reservoir.

only annual maximum daily discharges are shown prior to 1961.

Peak stages and discharges

\begin{tabular}{|c|c|c|c|c|c|c|c|}
\hline $\begin{array}{l}\text { Water } \\
\text { year }\end{array}$ & Date & $\begin{array}{c}\text { Gage } \\
\text { height } \\
\text { (feet) }\end{array}$ & $\begin{array}{l}\text { D1scharge } \\
\text { (cfs) }\end{array}$ & $\begin{array}{l}\text { Water } \\
\text { year }\end{array}$ & Date & $\begin{array}{c}\text { Gage } \\
\text { height } \\
\text { (feet) }\end{array}$ & $\begin{array}{c}\text { Discharge } \\
(\mathrm{cfs})\end{array}$ \\
\hline $\begin{array}{l}1909 \\
1910 \\
\end{array}$ & $\begin{array}{ll}\text { Jan. } 17, & 1909 \\
\text { Apr. } 19, & 1910\end{array}$ & $\overline{-}$ & $\begin{array}{l}a 8,040 \\
a 2,250\end{array}$ & 1940 & Mar. 31, 1940 & - & 4,610 \\
\hline 1916 & Apr. 11, 1916 & - & $\mathrm{a} 3,880$ & $\begin{array}{l}1941 \\
1942\end{array}$ & $\begin{array}{l}\text { May } 28,1941 \\
\text { June } 7,1942\end{array}$ & $\begin{array}{l}- \\
-\end{array}$ & $\begin{array}{l}1,450 \\
2,670\end{array}$ \\
\hline $\begin{array}{l}1918 \\
1919 \\
1920\end{array}$ & $\begin{array}{lrl}\text { Apr. } & 10,1918 \\
\text { May } & 3,1919 \\
\text { Apr. } 16, & 1920\end{array}$ & $\begin{array}{l}- \\
-\end{array}$ & $\begin{array}{r}a 1,900 \\
2,790 \\
1,190\end{array}$ & $\begin{array}{l}1943 \\
1944 \\
1945\end{array}$ & $\begin{array}{lr}\text { Jan. } 22, & 1943 \\
\text { Mar. } 13, & 1944 \\
\text { Feb. } & 2,1945\end{array}$ & $\overline{-}$ & $\begin{array}{r}7,570 \\
\text { b } 664 \\
2,390\end{array}$ \\
\hline $\begin{array}{l}1921 \\
1922 \\
1923 \\
1924 \\
1925\end{array}$ & $\begin{array}{lrl}\text { Mar. } & 19, & 1921 \\
\text { May } & 7, & 1922 \\
\text { Apr. } 18, & 1923 \\
\text { Feb. } 8, & 1924 \\
\text { Feb. } & 7, & 1925\end{array}$ & $\begin{array}{l}- \\
- \\
- \\
-\end{array}$ & $\begin{array}{r}2,040 \\
3,750 \\
2,960 \\
745 \\
2,890\end{array}$ & $\begin{array}{l}1946 \\
1947 \\
1948 \\
1949 \\
1950\end{array}$ & $\begin{array}{l}\text { Apr. 29, } 1946 \text {, } \\
\text { Jan. } 6,1947 \\
\text { June 10, } 1948 \\
\text { May 15, } 1949 \\
\text { May 2S, June 1, } \\
\quad 1950\end{array}$ & $\begin{array}{l}- \\
- \\
- \\
-\end{array}$ & $\begin{array}{r}1,510 \\
545 \\
632 \\
632 \\
1,330\end{array}$ \\
\hline $\begin{array}{l}1926 \\
1927 \\
1928 \\
1929 \\
1930\end{array}$ & $\begin{array}{l}\text { Apr. } 6,1926 \\
\text { May } 17,18,1927 \\
\text { Mar. } 28,1928 \\
\text { June 17, } 1929 \\
\text { Dec. 13, } 1929\end{array}$ & $\begin{array}{l}- \\
- \\
- \\
-\end{array}$ & $\begin{array}{r}964 \\
3,090 \\
\mathrm{~b} 12,000 \\
381 \\
865\end{array}$ & $\begin{array}{l}1951 \\
1952 \\
1953 \\
1954 \\
1955\end{array}$ & $\begin{array}{l}\text { Nov. } 22,1950 \\
\text { May } 4,1952 \\
\text { June 20, } 1953 \\
\text { Mar. 9, } 1954 \\
\text { June } 1,1955\end{array}$ & $\begin{array}{l}- \\
\overline{-} \\
\overline{-}\end{array}$ & $\begin{array}{r}\mathrm{b9}, 180 \\
6,240 \\
3,050 \\
2,050 \\
39.0\end{array}$ \\
\hline $\begin{array}{l}1931 \\
1932 \\
1933 \\
1934 \\
1935\end{array}$ & $\begin{array}{ll}\text { Mar. } 19, & 1931 \\
\text { May } 14, & 1932 \\
\text { May } & 31,1933 \\
\text { Mar. } 30,1934 \\
\text { Apr. } 21,1935\end{array}$ & $\begin{array}{l}- \\
\overline{-} \\
\bar{z}\end{array}$ & $\begin{aligned} & 87.0 \\
& 1,980 \\
& 811 \\
& 1,080 \\
& 1,490\end{aligned}$ & $\begin{array}{l}1956 \\
1957 \\
1958 \\
1959 \\
1960\end{array}$ & $\begin{array}{l}\text { Dec. 24, } 1955 \\
\text { June } 6,1957 \\
\text { May 20, } 1958 \\
\text { Feb. 17, } 1959 \\
\text { Feb. 8, } 1960\end{array}$ & $\begin{array}{l}- \\
- \\
5.47 \\
6.58\end{array}$ & $\begin{array}{l}6,160 \\
2,100 \\
3,720 \\
1,430 \\
2,430\end{array}$ \\
\hline $\begin{array}{l}1936 \\
1937 \\
1938 \\
1939 \\
\end{array}$ & $\begin{array}{l}\text { Apr. } 19,1936 \\
\text { Apr. 16, } 1937 \\
\text { Dec. 13, } 1937 \\
\text { Mar. 24, } 1939\end{array}$ & $\begin{array}{l}- \\
- \\
-\end{array}$ & $\begin{array}{r}2,170 \\
2,160 \\
8,970 \\
778\end{array}$ & $\begin{array}{l}1961 \\
1962 \\
1963\end{array}$ & $\begin{array}{l}\text { Aug. 24, } 1961 \\
\text { Apr. 1s, } 1962 \\
\text { Feb. 1, } 1963\end{array}$ & $\begin{array}{r}5.48 \\
5.69 \\
14.26\end{array}$ & $\begin{array}{r}1,480 \\
1,590 \\
18,400\end{array}$ \\
\hline
\end{tabular}

a Probable maximum dafly; records incomplete.

b Estimated.

Note.--Maximum dally mean discharges are shown prior to 1961. 
3517. Truckee River near Nixon, Nev.

Location.--Iat $39^{\circ} 46^{\prime} 40^{\prime \prime}$, Iong 119 $20^{\prime} 10^{\prime \prime}$, in SW $\frac{1}{4} \mathrm{NW} \frac{\mathrm{l}}{4}$ sec.18, T.22 N., R.24 E., on right bank 1 mile upstream from Pyramid Indian Reservation diversion dam, 4 miles south of Nixon, and 13 miles upstream from mouth.

Drainage area. $--1,869 \mathrm{sq} \mathrm{m} 1$.

Gage.--Recording. Altitude of gage is 3,940 ft (from topographic map).

Stage-discharge relation.--Defined by current-meter measurements below 11,000

if's and extended above on basis measurement of flow over darn.

Bankful1 stage.--Not subject to overflow.

Remarks.--Flow regulated by Lake Tahoe, Boca Reservoir, and otver lakes.

Truckee Canal often diverts practically all flow at Derby Dam about 25 miles upstream out of basin to Lahontan Reservoir. Only annual peaks are shown.

Peak stages and discharges

\begin{tabular}{|c|c|c|c|c|c|c|c|c|}
\hline $\begin{array}{l}\text { Water } \\
\text { year }\end{array}$ & Date & $\begin{array}{c}\text { Gage } \\
\text { height } \\
\text { (feet) }\end{array}$ & $\begin{array}{c}\text { Discharge } \\
(\mathrm{cfs})\end{array}$ & $\begin{array}{c}\text { Water } \\
\text { year }\end{array}$ & & Date & $\begin{array}{c}\text { Gage } \\
\text { height } \\
\text { (feet) }\end{array}$ & $\begin{array}{c}\text { D1scharge } \\
\text { (cfs) }\end{array}$ \\
\hline 1956 & \multirow{2}{*}{ 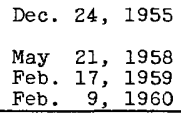 } & \multirow{2}{*}{$\begin{array}{r}14.1 \\
8.77 \\
4.81 \\
6.01 \\
\end{array}$} & \multirow{2}{*}{$\begin{array}{r}14,000 \\
5,160 \\
726 \\
1,560 \\
\end{array}$} & \multirow{2}{*}{$\begin{array}{l}1961 \\
1962 \\
1963\end{array}$} & \multirow{2}{*}{$\begin{array}{l}\text { Aug. } \\
\text { May } \\
\text { Feb. }\end{array}$} & \multirow{2}{*}{$\begin{array}{rr}25, & 1961 \\
9, & 1962 \\
2, & 1963\end{array}$} & \multirow{2}{*}{$\begin{array}{r}4.12 \\
5.15 \\
14.39\end{array}$} & \multirow{2}{*}{$\begin{array}{r}417 \\
920 \\
14,400\end{array}$} \\
\hline $\begin{array}{l}1958 \\
1959 \\
1960 \\
\end{array}$ & & & & & & & & \\
\hline
\end{tabular}

\section{BLACK ROCK DESERT}

3525. McDermitt Creek near McDermitt, Nev.

Location.--Lat $41^{\circ} 58^{\prime}$, long $117^{\circ} 50^{\prime}$, in $\operatorname{SE} \frac{1}{4} \mathrm{SE} \frac{1}{4} \mathrm{sec} .8, \mathrm{~T} .47 \mathrm{~N} ., \mathrm{R} .37 \mathrm{E}$. , on left bank $6 \frac{1}{2}$ miles southwest of McDermitt.

Drainage area. $--225 \mathrm{sq} \mathrm{mi}$. Mean altitude, 5,720 ft.

Gage.--Recording and concrete control. Altitude of gage is 4,545 f't (from topographic map).

Stage-discharge relation.--Defined by current-meter measurements below $460 \mathrm{cfs}$ and by slope-area measurements at $2,100 \mathrm{cfs}$ and $3,970 \mathrm{cfs}$.

Remarks.--Base for partial-duration series, $150 \mathrm{cfs}$.

Peak stages and discharges

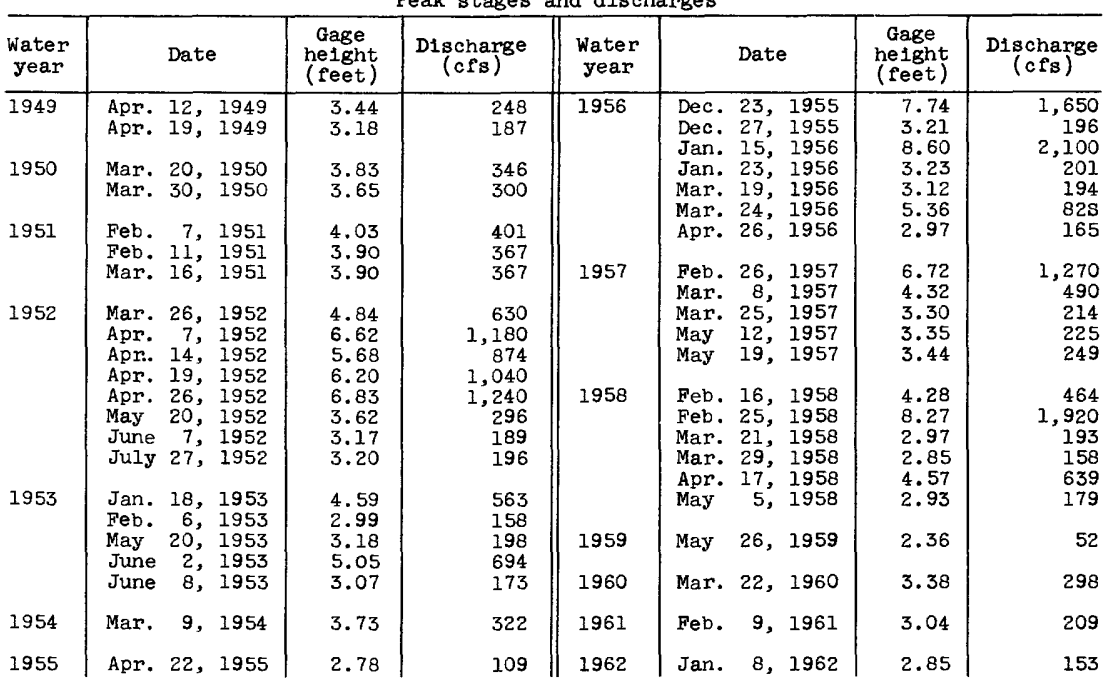


Peak stages and discharges of McDermitt Creek near McDermitt, Nev.--Continied

\begin{tabular}{|c|c|c|c|c|c|c|c|}
\hline $\begin{array}{l}\text { Water } \\
\text { year }\end{array}$ & Date & $\begin{array}{c}\text { Gage } \\
\text { helght } \\
\text { (feet) }\end{array}$ & $\begin{array}{c}\text { Discharge } \\
(\text { efs })\end{array}$ & $\begin{array}{l}\text { Water } \\
\text { year }\end{array}$ & Date & $\begin{array}{c}\text { Gage } \\
\text { helght } \\
\text { (feet) }\end{array}$ & $\begin{array}{c}D^{\text {secharge }} \\
\text { (cfs) }\end{array}$ \\
\hline 1962 & $\begin{array}{l}\text { Feb. } 10,1962 \\
\text { Feb. } 12,1962 \\
\text { Feb. } 15,1962 \\
\text { Mar. 19, } 1962 \\
\text { Mar. } 27,1962\end{array}$ & $\begin{array}{l}6.62 \\
2.87 \\
2.90 \\
2.96 \\
5.24\end{array}$ & $\begin{array}{r}1,800 \\
161 \\
168 \\
187 \\
1,140\end{array}$ & $\begin{array}{l}1962 \\
1963\end{array}$ & $\begin{array}{ll}\text { Apr. } & 1,1962 \\
\text { Feb. } & 1,1963 \\
\text { Apr. } & 7,1963\end{array}$ & $\begin{array}{l}4.25 \\
8.64 \\
2.72\end{array}$ & $\begin{array}{r}622 \\
3,970 \\
163\end{array}$ \\
\hline
\end{tabular}

3530. East Fork Quinn River near McDermitt, Nev.

Location.--Lat $41^{\circ} 59^{\prime}$, long $117^{\circ} 35^{\prime}$, in sec.9, T.47 N., R.39 E., on right bank

1 mile downstream from South Fork and 7 miles east of McDermitt.

Drainage area. $-140 \mathrm{sq} \mathrm{mi}$, approximately. Mean altitude, 6,110 ft.

Gage.--Recording. Altitude of gage is 4,700 ft (from topographic map).

Stage-discharge relation.--Defined by current-meter measurements.

Remarks.--Base for partial-duration series, 100 cfs.

Peak stages and discharges

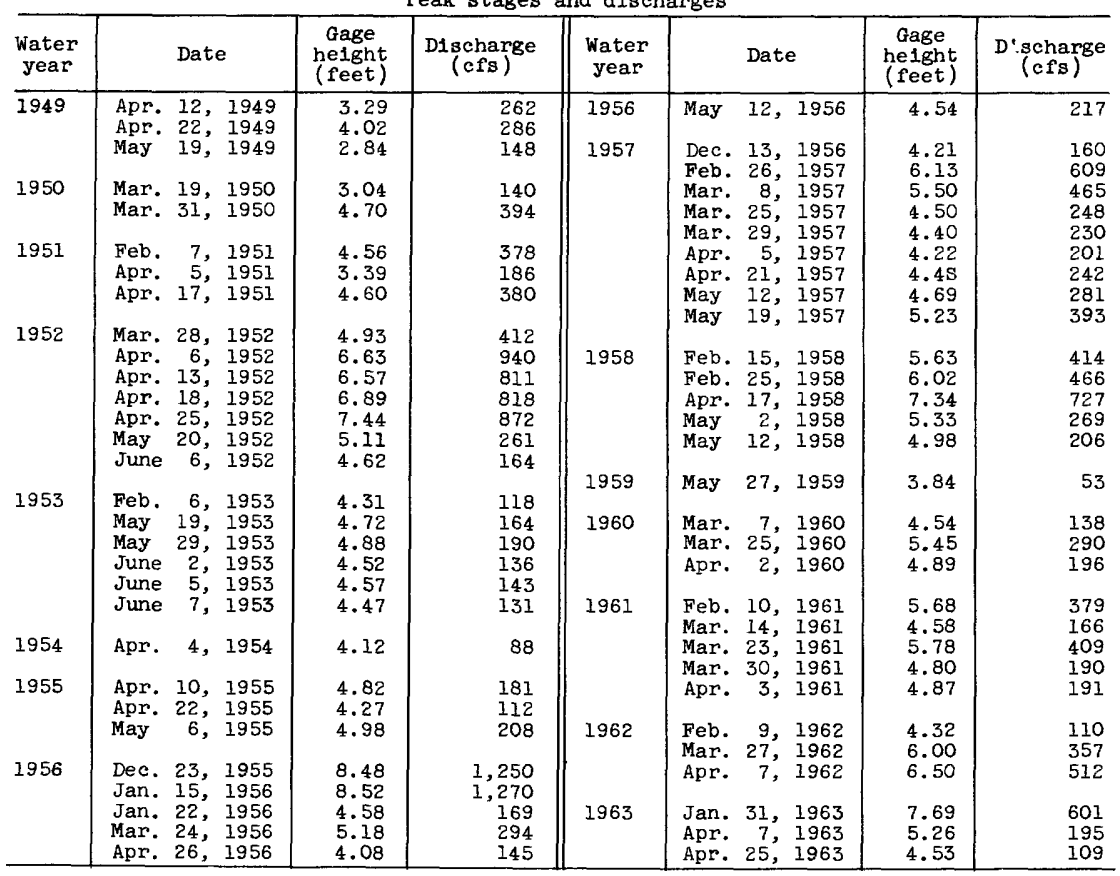


3535. Quinn River near McDermitt, Nev.

Location.--Lat $41^{\circ} 47^{\prime}$, long $117^{\circ} 48^{\prime}$, in SW $\frac{1}{4}$ sec.15, T.45 N., R.37 E., on left

bank $1 \frac{1}{2}$ miles upstream from Flat Creek and $15 \frac{1}{2}$ miles south of McDermitt.

Drainage area. $--1,100 \mathrm{sq} \mathrm{mi}$, approximately. Mean altitude, 5,420 ft.

Gage.--Recording. Altitude of gage is 4,240 ft (from river-prcfile map).

Stage-discharge relation.--Defined by current-meter measurements.

Remarks.--Several diversions above station for irrigation. Base for partial-

duration series, $100 \mathrm{cfs}$. Only annual peaks are shown after 1956.

\begin{tabular}{|c|c|c|c|c|c|c|c|c|c|}
\hline $\begin{array}{l}\text { Water } \\
\text { year }\end{array}$ & & Date & $\begin{array}{c}\text { Gage } \\
\text { height } \\
\text { (feet) }\end{array}$ & $\begin{array}{c}\text { Discharge } \\
\text { (cfs) }\end{array}$ & $\begin{array}{l}\text { Water } \\
\text { year }\end{array}$ & & Date & $\begin{array}{c}\text { Gage } \\
\text { helght } \\
\text { (feet) }\end{array}$ & $\begin{array}{c}\text { Discharge } \\
\text { (cfs) }\end{array}$ \\
\hline 1949 & $\begin{array}{l}\text { Apr. } \\
\text { May }\end{array}$ & $\begin{array}{ll}24, & 1949 \\
20, & 1949\end{array}$ & $\begin{array}{l}3.08 \\
3.44\end{array}$ & $\begin{array}{l}133 \\
188\end{array}$ & 1956 & $\begin{array}{l}\text { Jan. } \\
\text { Jan. } \\
\text { Mar. }\end{array}$ & $\begin{array}{ll}17, & 1956 \\
24, & 1956 \\
27, & 1956\end{array}$ & $\begin{array}{l}3.22 \\
2.95 \\
4.13\end{array}$ & $\begin{array}{l}261 \\
217 \\
423\end{array}$ \\
\hline 1950 & May & 5,1950 & 2.54 & 62 & & $\begin{array}{l}\text { Apr. } \\
\text { Apr. }\end{array}$ & $\begin{array}{ll}16, & 1956 \\
27, & 1956\end{array}$ & $\begin{array}{l}2.69 \\
3.70\end{array}$ & $\begin{array}{l}176 \\
345\end{array}$ \\
\hline 1951 & Apr. & 29,1951 & 3.63 & 219 & & $\begin{array}{l}\text { May } \\
\text { May }\end{array}$ & $\begin{array}{ll}12, & 1956 \\
30, & 1956\end{array}$ & $\begin{array}{l}3.45 \\
3.12\end{array}$ & $\begin{array}{l}300 \\
244\end{array}$ \\
\hline 1952 & $\begin{array}{l}\text { Apr. } \\
\text { Apr. } \\
\text { Apr. } \\
\text { Apr. }\end{array}$ & $\begin{array}{rr}8, & 1952 \\
14, & 1952 \\
20, & 1952 \\
27, & 1952\end{array}$ & $\begin{array}{l}8.01 \\
7.61 \\
7.48 \\
8.39\end{array}$ & $\begin{array}{l}1,400 \\
1,300 \\
1,310 \\
1,580\end{array}$ & $\begin{array}{l}1957 \\
1958 \\
1959 \\
1960\end{array}$ & $\begin{array}{l}\text { May } \\
\text { Apr. } \\
\text { Feb. } \\
\text { Apr. }\end{array}$ & $\begin{array}{rr}14, & 1957 \\
19, & 1958 \\
19, & 1959 \\
7, & 1960\end{array}$ & $\begin{array}{r}4.23 \\
5.72 \\
.59 \\
1.83\end{array}$ & $\begin{array}{c}482 \\
898 \\
5.0 \\
90\end{array}$ \\
\hline 1953 & June & 8, 1953 & 2.97 & 163 & 1961 & Apr. & 5, 1961 & 1.43 & 56 \\
\hline 1954 & Mar. & 25,1954 & .45 & 1.5 & $\begin{array}{l}1962 \\
1963\end{array}$ & $\begin{array}{l}\text { Apr. } \\
\text { Feb. }\end{array}$ & $\begin{array}{ll}8, & 1962 \\
2, & 1963\end{array}$ & $\begin{array}{l}4.55 \\
3.45\end{array}$ & $\begin{array}{l}588 \\
350\end{array}$ \\
\hline 1955 & May & 16,1955 & 1.27 & 30 & & & & & \\
\hline
\end{tabular}

HONEY LAKE BASIN

3565. Susan River at Susanville, Calif.

(Pub11shed as "near Susanville" 1900-1905)

Location.--Lat $40^{\circ} 25^{\prime} 0^{\prime \prime}$, long $120^{\circ} 40115^{\prime \prime}$, in NE $\frac{1}{1}$ sec. 31 , T.30 N., R. 12 E., on left bank $0.5 \mathrm{mile}$ west of Susanville and 1.1 miles upstream from Piute creek.

Drainage area. --192 sq $\mathrm{mi}$.

Gage.--Nonrecording prior to 0ct. 1, 1950, at several sites in vicinity of old powerplant about 0.9 mile upstream at various datums; recording thereafter. Datum of gage is $4,225.72 \mathrm{ft}$ above mean sea level, datum of 1929 .

Stage-discharge relation.--Defined by current-meter measurements below $840 \mathrm{cfs}$ and extended on basis of slope-area measurement at $3,600 \mathrm{cfs}$.

Remarks.--Diversions for irrigation of about 1,400 acres above station. Only annual maximum observed discharges are shown prior to 1951 . Base for partial-duration series, $400 \mathrm{cfs}$.

Peak stages and discharges

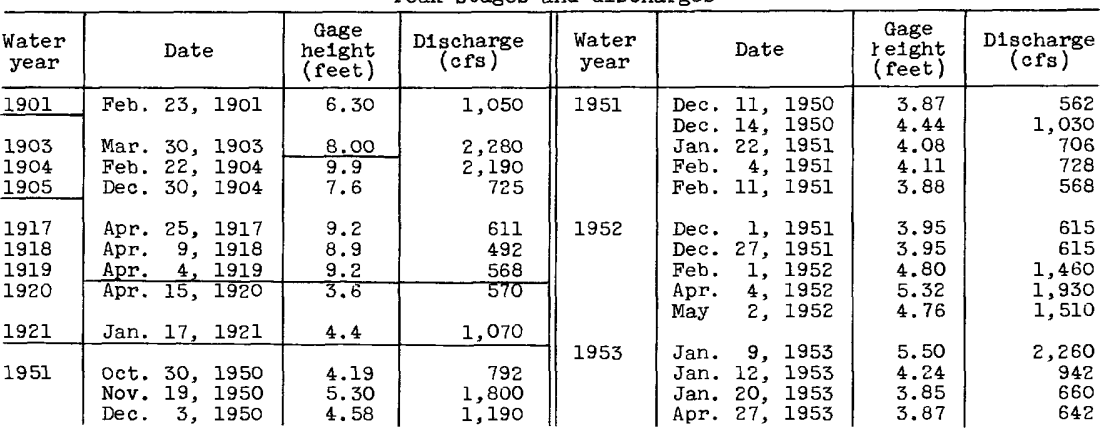


Peak stages and discharges of Susan River at Susanville, Calif.--Contin'sed

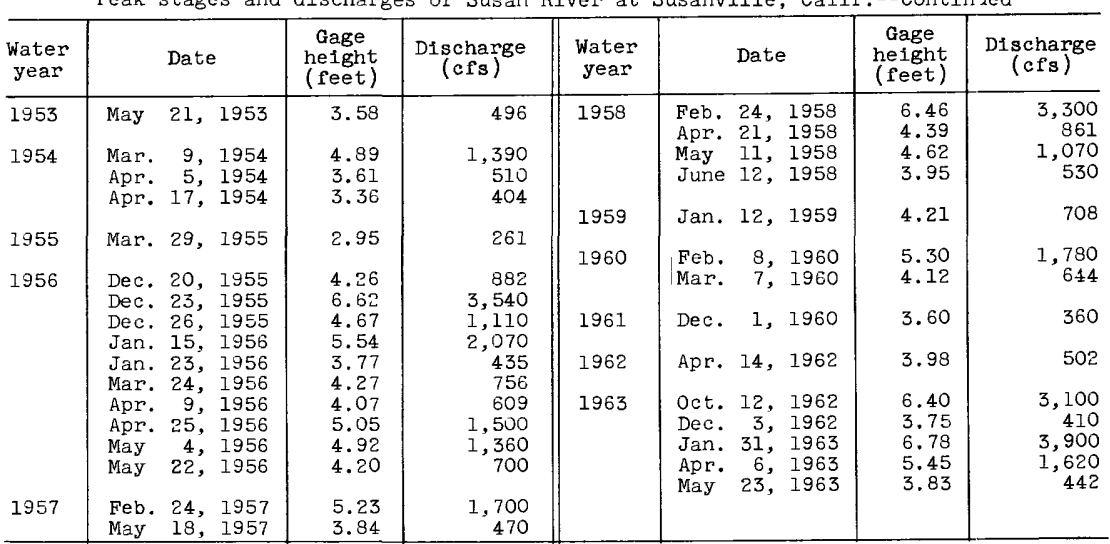

3585. Willow Creek near Susanville, Calif.

Location.--Lat $40^{\circ} 29^{\prime}$, long $120^{\circ} 32^{\prime}$, in NW $\frac{1}{4}$ sec.5, T.30 N., R.13 E., on left bank 4 miles upstream from Peters Valley Creek and 8 miles northeast of Susanville.

Drainage area.--92.5 sq mi, excludes that of Eagle Lake basin.

Gage.--Recording. Datum of gage is $4,836.27 \mathrm{ft}$ above mean sea level, unad justed.

Stage-discharge relation.--Defined by current-meter measurements below $420 \mathrm{cfs}$.

Remarks.--Diversions for irrigation of about 5,200 acres above station. Base for partial-duration series, $200 \mathrm{cfs}$.

\begin{tabular}{|c|c|c|c|c|c|c|c|}
\hline $\begin{array}{l}\text { Water } \\
\text { year }\end{array}$ & Date & $\begin{array}{l}\text { Gage } \\
\text { height } \\
\text { (feet) }\end{array}$ & $\begin{array}{l}\text { Discharge } \\
\text { (cfs) }\end{array}$ & $\begin{array}{c}\text { Water } \\
\text { year }\end{array}$ & Date & $\begin{array}{c}\text { Gage } \\
\text { helght } \\
\text { (feet) }\end{array}$ & $\begin{array}{c}\text { Discharge } \\
\text { (cfs) }\end{array}$ \\
\hline $\begin{array}{l}1951 \\
1952\end{array}$ & $\begin{array}{l}\text { Jan. } 23,1951 \\
\text { Apr. } \quad 6,1952\end{array}$ & $\begin{array}{l}3.89 \\
5.32\end{array}$ & $\begin{array}{l}216 \\
694\end{array}$ & 1958 & $\begin{array}{l}\text { Feb. } 25,1958 \\
\text { Apr. } 1,1958\end{array}$ & $\begin{array}{l}4.55 \\
3.95\end{array}$ & $\begin{array}{l}398 \\
299\end{array}$ \\
\hline 1953 & Jan. 9,1953 & 4.58 & 410 & 1959 & Feb. 17, 1959 & & 163 \\
\hline 1954 & Feb. 18,1954 & 2.96 & 72 & 1960 & Feb. 8,1960 & 5.09 & 596 \\
\hline 1955 & Mar. 10, 1955 & 2.86 & 62 & 1901 & Feb. 11, 1961 & 2.88 & 55 \\
\hline 1956 & $\begin{array}{ll}\text { Dec. } 20, & 1955 \\
\text { Dec. 23, } 1955\end{array}$ & $\begin{array}{l}4.10 \\
5.36\end{array}$ & $\begin{array}{l}270 \\
712\end{array}$ & 1962 & $\begin{array}{l}\text { Feb. } 9,1962 \\
\text { Feb. } 16,1962\end{array}$ & $\begin{array}{l}3.86 \\
3.83\end{array}$ & $\begin{array}{l}216 \\
209\end{array}$ \\
\hline & $\begin{array}{l}\text { Dec. 26, } 1955 \\
\text { Jan. } 15,1956 \\
\text { Mar. 20, } 1956\end{array}$ & $\begin{array}{l}4.72 \\
4.65 \\
4.35\end{array}$ & $\begin{array}{l}457 \\
432 \\
335\end{array}$ & 1963 & $\begin{array}{lr}\text { Oct. } 14,1962 \\
\text { Feb. } 1,1963\end{array}$ & $\begin{array}{l}5.25 \\
5.59\end{array}$ & $\begin{array}{l}663 \\
816\end{array}$ \\
\hline 1957 & Feb. 24,1957 & 5.01 & 564 & & & & \\
\hline
\end{tabular}


3595. Pine Creek near Westwood, Calif.

Location.--Iat $40^{\circ} 35^{\prime}$, long $121^{\circ} 06^{\prime}$, in SE $\frac{1}{4}$ sec.5, T.31 N., R.8 E., on right bank 1 mile southwest of Bogard Guard Station and 19 miles north of Westwood.

Drainage area. $--22.6 \mathrm{sq} \mathrm{ml}$. Mean altitude, 6,450 ft.

Gage.--Recording and concrete control. Altitude of gage is 5,70n ft (from topographic map).

Stage-discharge relation.--Defined by current-meter measurements below $90 \mathrm{cfs}$ and extended above by logarithmic plotting.

Remarks.--Base for partial-duration series, $35 \mathrm{cfs}$.

Peak stages and discharges

\begin{tabular}{|c|c|c|c|c|c|c|c|c|c|}
\hline $\begin{array}{l}\text { Water } \\
\text { year }\end{array}$ & & Date & $\begin{array}{c}\text { Gage } \\
\text { he1ght } \\
\text { (feet) }\end{array}$ & $\begin{array}{l}\text { Discharge } \\
\text { (cfs) }\end{array}$ & $\begin{array}{l}\text { Water } \\
\text { year }\end{array}$ & & Date & $\begin{array}{c}\text { Gage } \\
\text { he1ght } \\
\text { (feet) }\end{array}$ & $\begin{array}{c}\text { Discharge } \\
(\mathrm{cfs})\end{array}$ \\
\hline 1951 & $\begin{array}{l}\text { Oct. } \\
\text { Apr. } \\
\text { May }\end{array}$ & $\begin{array}{ll}30, & 1950 \\
15, & 1951 \\
11, & 1951\end{array}$ & $\begin{array}{l}3.39 \\
3.36 \\
3.35\end{array}$ & $\begin{array}{l}40 \\
36 \\
35\end{array}$ & 1956 & $\begin{array}{l}\text { Dec. } \\
\text { Jan. } \\
\text { May } \\
\text { May }\end{array}$ & $\begin{array}{rr}23, & 1955 \\
8, & 1956 \\
4, & 1956 \\
22, & 1956\end{array}$ & $\begin{array}{l}3.95 \\
3.33 \\
3.58 \\
3.88\end{array}$ & $\begin{array}{r}174 \\
37 \\
83 \\
156\end{array}$ \\
\hline 1952 & $\begin{array}{l}\text { May } \\
\text { June }\end{array}$ & $\begin{array}{rr}26, & 1952 \\
6, & 1952\end{array}$ & $\begin{array}{l}3.91 \\
3.73\end{array}$ & $\begin{array}{l}154 \\
107\end{array}$ & 1957 & May & 18, 1957 & & 143 \\
\hline 1953 & $\begin{array}{l}\text { Apr. } \\
\text { May } \\
\text { May } \\
\text { May }\end{array}$ & $\begin{array}{rr}27, & 1953 \\
5, & 1953 \\
21, & 1953 \\
30, & 1953\end{array}$ & $\begin{array}{l}3.44 \\
3.42 \\
3.69 \\
3.44\end{array}$ & $\begin{array}{l}48 \\
45 \\
98 \\
48\end{array}$ & 1958 & $\begin{array}{l}\text { Feb. } \\
\text { May } \\
\text { June }\end{array}$ & $\begin{array}{ll}25, & 1958 \\
21, & 1958 \\
12, & 1958\end{array}$ & $\begin{array}{l}3.92 \\
3.92 \\
3.59\end{array}$ & $\begin{array}{r}153 \\
153 \\
74\end{array}$ \\
\hline 1954 & $\begin{array}{l}\text { Apr. } \\
\text { May }\end{array}$ & $\begin{array}{rr}25, & 1954 \\
8, & 1954\end{array}$ & $\begin{array}{l}3.49 \\
3.68\end{array}$ & $\begin{array}{l}57 \\
96\end{array}$ & $\begin{array}{l}1959 \\
1960\end{array}$ & $\begin{array}{l}\text { Apr. } \\
\text { Apr. }\end{array}$ & $\begin{array}{l}26,1959 \\
20,1960\end{array}$ & $\begin{array}{l}3.25 \\
3.29\end{array}$ & $\begin{array}{l}28 \\
33\end{array}$ \\
\hline 1955 & May & 10,1955 & 3.25 & 24 & 1961 & May & 10,1961 & 3.27 & 30 \\
\hline 1956 & Dec. & 20,1955 & 3.38 & 39 & & & & & \\
\hline
\end{tabular}

\section{WARNER LAKES BASIN}

3660. Twentymile Creek near Adel, oreg.

(Published as "near Warner.Lake" 1910-22)

Location.--Lat $42^{\circ} 04^{\prime}$, long $119^{\circ} 57^{\prime}$, and NW $\frac{1}{4}$ sec.25, T.40 S., R.23 E., on left bank 8 miles downstream from confluence of Twelvemile and Fifteenmile Creeks and 8 miles southwest of Ade1.

Dralnage area.--194 $\mathrm{sq} \mathrm{mi}$, Including $46 \mathrm{sq} \mathrm{mi}$ in Cowhead Lake area. Mean altitude, $5,800 \mathrm{ft}$.

Gage.--Nonrecording at times prior to Sept. 21, 1940, at sites within I mile downstream at various datums; recording otherwise. Concrete control since June 28, 1952. Sept. 21, 1940, to Nov. 30, 1944, at site $1 \frac{3}{4}$ miles upstream at different datums. Mar. 12, 1945, to June 28, 1952 , at site $70 \mathrm{ft}$ upstream at datum $0.88 \mathrm{ft}$ higher. Datum of gage is $4,560.83 \mathrm{ft}$ above mean sea level, datum of 1929, supplementary adjustment of 1947.

Stage-discharge relation.--Defined by current-meter measurements below $603 \mathrm{cfs}$ and by contracted-opening measurement at 3,260 cfs.

Remarks.--Base for partial-duration series, $510 \mathrm{cfs}$. Only annual peaks are shown prior to 1941 .

Peak stages and discharges

\begin{tabular}{|c|c|c|c|c|c|c|c|}
\hline $\begin{array}{l}\text { Water } \\
\text { year }\end{array}$ & Date & $\begin{array}{c}\text { Gage } \\
\text { helght } \\
\text { (feet) }\end{array}$ & $\begin{array}{c}\text { Discharge } \\
(\mathrm{cfs})\end{array}$ & $\begin{array}{l}\text { Water } \\
\text { year }\end{array}$ & Date & $\begin{array}{c}\text { Gage } \\
\text { height } \\
\text { (feet) }\end{array}$ & $\begin{array}{c}\text { Discharge } \\
\text { (cfs) }\end{array}$ \\
\hline \multirow{2}{*}{$\begin{array}{l}1911 \\
1912 \\
1913 \\
1914 \\
1915\end{array}$} & \multirow{4}{*}{$\begin{array}{l}\text { Mar. } 30,1911 \\
\text { Mar. } 26,1912 \\
\text { Mar. } 30,1913 \\
\text { Mar. } 6,1914 \\
\text { May } 10,1915 \\
\text { Mar.140r15, } 1916 \\
\text { Mar. 18, } 1918 \\
\text { Apr. 4, } 1919\end{array}$} & \multirow{2}{*}{$\begin{array}{l}6.2 \\
4.2 \\
5.3 \\
6.5 \\
6.1\end{array}$} & \multirow{2}{*}{$\begin{array}{r}a 1,170 \\
464 \\
a 770 \\
1,140 \\
a 1,020\end{array}$} & $\begin{array}{l}1921 \\
1922 \\
\end{array}$ & $\begin{array}{l}\text { Mar. } 4,1921 \\
\text { Apr. } 26-27,1922\end{array}$ & $\begin{array}{l}9.2 \\
8.0 \\
\end{array}$ & $\begin{array}{l}2,000 \\
1,500 \\
\end{array}$ \\
\hline & & & & 1941 & $\begin{array}{l}\text { Feb. } 28,1941 \\
\text { Mar. 11, } 1941 \\
\text { Mar. } 17,1941\end{array}$ & $\begin{array}{l}2.87 \\
2.42 \\
2.74\end{array}$ & \multirow{3}{*}{$\begin{array}{r}1,060 \\
633 \\
935 \\
1,460 \\
660 \\
598\end{array}$} \\
\hline 1916 & & & & 1942 & Jan. 27, 1942 & 3.24 & \\
\hline $\begin{array}{l}1918 \\
1919 \\
\end{array}$ & & $\begin{array}{l}4.0 \\
9.6\end{array}$ & $\begin{array}{r}a 380 \\
a 2,400\end{array}$ & & $\begin{array}{l}\text { Apr. } 3,1942 \\
\text { May } 12,1942\end{array}$ & $\begin{array}{l}2.45 \\
2.38\end{array}$ & \\
\hline
\end{tabular}


Peak stages and discharges of Twentymlle Creek near Adel, Oreg.--Cont1nued

\begin{tabular}{|c|c|c|c|c|c|c|c|}
\hline $\begin{array}{l}\text { Water } \\
\text { year }\end{array}$ & Date & $\begin{array}{c}\text { Gage } \\
\text { he1ght } \\
\text { (feet) }\end{array}$ & $\begin{array}{c}\text { Discharge } \\
(\mathrm{cfs})\end{array}$ & $\begin{array}{l}\text { Water } \\
\text { year }\end{array}$ & Date & $\begin{array}{l}\text { Gage } \\
\text { helght } \\
\text { (feet) }\end{array}$ & $\begin{array}{c}\text { Digcharge } \\
(\mathrm{cfs})\end{array}$ \\
\hline 1943 & $\begin{array}{l}\text { Dec. } 27,1942 \\
\text { Dec. } 31,1942 \\
\text { Mar. } 8,1943 \\
\text { Mar. } 13,1943 \\
\text { Mar. } 26,1943 \\
\text { Apr. } 1,1943\end{array}$ & $\begin{array}{l}4.28 \\
2.82 \\
3.76 \\
3.57 \\
4.24 \\
2.35\end{array}$ & $\begin{array}{r}3,000 \\
1,020 \\
2,170 \\
1,900 \\
2,930 \\
615\end{array}$ & $\begin{array}{l}1953 \\
1954\end{array}$ & $\begin{array}{l}\text { June } 7,1953 \\
\text { Feb. 23, } 1954 \\
\text { Mar. 9, } 1954 \\
\text { Apr. 30, } 1955\end{array}$ & $\begin{array}{l}7.34 \\
4.62 \\
8.32 \\
4.93\end{array}$ & $\begin{array}{r}1,240 \\
564 \\
1,480 \\
520\end{array}$ \\
\hline 1944 & Mar. 17,1944 & 2.51 & 340 & \multirow[t]{2}{*}{1956} & \multirow{3}{*}{$\begin{array}{l}\text { Dec. } 19,1955 \\
\text { Dec. } 23,1955 \\
\text { Jan. } 15,1956 \\
\text { Jan. } 22,1956 \\
\text { Mar. } 24,1956 \\
\text { Mar. 29, } 1956 \\
\text { Dec. 11, } 1956 \\
\text { Feb. 24, } 1957 \\
\text { Mar. 5, } 1957\end{array}$} & 9.37 & \multirow{2}{*}{$\begin{array}{r}1,550 \\
3,260 \\
2,320 \\
896 \\
1,230 \\
594\end{array}$} \\
\hline 1945 & $\begin{array}{ll}\text { Apr. } 16, & 1945 \\
\text { June } 6,1945\end{array}$ & $\begin{array}{l}3.92 \\
4.18\end{array}$ & $\begin{array}{l}513 \\
561\end{array}$ & & & $\begin{array}{r}12.12 \\
7.03 \\
8.39\end{array}$ & \\
\hline 1946 & $\begin{array}{l}\text { Dec. 28, } 1945 \\
\text { Feb. } 27,1946 \\
\text { Mar. 9, } 1946 \\
\text { Mar. 19, } 1946\end{array}$ & $\begin{array}{l}9.7 \\
6.93 \\
4.26 \\
4.52\end{array}$ & $\begin{array}{r}1,930 \\
1,170 \\
552 \\
604\end{array}$ & 1957 & & $\begin{array}{r}5.52 \\
7.69 \\
10.41 \\
7.13\end{array}$ & $\begin{array}{r}594 \\
1,100 \\
1,850 \\
966\end{array}$ \\
\hline 1947 & Feb. 12,1947 & 7.90 & 1,420 & \multirow[t]{2}{*}{1958} & \multirow[b]{2}{*}{$\begin{array}{l}\text { Feb. } 12,1958 \\
\text { Feb. } 16,1958 \\
\text { Feb. 24, } 1958 \\
\text { Mar. 20, } 1958 \\
\text { Mar. 26, } 1958 \\
\text { Apr. 17, } 1958\end{array}$} & \multirow{2}{*}{$\begin{array}{r}7.13 \\
8.69 \\
12.01 \\
6.41 \\
5.45 \\
7.65\end{array}$} & \multirow{2}{*}{$\begin{array}{r}966 \\
1,350 \\
2,340 \\
800 \\
594 \\
1,090\end{array}$} \\
\hline 1949 & $\begin{array}{lll}\text { Apr. } & 14, & 1948 \\
\text { May } & 21, & 1948 \\
\text { June } & 5, & 1948 \\
\text { Apr. } & 8, & 1949\end{array}$ & $\begin{array}{l}5.21 \\
4.84 \\
7.58 \\
6.19\end{array}$ & $\begin{array}{r}742 \\
678 \\
1,340 \\
988\end{array}$ & & & & \\
\hline 1950 & $\begin{array}{l}\text { Jan. } 21,1950 \\
\text { Feb. } 19,1950 \\
\text { Feb. } 24,1950 \\
\text { Mar. } 17,1950 \\
\text { Mar. 19, } 1950 \\
\text { Mar. 31, } 1950\end{array}$ & $\begin{array}{l}4.05 \\
4.03 \\
5.51 \\
6.34 \\
4.57 \\
4.40\end{array}$ & $\begin{array}{r}540 \\
537 \\
832 \\
1,020 \\
652 \\
610\end{array}$ & $\begin{array}{l}1959 \\
1960\end{array}$ & $\begin{array}{l}\text { Mar. } 13,1959 \\
\text { Mar. } 7,1960 \\
\text { Mar. 13, } 1960 \\
\text { Mar. 18, } 1960\end{array}$ & $\begin{array}{l}3.53 \\
8.66 \\
5.37 \\
6.77\end{array}$ & $\begin{array}{r}204 \\
1,440 \\
612 \\
962\end{array}$ \\
\hline 1951 & Feb. 7,1951 & 9.8 & 1,990 & \multirow{3}{*}{$\begin{array}{l}1961 \\
1962 \\
1963\end{array}$} & \multirow{3}{*}{$\begin{array}{l}\text { Mar. 28, } 1961 \\
\text { Mar. 27, } 1962 \\
\text { Apr. 7, } 1962 \\
\text { May 21, } 1962 \\
\text { Oct. 13, } 1962 \\
\text { Dec. 2, } 1962 \\
\text { Feb. 1, } 1963 \\
\text { Feb. 3, } 1963 \\
\text { Apr. } 6,1963 \\
\text { Apr. 17, } 1963 \\
\text { Apr. 27, } 1963 \\
\text { May 11, } 1963\end{array}$} & \multirow{3}{*}{$\begin{array}{r}4.05 \\
6.28 \\
9.28 \\
6.50 \\
8.72 \\
10.82 \\
14.4 \\
11.75 \\
11.63 \\
5.40 \\
7.07 \\
5.05\end{array}$} & \multirow{3}{*}{$\begin{array}{r}306 \\
840 \\
1,620 \\
895 \\
1,460 \\
2,090 \\
3,160 \\
2,360 \\
2,330 \\
608 \\
1,040 \\
534\end{array}$} \\
\hline 1952 & $\begin{array}{l}\text { Mar. } 28,1952 \\
\text { Apr. } 6,1952 \\
\text { Apr. } 18,1952 \\
\text { Apr. } 25,1952\end{array}$ & $\begin{array}{l}5.79 \\
9.85 \\
8.74 \\
9.83 \\
\end{array}$ & $\begin{array}{r}888 \\
2,000 \\
1,670 \\
2,000 \\
\end{array}$ & & & & \\
\hline 1953 & $\begin{array}{l}\text { Jan. } 9,1953 \\
\text { Jan. 13, } 1953 \\
\text { Jan. 18, } 1953 \\
\text { Feb. 6, } 1953 \\
\text { Mar. 23, } 1953 \\
\text { May 19, } 1953\end{array}$ & $\begin{array}{l}7.05 \\
6.79 \\
9.16 \\
6.00 \\
8.23 \\
7.50\end{array}$ & $\begin{array}{r}1,160 \\
1,100 \\
1,690 \\
910 \\
1,460 \\
1,280\end{array}$ & & & & \\
\hline
\end{tabular}

3700. Camas Creek near Lakeview, Oreg.

Location.--Lat $42^{\circ} 13^{\prime}$, long $120^{\circ} 06^{\prime}$, in NW $\frac{1}{4}$ sec.2, T.39 S., R.22 E., on left bank 0.2 mile downstream from Blue Creek and 12 miles east of Lakeview.

Drainage area. $--63 \mathrm{sq} \mathrm{mi}$, approximately. Mean altitude, 6,210 ft.

Gage.--Nonrecording or recording prior to May 10, 1915, at site $500 \mathrm{ft}$ upstream at different datum; recording thereafter. Datum of gage is 5,472.41 ft above mean sea level (State Highway Department bench mark).

Stage-discharge relation.--Defined by current-meter measurements below $340 \mathrm{cfs}$ and by slope-area measurement at 1,630 cfs.

Remarks.--Diversions for 1rrigation of 1,200 acres above station. Base for partial-duration series, $290 \mathrm{cfs}$.

Peak stages and discharges

\begin{tabular}{|c|c|c|c|c|c|c|c|}
\hline $\begin{array}{l}\text { Water } \\
\text { year }\end{array}$ & Date & $\begin{array}{c}\text { Gage } \\
\text { helght } \\
\text { (feet) }\end{array}$ & $\begin{array}{c}\text { D1 scharge } \\
(\text { cfs })\end{array}$ & $\begin{array}{l}\text { Water } \\
\text { year }\end{array}$ & Date & $\begin{array}{c}\text { Gage } \\
\text { he1ght } \\
\text { (feet) }\end{array}$ & $\begin{array}{c}\text { D1 scharge } \\
(\text { cfs })\end{array}$ \\
\hline $\begin{array}{r}1913 \\
1914 \\
\end{array}$ & $\begin{array}{l}\text { Apr. 22, } 1913 \\
\text { Apr. 10, } 1914 \\
\end{array}$ & $\begin{array}{l}3.34 \\
4.47 \\
\end{array}$ & $\begin{array}{r}2255 \\
454 \\
\end{array}$ & \multirow{3}{*}{$\begin{array}{l}1952 \\
1953\end{array}$} & \multirow{3}{*}{ 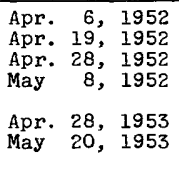 } & \multirow{3}{*}{$\begin{array}{l}3.47 \\
3.94 \\
4.24 \\
3.69 \\
3.50 \\
3.76\end{array}$} & \multirow{3}{*}{$\begin{array}{l}376 \\
536 \\
660 \\
447 \\
390 \\
471\end{array}$} \\
\hline 1950 & Apr. 22, 1950 & 3.46 & 340 & & & & \\
\hline 1951 & $\begin{array}{ll}\text { Apr. } & 10, \\
\text { May } 11, & 1951\end{array}$ & $\begin{array}{l}3.53 \\
3.16\end{array}$ & $\begin{array}{l}394 \\
290\end{array}$ & & & & \\
\hline
\end{tabular}

a Maximum observed. 
Peak stages and discharges of Camas Creek near Lakeview, Oreg.--Continued

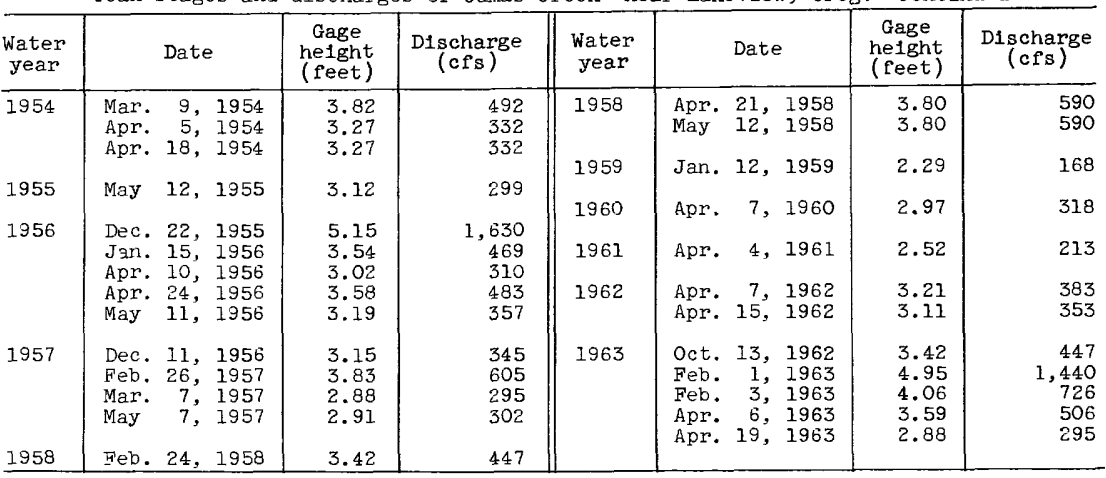

3710. Drake Creek near Adel, Oreg.

Location.--Lat $42^{\circ} 12^{\prime}$, long $120^{\circ} 00^{\prime}$, near center of sec.9, T.39 S., R.23 E., on left bank $800 \mathrm{ft}$ downstream from highway bridge and Parsnip Creek, $1 \mathrm{mile}$ upstream from mouth, and $6 \frac{1}{2}$ miles west of Adel.

Drainage area. $--67 \mathrm{sq} \mathrm{mi,} \mathrm{approximately.} \mathrm{Mean} \mathrm{altitude,} \mathrm{5,880} \mathrm{ft.}$

Gage.--Nonrecording prior to May 10, 1923, at site $800 \mathrm{ft}$ upstream at different datums; recording thereafter. Dec. 16, 1949, to June 21, 1951, at site $1,300 \mathrm{ft}$ upstream at different datum. Datum of gage is 5,075.42 $\mathrm{ft}$ above mean sea level (State Highway Department bench mark).

Stage-discharge relation.--Defined by current-meter measurements below 300 cfs and extended above by slope-area measurement at 4,050 cfs.

Remarks.--Diversions for irrigation of about 620 acres above station. Base for partial-duration series, $150 \mathrm{cfs}$. Only annual peaks are shown prior to 1950 .

Peak stages and discharges

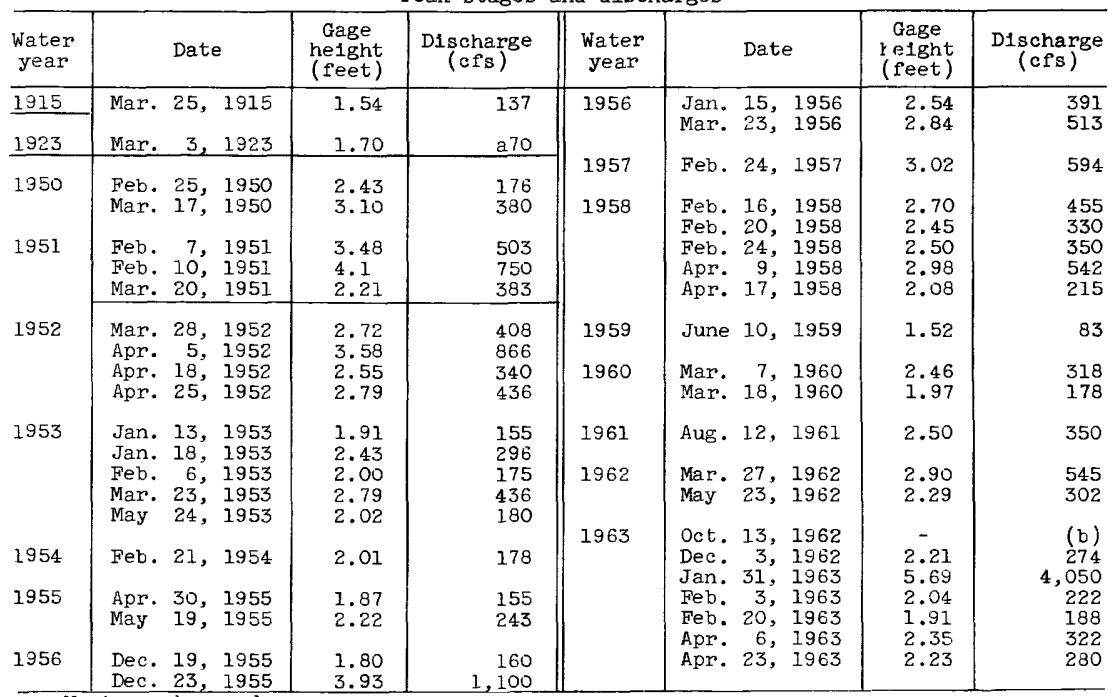

a Maximum observed.

b Peak above base, discharge not determined. 
3715. Deep Creek above Adel, Oreg.

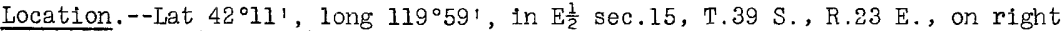
bank 0.3 mile downstream from Drake Creek and 5 miles west of Adel.

Drainage area. $--249 \mathrm{sq} \mathrm{mi}$. Mean altitude, 6,110 ft.

Gage.--Recording. Dec. 21, 1922, to Sept. 30, 1923, at different datum. Datum of gage is 4,966.7 ft above mean sea level (State Highway Department bench mark).

Stage-discharge relation.--Defined by current-meter measurements below 1,300 cfs on basis of velocity-area studies and by slope-area measurement at gage height, $7.3 \mathrm{ft}^{2}$.

Remarks.--Diversions for irrigation of 5,500 acres above station. Base for partial-duration series, $600 \mathrm{cfs}$.

Peak stages and discharges

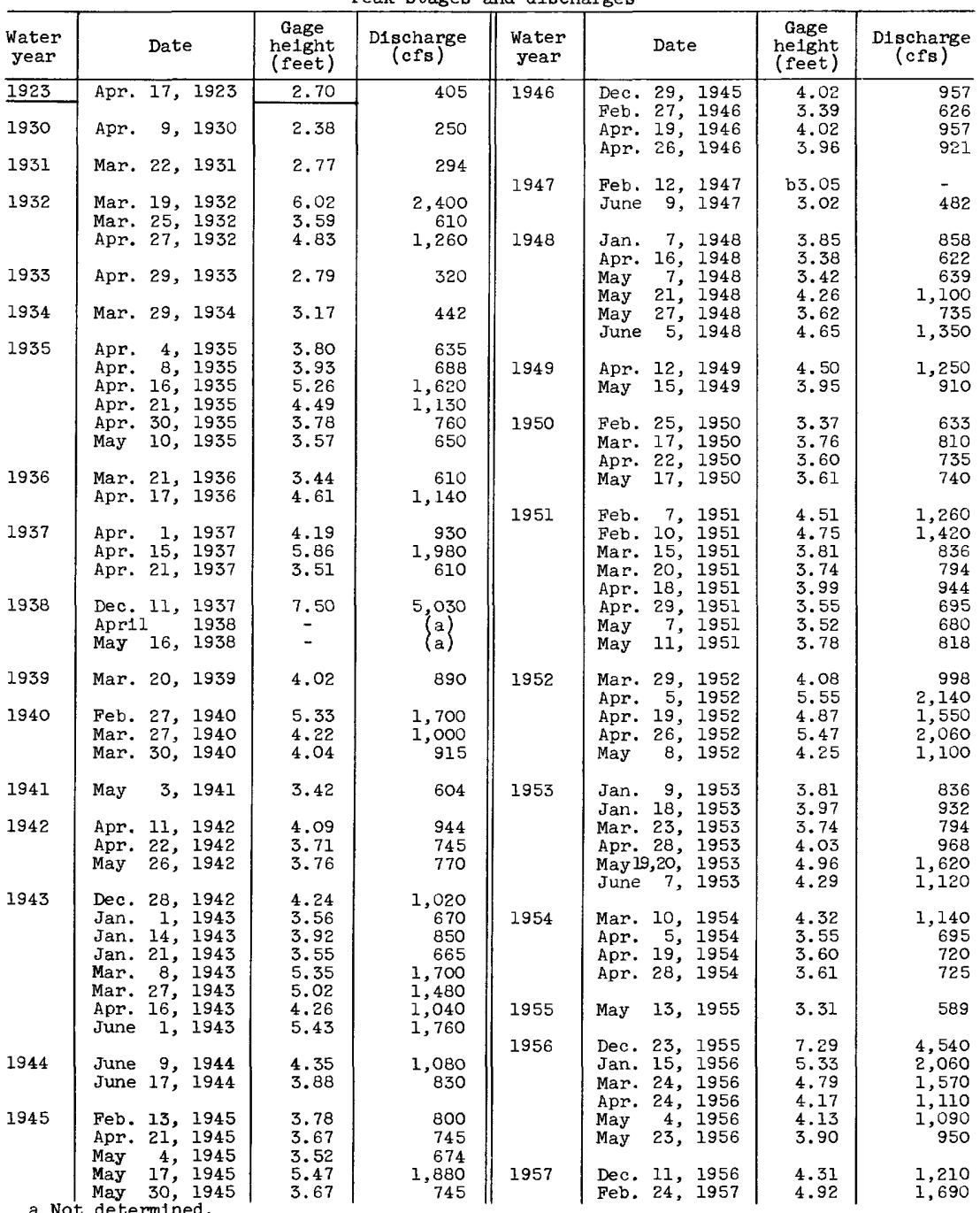

b Backwater from 1ce. 
Peak stages and discharges of Deep Creek above Adel, Oreg.--continued

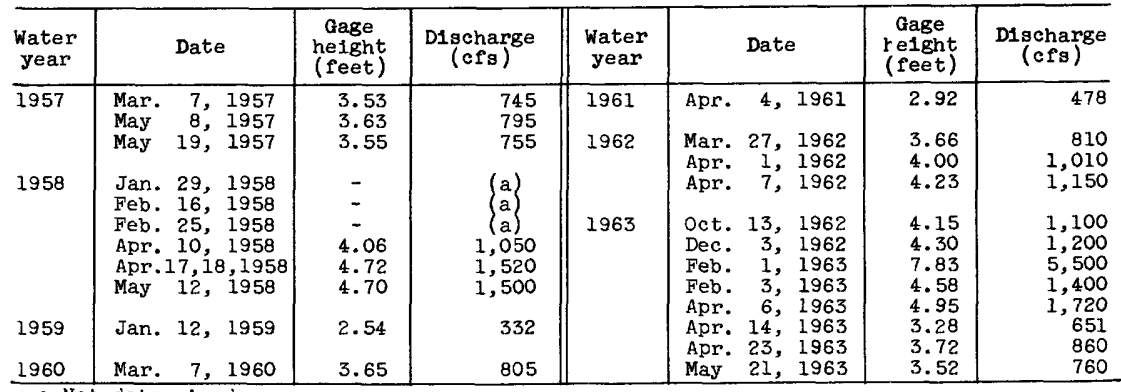

a Not determined.

3745. Deep Creek at Ade1, Oreg.

Location.--Lat $42^{\circ} 10^{\prime}$, long $119^{\circ} 54^{\prime}$, near center of sec.21, T.3 S S., R.24 E., on left bank at south edge of Adel and an eighth of a mile urstream from highway bridge.

Drainage area. $--274 \mathrm{sq} \mathrm{ml}$.

Gage.--Nonrecording prior to Mar. 10, 1914, and 1918-19; recording during remainder of perlod. Altitude of gage is 4,500 ft (from topographic map).

Stage-discharge relation.--Defined by current-meter measurements below 3,400 cfs and extended above by logarithmic plotting.

Remarks:--Flooding of lowlands during high-flow season, and by five canals within 2 miles upstream from station. Only annual peaks are shown (maximum observed prior to 1915).

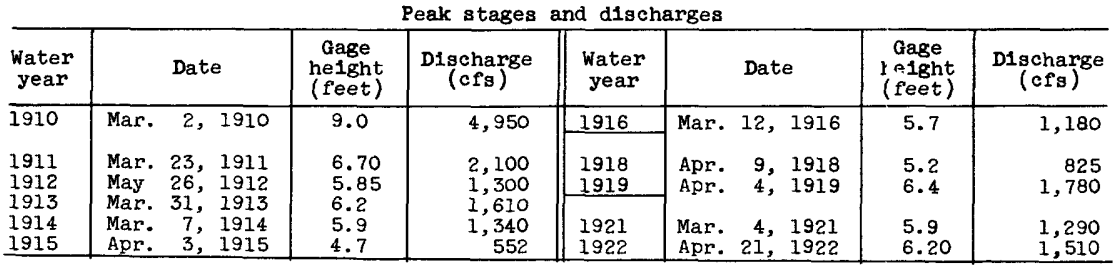

3785. Honey Creek near Plush, Oreg.

Location.--Lat $42^{\circ} 25^{\prime}$, long $119^{\circ} 55^{\prime}$, in NW $\frac{1}{4}$ sec.29, T.36 S., R.24 E., on right bank at mouth of canyon, 1 mile northwest of Plush and 4 miles downstream
from Twelvemile Creek.

Drainage area.--170 sq $\mathrm{ml}$, approximately. Mean altitude, 5,910 ft.

Gage.--Nonrecording prior to Jan, 13, 1912, Mar. 15 to Apr. 6, 1921, and Mar. 19 to June 30,1922 ; recording otherwise. Prior to Feb. 24, 1910, at site half a mile downstream at different datum. Feb. 24, 19j.0, to May 16, 1915, and Mar. 15, 1921, to June 30, 1922, half a mile upstream at different datums. May 1,1930 , to Aug. 30, 1959, $600 \mathrm{ft}$ downstream at datum $10.93 \mathrm{ft}$ lower and Sept. 1, 1959, to Aug. 21 , 1963 , at datum 12.46 ft lower. Datum of gage is $4,548.93 \mathrm{ft}$ above mean sea level, datum of .1929 , supplementary

Stage-discharge relation.--Defined by current-meter measurements below 2,300 cf's prior to Sept. I, 1959; defined by current-meter measurements below $80 \mathrm{cfs}$ and extended above on basis of slope-area measurement at $6,210 \mathrm{cfs}$.

Remarks.--Diversions for irrigation of about 2,300 acres above $s$ tation. Base for partial-duration series, $200 \mathrm{cfs}$. Only annual peaks are shown prior to
1912 . 
Peak stages and discharges of Honey Creek near Plush, Oreg.

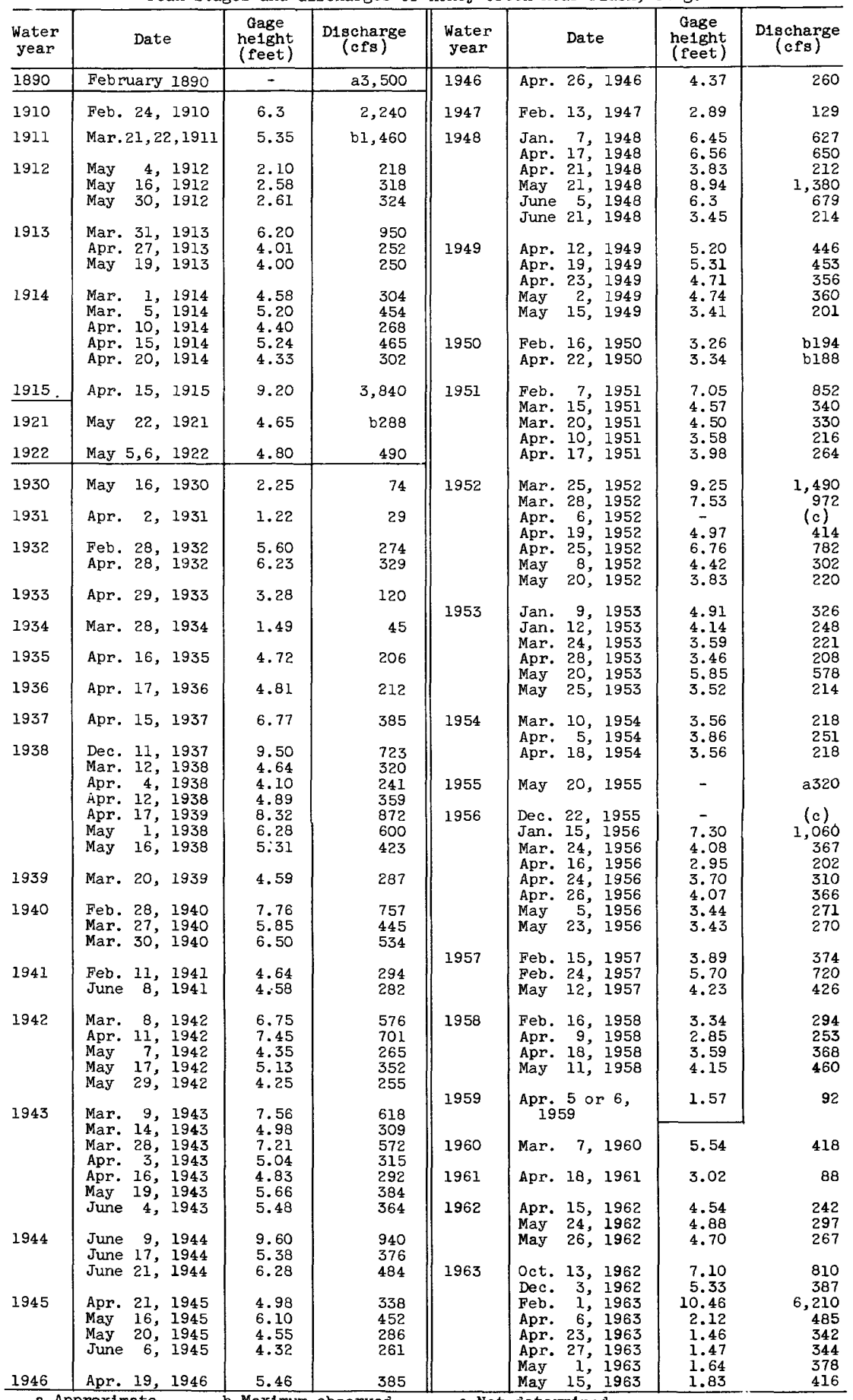


3840. Chewaucan River near Paisley, Oreg.

(Published as "above Conn ditch" prior to 1913 and from 1925 to 1955 , as "above Mi11 Creek" in 1913, and as "at Chewaucan Land \& Cattle Co. gage" in 1914)

Location. --Lat $42^{\circ} 42^{\prime}$, long $120^{\circ} 35^{\prime}$, in SW $\frac{1}{4} N W \frac{1}{4}$ sec. 26 , T.33 S., R.18 E., on left bank $1 \frac{1}{2}$ miles downstream from Mill Creek and $1 \frac{1}{2}$ miles southwest of

Drainage area. $--275 \mathrm{sq} \mathrm{mi}$. Mean altitude, 6,050 ft.

Gage.--Nonrecording prior to Jan. 20, 1914, and Jan. 27 to Oct. 6, 1956; recording otherwise. Prior to July 14,1912 , at site $1 \frac{1}{4}$ miles upstream at different datum. Nov. 6, 1912, to Sept. 30, 1921, at various sites within half a mile upstream from Mill Creek at various datums. May 1, 1924, to Jan. 26, 1956, at sites about $1 \frac{1}{4}$ miles upstream at different datums. Jan. 27, to oct. 6, 1956, at sites about 1 mile downstream at different datums. Datum of gage is 4,430 ft above mean sea level (river-profile survey).

Stage-discharge relation.--Defined by current-meter measurements.

Remarks.--Diversions for irrigation of about 2,500 acres above station. Base for partial-duration series, $500 \mathrm{cfs}$. Only annual peaks are shown prior to 1925 .

Peak stages and discharges

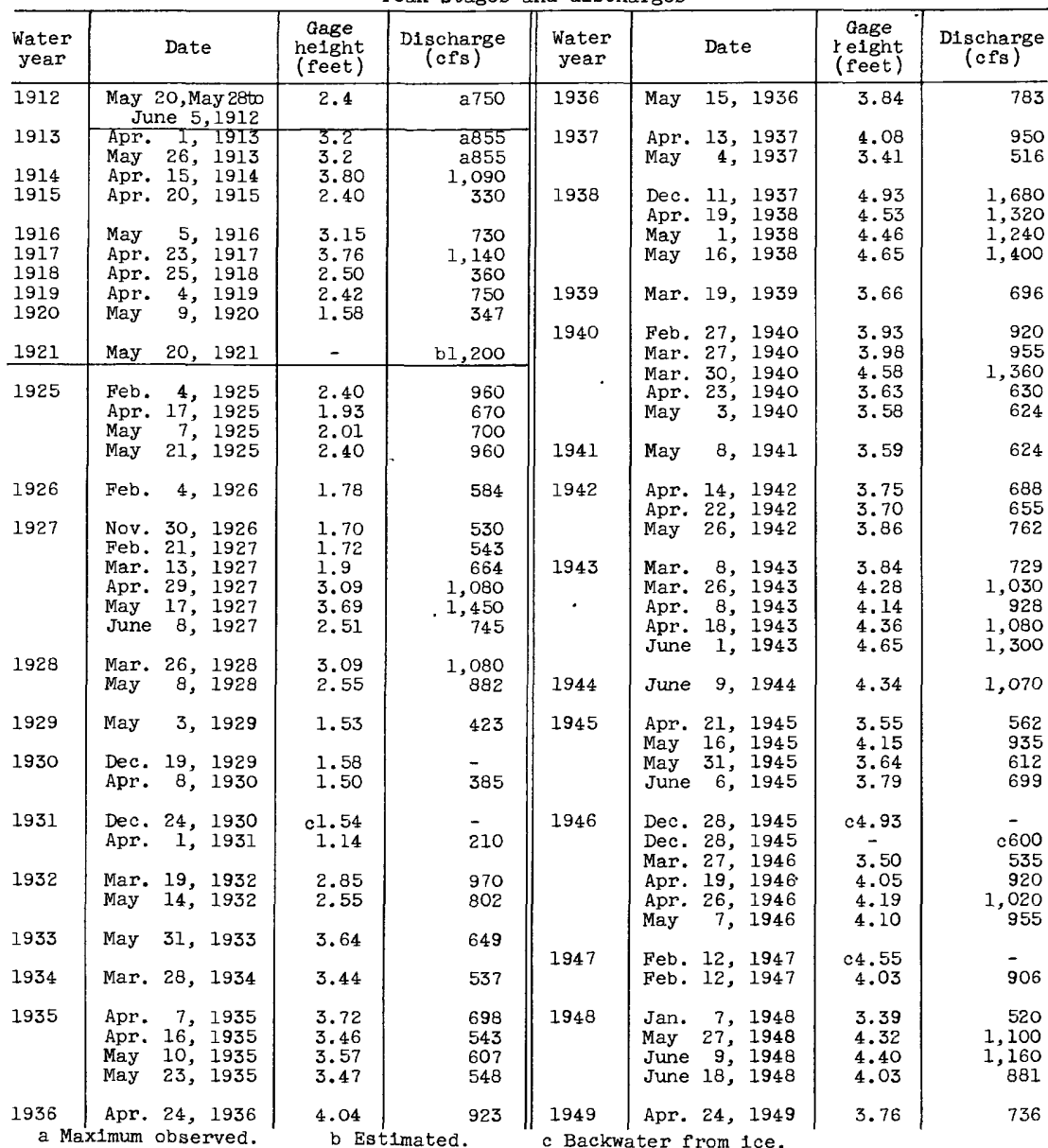


Peak stages and discharges of Chewaucan River near Paisley, Oreg.--Continued

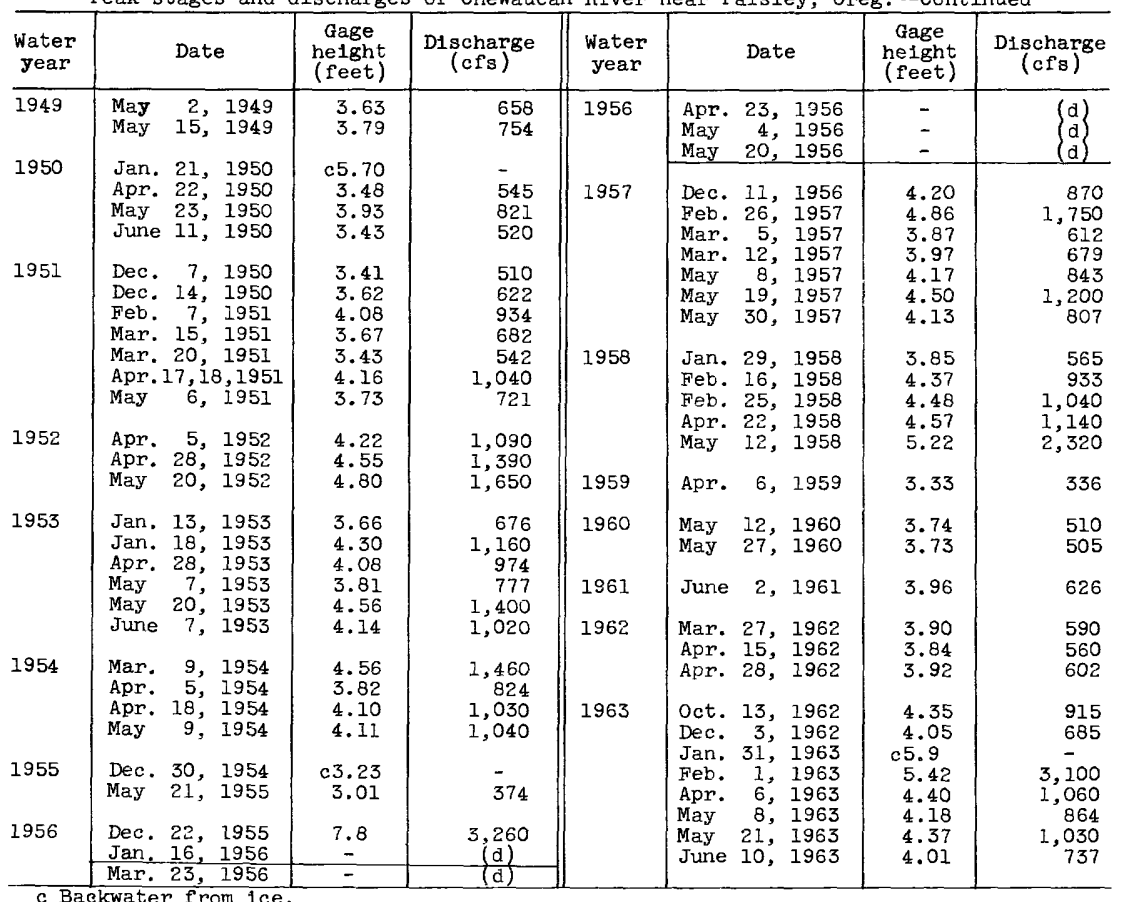

c Backwater from 1ce.

d Not determined.

3841. Chewaucan River at Paisley, Oreg.

Location.--Lat $42^{\circ} 42^{\prime}$, long $120^{\circ} 33^{\prime}$, in SE $\frac{1}{4}$ sec.23, T.33 S., R.18 E., on right

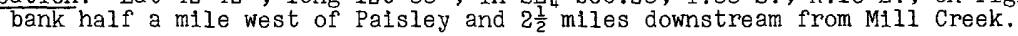

Drainage area. $--278 \mathrm{sq} \mathrm{ml}$.

Gage.--Nonrecording. Altitude of gage is 4,390 ft (from river-profile map).

Stage-discharge relation.--Defined by current-meter measurements below $800 \mathrm{cfs}$.

Bankfull stage. - $-8 \mathrm{ft}$.

Remarks.--Only annual maximum observed discharges are shown.

Maximum observed stages and discharges

\begin{tabular}{|c|c|c|c|c|c|c|c|c|c|}
\hline $\begin{array}{l}\text { Water } \\
\text { year }\end{array}$ & & Date & $\begin{array}{c}\text { Gage } \\
\text { height } \\
\text { (feet) }\end{array}$ & $\begin{array}{c}\text { Discharge } \\
\text { (cfs) }\end{array}$ & $\begin{array}{c}\text { Water } \\
\text { year }\end{array}$ & & Date & $\begin{array}{c}\text { Gage } \\
\text { height } \\
\text { (feet) }\end{array}$ & $\begin{array}{l}\text { Discharge } \\
\text { (cfs) }\end{array}$ \\
\hline 1905 & Jan. & 14,1905 & 5.2 & 332 & $\begin{array}{l}1910 \\
1911 \\
\end{array}$ & \multirow{3}{*}{\multicolumn{2}{|c|}{$\begin{array}{lrl}\text { Nov. } & 23,1909 \\
\text { May } & 5,1911 \\
\text { May } & 28, & 1913\end{array}$}} & \multirow{3}{*}{$\begin{array}{l}9.4 \\
6.8 \\
6.68\end{array}$} & \multirow{3}{*}{$\begin{array}{r}4,000 \\
992 \\
a 868\end{array}$} \\
\hline $\begin{array}{l}1906 \\
1907 \\
\end{array}$ & $\begin{array}{l}\text { May } \\
\text { Feb. }\end{array}$ & $\begin{array}{rr}10, & 1906 \\
4, & 1907\end{array}$ & $\begin{array}{l}7.0 \\
7.8\end{array}$ & $\begin{array}{l}1,000 \\
1,670\end{array}$ & \multirow[t]{2}{*}{1913} & & & & \\
\hline 1909 & May & 5,1909 & 7.1 & 1,180 & & & & & \\
\hline
\end{tabular}

a Maximum observed during period Apr. 17 to May 30 . 
3860. Chewaucan River at narrows, near Paisley, Oneg.

Location.--Lat $42^{\circ} 37^{\prime}$, long $120^{\circ} 25^{\prime}$, in NE $\frac{1}{4}$ sec.24, T.34 S., R.19 E., on left bank at constriction in Chewaucan Marsh and $8 \frac{1}{2}$ miles southeast of Palsley.

Drainage area. $--380 \mathrm{sq} \mathrm{mi}$, approximately.

Gage.--Nonrecording. Prior to Oct. 22 , 1916, at various sites within threequarters of a mile downstream and a quarter of a mile upstream at various datums. Altitude of gage is $4,300 \mathrm{ft}$ (from benchmark 1 mile southeast of station).

Stage-discharge relation.--Defined by current-meter measurements below $300 \mathrm{cfs}$.

Remarks.--Diversions for irrigation of 21,000 acres upstream from station.

Only annual maximum observed discharges are shown.

\begin{tabular}{l|c|c|c||c|c|c|r}
\hline $\begin{array}{c}\text { Water } \\
\text { year }\end{array}$ & Date & $\begin{array}{c}\text { Gage } \\
\text { ne1ght } \\
\text { (feet) }\end{array}$ & $\begin{array}{c}\text { Discharge } \\
\text { (cfs) }\end{array}$ & $\begin{array}{c}\text { Water } \\
\text { year }\end{array}$ & Date & $\begin{array}{c}\text { Gage } \\
\text { height } \\
\text { (feet) }\end{array}$ & $\begin{array}{c}\text { Discharge } \\
\text { (cfs) }\end{array}$ \\
\hline 1914 & Apr. 21, 1914 & 3.50 & 505 & 1918 & Apr. 10, 1918 & 2.4 & 365 \\
1915 & Apr. 26, 1915 & 1.8 & 154 & 1919 & Apr. 21, 1919 & 3.55 & 322 \\
1916 & May 10, 1916 & 3.8 & 366 & 1920 & Feb. 13, 1920 & 1.30 & 67 \\
\cline { 2 - 8 } 1917 & Apr. 24, 1917 & 3.7 & 710 & 1921 & May 21, 1921 & 4.65 & 832 \\
\hline
\end{tabular}

3865. Chewaucan River at Hotchkiss Ford, near Paisley, Oreg.

Location.--Lat $42^{\circ} 33^{\prime}$, long $120^{\circ} 19^{\prime}$, near line between secs. 11 and 12, T. 35 S., R.20 E., on left bank just below lower Chewaucan Marsh, 1 mile upstream from Willow Creek, and 15 miles southeast of Paisley.

Drainage area. $--430 \mathrm{sq} \mathrm{ml}$, approximately.

Gage.--Nonrecording. Prior to Dec. 27, 1918, $150 \mathrm{ft}$ downstream at different datum. Altitude of gage is $4,290 \mathrm{ft}$ (from elevation of Chewaucan Marsh).

Stage-discharge relation.--Defined by current-meter measurements.

Bankfull stage. - $-6 \mathrm{ft}$.

Remarks.--Diversions for irrigation of about 29,000 acres upstream from station. Only annual maximum observed discharges are shown.

Maximum observed stages and discharges

\begin{tabular}{l|c|c|c||c|c|c|r}
\hline $\begin{array}{c}\text { Water } \\
\text { year }\end{array}$ & Date & $\begin{array}{c}\text { Gage } \\
\text { height } \\
\text { (feet) }\end{array}$ & $\begin{array}{c}\text { Discharge } \\
\text { (cfs) }\end{array}$ & $\begin{array}{c}\text { Water } \\
\text { year }\end{array}$ & Date & $\begin{array}{c}\text { Gage } \\
\text { reight } \\
\text { (feet) }\end{array}$ & $\begin{array}{c}\text { Discharge } \\
\text { (cfs) }\end{array}$ \\
\hline 1914 & Apr.21-24,1914 & 4.50 & 400 & 1918 & Apr. 11, 1918 & 2.75 & 172 \\
1915 & Feb. 6, 1915 & 2.0 & 90 & 1919 & Apr. 7, 1919 & 4.70 & 108 \\
1916 & May 26, 1916 & 3.80 & 260 & 1920 & Jan. 29, 1920 & 1.95 & 72 \\
1917 & Apr. 26, 1917 & 4.55 & 506 & 1921 & May 1921 & - & $(\mathrm{a})$ \\
\hline
\end{tabular}

a Maximum between May 20 and 29 when water went over gage $(6.0 \mathrm{ft}$ ) ant exceeded $515 \mathrm{cf}$ s. 
3880. Ana River near Summer Lake, Oreg.

Location,--Lat $43^{\circ} 00^{1}$, long $120^{\circ} 45^{1}$, in SEl sec.6, T.30 S., R.17 E., on left bank 300 ft downstream from diversion dam and 2 miles northeast of town of Summer Lake.

Drainage area.--Indeterminate. Flow is almost entirely from springs within a mile upstream from gage site.

Gage.--Recording. Oct. 1, 1930, to Sept. 30, 1939, at site $80 \mathrm{ft}$ downstream at different datum. Altitude of gage is $4,160 \mathrm{ft}$ (from plans of Ana River diversion dam).

Stage-discharge relation.--Defined by current-meter measurements below $1.00 \mathrm{cfs}$.

Remarks. - All records presented herein include flow in Summer Lake Canal. which diverts $300 \mathrm{ft}$ above station for irrigation of lands along west side of Summer Lake. Source of stream is Ana River Springs, three-quarters of a mile above station, which are flooded over by pondage behind diversion dam. only annual peaks are shown.

\begin{tabular}{|c|c|c|c|c|c|c|c|}
\hline $\begin{array}{l}\text { Water } \\
\text { year }\end{array}$ & Date & $\begin{array}{c}\text { Gage } \\
\text { helght } \\
\text { (feet) }\end{array}$ & $\begin{array}{c}\text { Discharge } \\
(\mathrm{cfs})\end{array}$ & $\begin{array}{l}\text { Water } \\
\text { year }\end{array}$ & Date & $\begin{array}{l}\text { Gage } \\
\text { helght } \\
\text { (feet) }\end{array}$ & $\begin{array}{c}\text { Discharge } \\
(\mathrm{cfs})\end{array}$ \\
\hline $\begin{array}{l}1931 \\
1932 \\
1933 \\
1934 \\
\end{array}$ & $\begin{array}{lrr}\text { Nov. } 5, & 1930 \\
\text { May } 29, & 1932 \\
\text { June } 8, & 1933 \\
\text { Sept. } 10, & 1934\end{array}$ & $\begin{array}{l}3.53 \\
3.64 \\
3.77 \\
2.68\end{array}$ & $\begin{array}{l}172 \\
170 \\
176 \\
106\end{array}$ & \multirow{3}{*}{$\begin{array}{l}1955 \\
1956 \\
1957 \\
1958 \\
1959 \\
1960 \\
1961 \\
1962 \\
1963\end{array}$} & \multirow{3}{*}{$\begin{array}{l}\text { Sept.29, } 1955 \\
\text { Oct. 16, } 1955 \\
\text { Oct.5,6, } 1956 \\
\text { Dec. 7, } 1957 \text {, } \\
\text { Mar. 21, } 1958 \\
\text { Aug. 20, } 1959 \\
\text { Oct. 2, } 1959 \\
\text { Oct. 26, } 1960 \text {, } \\
\text { Sept.30, } 1961 \\
\text { Nov. 25, } 1961 \\
\text { Oct. 1, } 1962\end{array}$} & \multirow{3}{*}{$\begin{array}{l}2.80 \\
2.94 \\
2.69 \\
2.75 \\
= \\
- \\
- \\
- \\
-\end{array}$} & \multirow[t]{2}{*}{$\begin{array}{l}110 \\
124 \\
102 \\
118\end{array}$} \\
\hline $\begin{array}{l}1936 \\
1937 \\
1935 \\
1939 \\
\end{array}$ & $\begin{array}{l}\text { Sept.15, } 1936 \\
\text { Mar. 17, } 1937 \\
\text { Mar. 31, } 1938 \\
\text { Dec. 14, } 1938 \\
\end{array}$ & $\begin{array}{l}3.87 \\
3.20 \\
4.02 \\
3.05 \\
\end{array}$ & $\begin{array}{l}186 \\
122 \\
156 \\
117 \\
\end{array}$ & & & & \\
\hline $\begin{array}{l}1952 \\
1953 \\
1954 \\
\end{array}$ & $\begin{array}{lll}\text { Oct. } & 5,1951 \\
\text { Aug. } & 9, & 1953 \\
\text { Oct. } & 3, & 1953\end{array}$ & $\begin{array}{c}3.05 \\
- \\
-\end{array}$ & $\begin{array}{l}112 \\
145 \\
101\end{array}$ & & & & $\begin{array}{l}110 \\
129 \\
\end{array}$ \\
\hline
\end{tabular}

\section{SILVER LAKE BASIN}

3890. West Fork Silver Creek near Silver Lake, Oreg.

Location. --Lat $43^{\circ} 05^{\prime}$, long $121^{\circ} 05^{\prime}$, in NW $\frac{1}{4} \sec .8$, T.29 S., R.14 E., on left bank three-quarters of a mile upstream from mouth and 4 miles southwest of Silver Lake.

Drainage area. $--27 \mathrm{sq} \mathrm{ml}$, approximately.

Gage.--Recording, except nonrecording March to September 1928. Prior to

Oct. 18, 1921, at site half a mile downstream at different datum. Altitude of gage is $4,570 \mathrm{ft}$ (from levels to former gage).

Stage-discharge relation.--Defined by current-meter measurements below $20 \mathrm{cfs}$ prior to 1921, and below 90 cf's thereafter.

Bankfull stage. $--4 \mathrm{ft}$.

Remarks.--Records for water years 1929-32, furnished by State engineer of

Oregon. Only annual peaks are shown.

Peak stages and discharges

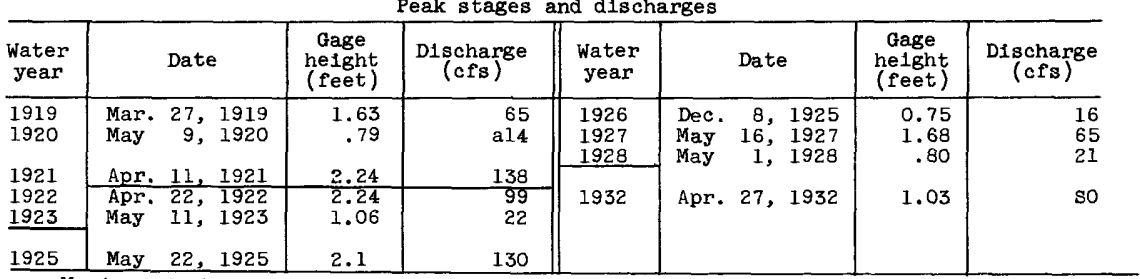

a Maximum during period Mar. 21 to July $31,1920$. 
3900. Silver Creek near Silver Lake, Oreg.

Location.--Lat $43^{\circ} 06^{1} 40^{\prime \prime}$, long $121^{\circ} 04^{\prime} 05^{\prime \prime}$, in SW $\frac{1}{4}$ sec.28, T.28 S, R.14 E, on right bank 1.5 miles downstream from diversion dam of Silver Lake Irrigation District, 1.5 miles southwest of town of Silver Lake, and 3 miles upstream from Bridge Creek.

Drainage area. $--180 \mathrm{sq} \mathrm{mi}$, approximately.

Gage.--Nonrecording prior to Mar. 24, 1919, 1923-27, and 1929; recording during remainder of period. Concrete control since Sept. 15, 1932. Datum lowered $1.00 \mathrm{ft}$ May 24, 1932. Datum of gage is $4,361.32 \mathrm{ft}$ above məan sea level, datum of 1929 .

Stage-discharge relation. --Defined by current-meter measurements below $700 \mathrm{cfs}$ and extended on basis of slope-area measurement at $900 \mathrm{cfs}$.

Bankfull stage. $--9 \mathrm{ft}$.

Remarks:--Flow regulated by reservoir (capacity, 800 acre-ft) above diversion dam 1.5 miles above station and by Thompson Valley Reservoir (capacity, 17,400 acre-ft) 11 miles above station. Silver Lake Irrigation District

Canal diverted 1.5 miles above station 1923-43. Only annual peaks are shown.

Peak stages and discharges

\begin{tabular}{|c|c|c|c|c|c|c|c|c|c|}
\hline $\begin{array}{l}\text { Water } \\
\text { year }\end{array}$ & & Date & $\begin{array}{c}\text { Gage } \\
\text { height } \\
\text { (feet) }\end{array}$ & $\underset{(\mathrm{cfs})}{\text { Discharge }}$ & $\begin{array}{c}\text { Water } \\
\text { year }\end{array}$ & & Date & $\begin{array}{c}\text { Gage } \\
\text { he1ght } \\
\text { (feet) }\end{array}$ & $\begin{array}{c}\text { Discharge } \\
\text { (cfs) }\end{array}$ \\
\hline 1905 & Apr. & 5,1905 & 2.8 & a203 & 1935 & May & 15,1935 & 2.57 & 54 \\
\hline $\begin{array}{l}1906 \\
1907 \\
\end{array}$ & $\begin{array}{l}\text { Apr. } \\
\text { Mar. }\end{array}$ & $\begin{array}{rr}9, & 1906 \\
20, & 1907\end{array}$ & $\begin{array}{r}5.52 \\
10.08\end{array}$ & $\begin{array}{r}a 664 \\
b 1,800\end{array}$ & $\begin{array}{l}1936 \\
1937\end{array}$ & $\begin{array}{l}\text { Apr. } \\
\text { Apr. }\end{array}$ & $\begin{array}{ll}13 & 1936 \\
15, & 1937\end{array}$ & $\begin{array}{l}2.43 \\
2.41\end{array}$ & $\begin{array}{r}42 \\
41\end{array}$ \\
\hline $\begin{array}{l}1909 \\
1910\end{array}$ & $\begin{array}{l}\text { May } \\
\text { Nov. }\end{array}$ & $\begin{array}{rr}5, & 1909 \\
23, & 1909\end{array}$ & $\begin{array}{l}4.2 \\
6.40\end{array}$ & $\begin{array}{l}\text { a.368 } \\
\text { a910 }\end{array}$ & $\begin{array}{l}1935 \\
1939 \\
1940\end{array}$ & $\begin{array}{l}\text { May } \\
\text { Apr. } \\
\text { Feb. }\end{array}$ & $\begin{array}{rr}1, & 1938 \\
21, & 1939 \\
28, & 1940\end{array}$ & $\begin{array}{l}4.89 \\
2.31 \\
3.96\end{array}$ & $\begin{array}{r}364 \\
35 \\
222\end{array}$ \\
\hline $\begin{array}{l}1911 \\
1912 \\
1913 \\
1914 \\
1915\end{array}$ & $\begin{array}{l}\text { Apr. } \\
\text { May } \\
\text { Apr. } \\
\text { Mar. } \\
\text { Mar. }\end{array}$ & $\begin{array}{c}2,1911 \\
15-18,1912 \\
26,1913 \\
19,1914 \\
20,1915\end{array}$ & $\begin{array}{l}5.2 \\
3.8 \\
4.0 \\
4.0 \\
1.95\end{array}$ & $\begin{array}{r}\text { a } 576 \\
\text { a.309 } \\
\text { a337 } \\
\text { a350 } \\
\text { a86 }\end{array}$ & $\begin{array}{l}1941 \\
1942 \\
1943 \\
1944 \\
1945\end{array}$ & $\begin{array}{l}\text { July } \\
\text { Apr. } \\
\text { Apr. } \\
\text { June } \\
\text { May }\end{array}$ & $\begin{array}{ll}1, & 1941 \\
15, & 1942 \\
15, & 1943 \\
16, & 1944 \\
29, & 1945\end{array}$ & $\begin{array}{l}2.42 \\
2.51 \\
5.95 \\
2.35 \\
2.46\end{array}$ & $\begin{array}{r}47 \\
54 \\
550 \\
38 \\
49\end{array}$ \\
\hline $\begin{array}{l}1916 \\
1917 \\
1918 \\
1919 \\
1920\end{array}$ & $\begin{array}{l}\text { Mar. } \\
\text { Apr. } \\
\text { Apr. } \\
\text { Apr. } \\
\text { May }\end{array}$ & $\begin{array}{rr}20, & 1916 \\
24, & 1917 \\
9, & 1918 \\
5, & 1919 \\
9, & 1920\end{array}$ & $\begin{array}{l}5.7 \\
5.1 \\
3.2 \\
4.35 \\
2.40\end{array}$ & $\begin{array}{r}a 710 \\
560 \\
217 \\
406 \\
137\end{array}$ & $\begin{array}{l}1946 \\
1947 \\
1948 \\
1949 \\
1950\end{array}$ & $\begin{array}{l}\text { Apr. } \\
\text { May } \\
\text { May } \\
\text { May } \\
\text { May }\end{array}$ & $\begin{array}{ll}27, & 1946 \\
27, & 1947 \\
27, & 1948 \\
14, & 1949 \\
24, & 1950\end{array}$ & $\begin{array}{l}2.51 \\
2.58 \\
2.69 \\
2.62 \\
2.69\end{array}$ & $\begin{array}{l}81 \\
58 \\
69 \\
63 \\
69\end{array}$ \\
\hline $\begin{array}{l}1921 \\
1922 \\
1923 \\
\end{array}$ & $\begin{array}{l}\text { Apr. } \\
\text { Apr. } \\
\text { June }\end{array}$ & $\begin{array}{l}11,1921 \\
26,1922 \\
15-181923\end{array}$ & $\begin{array}{l}4.20 \\
4.35 \\
1.4\end{array}$ & $\begin{array}{l}345 \\
378 \\
a 45\end{array}$ & $\begin{array}{l}1951 \\
1952 \\
1953\end{array}$ & $\begin{array}{l}\text { Apr. } \\
\text { Apr. } \\
\text { May }\end{array}$ & $\begin{array}{ll}15, & 1951 \\
26, & 1952 \\
21, & 1953\end{array}$ & $\begin{array}{l}4.74 \\
5.82 \\
3.98\end{array}$ & $\begin{array}{l}357 \\
544 \\
225\end{array}$ \\
\hline 1925 & May & 22,1925 & 2.30 & al22 & $\begin{array}{l}1954 \\
1955\end{array}$ & $\begin{array}{l}\text { Apr. } \\
\text { June } 3\end{array}$ & $\begin{array}{ll}23, & 1954 \\
3-6, & 1955\end{array}$ & $\begin{array}{l}5.17 \\
2.50\end{array}$ & $\begin{array}{r}434 \\
53\end{array}$ \\
\hline $\begin{array}{l}1926 \\
1927 \\
1928 \\
1929 \\
1930\end{array}$ & $\begin{array}{l}\text { May } \\
\text { May } \\
\text { May } \\
\text { May } \\
\text { Apr. }\end{array}$ & $\begin{array}{rr}28, & 1926 \\
16, & 1927 \\
13, & 1928 \\
18, & 1929 \\
9, & 1930\end{array}$ & $\begin{array}{r}1.40 \\
3.20 \\
1.20 \\
.97 \\
.93\end{array}$ & $\begin{array}{r}a 45 \\
\mathrm{a} 223 \\
48 \\
\mathrm{a} 26 \\
25\end{array}$ & $\begin{array}{l}1956 \\
1957 \\
1958 \\
1959 \\
1960\end{array}$ & $\begin{array}{l}\text { Dec. } \\
\text { Feb. } \\
\text { Apr. } \\
\text { May } \\
\text { June }\end{array}$ & $\begin{array}{rr}22, & 1955 \\
28, & 1957 \\
22, & 1958 \\
1, & 1959 \\
27, & 1960\end{array}$ & $\begin{array}{l}7.65 \\
4.82 \\
5.45 \\
2.36 \\
2.51\end{array}$ & $\begin{array}{r}930 \\
366 \\
520 \\
42 \\
54\end{array}$ \\
\hline $\begin{array}{l}1931 \\
1932 \\
1933 \\
1934\end{array}$ & $\begin{array}{l}\text { May } \\
\text { Apr. } \\
\text { May } \\
\text { May }\end{array}$ & $\begin{array}{ll}14, & 1931 \\
17, & 1932 \\
17, & 1933 \\
11, & 1934\end{array}$ & $\begin{array}{r}.78 \\
1.38 \\
2.38 \\
2.06\end{array}$ & $\begin{array}{l}16 \\
44 \\
37 \\
18\end{array}$ & $\begin{array}{l}1961 \\
1962 \\
1963\end{array}$ & $\begin{array}{l}\text { May } \\
\text { Apr. } \\
\text { Feb. }\end{array}$ & $\begin{array}{rr}20, & 1961 \\
5, & 1962 \\
1, & 1963\end{array}$ & $\begin{array}{l}2.51 \\
2.70 \\
4.02\end{array}$ & $\begin{array}{r}54 \\
76 \\
248\end{array}$ \\
\hline
\end{tabular}

a Maximum observed.

b Maximum observed during period Oct. 1 to Mar. 31, 1907. 
3910. Buck Creek near Silver Lake, Oreg.

(Published as Bear Creek 1905-6, 1909-ii)

Location.--Lat $43^{\circ} 08^{1}$, long $121^{\circ} 10^{1}$, in $\mathrm{N} \frac{1}{2}$ sec.22, T.28 S., R.13 E., on left bank $300 \mathrm{ft}$ downstream from highway bridge and 6 miles west of town of Silver Lake.

Drainage area.--290 sq $\mathrm{ml}$, approximately; at site used prior to $1919,310 \mathrm{sq} \mathrm{mi}$, approximately.

Gage.--Nonrecording prior to Apr. 13, 1922; recording thereafter. At site 4 miles downstream 1905-10, and $1 \frac{1}{2}$ miles downstream Mar. 13, 1919, tc Apr. 12, 1922, at different datums. Altitude of gage is $4,500 \mathrm{ft}$ (from topographic map).

Stage-discharge relation.--Defined by current-meter measurements below 65 cfs 1905-10, below $113 \mathrm{cfs} 1919-21$, and below $99 \mathrm{cfs}$ thereafter.

Bankfull stage.--4 ft at 1919-22 site; otherwise unknown.

Remarks.--Only annual peaks are shown (maximum observed prior to 1922).

\begin{tabular}{|c|c|c|c|c|c|c|c|}
\hline $\begin{array}{l}\text { Water } \\
\text { year }\end{array}$ & Date & $\begin{array}{c}\text { Gage } \\
\text { helght } \\
\text { (feet) }\end{array}$ & $\begin{array}{c}\text { Discharge } \\
(\mathrm{cfs})\end{array}$ & $\begin{array}{l}\text { Water } \\
\text { year }\end{array}$ & Date & $\begin{array}{c}\text { Gage } \\
\text { helght } \\
\text { (feet) }\end{array}$ & $\begin{array}{c}\text { Discharge } \\
(\mathrm{cfs})\end{array}$ \\
\hline 1905 & June 11,1905 & 5.45 & 55 & $\begin{array}{l}1919 \\
1920\end{array}$ & $\begin{array}{lll}\text { May } & 29, & 1919 \\
\text { May } & 21, & 1920\end{array}$ & $\begin{array}{l}4.1 \\
3.00\end{array}$ & $\begin{array}{r}120 \\
70\end{array}$ \\
\hline $\begin{array}{l}1906 \\
1907 \\
\end{array}$ & $\begin{array}{l}\text { June 12, } 1906 \\
\text { February } 1907\end{array}$ & $\begin{array}{l}5.75 \\
6.6\end{array}$ & $\begin{array}{r}83 \\
450\end{array}$ & 1921 & June 7,1921 & 4.6 & 164 \\
\hline $\begin{array}{l}1909 \\
1910\end{array}$ & $\begin{array}{l}\text { Jan. 21, } 1909 \\
\text { Feb. 28, } 1910\end{array}$ & $\begin{array}{l}8.0 \\
9.0 \\
\end{array}$ & $\begin{array}{l}249 \\
330 \\
\end{array}$ & $\begin{array}{l}1922 \\
1923\end{array}$ & $\begin{array}{l}\text { June } 4,1922 \\
\text { May } 16,1923\end{array}$ & $\begin{array}{l}2.33 \\
1.72\end{array}$ & $\begin{array}{l}138 \\
\text { a.75 }\end{array}$ \\
\hline
\end{tabular}

a Maximum during period March to September.

Note.--Maximum observed discharges prior to 1922.

\section{MALHEUR AND HARNEY LAKES BASIN}

3925. Silvies River near Silvies, Oreg.

Location.--Lat $43^{\circ} 55^{\prime}$, long $118^{\circ} 58^{1}$, in SE $\frac{1}{4}$ sec.14, T.19 S., R. 31 E., on left bank three-quarters of a mile downstream from Trout Creek and 8 miles south of Silvies.

Drainage area.--510 sq $\mathrm{mi}$, approximately.

Gage --Nonrecording. May 9 to June 26 , 1903, at site half a mile upstroam at different datum. Altitude of gage is 4,500 ft (from topographic map).

Stage-discharge relation.--Defined by current-meter measurements below $1,870 \mathrm{cfs}$.

Bankfull stage. $--8 \mathrm{ft}$.

Remarks.--Only annual peaks are shown (maximum observed except momentary maximum 1916).

Maximum observed stages and discharges

\begin{tabular}{|c|c|c|c|c|c|c|c|}
\hline $\begin{array}{l}\text { Water } \\
\text { year }\end{array}$ & Date & $\begin{array}{c}\text { Gage } \\
\text { neight } \\
\text { (feet) }\end{array}$ & $\begin{array}{c}\text { D1scharge } \\
(\mathrm{cfs})\end{array}$ & $\begin{array}{c}\text { Water } \\
\text { year }\end{array}$ & Date & $\begin{array}{c}\text { Gage } \\
\text { height } \\
\text { (feet) }\end{array}$ & $\begin{array}{c}\text { D1scharge } \\
\text { (cfs) }\end{array}$ \\
\hline $\begin{array}{l}1903 \\
1904 \\
\end{array}$ & $\begin{array}{lll}\text { May } & 9, & 1903 \\
\text { Apr. } & 16, & 1904\end{array}$ & $\frac{4.5}{12.15}$ & $\frac{a 200}{2,320}$ & 1912 & Apr. 30,1912 & 9.9 & 1,190 \\
\hline & Feb. 17,1909 & 9.3 & $8 \mathrm{~S} 2$ & 1916 & Apr. 2,1916 & 10.66 & bl, 590 \\
\hline 1911 & $\begin{array}{l}\text { Mar. 21, } 1910 \\
\text { Apr. 4, } 1911\end{array}$ & 10.9 & 1,650 & $\begin{array}{l}1921 \\
1922 \\
1923\end{array}$ & $\begin{array}{ll}\text { Apr. } 12,1921 \\
\text { Apr. } 24,1922 \\
\text { Apr. } 21,1923\end{array}$ & $\begin{array}{r}11.0 \\
9.2 \\
7.1\end{array}$ & $\begin{array}{r}1,920 \\
1,050 \\
518\end{array}$ \\
\hline
\end{tabular}

a Maximum observed during period May 9 to Sept. 31, 1903.

b Momentary maximum. 
3935. Silvies River near Burns, Oreg.

Location.--Lat $43^{\circ} 43^{\prime}$, long $119^{\circ} 11^{\prime}$, in NW $\frac{1}{4}$ sec.31, T.2I S., R.30 E., on left bank 5 miles downstream from Emigrant Creek and 11 miles northeast of Burns.

Drainage area. $--934 \mathrm{sq} \mathrm{mi}$. Mean altitude, 5,200 ft.

Gage.--Nonrecording prior to Dec. 1, 1911, and June 24, 1917, to Apr. 6, 1922, at site 3 miles downstream at different datums; recording otherwise. Dec. 1, 1911, to June 23,1917 , at site $1 \frac{3}{4}$ miles downstream at different datum. Apr. 7, 1922, to oct. $i, 1941$, at present site and datum. Oct. 2 , 194i, to oct. 3, 1951, at site $400 \mathrm{ft}$ downstream at same datum. Datim of gage is $4,195 \mathrm{ft}$ above mean sea level, datum of 1929, supplementary adjustment of 1947 (river-profile survey),

Stage-discharge relation.--Defined by current-meter measurements.

Remarks.--Diversions for irrigation above station primarily by flooding during high flow. Only annual peaks are shown.

Peak stages and discharges

\begin{tabular}{|c|c|c|c|c|c|c|c|}
\hline $\begin{array}{c}\text { Water } \\
\text { year }\end{array}$ & Date & $\begin{array}{c}\text { Gage } \\
\text { he1ght } \\
\text { (reet) }\end{array}$ & $\begin{array}{c}\text { D1scharge } \\
\text { (cfs) }\end{array}$ & $\begin{array}{c}\text { Water } \\
\text { year }\end{array}$ & Date & $\begin{array}{l}\text { Gage } \\
\text { he1ght } \\
\text { (feet) }\end{array}$ & $\begin{array}{c}\text { Discharge } \\
\text { (cfs) }\end{array}$ \\
\hline 1904 & Apr. 15, 1904 & 17.12 & 4,730 & 1936 & Apr. 17,1936 & 12.62 & \\
\hline 1906 & Apr. 9, 1906 & 15.0 & 2,100 & $\begin{array}{l}1937 \\
1938\end{array}$ & Apr. 17,1938 & 13.61 & 2,510 \\
\hline $\begin{array}{l}1909 \\
1910\end{array}$ & $\begin{array}{ll}\text { Jan. } 22, & 1909 \\
\text { Mar. 20, } 1910\end{array}$ & $\begin{array}{l}12.6 \\
15.9\end{array}$ & $\begin{array}{l}1,000 \\
3,270\end{array}$ & 1940 & Feb. 29,1940 & $\begin{array}{l}11.40 \\
12.49\end{array}$ & $\begin{array}{l}1,230 \\
1,690\end{array}$ \\
\hline $\begin{array}{l}1911 \\
1912 \\
1913 \\
1914 \\
1915\end{array}$ & $\begin{array}{lrr}\text { Apr. } & 5, & 1911 \\
\text { May } 12, & 1912 \\
\text { Apr. } & 22,1913 \\
\text { Apr. } 8, & 1914 \\
\text { Apr. } & 4, & 1915\end{array}$ & $\begin{array}{r}12.17 \\
15.29 \\
14.74 \\
15.64 \\
9.36\end{array}$ & $\begin{array}{r}924 \\
1,580 \\
1,420 \\
1,820 \\
607\end{array}$ & $\begin{array}{l}1941 \\
1942 \\
1943 \\
1944 \\
1945\end{array}$ & $\begin{array}{lr}\text { Apr. } 2, & 1941 \\
\text { Apr. } 13, & 1942 \\
\text { Apr. } 8, & 1943 \\
\text { Mar. 10, } 1944 \\
\text { Feb. 14, } 1945\end{array}$ & $\begin{array}{r}11.51 \\
12.97 \\
14.70 \\
7.43 \\
11.69\end{array}$ & $\begin{array}{r}1,270 \\
2,060 \\
3,830 \\
614 \\
1,360\end{array}$ \\
\hline $\begin{array}{l}1916 \\
1917\end{array}$ & $\begin{array}{l}\text { Apr. } 12,1916 \\
\text { Apr. } 27,1917\end{array}$ & $\begin{array}{l}16.84 \\
16.40 \\
\end{array}$ & $\begin{array}{r}2,610 \\
2,300 \\
\end{array}$ & $\begin{array}{l}1946 \\
1947\end{array}$ & $\begin{array}{l}\text { Apr. } 20,1946 \\
\text { Feb. } 15,1947 \\
\text { Apr. } 21,1947\end{array}$ & $\begin{array}{r}12.28 \\
\mathrm{a} 8.70 \\
7.00\end{array}$ & $\begin{array}{c}1,720 \\
- \\
669\end{array}$ \\
\hline $\begin{array}{l}1918 \\
1919 \\
1920\end{array}$ & $\begin{array}{lr}\text { Mar. } 27,1918 \\
\text { Apr. } 5,1919 \\
\text { Jan. } 28,1920\end{array}$ & $\begin{array}{l}9.05 \\
12.0 \\
10.6\end{array}$ & $\begin{array}{r}574 \\
1,450 \\
1,020\end{array}$ & $\begin{array}{l}1948 \\
1949 \\
1950\end{array}$ & $\begin{array}{ll}\text { May } 23, & 1948 \\
\text { Apr. } 13, & 1949 \\
\text { Apr. } 23, & 1950\end{array}$ & $\begin{array}{c}11.18 \\
9.8 \\
10.17\end{array}$ & $\begin{array}{l}1,360 \\
1,080 \\
1,150\end{array}$ \\
\hline $\begin{array}{l}1921 \\
1922 \\
1923 \\
1924 \\
1925\end{array}$ & 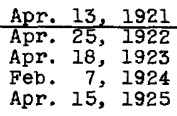 & $\begin{array}{r}13.55 \\
13.10 \\
9.98 \\
9.15 \\
9.67\end{array}$ & $\begin{array}{r}3,040 \\
1,640 \\
960 \\
640 \\
900\end{array}$ & $\begin{array}{l}1951 \\
1952 \\
1953 \\
1954 \\
1955\end{array}$ & $\begin{array}{lrl}\text { Apr. } & 8, & 1951 \\
\text { Apr. } 6, & 1952 \\
\text { Apr. } 28, & 1953 \\
\text { Mar. } 10, & 1954 \\
\text { May } 8,9, & 1955\end{array}$ & $\begin{array}{c}13.12 \\
15.2 \\
12.45 \\
- \\
6.04\end{array}$ & $\begin{array}{r}2,180 \\
\mathrm{~b} 4,960 \\
1,850 \\
\mathrm{~b} 800 \\
581\end{array}$ \\
\hline $\begin{array}{l}1926 \\
1927 \\
1928 \\
1929 \\
1930\end{array}$ & $\begin{array}{l}\text { Feb. } 8,1926 \\
\text { Apr. } 29,1927 \\
\text { Mar. } 12,1928 \\
\text { Mar. } 14,1929 \\
\text { Feb. } 14,1930\end{array}$ & $\begin{array}{r}8.15 \\
12.65 \\
11.70 \\
6.45 \\
5.34\end{array}$ & $\begin{array}{r}678 \\
1,520 \\
1,310 \\
464 \\
354\end{array}$ & $\begin{array}{l}1956 \\
1957 \\
1958 \\
1959 \\
1960\end{array}$ & $\begin{array}{l}\text { Mar. } 26,1956 \\
\text { Feb. } 25,1957 \\
\text { Apr. } 21,1958 \\
\text { Apr. } 6,1959 \\
\text { Apr. } 8,1960\end{array}$ & $\begin{array}{r}12.96 \\
14.17 \\
13.57 \\
4.80 \\
11.13\end{array}$ & $\begin{array}{r}2,090 \\
3,110 \\
2,530 \\
447 \\
1,530\end{array}$ \\
\hline $\begin{array}{l}1931 \\
1932 \\
1933 \\
1934 \\
1935 \\
\end{array}$ & $\begin{array}{l}\text { Apr. } 8,1931 \\
\text { Apr. } 15,1932 \\
\text { May } 2,1933 \\
\text { Dec. } 31,1933 \\
\text { Apr. } 16,1935\end{array}$ & $\begin{array}{r}3.94 \\
10.63 \\
8.02 \\
2.16 \\
9.48\end{array}$ & $\begin{array}{r}214 \\
1,080 \\
660 \\
75 \\
875\end{array}$ & $\begin{array}{l}1961 \\
1962 \\
1963\end{array}$ & $\begin{array}{lll}\text { Feb. } & 2,1961 \\
\text { Apr. } & 9,1962 \\
\text { Feb. } & 4,1963\end{array}$ & $\begin{array}{r}5.86 \\
9.49 \\
\text { a. } 2.71\end{array}$ & $\begin{array}{r}595 \\
1,200 \\
\text { (c) }\end{array}$ \\
\hline
\end{tabular}

a Backwater from lce.

b Estimated.

c Not determined. 
3960. Donner und Blitzen River near Frenchglen, Oreg.

(Published as "near Diamond" 1911-21, and as "at $\mathrm{p}$ ranch near Diamond" 1929-30)

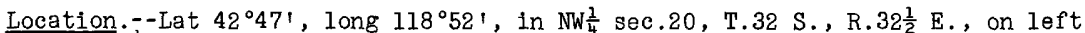
bank $1 \frac{1}{2}$ miles upstream from upper diversions for Malheur Migratory Waterfowl Refuge, 2 miles downstream from Fish Creek, and $3 \frac{1}{2}$ miles southeast of Frenchglen.

Drainage area.--200 sq mi, approximately. Mean altitude, 6,160 ft.

Gage.--Nonrecording prior to December 1937 at several sites within 2 miles downstream at different datums; recording and concrete control thereafter. Datum of gage is 4,254 ft above mean sea level (levels by Fish and Wildife Service).

Stage-discharge relation.--Defined by current-meter measurements.

Remarks.--Base for partial-duration series, $650 \mathrm{cfs}$. Only annual peaks are shown prior to 1938 .

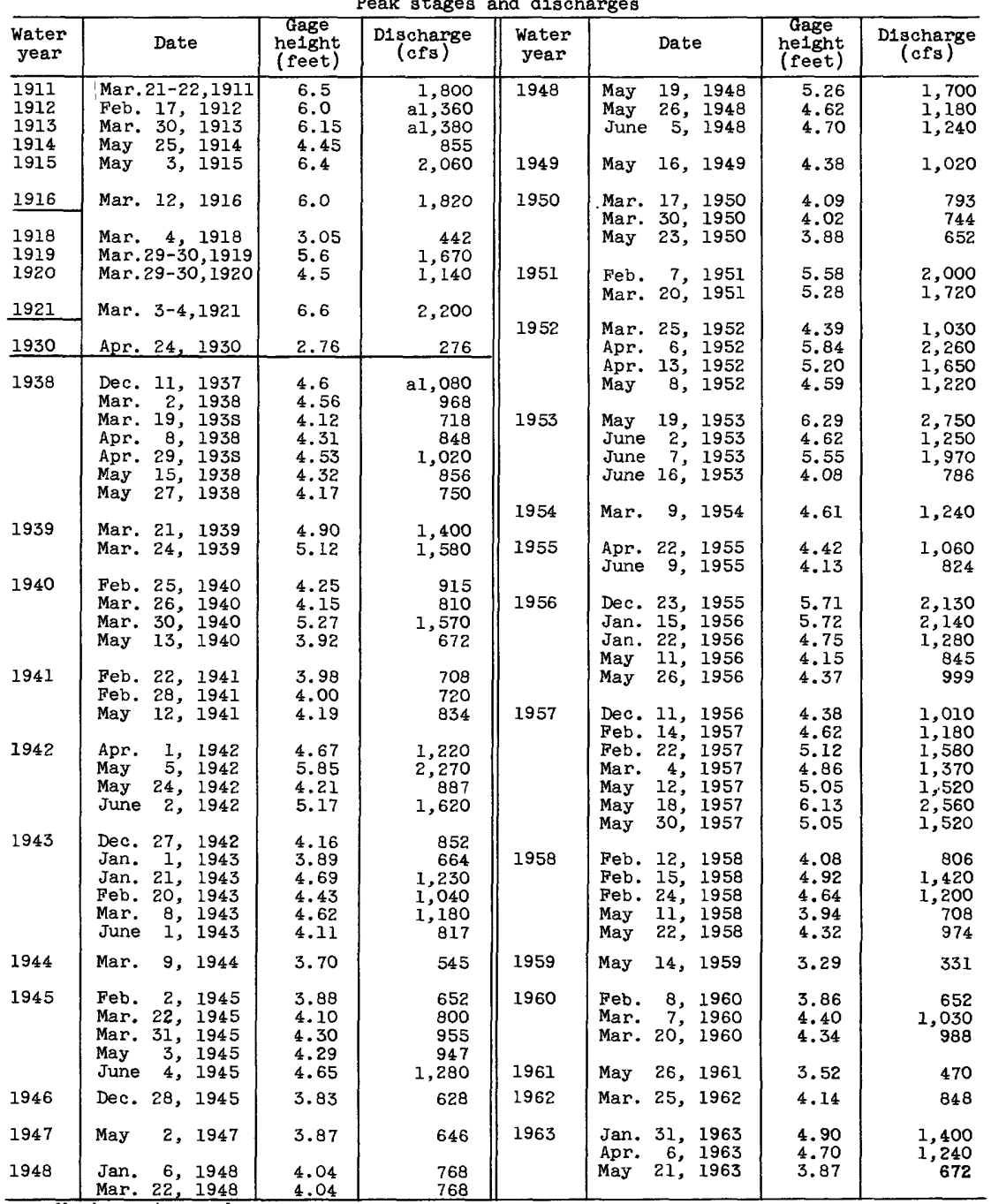




\section{Mud Creek near Diamond, Oreg.}

Location.--Lat $42^{\circ} 501^{\prime}$, long $118^{\circ} 51^{\prime}$, in NW $\frac{1}{4}$ sec.4, T.32 S., R. $32 \frac{1}{2}$ E., on left bank 3 miles east of Frenchglen and 16 miles southwest of Diamond.

Drainage area $--30 \mathrm{sq} \mathrm{ml}$, approximately.

Gage.--Nonrecording. Mar. 18, 1911, to Sept. 30, 1916, at dif serent datum.

Aititude of gage is $4,200 \mathrm{ft}$ (from topographic map).

Stage-discharge relation. --Defined by current-meter measurements below $20 \mathrm{cfs}$.

Remarks.--Records for 1930 furnished by State engineer of oregon. Only annual maximum observed discharges are shown.

¡Maximum observed stages and discharges

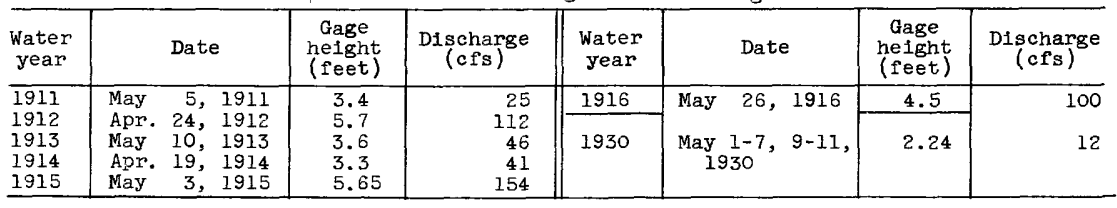

3970. Bridge Creek near Frenchglen, Oreg.

(Published as "near Diamond" 1911-16, 1930)

Location.--Lat $42^{\circ} 50^{\prime}$, long $118^{\circ} 51^{\prime}$, in NW $\frac{1}{4}$ sec.33, T.31 S., R.32 $\frac{1}{2}$ E., on right bank at mouth of canyon, $3 \frac{1}{2}$ miles northeast of Frenchglen.

Drainage area.--30 sq $\mathrm{mi}$, approximately. Mean altitude, 5,890 ft.

Gage.--Nonrecording prior to Aug. 23, 1939; recording and concrete control

thereafter. Prior to Dec. 21, 1937, at sites within 1 mile upstream at different datums. Dec. 21 , 1937, to May 17, 1938, at s1te 1,000 ft downstream at different datum. Datum of gage is $4,184.93 \mathrm{ft}$ above mear sea level (levels by Fish and Wildlife Service).

Stage-discharge relation.--Defined by current-meter measurements below 65 cf's and extended above by logarithmic plotting.

Remarks.--Base for partial-duration serles, $30 \mathrm{cfs}$. Only annuel peaks are shown prior to 1940 .

Peak stages and discharges

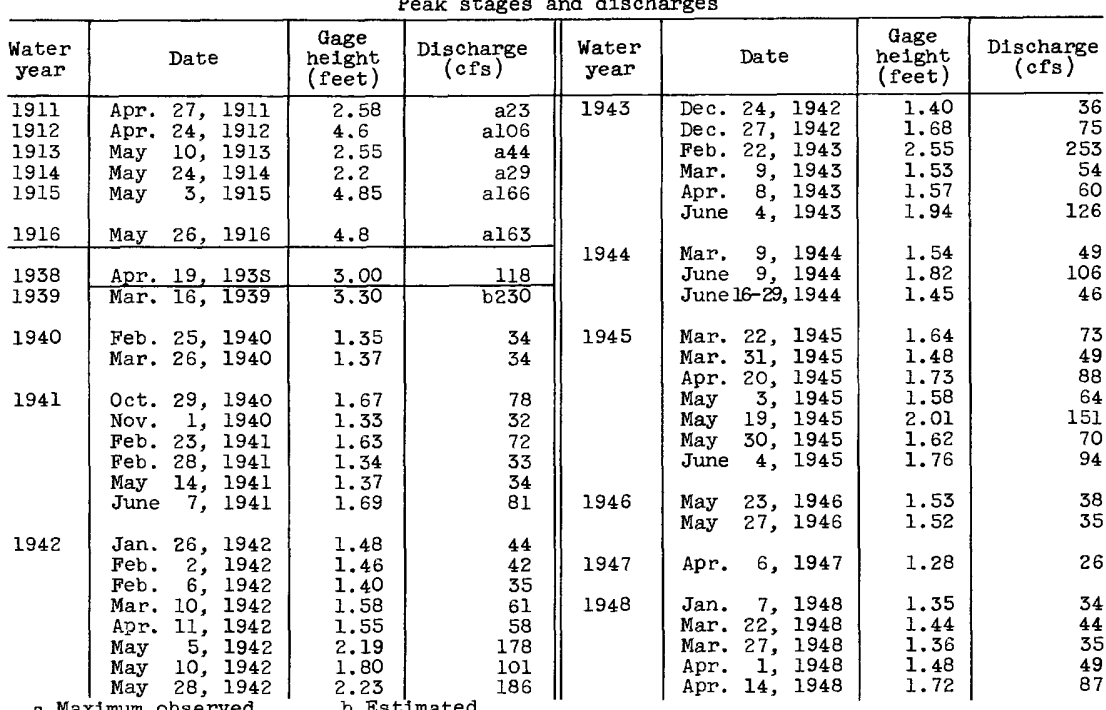


Peak stages and discharges of Bridge Creek near Frenchglen, Oreg.--Continued

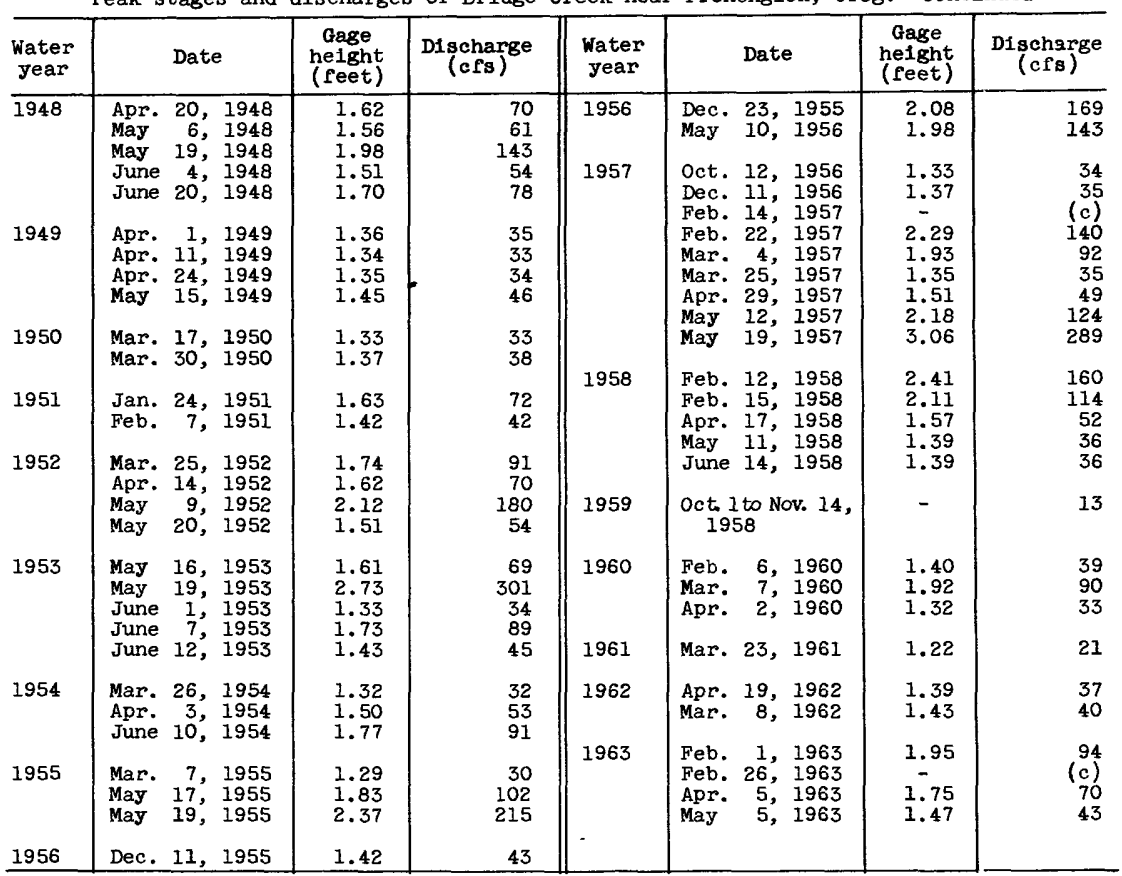

c Not determined.

3985. Donner und Blitzen RIver near Narrows, Oreg.

Location. --Lat $43^{\circ} 01^{1}$, long $118^{\circ} 50^{\prime}$, in $\mathrm{NE} \frac{1}{4}$ sec. 26 , T.29 S., R.31 E., on left bank at Grain Camp, 2 to 3 miles upstream from Kiger Creek and 18 miles north of Narrows.

Drainage area.--420 sq $\mathrm{mi}$, approximately.

Gage.--Nonrecording. Altitude of gage is $4,140 \mathrm{ft}$ (from topographic map).

Stage-discharge relation.--Defined by current-meter measurements below 670 cf's.

Remarks.--Diversions above station for irrigation of many thousand acres by flooding during high flow and by several canals. Only annual peaks are shown.

Peak stages and discharges

\begin{tabular}{|c|c|c|c|c|c|c|c|}
\hline $\begin{array}{l}\text { Water } \\
\text { year }\end{array}$ & Date & $\begin{array}{l}\text { Gage } \\
\text { helght } \\
\text { (feet) }\end{array}$ & $\begin{array}{c}\text { Discharge } \\
\text { (cfs) }\end{array}$ & $\begin{array}{l}\text { Water } \\
\text { Jear }\end{array}$ & Date & $\begin{array}{l}\text { Gage } \\
\text { helght } \\
\text { (feet) }\end{array}$ & $\begin{array}{c}\text { Dischargé } \\
(\mathrm{cfs})\end{array}$ \\
\hline $\begin{array}{l}1915 \\
1916 \\
1917 \\
\end{array}$ & $\begin{array}{ll}\text { May } 16, & 1915 \\
\text { June } 14, & 1916 \\
\text { March } & 1917 \\
\end{array}$ & $\begin{array}{l}5.2 \\
4.5 \\
7.5\end{array}$ & $\begin{array}{r}a 392 \\
2270 \\
780\end{array}$ & $\begin{array}{l}1918 \\
1919 \\
1920\end{array}$ & $\begin{array}{l}\text { May } 8,1918 \\
\text { Mar. } 30,1919 \\
\text { Mar. } 2, \text { May } 10, \\
11,22-24,1920\end{array}$ & $\begin{array}{l}3.5 \\
5.1 \\
4.7\end{array}$ & $\begin{array}{l}a 166 \\
a 432 \\
a 364\end{array}$ \\
\hline
\end{tabular}

a Maximum observed. 
3990. Kiger Creek near Diamond, Oreg.

Location.--Lat $43^{\circ} 00^{\prime}$, long $118^{\circ} 38^{\prime}$ in SW $\frac{1}{4}$ sec.3, T.30 S., R. 33 E., on left bank 2 miles southeast of Diamond and 18 miles northeast of Frenchglen.

Drainage area. $--75 \mathrm{sq} \mathrm{ml}$, approximately.

Gage.--Nonrecording prior to May 27, 1917, and since May 29, 19:1; recording May 27, 1917, to May 29, 1921. Near described site at different datums prior to May 30 , 1921. At site half a mile upstream at different datum

Mar. 11 to July 8, 1930. Altitude of gage is $4,250 \mathrm{ft}$ (from topographic map).

Stage-discharge relation.--Defined by current-meter measurements below $150 \mathrm{cfs}$.

Remarks.--Records for 1930 and 1941, furnished by State engineer of Oregon.

Only annual peaks are shown.

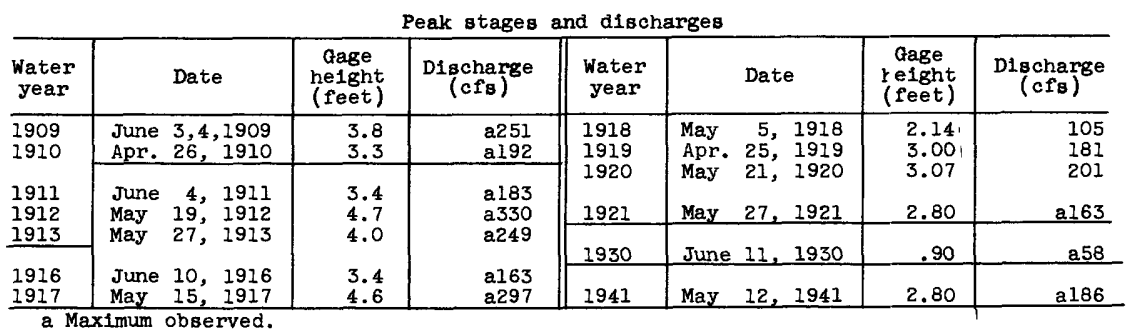

4000. McCoy Creek near Diamond, Oreg.

Location.--Lat $42^{\circ} 59^{\prime}$, long $118^{\circ} 43^{\prime}$, in SE $\frac{1}{4}$ sec.2, T.30 S., R. 3६. E., on right bank 3 miles southwest of Diamond and 15 miles northeast of Frenchglen.

Drainage area. $--45 \mathrm{sq} \mathrm{ml}$, approximately.

Gage.--Nonrecording. Prior to May 23, 1910, and May 1 to Sept. 30, 1919, at sites about 2 miles downstream, and May 23, 1910, to May 1, 1919, at sites within a half mile upstream, at different datums. Altitude cf gage is $4,200 \mathrm{ft}$ (from topographic map).

Stage-discharge relation.--Defined by current-meter measurements prior to 1922 and below 110 cf's thereafter.

Remarks.--Records for 1941 furnished by State engineer of oregon. Only annual peaks are shown.

\begin{tabular}{|c|c|c|c|c|c|c|c|}
\hline $\begin{array}{l}\text { Water } \\
\text { year }\end{array}$ & Date & $\begin{array}{c}\text { Gage } \\
\text { height } \\
\text { (feet) }\end{array}$ & $\begin{array}{l}\text { Discharge } \\
\text { (cfs) }\end{array}$ & $\begin{array}{l}\text { Water } \\
\text { year }\end{array}$ & Date & $\begin{array}{c}\text { Gage } \\
\text { holght } \\
\text { (feet) }\end{array}$ & $\begin{array}{c}\text { Discharge } \\
\text { (cfs) }\end{array}$ \\
\hline $\begin{array}{l}1909 \\
1910\end{array}$ & $\begin{array}{lrr}\text { June } & 5, & 1909 \\
\text { May } & 23, & 1910\end{array}$ & $\begin{array}{l}4.91 \\
3.65\end{array}$ & $\begin{array}{l}126 \\
280\end{array}$ & \multirow{3}{*}{$\begin{array}{l}1917 \\
1918 \\
1919 \\
1920\end{array}$} & 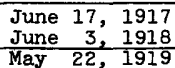 & $\begin{array}{l}5.06 \\
-3.28 \\
2.8\end{array}$ & $\begin{array}{r}300 \\
107 \\
205\end{array}$ \\
\hline $\begin{array}{l}1911 \\
1912\end{array}$ & $\begin{array}{l}\text { June } 11,1911 \\
\text { June } 7,1912\end{array}$ & $\begin{array}{l}5.4 \\
6.6\end{array}$ & $\begin{array}{l}203 \\
300\end{array}$ & & Ju1y 4,1920 & 4.20 & 2175 \\
\hline 1913 & May 28, 1913 & 4.6 & 207 & & 27,1921 & 5.00 & 264 \\
\hline 1914 & $\begin{array}{ll}\text { May } & 8,1914 \\
\text { June } & 5,1916 \\
\end{array}$ & $\begin{array}{l}3.2 \\
4.0\end{array}$ & $\begin{array}{r}2146 \\
190\end{array}$ & 1941 & May 12,1941 & 2.78 & a.385 \\
\hline
\end{tabular}

a Maximum observed. 
4010. Riddle Creek near Diamond, Oreg.

Location.--Lat $43^{\circ} 07^{\prime}$, long $118^{\circ} 37^{1}$, in $\mathrm{S} \frac{1}{2}$ sec. 23 , T.28 S., R.33 E., on right bank at highway bridge 8 miles north of Diamond and 20 miles southeast of Narrows.

Drainage area. --120 sq $\mathrm{mi}$, approximately.

Gage.--Nonrecording. Altitude of gage is 4,100 ft (from topographic map). Stage-discharge relation.--Defined by current-meter measurements below $100 \mathrm{cfs}$. Remarks.--Only annual peaks are shown.

\begin{tabular}{|c|c|c|c|c|c|c|c|}
\hline $\begin{array}{l}\text { Water } \\
\text { year }\end{array}$ & Date & $\begin{array}{l}\text { Gage } \\
\text { helght } \\
\text { (feet) }\end{array}$ & $\begin{array}{c}\text { Discharge } \\
\text { (cfs) }\end{array}$ & $\begin{array}{l}\text { Water } \\
\text { year }\end{array}$ & Date & $\begin{array}{c}\text { Gage } \\
\text { height } \\
\text { (feet) }\end{array}$ & $\begin{array}{c}\text { D1scharge } \\
(\mathrm{cfs})\end{array}$ \\
\hline $\begin{array}{l}1917 \\
1918 \\
1919 \\
\end{array}$ & $\begin{array}{l}\text { Mar. } 27,1917 \\
\text { Mar. } 28,1918 \\
\text { Mar. } 31,1919\end{array}$ & $\begin{array}{l}4.5 \\
1.53 \\
2.44\end{array}$ & $\begin{array}{r}\text { a330 } \\
\text { b50 } \\
\text { b106 }\end{array}$ & $\begin{array}{l}1920 \\
1921\end{array}$ & $\begin{array}{l}\text { Apr. 15, } 1920 \\
\text { Feb.10,11,1921 }\end{array}$ & $\begin{array}{l}2.30 \\
3.60 \\
\end{array}$ & $\begin{array}{r}\mathrm{b} 93 \\
\mathrm{~b} 219 \\
\end{array}$ \\
\hline
\end{tabular}

a Maximum during period Mar. 27 to Sept. 30, 1917.

b Maximum observed.

4015. Donner und Blitzen River near Voltage, Oreg.

Location.--Lat $43^{\circ} 16^{\prime}$, long $118^{\circ} 51^{\prime}$, in SW $\frac{1}{4}$ sec.2, T.27 S., R.31 E., on right bank just downstream from Sodhouse diversion dam of Fish and Wildilfe Service, $1 \frac{1}{2}$ miles south of headquarters for Malheur Migratory Waterfow 1 Refuge, and 2 miles southwest of Voltage.

Drainage area. $--760 \mathrm{sq} \mathrm{mi}$, approximately.

Gage.--Nonrecording prior to June 16, 1939, at site $30 \mathrm{ft}$ downstream; recording thereafter. Since May 19, 1938, supplementary staff gage at site $1 \frac{1}{2}$ miles downstream at different datum. Datum of gage is $4,097.58 \mathrm{ft}$ above mean sea level, datum of 1929 (levels by Fish and Wildlife Service).

Stage-discharge relation.--Defined by current-meter measurements below $400 \mathrm{cfs}$. Bankfull stage. - $-6 \mathrm{ft}$.

Remarks.--Most of flow diverted above station for irrigation and for flooding waterfowl refuge. Only annual peaks are shown.

\begin{tabular}{|c|c|c|c|c|c|c|c|}
\hline $\begin{array}{l}\text { Water } \\
\text { year }\end{array}$ & Date & $\begin{array}{l}\text { Gage } \\
\text { height } \\
\text { (feet) }\end{array}$ & $\begin{array}{c}\text { Discharge } \\
\text { (cfs) }\end{array}$ & $\begin{array}{l}\text { Water } \\
\text { year }\end{array}$ & Date & $\begin{array}{l}\text { Gage } \\
\text { helght } \\
\text { (feet) }\end{array}$ & $\begin{array}{c}\text { Discharge } \\
\text { (cfs) }\end{array}$ \\
\hline $\begin{array}{l}1938 \\
1939 \\
1940\end{array}$ & $\begin{array}{l}\text { Mar. } 4,1938 \\
\text { Mar. } 29,1939 \\
\text { September } 1940\end{array}$ & $\begin{array}{l}4.50 \\
6.70 \\
3.67\end{array}$ & $\begin{array}{r}a 403 \\
\text { a416 } \\
274\end{array}$ & $\begin{array}{l}1943 \\
1944 \\
1945\end{array}$ & $\begin{array}{ll}\text { Feb. } 25, & 1943 \\
\text { Oct. } 21, & 1943 \\
\text { May } 10, & 1945\end{array}$ & $\begin{array}{l}5.55 \\
3.60 \\
4.99\end{array}$ & $\begin{array}{l}522 \\
287 \\
464\end{array}$ \\
\hline $\begin{array}{l}1941 \\
1942 \\
\end{array}$ & $\begin{array}{l}\text { Feb. } 26,1941 \\
\text { Jan. } 30,1942\end{array}$ & $\begin{array}{l}4.35 \\
6.26\end{array}$ & $\begin{array}{l}356 \\
616\end{array}$ & 1946 & Nov. $\quad 5,1945$ & 4.15 & 362 \\
\hline
\end{tabular}

a Maximum observed.

4030. Silver Creek near Riley, Oreg.

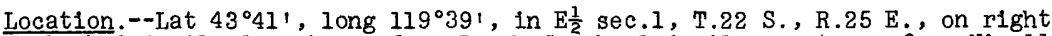
bank 0.4 mile downstream from Rough Creek, $i .4$ miles upstream from Nicoll Creek, and 14 miles northwest of Riley.

Drainage area. $--228 \mathrm{sq} \mathrm{ml}$. Mean altitude, 5,180 ft.

Gage.--Recording. Altitude of gage is $4,450 \mathrm{ft}$ (by barometer).

Stage-discharge relation.--Defined by current-meter measurements.

Remarks.--Base for partial-duration series, 350 cfs. 
Peak stages and discharges of S1lver Creek near Riley, oreg.

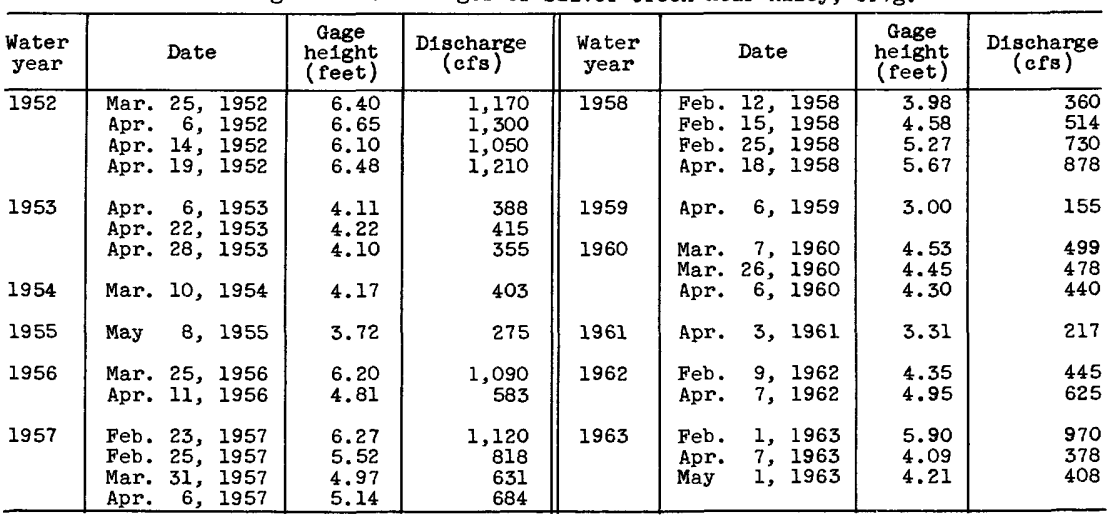

4035. Silver Creek above Suntex, Oreg.

(Published as "near Riley" 1904-6, 1909-11, and as "above Riley" 1912, 1914-18)

Location.--Lat $43^{\circ} 38^{\prime}$, long $119^{\circ} 40^{\prime}$, in NW/ sec.30, T.22 S., R.26 E., on right

bank 3 miles downstream from Nichols Creek and $3 \frac{1}{2}$ miles nort'iwest of Suntex.

Drainage area. $--260 \mathrm{sq} \mathrm{mi}$, approximately.

Gage.--Nonrecording prior to Mar. 6, 1921; recording thereafter. Prior to Feb. 15, 1909, at site $300 \mathrm{ft}$ downstream at different datum. Feb. 15, 1909, to Aug. 10, 1910, at described site at different datum. Dat um of gage is $4,339.70 \mathrm{ft}$ above mean sea level, unadjusted.

Stage-discharge relation.--Defined by current-meter measurements.

Remarks.--Diversions for irrigation above station. Records for 1925, furnished by State engineer of oregon. Only annual peaks are shown.

Peak stages and discharges

\begin{tabular}{|c|c|c|c|c|c|c|c|}
\hline $\begin{array}{l}\text { Water } \\
\text { year }\end{array}$ & Date & $\begin{array}{l}\text { Gage } \\
\text { he1ght } \\
\text { (feet) }\end{array}$ & $\begin{array}{c}\text { Discharge } \\
\text { (cfs) }\end{array}$ & $\begin{array}{l}\text { Water } \\
\text { year }\end{array}$ & Date & $\begin{array}{l}\text { Gage } \\
\text { relght } \\
\text { (feet) }\end{array}$ & $\begin{array}{c}\text { D1scharge } \\
(\mathrm{cfs})\end{array}$ \\
\hline $\begin{array}{l}.1904 \\
1905\end{array}$ & $\begin{array}{l}\text { Apr. 14, } 1904 \\
\text { Mar. 18, } 1905 \\
\text { Apr. 19, } 1906\end{array}$ & $\begin{array}{r}13.95 \\
8.90 \\
12.7 \\
\end{array}$ & $\begin{array}{r}a 1,760 \\
a 223 \\
a 870 \\
\end{array}$ & \multirow{3}{*}{$\begin{array}{l}1916 \\
1917 \\
1918 \\
1919 \\
1920 \\
1921 \\
1922 \\
1923 \\
\end{array}$} & \multirow{4}{*}{$\begin{array}{l}\text { Mar. 19, } 1916 \\
\text { Apr. 26, } 1917 \\
\text { Mar. 24, 28, } \\
1918 \\
\text { Apr. 4, } 1919 \\
\text { Jan. 27, } 1920 \\
\text { Apr. 3, } 1921 \\
\text { Apr. 23, } 1922 \\
\text { Apr. 16, } 1923 \\
\text { Feb. } 5,1925\end{array}$} & \multirow{4}{*}{$\begin{array}{l}7.2 \\
6.8 \\
3.65 \\
7.0 \\
6.3 \\
6.58 \\
7.9 \\
4.5 \\
7.6 \\
\end{array}$} & \multirow{4}{*}{$\begin{array}{r}a 695 \\
a 642 \\
a 236 \\
a 645 \\
520 \\
590 \\
955 \\
253\end{array}$} \\
\hline 1909 & \multirow{3}{*}{$\begin{array}{l}\text { Apr.3,14, } 1909 \\
\text { Apr. 1, } 1911 \\
\text { Apr. 30, } 1912 \\
\text { Apr. 18, } 1913 \\
\text { Mar. 19, } 1914 \\
\text { Apr. 3, } 1915\end{array}$} & 6.90 & \multirow{3}{*}{$\begin{array}{r}a 475 \\
b 610 \\
519 \\
a 701 \\
610 \\
\end{array}$} & & & & \\
\hline \multirow{2}{*}{$\begin{array}{l}1911 \\
1912 \\
1913 \\
1914 \\
1915 \\
\end{array}$} & & $\begin{array}{l}4.9 \\
- \\
5.3\end{array}$ & & & & & \\
\hline & & 6.0 & & 1925 & & & \\
\hline
\end{tabular}

a Maximum observed.

b Estimated dally. 
4060. Silver Creek near Narrows, Oreg.

Location.--Lat $43^{\circ} 23^{\prime}$, long $119^{\circ} 22^{\prime}$, in NW $\frac{1}{4}$ sec. 21 , T.25 S., R.28 E., on right bank 14 miles southeast of Riley and 22 miles northwest of town of Narrows.

Drainage area. $--630 \mathrm{sq} \mathrm{mi}$, approximately.

Gage.--Nonrecording. Altitude of gage is 4,140 ft (from topographic map).

Stage-discharge relation.--Defined by current-meter measurements.

Remarks.--Only annual maximum observed discharges are shown.

Maximum observed stages and discharges

\begin{tabular}{|c|c|c|c|c|c|c|c|}
\hline $\begin{array}{l}\text { Water } \\
\text { year }\end{array}$ & Date & $\begin{array}{c}\text { Gage } \\
\text { helght } \\
\text { (feet) }\end{array}$ & $\begin{array}{c}\text { Discharge } \\
\text { (cfs) }\end{array}$ & $\begin{array}{l}\text { Water } \\
\text { year }\end{array}$ & Date & $\begin{array}{c}\text { Gage } \\
\text { height } \\
\text { (feet) }\end{array}$ & $\begin{array}{c}\text { Discharge } \\
\text { (cfs) }\end{array}$ \\
\hline 1917 & Apr. 29,1917 & 4.5 & 419 & 1921 & Apr. 5, 1921 & 4.75 & 391 \\
\hline $\begin{array}{l}1919 \\
1920 \\
\end{array}$ & $\begin{array}{l}\text { Apr. } 7,1919 \\
\text { Apr. } 30,1920\end{array}$ & $\begin{array}{l}4.7 \\
3.4 \\
\end{array}$ & $\begin{array}{l}360 \\
156\end{array}$ & $\begin{array}{l}1924 \\
1923\end{array}$ & Apr. 20, 1923 & 3.30 & 150 \\
\hline
\end{tabular}

\section{CATLOW VALLEY BASIN}

4063. Home Creek near Beckley, Oreg.
(Published as "near Narrows" 1911 .

Location.--Lat $42^{\circ} 33^{\prime}$, long $118^{\circ} 56^{\prime}$, in NE $\frac{1}{4}$ sec.10, T.35 S., R. 32 E., on left bank 12 miles southeast of former town of Beckley and 19 miles soutl of Frenchglen.

Drainage area. $--38 \mathrm{sq} \mathrm{mi}$, approximately.

Gage.--Nonrecording. Prior to Mar. 13, 1930, at nearby site at different datums. Altitude of gage is $4,600 \mathrm{ft}$ (from topographic map).

Stage-discharge relation.--Defined by current-meter measurements below $140 \mathrm{cfs}$. Bankfull stage. $--2.4 \mathrm{ft}$.

Remarks.--Records for 1930, furmished by State engineer of Oregon. Only annual peaks are shown.

Peak stages and discharges

\begin{tabular}{|c|c|c|c|c|c|c|c|}
\hline $\begin{array}{l}\text { Water } \\
\text { year }\end{array}$ & Date & $\begin{array}{c}\text { Gage } \\
\text { height } \\
\text { (feet) }\end{array}$ & $\begin{array}{c}\text { D1scharge } \\
(\mathrm{cfs})\end{array}$ & $\begin{array}{l}\text { Water } \\
\text { year }\end{array}$ & Date & $\begin{array}{c}\text { Gage } \\
\text { height } \\
\text { (feet) }\end{array}$ & $\begin{array}{c}\text { D1scharge } \\
\text { (cfs) }\end{array}$ \\
\hline $\begin{array}{l}1911 \\
1912 \\
\end{array}$ & $\begin{array}{l}\text { May } 5,1911 \\
\text { Apr. } 27,1912\end{array}$ & $\begin{array}{l}2.8 \\
4.7 \\
\end{array}$ & $\begin{array}{r}\text { a75 } \\
\text { b330 }\end{array}$ & $\begin{array}{l}1916 \\
1917 \\
\end{array}$ & $\begin{array}{lr}\text { May } & 25, \\
\text { May } & 1,1916 \\
\end{array}$ & $\begin{array}{r}3.4 \\
4.5 \\
\end{array}$ & $\begin{array}{r}\mathrm{b} 104 \\
250 \\
\end{array}$ \\
\hline$\underline{1915}$ & 5,1915 & 4.0 & b165 & 1930 & Apr. 8,1930 & 1.30 & b30 \\
\hline
\end{tabular}

a. For period May 5 to July 30, 1911.

b Maximum observed. 
4065. Trout Creek near Den1o, Nev.

(Published as "near Denio, Oreg." prior to 1962)

Location.--Lat $42^{\circ} 10^{\prime}$, long $118^{\circ} 28^{\prime}$, in SW $\frac{1}{4}$ sec.26, T.39 S., R.36 E., on right bank 0.4 mile upstream from bridge at mouth of canyon, 5 miles east of

Trout Creek Ranch, and 14 miles northeast of Denio.

Drainage area. $--88 \mathrm{sq} \mathrm{mi}$, approximately. Mean altitude, 5,920 ft.

Gage.--Nonrecording prior to Apr. 1, 1912, at bridge $0.4 \mathrm{mile}$ downstream at different datum; recording thereafter. Apr. 28, 1922, to June 14, 1932 , $10 \mathrm{ft}$ upstream at datum $0.50 \mathrm{ft}$ higher. Datum of gage is $4,351.52 \mathrm{ft}$ above mean sea level, datum of 1929 , supplementary adjustment of 1947 .

Stage-discharge relation.--Defined by current-meter measurements below 230 efs and extended above by logarithmic plotting.

Remarks.--Base for partial-duration series, $50 \mathrm{cfs}$. On1y annua]. peaks are shown prior to 1925 .

Peak stages and discharges

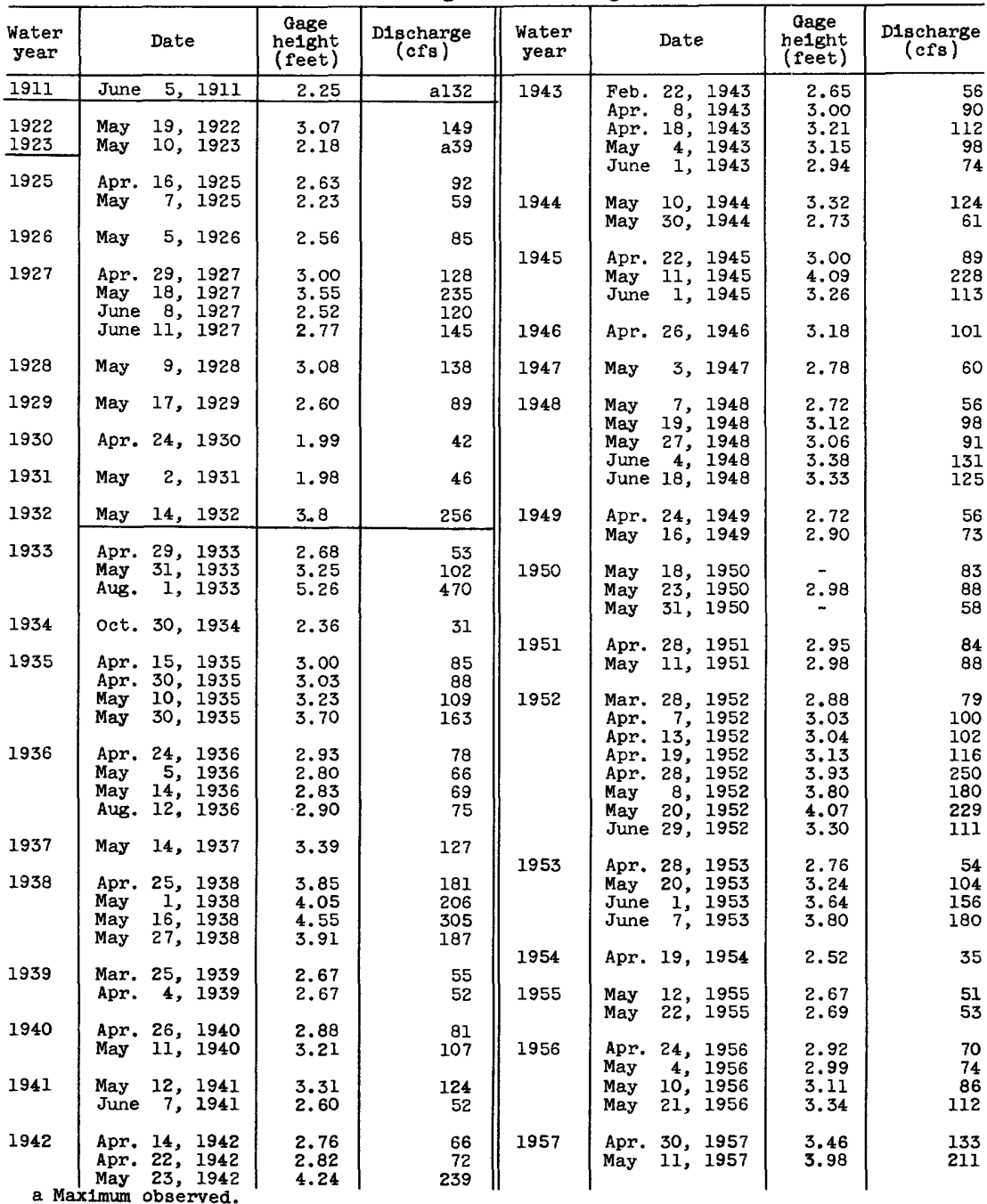


Peak stages and discharges of Trout Creek near Denio, Nev.--Continued

\begin{tabular}{|c|c|c|c|c|c|c|c|c|c|}
\hline $\begin{array}{l}\text { Water } \\
\text { year }\end{array}$ & \multicolumn{2}{|r|}{ Date } & $\begin{array}{c}\text { Gage } \\
\text { helght } \\
\text { (feet) }\end{array}$ & $\begin{array}{c}\text { Discharge } \\
\text { (cfs) }\end{array}$ & $\begin{array}{l}\text { Water } \\
\text { year }\end{array}$ & \multicolumn{2}{|r|}{ Date } & $\begin{array}{c}\text { Gage } \\
\text { height } \\
\text { (feet) }\end{array}$ & $\begin{array}{c}\text { Di scharge } \\
\text { (cfs) }\end{array}$ \\
\hline 1958 & $\begin{array}{l}\text { Feb. } \\
\text { Apr. } \\
\text { May } \\
\text { May } \\
\text { June } \\
\text { June }\end{array}$ & $\begin{array}{rr}15, & 1958 \\
22, & 1958 \\
12, & 1958 \\
19, & 1958 \\
3, & 1958 \\
11, & 1958\end{array}$ & $\begin{array}{l}3.03 \\
3.19 \\
3.52 \\
3.50 \\
3.07 \\
3.06\end{array}$ & $\begin{array}{r}83 \\
100 \\
141 \\
138 \\
87 \\
86\end{array}$ & 1963 & $\begin{array}{l}\text { Apr. } \\
\text { May } \\
\text { May } \\
\text { Jan. } \\
\text { Feb. }\end{array}$ & $\begin{array}{rr}25, & 1962 \\
8, & 1962 \\
26, & 1962 \\
31, & 1963 \\
5, & 1963\end{array}$ & $\begin{array}{r}3.05 \\
3.03 \\
2.79 \\
\text { b4.50 } \\
2.79\end{array}$ & $\begin{array}{r}87 \\
84 \\
55 \\
\text { (c) } \\
60\end{array}$ \\
\hline 1959 & May & 26,1959 & 2.47 & 35 & & May & 1,1963 & 3.22 & 110 \\
\hline 1960 & $\begin{array}{l}\text { May } \\
\text { June }\end{array}$ & $\begin{array}{rr}13, & 1960 \\
1, & 1960\end{array}$ & $\begin{array}{l}3.04 \\
2.74\end{array}$ & $\begin{array}{l}80 \\
51\end{array}$ & & $\begin{array}{l}\text { May } \\
\text { June }\end{array}$ & $\begin{array}{ll}20, & 1963 \\
16, & 1963\end{array}$ & $\begin{array}{l}3.22 \\
2.79\end{array}$ & $\begin{array}{r}110 \\
60\end{array}$ \\
\hline $196 I$ & June & 4,1961 & 3.16 & 77 & & & & & \\
\hline
\end{tabular}

b Backwater from ice.

c Not determined. 
Berwick, V. K., 1962, Mloods in Utah, magnitude and frequency: U.S. Geol. Survey Circ. 457, $24 \mathrm{p}$.

Chow, Ven $\mathrm{Te}, 1950$, Discussion of annual floods and the partial-duration flood series, by W. B. Langbein: Am. Geophys. Union Trans., v. 3), p. 939-941.

Dalrymple, Tate, 1960, Flood-frequency analyses: U.S. Geol. Survey WaterSupply Paper 1543-A, 80 p.

Gumbel, E. J., 1958, Statistics of extremes: New York, Columbia Univ. Press, $375 \mathrm{p}$.

Hulsing, H., and Kall10, N. A., 1964, Magnitude and frequency of floods in the United States; Part 14, Pacific slope basins in Oregon and lower Columbia River basin: U.S. Geol. Survey Water-Supply Paper 1689, 327 p.

Langbein, W. B., 1949, Annual floods and the partial-duration flood series: Am. Geophys. Union Trans., v. 30, p. 879-881.

Langbejin, W. B., and others, 1947, Topographic characteristics of drainage basins: U.S. Geol. Survey Water-Supply Paper 968-C, p. 125-157.

Patterson, James L., 1965, Magnitude and frequency of floods in the United States; Part 9, Colorado River basin: U.S. Geol. Survey Water-Supply Paper 1683,475 p.

Powell, R. W., 1943, A simple method of estimating flood frequency: Civil Eng., v. 13, no.2, p. 105-107.

Thomas, C. A., Broom, H. C., and Cummans, J. E., 1963, Magnitude and frequency of floods in the United States; Part 13, Snake River basin: U.S. Geol. Survey Water-Supply Paper 1688, $250 \mathrm{p}$.

Woolley, R. R., 1946, Cloudburst floods in Utah, 1850-1938: U.S. Geol. Survey Water-Supply Paper 994, 128 p. 


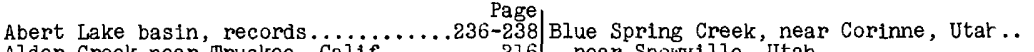

Alder Creek near Truckee, Calif...... 216 near Snowville, Utah............ 119

Alvord Lake basin, records.........250-251 Borrego Palm Creek near Borrego

Amargosa Creek tributary near

Palmdale, Calif...................

near American Fork, Utah........

Ana River near Summer Lake, Oreg......

Analysis of data $\ldots \ldots \ldots \ldots \ldots \ldots \ldots \ldots$

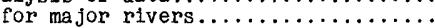

limitations.

Andreas Creek near Paim Springs,

Calif......

Ant1mony Creek near Antimony, Utah....

Area, description...

Asay Creek above West Fork, near

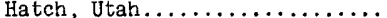

Ashdown Creek near Cedar City, Utah...

Badger Creek tributary near Vya, Nev. .

Baker Creek at narrows, near Baker

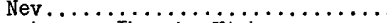

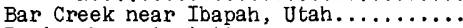

Basin characteristics............

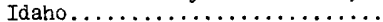

Bear River, above sublette creek, near

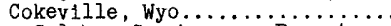

above Sulphur Creek, near Evanstö,

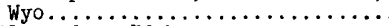

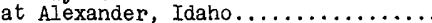

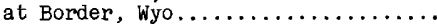

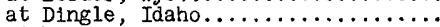

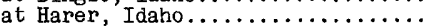

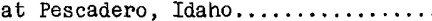

at Soda Springs, Idaho ........................

below Pixley Dam, near Cokevilie.

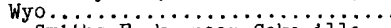

below smiths Fork, near Cokevilie; Wyo $\ldots \ldots \ldots \ldots \ldots \ldots \ldots \ldots$

below Stewart Dam, near Montpelier,

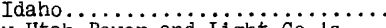

below Utah Power and Light $\mathrm{Co}$.'s

tailrace, at Oneida, Idaho......

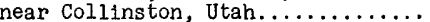

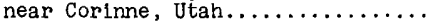

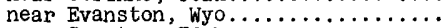

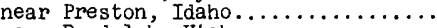

near Randolph, Utah.

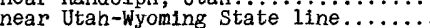

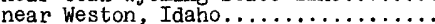

near Woodruff, Utah......................

Beaver River, at Adamsvilie, Utah..... 137

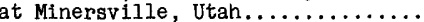

at Rockyford Dám, near Minersiilie,

Utah................... 138

near Beaver, Utah................ 136

Beaver River basin, records...........

Big Cottonwood Creek near Sait Lake

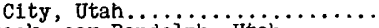

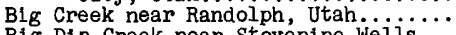

Big Dip Creek near Stovepipe Weils, Calif...

158 Briddleman Springs Creek at ciark

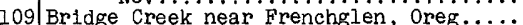

239 Bristol Lake basin, records ............ i45-146

5 Buck Creek near Silver Lake; Oreg...... 241

9,19 Buckeye Creek near Bridgeport, Cailf... 175

19

Campbell Creek, near Austin, Nev ....... 39

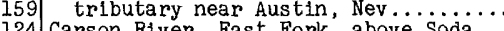

Carson River, East Fork, above Soda Springs ranger station, near

East Fork, near Gardnervilie, Nev.... 188

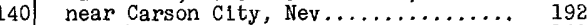

near Empire, Nev $\ldots \ldots \ldots \ldots \ldots \ldots \ldots \ldots . \ldots \ldots \ldots . \ldots \ldots$

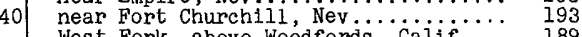

14 West Fork, above Woodfords, Cailf.... 189

118 Carson River basin, records............185-194

2,8 Catlow valley basin, records.............. 249

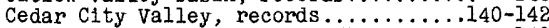

38 Center Creek near Parowan, Utah........ 140

Centerville Creek above diversions,

50 near Centervilie, Utah.......... 94

42 Chalk Creek (Pavant Valley) near Fill- 135

60 Chalk Creek (Weber River basin) at

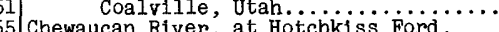

Chewaucan River, at Hotchkiss Ford,

54 near Paisley, oreg........... 238

59 at narrows, near Paisley, Oreg...... 238

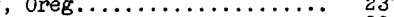

9 City Creek near Salt Lake city, Ütah.... 116

Clarkston Creek near Newton, Utah...... 71

51 Clear Creek (Carson River basin) near

Carson City, Nev............ 191

55 Clear Creek (Humboldt River basin)

above Clear Creek Ranch, near 61 Clear Creek (Sevier Lake basinj) $\ldots$ above

near Sevier; Utah....

at Sevier, Utah............... 127

Coal Creek, above Right Hand Creek, near Cedar city, Utah............

near Cedar City, Utah............. 141

4 Convict Creek near Mammoth Lakes,

Calif.................... 160

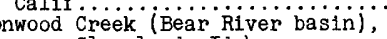

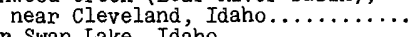

near Swan Iake, Idaho.................... 60 near Enterprise, Utah..........

Cottonwood Creek (Humboldt River bas in),

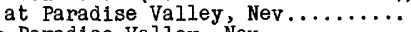

near Paradise Valley, Nev........... 209

112 Cottonwood Creek (Owens Lake basin),

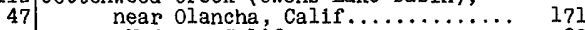

near Mojave, Calif ..............

144 Cottonwood Créek (Weber River basin) at

166 Hoytsville, Utah............. 38

Big Pine Creek near Big Pine, Calif...

Big Rock Creek near Valyermo, Calif...

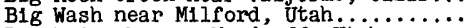

Birch Creek near Woodruff, Jtah.........

156 Coyote Creek near Borrego Springs

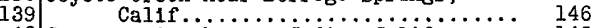

46 Creosote Creek near cadiz, Caijif....... 145

Bishop Creek near Bishop, Calif....... 166 Crust Creek near Westend, Calif........ 160

Black Rock desert, records........39,226-228 Cub River, above Maple Creek, near

Blacksmith Fork, above Utah Power \& Light Co.'s dam, near Hyrum,

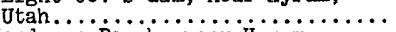

at Hardware Ranch, near Hyrum,

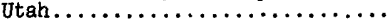

at municipal powerplant, near Hyrum,

Utah....................

below Utah Power \& isght co.'s plant,

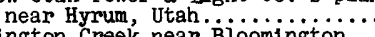

Bloomington Creek near Bloomington,

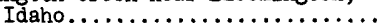

70

near

69 Dairy Fork near Thistle, Utah......... 98

Deep Creek (Bear River basinj below

69 First Creek, near Malad C1ty, Idaho 77

Deep Creek. (Great Salt Lake desert)

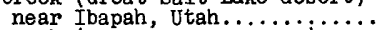

Deep Creek (Mojave River basin) neax

Hesperia, Calif.............. 
Deep Creek (tributary to Great Salt Lake) near Holbrook, Idaho..... Deep Creek (Wamer Lakes basin),

above Adel, Oreg..............

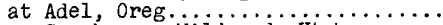

Deen Creek near wildwood, Utah.......

Devil Creek, above Campbell Creek, near Malad City, Idaho.

above Evans dividers, near Malad

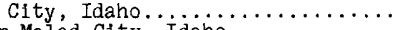

near Malad City, Idaho............ Thistle Utah

near Thistle, Utah.

Dixie valley, tributary near Eastgage,

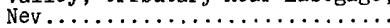

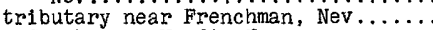

Dog Creek near Verdi, Nev............

Donner Creek, at Donner Lake, near

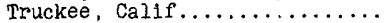

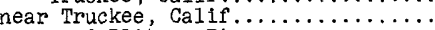

Donner und Blitzen River, near

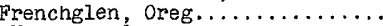

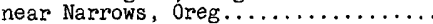

near Voltage, oreg...

Dove Creek near Park Valiey, Jiah.......

Drake Creek near Adel, Oreg...........

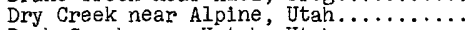

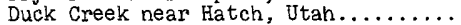

Duncan Creek near Cedar City, Utah....

\section{Eagle creek at mouth of canyon, near}

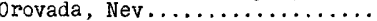

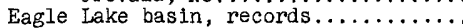

East Canyon Creek, below diversions,

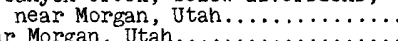

East Walker River, above strosnider ditch, near Mason, Nev.........

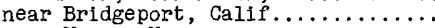
near Mason, Nev.

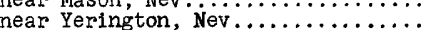

Echo Cliff Wash near Echo, Utah.......

Eldorado Canyon near Rye Patch, Nev...

Emigration Creek near Salt Lake City, Utah..

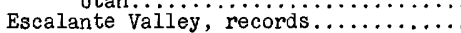

Farmington Creek above diversions, near Farmington, Utah..........

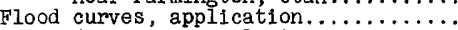

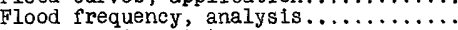

at a gaging station.............

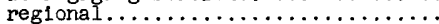

Flood series, two types.

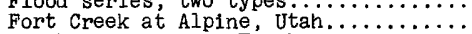

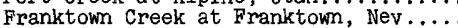

Fremont Wash near Paragonah, Utah.....

Gabbs Valley tributary near Luning, Nev.

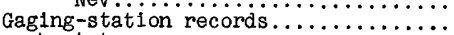

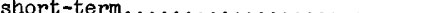

Georgetown Creek near Georgetown;

Idaho....................

Goodale Creek near Aberdeen, Calif....
Gourd Creek near Ludlow, Calif.......

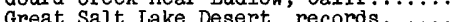

Great Salt Iake tributary near

Willard, Utah............

Green Creek near Bridgeport, Caijif.... Guana Valley basin, records..........

Hardscrabble Creek near Porterville, Hereford Canyon near Howeij, Utä....... High Creek near Richmond, Utah........ Hobble Creek near Springville, Utah... Holmes Creek near Raysville, Utah..... Home Creek near Beckley, Orég.........

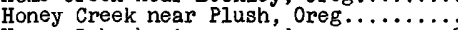
Honey Lake basin, records...................... Calif creek near Markleevilie,

Humboldt River, at Battie Mountain,

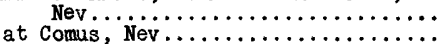
at Dunphy, Nev...

$\ldots \ldots \ldots \ldots$

at Palisade, Nev............

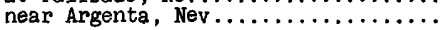

Page,

Humboldt River, near Carlin, Nev.......

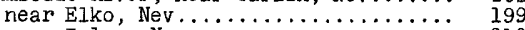

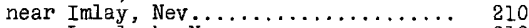

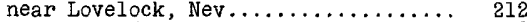
near Rose Creek, Nev.............. 210

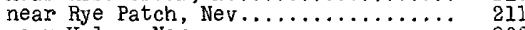
near Valmy, Nev.............. 206 North Fork, at Devils Gite, near

Halleck, Nev................ 197

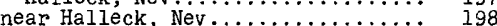

South Fork, above Dixie Creek, near

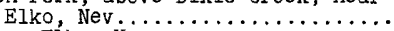

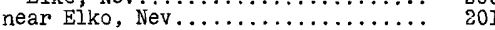

near Lee, Nev ................. 199

Humboldt River basin, records.......39,194-212

39 Humboldt Salt Marsh, records......... 39

39
222

Ibex Creek near Tecopa, Calif......... 144

214 Independence Creek (Owens Lake basin),

$214 \quad$ Independence Creek below Pinyon Creek, near Independence, Calif............... 169

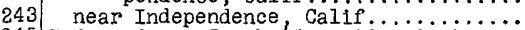

245 Independence Creek (Pyramid and Winne-

247 Independence Lakes basin) rear Truckee,

119

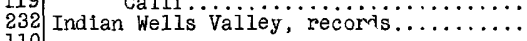

110

120 Jim Creek near Tuscarora, Nev.........

142 Jordan River, at narrows rear Lehi, Utah.................. 111

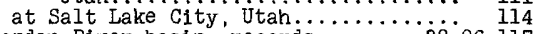

40 Jordan River basin, records.........38,96-117

230 Joshua Creek near Mo Jave, Cailf....... 159

86 Kiger Creek near Diamond, Oreg........ 246

84 Ko ehn Lake basin, records.............. 159

177 Lamollle Creek, near Halleck, Nev...... 197

176 near Lamollle, Nev.............. 196

178 Lee Vining Creek near Le Vining,

177

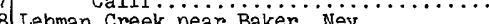

Little Bear River, East Fork, near

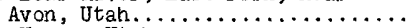

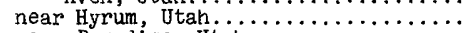

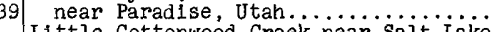

Little Cottonwood Creek near Salt lake

92 Little Danish Canyon near Maiad City,

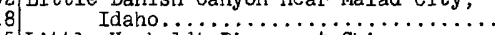

Little Humboldt River, at Chimey damsite, near Paradise Valley,

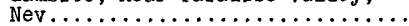

110 Little Malad River, above Elkhom Resèr-

223 voir near Malad City Idako.

below Elkhom Reservoir near Malad

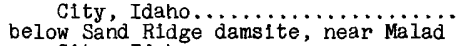

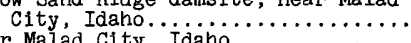

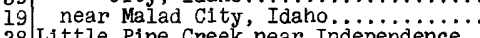

38 Little Pine Creek near Independence,

8 Iittle Rock Creek near Little Rock, Calif...

Little Trucke River, abov Boca Reser-

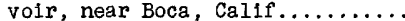

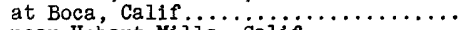
38
174
Little Valley Wash near Gold Hiii,

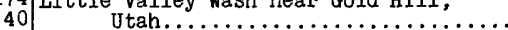

Little Walker River near B.idgeport, Calif.................... 179

85 Logan River, above state dam, near

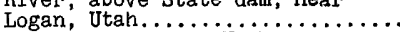

66 tributary near Logan, Utah.......... 102 Lone PIne Creek near Lone PIne, Cailf.

2 Lost Creek, at Devils Slide, Utah...... $\begin{array}{r}249 \\ 234 \\ \hline\end{array}$

9 McCoy Creek near Dlamond, Oreg........ 246 McDermitt Creek near McDernttt, Nev.... 226

188 Maggle Creek at Carlin, Ner...........39,202

Malad River, at Woodruff, Idaho............ 77

205 below springs, near Malad City, Idaho

near Plymouth, Utah............ 38

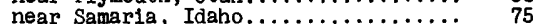

203 Malheur and Hamey Lakes besin, 
Mammoth Creek near Hatch, Utah....... Maple Creek near Franklin, Idaho..... Martin Creek near Paradise Valley, Nev.

Martis Creek near Truckee, Calif ....

Marys River, above Hot Springs Creek,

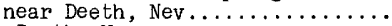
near Deeth, Nev.

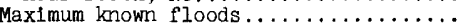

Mean annual flood

Midway Creek near Hatch, Utah........... Milberry Creek at Markleeville, Calif..

Mill Canyon near Glenwood, Utah...........

Mill Creek (lower tributary to Bear River near Liberty, Idaho...

Mill Creek (tributary to Bear Rlver) at Utah-Wyoming State line..

Mill Creek (tributary to Great Salt Lake) at Mueller Park, near

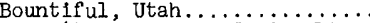

Mill Creek (tributary to Jordan River) near Salt Lake City, Utah.

Mink Creek, below Dry Fork, near Mink

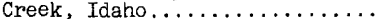

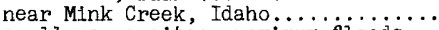
Miscellaneous sites, maximum fioods... Mojave River, at Barstow, Calif.

at lower narrows near Victorvilie. Calif......................

West Fork, near Hesperia, Calif.... 15

Mojave River basin, records........ is $1-155$ Mono Lake basin, records........................ near Montpelier, Idaho..........

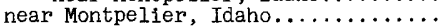

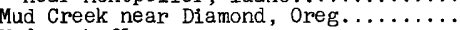

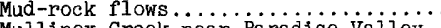

Mullinex Creek near Paradise Valley, Nev ......................

Oak Creek (Antelope Valley) near Mo jave, Calif.................

oak Creek (Owens Lake basin) near Independence, Calif . $\ldots \ldots \ldots \ldots$

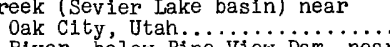
River, bélow Pine View Dam, near Ogden, Utah................

Middle Fork, at Huntsvilie, utah....

near Ogden, Utah..................

South Fork near Huntsville, Utah.
tter Creek (Bear River basin) near

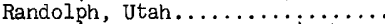

otter Creek (Sevier Lake basin) a äove reservolr, near Antimony, Utah. .

owens Lake basin, records........39,i60-172

Owens River, at Keeler Bridge, near Lone Pine, Calif ..............

at Pleasant Valley, near Bishop,

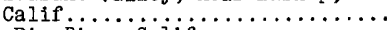
near Big Pine, Calif.............

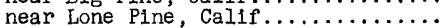

near Round Valley, Calif..........

Palm Canyon Creek near Palm Springs,

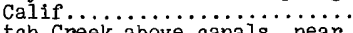

Panguitch Creek above canals, near

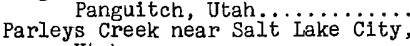

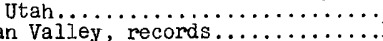
Parowan Valiey, records .............

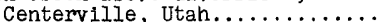

Pavant valley, records.................. $355-136$ Payson Creek, above diversions, near

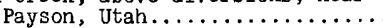

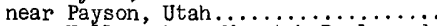

Perrys Hollow above Wasatch Boulevard, at Salt Lake City, Utah........ Peterson Creek near Sigurd, Utah........ Pewee Creek near Randsburg, Calif...... Phelps Canyon near Alpine, Utah...... Ple Creek near Tuscarora, Nev........

Plne Creek (Antelope Valiey) near

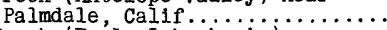

Pine Creek (Eagle Iake basinj near Westwood, Calif............

113
Page

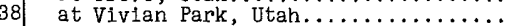

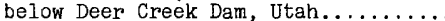

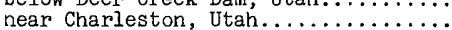

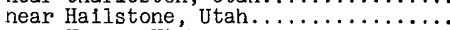

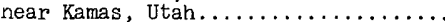

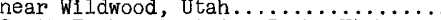
South Fork, at Vlvian Park, Utah..... 95 Pyramid and Winnemucca Lakes basin,

Quinn River, East Fork, near McDermitt,

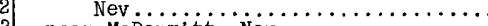

154 Randolph Creek near Randolph, Utah..... Rebel Creek near Orovada, Nev.......... 53 Red Canyon tributary near Bryce Canyon, Reese River, near Battie Mountain, Nev near Ione, Nev .................. 206

56 Ricks Creek above diversions, near 56 Centerv1lle, Utah............ 93 44 Riddle Creek near Diamond, oreg.........

17 Right Hand Fork Government Canyon near

39 Robinson Creek at Twin Lakes outiet. near Bridgeport, Calif......... 175

Rock Canyon near Hatch, Utah.......... 38

159 Rock Creek (Humboldt River basin) near Battle Mountain, Nev........

168 Rock Creek (Owens Lake basin), at

Little Round Valley, near Bishop, Calif..

at Sherwin Hiii, near Bishop, Caifi...

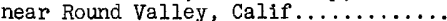

89 Rock Creek (tributary to Great Sait

$90 \quad$ Rock Creek (tributary , at Holbrook, Idaho........

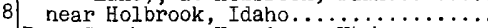
Rose Creek near Herriman, Utah.........

48 Round Valley Creek near Wallsburg, 124 Rush Creek above Grant Iake, near Jure rek above Grant Lake, near Jure Rush Valley, records............... 117

Sagehen Creek near Truckee, Calif..... 219

165 Salina Creek at Salina, Utah............ 129

167 Salsberry Creek near Shoshone, Cailf... 145

170 Salt Creek (Bear River basin) near

61 Geneva Idaho................ 52 Salt Creek (Jordan River basin) at $\ldots . . .96$

149 Salt Wells Creek near Westend, Calif... 160 Salton Sea basin, records............

122 San Felipe Creek near Julian, Caiji... 146 San Pitch River near Gunnison, Jtah.... 131

115 Secret Creek near Halleck, Nev ......... 196 39-140 Sevier Lake basin, records........38,i20-135 Sevier River, above Clear Creek, near

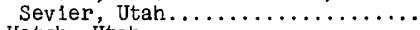

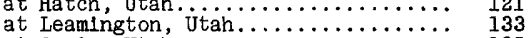

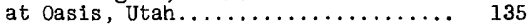
Sevier Utah.......... near Marysulije

go

130
215

217

108

108
106

105

104
103

103

106
107

22

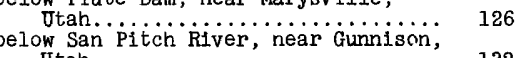
Utah.......................... 132 East Fork, near Kingston, Utah....... 125 near Circleville, Utah............. 123 near Delta, Jtah................ 134 near Gunnison, Utah.................. 130

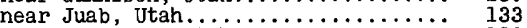
near Kingston, Utah.............. 123 
Sevier River, near Lynndyl, Utah.....

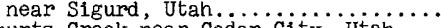
Shurtz Creek near Cedar City, Utah... Silver Canyon Creek near Laws, Calif. Silver Creek (Carson River basin) near Markleeville, Calif

Silver Creek (Malheur and Harney Lakes basin), above Suntex, Oreg......

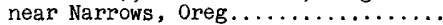

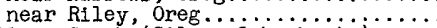
Silver Creek (Silver Lake basin), near Silver Lake, Oreg.

West Fork near Silver lake Oreg... Silver Creek (Weber River basin) near Wanship, Utah.............

Silver King Creek near Colëilie;

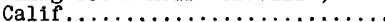

Silver Iake basin, records..........23

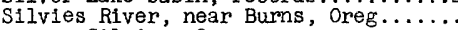

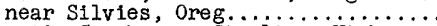
Sixmile Creek near Sterïing, Utä.....

Skinner Creek at Nounan, Idaho...

Sleepy Hollow tributary to Beaver Creek, near Collinston, Jtah....

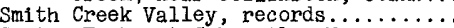

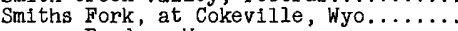

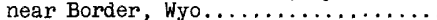
Snake Creek near Charleston, Utah..... Snake Valley, records.............. tributary near Garrison, Jtah........ Soda Creek near Soda Springs, Idaho...

South Coal Fork near Mount Pleasant, Utah... South Willow Creek near Gerlach, Nev.
Spanish Fork, at Castilla, Utah.......

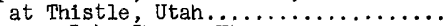

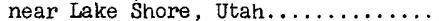

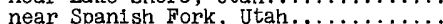
nencer Canyon Creek near Fairmont,

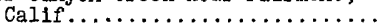

Spring Canyon Creek near orovada, Spring Creek (Death Valièj) at Furnace

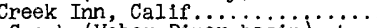

Spring Creek (Weber River basin) at Huntsville, Jtah.............

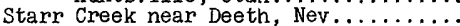

Stauffer Creek near Nounan, Idaho.....

Stone Creek above diversions, near Bountiful, Jtah.............

Sulphur Creek, above reservoir, near

Evanston, Wyo..............

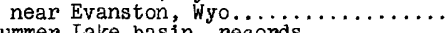

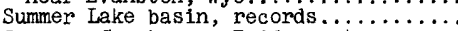

Summers Creek near Bridgeport.

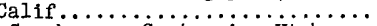

Summit Creek near Santaquin, Utah......

Surplus Canal at Salt Lake City, Utah.

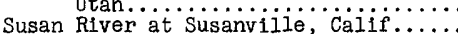

Susie Creek near Carlin, Nev.........

Swager Creek near Bridgeport

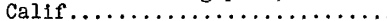

Taboose Creek near Aberdeen, Calif.... Tahquitz Creek near Palm Springs, le Creek (Great Säit İke tribu-

Tenmile Creek (Great Salt Lake
tary) West Fork, near Park

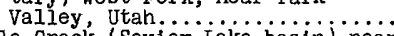

Tenmile Creek (Sevier Lake basin) near Marysville, Utah..............

Thomas Creek near Winnemucca . Nev....

Thomas Fork, near Geneva, Idaho.......

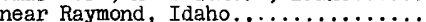
near Wyoming-Idaho state ine.......
Page,

134

128

142

187

248

247

Truckee River, at Clarks, Nev.........

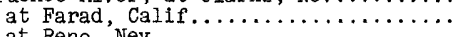

at Reno, Nev $\ldots \ldots \ldots \ldots \ldots \ldots \ldots \ldots \ldots$

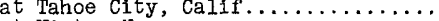

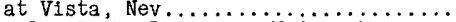

below Derby Dam, near Vadsworth,

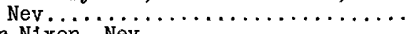

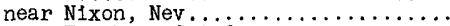

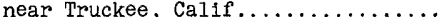

tributary near Sparks, Nev...........

241 tributary near Truckee, Calif.......

58 Twentymlle Creek near Adel, oreg........

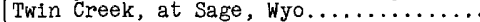

38

39

51

104

143

Vernon Creek near Vernon, Utah.........

59

39

40

100

98

101

158

40

144

89

194
58

95

95 Weber River basin, records.........38,78-91

West Walker River, at Hoye Bridge,

114 near Wellington, Nev...................

39 Whiter creek near Huntsvilie,

Willow Creek (Black Rock Desert basin)

176 near Orovada, Nev . bäinj near

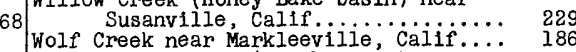

148 Wood Canyon Creek (Black Rock Desert

basin) near Orovada, Nev .......

119

Wood Canyon Creek (Great Salt lake

Woodruff Creek near Woodriff, Utah....

39 Yellow Creek near Evanston, Wyo....... 38,44

52 Yucca Creek near Yucca Grive, Cailf.... it

53

53 Zzyzx Creek near Baker, Calif........
38

Page

39

118

224
221

222

224

225

213

39
39

170
230

49
131

117
173

185
183

185
184

184
-235

84
82

82
-86 







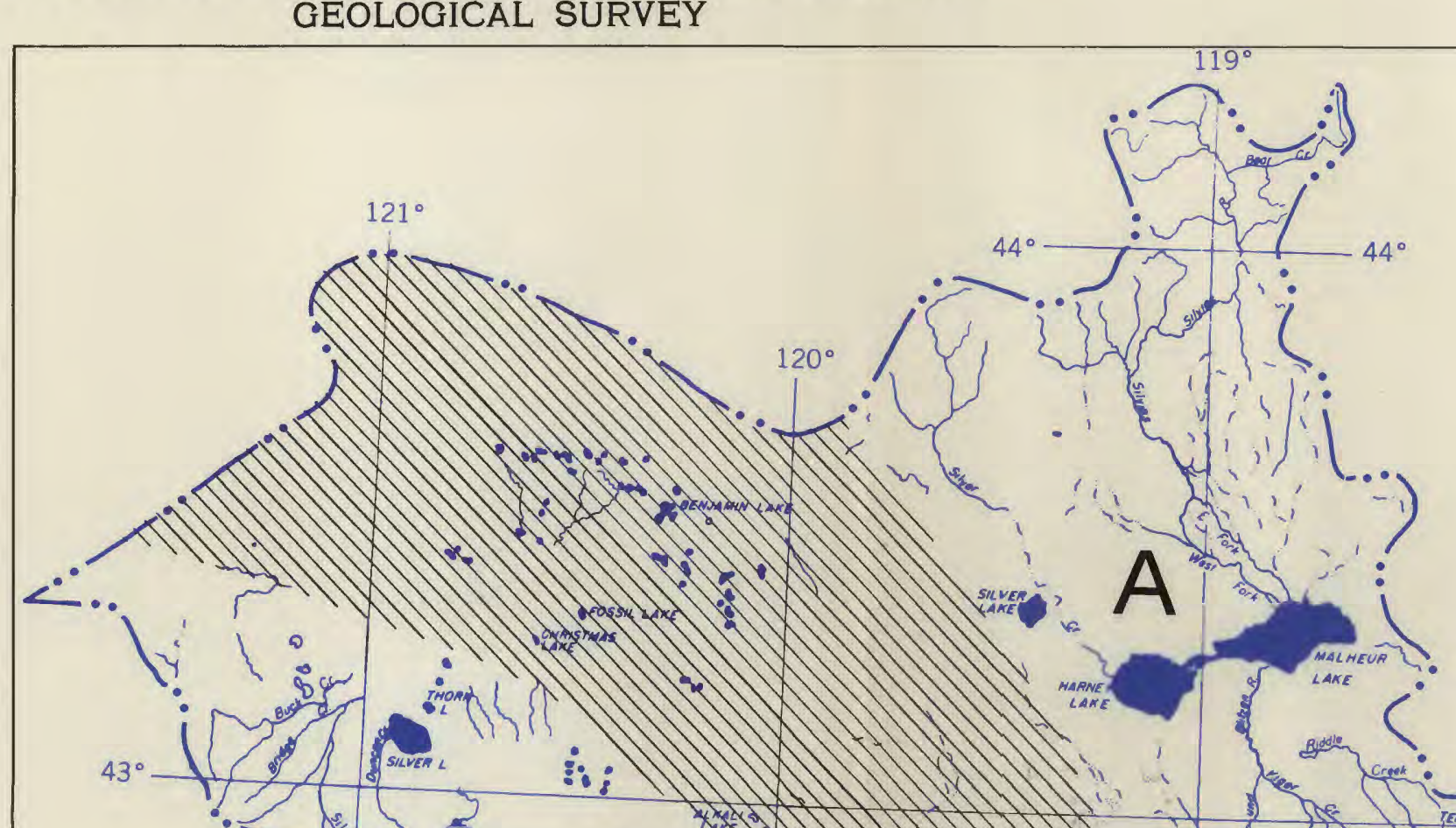

$1=A$

in $y=$ er?
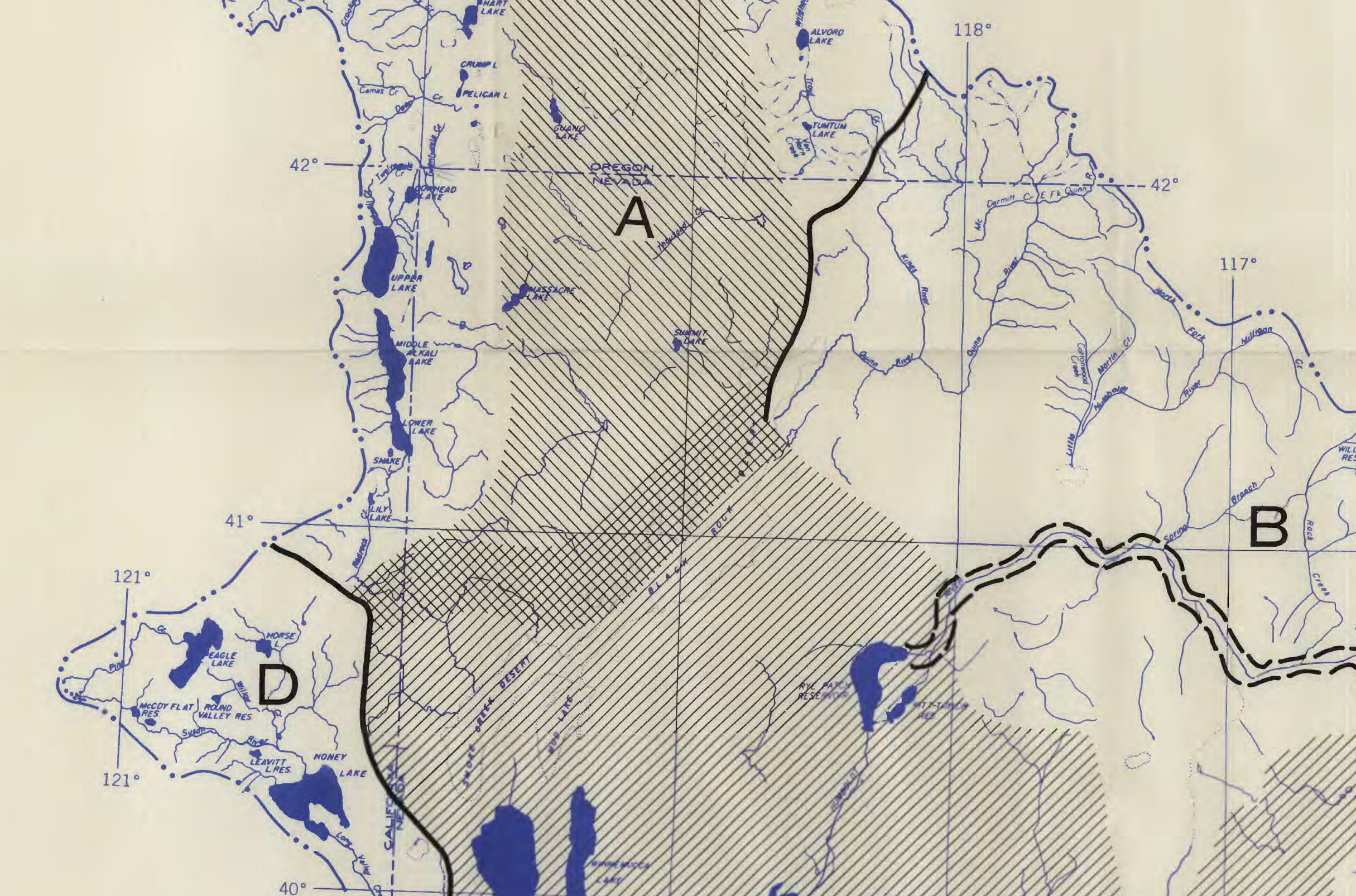

-
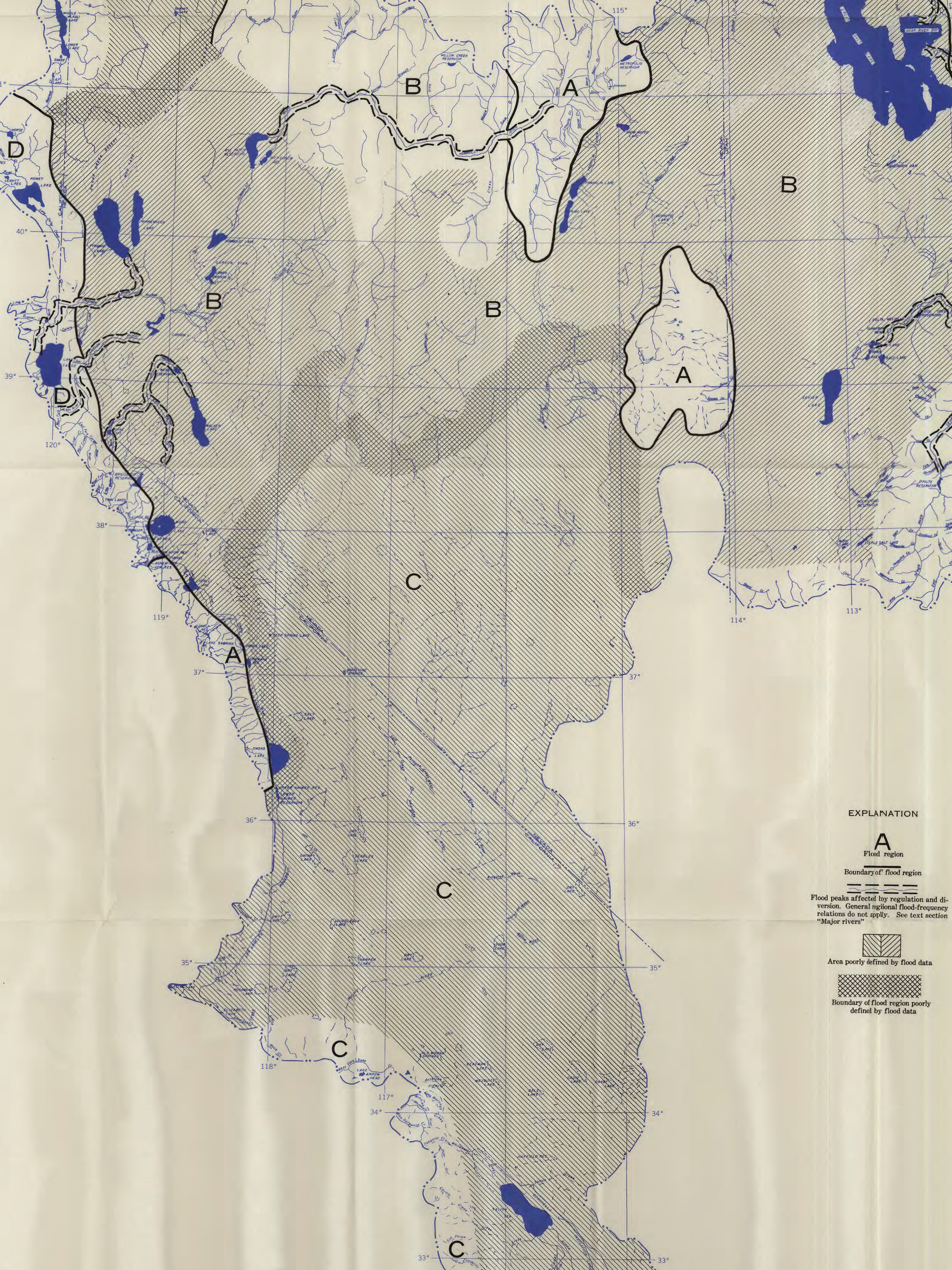